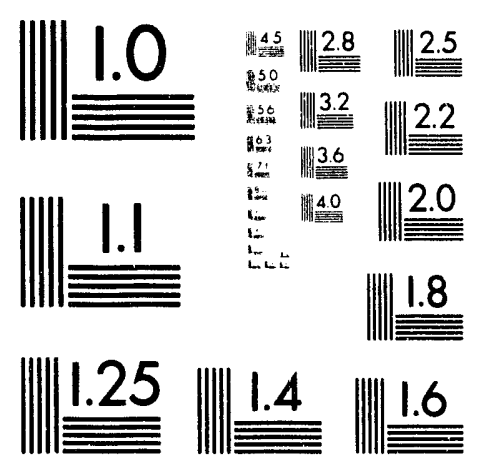



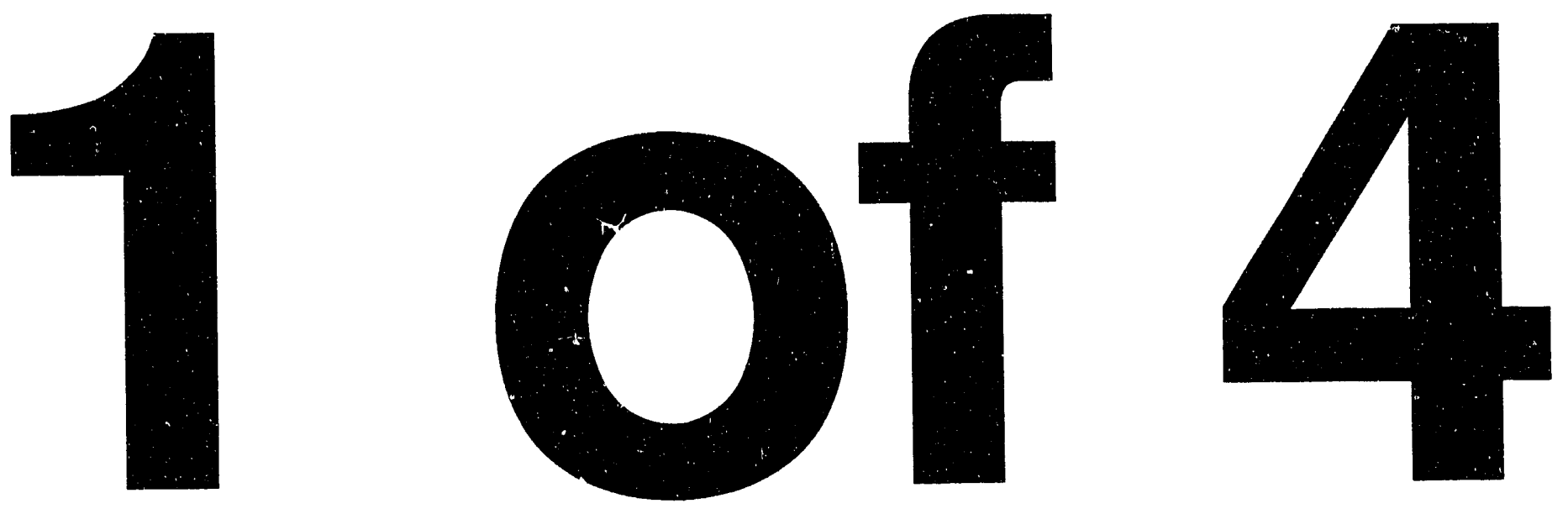


\section{Brine Sampling and \\ Evaluation Program 1990 Report}

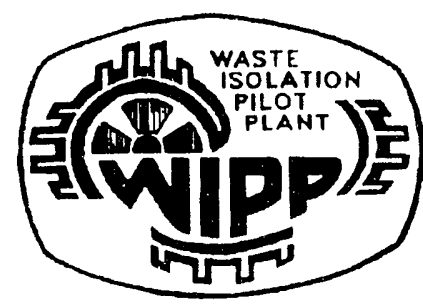

Waste Isolation Pilot Plant 
This document is issued by Westinghouse Electric Corporation, Waste Isolation Division, as the Managing and Operating Contractor for the Department of Energy, Waste Isolation Pilot Plant, Carisbad, New Mexico 88221.

DOE CONTRACT NUMBER: DE-ACO4-86AL31950

\section{DISCLAIMER}

This document was prepared as an account of work sponsored by an agency of the United States Government. Neither the United States Government nor any agency thereof, nor any of their employees, makes any warranty, express or implied, or assumes any legal liability or responsibility for the accuracy, completeness, or usefulness of any information, apparatus, product, or process disclosed, or represents that its use would not infringe privately owned rights. References herein to any specific commercial product, process, or service by trade name, trademark, manufacturer, or otherwise, does not necessarily constitute or imply its endorsement, recommendation. or favoring by the United States Government or any agency thereof. The views and opinions of authors expressed herein do not necessarily state or reflect those of the United States Government or any agency thereof.

This document has been reproduced directly from the best possible copy. It is available to DOE and DOE contractors at the following address:

Office of Scientific and Technical Information

P.O. Box 62

Oak Ridge. TN 37831

Prices available from (615) 576-8401; FTS 626-8401

Available to the public from the National Technical Information Service

U.S. Department of Commerce 5285 Port Royal Road Springfield, VA 22161 


\title{
BRINE SAMPLING AND EVALUATION PROGRAM 1990 REPORT
}

DOE-WIPP 91-036

August 1991

\begin{abstract}
AUTHORS
D. E. Deal-IT Corporation

R. J. Abitz-IT Corporation

J. Myers-IT Corporation

J. B. Case-IT Corporation

D. S. Belski-Westinghouse Electric Corporation

M. L. Martin-IT Corporation

W. M. Roggenthen-IT Corporation
\end{abstract}

Any comments or questions regarding this report should be directed to the U.S. Department of Energy

WIPP Project Office

P. O. Box 3090

Carlsbad, New Mexico 88221

\author{
or to the Manager, \\ Engineering Department \\ Westinghouse Electric Corporation \\ P.O. Box 2978 \\ Carlsbad, New Mexico 88221
}

This report was prepared for the U.S. Department of Energy by the Engineering and Repository Technology Department of the Management and Operating Contractor, Waste Isolation Pilot Plant, under Contract No. DEAC04-86AL31950.

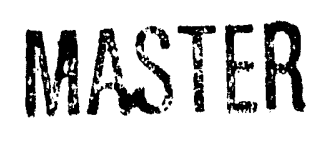




\section{Table of Contents}

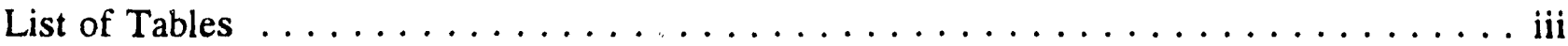

List of Figures $\ldots \ldots \ldots \ldots \ldots \ldots \ldots \ldots \ldots \ldots \ldots \ldots \ldots \ldots \ldots$ iv

List of Abbreviations/Acronyms $\ldots \ldots \ldots \ldots \ldots \ldots \ldots \ldots \ldots \ldots \ldots \ldots \ldots \ldots \ldots \ldots$

Acknowledgments $\ldots \ldots \ldots \ldots \ldots \ldots \ldots \ldots \ldots \ldots \ldots \ldots \ldots \ldots \ldots \ldots \ldots \ldots$

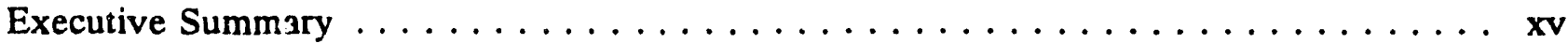

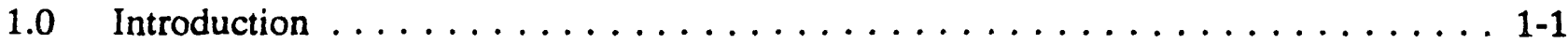

2.0 Monitoring of Brine Inflow Parameters . . . . . . . . . . . . . . 2-1

2.1 Introduction $\ldots \ldots \ldots \ldots \ldots \ldots \ldots \ldots \ldots \ldots \ldots \ldots \ldots \ldots \ldots \ldots$

2.2 Brine Seepage on Vertical Surfaces (Weeps) . . . . . . . . . . . . 2-1

2.2.1 Observations When Surfaces Were Newly Excavated . . . . . . . . . 2-1

2.2.2 Growth of Encrustations with Time $\ldots \ldots \ldots \ldots \ldots \ldots$ 2-1

2.3 Brine Seepage from the Back . . . . . . . . . . . . . . . 2-9

2.4 Summary of Rib and Back Observations . . . . . . . . . . . . . . 2-9

2.5 Damp or Wet Areas on Floors . . . . . . . . . . . . . . . 2-11

2.6 South Exploratory Drift . . . . . . . . . . . . . . . . . . 2-15

2.7 Downholes and Brine Beneath the Floor . . . . . . . . . . . . . . 2-15

2.7.1 Macrofractures Beneath the Floor and Observations in the Shaft

Sumps .......................... 2-19

2.7.2 Moisture Content . . . . . . . . . . . . . . . . . 2-20

2.7.3 Data from the Heated Experimental Area and Room G . . . . . . . 2-20

2.7.3.1 Downholes in the Northeastern Heated Experimental Area . 2-23

2.7.3.2 Downholes in Room G . . . . . . . . . . . . . . . . 2-24

2.7.4 Discussion of Data Acquisition and Analyses . . . . . . . . . . 2-24

2.7.5 Data Interpretation . . . . . . . . . . . . . . . 2-30

2.8 Upholes and Brine Above the Back . . . . . . . . . . . . . . 2-31

2.8.1 Observations of Brine Seepage from Rock Bolts in Rooms C1 and

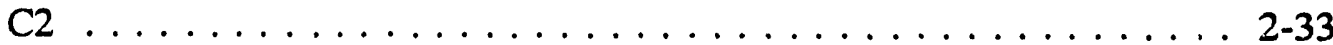

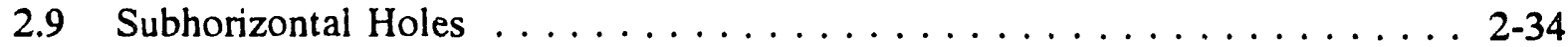

3.0 Geochemistry of BSEP Brines . . . . . . . . . . . . . . . 3-1

3.1 Simple Statistics for 1989 and 1990 Analytical Results . . . . . . . . . . . 3-2

3.1.1 Major-Element Composition of BSEP Brines and Brine Weeps . . . . 3-4

3.1.2 Physical and Additional Chemical Parameters of BSEP Brines . . . 3-15

3.1.2.1 UNC and IT Parameters ............. 3-15

3.1.2.2 UNC Parameters . . . . . . . . . . . . . 3-22 


\section{Table of Contents (Continued)}

3.1.2.3 Discussion ..................... 3-22

3.1.3 Results for Archived DHP402A Samples . . . . . . . . . . 3-38

3.2 Element-Ratio and Solubility Diagrams . . . . . . . . . . . . . 3-40

3.2.1 Element-Ratio Diagrams . . . . . . . . . . . . . . . 3-40

3.2.2 Results of EQ3NR Modeling and Solubility Diagrams . . . . . . . 3-44

3.3 Evaluation of the Migration of Synthetic Brine to the GSEEP Location . . 3-56

3.4 Conclusions . . . . . . . . . . . . . . . . . . . . . 3-59

4.0 Modeling and Analysis-Long Horizontal Drill Holes . . . . . . . . . . . . 4-1

4.1 Introduction $\ldots \ldots \ldots \ldots \ldots \ldots \ldots \ldots \ldots \ldots$

4.2 Model Descriptions . . . . . . . . . . . . . . . . . . . 4-2

4.2 .1 VISCOT/BISCITS Analysis . . . . . . . . . . . . . . 4-2

4.2 .2 Simplified Finite-Difference Analysis . . . . . . . . . . . . 4-4

4.2 .3 Model Input Properties . . . . . . . . . . . . . . . . . 4-4

4.3 Results of VISCOT Analysis . . . . . . . . . . . . . . . 4-6

4.4 BISCITS Analysis $\ldots \ldots \ldots \ldots \ldots \ldots \ldots \ldots \ldots \ldots \ldots \ldots \ldots$

4.5 One-Dimensional Finite-Difference Analysis . . . . . . . . . . . 4-7

4.6 Release of Brine from the DRZ Due to Depressurization . . . . . . . . 4-17

4.7 Comparison of Predicted Seepage and Field Observations . . . . . . . 4 4-27

4.8 Conclusions ............................. 4-35

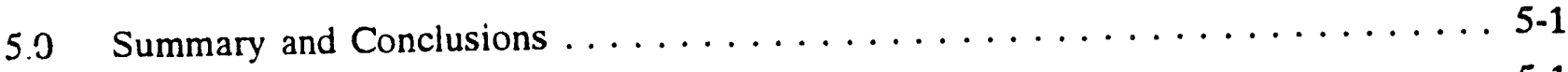

5.1 Brine Observations . . . . . . . . . . . . . . . . . . . 5-1

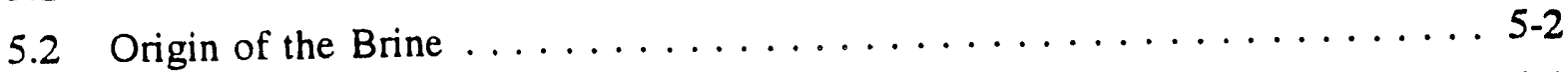

5.3 Hydrologic Systems $\ldots \ldots \ldots \ldots \ldots \ldots \ldots \ldots \ldots \ldots \ldots \ldots$

5.4 Development of the Deformational Environment $\ldots \ldots \ldots \ldots \ldots \ldots \ldots$

5.5 Flow Conditions . . . . . . . . . . . . . . . . . . . 5-6

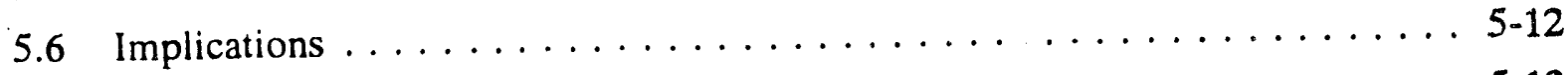

5.7 Further Investigations $\ldots \ldots \ldots \ldots \ldots \ldots \ldots \ldots \ldots \ldots \ldots \ldots \ldots$

6.0 References .............................. 6-1

Appendix A-Brine Accumulation

Appendix B-Graphs of Brine Accumulation Data

Appendix C-1990 Analytical Results

Appendix D-Simple Statistics

Appendix E-Activity Plan 


\section{List of Tables}

Table

Title

1-1 Points to be Considered When Evaluating BSEP Data

1-2 Stratigraphy in North End of the WIPP Underground Workings Based on Room A1 and G Drill Holes

2-1 Brine Accumulation Summaries for Downholes, Upholes, and Subhorizontal Holes

3-1 Drill Holes Sampled for Brine in 1989 and 1990

3-2 Comparison of Mean Values (mg/L, Except for SG and $\mathrm{pH}$ ) for UNC-Geotech Nonarchived (NA) and Archived (A) DHP402A Samples

3-3 Saturation Indices (SI) Based on EQ3NR Modeling Results Using UNC Brine Analyses

3-4 Saturation Indices (SI) Based on EQ3NR Modeling Results Using IT Brine Analyses

3-5 Composition of Brines Recovered from Room $J$ and GSEEP

4-1 Salt/Brine Material Constitutive Properties 


\section{List of Figures}

Figure

$1-1$

$1-2$

$1-3$

$2-1$

$2-2$

$2-3$

$2-4$

$2-5$

2-6

$2-7$

$2-8$

$2-9$

2-10

\section{Title}

WIPP Location in Southeastern New Mexico

Surface and Underground Layout of the WIPP Facility

Generalized Stratigraphic Cross Section

Map of the WIPP Undergrourd Workings Showing BSEP Observation Locations as of December 31, 1990

Mining machine cutting the S90 drift west of W170 on October 16, 1987. New drift shows progression of weep development. The first $4 \mathrm{~m}$ on the left is 4 days old and the next $4 \mathrm{~m}$ is 3 days old.

West rib of W170 between S1600 and S1950 showing moist areas below clay $\mathrm{F}$ and along the orange band. Photograph taken March 1987, about 15 months after excavation.

Geologic Cross Section of the Facility with Unit Number Designations

Brine weeping from clay $G$ at the base of anhydrite "a." This clay is about $2 \mathrm{~m}$ above the ceiling of most of the repository-level excavations and is the likely source of the moisture that seeps down roof bolts in drifts at that level. This photograph was taken in the Air Intake Shaft station on February 24, 1988.

White salt encrustations forming above and below the orange band in Room 6, Panel 1.

Clear Halite Beds with No Measurable Permeability (Less than $1 \times 10^{-23} \mathrm{~m}^{2}$ ) Constrain Brine Flow. Tested Beds Shown as a Shaded Pattern, Question Marks Indicate Untested Beds with Same Lithology.

Cross Section of Fracturing Around a 4-m-High, 10-m-Wide Waste Storage Room at the WIPP

Part of a near-vertical dish-shaped fracture exposed in the east rib of Room 7, Panel 1.

Structure Contour Map on the Top of the Orange Band. Contour Interval is 1 Foot, and Elevations are in Feet. 


\section{List of Figures (Continued)}

Figure

$2-11$

$2-12$

$2-13$

\section{Title}

South end of the south exploratory drift (E140 at about S3630) on November 13, 1987. This drift was excavated in January 1983, about 5 years prior to this photograph. Clay $F$ is exposed in the rib, and the area is very dry. There are almost no salt encrustations and no evidence that much brine has ever seeped into this area.

Photograph of dry subhorizontal fracture approximately $5 \mathrm{~mm}$ wide exposed in the Waste Shaft just below the floor of the station

Correlation of the Stratigraphy with Downholes in the Northern Part of the Facility

Eleven-Point Avcrage Versus Actual Data for Hole DH38

Eleven Point Average Versus Actual Data for Hole BX01

Eleven Point Average Versus Actual Data for Hole A1X01

Correlation of the Stratigraphy with Upholes in the Northern Part of the Facility

Profile of Long Drill Hole OH20

Profile of Long Drill Hole OH23

Profile of Long Drill Hole OH26

Distribution of chloride in Salado Formation brines recovered from underground locations at the WIPP. Note that the highest group along the $\mathbf{x}$-axis represents a greater range of chloride values relative to other groups. Drill hole indicators for UNC and IT data are discussed in the text.

Distribution of sodium in Salado Formation brines recovered from underground locations at the WIPP. Drill hole indicators for UNC and IT data are discussed in tite text.

Distribution of magnesium in Salado Formation brints recovered from underground locations at the WIPP. Drill hole indicators for UNC and IT data are discussed in the text. 


\section{List of Figures (Continued)}

Figure

3-4 Distribution of potassium in Salado Formation brines recovered from underground locations at the WIPP. Note that the highest group along the $\mathrm{x}$-axis represents a greater range of potassium values relative to other groups. Drill hole indicators for UNC and IT data are discussed in the text.

3-5 Distribution of sulfate in Salado Formation brines recovered from underground locations at WIPP. Drill hole indicators for UNC and IT data are discussed in the text.

3-6 Distribution of boron in Salado Formation brines recovered from underground locations at the WIPP. Drill hole indicators for UNC and IT data are discussed in the text.

3-7 Distribution of bromide in Salado Formation brines recovered from underground locations at the WIPP. Dill hole indicators for UNC and IT data are discussed in the text.

3-8 Distribution of calcium in Salado Formation brines recovered from underground locations at the WIPP. Note that the highest group along the $x$-axis represents a greater range of calcium values relative to other groups. Drill hole indicators for UNC and IT data are discussed in the text.

3-9 Distribution of specific gravity in Salado Formation brines recovered from underground locations aî the WIPP. Drill hole indicators are discussed in the text.

3-10 Distribution of total dissolved solids in Salado Formation brines recovered from underground locations at the WIPP. Drill hole indicators are discussed in the text.

3-11 Distribution of $\mathrm{pH}$ in Salado Formation brines recovered from underground locations at the WIPP. Drill hole indicators are discussed in the text.

3-12 Distribution of alkalinity in Salado Formation brines recovered from underground locations at the WIPP. Drill hole indicator: are discussed in the text. 
List of Figures (Continued)

Figure

Title

3-13 Distribution of total inorganic carbon in Salado Formation brines recovered from underground locations at the WIPP. Drill hole indicators are discussed in the text.

3-14 Distribution of ammonium in Salado Formation brines recovered from underground locations at the WIPP. Drill hole indicators are discussed in the text.

3-15 Distribution of fluoride in Salado Formation brines recovered from underground locations at the WIPP. Drill hole indicators are discussed in the text.

3-16 Distribution of iodide in Salado Formation brines recovered from underground locations at the WIPP. Drill hole indicators are discussed in the text.

3-17 Distribution of nitrate in Salado Formation brines recovered from underground locations at the WIPP. Asterisk following drill hole identification indicates a detection limit value. Drill hole indicators are discussed in the text.

3-18 Distribution of manganese in Salado Formation brines recovered from underground locations at the WIPP. Drill hole indicators are discussed in the text.

3-19 Distribution of silicon in Salado Formation brines recovered from underground locations at the WIPP. LLD noted for IT (0.2) and UNC (0.5) data. Note that the highest group along the $x$-axis represents a greater range of silicon values relative to other groups. Drill hole indicators are discussed in the text.

3-20 Distribution of strontium in Salado Formation brines recovered from underground locations at the WIPP. Drill hole indicators are discussed in the text.

3-21 Distribution of phosphorous in Salado Formation brines recovered from underground locations at the WIPP. Note most observations lie at the LLD. Asterisk following drill hole identification indicates a higher detection limit value. Drill hole indicators are discussed in the text. 


\section{List of Figures (Continued)}

Figure

3-23

$3-24$

$3-25$

3-26

$3-27$

3-28

3-29

3-30

\section{Title}

Distribution of aluminum in Salado Formation brines recovered from underground locations at the WIPP. Note LLD. Drill hole indicators are discussed in the text.

Distribution of arsenic in Salado Formation brines recovered from underground locations at the WIPP. Asterisk following drill hole identification indicates a detection limit value. Drill hole indicators are discussed in the text.

Distribution of barium in Salado Formation brines recovered from underground locations at the WIPP. Drill hole indicators are discussed in the text.

Distribution of iron in Salado Formation brines recovered from underground locations at WIPP. Note LLD. Hole DHP402A has a steel rod wedged in the bottom, G090 contains steel instrumentation, and A2X01 has a pair of scissors in the bottom. Other drill hole indicators are discussed in the text.

Distribution of TOC in Salado Formation brines recovered from underground locations at the WIPP. Note that the highest group along the $x$-axis represents a greater range of TOC values relative to other groups. Drill hole indicators are discussed in the text.

Distribution of cesium in Saiado Formation brines recovered from underground locations at the WIPP. Drill hole indicators are discussed in the text.

Distribution of rubidium in Salado Formation brines recovered from underground locations at the WIPP. Drill hole indicators are discussed in the text.

Variation of $\mathrm{Na} / \mathrm{Cl}$ and $\mathrm{Ca} / \mathrm{SO}_{4}$ weight ratios in Salado Formation brines recovered from underground locations at the WIPP. Filled symbols indicate upholes. See text for discussion of mixing lines and evaporation trend.

Variation of $\mathrm{Na} / \mathrm{Cl}$ and $\mathrm{K} / \mathrm{Mg}$ weight ratios in Salado Formation brines recovered from uriderground locations at the WIPP. Filled symbols indicate upholes. See text for discussion of mixing lines and evaporation trend. 
List of Figures (Continued)

Figure

3-31 Variation of $\mathrm{Na}$ and $\mathrm{Cl}$ in Salado Formation brines recovered from underground locations at the WIPP. Filled symbols indicate upholes. Halite saturation field determined with the EQ3NR geochemical code using brine compositions.

3-32 Variation of $\mathrm{Ca}$ and $\mathrm{SO}_{4}$ in Salado Formation brines recovered from underground locations at the WIPP. Filled symbols indicate upholes. Arhydrite saturation field determined with the EQ3NR geochemical code using brine compositions.

3-33 Variation of $\mathrm{Sr}$ and $\mathrm{SO}_{4}$ in Salado Formation brines recovered from underground locations at the WIPP. Filled symbols indicate upholes. Celestite saturation field determined with the EQ3NR geocinemical code using brine compositions.

3-34 Variation of $\mathrm{Mg}$ and $\mathrm{HCO}_{3}$ in Salado Formation brines recovered from underground locations at the WIPP. Filled symbols indicate upholes. Half-filled symbols indicate samples that are saturated with magnesite. Magnesite saturation field determined at a $\mathrm{pH}$ of 6.0 , 6.1, 6.2 with the EQ3NR geochemical code using brine compositions. See text for discussion of $\mathrm{pH}$ boundaries.

4-1 Finite-Element Mesh for a 7.6-cm-Diameter Subhorizontal Borehole Model

4-2 Porosity Versus Radial Distance of a 7.6-cm-Diameter Drill Hole

4-3 Permeability Versus Radial Distance for a 7.6-cm-Diameter Drill Hole

4-4 Flow Rate Versus Time for the BISCITS Model for a 7.6-cmDiameter Drill Hole for Far-Field Flow

4-5 Cumulative Flow Versus Time for the BISCITS Model for a 7.6-cmDiameter Drill Hole for Far-Field Flow

4-6 Potential Distribution for the Far-Field, High-Intrinsic Permeability (1 nanodarcy, $10^{-21} \mathrm{~m}^{2}$ ), Finite-Difference Model for a $7.6-\mathrm{cm}$ Diameter Drill Hole 
List of Figures (Continued)

Figure

Title

4-7 Flow Rate Versus Time for the Far-Field, High-Intrinsic

Permeability (1 nanodarcy, $10^{-21} \mathrm{~m}^{2}$ ), Finite-Difference Model for a 7.6-cm-Diameter Drill Hole

4-8 Cumulative Flow Versus Time for the Far-Field, High-Intrinsic Permeability (1 nanodarcy, $10^{-21} \mathrm{~m}^{2}$ ), Finite-Difference Model for a 7.6-cm-Diameter Drill Hole

4-9 Potential Distribution for the Far-Field Low-Intrinsic Permeability (0.1 nanodarcy, $10^{-22} \mathrm{~m}^{2}$ ), Finite-Difference Model for a $7.6-\mathrm{cm}$ Diameter Drill Hole

4-10 Flow Rate Versus Time for the Far-Field, Low-Intrinsic Permeability $\left(0.1\right.$ nanodarcy or $\left.10^{-22} \mathrm{~m}^{2}\right)$, Finite-Difference Model for a $7.6-\mathrm{cm}$ Diameter Drill Hole

4-11 Cumulative Flow Versus Time for the Far-Field, Low-Intrinsic Permeability ( 0.1 nanodarcy or $10^{-22} \mathrm{~m}^{2}$ ), Finite-Difference Model for a 7.6-cm-Diameter Drill Hole

4-12 Potential Distribution for the Near-Field, High-Intrinsic Permeability (1 nanodarcy or $10^{-21} \mathrm{~m}^{2}$ ), Finite-Difference Model for a $7.6-\mathrm{cm}$ Diameter Drill Hole

4-13 Flow Rate Versus Time for the Near-Field, High-Intrinsic Permeability (1 nanodarcy or $10^{-21} \mathrm{~m}^{2}$ ), Finite-Difference Model for a 7.6-cm-Diameter Drill Hole

4-14 Cumulative Flow Versus Time for the Near-Field, High-Intrinsic Permeability ( 1 nanodarcy or $10^{-21} \mathrm{~m}^{2}$ ), Finite-Difference Model for a 7.6-cm-Diameter Drill Hole

4-15 Potential Distribution for the Near-Field Low-Intrinsic Permeability (1 nanodarcy or $10^{-21} \mathrm{~m}^{2}$ ), Finite-Difference Model for a $7.6-\mathrm{cm}$ Diameter Drill Hole

4-16 Flow Rate Versus Time for the Near-Field, Low-Intrinsic Permeability ( 1 nanodarcy or $10^{-21} \mathrm{~m}^{2}$ ), Finite-Difference Model for a 7.6-cm-Diameter Drill Hole 
List of Figures (Continued)

Figure

Tit/e

4-17 Cumulative Flow Versus Time for the Near-Field, Low-Intrinsic Permeability (0.1 nanodarcy or $10^{-22} \mathrm{~m}^{2}$ ), Finite-Difference Model for a 7.6-cm-Diameter Drill Hole

4-18 Volume of Brine Released from the DRZ for a Borehole-Sized Excavation $46 \mathrm{~m}$ Long

4-19 Volume of Brine Released from the DRZ for a Shaft-Sized or a Rrom-Sized Excavation $91.4 \mathrm{~m}$ (300 ft) Long

4-20 Horizontal Drill Hole OH20 Brine Inflow Rate Simple 11-Point Moving Average

4-21 Horizontal Drill Hole OH20 Cumulative Brine Inflow

4-22 Horizontal Drill Hole OH23 Brine Inflow Rate Simple 11-Point Moving Average

4-23 Horizontal Drill Hole OH23 Cumulative Brine Inflow

4-24 Horizontal Drill Hole OH26 Brine Inflow Rate Simple 11-Point Moving Average

4-25 Horizontal Drill Hole OH26 Cumulative Brine Inflow

5-1 Diagrammatic vertical cross sections of a rectangular excavation in homogeneous salt one day and two years after mining. Zone $A$ is the mined opening; zone B is the zone of elastic deformation, brittle failure, and macrofracturing with atmospheric pore pressures; zone $\mathrm{C}$ is the zone of plastic deformation and dilatency, with pore pressures increasing from atmospheric to lithostatic; and zone $D$ is undisturbed salt with lithostatic pore pressures. The DRZ is composed of both zone $B$ and zone $C$.

5-2 Diagrammatic vertical cross section of a WIPP storage room in bedded salt, approximately six years after mining. Zones $\mathrm{A}, \mathrm{B}, \mathrm{C}$, and $D$ are the same as in Figure 5-1. Arrows indicate brine seepage as a result of compaction of clays at clay $F$ and above and below the orange band.

5-3 Vertical Cross Section Through a Mature DRZ Around a WIPP Waste Storage Room 4-m High and 10-m Wide 


\section{List of Abbreviations/Acronyms}

A

$\mathrm{BaSO}_{4}$

BSEP

$\mathrm{Ca} / \mathrm{SO}_{4}$

$\mathrm{CaF}_{7}$

$\mathrm{CaMg}\left(\mathrm{CO}_{3}\right)_{2}$

$\mathrm{CaSO}_{4} \cdot 2 \mathrm{H}_{2} \mathrm{O}$

cfm

CH-TRU

$\mathrm{cm}$

DOE

DRZ

EATF

$\mathrm{Fe}(\mathrm{OH})_{2}$

$\mathrm{g} / \mathrm{kg}$

$\mathrm{g} / \mathrm{L}$

HMW

IAP

IT

$\mathrm{K} / \mathrm{Mg}$

$\mathrm{K}_{2} \mathrm{Ca}\left(\mathrm{SO}_{4}\right)_{2} \cdot \mathrm{H}_{2} \mathrm{O}$

$\mathrm{K}_{2} \mathrm{Ca}_{2} \mathrm{Mg}\left(\mathrm{SO}_{4}\right)_{4} \cdot 2 \mathrm{H}_{2} \mathrm{O}$ $\mathrm{kg} / \mathrm{L}$

Ksp

L

$\mathrm{L} / \mathrm{s}$

m

$\mathrm{Ma}_{2} \mathrm{Ca}\left(\mathrm{SO}_{4}\right)_{2}$

MB 139

$\mathrm{mg} / \mathrm{L}$

$\mathrm{MgCO}_{3}$

$\mathrm{MPa}$

$\mathrm{mV}$

NA

$\mathrm{Na} / \mathrm{Cl}$

ppm

ppt

PVC

RCRA

SI

SNL/NM

SPDV

$\mathrm{SrSO}_{4}$

TDS archived

barite

Brine Sampling and Evaluation Program

calcium/sulfate

fluorite

dolomite

gypsum

cubic feet per minute

contact-handled transuranic

centimeter

U.S. Department of Engery

disturbed rock zone

Engineered Alternatives Task Force

amakinite

grams per kilogram

grams per liter

Harvey-Moeller-Weare

ion activity product

IT Corporation

potassium/magnesium

syngenite

polyhalite

kilograms per liter

mineral solubility product

liter(s)

liters per second

meter(s)

glauberite

Marker Bed 139

milligrams/liter

magnesite

megapascals

millivolts

nonarchived

sodium/chloride

parts per million

parts per thousand

polyvinyl chloride

Resource Conservaiton and Recovery Act

saturation index

Sandia National Laboratories/New Mexico

Site Preliminary Design Validation

celesite

total dissolved solids 


\section{List of Abbreviations/Acronyms (Continued)}

TIC

TOC

UNC

VOC

Westinghouse

WIPP

${ }^{\circ} \mathrm{C}$ total inorganic carbon

total organic carbon

United Nuclear Corporation

volatile organic compounds

Westinghcuse Electric Corporation

Waste Isolution and Pilot Plant

degrees Celsius 


\section{Acknowledgments}

Dr. Dwight Deal provides the overall direction of the Brine Sampling and Evaluation Program (BSEP). Dr. Rich Abitz coordinates the geochemical analyses. Mr. John Case is responsible for the overall direction of the modeling of brine seepage into long subhorizontal drill holes. Dr. Saeid Saeb, Mr. Mike Wallace (now with Re-Spec, Albuquerque, New Mexico), and Ms. Kathy Verhage supported the numerical modeling and associated quality control.

Dr. Bill Roggenthen, who is on loan to the WIPP from the South Dakota School of Mines, has assisted the BSEP in many ways. He contributed brine inflow observations in Section 2 and made many good suggestions throughout the text, which significantly improved this report.

Dr. Jon Myers provided input on the importance of the BSEP to the assessment of long-term facility performance, as well as critical reading and editorial assistance.

Dr. Jim Krumhansl of Sandia National Laboratories/New Mexico, reviewed Chapter 3, Geochemistry of BSEP Brines, and made some helpful comments.

Mr. Dave Belski is responsible for the routine collection of brine from the drill holes in the repository, sample measuring, processing and data analyses. Mr. Belski spent tedious hours scraping brine encrustations from the ribs of the repository. Mr. Mel Balderrama and Ms. Merrie Martin assisted with the underground and surface procedures.

Ms. Martin and Mr. Jeffrey Clark are responsible for the data entry and analyses of the brine sampling. Mr. Belski is responsible for the data entry and analyses of the moisture content of the brine weeps.

Ms. Kathi McKenna and Ms. Pamela James Lipponer coordinated the word processing and drafting at the IT-Albuquerque office. Many thanks to the staff of the Word Processing, Technical Editing, and Drafting Departments of the IT-Albuquerque office for their many hours of professional support. 


\section{Executive Summary}

The data presented in this report are the result of Brine Sampling and Evaluation Program (BSEP) activities at the Waste Isolation Pilot Plant (WIPP) during 1990. When excavations began in 1982, small brine seepages (weeps) were observed on the walls. These brine occurrences were initially described as part of the Site Validation Program. Brine studies were formalized in 1985. The BSEP activities document and investigate the origins, hydraulic characteristics, extent, and composition of brine occurrences in the Permian Salado Formation and seepage of that brine into the excavations at the WIPP. The brine chemistry is important because it assists in understanding the origin of the brine and because it may affect possible chemical reactions in the buried waste after sealing the repository. The volume of brine and the hydrologic system that drives the brine seepage also need to be understood to assess the long-term performance of the repository.

After more than eight years of observations (1982-1990), no credible evidence exists to indicate that enough naturally occurring brine will seep into the WIPP excavations to be of practical concern. The detailed observations and analyses summarized herein and in previous BSEP reports confirm the evidence apparent during casual visits to the underground workings - that the excavations are remarkably dry.

Previous BSEP reports (Deal and Case, 1987; Deal and others, 1987; Deal and others, 1989; Deal and others, 1991) described the results of ongoing activities that monitor brine inflow into boreholes in the facility, moisture content of the Salado Formation, brine geochemistry, and brine weeps and crusts. The information provided in this report updates past work and describes progress made during calendar year 1990.

During 1990, BSEP activities focused on three major areas to describe and quantify brine activity: (1) monitoring of brine inflow, e.g., measuring brines recovered from holes drilled downward from the underground drifts (downholes), upward from the underground drifts (upholes), and subhorizontal holes; (2) further characterizing the brine geochemistry; and (3) modeling of brine flow into long boreholes with an emphasis on attempts to distinguish between near-field versus far-field flow.

Monitoring Brine Inflow. The 1990 results of the relative amounts of brine seepage between downholes, upholes, and subhorizontal holes continue trends found in earlier reports. Typically, upholes produce significantly smaller amounts of brine than the downholes and 
tend to cease production after two to three years. Vertical holes yield inconsistent data, even when closely spaced. Subhorizontal holes continue to have very low brine inflow rates and remain dry when they are older than two and a half years. Horizontal holes provide consistent and comparable data sets.

Brine recovery from downholes substantially differs from holes drilled in other orientations. Downholes tend to produce brine over extended periods of time and sometimes show increased seepage rates for several months to a year or more. Closely spaced holes may have seepage rates, volumes, and brine levels varying by two orders of magnitude or more. Many downholes, such as the one in Waste Storage Panel 1 at S1950-E1320, receive water introduced to the underground from sources other than the Salado Formation. Throughout the facility, much of the brine in downholes appears to be a mixture of Salado Formation brine and construction water spread upon the floors for salt-dust control or roadway consolidation.

Weeps (small moist areas and salt encrustations formed by their evaporation) form slowly on vertical surfaces. Eighteen weep areas that were described and mapped in November 1982 were relocated and rephotographed. All areas were dry after five and a half years.

The south exploratory drift slopes southward to a dead end, with little air exchange due to restricted ventilation. If significant amounts of brine were seeping into the south exploratory drift, there should be some evidence of moisture. Inspection during 1989 found this to be a dry area. There was no detectable moisture on the ribs or floor and only a few salt encrustations were found. Although these data are difficult to quantify, it seems that significant quantities of b ine seeping into this drift over the six years since its construction in 1983 would be shown by much more evidence of moisture than has been observed.

Observations were made of Marker Bed 139 and the fractured zone that develops beneath the floor of the WIPP excavations in the sumps of the Salt Handling Shaft and the Waste Handling Shaft. Fractures were observed, but no brine was seeping into the shafts. Since both of these shafts are downslope from extensive parts of the workings that are known to be underlain by brine-filled fractures, the observation argues strongly that a hydrologically connected macrofracture system has not developed beneath those drifts. One of those drifts is the E0 drift, which is one of the widest ( 7.6 meters [m]) and oldest (seven years, excavated in 1984) drifts at the WIPP. It is possible that the typical width of the entry drifts (less than $7.6 \mathrm{~m}$ ) is too narrow to allow the development of the type of fracturing observed beneath the 10 -m-wide storage rooms. 
The relative importance of these two systems needs to be determined. For example, if there is sufficient far-field flow into the repository, then enough brine may come into the excavations to completely corrode the metal in the waste and the waste drums; therefore, the potential for hydrogen generation due to corrosion will be limited by the total metal inventory. If brine seepage is a purely local phenomena due to redistribution of brine in the immediate vicinity of the excavations, there may be insufficient brine available to cause much corrosion after closure. In the latter case, hydrogen generation will be limited by brine availability and may not be a putential problem. Calculations indicate that it will take approximately 220,000 liters $(\mathrm{L})$ of brine per room to corrode all of the metals contained in the waste and waste drums emplaced in each waste storage room.

If no far-field flow exists, and radial flow occurs in a vertical plane toward a waste storage room, then release of brine from the DRZ around the excavations due to depressurization is estimated to produce about $150,000 \mathrm{~L}$ of brine. This volume is on the same order of magnitude as the volume of brine $(220,000 \mathrm{~L})$ necessary to corrode all the metal in the waste and waste storage drums in a waste storage room. Anoxic corrosion will consume brine and produce metal oxides and hydrogen. If the volume of brine entering the repository is less than that required to completely corrode the metal, then all of the brine that comes in contact with metal will be consumed.

There is good evicience that the assumption of radial flow in a vertical plane does not hold for the WIPP. The undisturbed clear halite units have such low permeability (or none at all) that flow is probably constrained and occurs only horizontally, parallel to bedding. Brine may only be able to drain from that part of the DRZ horizontally adjacent to the storage room. The volume of rock involved is about 7 percent of that involved in the estimate above. Assuming that the growth of fractures will tap a slightly thicker stratigraphic interval, including some strata above and below the 4-m-high storage room, an estimate of about 10 percent seems reasonable. In that case, less than one-tenth of the $150,000 \mathrm{~L}$ estimated above may enter the repository to react with the metal emplaced there and produce hydrogen gas by corrosion. If compaction of the clays is the major source of the brine rather than release of brine from the DRZ due to depressurization, then even less brine may enter the repository. In that case, the generation of large quantities of hydrogen gas is unlikely or even impossible.

The predicted consequences of human-intrusion events, the fate of waste-generated gases, and the migration of the hazardous constituents during undisturbed performance are all sensitive to brine inflow assumptions, even if both of the proposed systems yield similar volumes of brine 
during the pressurization phase after sealing. If the far-field model is valid, a humanintrusion event (drilling into the sealed repository at some future date) will lower fluid pressure in the waste storage rooms, create pressure gradients toward the rooms, and reinstate far-field flow. This will lead to a greater release of radionuclides from the repository as the inflowing brine infiltrates through the waste and flows up the drill hole. Alternatively, if the near-field model is valid, the only brine available for transport of radionuclides is the volume of brine that is trapped in the room at the time of sealing.

Predicting the fate of waste-generated gases is also dependent upon the hydrologic system assumed to be operational. If brine can flow through the far-field, excess gas pressure can probably be dissipated through the host rock; but if far-field flow is not a viable concept, gas generation from microbial or radiolytic decomposition of organic materials may yield very high local pressures. Analysis by the WIPP Engineered Alternatives Task Force has shown that predicted peak pressures are highly dependent upon the assumed mechanisms by which fluids can flow through the undisturbed host rock.

Another long-term performance concern is the migration of Resource Conservation and Recovery Act listed hazardous constituents from the repository. If far-field flow is valid, the generation of excess gas pressure within the repository may force gas, possibly contaminated with volatile organic compounds (VOC), across the RCRA unit boundary. However, if the far-field flow does not occur, there will be less of a potential for VOC migration.

Future Work. Although much is known about the brine seepages at the WIPP, there are still areas that need further examination. As stated above, the idea of far-field flow seems unlikely or hypothetically impossible but remains an important modeling concept that has not been disproved. The relative importance of near-field versus far-field flow remains an item of significant importance and should be resolved. The following questions need to be answered:

- Does the clay contain enough brine that can be squeezed out by vertical loading to explain all of the brine seepage observed at the WIPP?

- Is there enough volume present in void spaces and fractures in the DRZ beneath the floors of the excavations to hold large quantities of brine out of sight, and are those fractures connected well enough to allow brine (or gas) to flow downgradient and beneath potential seals?

- Does any far-field component of flow exist? 


\subsection{Introduction}

The Waste Isolation Pilot Plant (WIPP), a U.S. Department of Energy (DOE) research facility, was established to demonstrate the safe disposal of defense-generated radioactive waste in the United States. The WIPP facility is 42 kilometers east of Carlsbad, New Mexico (Figure 1-1). The repository is approximately 655 meters (m) below the surface (Figure 1-2) in the Salado Formation. The Salado Formation and underlying Castile Formation make up an evaporite sequence over $1,000 \mathrm{~m}$ thick (Figure 1-3). An extensive program of site characterization was initiated in 1976 (Powers and others, 1978; Bechtel, 1983) and continued through 1990 (Deal and others, 1991). The hydrogeological activities of the Brine Sampling and Evaluation Program (BSEP) is part of a continuing effort to refine the understanding of the repository geology. The data in this report constitute updates of previous studies (Deal and Câse, 1987; Deal and others, 1987; Deal and others, 1989; Deal and others, 1991).

Brine studies began in 1982 as part of the Site Validation Program (Black and others, 1983) and were formalized in 1985 by Morse and Hassinger. The focus of BSEP is the origin, hydraulic characteristics, extent, and chemical composition of brine in the Salado Formation at the repository horizon and seepage of that brine into the excavations at the WIPP. Although the repository is dry, brine weeps from exposed surfaces, accumulates in drill holes, and forms encrustations on the ribs. The chemistry of the brine may affect chemical reactions that might occur in the buried waste, and the volume of brine and the hydrologic system that drive the brine seepage need to be understood to assess the long-term performance of the repository after closure.

Possible brine inflow systems have been discussed in previous BSEP reports. There are basically two systems: one in which far-field flow occurs through undisturbed rock outside of the zone of rock deformation (Disturbed Rock Zone [DRZ]) and a local near-field system where brine is redistributed within the DRZ. Additional effects, such as gas exsolution, development of enhanced porosity and permeability within the DRZ, and preferential flow along bedding planes may modify brine inflow, but it is fundamentally important to distinguish between far-field sources and local, relatively limited redistribution of brine in the immediate vicinity of the WIPP excavations. In both cases the driving mechanism is the pressure gradient caused by the excavation of the underground openings. Flow pathways are through permeable interbeds, along stratigraphic discontinuities, or through fractures. 


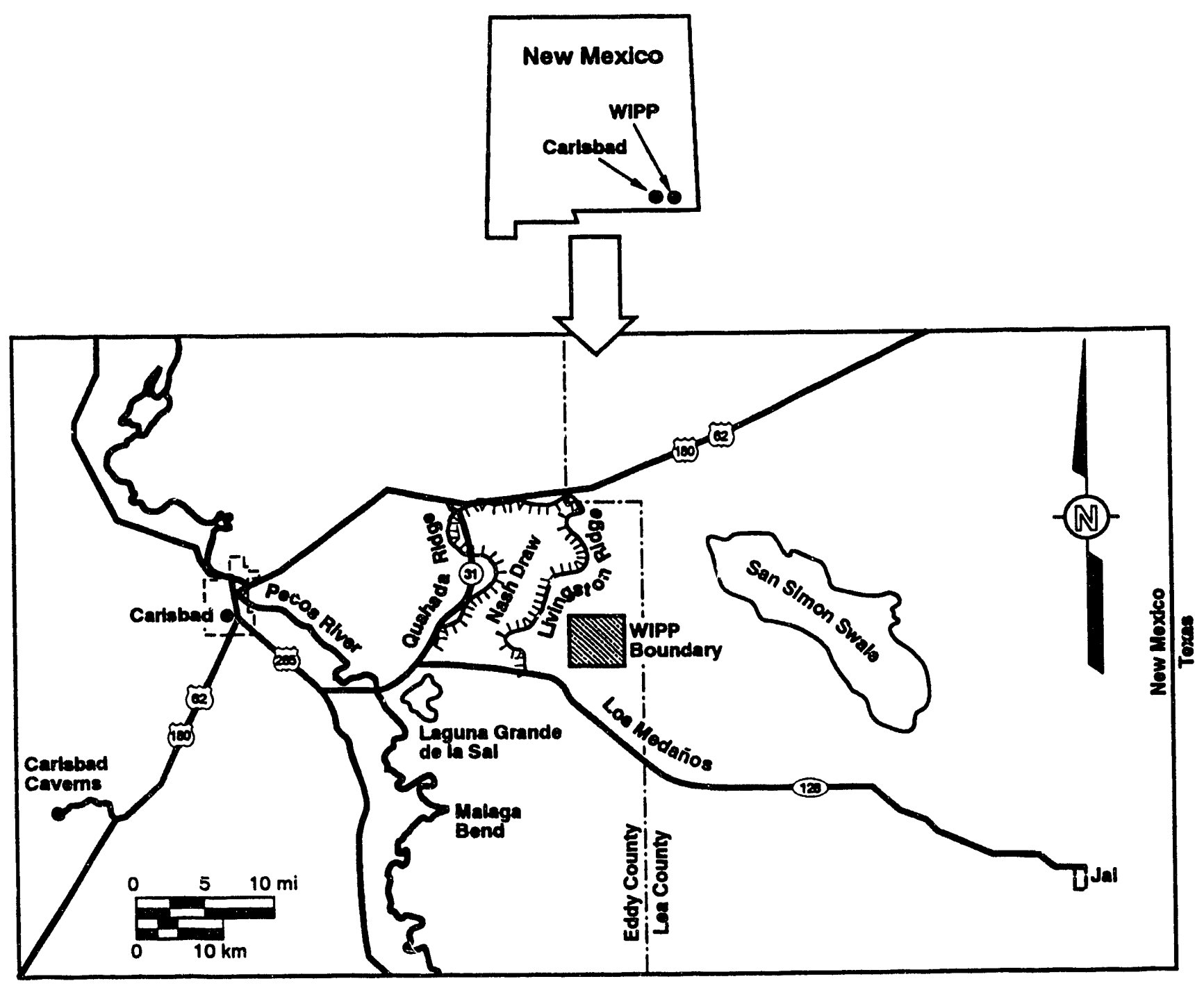

Figure 1-1

WIPP Location in Southeastern New Mexico 
2
2
8
$\overline{8}$
$\frac{8}{8}$

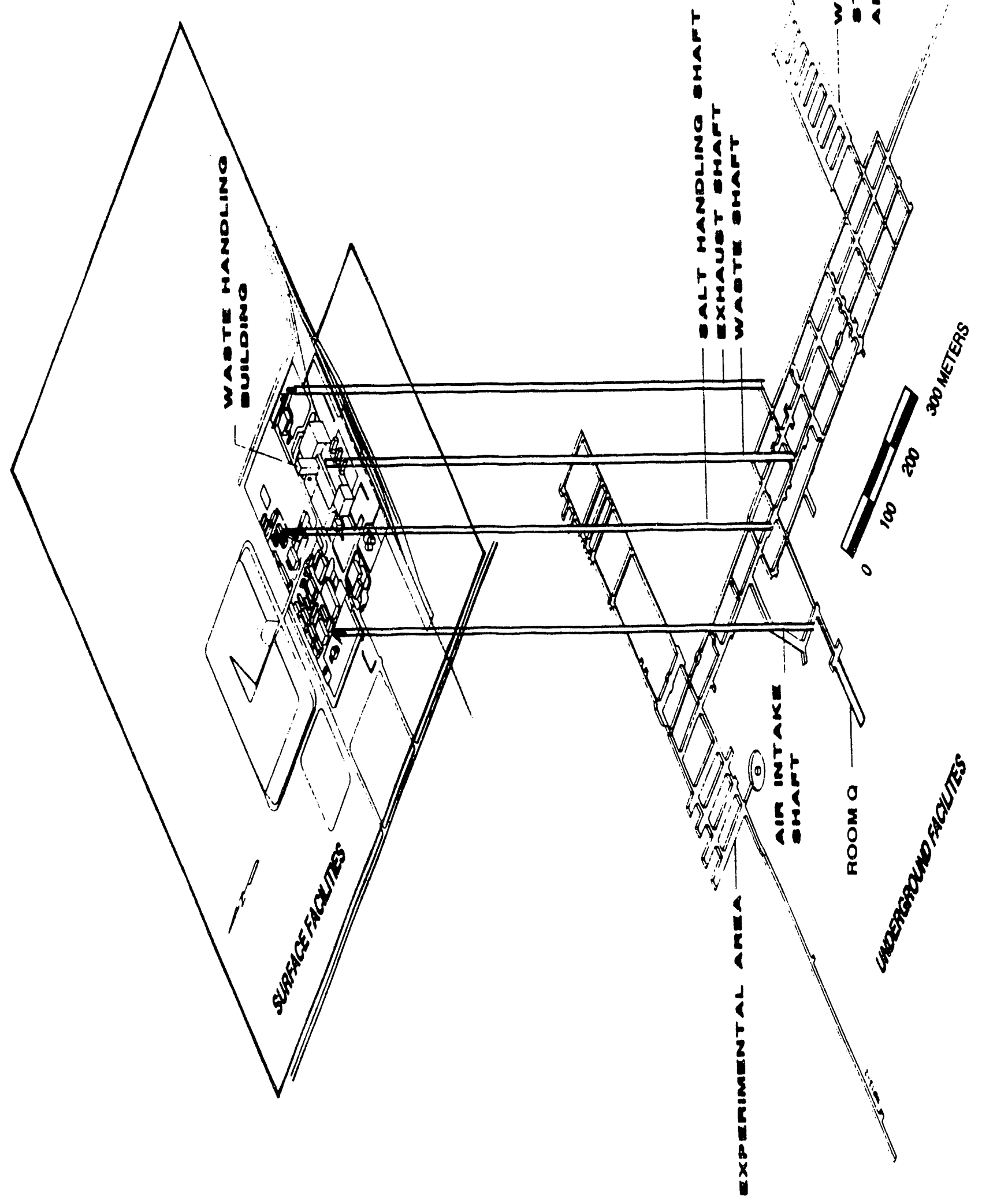




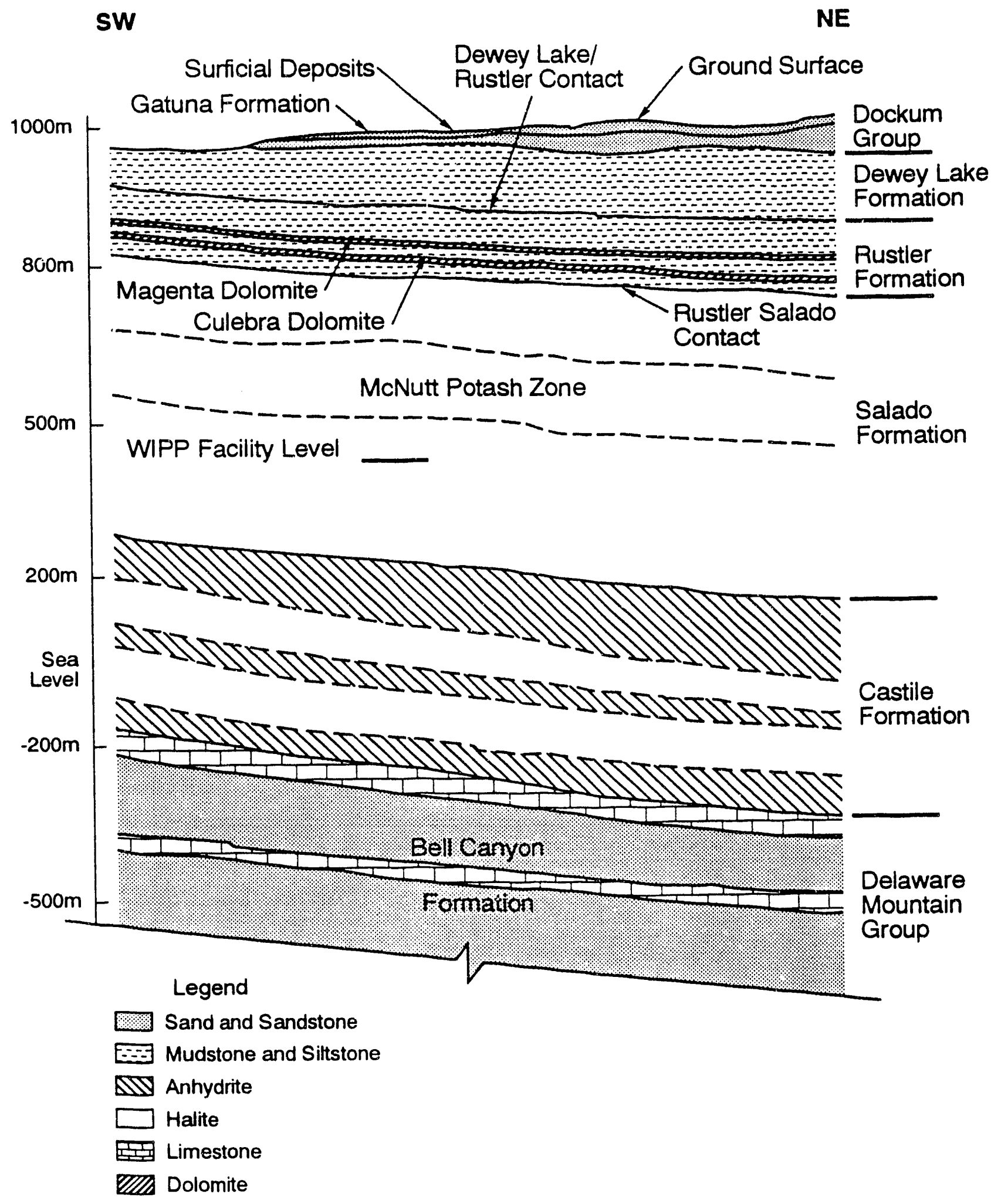

Figure 1-3

Generalized Stratigraphic Cross Section (Modified from Figure 1-2, Deal and Case, 1987) 
The relative importance of these two systems needs to be determined. For example, if there is sufficient far-field flow into the repository, then enough brine may come into the excavations to completely corrode the metal in the waste and the waste drums; therefore, the potential for hydrogen generation due to the corrosion will be limited by the total metal inventory. If brine seepage is a purely local phenomena due to redistribution of brine in the immediate vicinity of the excavations, there may be insufficient brine available to cause much corrosion after closure. In the latter case, gas generation will be limited by brine availability and may not be a potential problem.

The predicted consequences of human-intrusion events, the fate of the waste-generated gases, and the migration of the hazardous constituents during undisturbed performance are all sensitive to brine inflow assumptions, even if both of the proposed systems yield similar volumes of brine during the pressurization phase. If the far-field model is valid, a humanintrusion event (drilling into the sealed repository at a future date) will lower fluid pressure in the waste storage rooms, create pressure gradients toward the rooms, and reinstate far-field flow. This will lead to a greater release of radionuclides from the repository as the inflowing brine infiltrates through the waste and flows up the drill hole. Alternatively, if the near-field model is valid, the only brine available for transport of radionuclides is the volume of brine that is trapped in the room at the time of sealing.

Predicting the fate of waste-generated gases is also dependent upon the hydrologic system assumed to be operational. If brine can flow through the far-field, then excess gas pressure can probably be dissipated through the nost rock; however, if far-field flow is not a viable concept, gas generation from microbial or radiolytic decomposition of organic matcrials may yield very high local pressures. Analysis by the WIPP Engineered Alternatives Task Force (EATF) has shown that predicted peak pressures are highly dependent upon the mechanisms by which fluids can. Ilow through the undisturbed host rock (DOE, 1991).

Another long-term performance concern is the migration of Resource Conservation and Recovery Act (RCRA) listed hazardous constituents from the repository. If far-field flow is valid, the generation of excess gas pressure within the repository may force gas, possibly contaminated with volatile organic compounds (VOC), across the RCRA unit boundary. However, if the far-field flow does not occur, there will be less potential for VOC migration.

Certain collection techniques and general observations should be considered when evaluating the BSEP data. These are listed in Table 1-1. Care should also be exercised when 


\section{Table 1-1}

\section{Points to be Considered When Evaluating BSEP Data}

1. Many of the downholes are contaminated with water spread on the floor for construction purposes or salt-dust control.

2. All downholes were originally pumped with a bailer on a two-week interval. During 1989, pressure-suction moisture collection devices were installed in the holes. These devices have a capacity of less than 1 liter, and the sampling frequency was increased to once a week. The limited capacity of the collection device requires sampling on the following day for quantities of a halfliter or more. The two-day total is then averaged (see Appendix A).

3. Brine seepages are small and chemically distinct from brines in the Rustler Formation and Castile Formation.

4. Brine occurrences, particularly those evidenced as halite efflorescences, are ubiquitous on ribs (walls) but not the back (roof) in recently mined areas throughout the WIPP underground.

5. Brine seepage rates into test drilholes are low, usually on the order of a few hundredths of a liter per day or less.

6. Although small when measured in terms of liters per day at any given location, cumulative seepage volumes may be significant when measured in terms of the entire repository over many years.

7. Brine seepage into downholes can vary several orders of magnitude between locations, even when locations are less than 1 meter apart.

8. Upholes and downholes show a pattern of an initial, maximum flow rate that riduces to a steadier (or much more slowly declining) flow rate over the time period during which measurements have been made. Many of the upholes dry up completely.

9. Vertical drill holes yield inconsistent data, but horizontal drill holes provide consistent and comparable data sets.

10. The details of flow in these very low-permeability units are quite complex, have very low velocities, appear to involve small volumes of brine, and require testing over long periods of time during which the very properties being tested change; therefore, they are difficult to quantify. 
interpreting the various diagrams of drill hole lengths and stratigraphic thicknesses. Although the strata at the WIPP are remarkably uniform in both composition and thickness, some variation occurs. As a result, there are significant, albeit small, differences from north to south and from east to west within the WIPP excavations. To facilitate the modeling of excavation performance, a meeting was held in 1983 with DOE; Bechtel National, Inc.; Sandia National Laboratories/New Mexico (SNL/NM); and the technical services contractor (Westinghouse Electric Corporation [Westinghouse] and IT Corporation [IT]) to develop a consensus on the average thicknesses and rock properties that exist near the excavations (Krieg, 1984). The resulting 1983 reference stratigraphy is not an actual measured section and is defined in relation to distances above and below clay $\mathrm{G}$, which is located at the base of anhydrite "b," approximately $2 \mathrm{~m}$ above the roof of the repository level excavations (Table 1-2).

Table 1-2 compares that reference stratigraphy to the stratigraphy observed in two sets of drill holes: A1X01 and A1X02 in Room A1 in the northeastern part of the repository excavations and DH35 and DH36 in Room G in the northwestern part of the excavations. The distances from the drill hole data are used in the discussions in Chapter 2 of this report. If the precise relationship between the stratigraphy and a given drill hole is important, the drilling log and/or core from the specific hole should be consulted.

Activities in 1990 provided additional information on the brine inflow in the repository (Chapter 2), geochemical properties of the brine (Chapter 3), and numerical modeling of seepage into long, small-diameter subhorizontal drill holes (Chapter 4). Chapter 5 is a summary, not only of the 1990 work, but of all work to date.

Appendix A provides detailed information of the brine inflow from drill holes monitored for this program. The information includes drill hole, date, time, liters (L) removed, days since January 1, 1985 (an arbitrary reference date), the cumulative $L$ collected, inflow rates in $L$ per day, and a remarks column. Appendix B contains graphs of the data from Appendix A, presented as an 11-point moving average of the data. This averaging reduces noise introduced by collection techniques and presents a more accurate picture of the real variations in brine seepage rates than would be presented by plots of raw data. Appendix $\mathrm{C}$ shows the analytical results of the chemical analyses, including ion concentration in milligrams per liter ( $\mathrm{mg} / \mathrm{L}$ ), pH, specific conductivity, and alkalinity. Appendix D summarizes the statistical analyses of the geochemical data. Appendix $E$ is an activity plan proposed to provide additional brine seepage data. This report constitutes a permanent quality assurance record 


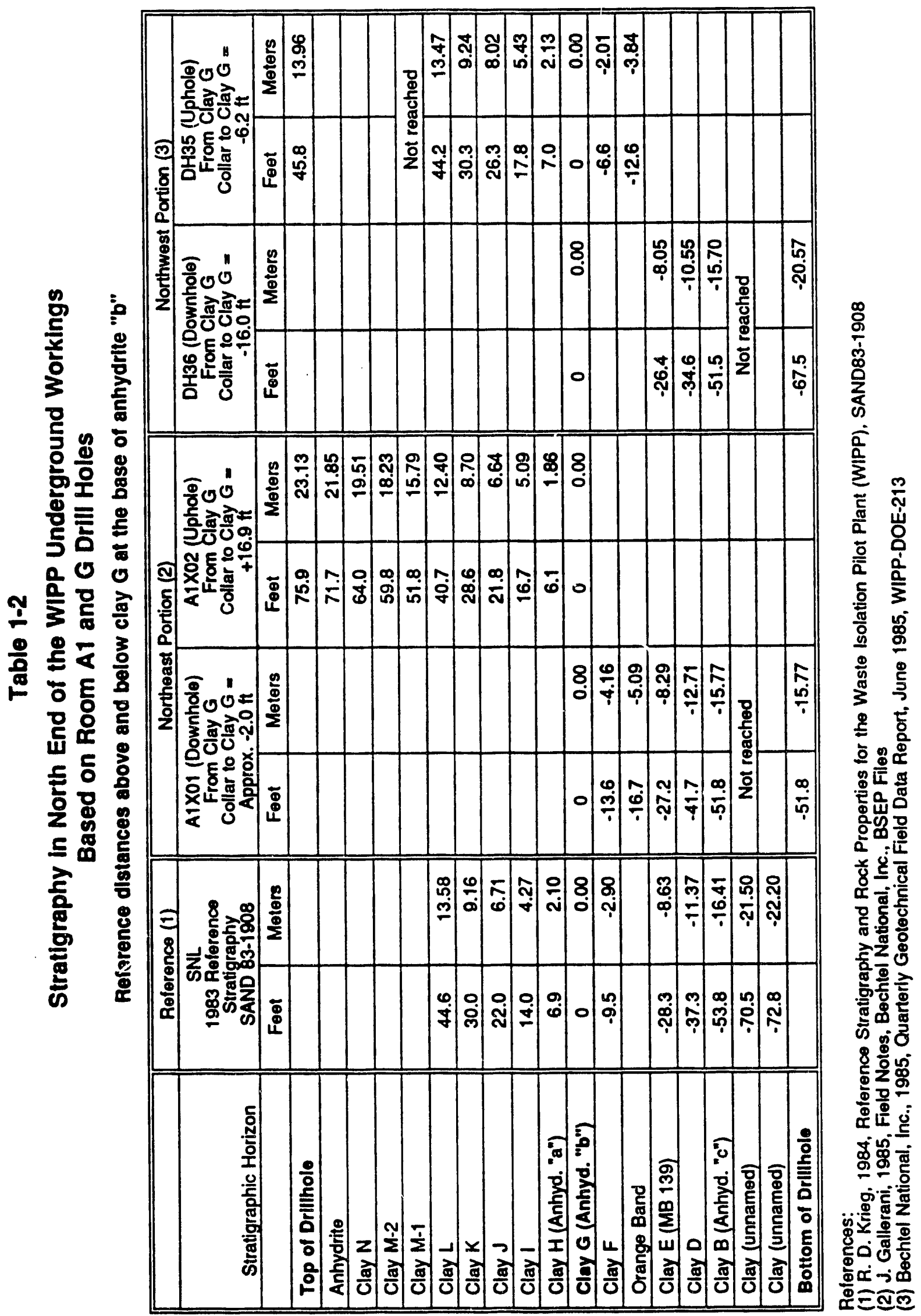


and will be retained for this purpose, as stipulated in the quality assurance sections of the Geotechnical Engineering Program plans and procedures. 


\subsection{Monitoring of Brine Inflow Parameters}

\subsection{Introduction}

Brine seepage observations in underground locations at the WIPP began as early as 1982. Information regarding the inflow of brine was derived from observations and mapping of moist areas and measurements of brine seeping into holes drilled downward from the floor, upward from the back (roof), and subhorizontally from the rib (wall) of the facility. The locations of the BSEP observation holes are shown in Figure 2-1, superimposed on a map of the facility as it existed on December 31, 1990. The underground locations of these boreholes are listed in Table A-1 of Appendix A. Appendix A lists the quantity of brine removed, calculated inflow rates in $\mathrm{L}$ per day, and cumulative $\mathrm{L}$ for all the boreholes monitored in 1990. The brine accumulations from these boreholes at the repository horizon and the stratigraphy of the Salado Formation have been discussed in previous reports (Deal and Case, 1987; Deal and others, 1987; Deal, 1988; Deal and Roggenthen, 1989; Deal and others, 1989; and Deal and Roggenthen, 1991; and Deal and others, 1991). In addition to recording 1990 BSEP activities, some observations made in previous years but not noted in earlier reports are included in this document.

\subsection{Brine Seepage on Vertical Surfaces (Weeps)}

\subsubsection{Observations When Surfaces Were Newly Excavated}

The initial mining of the East 0 drift began October 14, 1982, with a continuous mining machine. Small moist areas began to appear on freshly mined surfaces (TSC-D'Appolonia, 1983a; TSC-D'Appolonia, 1983b). Alcorn (1983) summarized that work and documented the occurrences with a number of photographs and detailed maps. Effervescing moist areas on newly mined surfaces were described by Deal and Case (1987):

"Small quantities of gas are associated with some weeps. Slowly bubbling $v$ ret areas, usually about 2 to 3 centimeters in diameter, are occasionally very noticeable within a few minutes of mining. The bubbling usually decreases within an hour or two after mining, and the rate of inflow to freshly mined surfaces of both brine and gas decreases rapidly."

\subsubsection{Growth of Encrustations with Time}

In November 1982, 18 weep areas were described and marked with a tag fixed to the salt bedrock with a ram-set nail to allow repeat observations of exactly the same area. By April 1983 , three of those areas were destroyed by mining, nine appeared dry, four were moist but 


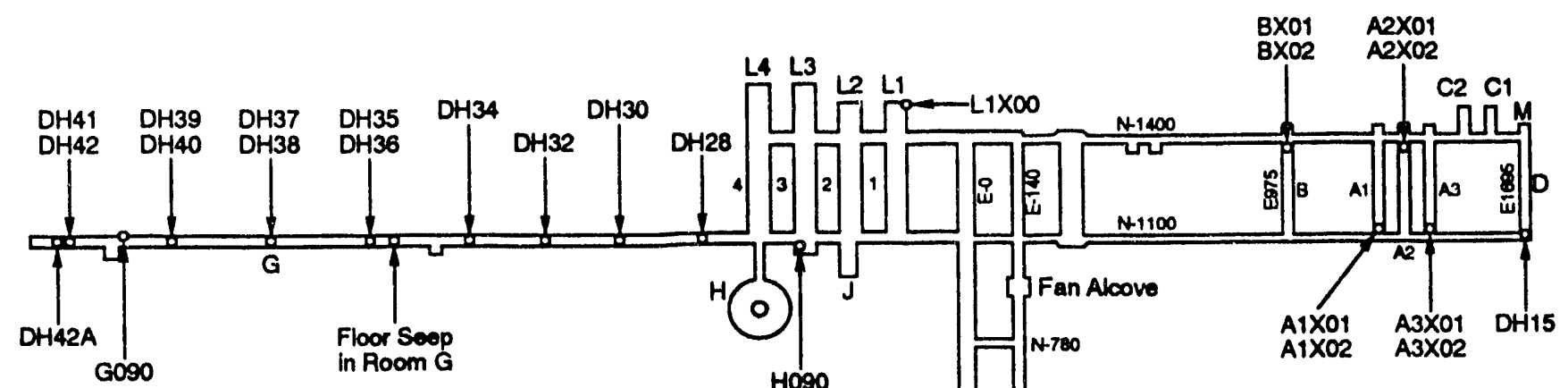

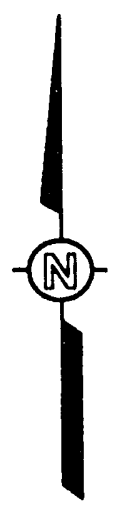

\section{Legend}

Completed Excavation 12/31/90

Planned Excavation

Drillhole(s) used tor brine

Observation

Represents 2 or more drill $\quad \square$ holes

\section{Note}

1. Mine coordinates in feet from the center of the salt handling shaft

2. Dritt widths not to scalo, enlarged $2 X$ for clarity

$\underbrace{0}_{0} \quad 400 \quad 800 \mathrm{FT}$

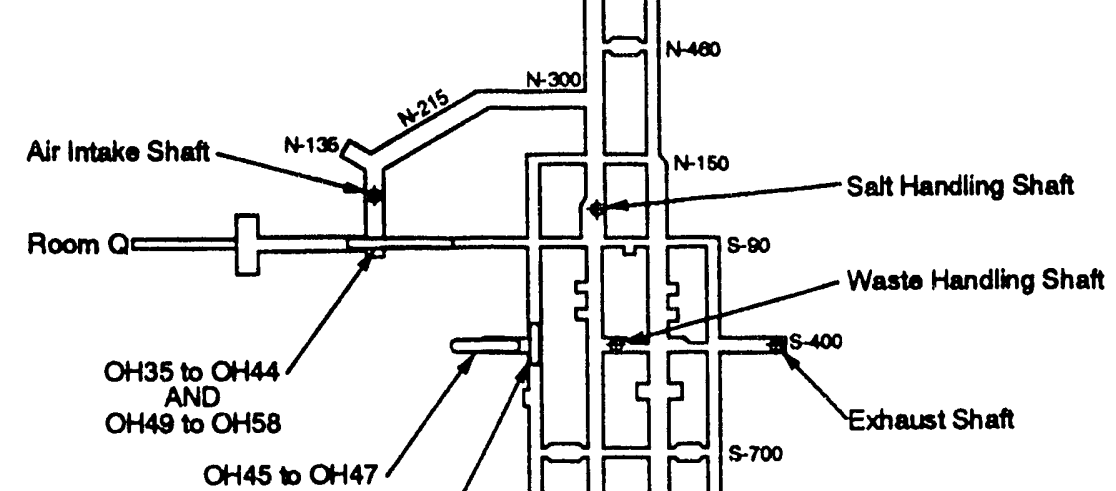

OH59 to OH69
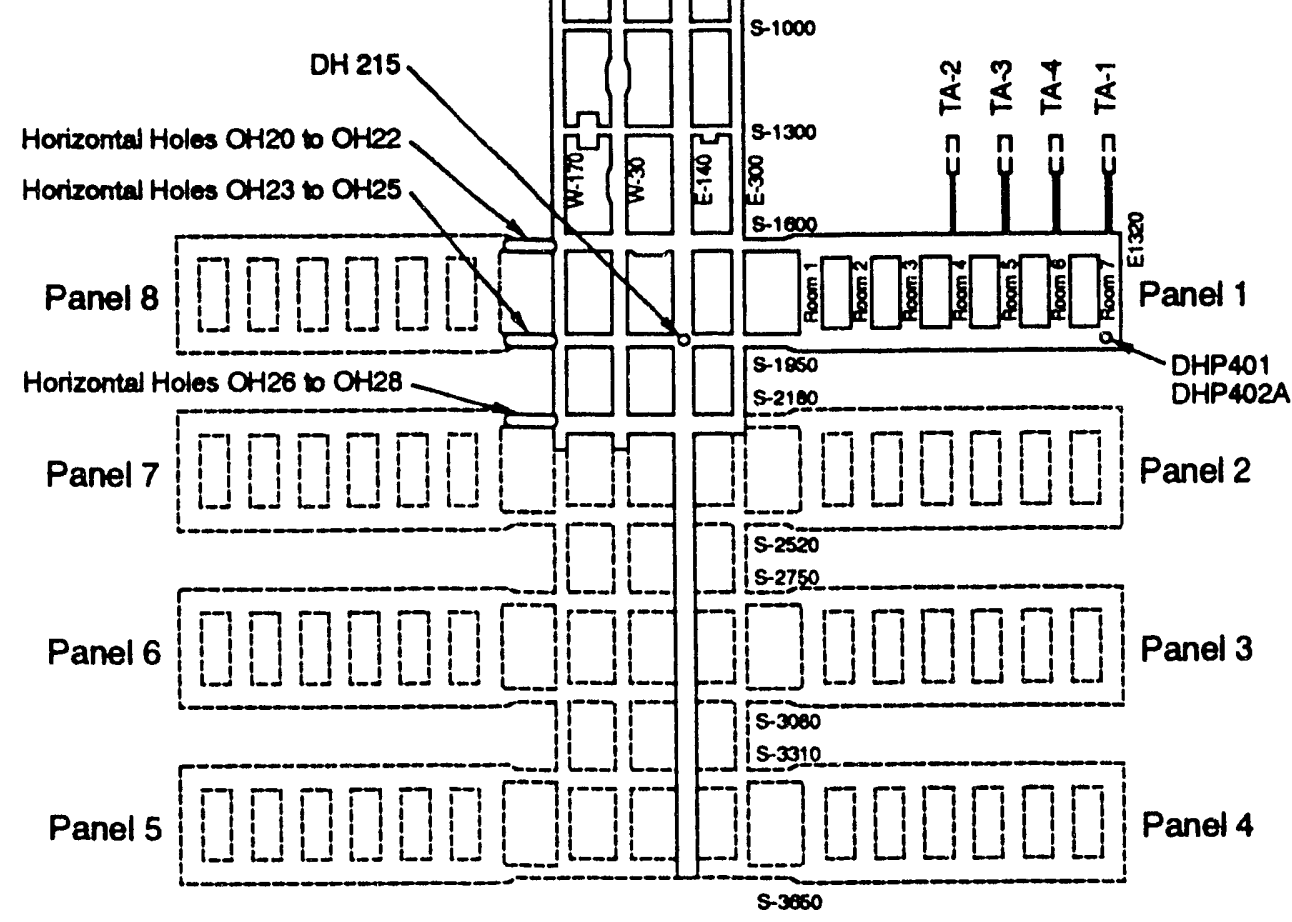

Panel 3

Panel 4

Figure 2-1

Map of WIPP Underground Working Showing BSEP

Observation Locations as of December 31, 1990 
lacking encrustations, and two were forming encrustations. Eight locations photodocumented in November 1982 were rephotographed in February 1988-five and a half years later. These photos show areas of the west wall of the E0 drift, at N164.4, N171.5, N174.2, N177.0, N183.5, S328.0, S398.7, and S400. These locations were dry by 1988 .

The pattern of moisture release varies with time. After initial bubbling ceases, additional moisture appears slowly over periods of hours or days (Figure 2-2) (Deal and Case, 1987). Several months after mining, moist areas on vertical surfaces have become common and often remain moist for another year (Figure 2-3). Moist areas are concentrated at and below the orange band (Map unit 1) and the clay seam that separates Map Units 4 and 5 (clay F) (Figure 2-4). Clay G, just below anhydrite "a," appears to contain more brine (Figure 2-5) but is not exposed in most of the WIPP excavations. Evidence of moisture and the presence of weeps varies directly with clay content of the strata (Alcorn, 1983; Deal and others, 1989). The greater the clay content, the more persistent and greater the number of weeps. There appears to be a slightly greater clay content in the repository-horizon strata exposed in Room $\mathrm{G}$, which is probably the reason that there are more salt encrustations on the walls of Room $G$ than in most other parts of the excavations. Weeps have been observed on all exposed vertical surfaces at the repository horizon, including clear halite (Deal and Case, 1987).

Small, white encrustations of precipitated salt form between the damp areas (Figure 2-6). A few months after excavation, most appear dry on the surface, but are damp within. This indicates that the brine inflow has decreased in volume and not ceased entirely (Deal and Case, 1987). The encrustations cease to grow a few years after excavation.

When an aged excavation is slightly enlarged, weeping and encrustation growth is renewed. As the DRZ develops around the excavations (Deal and Roggenthen, 1991), porosity and permeability close as the excavation increases. There may be a relative increase in permeability of 40 percent or more (refer to Section 4.3; Deal and other, 1989, Section 5.8.2.2). When the aged surface is trimmed, the stress gradient close to the excavation is readjusted. The increased permeability with respect to initial conditions allows brine seepage to be rejuvenated on the trimmed surface.

The chemical analyses (Krumhansl and others, 1987) of weep encrustations are magnesium deficient relative to typical brine geochemistries due to precipitation in an open system where there is a continual input of brine (refer to Section 3.2.1). The ambient air at the repository horizon is incapable of evaporating all of the brine that seeps into the excavations 


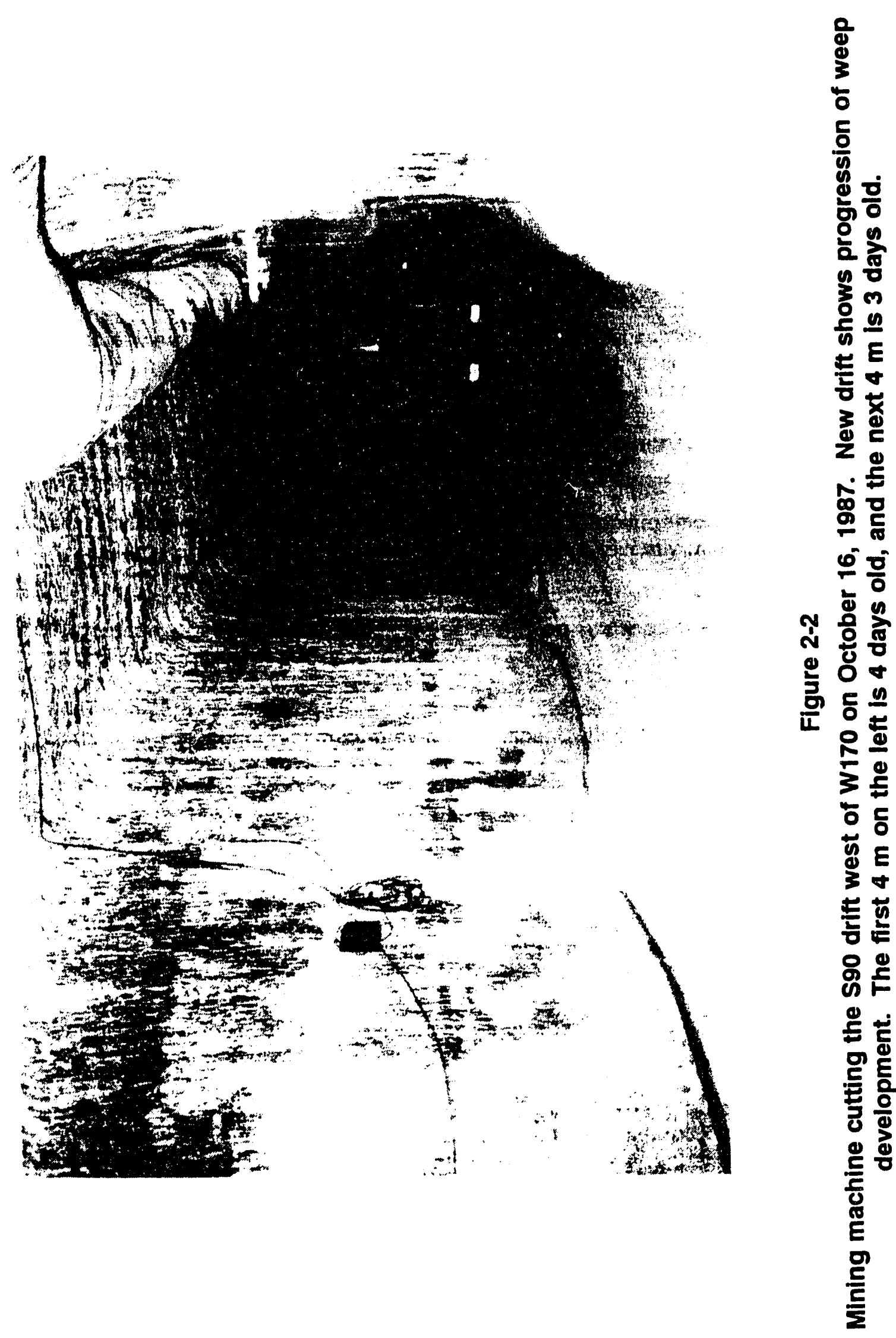



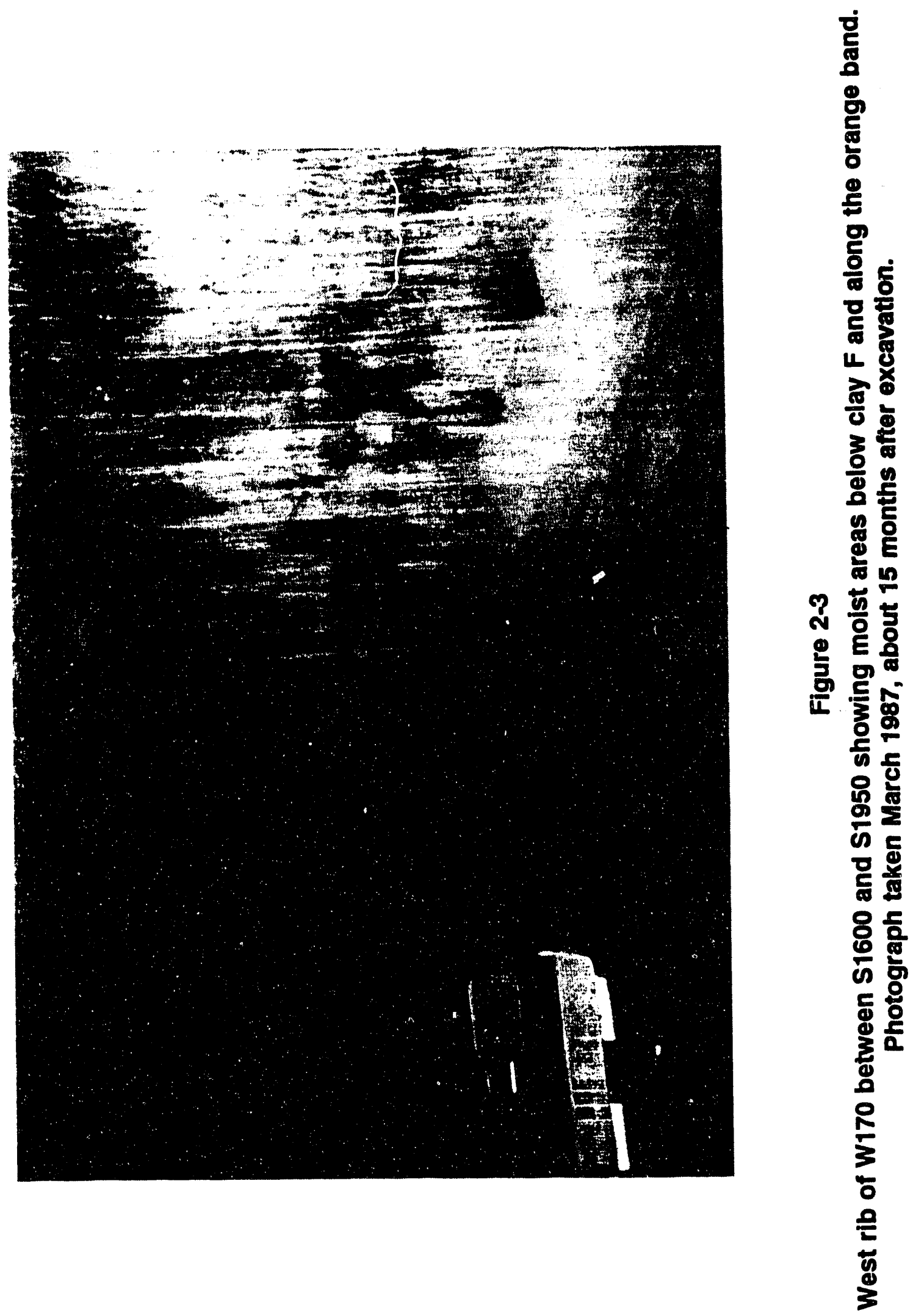


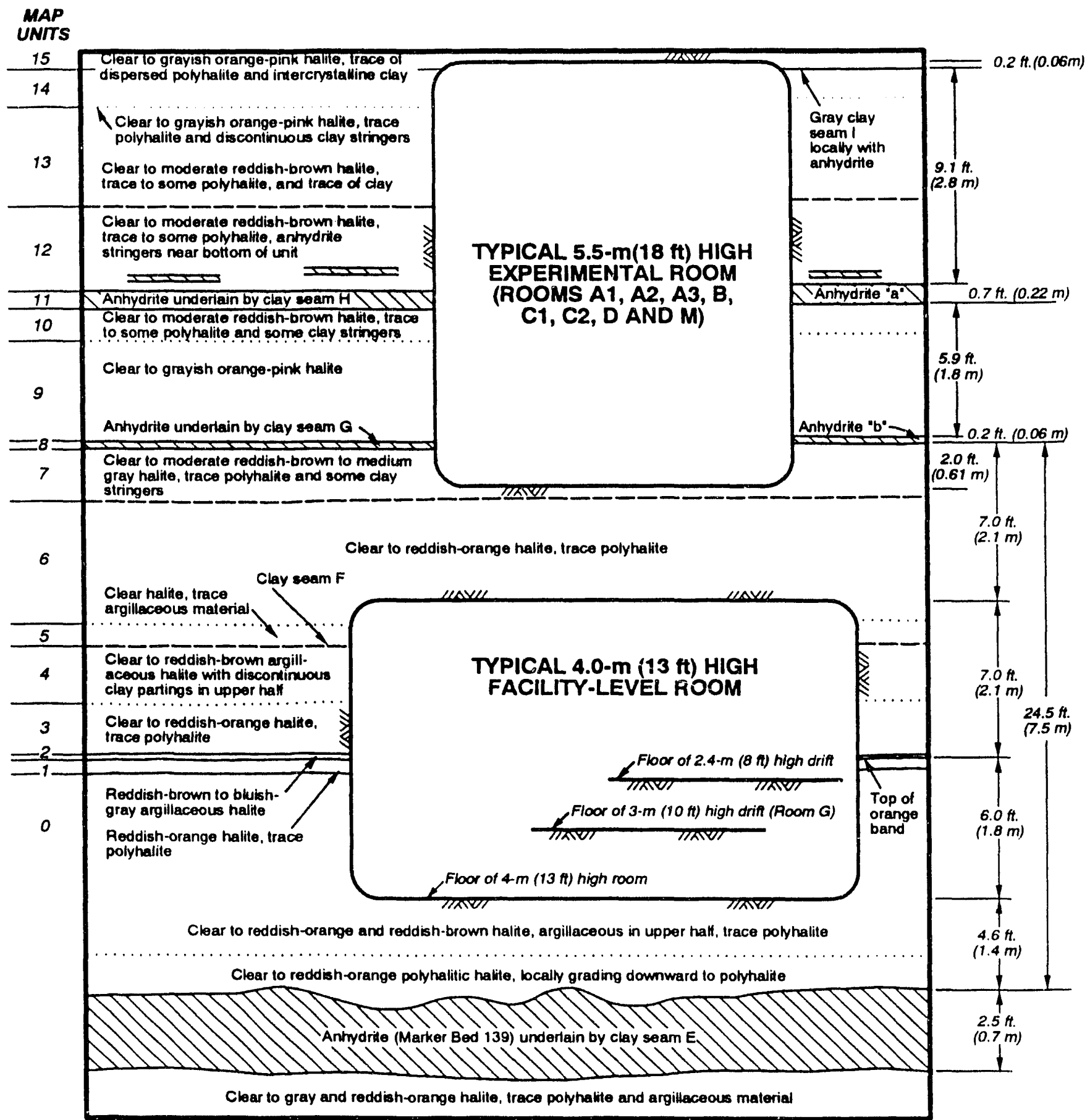

\section{NOTES:}

1. Dimensions and lithologic descriptions are derived primarity from corehole and geologic mapping dala from the four lest rooms and experimental area.

2. Unit thicknesses are approximate and vary slightly.

3. Room dimensions have changed with time due to salt-creep closure. (After Deal and Case, 1987)

Figure 2-4

\section{Geologic Cross Section of the Facility with Unit Number Designations (Modified from Bechtel, 1985)}




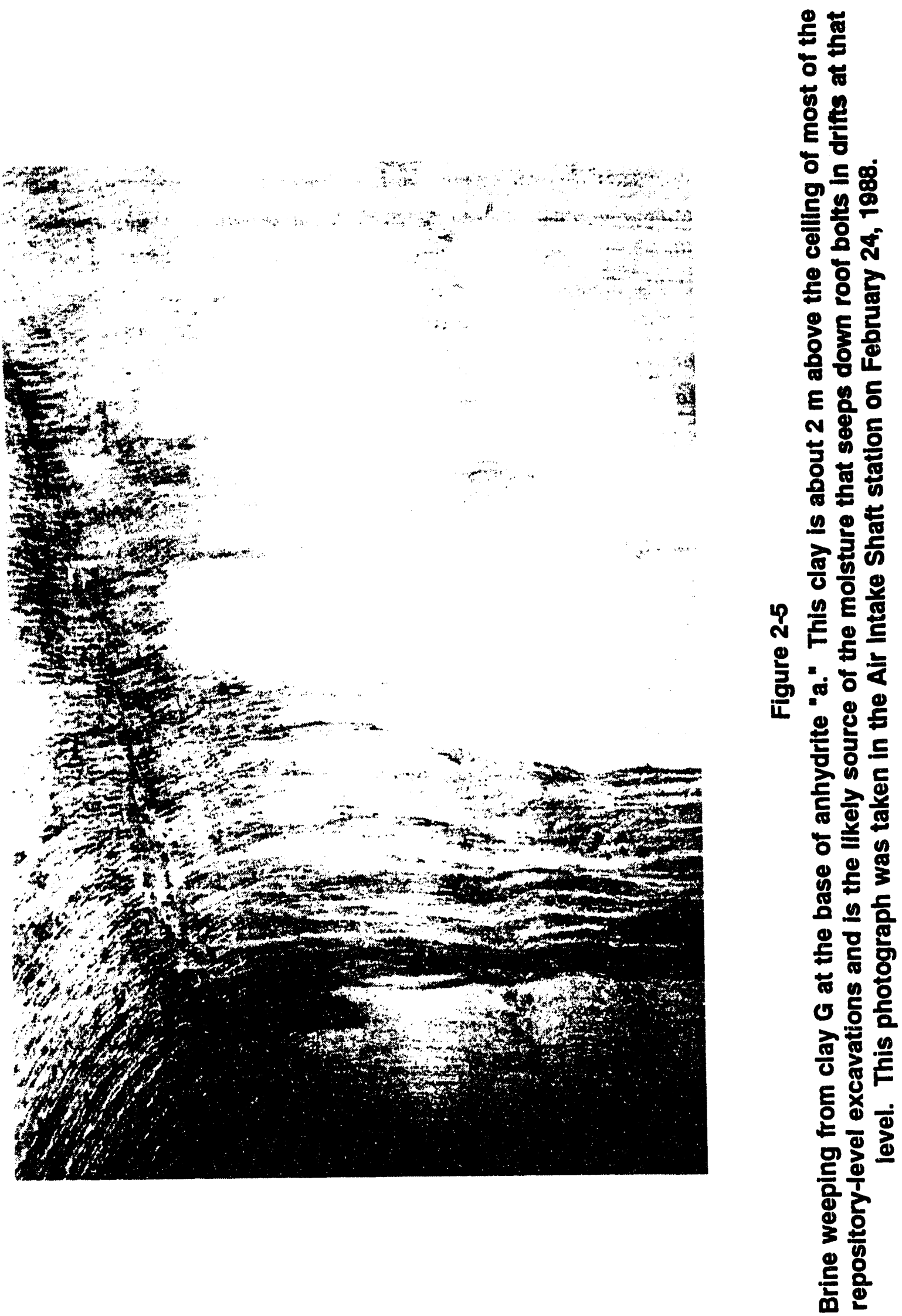




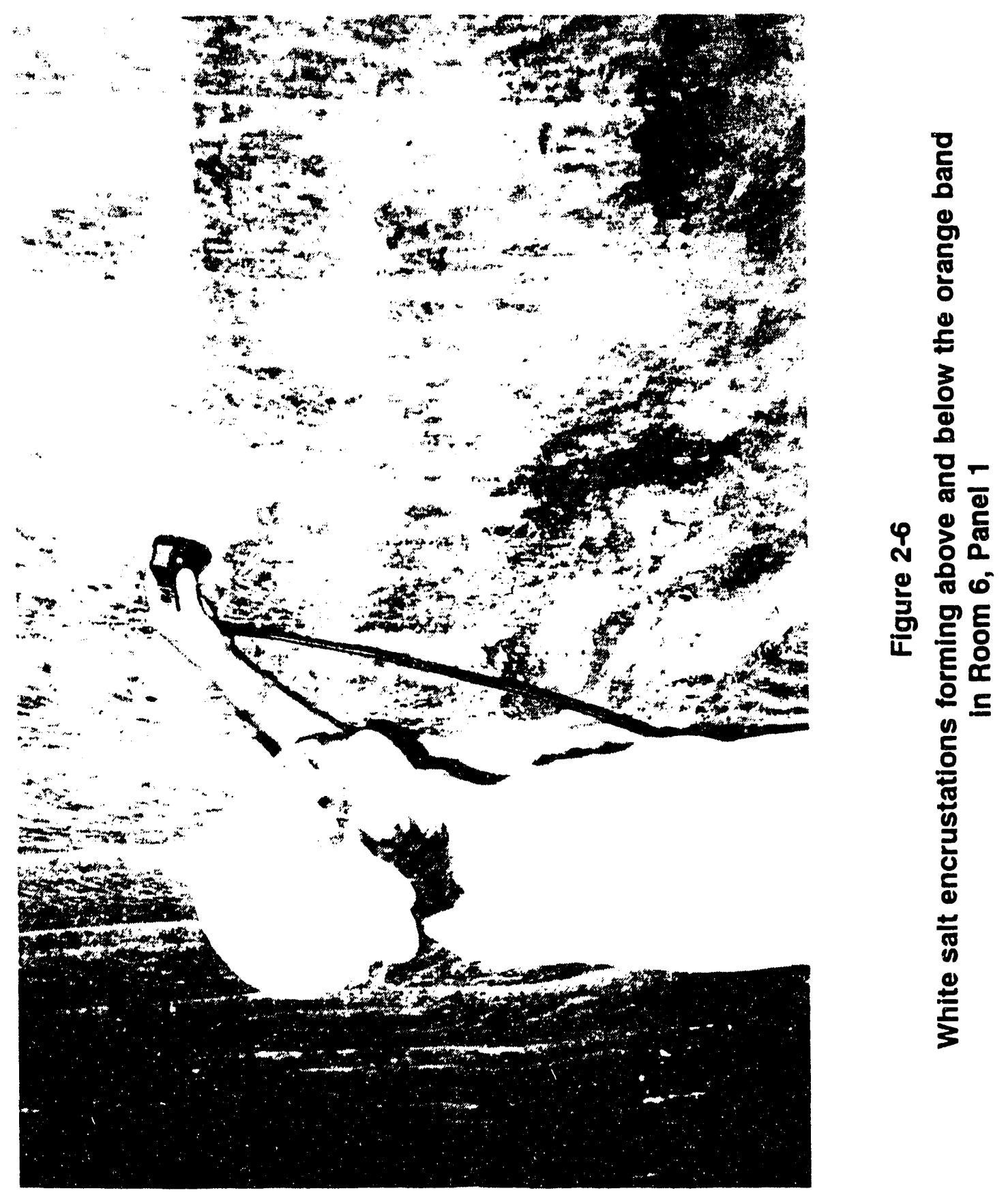


(Krumhansl and others, 1987; Deal and others, 1989), particularly the high-magnesium brines resulting from concentration by precipitation of halite. The salt dilates and becomes more porous as it creeps into th: excavations; preliminary modeling around room-size (shaft-size) excavations indicates an approximately 40 percent relative increase in porosity near the excavations (refer to Section 4.3; Deal and others, 1989, Section 5.8.2.2). The brine remaining after evaporation may occupy the i.acreased forosity in the zone of dilatancy behind the walls, collect on the floor, or seep into fractures or pores below the drifts.

\subsection{Brine Seepage from the Back}

Weeps and salt encrustations are more common and persistent on the ribs than on the back of the excavation (sce TaLic 1-1, point 4) (Deal and Case, 1987; Deal and others, 1987; Deal and others, 1989). This strongly suggests that the brine flows horizontally along bedding with little vertical flow across bedding, at least until open fractures develop that permit the brine to drain downward (Deal and Ruggenthen, 1991). The clear halite units may be effectively impermeable. State-of-the-art testing (Beauheim and Holt, 1990; Beauheim and Howarth, 1991) was unable to measure any permeability, indicating that if it exists at all, intrinsic permeability of the clear halite units is less than $1 \times 10^{-23} \mathrm{~m}^{2}(0.01$ nanodarcy), the limit of the test equipment. Consequently, the clear halite units (map units 0 [lower part], 3 , $6,9,13$, and the clear halite below clay B) prohibit vertical brine flow in the undistur.ed Salado Formation (Figure 2-7). Clay seams and partings further inhibit flow across bedding. The only observed brine seeps from the cfili:g occur when drill holes cut the clear halite in the roof, clay seams (Figure 2-5), and interbeds above them. In these cases, brine from upholes seeps to the collar and forms sait stalactites (Deal and Case, 1987, Section 3.1.2.2).

\subsection{Sumfriary of Rib and Back Observations}

A DKZ develops around newly mined openings in salt where deviatoric stress can provide a driving mechanism for brine seepage (Deal and Case, 1987). The first few hours after the excavation of a new opening, a DRZ develops a short distance into the surrounding rocks with a high deviatoric stress close to the opening. Gas exsolving from the brine is also driven toward the opening, and bubbling moist spots appear along the mined face.

Within a day, the DRZ extends farther from the excavated surface; the decreased stress gradients reduce the rate of brine and gas flow. Brine is preferentially associated with those lithologic units that contain the mest claj (clay F and the clays above and below the orange band). Rrine gradually becomes evident aiong these units, and patches of brine often extend downward from them (Figures 2-2 and 2-3). These patches are most apparent for a year or 


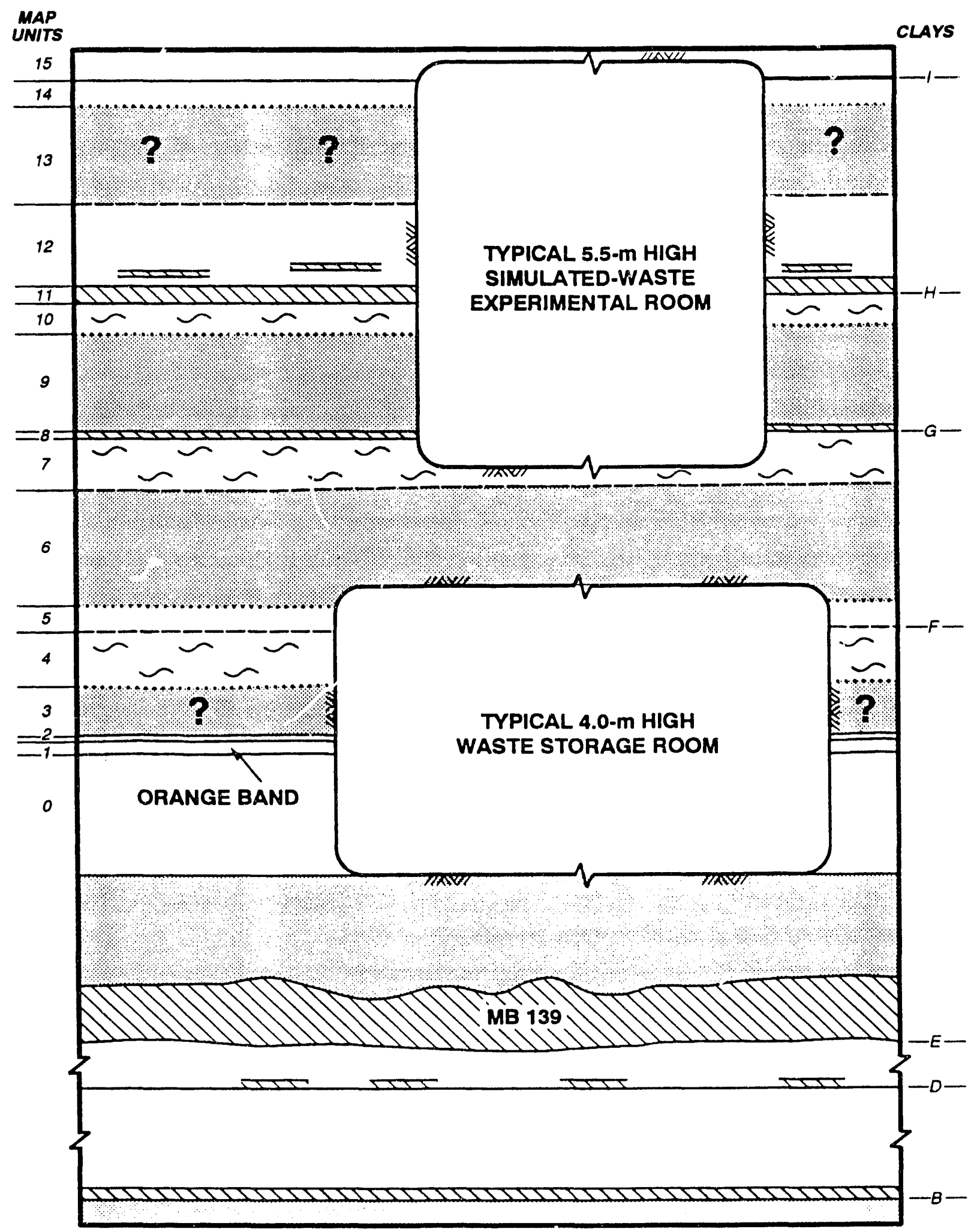

Figure 2-7

Clear Halite Beds with No Measurable Permeability (Less than $1 \times 10-23 \mathrm{~m}^{2}$ ) Constrain Brine Flows. Tested Beds Shown as a Shaded Pattern, Question Marks Indicate Untested Beds with Same Lithology (from Beauheim and Howarth, 1991). 
two after excavation. Salt encrustations form due to brine evaporation in the repository atmosphere.

Stress gradients decrease toward the openings with age. Dish-shaped fractures develop in the ribs (Figures 2-8 and 2-9), interdicting additional subhorizontal flow toward the openings (Deal and Roggenthen, 1991). The accumulation of moisture and the growth of weep encrustations on vertical surfaces in the WIPP usually ceases one and a half to two years after excavation.

\subsection{Damp or Wet Areas on Floors}

Moist areas on the floor have been discussed previousiy by Deal and Case (1987), Deal and others (1987), Deal and others (1989), and Deal and others (1991). A brine seep on the floor of Room G (known as GSEEP), located at approximately N1100 W1140, is the only persistently moist area in the WIPP excavations. Inflow data for GSEEP is contained in Appendix A with a smoothed graph of the data in Appendix B. A description of the location and a discussion of the seepage history through December 1988 is contained in Deal and others (1989). The seepage rate reached a maximum of $0.75 \mathrm{~L}$ per day in April 1989 but declined to $0.4 \mathrm{~L}$ per day by December 1990. A total of $875 \mathrm{~L}$ have been collected, and more has evaporated into the air circulated through the WIPP workings.

The brine chemistry of GSEEP differs from uncontaminated downholes (refer to Chapter 3). The chemical differences indicate some dilution by dissolving Salado salt in fresher water and/or partial evaporation. The dilution was probably accomplished by mixing normal Salado Formation brine with artificial brine spread on the floors for sait-dust control (refer to Section 3.3). Although water has not been spread for construction purposes in Room G, such water has been spread in the $G$ Access drift, the Site Preliminary Design Validation (SPDV) Rooms, and E0 drift. Examination of the structural contour map (Figure 2-10), with the assumption that gravity flow can only take place beneath the drifts after fracturing has occurred (not down-dip in unfractured rock), shows that the location of GSEEP corresponds to a small flexure, which could channel brine toward the GSEEP location. Water spread on floors as far away as $\mathrm{N} 1400$ and E0 or used in experiments in Room J are possible sources for the brine. These sources are unlikely because this would require that water from these locations move downslope through fractures in the DRZ to the structural low point (the approximate location of GSEEP) and then find its way to the surface of Room $G$. This movement of brine apparently does not occur, primarily because sizeable air-filled fractures are intersected by a large- (91-centimeter [cm]) diameter, 3.6-m-deep drill hole at the intersection of SPDV Room 4 and the N1100 drift. Additionally, drill hole DH36, located 


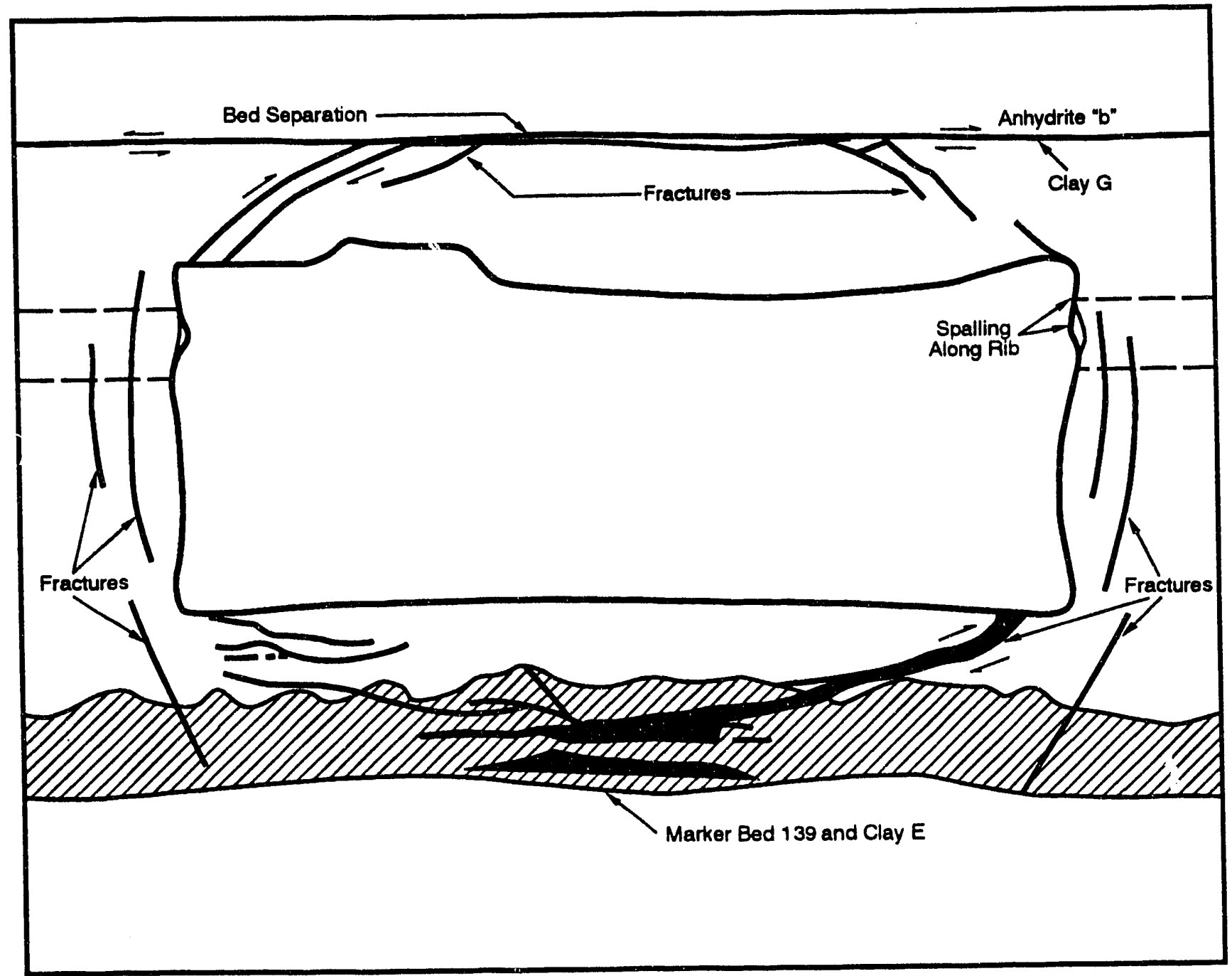

Figure 2-8

Cross Section of Fracturing Around a 4-m-High, 10-m-Wide Waste Storage Room at the WIPP 


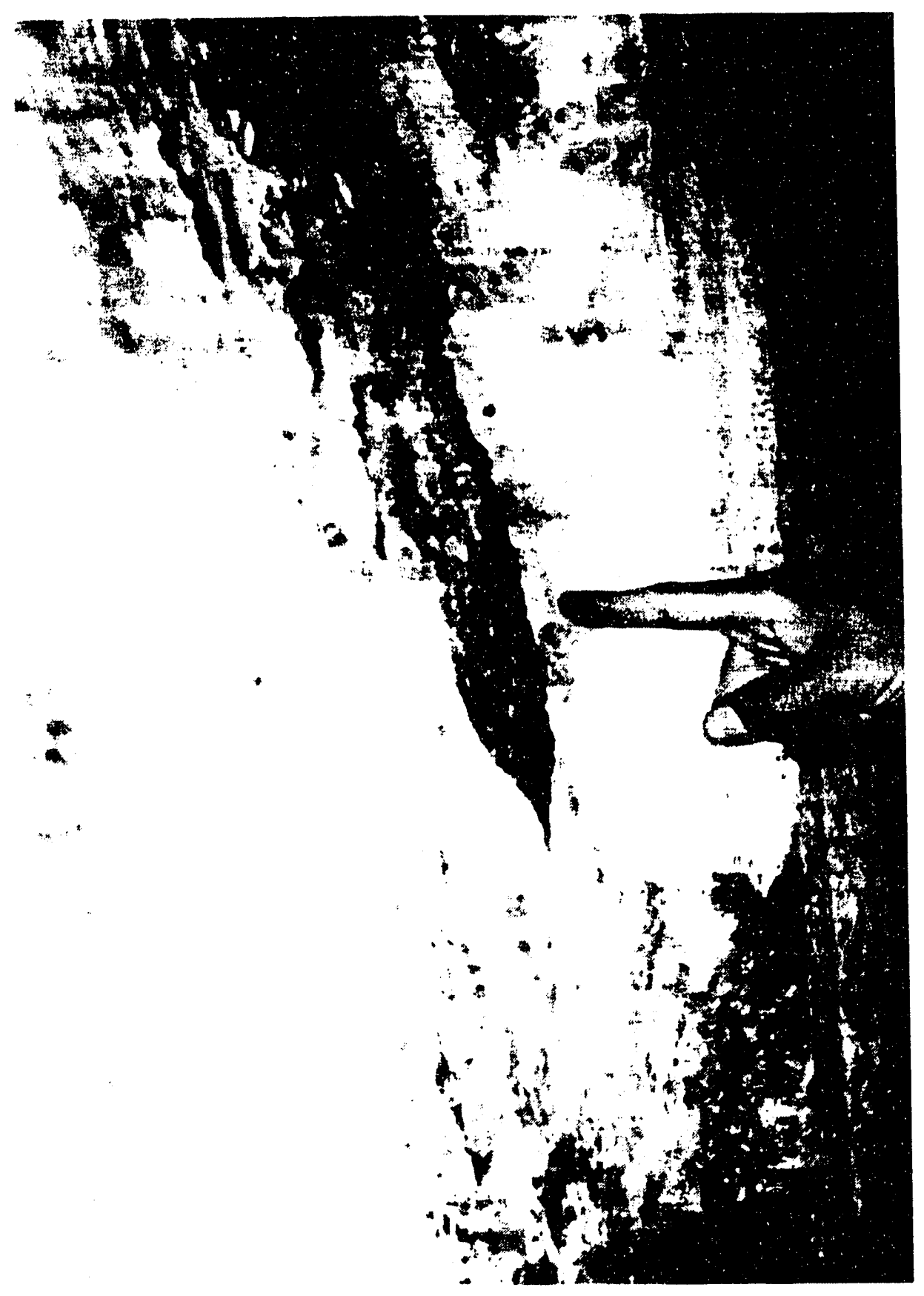

Figure 2-9

Part of a near-vertical dish-shaped fracture exposed in the east rib of Room 7, Panel 1. 
13.7 $\mathrm{m}$ west of GSEEP, contains brine with normal chemistry. The top and bottom of Marker Bed 139 (MB 139) can be observed in DH36, and although fractures occur in the upper several meters, walls of the hole within a few meters of the floor of the drift are dry. No brine is seeping into $\mathrm{DH} 36$ from fractures immediately beneath the floor of Room $\mathrm{G}$. It is doubtful that fracturing beneath the floor could route brine moving some distance from the east to the surface at GSEEP and not also provide a pathway for it to flow the additional distance westward to DH36. Chemical analyses of brines collected from drill holes occurring between GSEEP and Room $\mathrm{J}$ are discussed in Chapter 3, Section 3.3 and show it to be unlikely that brine is moving from Room $\mathrm{J}$ to GSEEP.

Examination of the local topography (WIPP underground survey maps, WIPP mining engineering files) shows that the G Access drift, the drift immediately east of the GSEEP location, slopes westward toward GSEEP and that the GSEEP location is at a topographically low spot. Artificial brine has been spread in the G Access drift (WIPP underground operations files) and could readily seep downslope, either on the drift floor or through the layer of unconsolidated muck that blankets the floor. It is unlikely that this brine would move westward, slightly upslope, to the location of downhole DH36, which contains brine with normal chemistry. Therefore, it is probable that the GSEEP brines originated as brines of normal Salado brine composition seeping out of map unit $O$ (Figure 2-4), diluted by a component of artificial brine spread on the floor of the $G$ Access drift and modified by partial evaporation.

As noted in Section 2.2.2, Room G appears to have more weeps (salt encrustations) and more clay than other parts of the excavations, which suggests that this northwesterly part of the facility is slightly more moist than the rest. The floor of Room $G$ is also stratigraphically about $1 \mathrm{~m}$ higher than the SPDV or waste storage rooms and is cut in map unit $O$. Brine that seeps out of the lower part of the ribs and forms encrustations elsewhere would be beneath the floor of Room $G$ and a potential source for the GSEEP brine. Additionally, the ventilation in Room $G$ is approximately 15,000 cubic feet per minute $(\mathrm{cm})$ compared to the 45,000 ( 1 fan) to 75,000 ( 2 fans) cfm in N1100 and N1420. Room G maintains a constant flow rate of $15,000 \mathrm{cfm}$ with two booster fans, regardless of the air flow in the adjoining drifts. Occasionally, the $15,000 \mathrm{cfm}$ decreases to $3,000 \mathrm{cfm}$ with only one booster fan operating. The possibility of reduced air flow in Room G may result in reduced evaporation rates, which coupled with a slightly greater moisture content in the rocks in the vicinity may allow the accumulation of moisture near the floor in GSEEP. 


\subsection{South Exploratory Drift}

The WIPP repository is excavated stratigraphically with respect to the orange band (Figure 2-4). These beds (and therefore the underground workings) dip 2 to 3 degrees, dropping over $6.5 \mathrm{~m}$ in elevation to the southeast (Figure 2-10; Francke and others, 199()). The South Exploratory Drift (E140) was excavated January 1983 to confirm the geology of the southern part of the disposal area. The southern $500 \mathrm{~m}$ of this drift is seldom visited and slopes southward to a dead end; therefore, if significant amounts of brine were seeping into this drift, the minimal evaporation and sloping nature of the floor should result in the accumulation of brine at the south end of the drift. In November 1987, almost five years after excavation and in May 1989, six years and four months after excavation, this drift was inspected for evidence of brine or brine seepage. The floor was dry, and the only evidence of moisture was the presence of a few salt encrustations on the ribs. If much brine flowed downslope to the south end and evaporated, salt crusts should be evident. No such salt crusts or brine pools existed (Figure 2-11). No detectable moisture was found on the ribs or floor. Overall, the area was dry. Although this data is difficult to quantify, only nonsignificant quantities of brine have been seeping into this drift over six years; otherwise, there would have been more evidence of moisture.

\subsection{Downholes and Brine Beneath the Floor}

Deal and Case (1987; Table 3-1) discussed brine inflow in 13 downholes with observations beginning in late 1984 and early 1985 . December 31, 1990, marked six years of observation. Four downholes (A1X01, A3X01, DH40, and DH42A) showed steady inflow; one (OH46) was increasing; and six (A2X01, BX01, DH36, DH38, DH42, and DHP402A) were decreasing. Four (IG201, IG202, L1X00, and NG252) of the original 13 could no longer be observed. Table 2-1 summarizes the most important data obtained from the downholes, with additional information in Appendix A.

The first nine downholes in Table 2-1 are of particular interest because they are located in areas where water has not been spread during construction in the six years of observation; therefore, the brine collected from these holes was derived totally from within the Salado Formation. Brine chemistries from these holes differ from chemical signatures associated with construction brines. Many downholes have been observed during the BSEP program (Appendix A, Table A-1) but in most cases, contamination with non-Salado water is known or suspected, making interpretations of natural processes difficult. This has been confirmed in most holes by the chemical composition of the brine, which clearly indicates the mixing of waters with discrete and different chemical signatures (Chapter 3 of this report; Deal and 


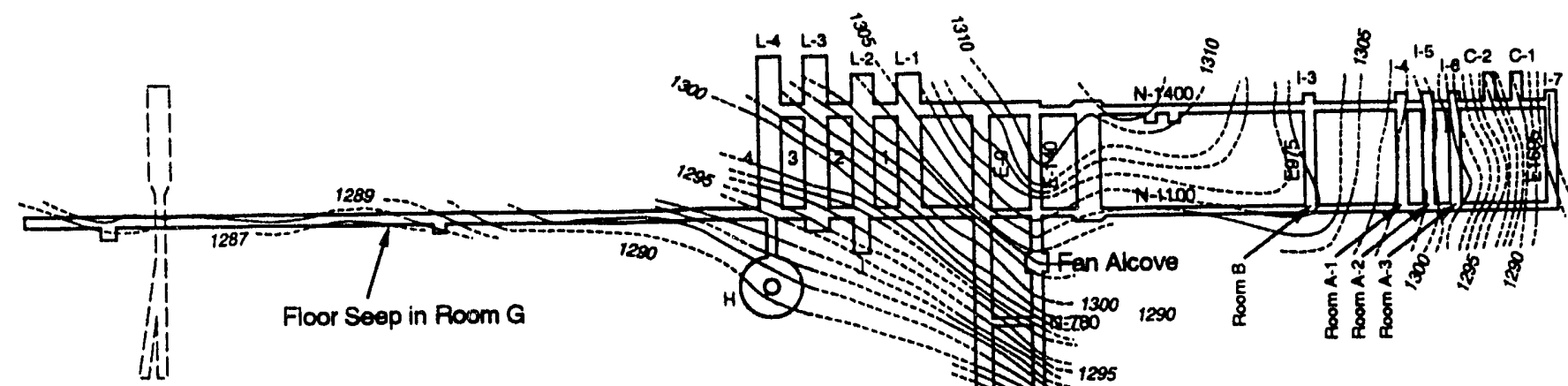

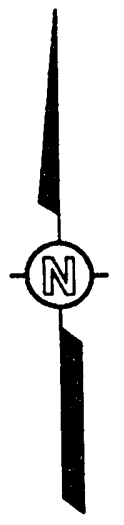

Legend

Completed Excavation 10/23/90

Plamed Excavation

\section{Notes}

1. Mine coordinates in feet from the center of the salt handling shaft

2. Contour interval 1 toot

3. Contour elevations are above sea level contour

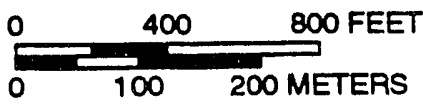

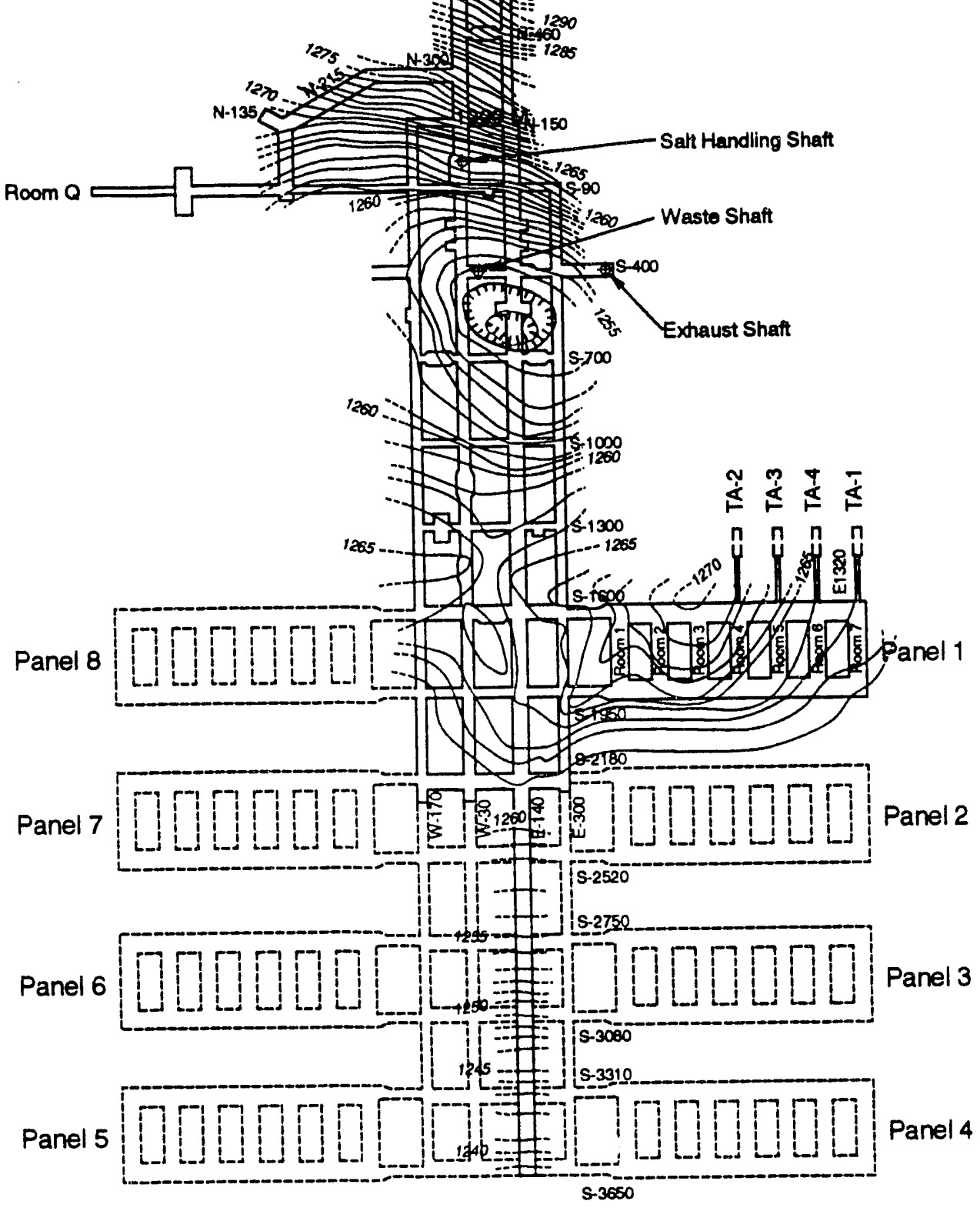

Figure 2-10

Structure Contour Map on the Top of the Orange Band. Contour Interval is 1 Foot, and Elevations are in Feet

(Francke and Others, 1990). 


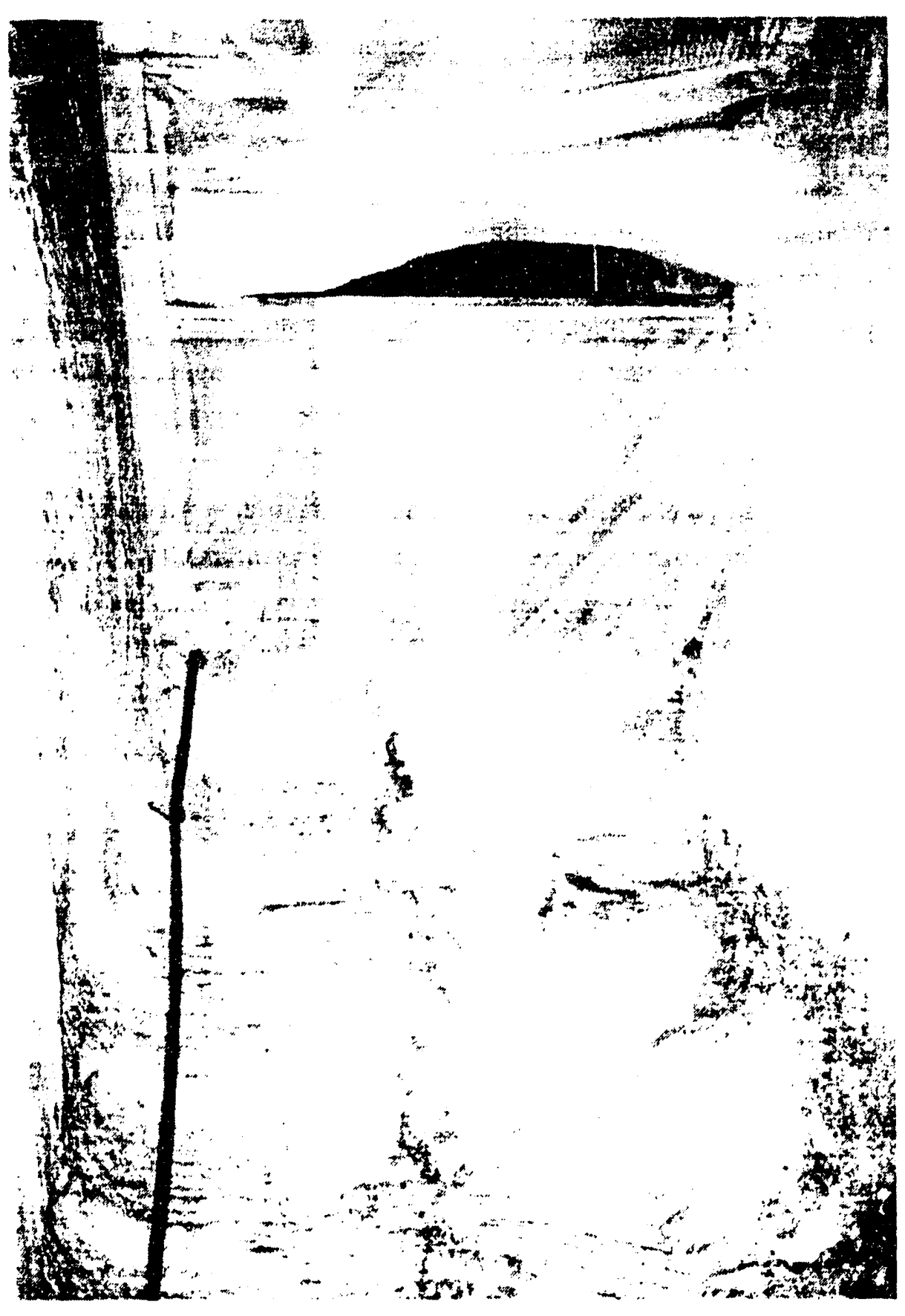

듬

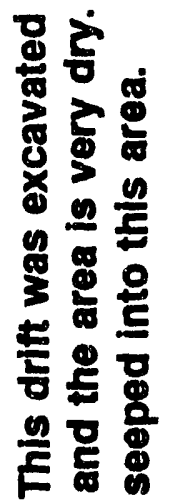

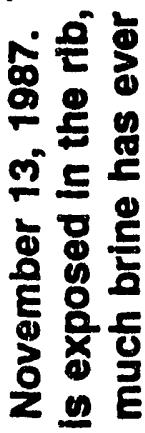

54 世

돈

중

(20

\%.

스응

马ํํㅇ

용

용 을 응

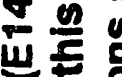

토울

는

능흔 룽

웅옹

응 헝

จ 2

득홍ㅁㅇ

우

○

웡롱 
Table 2-1

Brine Accumulation Summary For Downholes

\begin{tabular}{|c|c|c|c|c|c|c|c|c|}
\hline Hole & $\begin{array}{l}\text { Room Or } \\
\text { Location }\end{array}$ & $\begin{array}{l}\text { Date Area } \\
\text { Excavated }\end{array}$ & $\begin{array}{c}\text { Date Hole } \\
\text { Drilled }\end{array}$ & $\begin{array}{l}\text { Date First } \\
\text { Observed }\end{array}$ & $\begin{array}{l}\text { Approx } \\
\text { Maximum } \\
\text { Intlow } \\
(\text { (L) Day) }\end{array}$ & $\begin{array}{l}\text { Approx. } \\
\text { Inflow } \\
12 / 90 \\
\text { (L/Day) }\end{array}$ & $\begin{array}{l}\text { Infiow } \\
\text { Trend } \\
12 / 90 \\
(1 . S . D .)^{b}\end{array}$ & $\begin{array}{l}\text { Approx. } \\
\text { Total Vol. } \\
\text { Romoved by } \\
12 / 90(\mathrm{~L})\end{array}$ \\
\hline $\begin{array}{l}\text { A1X01 } \\
\text { A2X01 } \\
\text { A3X01 } \\
\text { BX01 } \\
\text { DH36 } \\
\text { DH38 } \\
\text { DH40 } \\
\text { DH42 } \\
\text { DH42A } \\
\text { DHP402A } \\
\text { OH46 }\end{array}$ & $\begin{array}{l}A 1 \\
A 2 \\
A 3 \\
B \\
G \\
G \\
G \\
G \\
G \\
\text { S1950/E1330 } \\
\text { S390M } 320\end{array}$ & $\begin{array}{c}10 / 84 \\
7 / 84 \\
11 / 84 \\
6 / 84 \\
12 / 84 \\
12 / 84 \\
12 / 84 \\
12 / 84 \\
12 / 84 \\
10 / 86 \\
5 / 89\end{array}$ & $\begin{array}{l}2 / 85 \\
2 / 85 \\
1 / 85 \\
1 / 85 \\
1 / 85 \\
1 / 85 \\
1 / 85 \\
1 / 85 \\
1 / 85 \\
12 / 86 \\
6 / 89\end{array}$ & $\begin{array}{l}3 / 85 \\
2 / 85 \\
2 / 85 \\
1 / 85 \\
1 / 85 \\
1 / 85 \\
1 / 85 \\
1 / 85 \\
1 / 85 \\
12 / 86 \\
7 / 89\end{array}$ & $\begin{array}{l}0.05 \\
0.12 \\
0.03 \\
0.03 \\
0.28 \\
0.18 \\
0.04 \\
0.05 \\
0.2 \\
4.0 \\
0.04\end{array}$ & $\begin{array}{l}0.03 \\
0.02 \\
0.02 \\
0.03 \\
0.09 \\
0.03 \\
0.004 \\
0.02 \\
0.06 \\
0.3 \\
0.01\end{array}$ & $\begin{array}{l}\text { S } \\
D \\
\text { S } \\
D \\
D \\
D \\
\text { S } \\
D \\
\text { S } \\
D \\
1\end{array}$ & $\begin{array}{r}60 \\
54 \\
48 \\
94 \\
354 \\
95 \\
9 \\
49 \\
178 \\
605 \\
9\end{array}$ \\
\hline
\end{tabular}

Brine Accumulation Summary for Upholes

\begin{tabular}{|c|c|c|c|c|c|c|c|c|}
\hline Hole & $\begin{array}{l}\text { Room Or } \\
\text { Location }\end{array}$ & $\begin{array}{l}\text { Date Area } \\
\text { Excavated }\end{array}$ & $\begin{array}{c}\text { Date Hole } \\
\text { Drilled }\end{array}$ & $\begin{array}{l}\text { Date First } \\
\text { Observed }\end{array}$ & $\begin{array}{l}\text { Approx. } \\
\text { Maximum } \\
\text { Infiow } \\
\text { (L/Day) }^{\text {(LDa }}\end{array}$ & $\begin{array}{l}\text { Approx. } \\
\text { Inflow } \\
12 / 90 \\
\text { (LDay) }\end{array}$ & $\begin{array}{l}\text { Inflow } \\
\text { Trend } \\
\text { 12/90 } \\
\text { (1.S.D.) }\end{array}$ & $\begin{array}{l}\text { Approx. } \\
\text { Total Vol. } \\
\text { Removed by } \\
12 / 90(L)\end{array}$ \\
\hline $\begin{array}{l}\text { A1X02 } \\
\text { DH15 } \\
\text { DH35 } \\
\text { DH37 } \\
\text { DH39 } \\
\text { DH41 } \\
\text { DH215 } \\
\text { DHP401 } \\
\text { OH47 }\end{array}$ & $\begin{array}{l}\text { A1 } \\
\text { N1104/E1688 } \\
\text { G } \\
\text { G } \\
\text { G } \\
\text { G } \\
\text { S1960/E153 } \\
\text { S1950/E1330 } \\
\text { S390N320 }\end{array}$ & $\begin{array}{c}10 / 84 \\
3 / 84 \\
12 / 84 \\
12 / 84 \\
12 / 84 \\
12 / 84 \\
1 / 83 \\
10 / 86 \\
5 / 89\end{array}$ & $\begin{array}{l}3 / 85 \\
3 / 84 \\
1 / 85 \\
1 / 85 \\
1 / 85 \\
1 / 85 \\
2 / 83 \\
1 / 87 \\
7 / 89\end{array}$ & $\begin{array}{l}3 / 85 \\
5 / 86 \\
2 / 85 \\
2 / 85 \\
2 / 85 \\
2 / 85 \\
4 / 84 \\
3 / 87 \\
8 / 89\end{array}$ & $\begin{array}{c}0.09 \\
0.01 \\
0.02 \\
0.01 \\
\text { Trace } \\
\text { Trace } \\
0.09 \\
0.008 \\
0.030\end{array}$ & $\begin{array}{l}0.03 \\
0 \\
0 \\
0 \\
0 \\
0 \\
0 \\
0 \\
0.005\end{array}$ & $\begin{array}{l}\text { D } \\
\text { DRY } \\
\text { DRY } \\
\text { DRY } \\
\text { DRY } \\
\text { DRY } \\
\text { DRY } \\
\text { DRY } \\
S\end{array}$ & $\begin{array}{r}64 \\
4 \\
4 \\
1 \\
0 \\
0 \\
18 \\
2 \\
4\end{array}$ \\
\hline
\end{tabular}

\section{Brine Accumulation Summary for Subhorizontal Holes}

\begin{tabular}{|c|c|c|c|c|c|c|c|c|}
\hline Hole & $\begin{array}{l}\text { Poom Or } \\
\text { Location }\end{array}$ & $\begin{array}{l}\text { Date Area } \\
\text { Excavated }\end{array}$ & $\begin{array}{c}\text { Date Hole } \\
\text { Drilled }\end{array}$ & $\begin{array}{l}\text { Date First } \\
\text { Observed }\end{array}$ & $\begin{array}{c}\text { Approx. } \\
\text { Maximum } \\
\text { Inflow } \\
(\text { L/Day) } \\
\end{array}$ & $\begin{array}{l}\text { Approx. } \\
\text { Inflow } \\
12 / 90 \\
\text { (L/Day) }\end{array}$ & $\begin{array}{l}\text { Infiow } \\
\text { Trend } \\
12 / 90 \\
\text { (I.S.D.) }\end{array}$ & $\begin{array}{l}\text { Approx. } \\
\text { Total Vol. } \\
\text { Removed by } \\
12 / 90(\mathrm{~L}) \\
\end{array}$ \\
\hline $\begin{array}{l}\mathrm{OH} 20 \\
\text { OH21 } \\
\text { OH222 } \\
\text { OH23 } \\
\text { OH24 } \\
\text { OH25 } \\
\text { OH26 } \\
\text { OH227 } \\
\text { OH27A } \\
\text { OH28 } \\
\text { OH45 }\end{array}$ & $\begin{array}{l}\text { S1600N W170 } \\
\text { S1600N } 170 \\
\text { S1600N170 } \\
\text { S1950N170 } \\
\text { S1950N } 170 \\
\text { S1950N } 170 \\
\text { S2150N } 170 \\
\text { S2150N } 170 \\
\text { S2150N } 170 \\
\text { S2150N } 170 \\
\text { S390N } 1725\end{array}$ & $\begin{array}{c}9 / 85 \\
9 / 85 \\
9 / 85 \\
12 / 85 \\
12 / 85 \\
12 / 85 \\
8 / 86 \\
8 / 86 \\
8 / 86 \\
8 / 86 \\
5 / 89\end{array}$ & $\begin{array}{c}3 / 89 \\
12 / 88 \\
12 / 88 \\
2 / 89 \\
3 / 89 \\
3 / 89 \\
3 / 89 \\
4 / 89 \\
4 / 89 \\
4 / 89 \\
6 / 89\end{array}$ & $\begin{array}{l}3 / 89 \\
2 / 89 \\
2 / 89 \\
2 / 89 \\
3 / 89 \\
3 / 8 \\
3 / 89 \\
4 / 89 \\
4 / 89 \\
4 / 89 \\
6 / 89\end{array}$ & $\begin{array}{l}0.02 \\
0 \\
0 \\
0.06 \\
0.002 \\
0.001 \\
0.04 \\
0.001 \\
0.02 \\
0.008 \\
0.03\end{array}$ & $\begin{array}{l}0.01 \\
0 \\
0 \\
0.01 \\
0 \\
0 \\
0.02 \\
0 \\
0 \\
0.003 \\
0.001\end{array}$ & $\begin{array}{c}S \\
\text { DRY } \\
\text { DRY } \\
D \\
\text { DRY } \\
\text { DRY } \\
D \\
\text { DRY } \\
\text { DRY } \\
D \\
D\end{array}$ & $\begin{array}{c}7 \\
0 \\
0 \\
13 \\
0.2 \\
0.01 \\
11 \\
0.2 \\
0.3 \\
1 \\
3\end{array}$ \\
\hline
\end{tabular}

Liters (L) per day.

Data summarized and rounded from Appendices A and B. I = Increasing; $S=$ Steady; $D=$ Decreasing. 
others, 1989; Deal and others, 1991). In some cases inflow rates vary directly with known water-spreading practices.

\subsubsection{Macrofractures Beneath the Floor and Observations in the Shaft Sumps}

As the excavations age, a zone of macrofractures form beneath the floor of the drifts, locally forming relatively high permeability zones (Figure 2-8; Deal and others, 1991; Deal and Roggenthen, 1991). In some cases (e.g., EES12B, EES21B, L2C03, L2C25, NG252, OH36, $\mathrm{OH} 37, \mathrm{OH} 41$, and $\mathrm{OH} 42$ ), brine could be seen flowing into the holes from open fractures. A local increase in permeability results in significant increases in inflow, especially in those parts of the workings where construction waters are spread on the floor. A high variability in seepage exists in some of these holes, even when closely spaced, e.g., MIIT holes (Deal and Case, 1987) and L1S holes (Deal and others, 1989).

The presence of the brittle anhydrite MB 139 exacerbates the fracturing beneath the floor (Bechtel, 1983, 1986; Deal and Roggenthen, 1991). It has been observed that interconnected fracture systems occur beneath the floor in some parts of the WIPP workings (Bechtel, 1986; Deal and others, 1991). Hydrologic testing of brine-filled macrofractures in the vicinity of the Air Intake Shaft at W620 and S90 was accomplished successfully (Deal and others, 1991, Section 4). These observations and test results have shown that interconnected fractures can occur at drift intersections and have led to speculation that a continuously connected system of large fractures may develop with time and provide a pathway for brine movement beneath the floor of the excavation, possibly bypassing efforts to seal certain drifts or contaminating naturally occurring brine with introduced, artificial brines (see discussion of GSEEP and Room $\mathrm{J}$ in Sections 2.5 and 3.3 of this report). However, the existence of such a large-scale interconnected fracture system has not been proved.

Large quantities (thousands of liters) of brine are known to have been spread in the E0, N1100, and N1420 drifts for dust control (WIPP construction files), and fractures under intersections in the northern part of the excavations are brine-filled (WIPP Geotechnical Engineering, Excavation Effects Files). Enough undersaturated brine was spread in the vicinity of E0 and N1100 so that solution took place in instrumented downholes, the instrument anchors were loosened by dissolution, and the instruments failed and were removed (WIPP Geotechnical Engineering, Geotechnical Instrumentation Maintenance Files).

Inspection of the structural contour map on top of the orange band (Figure 2-10) or the elevation map of the floor of the WIPP workings (WIPP Engineering Files) shows that most of the northern part of the excavations slope southward to the Salt Handling Shaft. 
Additionally, that slope continues southward toward the Waste Handling Shaft, which happens to be located near a structural low spot, centered at approximately S600 E140. Perhaps not coincidentally, a downhole at S850 flowed brine for a number of months until it was plugged during the excavations that lowered the floor (Deal and Case, 1987, Section 3.1.2.1).

If a hydrologically connected macrofracture system has developed beneath the E0 drift, then brine should be driven southward by gravity and discharged into the $45-\mathrm{m}$ deep sumps at the Salt Handling and Waste Handling Shafts. Periodic inspections of these shaft sumps show that fractured anhydrite and salt are exposed beneath the drift floors but that these fractures are dry (Figure 2-12). The fact that no brine is seeping out of the fractures into the shaft sumps argues strongly that a hydrologically connected macrofracture system has not developed beneath the E0 drift, which is one of the widest $(7.6 \mathrm{~m})$ and oldest (seven years, excavated in 1984) drifts at the WIPP. The degree of fracturing is a function of drift width and age (Deal and others, 1991). It is possible that the typical width of the entry drifts (less than $7.6 \mathrm{~m}$ ) is too narrow to allow the type of fracturing observed beneath the 10 -m-wide waste storage rooms (Bechtel, 1986) or S90 E640 intersection (Deal and others, 1991, Section 4.4.1) to develop. Additional testing has been proposed to determine hydrologic conductivity beneath the EO drift.

\subsubsection{Moisture Content}

Moisture content of the rocks exposed in drill holes varies directly with clay content (Deal and others, 1989). Preliminary hydraulic testing of the beds near the repository level has found that the hydraulic conductivity of relatively pure halite is immeasurably low; argillaceous halite ranges from $1 \times 10^{-9}$ to $2 \times 10^{-8} \mathrm{~m} /$ day; and anhydrite MB 139 ranges from $3 \times 10^{-8}$ to $6 \times 10^{-7} \mathrm{~m} /$ day (Beauheim and Holt, 1990). From this and other data, Deal and Roggenthen (1991) concluded that brine seepage is more likely from clay seams, partings, and along interbeds (especially anhydrite) than through massive, clear halite. Relative moisture content has been calculated from direct measurement and geophysical induction logging techniques (Deal and others, 1989, Chapter 4 and Appendix H). The calculated moisture content shows that clays at depth (clays $B$ and $D$ ) are more moist than the orange band and clay $\mathrm{F}$, which are exposed in the facility horizon excavations; therefore, extrapolating inflow estimates based on drill holes is expected to yield higher brine seepage rates and volumes than will be experienced in real waste storage rooms.

\subsubsection{Data from the Heated Experimental Area and Room G}

The nine downholes mentioned previously that seem to remain uncontaminated are located in the northern part of the repository (Figure 2-1). The first four are in the northeastern heated 


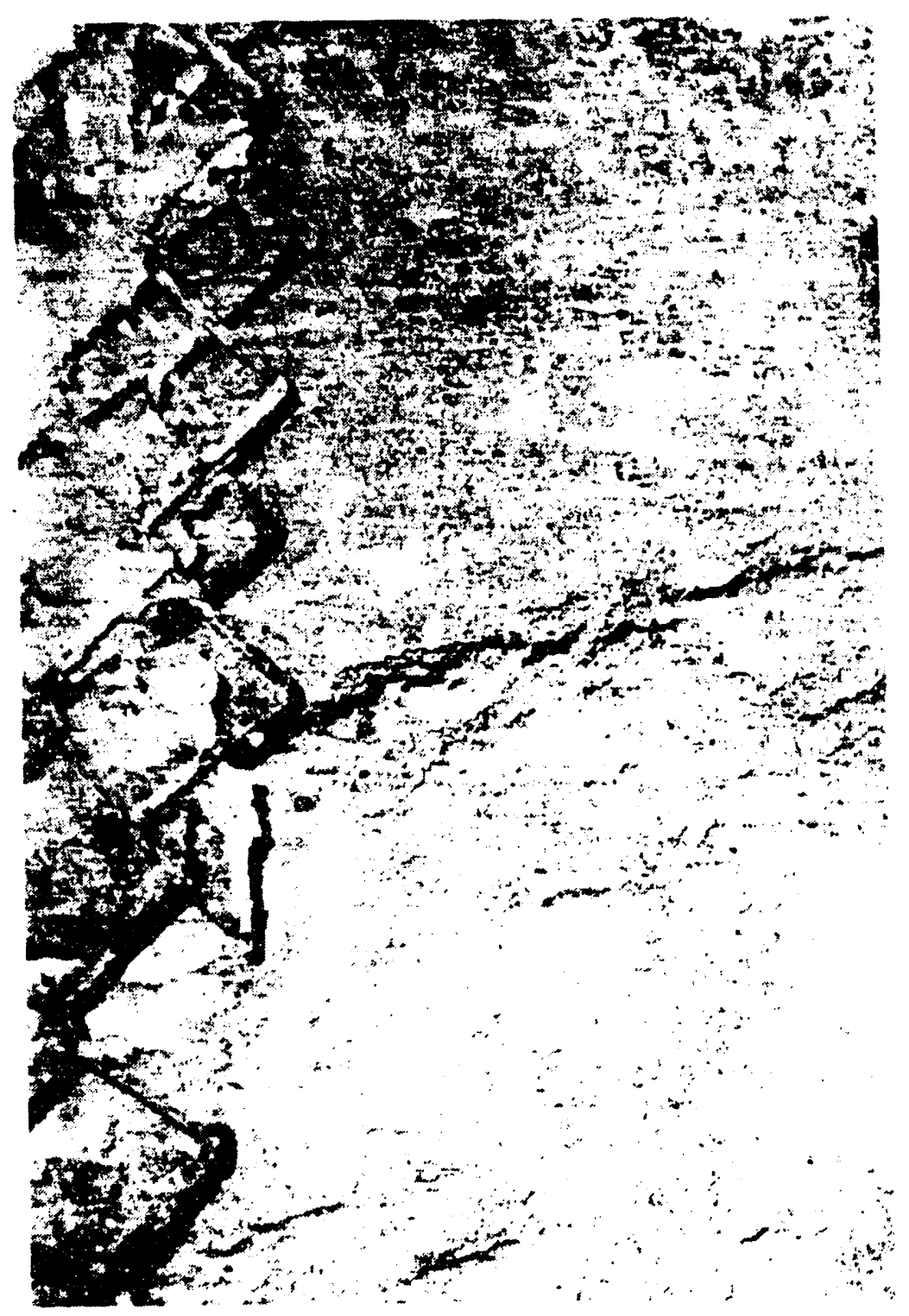

Figure 2-12

Photograph of dry subhorizontal fracture approximately $5 \mathrm{~mm}$ wide exposed in the Waste Handling Shaft, Just below the floor of the station. 


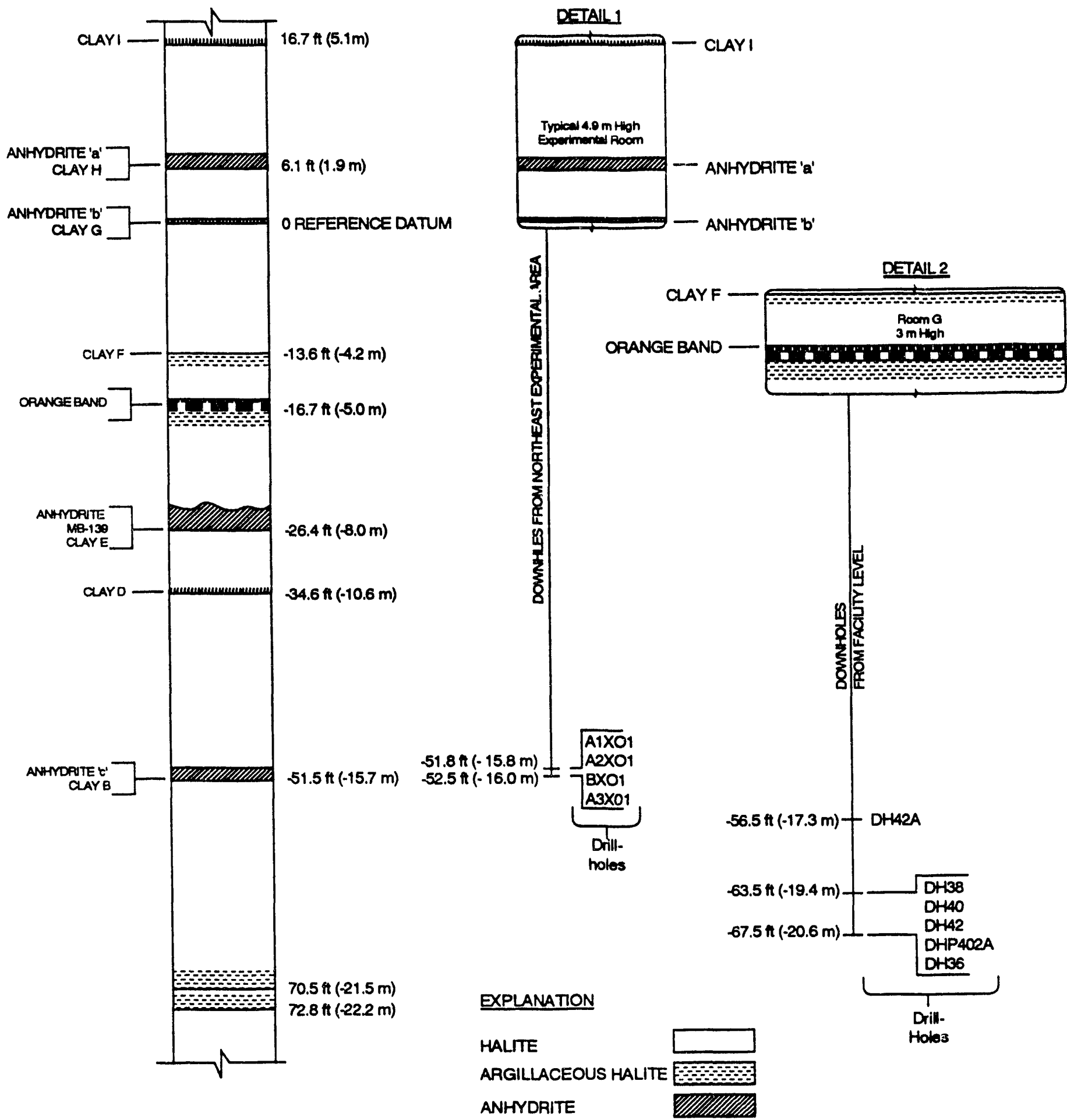

NOTE: See Table 1.2. Distances above and below anhydrite "b" (clay G) vary from place to place in the WIPP excavations due to natural changes in stratigraphic thickness. This figure has been adjusted to represent thicknesses in the northern part of the workings. Distances from clay $E$ down are from Room $\mathrm{G}$ and from the orange band up are from Room $\mathrm{A} 1$.

Figure 2-13 
experimental area and the last five are in Room G, the northwesternmost room. Eight of the holes are about $15 \mathrm{~m}$ deep, and DH42A is $12 \mathrm{~m}$ deep. All of these holes have a similar six-year seepage pattern (Appendix B), although these holes are at different stratigraphic horizons and pe .etrate slightly different units (Figure 2-13). The seepage rate varies more than $t$ orders of magnitude between these downholes. These holes were drilled into relatively undisturbed salt shortly after the drift or room was excavated and monitored from the time of drilling. The following conclusions, first reached in 1986 (Deal and Case, 1987), have been confirmed:

- Immediately after drilling a hole, a few days elapse where little or no brine seeps into the hole.

- After the initial no-flow or low-flow period, brine seepage quickly reaches a maximum and then begin's to decline.

- Seepage rates decrease over a period of several months to steadier, long-term trends.

The overall pattern (Appendix $\mathrm{F}_{\text {) }}$ ) of the long-term trends varies between holes. BX01, DH36, DH38, DH42, and DH42A have decreasing seepage rates, although DH42A appears to be steady in 1990 (Table 2-1). A1X01 and A3X01 were fairly steady through the middle of 1989 , but suggest a slightly increasing seepage rate over the last one and a half years. Both appeared fairly steady in 1990 (Table 2-1). A2X01 was steady until 1990, when seepage began to decrease. The very small amount of brine seepage into DH40 makes it difficult to determine a trend.

\subsubsection{Downholes in the Northeastern Heated Experimental Area} $\mathrm{A} 1 \mathrm{X} 01, \mathrm{~A} 2 \mathrm{X01}, \mathrm{A} 3 \mathrm{X} 01$, and BX01 in the northeastern heated experimental area (Figure 2-1) are about $15 \mathrm{~m}$ deep. Since the floor of these rooms is at a stratigraphic level approximately $5.5 \mathrm{~m}$ higher than the typical floor at the repository level, a slightly different stratigraphic sequence is penetrated here than in Room G (Figure 2-13). The downholes in the northeastern experimental area intersect clay $F$ at approximately $4.2 \mathrm{~m}$, clay $\mathrm{D}$ at $10.6 \mathrm{~m}$, and all intersect anhydrite "c" and clay B at the bottom of the hole. Clay B is more than $1 \mathrm{~cm}$ thick in A1X01 and is a probable source of brine.

The halo of deformation (the DRZ) (Deal and Roggenthen, 1991) that develops around the WIPP excavations invoives a different stratiga aphic section at the higher experimental level than at the repository level. Fracturing beneath the floor in the experimental area devel ops in fairly pure halite. MB 139 occurs at a depth of $8 \mathrm{~m}$ and is un.ikely to experience the d. ree 
of fracturing seen beneath the facility level excavations, where it typically occurs about $2 \mathrm{~m}$ beneath the floor.

Room A1 was excavated in October 1984, and hole A1X01 was drilled in the south end in February 1985. This experimental room was heated from October 2, 1985, to July 14, 1990. Brine seepage showed no obvious response to the heaters being turned on or off.

Room A2 was excavated in July 1984, and A2X01 was drilled in the north end in February 1985. Heaters for the experiments were turned on October 10, 1985. Seepage remained fairly steady until May 1990, when the rate started to decline. This decline may or may not be associated with a rock fall that occurred June 19,1990, which broke the power line to the heaters and turned them off. Brine seepage showed no obvious response to the heaters being turned on.

Room A3 was excavated in November 1984, and hole A3X01 was completed in the south end in January 1985. The experiments were heated from October 2, 1985 to August 23, 1990. Brine seepage rates showed no response to turning the heaters on. A decline in the seepage rate occurred about the same time the heaters were turned off but may have been coincidental.

Room B was excavated in June 1984, and hole BX01 was drilled in the north end in January 1985. The experiments were heated from April 23, 1985, to January 30, 1989. Brine seepage showed no obvious response to the heaters being turned on or off.

\subsubsection{Downholes in Room G}

Room G was completed in December 1984 and is the northwestern-most room in the experimental section of the repository. Room $\mathrm{G}$ is only $10 \mathrm{ft}$ high; as a result, the floor is about $1 \mathrm{~m}$ higher (stratigraphically) than the repository level. DH36, DH38, DH40, and DH42 are evenly spaced $15-\mathrm{m}$ downholes (Figure 2-1) drilled in January 1985 . DH42A, $12 \mathrm{~m}$ deep and $2 \mathrm{~m}$ west of $\mathrm{DH} 42$, is the westernmost hole drilled in the WIPP workings. These holes intersect anhydrite MB 139 between 2.7 and $3.7 \mathrm{~m}$, clay D at $5.7 \mathrm{~m}$, and anhydrite "c" and clay B at $10.8 \mathrm{~m}$ (Figure 2-13). Clay B is more than $1 \mathrm{~cm}$ thick. Clays B and $D$ are probably the source of most of the brine seeping into these holes.

\subsubsection{Discussion of Data Acquisition and Analyses}

It has been a challenge to collect small quantities of brine from the bottom of the $15-\mathrm{m}$ downholes (Deal and Case, 1987). The difficulty lies in uniformly collecting the very small 
amounts of brine that have seeped into the hole since the last time the hole was sampled. Several different sampling methods have been used, and each technique has unique problems. The change in sampling methods are sometimes reflected as apparent variations in seepage rates (Appendix B).

To compensate for sampling-induced apparent variations in seepage rates, the graphs of the seepage data presented in Appendix B have been smoothed for most locations using an 11-point moving average (the average of the data point and the five points on each side of the data point) and a standard statistical software package (Statgraphics, Version 4.0). At the beginning and end of each curve, the trend is distorted by the smoothing function because the number of data points falls below five on one side of the averaging point; therefore, unsmoothed data appears for the first few points at the beginning and end of each curve for a more accurate graphical representation of the seepage trends. Figures 2-14, 2-15, and 2-16 show the effect of the smoothing on the actual data.

For the first four years of the sampling program, the usual downhole sampling technique employed a bailer with a check-valve on the end of a single 20-m length of tubing (Deal and Case, 1987). A hand-powered high-volume, low-vacuum pump designed to inflate and deflate rubber life rafts was connected to the tubing. The bailer was lowered to the bottom of the drill hole. The hand pump was used to draw brine into the bailer. The bailer was then pulled out of the hole, emptied into a container, and the brine measured. The technician examined the hole to verify that all the brine was evacuated, a major advantage of this technique. Occasionally the suction line or check valve failed and brine was released back into the drill hole, but it was recovered the next time the hole was sampled. The data for that sampling period would appear to show anomalously low brine seepage, but would be followed by an anomalously high value. This is illustrated in the plot of the data for DH38 (Figure 2-14). On February 28, 1986 (day 423 on the plot), the remarks (Appendix A) indicated a substantial volume was emptied into the hole due to a break in the suction line. Figure 2-14 shows the result, with a low seepage rate calculated for day 423 followed by a high value for day 429 . A similar event occurred on days 449 and 456.

The bailer currently is used only to evacuate holes when weekly sampling is impossible and fairly large quantities of brine (more than one-half $\mathrm{L}$ ) have to be removed. The sampling technique was changed in the downholes in October 1989 (approximately day 1,740). The development of unstable back conditions in the heated experimental rooms (A1, A2, A3, and $B$ ) necessitated this change to allow sampling from a safe location. A pressure-suction moisture collecting device was installed. These are standard soil moisture collection devices 

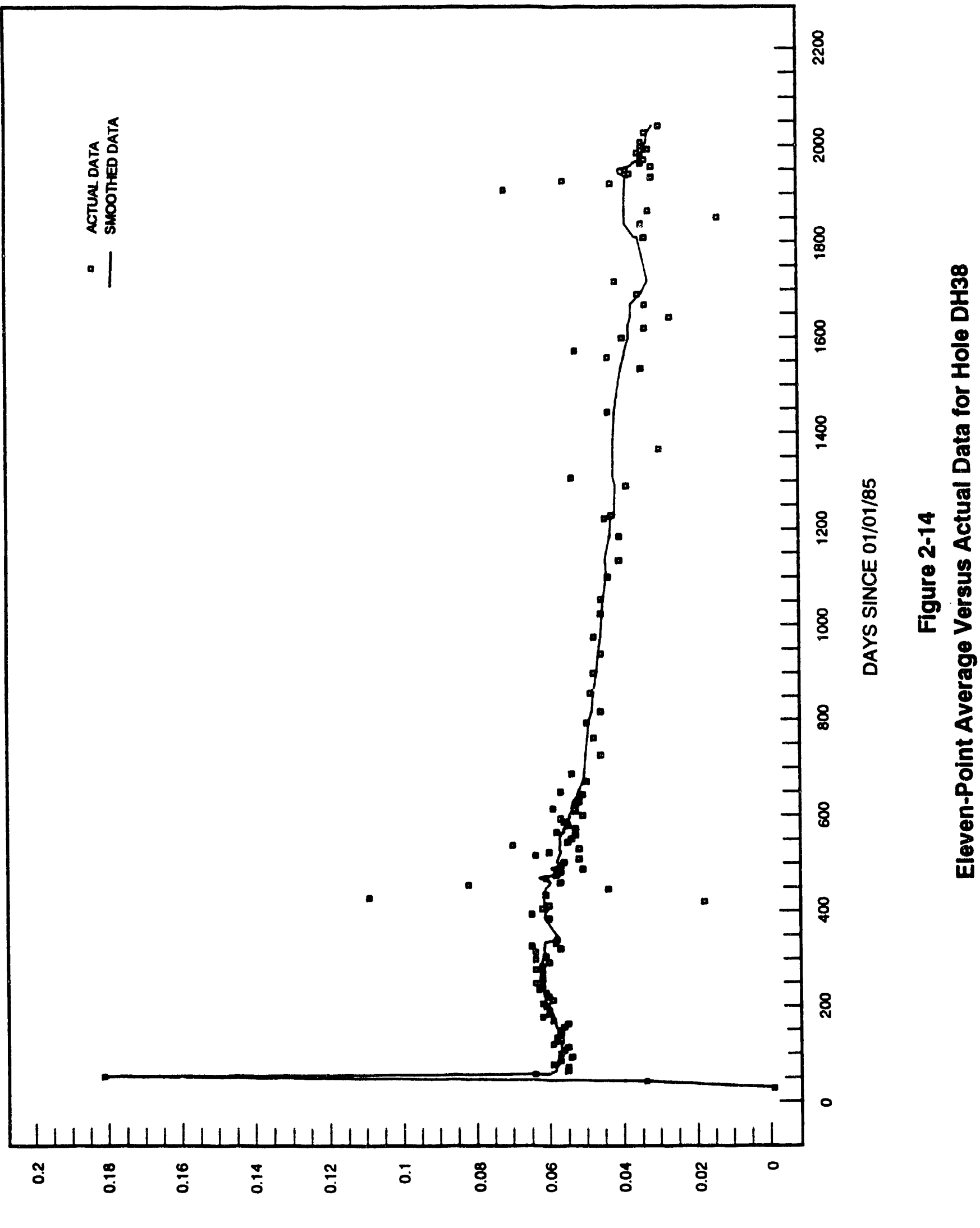

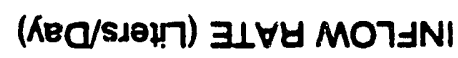




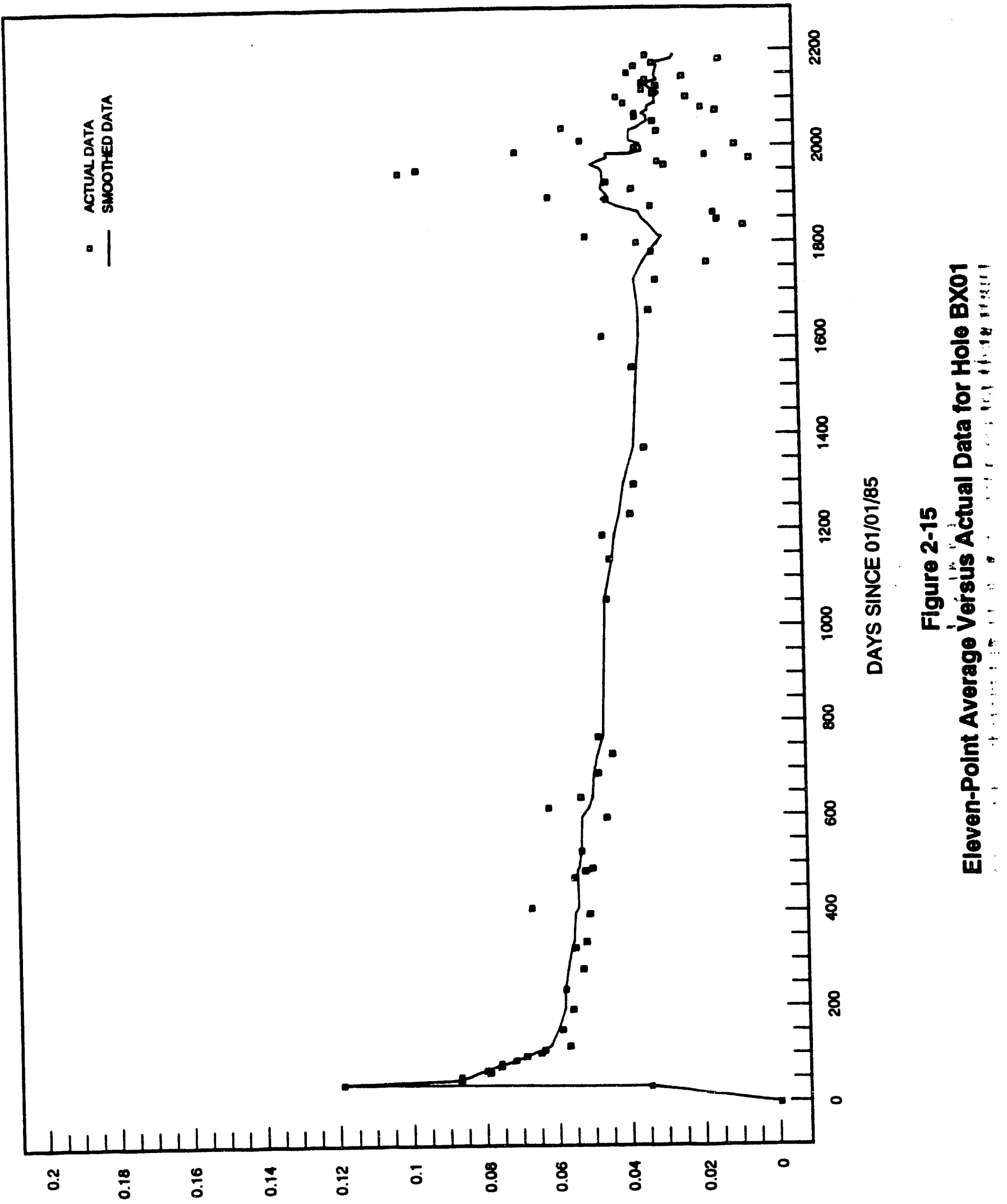

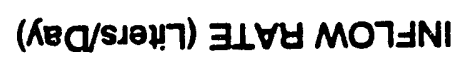




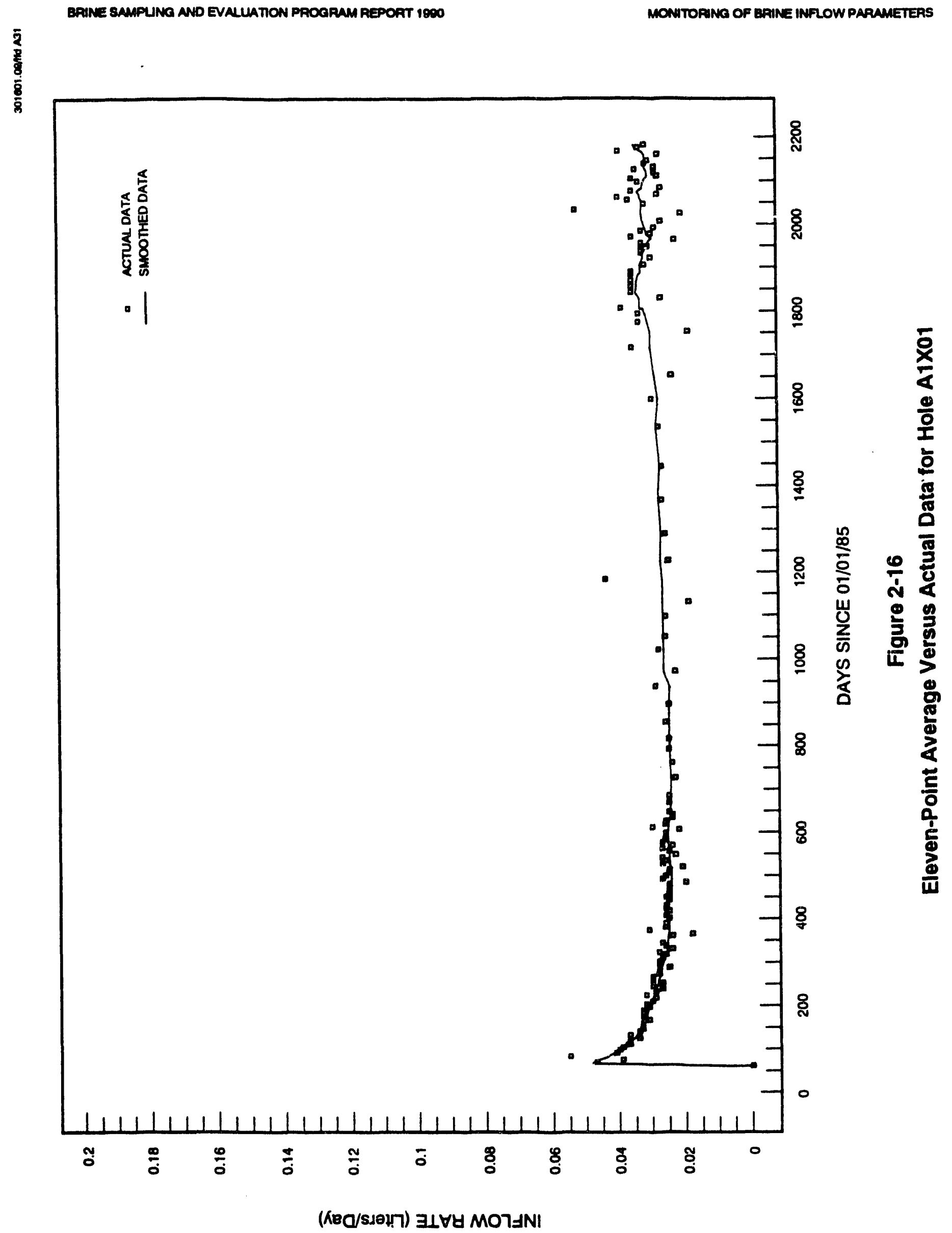


consisting of a short length of polyvinyl chloride (PVC) pipe with a porous cup attached to the bottom and two lengths of flexible tubing entering the top through a two-hole stopper. One tube extends to the bottom of the porous cup and the other ends just inside the stopper. The sampler is placed in the bottom of the hole, and a hand-pump is used to lower the pressure approximately 50 centibars below atmospheric. The partial vacuum draws brine through the porous cup into the PVC pipe during the sampling interval. At the time of sampling, the vacuum is released and air is pumped down the short tube, which forces brine up the longer tube to the collecting point. The maximum capacity of most of the devices is approximately $0.8 \mathrm{~L}$ (a few have longer PVC collection pipes and hold about $1 \mathrm{~L}$ ). If the volume collected is more than $0.5 \mathrm{~L}$, there is a possibility that not all of the brine that has accumulated in the hole has been collected in the sampler. The technician establishes the vacuum, returning the next day to continue collection activities.

Several advantages to the soil moisture collection devices are: the collar of the drill hole can be sealed, which prevents loss of brine due to evaporation; the chance of sample contamination is reduced; and sampling can occur from a remote, safe location. Disadvantages include: the volume is limited by the size of the sampler; loss of vacuum; clogged tubes; the ceramic cup is easily broken; and, for inaccessible holes, the inability to visually verify the complete evacuation of the brine. These devices work quite well but require weekly, rather than monthly, sampling so that accumulations do not exceed the capacity of the collecting device. For ease of routine sampling, these devices are currently used in all locations.

Plots of the brine seepage data for those holes producing much more than 0.5 to $0.8 \mathrm{~L}$ per week show a decrease in seepage rates shortly after the samplers were installed (about 1,740 days on Figures 2-14, 2-15, and 2-16). The drill holes had previously been evacuated only once a month with the bailer. The soil moisture devices are too small to accumulate all of the brine in some of the drill holes. Brine was left in the holes, resulting in an apparent decrease in seepage rates. In January 1990 (day 1,830), the sampling frequency was increased to once a week, which eliminated that problem (Figure 2-15). The scatter of the data points also increased at 1,740 days for the downholes after the change in the sampling technique. This is evident in the case of BX01 (Figure 2-15), which is now inaccessible. It is impossible to visually verify that all the brine accumulating in BX01 was collected by the sampling device.

Other locations are accessible to visually verify complete sampling, repair, and maintenance of the devices. If visual inspection indicates incomplete removal of the brine, repeated 
sampling is done until all of the brine is collected. This is reflected in Figure 2-14, where the scatter in the data was reduced in the latter part of 1990 . The change in sampling technology has resulted in an irregular shape of the smoothed data curve (after day 1,740 in Figures 2-14, 2-15, and 2-16).

\subsubsection{Data Interpretation}

The maximum seepage into new drill holes in new drifts occurs one to three weeks after drilling the hole. In relation to later flow, the graphical representation of that maximum varies from a pronounced spike (Appendix B; DH38, A2X01, BX01, and DH40) to a less prominent peak (Appendix B; A3X01 and DH42). The reason for the consistent presence of this early inflow peak is explained by a phenomenon associated with brine weeps.

Observations of weeps on newly mined surfaces (Section 2.2.1) show that exsolving gas plays an important early time role in their formation.

Gas exsolving from the brine may provide a driving mechanism that could explain this early time seepage behavior in the drill holes. This hypothesis assumes that the early-time flow is dominated by the relatively sudden discharge of gas in the drill hole that results from lowering the confining pressure from about 15 megapascals (MPa) to atmospheric. The initial discharge would be mostly gas without much fluid (explaining the week or two of no detectable brine seepage), followed by gas-driven brine during the next several months. This is somewhat analogous to uncorking a warm bottle of champagne: gas flows out of the bottle followed by the head. Another factor in the lack of early-time flow is probably that the rock is dilating rapidly in the DRZ due to stress release and that brine has to fill up the dilating pores around the drill hole before excess brine can flow out.

After the gas has dissipated, flow becomes dominated by compaction of the clays near the drill hole or by the deviatoric stress on the liquid fraction, and brine seeps into the drill hole at a more constant rate. In the deforming salt environment, porosity and permeability close to the excavations change dramatically with time (Deal and Roggenthen, 1991), and after a few years, new plumbing systems developed by macrofracturing dominates. Local variations in fracturing can make large differences in the seepage behavior of a given downhole (see discussion of the L1S holes in Deal and others, 1989). The fracturing becomes quite noticeable a year after the excavation and is well developed after two years.

The graph for DH38 (Figure 2-14) has an anomalous bulge in the plot of the seepage rate approximately one to two years after the room was excavated (200 to 500 days).

Examination of the graphs of downholes in Room $G$ indicated that a similar phenomenon is 
evident in DH36 and DH42A and less pronounced in DH40 and DH42 (Appendix B). However, similar bulges in the plots of the downholes in the northeastern heated experimental area (A1X01, A2X01, A3X01, and BX01) are not evident. The increase in the seepage rate in DH38 occurring approximately one to one and a half years after excavation of the room may be the result of an increase in porosity, permeability, and macrofracturing that occurs in the DRZ during this time. MB 139, a brittle anhydrite about $3 \mathrm{~m}$ below the floor of Room G, exacerbates the development of the macrofracturing, providing an enhanced delivery system for brine inflow. A similar increase in the seepage rate is not seen in downholes drilled in the experimental area, perhaps because MB 139 is $8 \mathrm{~m}$ below the floor and much less affected by the development of the DRZ.

\subsection{Upholes and Brine Above the Back}

Upholes characteristically produce less brine for shorter periods of time than downholes. Part of this can be attributed to greater evaporation caused by less effective sealing of upholes (Deal and Case, 1987) and loss of moisture by dispersion from the hole collar into the salt. Loss of moisture by evaporation is evident from salt crust buildup in and around most of the upholes. Chemical data (Deal and others, 1989; Abitz and others, 1990), which confirms compositional differences between brine samples from upholes and downholes, can be explained by the partial evaporation of a brine with typical downhole composition to produce the uphole brine. Although the stratigraphy exposed in the upholes (Figure 2-17) is slightly different from that exposed in the downholes, it is unclear whether this contributes significantly to the differences in either brine quantity or chemistry (Deal and others, 1989). Summary data for selected upholes are presented in Table 2-1. Of nine upholes listed in 1985, only A1X02 continues to produce brine. (Upholes A2X02, A3X02, and BX02 are no longer monitored.) As discussed in Deal and others (1989), A1X02 is longer than any of the other upholes $(18 \mathrm{~m})$ and intersects an additional anhydrite unit not penetrated by any other uphole. No associated clay was observed in the core, but clay commonly occurs below anhydrite stringers and may be discontinuous at this horizon. Additional data are presented in Appendix A.

Drill holes in the back that intersect overlying clay layers (clays $\mathrm{J}$ and $\mathrm{K}$ and argillaceous halite between the two clays), including those for the placement of rock bolts, commonly drip brine for a period of several months, often forming halite stalactites. Seepage is particularly notable when the drifts are allowed to age for several years, allowing bed separations to form prior to drilling. This has been noted in the heated experimental area, as discussed below. 


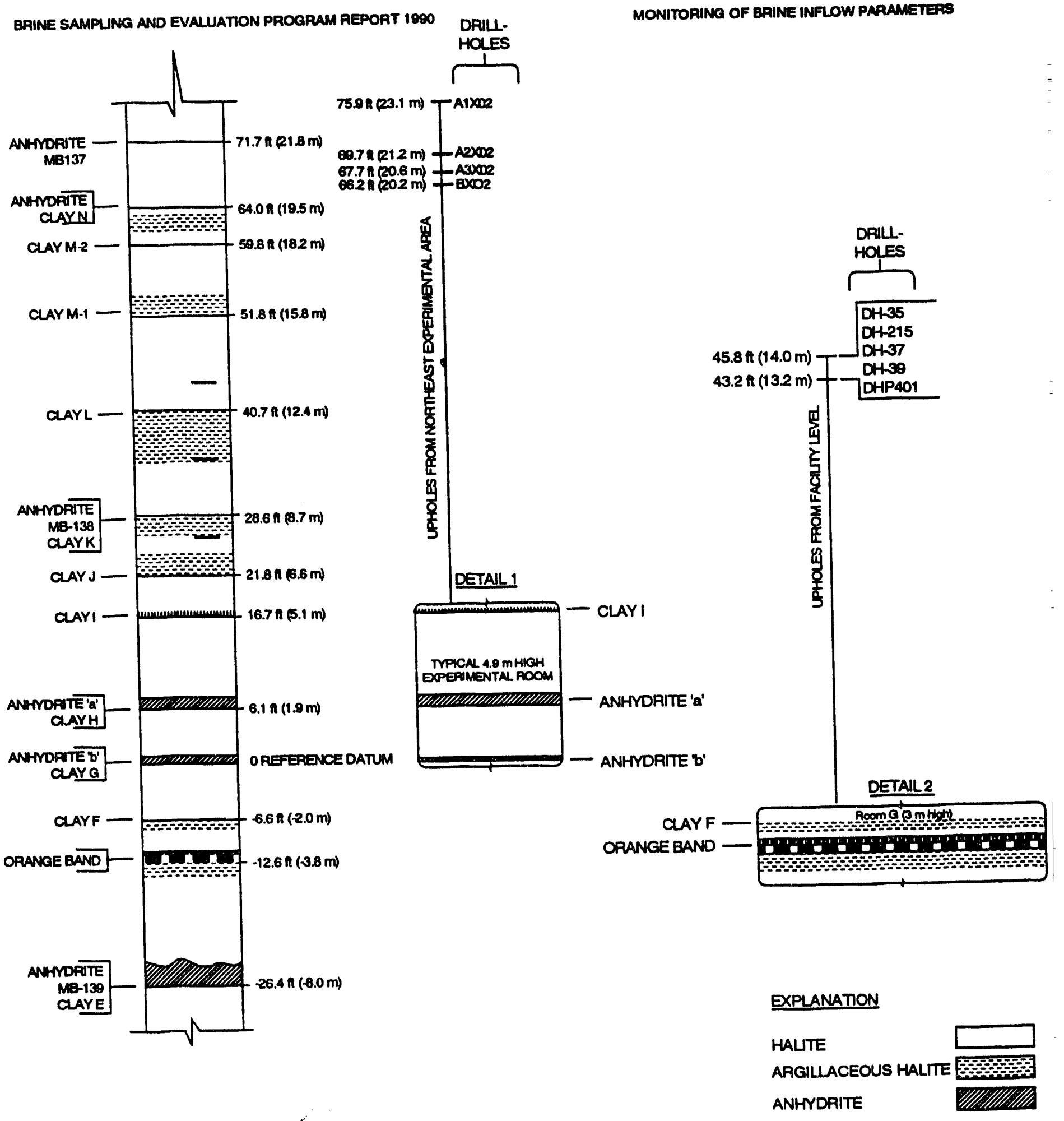

NOTE: See Table 1.2. Distances above and below anthydrite "b" (clay G) vary from place to place in the WipP excavations due to natural changes in stratigraphic thickness. This figure has been adjusted to represent thichesses in the northem part of the workings. Distances below the zero datum (day G) are from Room G, distances above clay $G$ are from Room A1.

Figure 2-17

Correlation of the Stratigraphy with Upholes in the Northern Part of the Facility 


\subsubsection{Observations of Brine Seopage from Rock Bolts in Rooms C1 and C2}

Small salt stalactites and moist areas developed around the heads of rock bolts installed in the summer of 1990 in Rooms C1 and C2. The seepage appears similar to that which was observed in 1987 and 1988 in Room D, in the A Rooms, and in Room B. The interpretation of the seepage information regarding the A Rooms and B Room is affected by the heaters used in them.

Rooms D, C1, and C2 were all excavated in March and April 1984 (Bechtel, 1985) and were allowed to age for a number of years prior to bolting. Bed separations developed in the back after a few years. Although moisture can accumulate in the resultant gaps, many years of observations document that spontaneous seepage to the back is rare. Stalactites and moist areas in the back almost always occur in association with drill holes placed for observation, geological investigations, installation of instrumentation, or roof bolts.

Roof bolts, $2 \mathrm{~m}$ in length, were installed in Room D in March 1987, about three years after mining. Approximately a month after bolting, seepage began at the bolt heads, and stalactites of salt began to form. By February 1988, the back in Room D was festooned with salt stalactites hanging from the bolt heads. Moist areas on the back around the bolts were obvious. Gradually, over the spring and summer of 1988 , the seepage slowed and by the following winter, the back had become noticeably dryer. However, some seepage has continued through 1990, especially at the south end of the room. The summary observation is that the back of Room D became noticeably moist for the year or so following bolting and then began to dry up. The back of Room $D$ also appeared to be more moist than the back of other rooms excavated at the lower facility level (the SPDV Rooms and Panel 1), which also had been roof bolted some time after excavation.

The observations in Room $D$ parallel those made by the experimental operations geotechnicians working in heated experimental Rooms A1, A2, A3, and B. As noted above, however, the fact that these rooms were heated makes it more difficult to compare brine seepage and other events to unheated areas of the WIPP excavations.

Rooms C1 and C2 were bolted with 2.4-m roof bolts in July 1990, about six years after excavation. The bolt heads apparently had started to become moist in August 1990, and stalactites had started to form. By December 1990, several stalactites had become fairly long, and obvious moist areas around the bolt heads had developed. 
Moisture content of the Salado Formation beds near the facility horizon at WIPP are known to correlate directly with clay content (Deal and others, 1989, Sections 4.1 and 4.2). Bolts placed in the back at this higher experimental level penetrate clay $\mathrm{J}$ and the argillaceous halite above it (between clay $J$ and clay $K$, which is at the base of MB 138), known to be one of the most moist of the strata near the facility horizon at the WIPP. The moisture content of this unit appears to be approximately twice that of clay G (Deal and others, 1989, Appendix $\mathrm{H}$ ), the moisture-bearing horizon about $2 \mathrm{~m}$ above the back at the facility horizon (SPDV Room and Panel 1).

The undisturbed back in the workings at the WIPP rarely show evidence of brine seeps or weeps. Drill holes, however, provide a route for brine to move across effectively impermeable clear halite beds, and seepage from drill holes in the back is a common occurrence at the WIPP. Typically, upholes start to show evidence of brine seepage a month or so after drilling, exhibit their most active seepage for the following year or so, and then gradually dry up. Rooms $\mathrm{C} 1$ and $\mathrm{C} 2$ show this very typical behavior.

Roof bolts placed into the back of Rooms A1, A2, A3, B, C1, C2, and D will penetrate clay $\mathrm{J}$, the argillaceous halite above it, and clay $\mathrm{K}$. Roof bolts placed into the back of the facility horizon (SPDV rooms and Panel 1) will penetrate clay G (at the base of anhydrite "b"). Since there is good evidence that clays $\mathrm{J}$ and $\mathrm{K}$ are significantly more moist than clay G (Deal and others, 1989, Appendix H), bolts placed in the higher experimental area are likely to develop more brine seepage than bolts placed in the back of the facility level. The amount of seepage that occurred in Rooms C1 and C2 in 1989 and 1990 probably cannot occur in the waste storage rooms because the source of the moisture (clay $\mathrm{J}$, the argillaceous halite above it, and clay $\mathrm{K}$ ) is more than $8.5 \mathrm{~m}$ above the back of the storage rooms and will not be penetrated by the boreholes normally used for bolting ( $4 \mathrm{~m}$ or less).

\subsection{Subhorizontal Holes}

During 1989, 11 subhorizontal brine sampling holes were drilled to investigate the brine seepage from the WIPP facility stratigraphic horizon. The holes are oriented slightly downward from the opening to accumulate brine at the end of the hole where it can be collected and measured without loss to fractures near the excavations. Ten of the 11 holes were drilled westward from the W170 drift at the location of future entries to Panels 7 and 8 at S1600, S1950, and S2150 (Figure 2-1). This part of the W170 was excavated in September 1985 at S1950; December 1985 at S1900; and in August 1986 at S2150 and is considered to have a mature DRZ developed around it. Three of the holes (OH20, OH23, and $\mathrm{OH} 26$ ), which are $46 \mathrm{~m}$ long and $7.6 \mathrm{~cm}$ in diameter, started in the clayey halite (map unit 4) 
above the orange band and angled downward (Figures 2-18, 2-19, and 2-20), so that they end in the clear halite (map unit 0 ) below the orange band (Figure 2-4). The 46-m holes reached the orange band about $15 \mathrm{~m}$ into the holes. Hole OH27A was started at the initial location for $\mathrm{OH} 27$ but was terminated at a depth of $1.2 \mathrm{~m}$ due to drilling problems. The six remaining $15-\mathrm{m}$ holes were drilled either above or below the orange band. One $15-\mathrm{m}$ hole (OH45) was drilled in a newer excavation in May 1989 at $\mathbf{S 4 0 0}$ that cuts the same stratigraphic interval as the three 46-m holes.

The holes are monitored for brine inflow. When tubing was removed from the 46-m holes for maintenance of the moisture collection devices, dry tubing was observed for about the first $15 \mathrm{~m}$. In $\mathrm{OH} 23$, the device was pulled twice. Both times, approximately 12 to $15 \mathrm{~m}$ of tubing was dry. It is not known conclusively what rock unit is encountered at that depth in the holes (these holes were not cored) nor whether there is brine inflow from deeper than $15 \mathrm{~m}$.

Several of the holes have produced measurable quantities of brine (Table 2-1, Appendix A). The 46-m holes provide the most uniform and comparable set of measurements yet obtained in the BSEP and have all produced orders of magnitude more brine than the $15-\mathrm{m}$ holes. The longer holes are still producing, while the shorter holes are dry - or essentially dry - with one exception. The exception is $\mathrm{OH} 45$, a $15-\mathrm{m}$ hole that cuts the same stratigraphic interval as the 46-m-long holes, which was drilled in a more recently mined area at W170, over $300 \mathrm{~m}$ north of $\mathrm{OH} 20, \mathrm{OH} 23$, and $\mathrm{OH} 26$. Lateral variation may play a minor role in the difference in brine seepage. This is considered to be unlikely, as Deal and others (1989) found no significant lateral variation in moisture content for any of the stratigraphic units exposed in the excavations.

Two explanations can be offered for the brine seepage observations: (1) The longer holes are tapping an area that is not dewatered, because they extend past the relatively old W170 drift DRZ. As a result, they may only tap about $30 \mathrm{~m}$ of undisturbed salt (in this case, the one $15-\mathrm{m}$ hole would still produce brine because it was drilled from a young excavation where a significant DRZ had not yet developed). (2) Brine flows preferentially along stratigraphic boundaries, so the clay units at the top and bottom of the orange band may be the only significant source of brine (see discussion in Section 2.3). Therefore, only the four holes $(\mathrm{OH} 20, \mathrm{OH} 23, \mathrm{OH} 26$, and $\mathrm{OH} 45)$ that cut the orange band accumulate brine. 


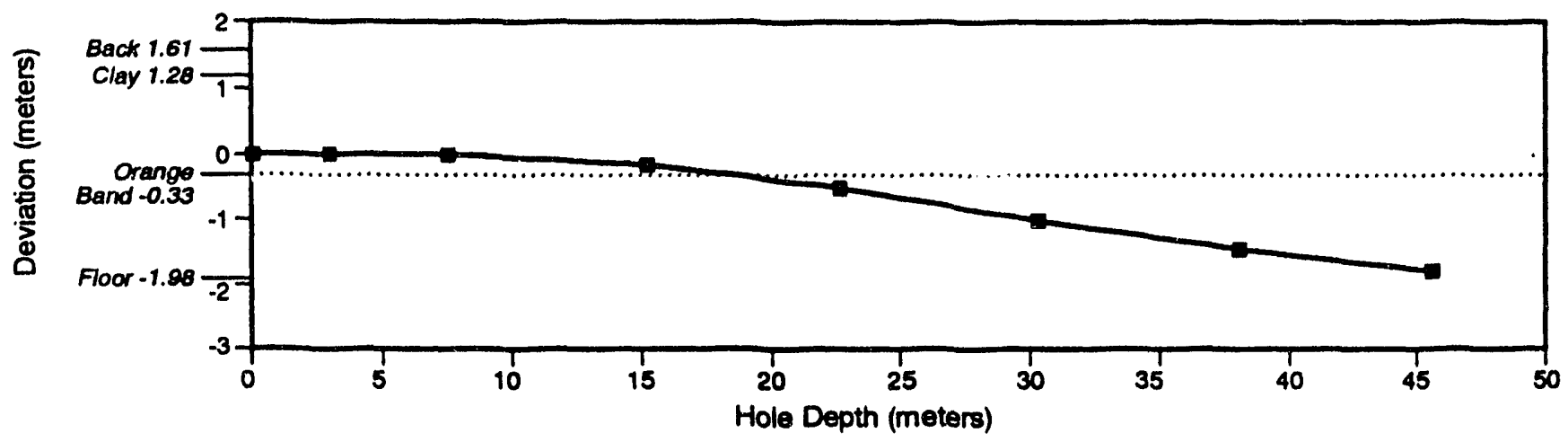

Figure 2-18

Profile of Long Drill Hole OH2O

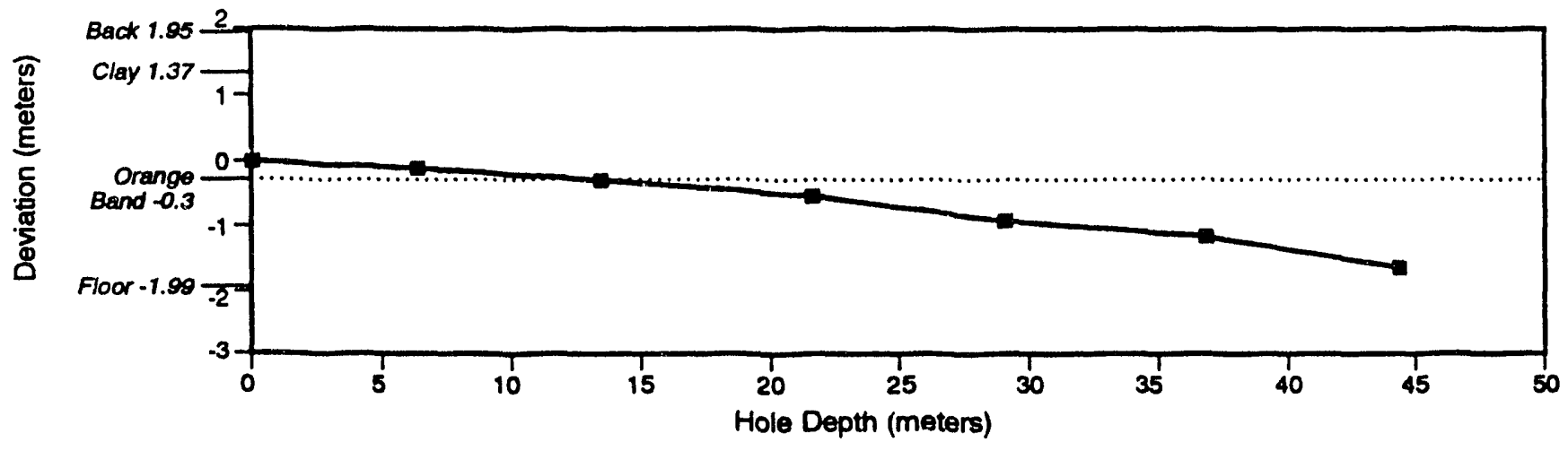

Figure 2-19

Profile of Long Drill Hole OH23

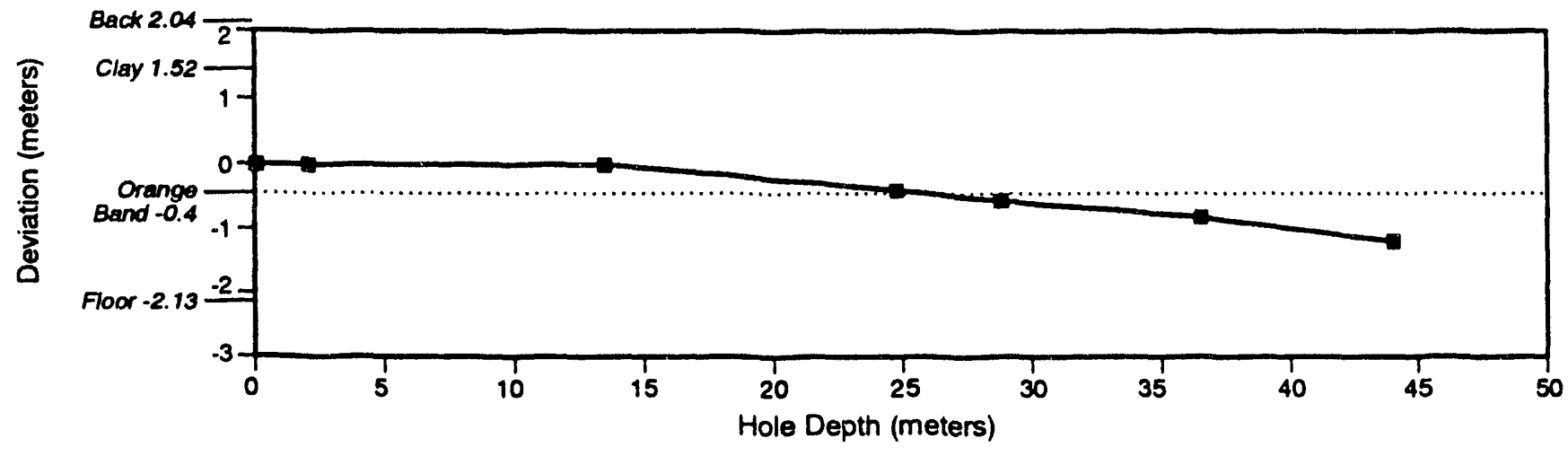

Figure 2-20

Profile of Long Drill Hole OH26

NOTE: These holes were not cored. The position of the orange band is projected, and the actual point at which the drill hole crosses the orange band is unknown. 
To improve the understanding of the mechanisms that affect brine seeping from the Salado Formation at the W:PP site, an additional BSE: drilling program has been proposed (Appendix E) to discriminate betweer the possibilities considered in this report. 


\subsection{Geochemistry of BSEP Brines}

The geochemistry of brines recovered from the WIPP repository horizon have been the subject of numerous studies (Stein and Krumhansl, 1986; Krumhansl and Stockman, 1987; Stein and Krumhansl, 1988; Deal and others, 1989; Abitz and others, 1990; Krumhansl and others, 1991), and the reader should refer to these publications for background information and more detailed discussions of the interpretation and origin of WIPP brines. The following discussion will be limited to the geochemical data obtained on brines collected during the 1989 and 1990 calendar years as part of the BSEP. The intent of this chapter is to:

- Present simple statistics on the 1989 and 1990 BSEP chemical analyses of brine recovered from down, up, and subhorizontal holes

- Compare the 1989 and 1990 BSEP chemical data to chemical data obtained from brine weeps (Krumhansl and others, 1991)

- Discuss analytical results on archived brine samples

- Address the issue raised in Deal and others (1989) on the possibility of migration of synthetic brine out of Room $J$ along fractures beneath the floor to the GSEEP sampling location.

Chemical analyses of brine obtained in 1989 are reported in Deal and others (1991), and data obtained in 1990 are reported in Appendix C of this report.

A statistical analysis of BSEP brine compositions was last presented in Deal and others (1989). Many of the holes discussed in Deal and others (1989) are no longer producing brine, and new holes have been added to locations being samplec for brine. Therefore, simple statistics (Appendix D) were prepared to summarize the 1989 and 1990 data for the 31 holes currently producing a sufficient volume of brine for anaiysis.

Histograms, element-ratio plots, and solubility diagrams were constructed using the mean values calculated from analyses obtained from each drill hole location (Figure 2-1).

Analytical data on the major elements in brine weeps (Krumhansl and others, 1991) collected from the WIPP repository are presented along with the BSEP data. The histograms illustrate the distribution of a given parameter in Salado Formation brines for up to three independent laboratories: United Nuclear Corporation (UNC), IT, and SNL/NM. Element-ratio plots are similar to those presented in Stein and Krumhansl (1988), Deal and others (1989), Abitz and others (1990), and Krumhans! and others (1991) to allow comparisons of data collected prior 
to 1989 with the 1989 and 1990 data. Solubility diagrams have been constructed for halite, anhydrite, magnesite, and celestite using the geochemical speciation/solubility code EQ3NR (Wolery, 1983).

During the 1990 calendar year, brine was collected (March 21, 1990) from drill hole DHP402A and was archived to evaluate the affect of storage on the chemical composition of the brine. The archived brine was analyzed approximately three, six, and nine months after collection. The reported results are similar to those obtained on DHP402A samples collected and analyzed in March of 1990.

Deal and others (1989) questioned whether synthetic brine may have migrated out of Room J along fractures beneath the floor to GSEEP. In 1989 and 1990, analysis for cesium and iodide was performed as part of a fluid-mixing analysis to determine whether a component of synthetic brine was present at GSEEP. Cesium and iodide are present in the synthetic brine at concentrations one to three orders of magnitude greater than in most naturally occurring Salado Formation brines; therefore, they are excellent indicators of the presence of the synthetic brine. No abnormally high values for cesium or iodide were found at GSEEP.

\subsection{Simple Statistics for 1989 and 1990 Analytical Results}

Analytical data (Appendix C) were obtained for samples collected from 31 BSEP drill holes (see Figure 2-1 for drill hole locations) that produced a sufficient volume of brine for analysis in 1989 and 1990. The identification and orientation of the holes are given in Table 3-1. Of these, 30 had multiple analyses. The calculated simple statistics appear in Appendix D. UNC was chosen as the principal analytical laboratory when limited sample volumes warranted use of only a single laboratory. Therefore, several drill holes are represented solely by UNC analytical results. The choice to use UNC as the principal laboratory was based on their capability to analyze a larger suite of parameters and the greater sensitivity of their analytical techniques.

Mean values were calculated for each drill hole (Appendix D) using UNC and IT analytical results from 1989 and 1990 (Appendix C) and are summarized in histograms presented in the following sections. For UNC and IT data, subhorizontal holes $(\mathrm{OH} 20, \mathrm{OH} 23, \mathrm{OH} 26$, and $\mathrm{OH} 45$ ), upholes (A1X02 and OH47), and downholes suspected to contain a component of spread water (e.g., G090, GSEEP, H090, OH66, OH67, and L1X00) are indicated on the histograms to show their distribution relative to downholes (Table 3-1). 
Table 3-1

Drill Holes Sampled for Brine in 1989 and 1990

\begin{tabular}{cccc}
\hline Downholes $^{\mathrm{a}}$ & $\begin{array}{c}\text { Suspect } \\
\text { Downholes }\end{array}$ & Upholes & $\begin{array}{c}\text { Subhorizontal } \\
\text { Holes }\end{array}$ \\
\hline A1X01 & DH28 & A1X02 & OH20 \\
A2X01 & DH30 & OH47 & OH23 \\
A3X01 & DH32 & & OH26 \\
BX01 & DH34 & OH28 \\
DH36 & DHP402A & OH45 \\
DH38 & G090 & \\
DH40 & GSEEP & \\
DH42 & H090 & \\
DH42A & L1X00 & \\
NG252 & OH62 & \\
OH46 & OH63 & \\
& OH66 & \\
& OH67 & \\
& & \\
\end{tabular}

These downholes are not separately indicated on the following histograms. Data from them clusters tightly and makes the dominant pattern. Suspected downholes, upholes, and subhorizontal holes are noted on the histograms to show their distribution relative to the downholes.

buspect holes may be contaminated with water spread on drift floor for roadbed consolidation. 
Upholes and suspect downholes generally fall in outlier areas, relative to the modes shown in Figures 3-1 to 3-8. However, there is no strong indication that subhorizontal holes recover brines with chemistry greatly different than uncontaminated downholes, as the subhorizontal data lie close to or in the range observed for the mode of a given parameter. Histograms that summarize major-element distribution for UNC and IT data also show SNL/NM analytical data obtained on brine-weep samples (Krumhansl and others, 1991).

The SNL/NM data represent analyses obtained from brine weeps recovered at three locations in the underground workings. The first weep array was located near the corner of the Room $Q$ entryway. The second array was located at the south end of the repository across from Panel 1, Room 1; and the third array was installed at the north end of the repository in Room L-4. The SNL/NM brine-weep data have not been statistically reduced because each analysis represents a distinct location, and analyses from each weep array (i.e., SNL/NM-1, SNL/NM-2, and SNL/NM-3) are depicted separately on the histograms.

Additionally, the SNL/NM data were reported in parts per thousand (ppt) or grams per kilogram ( $\mathrm{g} / \mathrm{kg}$ ), without density data to convert to grams per liter $(\mathrm{g} / \mathrm{L})$. An average density value of 1.22 kilograms per liter ( $\mathrm{kg} / \mathrm{L}$ ) was used to convert ppt to $\mathrm{g} / \mathrm{L}$ so that UNC and IT data could be compared to SNL/NM data. This density value was chosen based on the most common specific-gravity value reported for BSEP samples.

\subsubsection{Major-Element Composition of BSEP Brines and Brine Weeps}

The principal constituents in samples recovered from drill holes (UNC and IT data) and brine weeps (SNL/NM data) are, in decreasing abundance, chloride, sodium, magnesium, potassium, sulfate, boron, bromide, and calcium. Each histogram discussed below shows the frequency distribution of the given parameter for UNC and IT mean values, while the individual analyses for each weep array have been charted for the SNL/NM data. The $y$-axis corresponds to the number (i.e., frequency) of observations that fall into the parameter range given along the $x$-axis. For UNC and IT, the total number of observations will be equal to 31 and 23, respectively, which represents the number of drill holes with calculated mean values. For SNL/NM weep arrays 1 through 3, the number of observations corresponds to the number of individual analyses obtained on each weep array $($ SNL $/ N M-1=30$, SNL $/ N M-2=$ 23, SNL/NM-3 =24).

Chloride. Mean values for chloride are concentrated in the greater than 190 to $195 \mathrm{~g} / \mathrm{L}$ range for UNC and the greater than 195 to $200 \mathrm{~g} / \mathrm{L}$ range for IT (Figure 3-1). Both the IT 


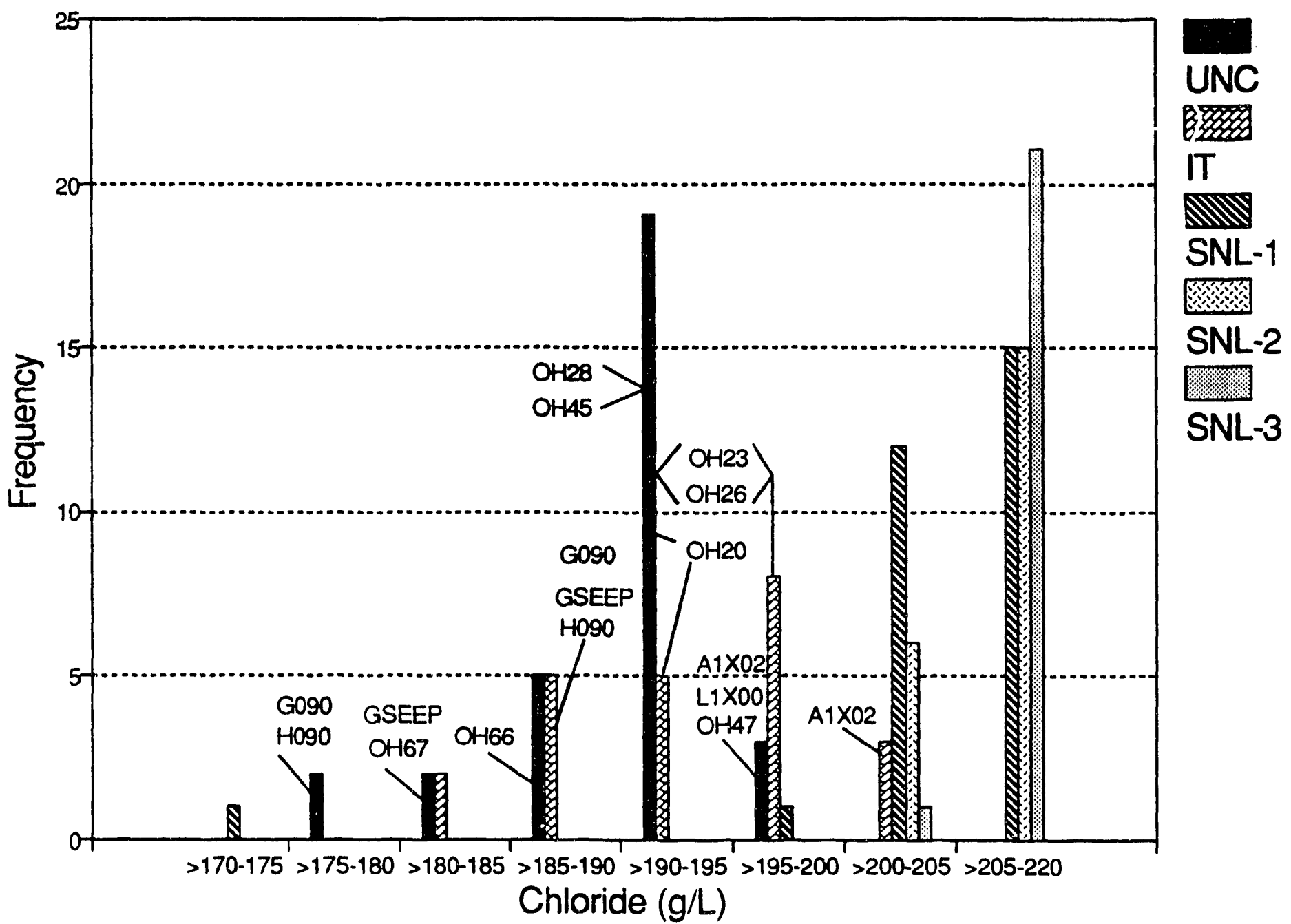

Figure 3-1

Distribution of chloride in Salado Formation brines recovered from underground locations at the WIPP. Note that the highest group along the $x$-axis represents a greater range of chloride values relative to other groups. Drill hole indicators for UNC and IT data are discussed in the text. 


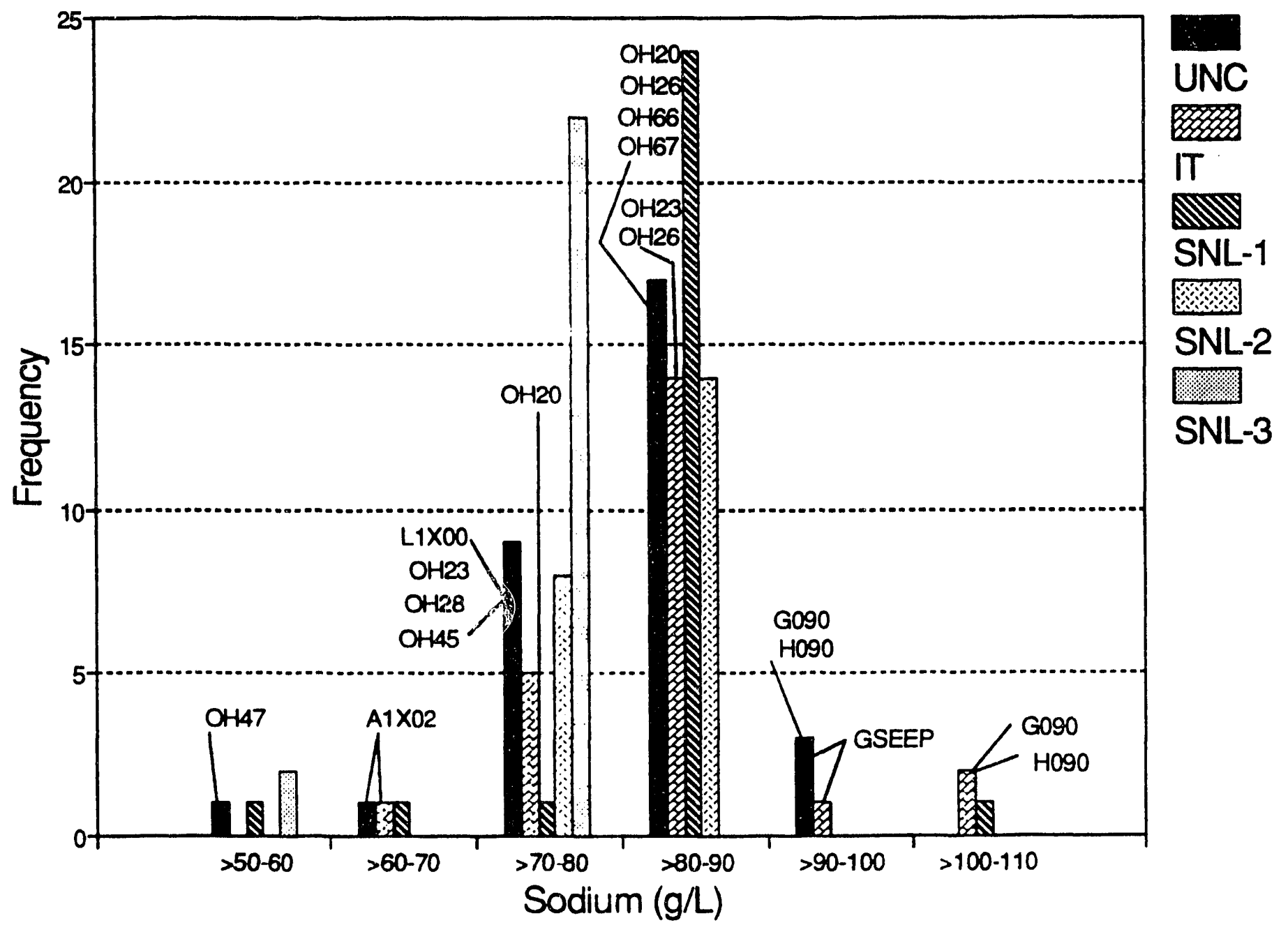

Figure 3-2

Distribution of sodium in Salado Formation brines recovered from underground locations at the WIPP. Drill hole indicators for UNC and IT data are discussed in the text. 


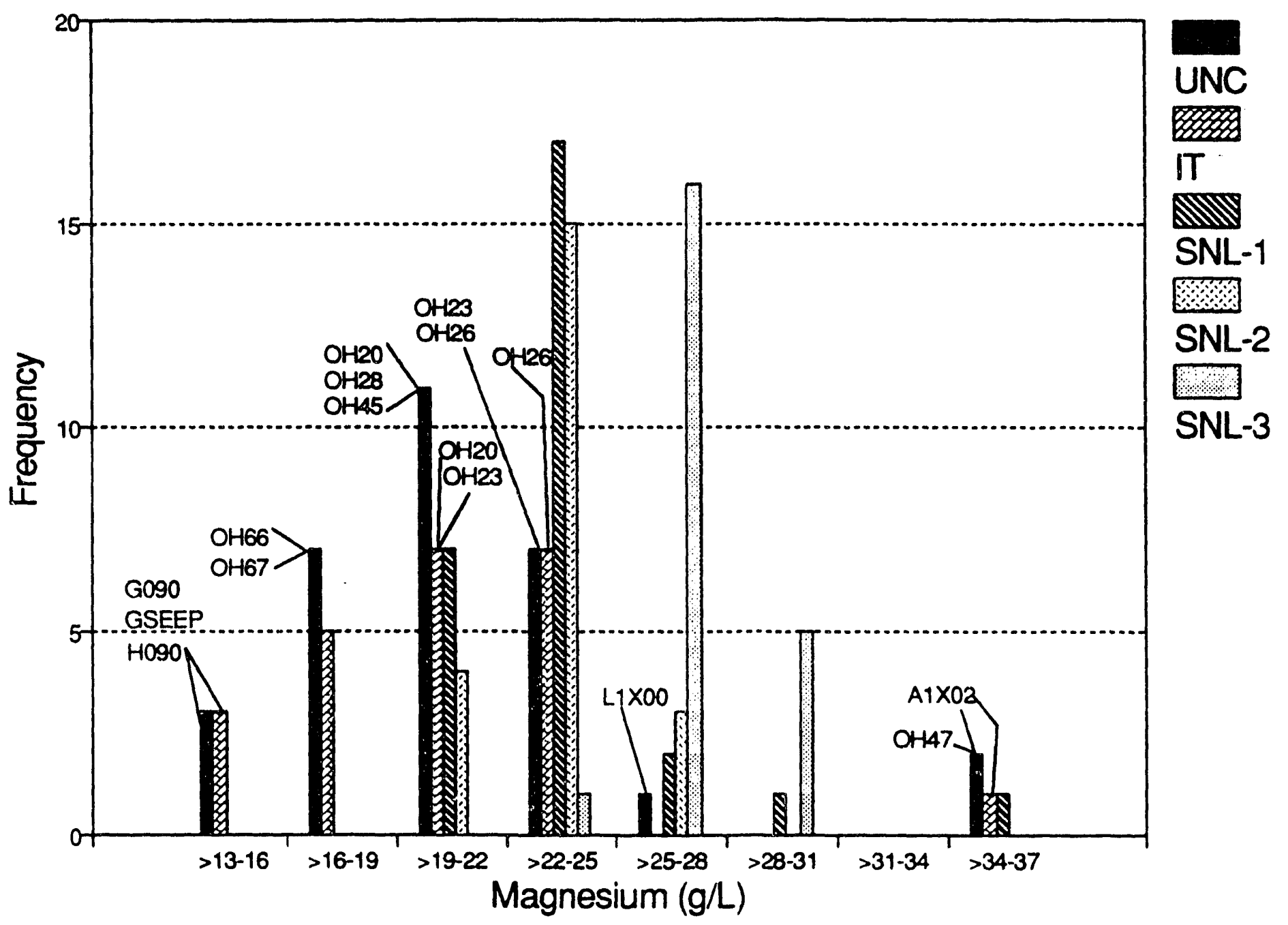

Figure 3-3

Distribution of magnesium in Salado Formation brines recovered from underground locations at the WIPP. Drill hole indicators for UNC and IT data are discussed in the text. 

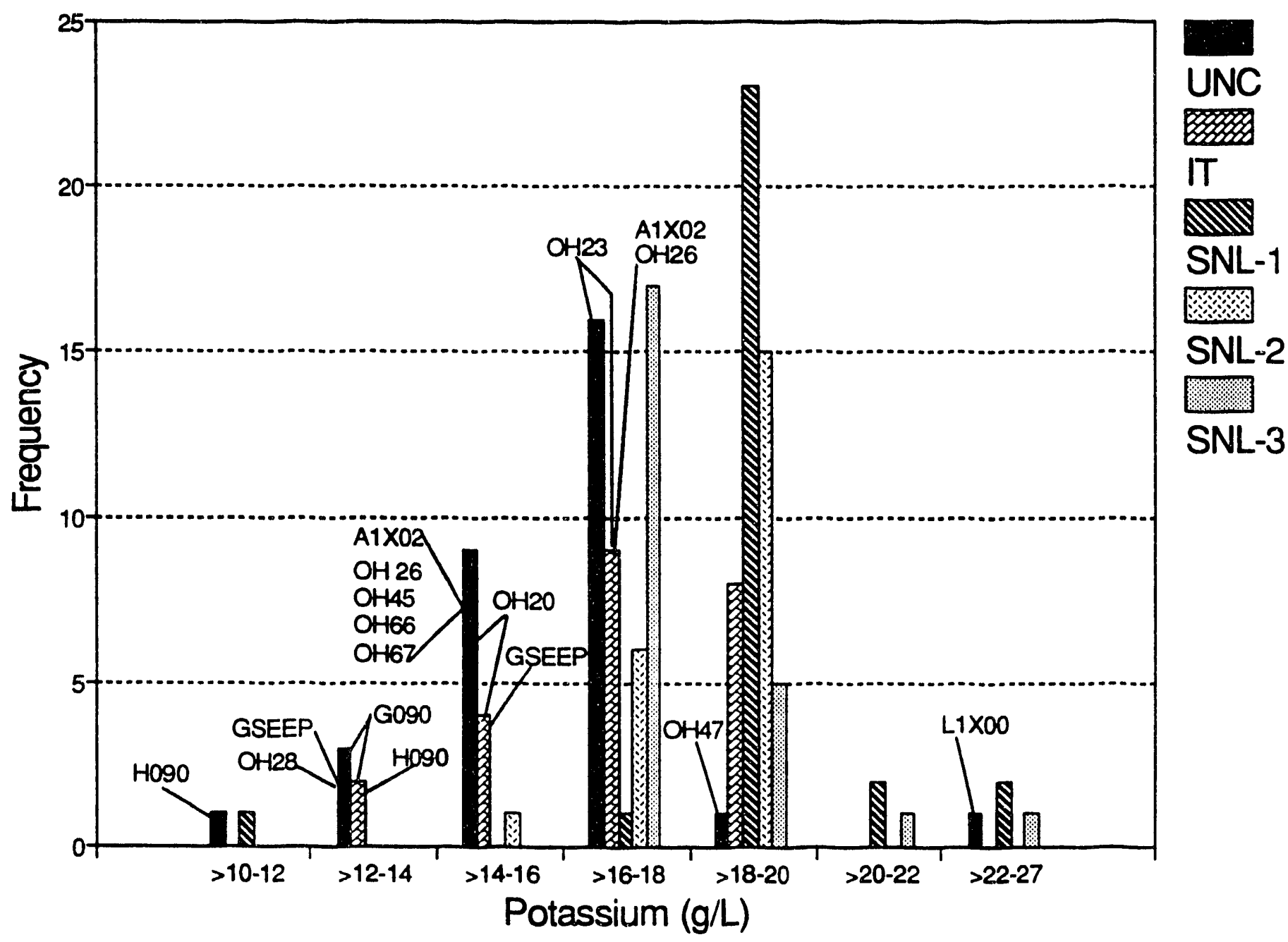

Figure 3-4

Distribution of potassium in Salado Formation brines recovered from underground locations at the WIPP. Note that the highest group along the $x$-axis represents a greater range of potassium values relative to other groups. Drill hole indicators for UNC and $\pi$ data are discussed in the text. 


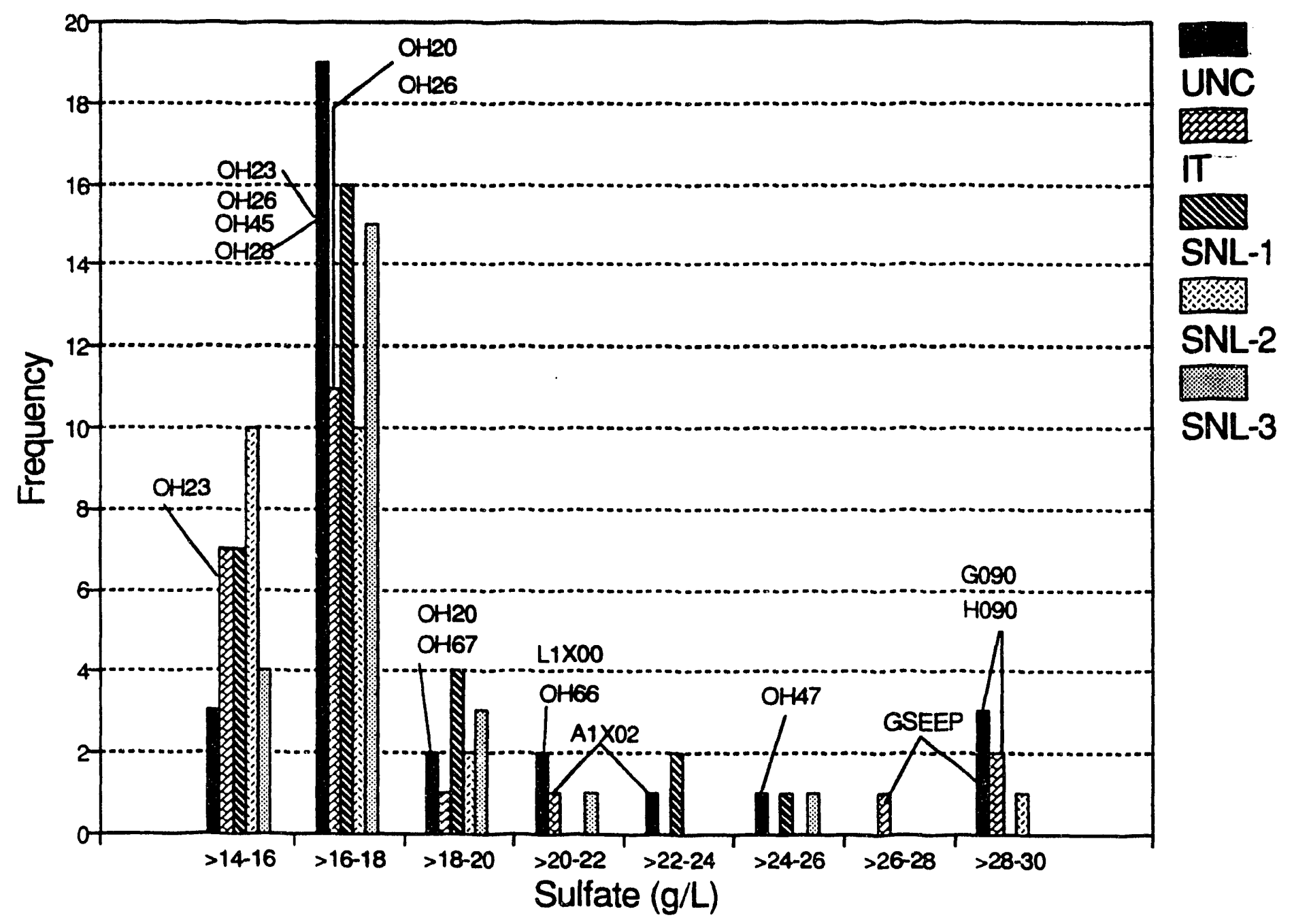

Figure 3-5

Distribution of sulfate in Salado Formation brines recovered from underground locations at the WIPP. Drill hole indicators for UNC and IT data are discussed in the text. 


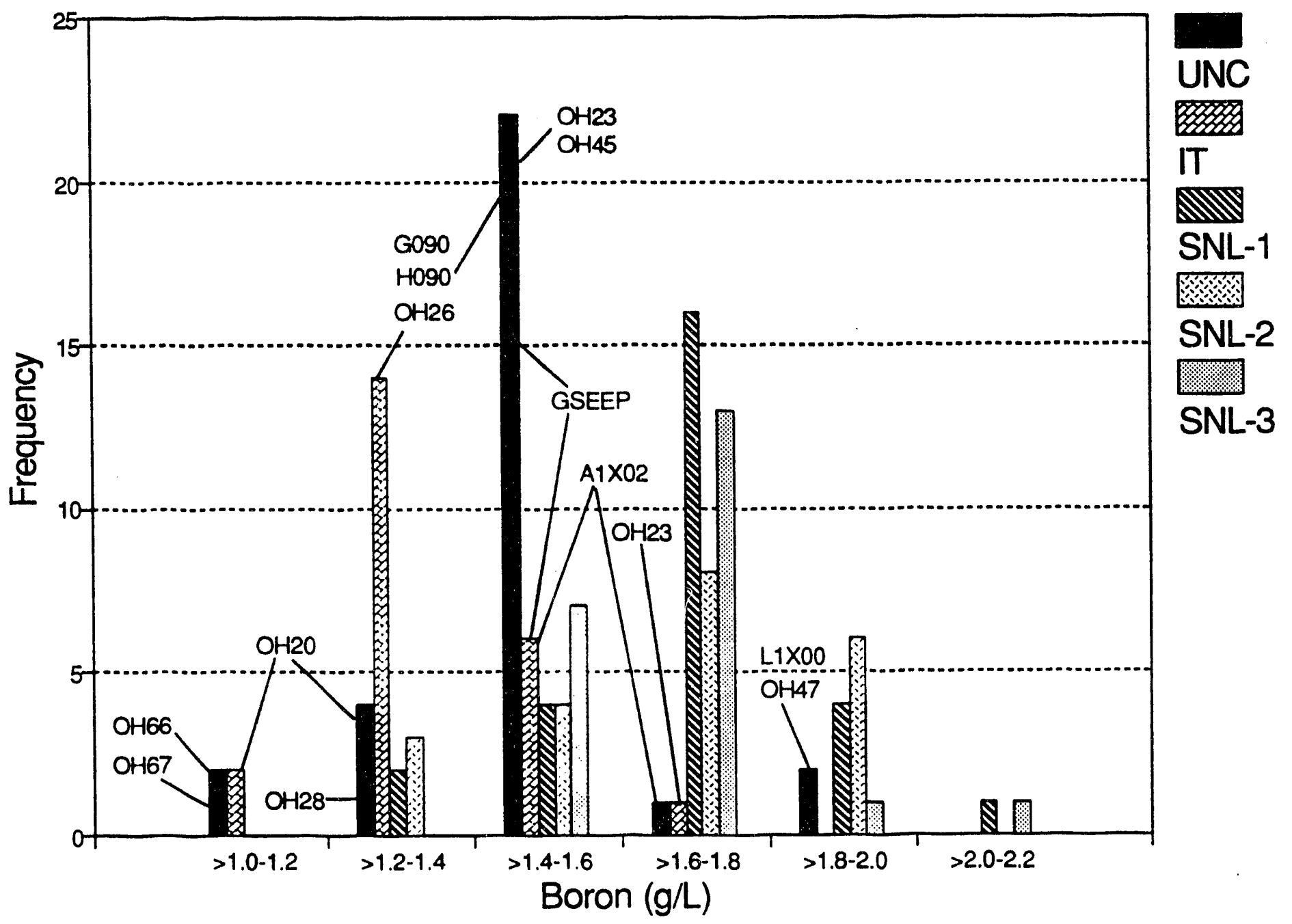

Figure 3-6

Distribution of boron in Salado Formation brines recovered from underground locations at the WIPP. Drill hole indicators for UNC and IT data are discussed in the text. 


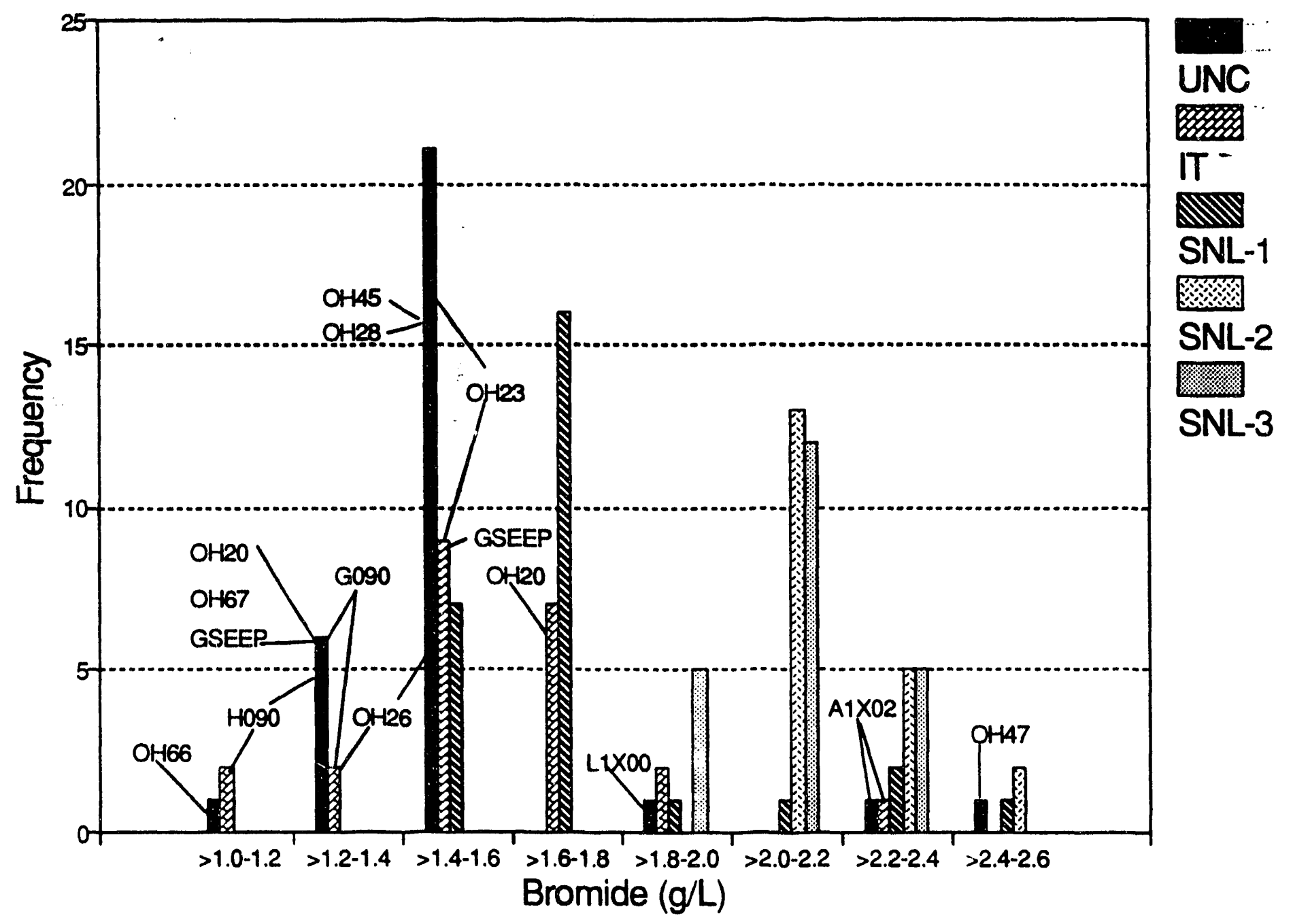

Figure 3-7

Distribution of bromide in Salado Formation brines recovered from underground locations at the WIPP. Drill hole indicators for UNC and IT data are discussed in the text. 


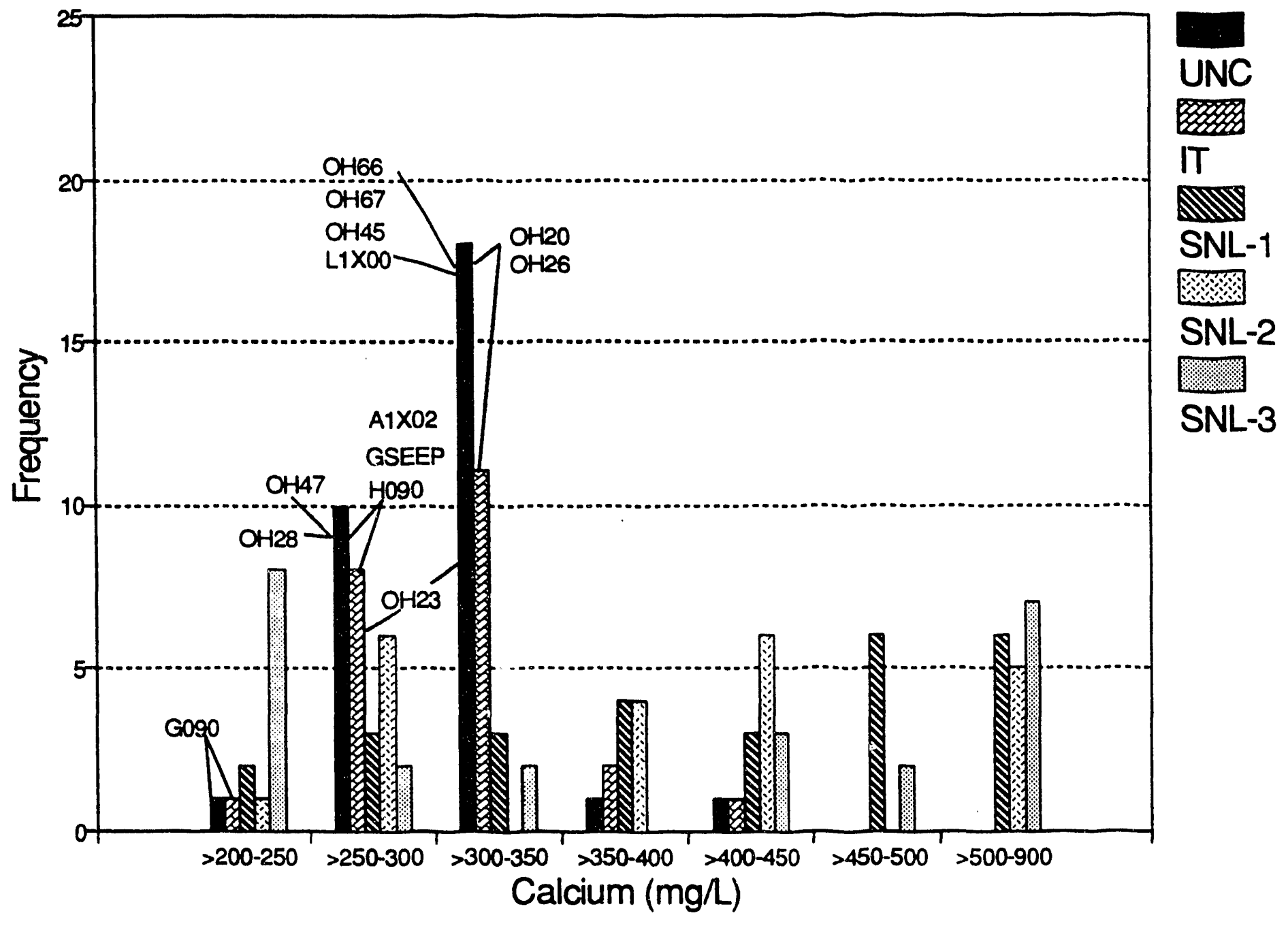

Figure 3-8

Distribution of calcium in Salado Formation brines recovered from underground locations at the WIPP. Note that the highest group along the $x$-axis represents a greater range of calcium values relative to other groups. Drill hole indicators for UNC and IT data are discussed in the text. 
and UNC distributions are skewed toward lower chloride values. SNLNM analytical results are markedly higher than IT and UNC mean values, with all three weep-array modes lying in the range of greater than 205 to $220 \mathrm{~g} / \mathrm{L}$ (note the greater range for chloride reported in this cell).

Sodium. Plotted results for sodium (Figure 3-2) show IT and SNL/NM-1 to have nearly normal distributions and modes that lie at greater than 80 to $90 \mathrm{~g} / \mathrm{L}$. UNC, SNL/NM-2, and SNLNM-3 data are skewed toward lower values, with UNC and SNLNM-2 modes similar to IT and SNLNM-1. The mode for SNL/NM-3 lies in a lower range of greater than 70 to 80 g/L.

Magnesium. Statistical results for magnesium (Figure 3-3) show UNC data to have a nearly normal distribution if the two outlier points at greater than 34 to $37 \mathrm{~g} / \mathrm{L}$ are omitted. UNC data have a mode between greater than 19 to $22 \mathrm{~g} / \mathrm{L}$, while the mode for IT values falls over a broader range between greater than 19 to $25 \mathrm{~g} / \mathrm{L}$. Statistical data for IT is skewed toward lower magnesium values, with the exception of one outlier at greater than 34 to $37 \mathrm{~g} / \mathrm{L}$. The SNLNM arrays tend to show normal distributions but with modes occurring at greater than 22 to $25 \mathrm{~g} / \mathrm{L}$ (SNL/NM-1 and SNL/NM-2) and greater than 25 to $28 \mathrm{~g} / \mathrm{L}$ (SNL/NM-3).

Potassium. The frequency distribution diagram for potassium (Figure 3-4) indicates UNC and IT data are skewed to lower values, with a UNC outlier at greater than 22 to $27 \mathrm{~g} / \mathrm{L}$. SNL/NM-1 and SNL/NM-3 are skewed toward higher values and SNL/NM-2 toward lower values. SNL/NM-1 and SNL/NM-2 have a higher mode value than SNLNM-3, UNC, and IT. UNC, IT, and SNL/NM-3 have mode values in the greater than 16 to $18 \mathrm{~g} / \mathrm{L}$ range, while SNL/NM-1 and SNL/NM-2 have modes occurring at greater than 18 to $20 \mathrm{~g} / \mathrm{L}$.

Sulfate. All analytical laboratories have most of their sulfate values bracketed between greater than 16 to $18 \mathrm{~g} / \mathrm{L}$ (Figure 3-5), with distributions slightly skewed to higher sulfate values.

Boron. The frequency distribution for boron (Figure 3-6) is nearly normal for all analytical laboratories and appears normal when all laboratories are considered simultaneously. UNC results indicate that the mode lies at greater than 1.4 to $1.6 \mathrm{~g} / \mathrm{L}$, while IT results show a mode in the range of greater than 1.2 to $1.4 \mathrm{~g} / \mathrm{L}$. Analyses from SNL/NM weep arrays show the mode to lie at higher values of greater than 1.6 to $1.8 \mathrm{~g} / \mathrm{L}$, relative to UNC and IT values. 
Bromide. Statistical and analytical results for bromide (Figure 3-7) indicate that the mode for UNC and IT data falls at greater than 1.4 to $1.6 \mathrm{~g} / \mathrm{L}$. Results for IT suggest a near normal distribution, while UNC results are skewed toward higher values. SNL/NM-1 has a mode that lies in the range of greater than 1.6 to $1.8 \mathrm{~g} / \mathrm{L}$, and SNL/NM-2 and SNL/NM-3 have mode values falling in the range of greater than 2.0 to $2.2 \mathrm{~g} / \mathrm{L}$. SNL/NM-1 and SNL/NM-2 are skewed toward higher values, while SNL/NM-3 shows a normal distribution.

Calcium. UNC and IT statistical results for calcium show a nearly normal distribution, with their modes lying in the greater than 300 to $350 \mathrm{mg} / \mathrm{L}$ range (Figure 3-8). The data for SNL/NM-2 and SNL/NM-3 plot as bimodal distributions; less than $300 \mathrm{mg} / \mathrm{L}$ and greater than $350 \mathrm{mg} / \mathrm{L}$ for SNL/NM-2 and less than $350 \mathrm{mg} / \mathrm{L}$ and greater than $400 \mathrm{mg} / \mathrm{L}$ for SNL/NM-3. SNL/NM-1 data is distributed across all divisions rather evenly. About half of all SNL/NM values lie at greater than 500 to $900 \mathrm{mg} / \mathrm{L}$ (note the greater range for calcium reported in this cell).

Discussion. The frequency distributions in Figures 3-1 through 3-8 suggest chloride, magnesium, potassium, boron, bromide, and calcium values in SNL/NM weep arrays tend toward higher concentrations, relativ t to UNC and IT data obtained on brine samples from drill holes. This difference may be attributed to not knowing the true density of the weep brines, thus yielding values in $\mathrm{g} / \mathrm{L}$ that are too high if the assumed density of $1.22 \mathrm{~kg} / \mathrm{L}$ is too great. Alternatively, with the exception of calcium, the increase in these parameters is expected when brine is evaporated prior to collection and analysis. Calcium is not expected to increase during evaporation because the brines are saturated with anhydrite and evaporation will iesult in precipitation of anhydrite, with concomitant lowering of the calcium concentration. This is demonstrated by the increase in these parameters, except calcium, for uphole samples collected and analyzed as part of the UNC and IT data (note values for A1X02 and $\mathrm{OH} 47$ in Figures 3-1 through 3-8).

Likewise, many of the skewed trends toward higher or lower values can result from evaporation or dilution of the brine prior to collection and analysis. Evaporation is most likely to produce a skewed trend toward higher values for bromide, chloride, sulfate, boron, magnesium, and potassium, and a skewness toward lower values for calcium and sodium due to precipitation of anhydrite and halite. Dilution of the brine by construction waters spread on the drift floors for roadway consolidation can produce a skewness toward lower values for all parameters, except chloride and socium. Chloride and sodium are not expected to be diluted because the spread water is undersaturated with halite, and it will readily dissolve the 
halite along the roadbed surface. SNL/NM weep arrays are not affected by construction waters, but the large dilution factors involved in the recovery of brine absorbed on filter paper and polyethylene sponges placed in the weep arrays could produce skewed patterns toward lower or higher concentration values.

\subsubsection{Physical and Additional Chemical Parameters of BSEP Brines}

BSEP brines have been characterized by UNC and IT for specific gravity, total dissolved solids (TDS), pH, extended alkalinity, total inorganic carbon (TIC), ammonium, fluoride, iodide, nitrate, manganese, silicon, and strontium, and solely by UNC for total organic carbon (TOC), phosphorus, aluminum, arsenic, barium, cesium, iron, and rubidium. The latter parameters were analyzed exclusively by UNC because IT could not reach the required detection sensitivity (due to large dilution factors) to report meaningful results.

\subsubsection{UNC and IT Parameters}

Specific Gravity-Mean values for specific gravity (Figure 3-9) indicate a nearly normal distribution for IT results and a slight skewness toward higher values for UNC data. Both analytical groups have mode values at greater than 1.21 to 1.22 .

Total Dissolved Solids-The frequency distribution for TDS (Figure 3-10) shows UNC values to have a near normal distribution and IT data to have a skewness toward higher values. Mode values are markedly different (see Section 3.1.2.3) for the two groups; UNC at greater than 370 to $380 \mathrm{~g} / \mathrm{L}$ and IT at greater than 350 to $360 \mathrm{~g} / \mathrm{L}$.

pH-Results for $\mathrm{pH}$ (Figure 3-11) reveal a bimodal distribution, with values less than 5.7 and greater than 5.9. INC and IT data show similar mode values at greater than 6.0 to 6.1 , and a slight skewness toward higher values for data greater than 5.9.

Extended Alkalinity-Extended alkalinity was measured to an endpoint $\mathrm{pH}$ of 2.5 , and is reported as equivalent bicarbonate $\left(\mathrm{HCO}_{3}\right)$. The results (Figure 3-12) are normally distributed for IT and skewed toward higher values for UNC. The mode for both groups occurs at greater than 800 to $900 \mathrm{mg} \mathrm{HCO}_{3}^{-} / \mathrm{L}$.

Total Inorganic Carbon-UNC and IT results for TIC (Figure 3-13) are reported as equivalent bicarbonate, and they show a skewness toward higher values. The mode for UNC lies at greater than 4 to $6 \mathrm{mg} \mathrm{HCO}_{3}^{-} / \mathrm{L}$, and for IT it is less than $4 \mathrm{mg} \mathrm{HCO}_{3}^{-} / \mathrm{L}$.

Ammonium - The frequency distribution for ammonium (Figure 3-14) indicates that UNC and IT data have a near normal distribution, with both modes occurring at greater than 140 to $160 \mathrm{mg} / \mathrm{L}$. 


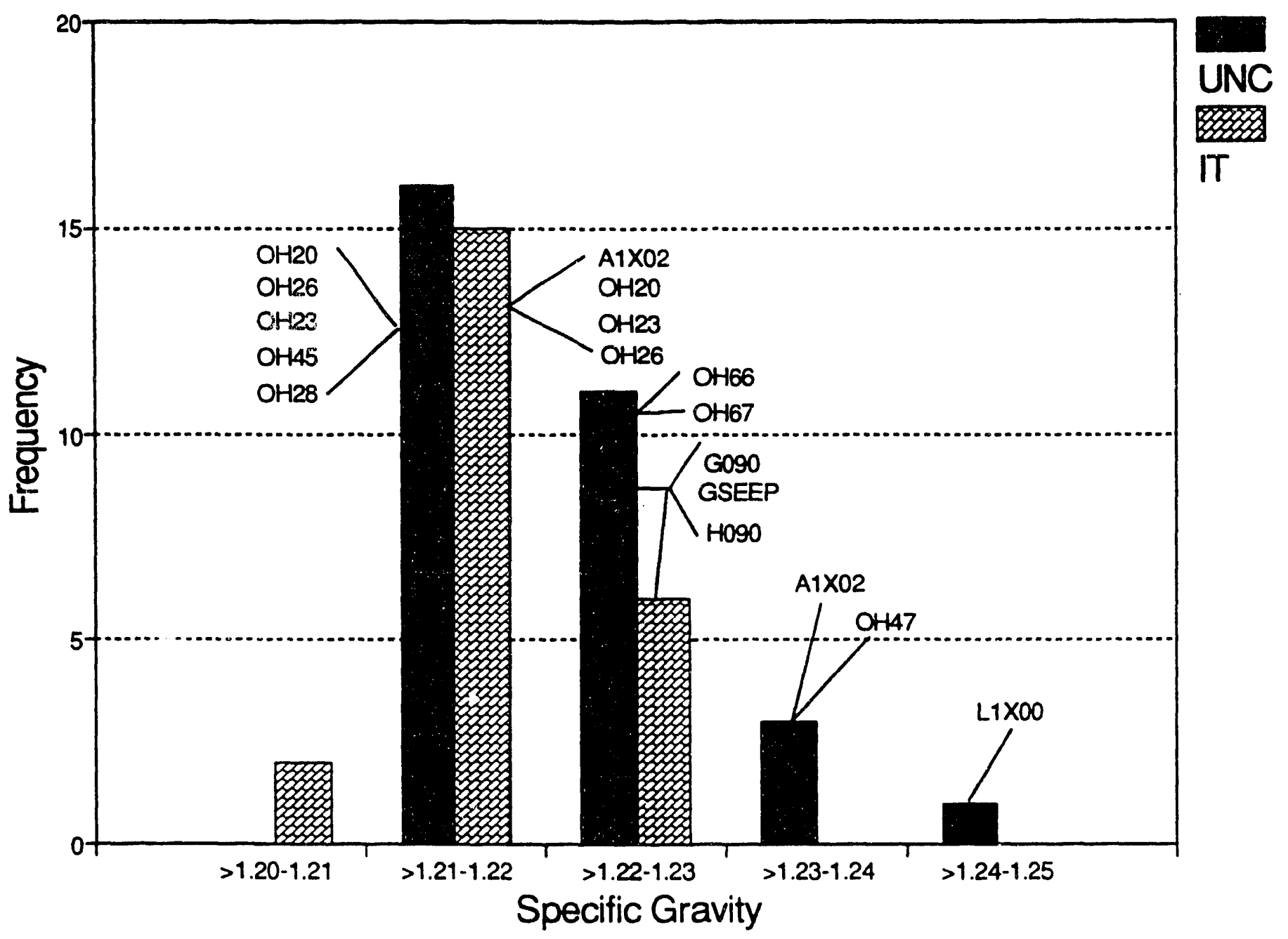

Figure 3-9

Distribution of specific gravity in Salado Formation brines recovered from underground locations at the WIPP. Drill hole indicators are discussed in the text. 


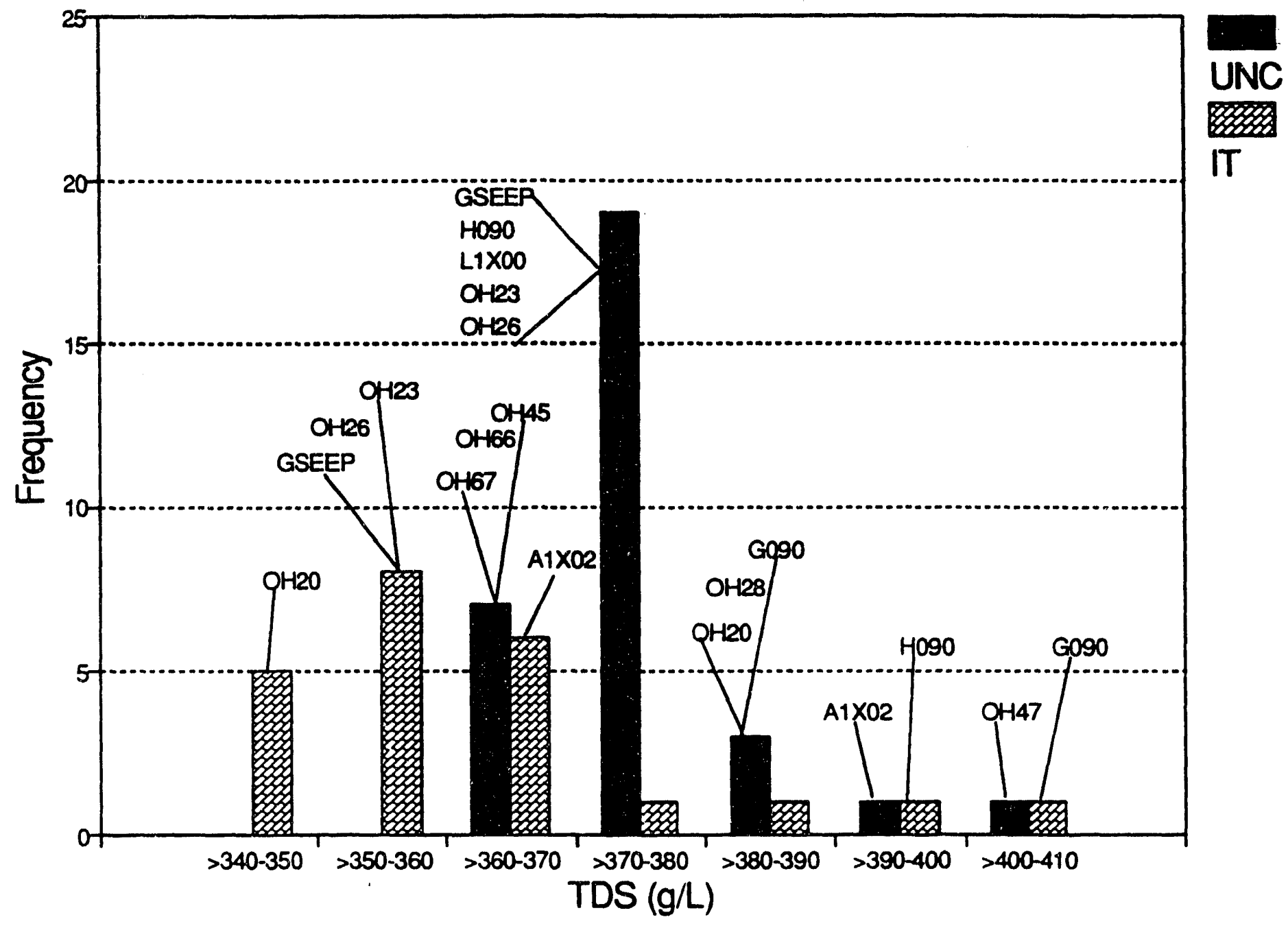

Figure 3-10

Distribution of total dissolved solids in Salado Formation brines recovered from underground locations at the WIPP. Drill hole indicators are discussed in the text. 


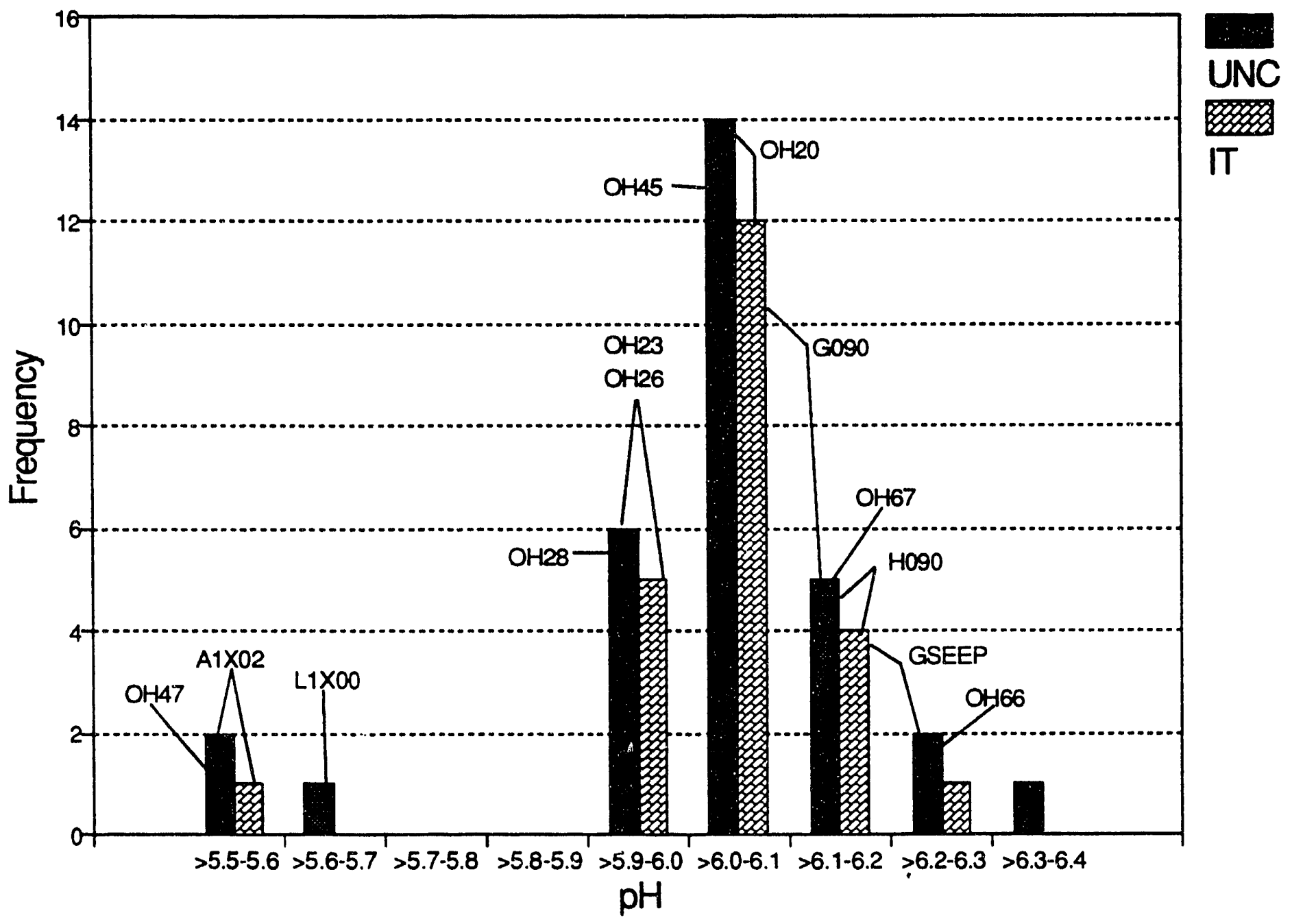

Figure 3-11

Distribution of pH in Salado Formation brines recovered from underground locations at the WIPP. Drill hole indicators are discussed in the text. 


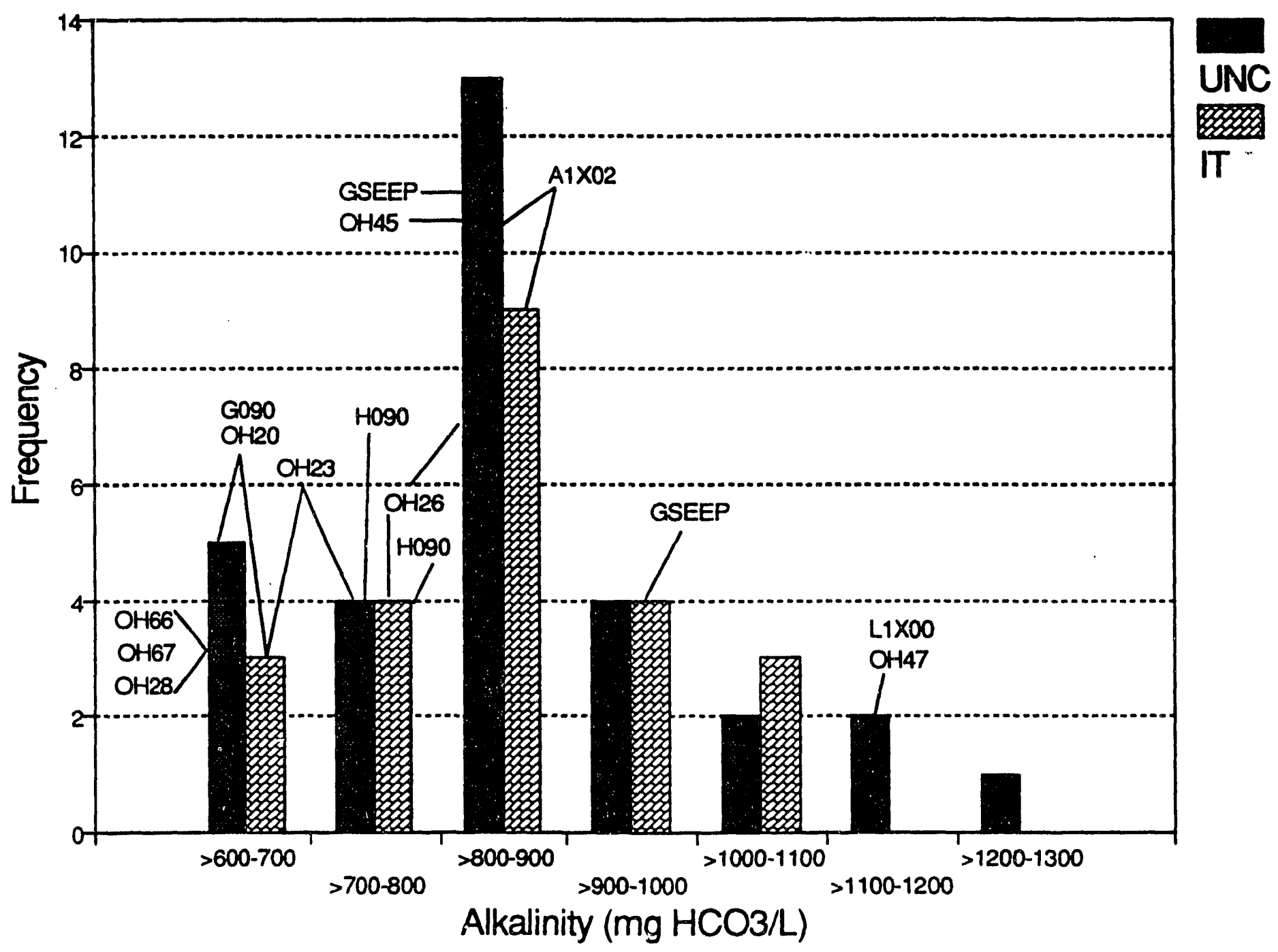

Figure 3-12

Distribution of alkalinity in Salado Formation brines recovered from underground locations at the WIPP.

Drill hole indicators are discussed in the text. 


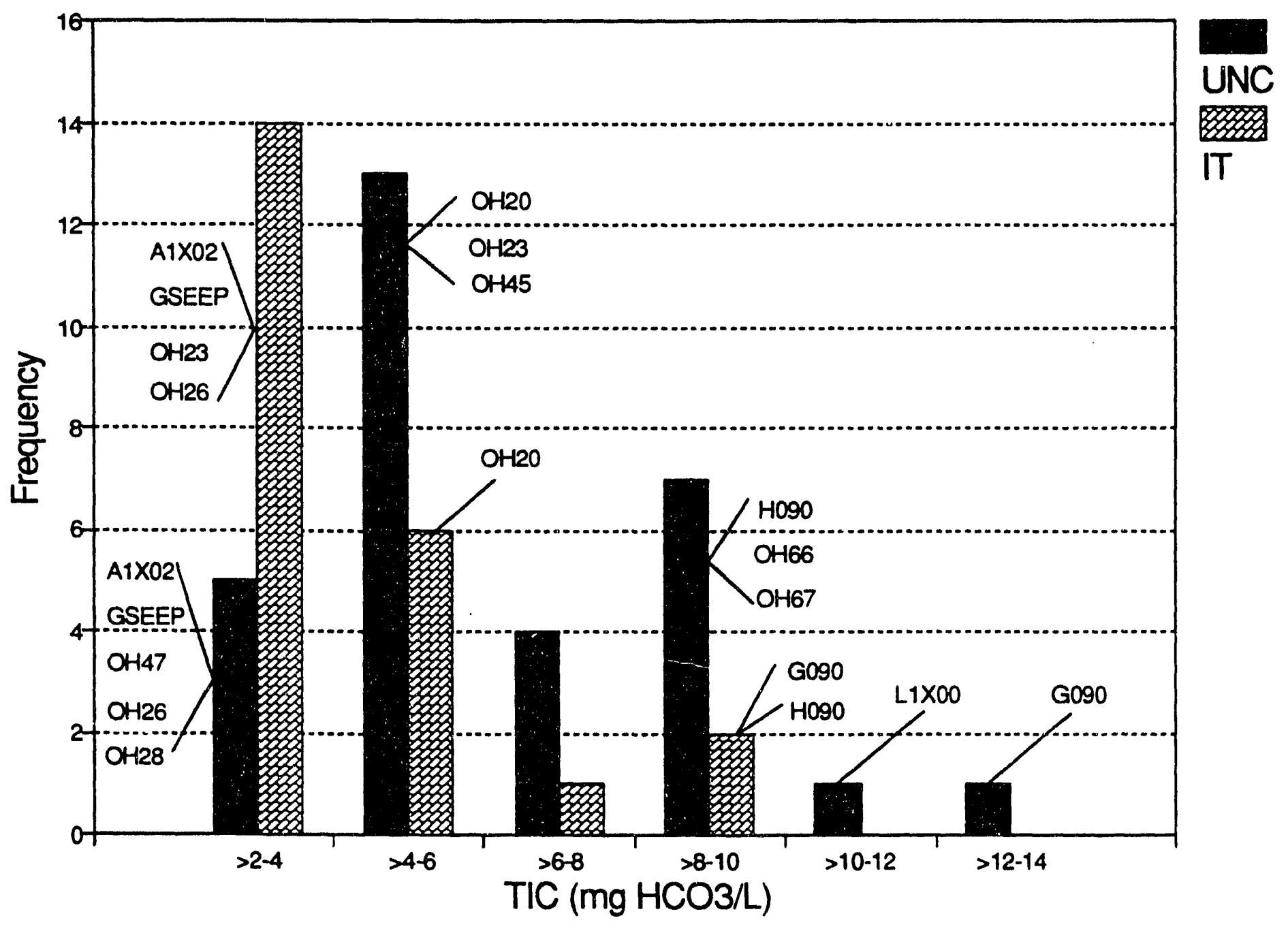

Figure 3-13

Distribution of total inorganic carbon in Salado Formation brines recovered from underground locations at the WIPP.

Drill hole indicators are discussed in the text. 


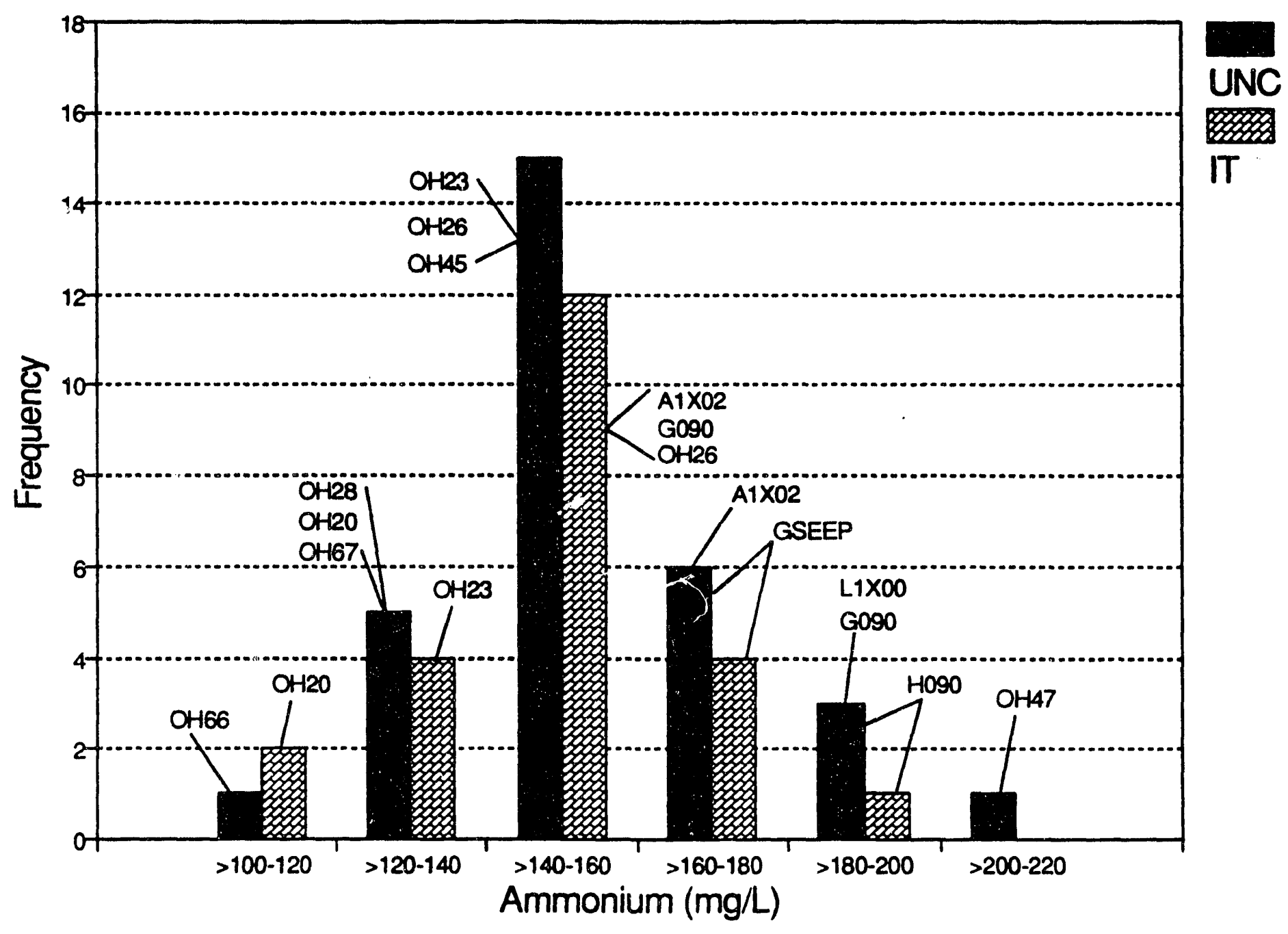

Figure 3-1.4

Distribution of ammonium in Salado Formation brines recovered from underground locations at the WIPP.

Drill hole indicators are discussed in the text. 
Fluoride-Fluoride results (Figure 3-15) reveal UNC data as skewed toward higher values and IT data as weakly bimodal. UNC has its mode occurring at greater than 3 to $4 \mathrm{mg} / \mathrm{L}$, and IT has two modes at greater than 4 to $5 \mathrm{mg} / \mathrm{L}$ and greater than 6 to $7 \mathrm{mg} / \mathrm{L}$.

lodide-Plotted results for iodide (Figure 3-16) show the UNC and IT distributions as nearly normal, with both modes occurring at greater than 15 to $17 \mathrm{mg} / \mathrm{L}$.

Nitrate-Mean values for nitrate (Figure 3-17) indicate UNC and IT data to be skewed toward higher values. The mode for IT occurs at less than $0.5 \mathrm{mg} / \mathrm{L}$ and at greater than 0.5 to $1.0 \mathrm{mg} / \mathrm{L}$ for UNC. This distribution is due to reported analytical results at the lower limit of detection, which is dependent on sample dilution and varies from 0.1 to $0.5 \mathrm{mg} / \mathrm{L}$ for IT and 0.5 to $1.0 \mathrm{mg} / \mathrm{L}$ for UNC.

Manganese-The frequency distribution for manganese (Figure 3-18) reveals a slight skewness toward higher values for both analytical groups, with UNC and IT modes lying in the greater than 1 to $2 \mathrm{mg} / \mathrm{L}$ range.

Silicon-Silicon distribution (Figure 3-19) is nearly normal for UNC and skewed to lower values for IT, but the modes are markedly different due to differences in the analytical techniques (Deal and others, 1989). UNC has a mode at greater than 1.5 to $2.0 \mathrm{mg} / \mathrm{L}$ and IT at greater than 0.5 to $1.0 \mathrm{mg} / \mathrm{L}$.

Strontium-The frequency distribution for strontium (Figure 3-20) shows UNC and IT data to be skewed toward higher concentrations. The mode for UNC falls at greater than 1 to $2 \mathrm{mg} / \mathrm{L}$ and for IT at greater than 2 to $3 \mathrm{mg} / \mathrm{L}$.

\subsubsection{UNC Parameters}

The frequency distributions for phosphorus, (Figure 3-21), aluminum (Figure 3-22), arsenic (Figure 3-23), barium (Figure 3-24), iron (Figure 3-25), and TOC (Figure 3-26) are skewed toward higher concentrations, with modes corresponding to less than (all values) $0.1,0.2$, $0.005,0.04,1$, and $5 \mathrm{mg} / \mathrm{L}$, respectively.

Cesium and rubidium results (Figures 3-27 and 3-28) show nearly normal distributions, with some skewness towards higher concentrations for rubidium. The cesium mode occurs at greater than 0.25 to $0.30 \mathrm{mg} / \mathrm{L}$ and the nubidium mode at greater than 15 to $16 \mathrm{mg} / \mathrm{L}$.

\subsubsection{Discussion}

Skewed distributions in the UNC and IT data are most likely to arise from reporting detection limit values on the histograms and evaporation or dilution of brine prior to collection and analysis. Detection limit values are plotted in the lowest value cell, which will tend to skew results towards higher values (e.g., nitrate in Figure 3-17). Brine recovered from downholes may be diluted by water spread on the roadbed to consolidate the surface. A component of 


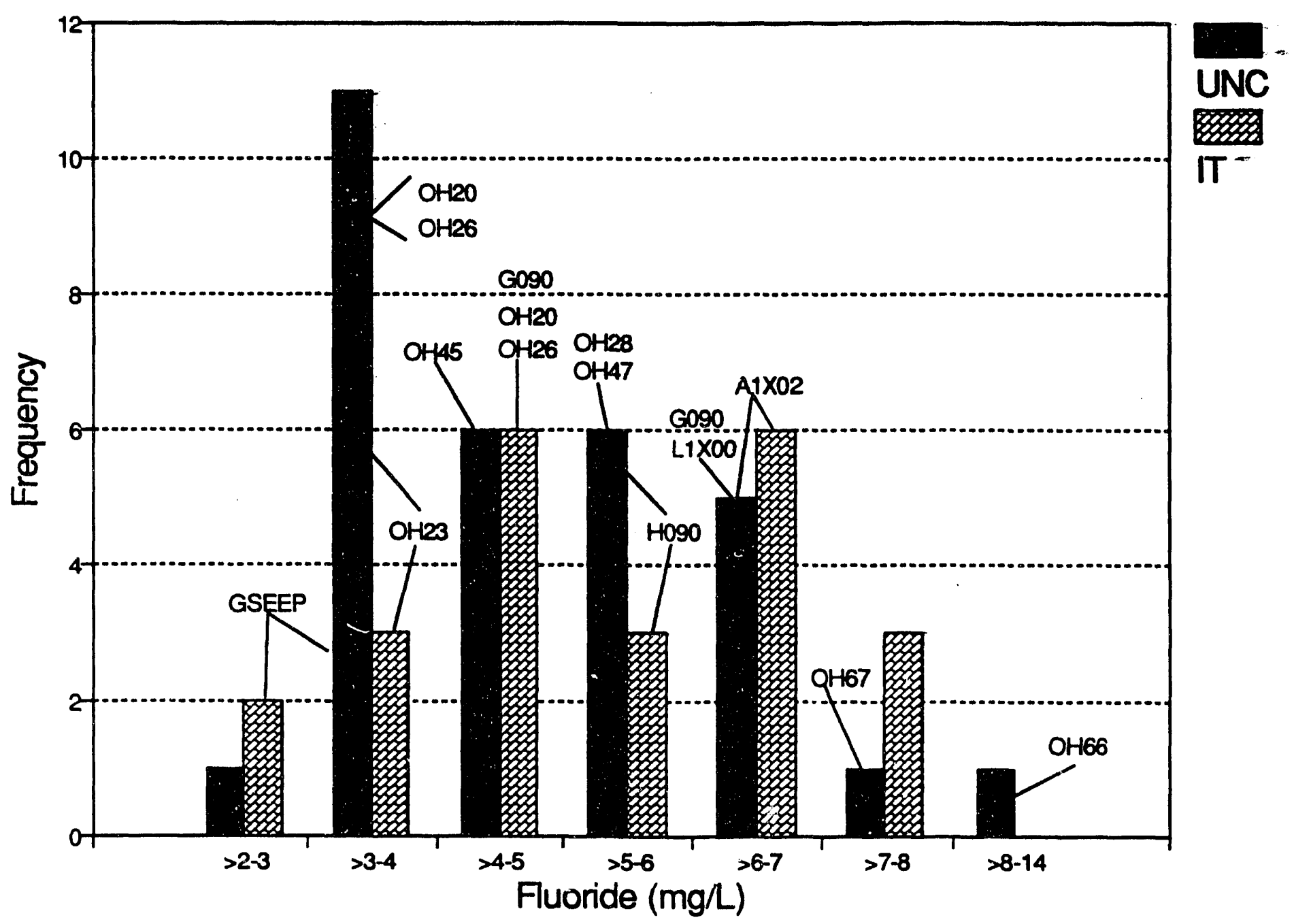

Figure 3-15

Distribution of fluoride in Salado Formation brines recovered from underground locations at the WIPP. Drill hole indicators are discussed in the text. 


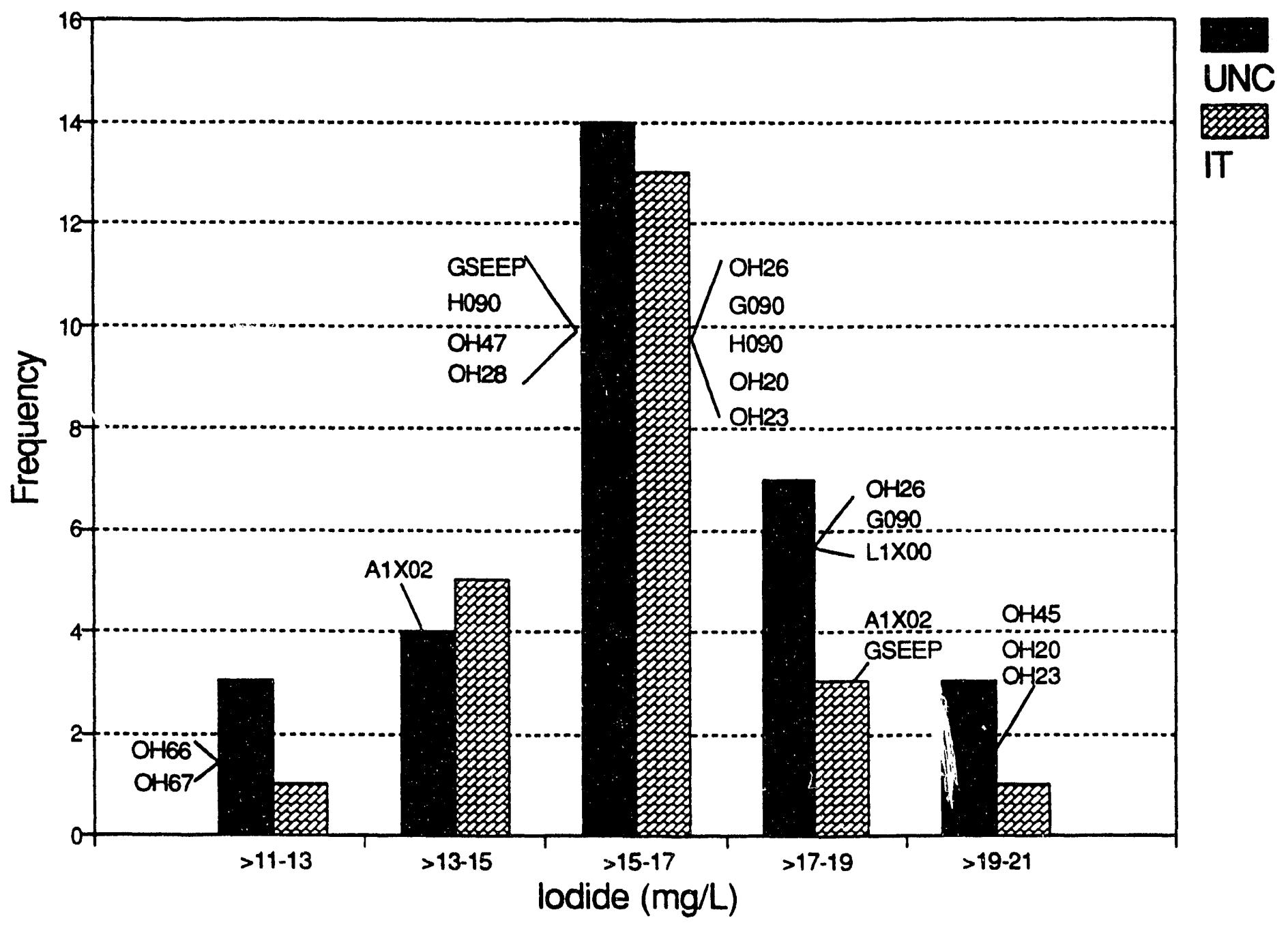

Figure 3-16

Distribution of lodide in Salado Formation brines recovered from underground locations at the WIPP.

Drill hole indicators are discussed in the text. 


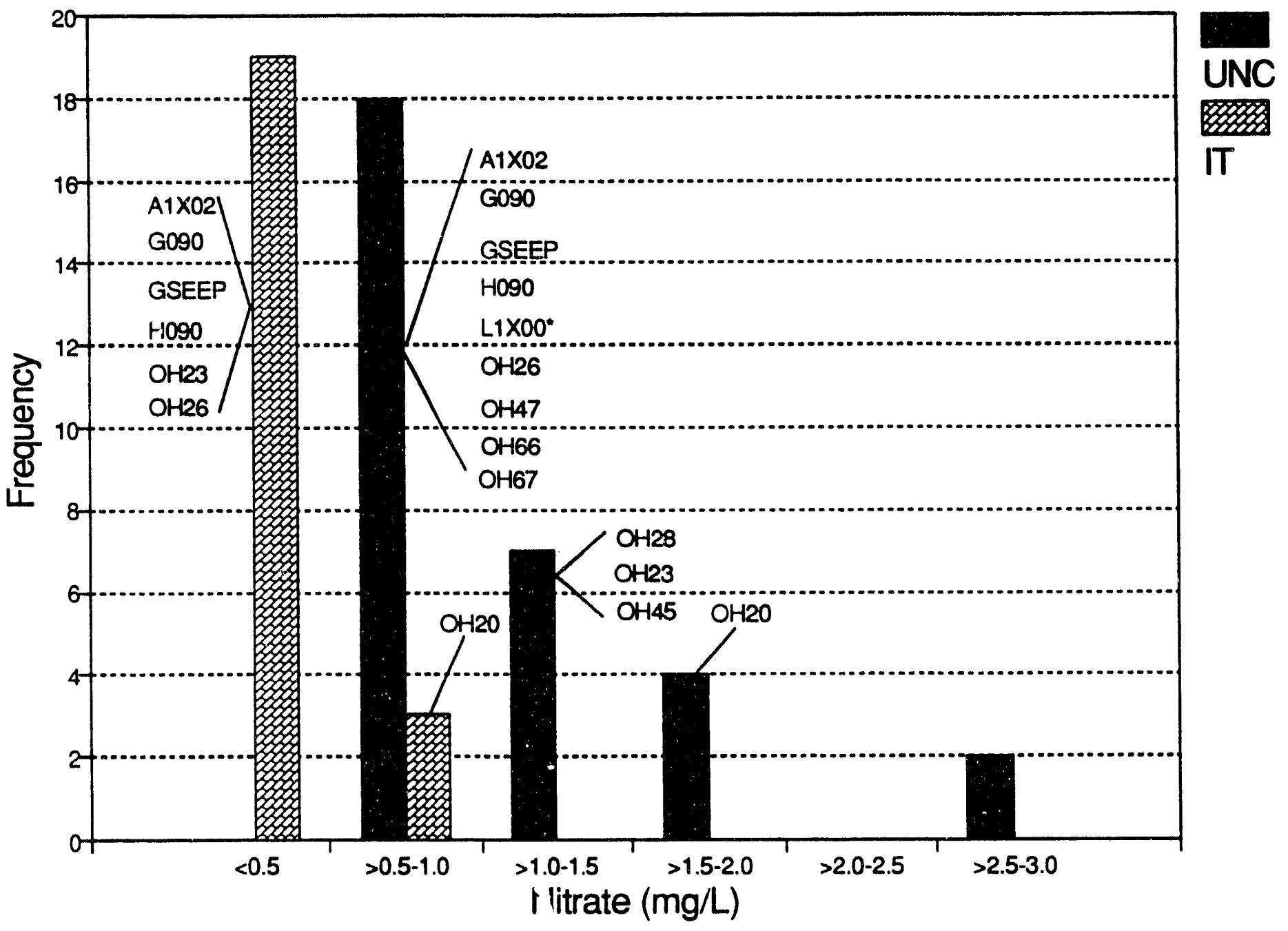

Figure 3-17

Distribution of nitrate in Salado Formation brines recovered from underground locations at the WIPP. Asterisk following drill hole identification indicates a detection limit value. Drill hole indicators are discussed in the text. 


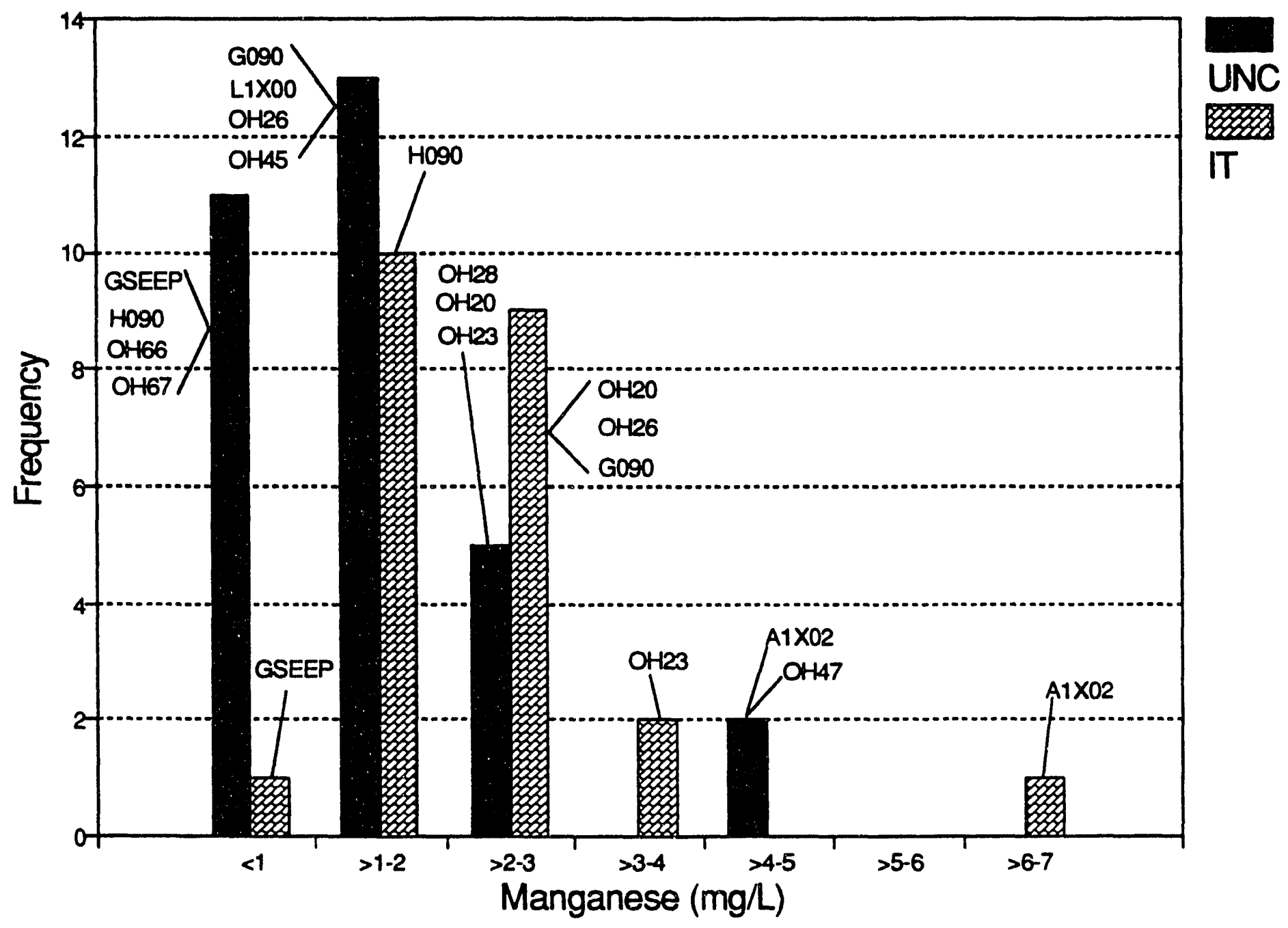

Figure 3-18

Distribution of manganese in Salado Formation brines recovered from underground locations at the W!PP.

Drill hole indicators are discussed in the text. 


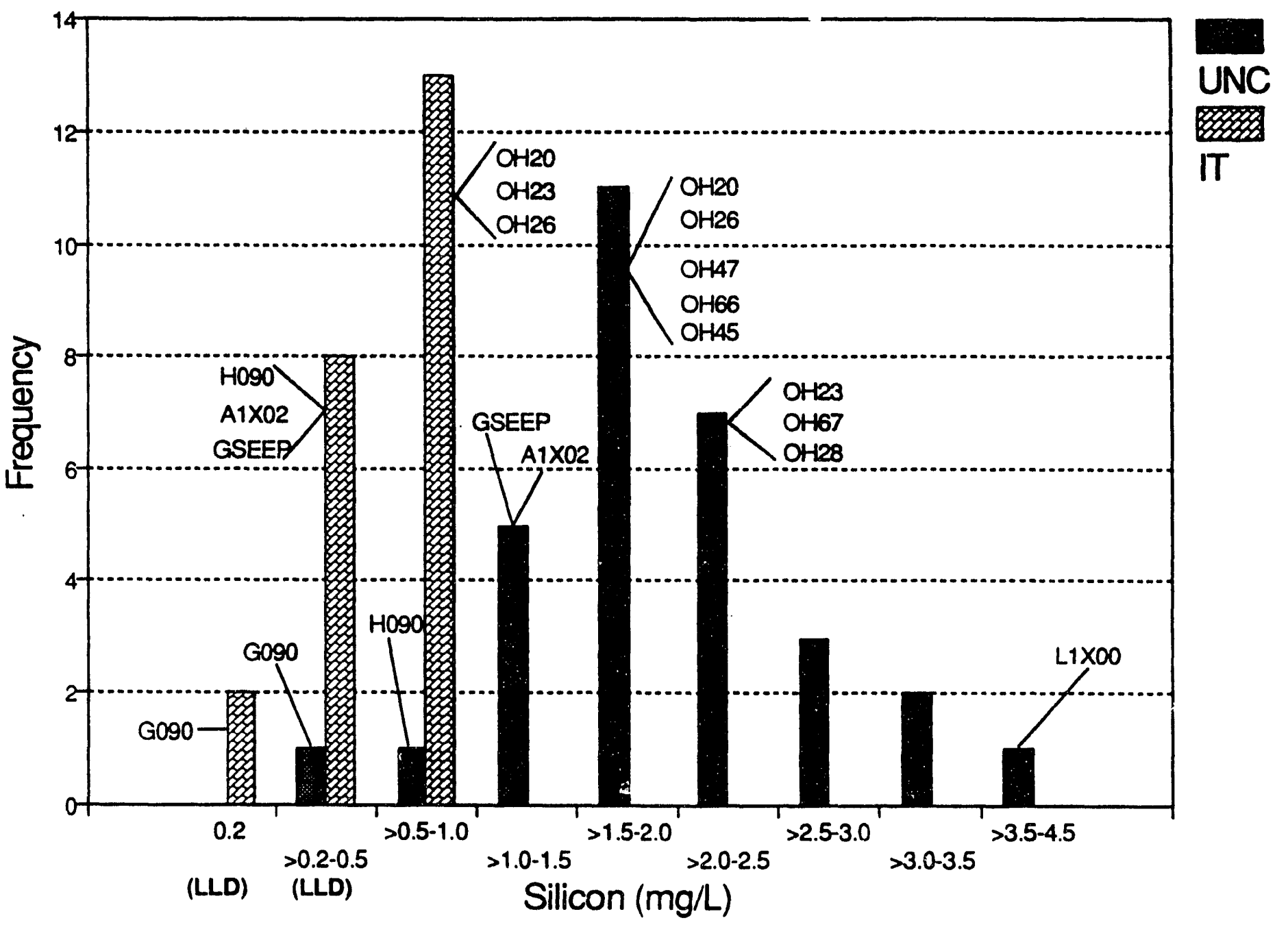

Figure 3-19

Distribution of silicon in Salado Formation brines recovered from underground locations at the WIPP. LLD noted for IT (0.2) and UNC (0.5) data. Note that the highest group along the $x$-axis represents a greater range of silicon values relative to other groups. Drill hole indicators are discussed in the text. 


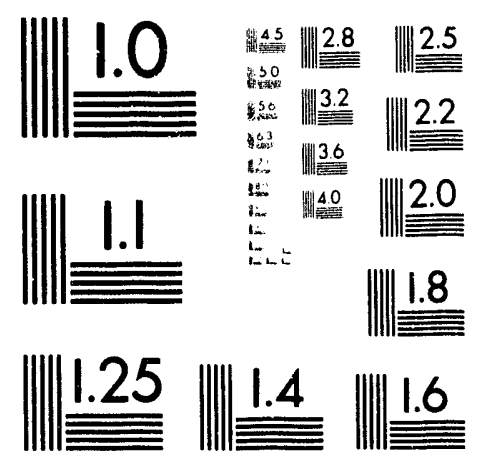



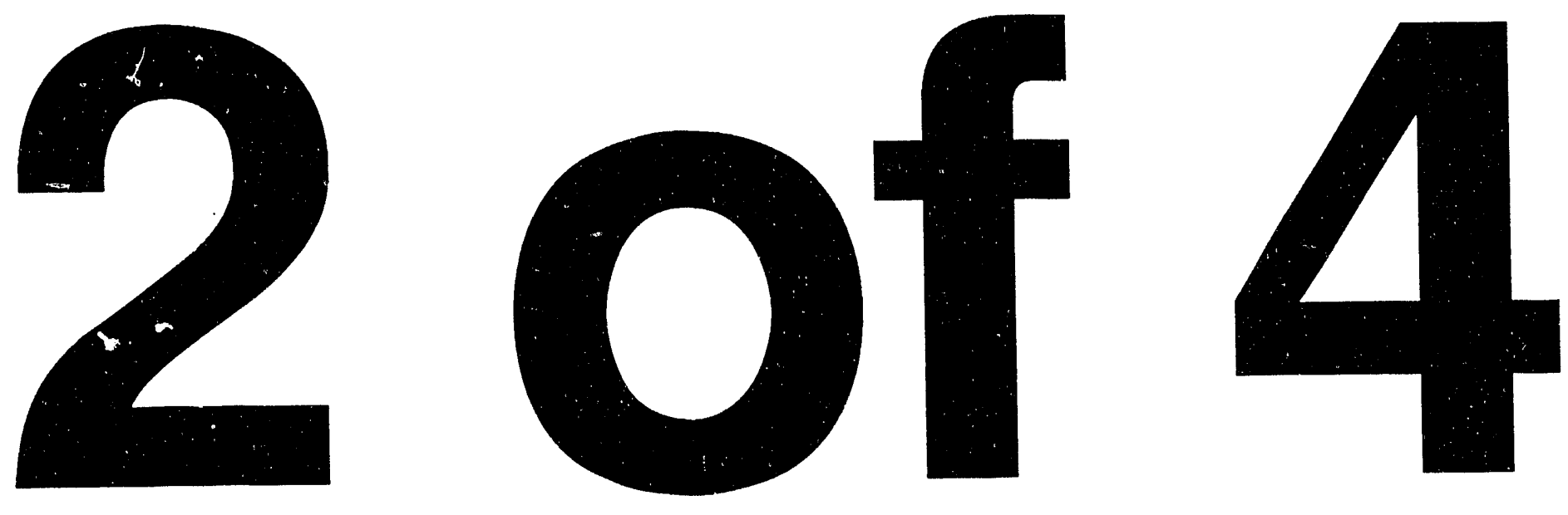


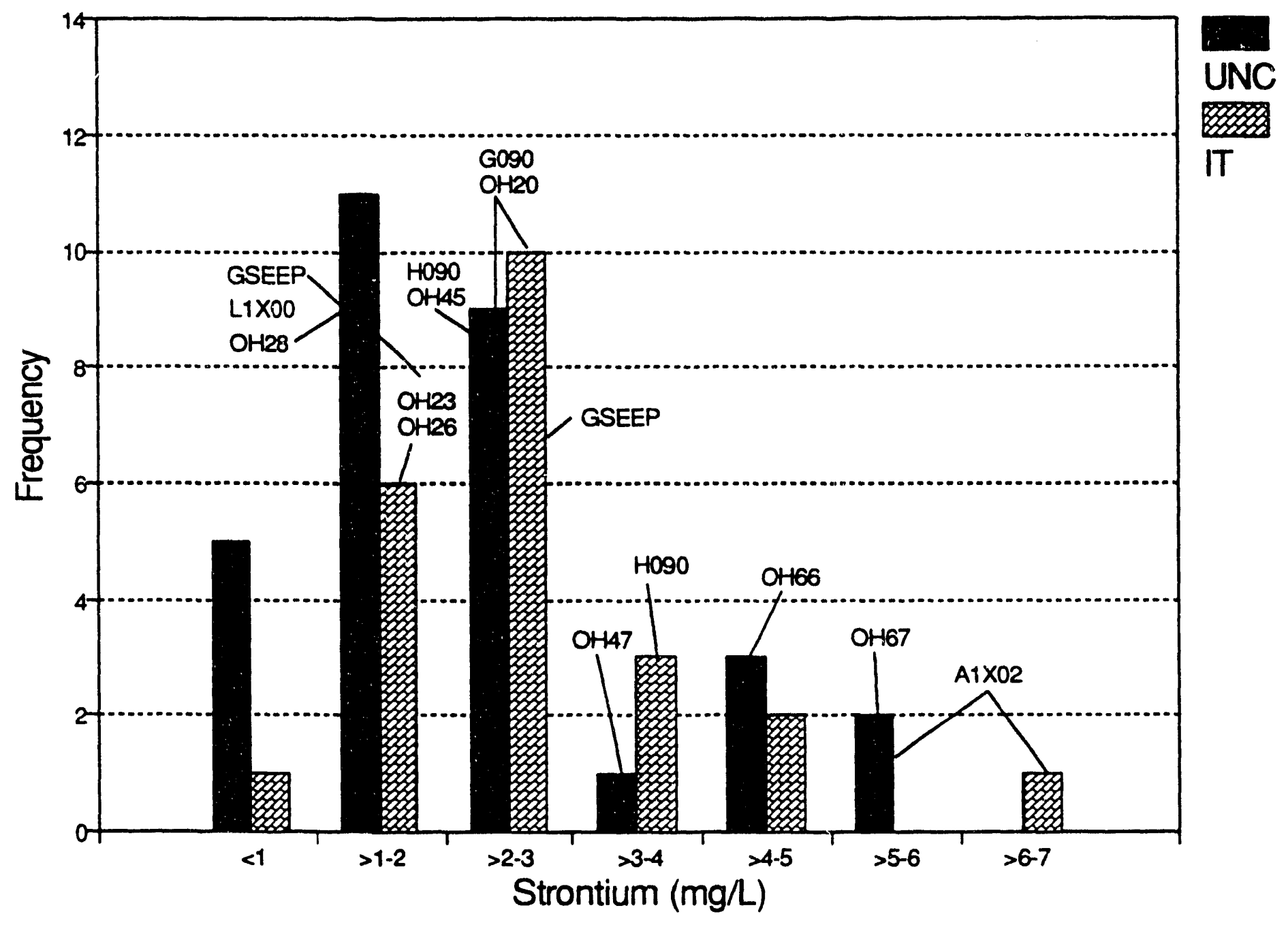

Figure 3-20

Distribution of strontium in Salado Formation brines recovered from underground locations at the WIPP. Drill hole indicators are discussed in the text. 


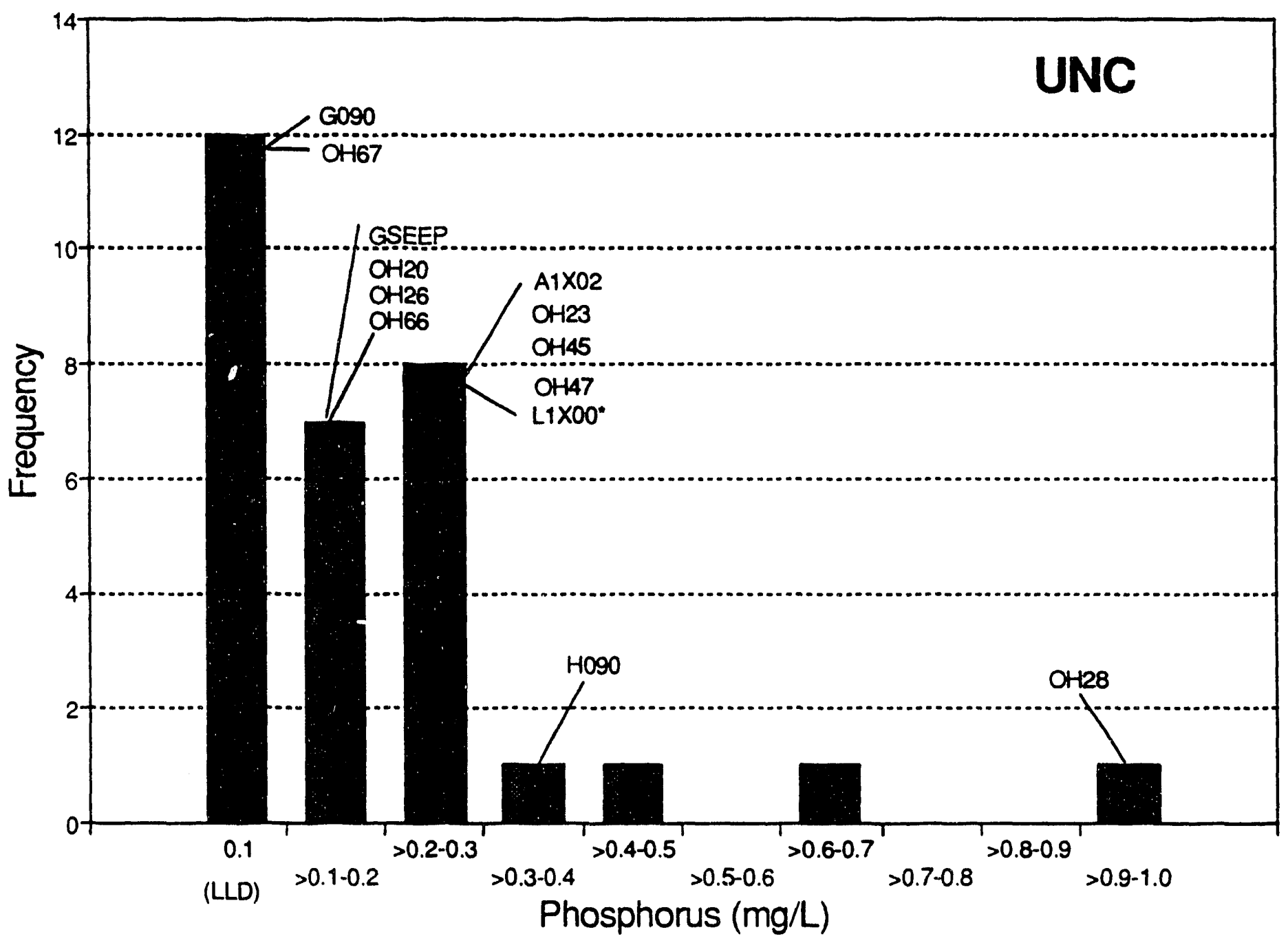

Figure 3-21

Distribution of phosphorous in Salado Formation brines recovered from underground locations at the WIPP. Note most observations lie at the LLD. Asterisk following drill hole identification indicates a higher detection limit value. Drill hole indicators are discussed in the text. 


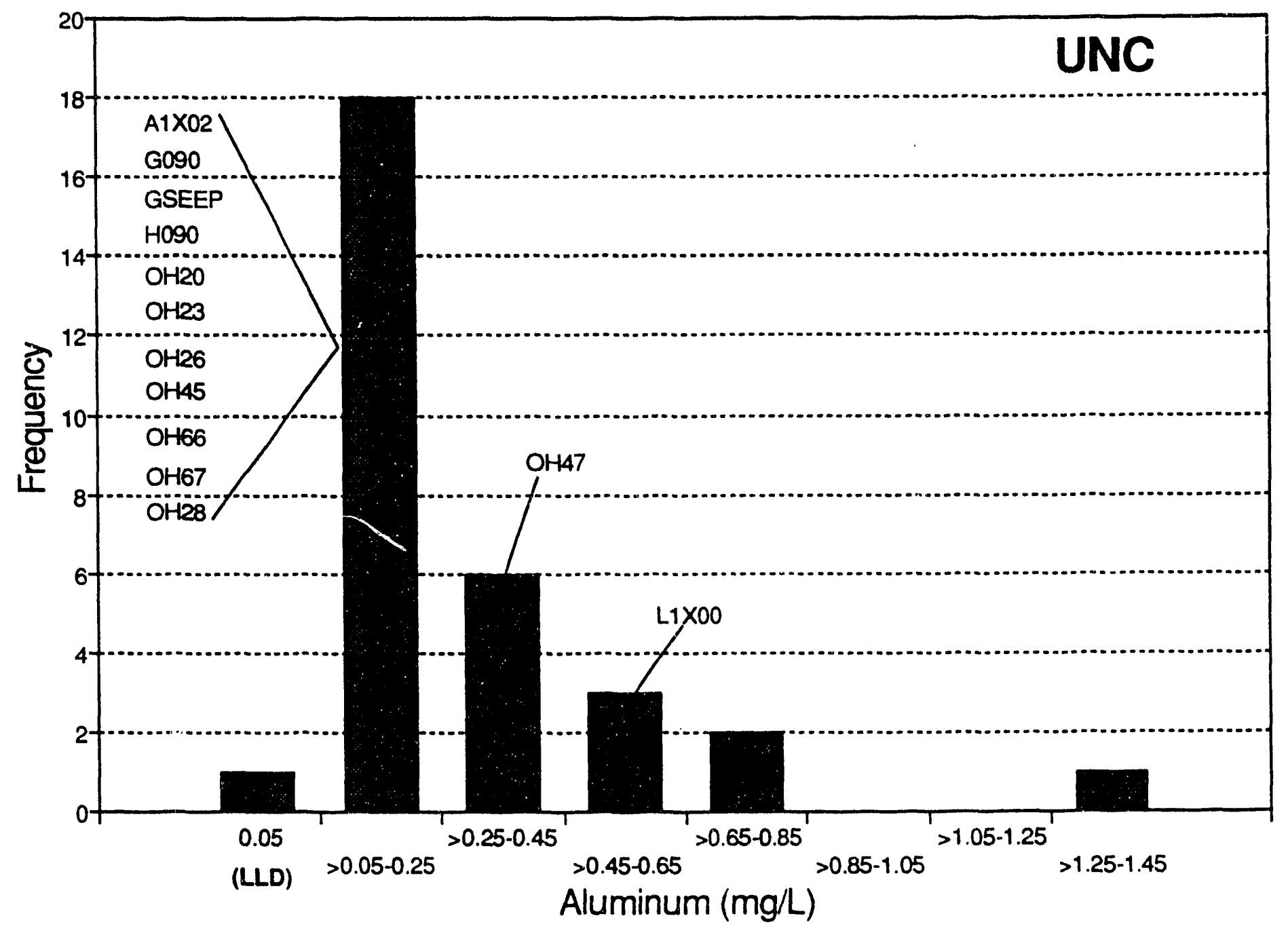

Figure 3-22

Distribution of aluminum in Salado Formation brines recovered from underground locations at the WIPP. Note LLD.

Drill hole indicators are discussed in the text. 


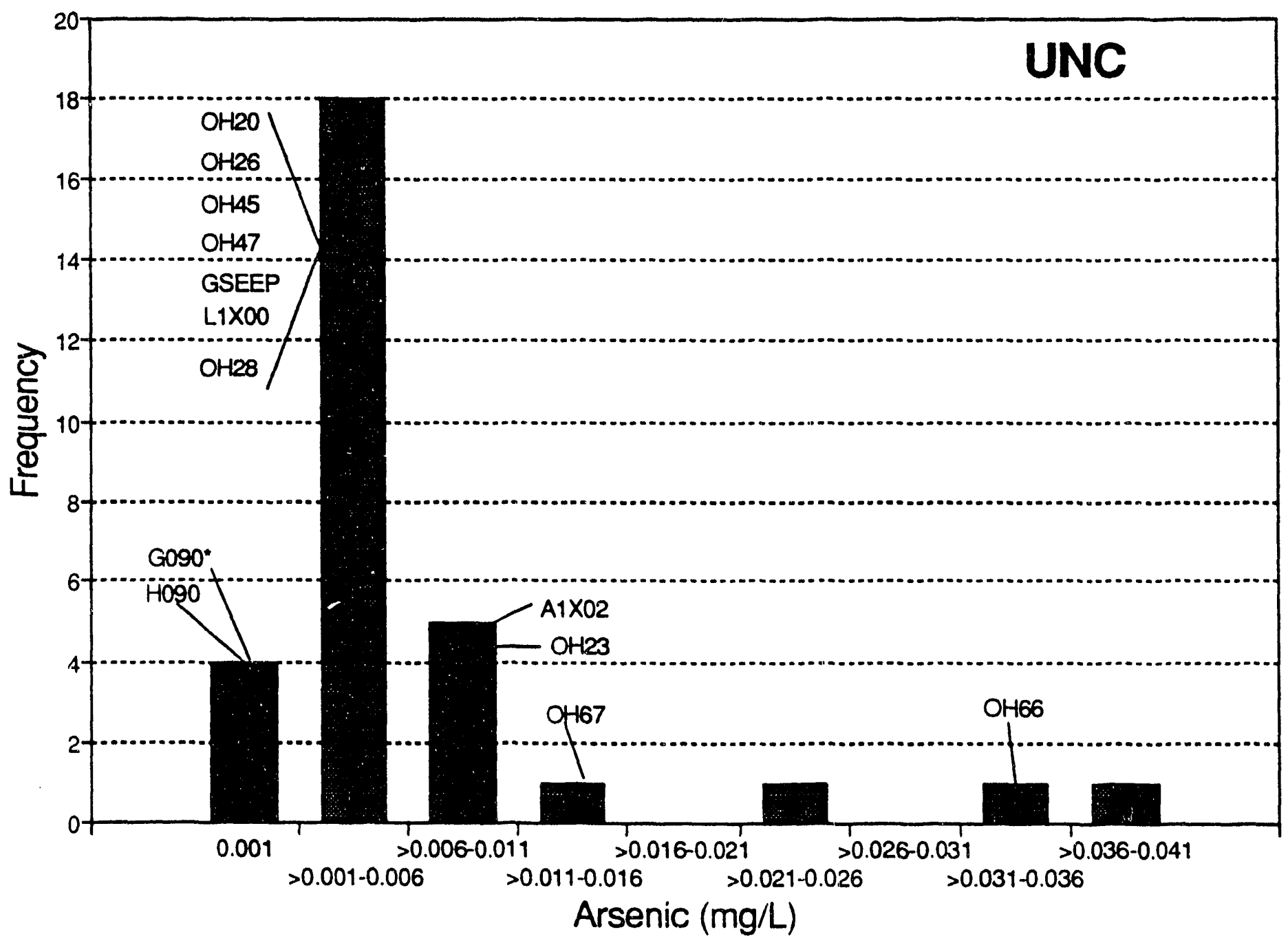

Figure 3-23

Distribution of arsenic in Salado Formation brines recovered from underground locations at the WIPP. Asterisk following drill hole identification indicates a detection limit value. Drill hole indicators are discussed in the text. 


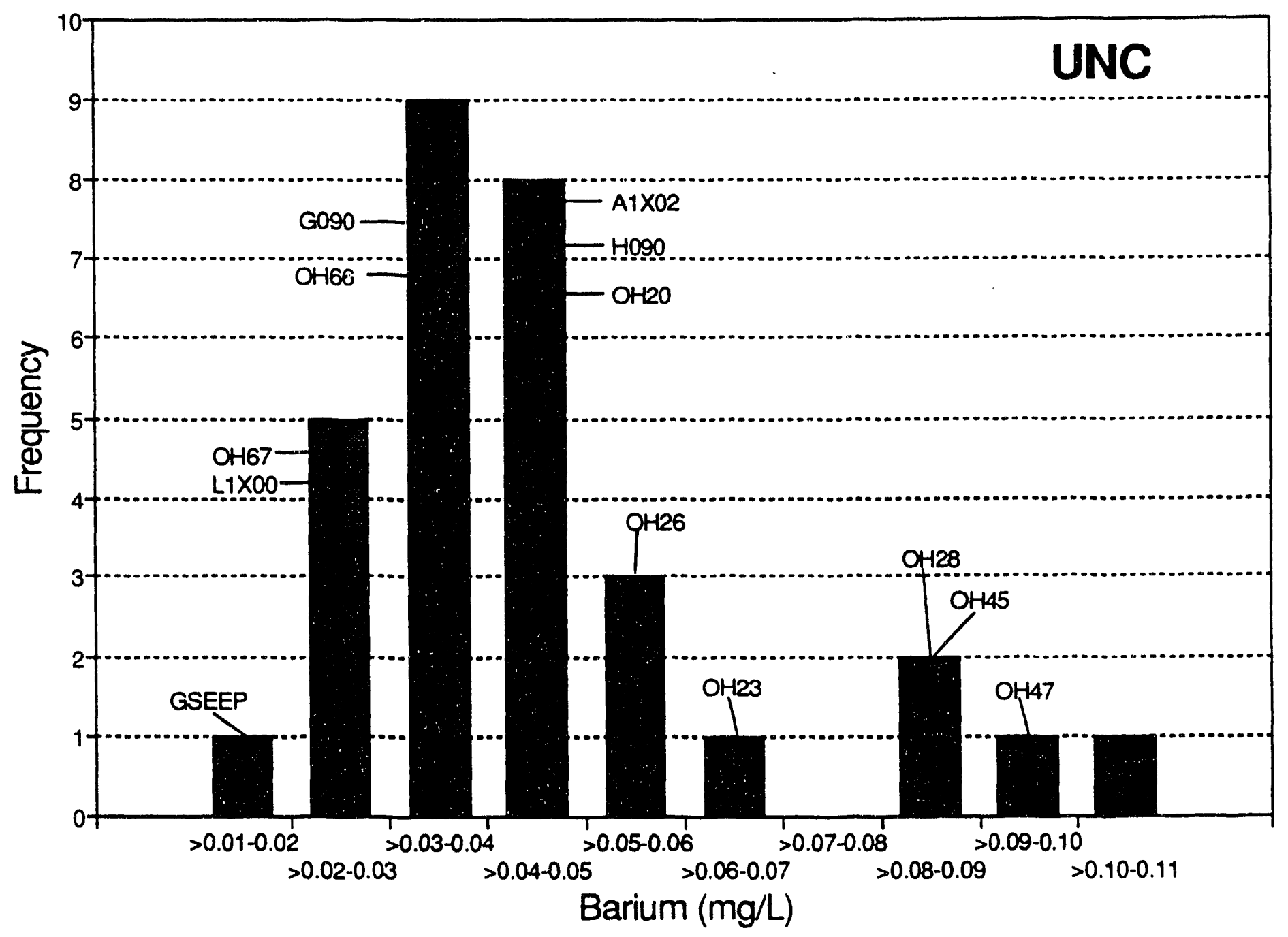

Figure 3-24

Distribution of barium in Salado Formation brines recovered from underground locations at the WIPP. Drill hole indicators are discussed in the text. 


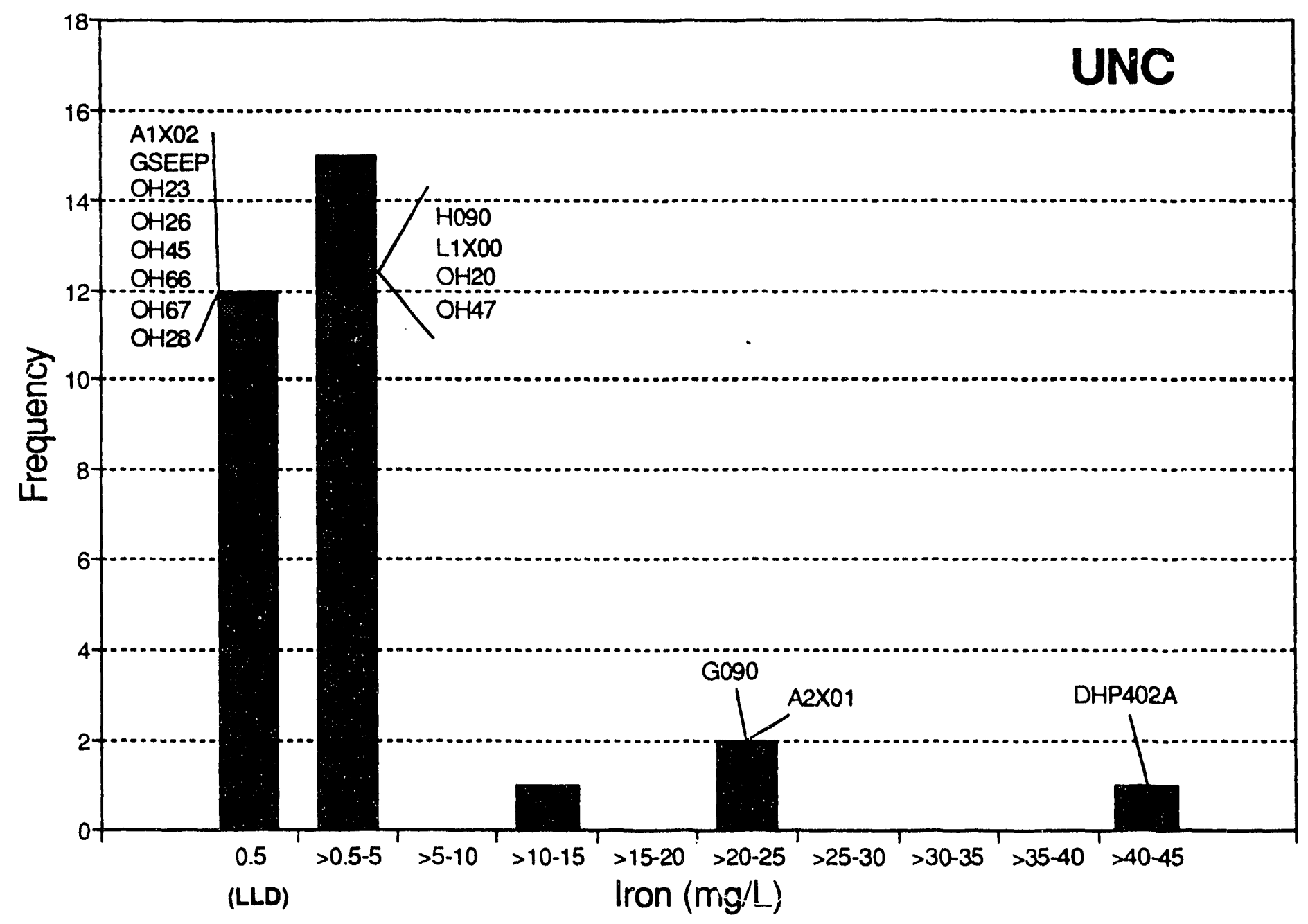

Figure 3-25

Distribution of iron in Salado Formation brines recovered from underground locations at the WIPP. Note LLD. Hole DHP402A has a steel rod wedged in the bottom, G090 contains steel instrumentation, and A2X01 has a pair of scissors in the bottom. Other drill hole indicators are discussed in the text. 


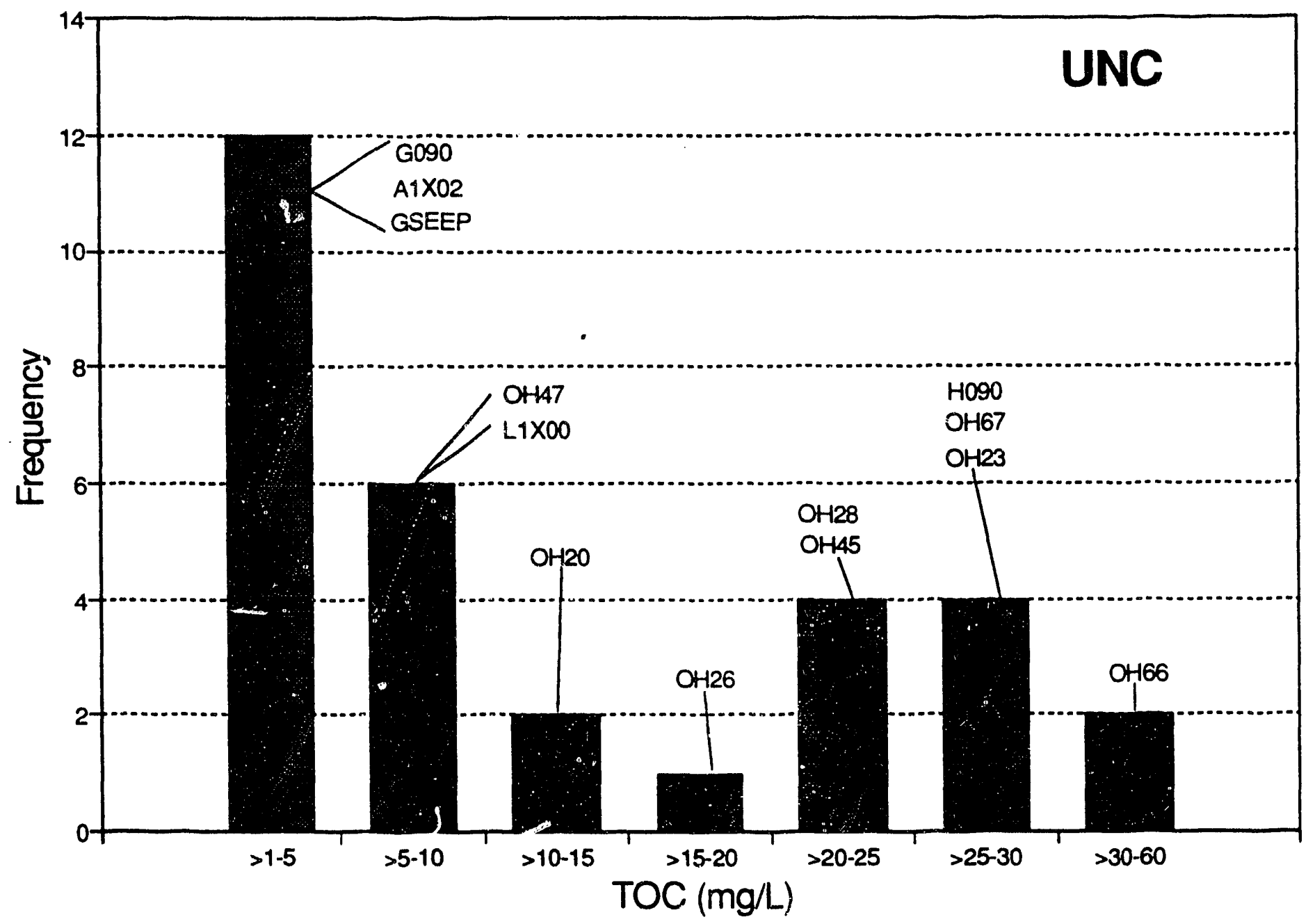

Figure 3-26

Distribution of TOC in Salado Formation brines recovered from underground locations at the WIPP. Note that the highest group along the $x$-axis represents a greater range of TOC values relative to other groups.

Drill hole indicators are discussed in the text. 


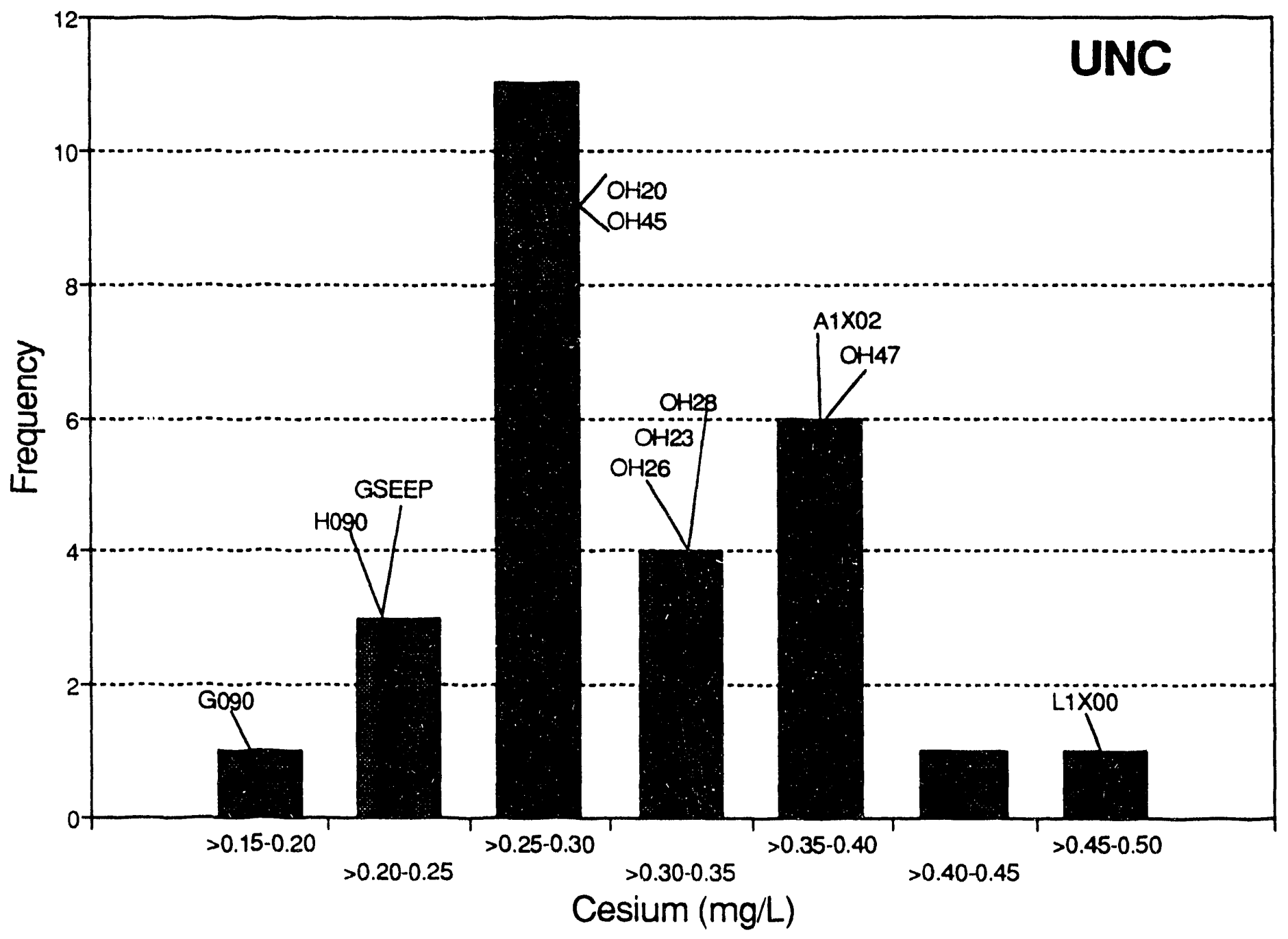

Figure 3-27

Distribution of cesium in Salado Formation brines recovered from underground locations at the WIPP. Drill hole indicators are discussed in the text. 


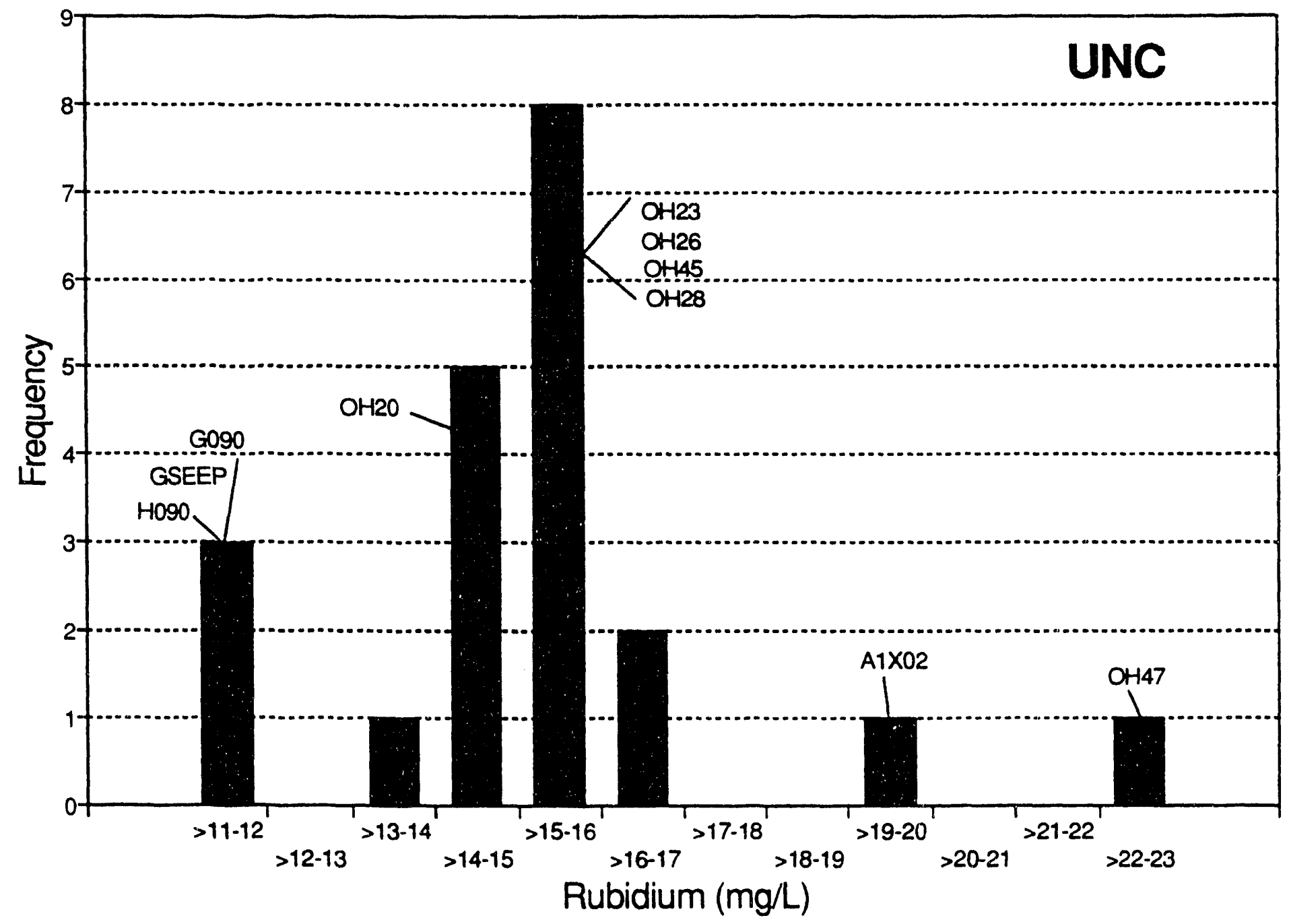

Figure 3-28

Distribution of rubidium in Salado Formation brines recovered from underground locations at the WIPP.

Drill hole indicators are discussed in the text. 
the spread water is derived from the overlying Culebra Dolomite, and this component skews results for suspect downholes to higher values for TIC (Figure 3-13). For some of the suspect downholes, pH and strontium distributions (Figures 3-11 and 3-20) may also be affected. Evaporation of brine will skew most distributions toward higher values and $\mathrm{pH}$ toward lower values. The bimodal distribution for $\mathrm{pH}$ (Figure 3-11) arises from upholes plotting 2 : lower $\mathrm{pH}$ values due to evaporation and concentration of the hydrogen ion in uphole samples.

In some instances, marked differences in the modes between UNC and IT data can be linked to different laboratory procedures. As noted in Deal and others (1989), the difference in TDS results (Figure 3-10) is due to the temperature of determination for TDS; 105 degrees Celsius $\left({ }^{\circ} \mathrm{C}\right)$ for UNC and $180^{\circ} \mathrm{C}$ for IT. The higher temperature used in the IT procedure results in the decomposition of hydrated salts (e.g., $\mathrm{MgCl}_{2} \cdot 6 \mathrm{H}_{2} \mathrm{O}$ ), yielding a lower TDS measurement. Fluoride, nitrate, silicon, and strontium modes (Figures 3-15, 3-17, 3-19, and 3-20) may be different because each laboratory uses a slightly different analytical method (Deal and others, 1989).

Figures 3-9 through 3-20 also identify the distribution of UNC and IT data on subhorizontal holes (OH20, OH23, OH26, and $\mathrm{OH} 45)$, upholes (A1X02 and $\mathrm{OH} 47$ ), and some suspect downholes (G090, GSEEP, H090, OH66, OH67). Data on upholes fall into outlier areas for $\mathrm{pH}$, specific gravity, and TDS and infrequently for alkalinity, ammonium, and manganese. Suspect downholes are in outlier areas for $\mathrm{pH}$, specific gravity, TDS, TIC, ammonium, silicon, and strontium. Some subhorizontal holes plot in outlier areas for TDS, alkalinity, iodide, and ammonium. The iodide outliers for UNC can be traced to values that are anomalously high for data received on brine samples collected in the fall of 1989 (see analyses for $\mathrm{OH} 20$ and $\mathrm{OH} 23$ in Appendix C).

The skewness toward higher concentrations for phosphorous, aluminum, arsenic, barium, and TOC is due to detection-limit values for these parameters lying in the range of the low value shown on the appropriate frequency distribution. A slight skewness observed in the rubidium distribution is correlated to high concentrations reported for brines sampled from upholes. Three of the holes high in iron-A2X01, G090, and DHP402A-are known to contain steel or iron scissors, instrumentation, or rods.

Figures 3-21 through 3-28 also identify the distribution of UNC data on subhorizontal holes, upholes, and suspect downholes. Data on upholes fall into outlier areas for rubidium and infrequently for barium. Suspect downholes infrequently lie in outlier regions for arsenic, 
cesium, and TOC. However, there is no strong indication that subhorizontal holes recover brines with chemistry greatly different than uncontaminated downholes, as the subhorizontal data lie close to or in the range observed for the mode of a given parameter.

\subsubsection{Results for Archived DHP.402A Samples}

Brine collected from DHP402A during the 1990 first-quarter sampling round (March 21) was split into samples shipped for immediate analysis and samples archived for three to nine months. The elapsed time between initial sampling and subsequent shipments of archived brine to the analytical laboratory is given in Table 3-2 with UNC mean values for nonarchived (samples shipped March 21) and archived samples.

Results presented in Table 3-2 indicate that holding times may be important for aluminum and iron. Aluminum and iron are normally present only in very small concentrations in the WIPP brines, but instruments placed in the holes or equipment dropped in downholes may increase these concentraiions. None of the principal constituents in DHP402A brine appear to be affected by holding times of up to nine months. The concentrations of aluminum and iron are decreased in archived brine, relative to freshly sampled and analyzed brine. This ojservation suggests that oxyhydroxide precipitates lower aluminum and iron concentrations when the brine is removed from the hole and archived for extended periods of time.

For example, the aluminum concentration of in situ brine may be controlled by the solubility of clay or oxyhydroxide minerals present in the Salado Formation or by, the dissolution of aluminum metal present as instruments in some holes. However, when the brine is collected and archived, an oxyhydroxide with a lower free energy than those present in the Salado Formation may precipitate and lower the aluminum concentration in the archived sample.

The high iron concentration in nonarchived DHP402A brine is attributed to a rock bolt that was accidently dropped into the hole and is now wedged in the bottom. After archived samples have been removed from contact with the steel rock bolt, the iron concentration will probably be controlled by the solubility of an iron oxyhydroxide, rather than the dissolution of the steel rock bolt. Precipitation of iron oxyhydroxide will decrease the iron concentration in the archived brine. A noticeable orange precipitate in the bottom of archived brine samples indicates that iron oxyhydroxide forms in these samples. 
Table 3-2

Comparison of Mean Values ( $\mathrm{mg} / \mathrm{L}$ Except for SG and pH) for UNC-Geotech Nonarchived (NA) and Archived (A) DHP402A Samples

\begin{tabular}{lcccc}
\hline Elapsed & $\mathrm{NA}$ & $\mathrm{A}$ & $\mathrm{A}$ & $\mathrm{A}$ \\
Time (days) & 0 & 93 & 183 & 274 \\
\hline $\mathrm{SG}$ & 1.22 & 1.22 & 1.22 & 1.23 \\
$\mathrm{TDS}$ & 387,000 & 381,000 & 383,000 & 374,000 \\
$\mathrm{PH}$ & 6.0 & 6.0 & 5.9 & 6.0 \\
Ext Alk & 756 & 744 & 745 & 726 \\
$\mathrm{TIC}^{\mathrm{b}}$ & 5.8 & 4.4 & 3.0 & 5.1 \\
$\mathrm{TOC}$ & 2 & 3 & 2 & 3 \\
$\mathrm{Br}$ & 1,600 & 1,530 & 1,520 & 1,560 \\
$\mathrm{Cl}$ & 190,000 & 189,000 & 198,000 & 199,000 \\
$\mathrm{~F}$ & 6 & 4 & 7 & 6 \\
$\mathrm{I}$ & 13.0 & 13.1 & 12.8 & 13.4 \\
$\mathrm{NH}{ }^{+}$ & 130 & 150 & 131 & 121 \\
$\mathrm{NO}{ }_{3}^{-}$ & 0.9 & 1.4 & 1.2 & 0.5 \\
$\mathrm{P}$ & $<0.1$ & $<0.1$ & $<0.1$ & $<0.1$ \\
$\mathrm{SO}{ }^{-2}$ & 18,000 & 17,100 & 17,700 & 17,800 \\
$\mathrm{Al}$ & 0.093 & 0.078 & $<0.05$ & $<0.05$ \\
$\mathrm{As}$ & $<0.001$ & $<0.001$ & $<0.001$ & $<0.001$ \\
$\mathrm{~B}$ & 1,340 & 1,190 & 1,310 & 1,300 \\
$\mathrm{Ba}$ & 0.031 & 0.098 & 0.085 & 0.044 \\
$\mathrm{Ca}$ & 313 & 296 & 304 & 295 \\
$\mathrm{Cs}$ & 0.355 & 0.373 & 0.335 & 0.367 \\
$\mathrm{Fe}$ & 87.5 & $<0.5$ & $<0.5$ & $<0.5$ \\
$\mathrm{~K}$ & 14,100 & 13,200 & 13,700 & 15,000 \\
$\mathrm{Mg}$ & 25,100 & 23,700 & 23,800 & 24,500 \\
$\mathrm{Mn}$ & 2.71 & 2.55 & 2.52 & 2.72 \\
$\mathrm{Na}$ & 80,000 & 75,300 & 75,500 & 76,100 \\
$\mathrm{Rb}$ & 16.3 & 15.6 & 16.7 & 14.8 \\
$\mathrm{Si}$ & $<0.5$ & $<0.5$ & $<0.5$ & $<0.5$ \\
$\mathrm{Sr}$ & 4.14 & 4.04 & 3.92 & 4.18 \\
& & & &
\end{tabular}

aExtended alkalinity (endpoint $\mathrm{pH}=2.5$ ) values reported as equivalent $\mathrm{HCO}_{3}$.

'Total inorganic carbon reported as equivalent $\mathrm{HCO}_{3}$. 


\subsection{Element-Ratio and Solubility Diagrams}

Insight into the origin of BSEP brines is provided by examining element-ratio and solubility diagrams. Element-ratio diagrams for $\mathrm{Na} / \mathrm{Cl}$ versus potassium/magnesium $(\mathrm{K} / \mathrm{Mg})$ and $\mathrm{Na} / \mathrm{Cl}$ versus calcium/sulfate $\left(\mathrm{Ca} / \mathrm{SO}_{4}\right)$ were chosen to summarize the major-element chemistry of the BSEP and weep-array brines, as these diagrams can readily be compared to previous plots for fluid inclusions, brine weeps, and BSEP brines (Stein and Krumhansl, 1988; Deal and others, 1989; Abitz and others, 1990; Krumhansl and others, 1991).

Solubility diagrams were constructed using the mean values calculated from 1989 and 19,00 BSEP brine data, SNLNM weep-array data (Krumhansl and others, 1991), and the geochemical code EQ3NR (Wolery, 1983). Diagrams for halite, anhydrite, magnesite, and celestite were constructed because these minerals are observed in the Salado Formation (Stein and Krumhansl, 1988), and the saturation fields are easily represented on two-dimensional plots.

\subsubsection{Element-Ratio Diagrams}

Plotted ratios (by weight) of $\mathrm{Na} / \mathrm{Cl}$ versus $\mathrm{Ca} / \mathrm{SO}_{4}$ (Figure 3-29) reveal several trends for the UNC, IT, and SNL/NM data. The SNL/NM evaporation trend was obtained from Krumhansl and others (1991), and represents the evaporation of a brine sample collected from a floor hole near the Room $\mathrm{Q}$ entry. An $\mathrm{Na} / \mathrm{Cl}$ ratio of 0.2 corresponds to the evaporation of about 40 percent (by weight) of the sample. Some of the SNL/NM weep-array data (Krumhansl and others, 1991) parallel the evaporation trend at higher $\mathrm{Na} / \mathrm{Cl}$ values. Brine samples recovered from upholes (filled circles and square) straddle the evaporation trend, because some evaporation of the brine takes place prior to collection. Figure 3-29 indicates anhydrite $\left(\mathrm{CaSO}_{4}\right)$ may precipitate with halite $(\mathrm{NaCl})$ during the evaporation of up-hole brine, as $\mathrm{Na} / \mathrm{Cl}$ and $\mathrm{Ca} / \mathrm{SO}_{4}$ ratios decrease with increasing evaporation.

The $\mathrm{NaCl}$ mixing line in Figure 3-29 was constructed by assuming that a solution saturated with halite only $\left(\mathrm{Na} / \mathrm{Cl}=0.64 ; \mathrm{Ca} / \mathrm{SO}_{4}=0\right)$ is mixed with the SNL/NM brine sample collected in Room Q access (Krumhansl and others, 1991). UNC and IT data for suspect holes G090, GSEEP, and H090 cluster along the upper segment of this line. These drill holes may contain a component of the indicated artificial brine that was derived from water spread on drift floors to reconsolidate the halite or, in the case of G090, artificial brine that was used as drilling fluid for a hydrofracture experiment. Addition of this spread water to BSEP brines would result in some dilution of the brine and probably decrease the ammonium, boron, magnesium, potassium, and sulfate concentrations of the original brine. However, the 


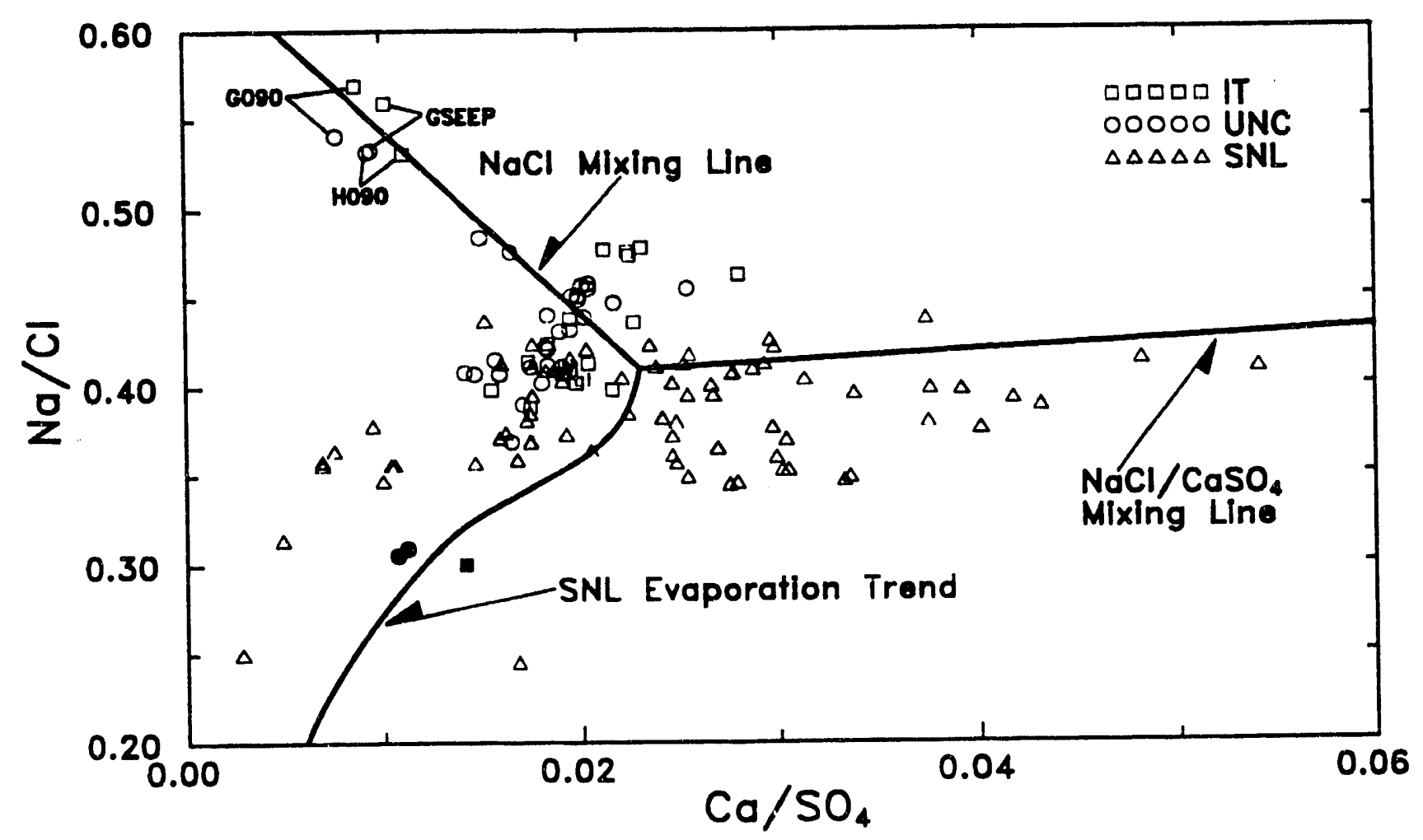

Figure 3-29

Variation of $\mathrm{Na} / \mathrm{Cl}$ and $\mathrm{Ca} / \mathrm{SO}_{4}$ weight ratios in Salado Formation brines recovered from underground locations at the WIPP. Filled symbols indicate upholes. See text for discussion of mixing lines and evaporation trend. 
statistical data for holes G090, GSEEP, and H090 (Appendix D) indicate concentrations of ammonium and boron are similar to those observed in most downholes, magnesium and potassium concentrations are relatively lower, and sulfate concentrations are relatively higher. The statistical data suggest that if spread water is mixing with BSEP brines, the composition of the spread water is more complex than a simple solution saturated with halite, and/or evaporation and precipitation processes are acting on the mixture to influence the composition of the mixture.

The $\mathrm{NaCl} / \mathrm{CaSO}_{4}$ mixing line in Figure 3-29 was constructed by assuming that a saturated halite and anhydrite solution $\left(\mathrm{Na} / \mathrm{Cl}=0.64 ; \mathrm{Ca} / \mathrm{SO}_{4}=0.42\right)$ is mixed with the SNL/NM brine sample collected in Room $Q$ access. About half of the SNL/NM weep-array data lie near or along this line, suggesting that a component derived from a solution saturated with halite and anhydrite is present in the weep-array brine samples. This saturated solution could be derived from any of several anhydrite interbeds. However, the SNL/NM arrays were designed to sample distinct stratigraphic horizons present at the repository level, and no anhydrite beds are exposed in the sampled stratigraphic interval. Therefore, high $\mathrm{Ca} / \mathrm{SO}_{4}$ ratios may arise from reported concentrations of calcium (see Figure 3-8) that are too high. Among the major elements in BSEP and weep-array brines, calcium is least abundant; and large dilution factors prior to analysis will affect the accuracy of reported calcium values to a greater extent than chloride, sodium, and sulfate results. The calcium concentrations in weep-array brines are further discussed in Section 3.2.2.

Variation of the $\mathrm{Na} / \mathrm{Cl}$ ratio with increasing $\mathrm{K} / \mathrm{Mg}$ ratios (by weight) is shown in Figure 3-30 with the SNL/NM evaporation trend and a hypothetical mixing line. In contrast to the data in Figure 3-29, few data points lie along the SNLANM evaporation trend. UNC and IT data collected from upholes (filled circles and square) have $\mathrm{K} / \mathrm{Mg}$ ratios that lie well left of the trend. The difference between the data from upholes, which are affected by evaporation prior to collection, and the SNL/NM evaporation trend may be due, respectively, to open and closed evaporation scenarios.

In an open system approximated by upholes, continual input to the reservoir of brine in the collection container will prevent extreme evaporation conditions that lead to the precipitation of potassium/magnesium salts. Under these conditions, potassium may precipitate as sylvite or substitute in the halite structure to lower the $\mathrm{K} / \mathrm{Mg}$ ratio relative to the SNL/NM evaporation trend. In contrast, the $\mathrm{K} / \mathrm{Mg}$ ratio will decrease less in a closed system where both potassium and magnesium are removed by the precipitation of bittern salts. For the brine 


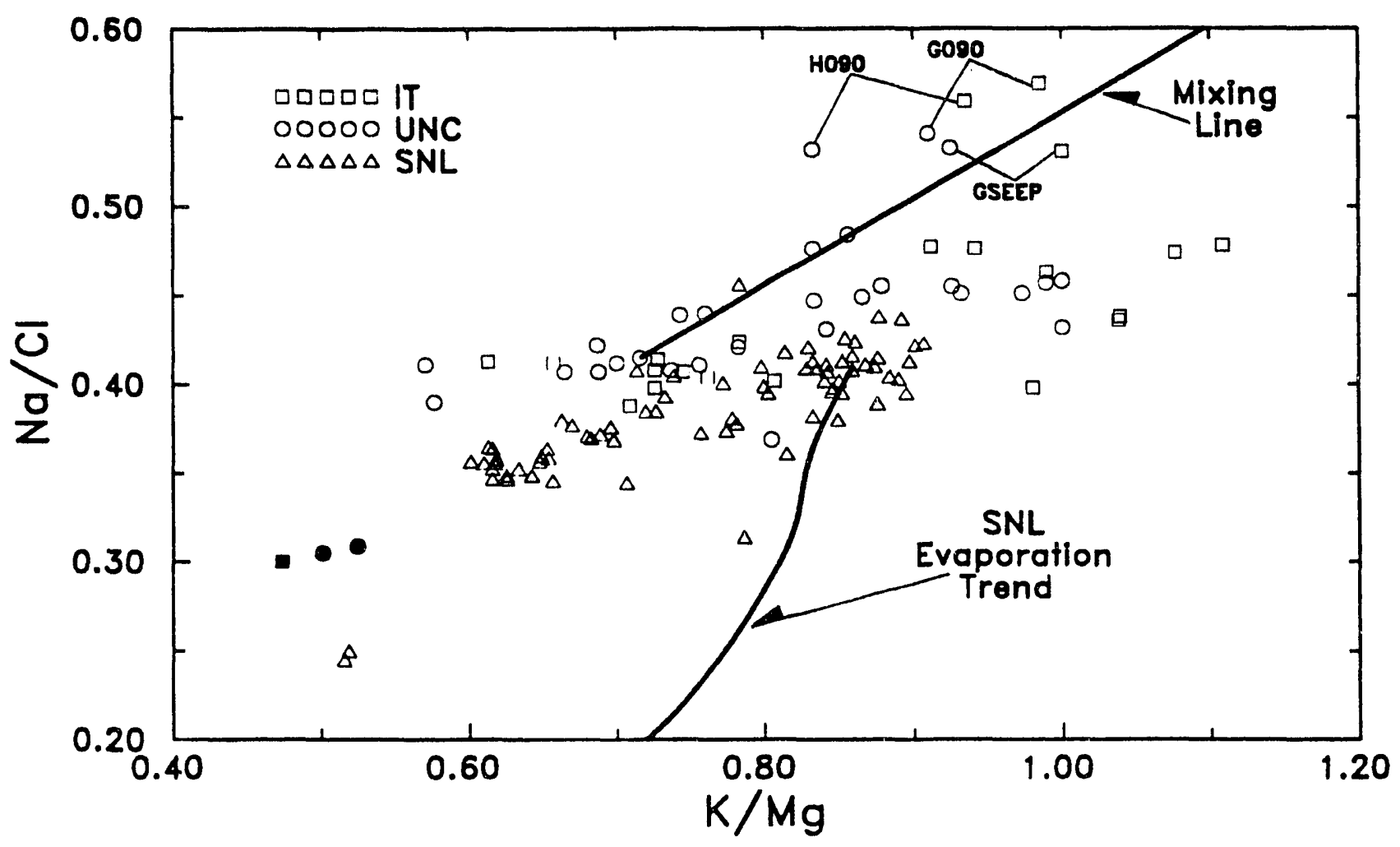

Figure 3-30

Variation of $\mathrm{Na} / \mathrm{Cl}$ and $\mathrm{K} / \mathrm{Mg}$ weight ratios in Salado Formation brines recovered from underground locations at the WIPP. Filled symbols indicate upholes. See text for discussion of mixing lines and evaporation trend. 
recovered from upholes, a steady-state condition is probably attained where only halite, sylvite, and anhydrite are actively precipitating. This hypothesis is consistent with the SNL/NM evaporation trends and data presented in Figures 3-29 and 3-30.

In Figure 3-29, the $\mathrm{NaCl}$ mixing line was proposed to account for the increasing $\mathrm{Na} / \mathrm{Cl}$ and decreasing $\mathrm{Ca} / \mathrm{SO}_{4}$ trend displayed by some data. These same data straddle the hypothetical mixing line in Figure 3-30, which illustrates the mixing of a solution saturated with halite that contains potassium and magnesium $(\mathrm{Na} / \mathrm{Cl}=0.65 ; \mathrm{K} / \mathrm{Mg}=1.2)$ with brine recovered from BX01. If the saturated solution is derived from water spread on the drift floors, potassium and magnesium are expected to be present because there is limited substitution of these elements in the halite structure. Dean (1978) reported major-element compositions for halite, and the average composition yields $\mathrm{Na} / \mathrm{Cl}$ and $\mathrm{K} / \mathrm{Mg}$ ratios of 0.65 and 1.2 , respectively. The mixing line in Figure 3-30 has been drawn assuming the halite noted above is dissolved to form a saturated solution with identical $\mathrm{Na} / \mathrm{Cl}$ and $\mathrm{K} / \mathrm{Mg}$ ratios.

\subsubsection{Results of EQ3NR Modeling and Solubility Diagrams}

Aqueous-speciation and mineral-solubility modeling were carried out with the EQ3NR gecchemical code using the Pitzer option (Wolery, 1983). Computer runs utilized both the Pitzer and Harvie-Moeller-Weare (HMW) databases for ion-interaction parameters, because all of the available analytes are not incorporated into a single database. Input files for the Pitzer runs contained the analytes $\mathrm{pH}$, ammonium, bromide, chloride, fluoride, iodide, nitrate, sulfate, barium, calcium. magnesium, manganese, potassium, sodium, and strontium. Eh was estimated using the ammonium/nitrate couple, which yielded a bounding upper limit of about 400 millivolts $(\mathrm{mV})$. For the HMW database, the input files contained analytical results for $\mathrm{pH}$, bicarbonate (as converted total inorganic carbon), chloride, sulfate, calcium, magnesium, potassium, and sodium. Eh was entered as $400 \mathrm{mV}$, based on the results generated with the ammonium/nitrate couple using the Pitzer database.

Solubility results generated from the EQ3NR runs are given in Tables 3-3 (UNC) and 3-4 (IT). Minerals are listed with their saturation index (SI), which is defined as:

$$
\mathrm{SI}=\log (\mathrm{IAP} / \mathrm{Ksp})
$$

where

LAP $=$ ion activity product

$\mathrm{Ksp}=$ the mineral solubility product. 
In general, undersaturation, saturation, and supersaturation of a mineral are indicated by negative, zero, and positive SI values, respectively. However, uncertainty associated with the thermodynamic data results in a range of saturation of -0.364 to $+0.364 \mathrm{SI}$ at $27^{\circ} \mathrm{C}$. That is, minerals are supersaturated above an $\mathrm{SI}=+0.364$ and undersaturated below an $\mathrm{SI}=-\hat{v} .364$. SI values reported in Tables 3-3 and 3-4 were obtained from runs that used the HMW ioninteraction parameters, except for the minerals barite, celestite, and fluorite. The SI values for the latter three minerals were obtained with the Pitzer ion-interaction parameters, because barium, strontium, and fluoride interaction parameters are absent in the HMW database.

The modeling results (Tables 3-3 and 3-4) indicate that the compositions of WIPP brines reflect equilibration with evaporite salts. SI derived from EQ3NR runs with the UNC sulfate analyses (Table 3-3) reveal that all WIPP brines are saturated or supersaturated with anhydrite $\left(\mathrm{CaSO}_{4}\right)$, barite $\left(\mathrm{BaSO}_{4}\right)$, fluorite $\left(\mathrm{CaF}_{2}\right)$, glauberite $\left(\mathrm{Na}_{2} \mathrm{Ca}\left(\mathrm{SO}_{4}\right)_{2}\right)$, gypsum $\left(\mathrm{CaSO}_{4} \cdot 2 \mathrm{H}_{2} \mathrm{O}\right)$, and halite $(\mathrm{NaCl})$, and some brines are saturated with dolomite $\left(\mathrm{CaMg}\left(\mathrm{CO}_{3}\right)_{2}\right)$ and magnesite $\left(\mathrm{MgCO}_{3}\right)$. SI values for celestite $\left(\mathrm{SrSO}_{4}\right)$, polyhalite $\left(\mathrm{K}_{2} \mathrm{Ca}_{2} \mathrm{Mg}\left(\mathrm{SO}_{4}\right)_{4} \cdot 2 \mathrm{H}_{2} \mathrm{O}\right)$, and syngenite $\left(\mathrm{K}_{2} \mathrm{Ca}\left(\mathrm{SO}_{4}\right)_{2} \cdot \mathrm{H}_{2} \mathrm{O}\right)$ are saturated for brines recovered from several drill holes. For EQ3NR runs based on the IT analytical results (Table 3-4), SI values indicate all brines are saturated or supersaturated with anhydrite, fluorite, and halite-most with respect to glauberite and gypsum-and several drill holes are saturated with respect to celestite.

Modeling results reported in Tables 3-3 and 3-4 are in agreement with the observed mineralogy present at the WIPP repository horizon. At this level, Salado Formation mineralogy consists primarily of halite with thin horizons of anhydrite and trace amounts of quartz, polyhalite, gypsum, magnesite, and clay minerals (Stein and Krumhansl, 1988). Barite, celestite, dolomite, glauberite, and syngenite have not been identified in the predominantly halitic samples studied to date. Although barite and celestite may be present in the anhydrite interbeds, glauberite and syngenite are not as likely to be found in the anhydrite, because the high $\mathrm{Mg}$ concentrations in the intergranular brines would favor the formation of polyhalite. The saturation fields for halite, anhydrite, celestite, and magnesite (evaluated at $\mathrm{pH}=6.1$ ) have been plotted in Figures 3-31 through 3-34, along with the UNC, IT, and SNL/NM (halite and anhydrite only) data.

Halite - With the exception of a single SNL/NM data point in the supersaturated field (Figure 3-31), all data plot in the saturated field. UNC and IT upholes fall below the main cluster of UNC and IT data points because halite is actively precipitating from brine collected in uphole containers. Active halite precipitation will lower the $\mathrm{Na} / \mathrm{Cl}$ weight ratio because a 
Table 3-3

Saturation Indices (SI) Based on EQ3NR Modeling Results Using UNC Brine Analyses

\begin{tabular}{|c|c|c|c|c|c|c|}
\hline & A1X01-d & $A 1 \times 02-U$ & $A 2 \times 01-d$ & $A 3 \times 01-d$ & $B \times 01-d$ & DH28-d \\
\hline anhydrite & $-0.145 \mathrm{~s}$ & $0.011 \mathrm{~s}$ & $-0.160 \mathrm{~s}$ & $-0.163 \mathrm{~s}$ & $-0.179 \mathrm{~s}$ & $-0.067 \mathrm{~s}$ \\
\hline barite & $0.638 \mathrm{ss}$ & 0.767 ss & $0.781 \mathrm{ss}$ & $0.616 \mathrm{ss}$ & $0.636 \mathrm{ss}$ & 0.556 ss \\
\hline bassanite & -0.848 us & -0.699 us & -0.861 us & -0.864 us & -0.880 us & -0.768 us \\
\hline celestite $^{b}$ & -0.613 us & $0.029 \mathrm{~s}$ & -0.920 us & -0.630 us & -0.595 us & -0.678 us \\
\hline dolomite & -1.356 us & -3.060 us & -1.111 us & -1.230 us & -1.169 us & -0.642 us \\
\hline fluorite $b$ & $1.071 \mathrm{ss}$ & $1.058 \mathrm{ss}$ & $1.057 \mathrm{ss}$ & 1.201 ss & $1.200 \mathrm{ss}$ & 0.618 ss \\
\hline glauberite & $-0.164 \mathrm{~s}$ & $-0.051 \mathrm{~s}$ & $-0.229 \mathrm{~s}$ & $-0.234 \mathrm{~s}$ & $-0.248 \mathrm{~s}$ & $-0.093 \mathrm{~s}$ \\
\hline gypsum & $-0.285 \mathrm{~s}$ & $-0.158 \mathrm{~s}$ & $-0.290 \mathrm{~s}$ & $-0.295 \mathrm{~s}$ & $-0.308 \mathrm{~s}$ & $-0.196 \mathrm{~s}$ \\
\hline halite & $0.000 \mathrm{~s}$ & $0.019 \mathrm{~s}$ & $-0.037 \mathrm{~s}$ & $-0.029 \mathrm{~s}$ & $-0.037 \mathrm{~s}$ & $-0.022 \mathrm{~s}$ \\
\hline magnesite & -0.587 us & -1.324 us & -0.486 us & -0.542 us & -0.522 us & $-0.350 \mathrm{~s}$ \\
\hline polyhalite & -0.850 us & $-0.107 \mathrm{~s}$ & -0.946 us & -0.975 us & -1.030 us & -0.830 us \\
\hline sylvite & -0.683 us & -0.607 us & -0.705 us & -0.707 us & -0.711 us & -0.694 us \\
\hline syngenite & -0.880 us & -0.666 us & -0.909 us & -0.936 us & -0.940 us & -0.780 us \\
\hline \multirow[t]{2}{*}{ thenardite } & -0.877 us & -0.919 us & -0.927 us & -0.929 us & -0.926 us & -0.883 us \\
\hline & DH30-d & DH32-d & DH34-d & $D H 36-d$ & DH38-d & DH40-d \\
\hline anhydrite & $-0.107 \mathrm{~s}$ & $-0.119 \mathrm{~s}$ & $0.016 \mathrm{~s}$ & $-0.133 \mathrm{~s}$ & $-0.118 \mathrm{~s}$ & $-0.104 \mathrm{~s}$ \\
\hline barite ${ }^{b}$ & 0.580 ss & 0.469 ss & $0.584 \mathrm{ss}$ & 0.443 ss & 0.452 ss & $1.030 \mathrm{ss}$ \\
\hline bassanite & -0.808 us & -0.820 us & -0.684 us & -0.832 us & -0.818 us & -0.804 us \\
\hline celestite $^{b}$ & -0.508 us & -0.536 us & $-0.287 \mathrm{~s}$ & -0.767 us & -0.942 us & -1.084 us \\
\hline dolomite & -1.087 us & -1.133 us & -0.682 us & -1.190 us & -0.639 us & $-0.003 \mathrm{~s}$ \\
\hline fluorite $^{b}$ & $0.841 \mathrm{ss}$ & $0.840 \mathrm{ss}$ & 0.978 ss & $0.840 \mathrm{ss}$ & 0.878 ss & $1.082 \mathrm{ss}$ \\
\hline glauberite & $-0.126 \mathrm{~s}$ & $-0.140 \mathrm{~s}$ & $0.011 \mathrm{~s}$ & $-0.167 \mathrm{~s}$ & $-0.140 \mathrm{~s}$ & $-0.154 \mathrm{~s}$ \\
\hline gypsum. & $-0.238 \mathrm{~s}$ & $-0.249 \mathrm{~s}$ & $-0.111 \mathrm{~s}$ & $-0.259 \mathrm{~s}$ & $-0.246 \mathrm{~s}$ & $-0.230 \mathrm{~s}$ \\
\hline halite & $-0.014 \mathrm{~s}$ & $-0.012 \mathrm{~s}$ & $-0.021 \mathrm{~s}$ & $-0.028 \mathrm{~s}$ & $-0.016 \mathrm{~s}$ & $-0.036 \mathrm{~s}$ \\
\hline magnesite & -0.554 us & -0.583 us & -0.426 us & -0.613 us & $-0.344 \mathrm{~s}$ & $-0.021 \mathrm{~s}$ \\
\hline polyhalite & -0.883 us & -0.946 us & -0.658 us & -0.972 us & -0.924 us & -0.876 us \\
\hline sylvite & -0.674 us & -0.679 us & -0.687 us & -0.681 us & -0.667 us & -0.674 us \\
\hline syngenite & -0.791 us & -0.818 us & -0.664 us & -0.815 us & -0.784 us & -0.773 us \\
\hline thenardite & -0.876 us & -0.877 us & -0.862 us & -0.891 us & -0.879 us & -0.907 us \\
\hline
\end{tabular}

Refer to notes at end of table. 
Table 3-3 (Continued)

Saturation Indices (SI) Based on EQJNR Modeling Results Using UNC Brine Analyses

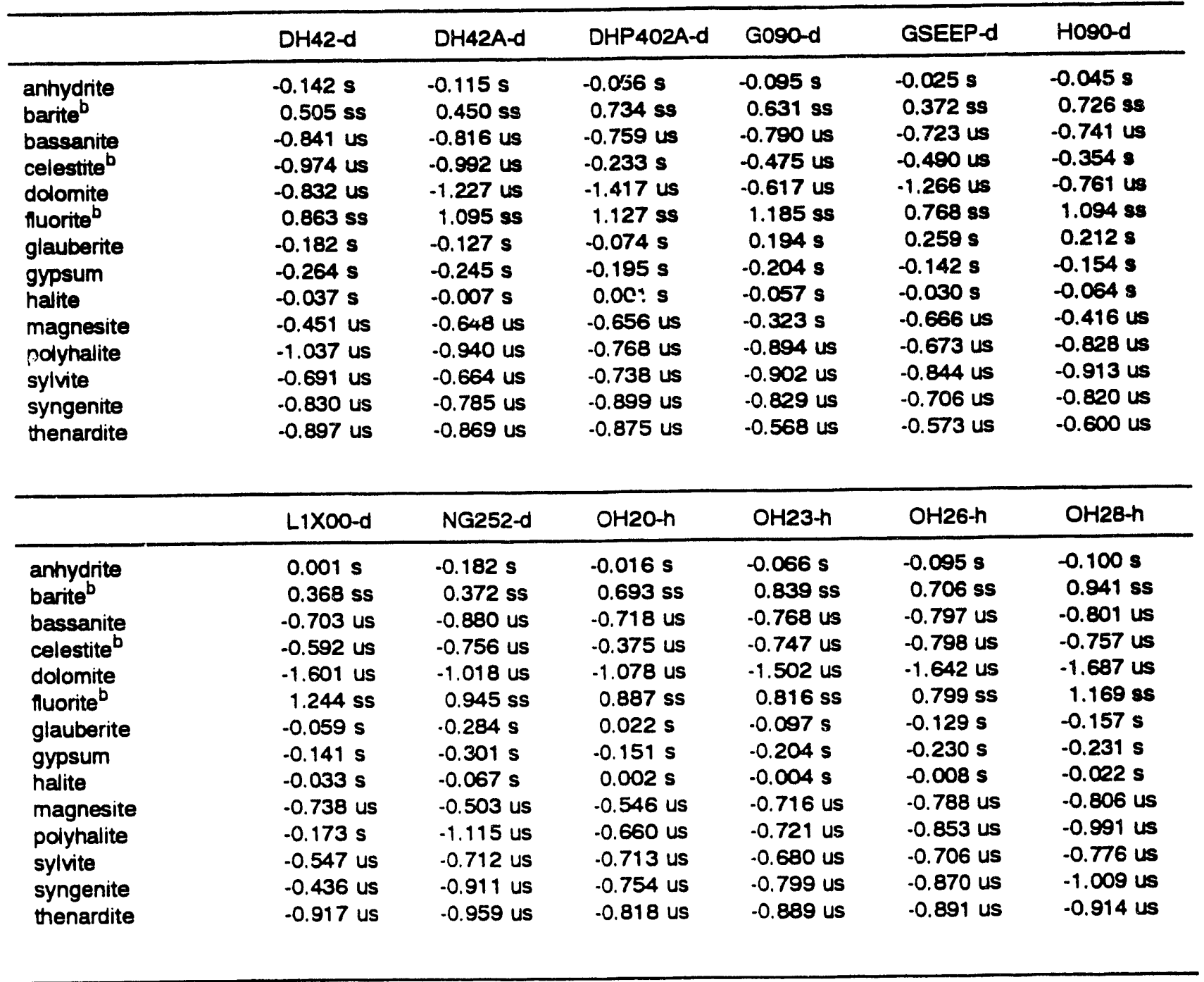

Refer to notes at end of table. 
Table 3-3 (Continued)

Saturation Indices (SI) Based on EQ3NR Modeling Results Using UNC Brine Analyses

\begin{tabular}{|c|c|c|c|c|c|c|}
\hline & OH45-h & OH46-d & $\mathrm{OH} 47-\mathrm{u}$ & OH62-d & OH63-d & OH66-d \\
\hline & $-0.300 \mathrm{~s}$ & $-0.123 \mathrm{~s}$ & $0.089 \mathrm{~s}$ & $\begin{array}{c}-0.138 \mathrm{~s} \\
0.446 \mathrm{ss}\end{array}$ & $\begin{array}{c}-0.132 \mathrm{~s} \\
0.638 \mathrm{ss}\end{array}$ & $\begin{array}{c}-0.049 \mathrm{~s} \\
0.569 \mathrm{ss}\end{array}$ \\
\hline $\begin{array}{l}\text { barite } \\
\text { bassanite }\end{array}$ & 0.764 ss & 0.837 ss & $\begin{array}{r}1.166 \text { ss } \\
-0.622 \text { us }\end{array}$ & $\begin{array}{c}0.446 \text { ss } \\
-0.837 \text { us }\end{array}$ & $\begin{array}{c}0.638 \text { ss } \\
-0.830 \text { us }\end{array}$ & -0.746 us \\
\hline & -0.989 us & -0.825 us & -0.622 us & & -0.482 us & $-0.210 \mathrm{~s}$ \\
\hline $\begin{array}{l}\text { celestiteb } \\
\text { dolomite }\end{array}$ & -0.625 us & -0.586 us & $-0.090 \mathrm{~s}$ & $\begin{array}{l}-0.485 \text { us } \\
-1.391 \text { us }\end{array}$ & $\begin{array}{l}-0.482 \text { us } \\
-1.455 \text { us }\end{array}$ & $\begin{array}{r}-0.210 \mathrm{~s} \\
-0.357 \mathrm{~s}\end{array}$ \\
\hline dolomite & -1.289 us & -1.154 us & -2.770 us & & $\begin{array}{r}-1.455 \text { us } \\
0.776 \mathrm{ss}\end{array}$ & \\
\hline & $0.646 \mathrm{ss}$ & 0.997 ss & 0.985 ss & $0.957 \mathrm{ss}$ & & $1.832 \mathrm{s8}$ \\
\hline glauberite & -0.581 us & $-0.177 \mathrm{~s}$ & $0.063 \mathrm{~s}$ & $-0.215 \mathrm{~s}$ & $-0.220 \mathrm{~s}$ & 0.0488 \\
\hline gypsum & -0.384 us & $-0.257 \mathrm{~s}$ & $-0.081 \mathrm{~s}$ & $-0.260 \mathrm{~s}$ & $-0.252 \mathrm{~s}$ & $-0.164 \mathrm{~s}$ \\
\hline halite & $-0.228 \mathrm{~s}$ & $-0.015 \mathrm{~s}$ & $0.012 \mathrm{~s}$ & $-0.056 \mathrm{~s}$ & $-0.065 \mathrm{~s}$ & $-0.055 \mathrm{~s}$ \\
\hline magnesite & -0.651 us & -0.547 us & -1.193 us & -0.695 us & -0.732 us & $-0.219 \mathrm{~s}$ \\
\hline polyhalite & -1.595 us & -0.871 us & $0.254 \mathrm{~s}$ & -1.026 us & -0.996 us & -0.791 us \\
\hline sylvite & -0.851 us & -0.668 us & -0.552 us & -0.727 us & -0.722 us & -0.791 us \\
\hline syngenite & -1.148 us & -0.827 us & -0.429 us & -0.898 us & -0.873 us & -0.762 us \\
\hline thenardite & -1.138 us & -0.910 us & -0.883 us & -0.934 us & -0.946 us & -0.760 us \\
\hline
\end{tabular}

\begin{tabular}{ll}
\hline & OH67-d \\
\hline anhydrite $_{\text {barite }^{b}}$ & $-0.087 \mathrm{~s}$ \\
bassanite $_{\text {celestite }}^{\mathrm{b}}$ & $0.464 \mathrm{ss}$ \\
dolomite & $-0.783 \mathrm{us}$ \\
fuorite & $-0.159 \mathrm{~s}$ \\
glauberite & $-0.593 \mathrm{us}$ \\
gypsum & $1.382 \mathrm{ss}$ \\
halite & $-0.049 \mathrm{~s}$ \\
magnesite & $-0.201 \mathrm{~s}$ \\
polyhalite & $-0.068 \mathrm{~s}$ \\
sylvite & $-0.332 \mathrm{~s}$ \\
syngenite & $-0.900 \mathrm{us}$ \\
thenardite & $-0.780 \mathrm{us}$ \\
& -0.807 us \\
& -0.819 us \\
\hline
\end{tabular}

Letters following drill hole identification indicate orientation of hole as up (u), down (d), or subhorizontal (h). Letters following the SI number indicate undersaturation (us), saturation (s), or supersaturation (ss). ${ }^{a} S 1=[\log (i o n-a c t i v i t y$ product/solubility product) $]$.

bineral SI obtained with the Pitzer thermodynamic database; all others with the Harvie-Moller-Weare database. 
Table 3-4

Saturation Indices (SI) Based On EQ3NR Modeling Results Using IT Brine Analyses

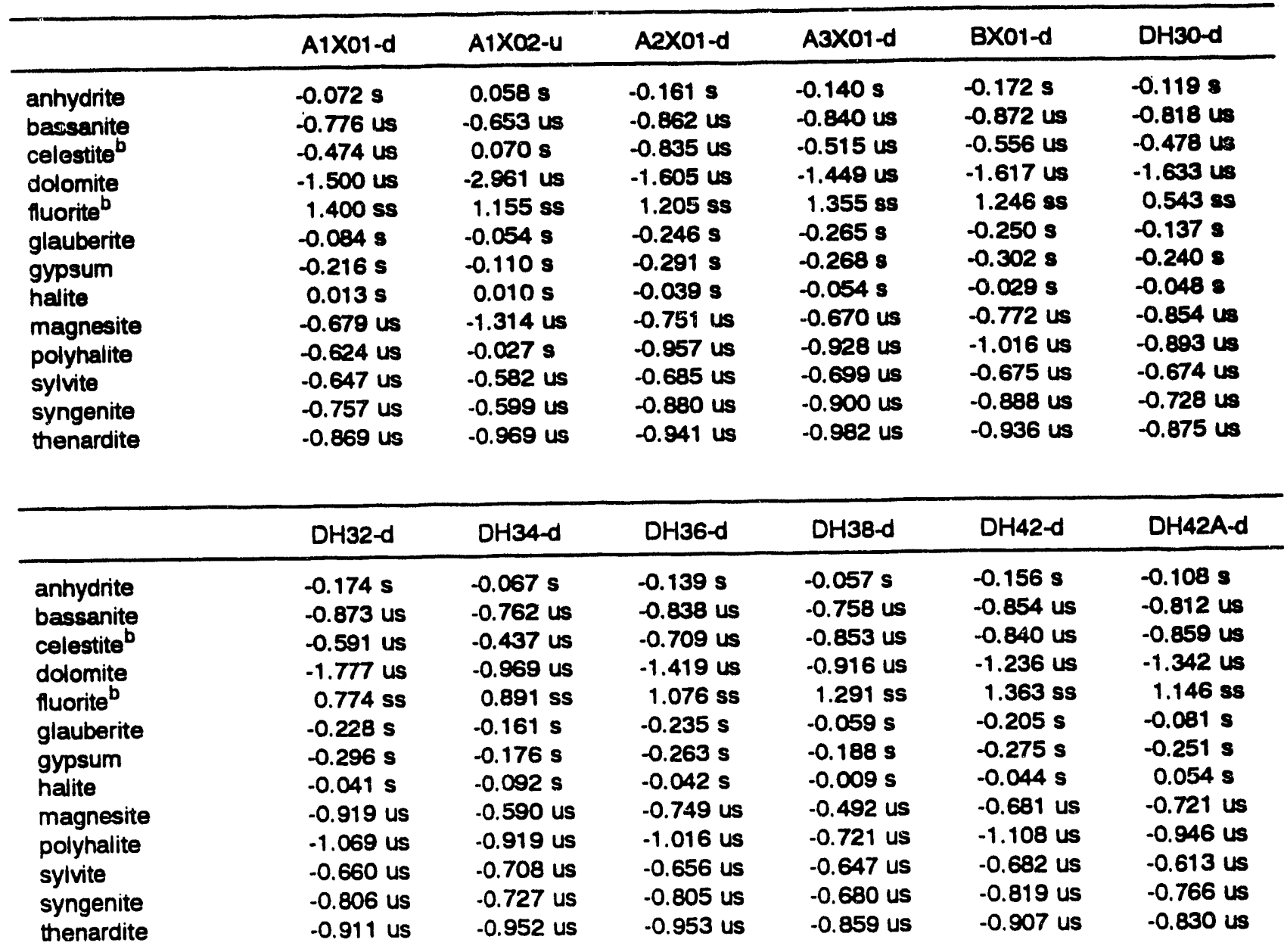

Refer to notes at end of table. 
Table 3-4 (Continued)

Saturation Indices (SI) Based On EQ3NR Modeling Results Using IT Brine Analyses

\begin{tabular}{|c|c|c|c|c|c|c|}
\hline & DHP402A-d & Go90-d & GSEEP- $d$ & HoSO-d & NG252-d & $\mathrm{OH} 2 \mathrm{O}-\mathrm{h}$ \\
\hline $\begin{array}{l}\text { anhydrite } \\
\text { bassanite } \\
\text { celestite }^{b} \\
\text { dolomite } \\
\text { fluorite } \\
\text { glauberite } \\
\text { gypsum } \\
\text { halite } \\
\text { magnesite } \\
\text { polyhalite } \\
\text { sylvite } \\
\text { syngenite } \\
\text { thenardite }\end{array}$ & $\begin{array}{l}-0.083 \mathrm{~s} \\
-0.783 \text { us } \\
-0.299 \mathrm{~s} \\
-1.597 \text { us } \\
1.251 \mathrm{ss} \\
-0.160 \mathrm{~s} \\
-0.209 \mathrm{~s} \\
-0.050 \mathrm{~s} \\
-0.781 \text { us } \\
-0.871 \text { us } \\
-0.741 \text { us } \\
-0.886 \text { us } \\
-0.934 \text { us }\end{array}$ & $\begin{array}{l}0.041 \mathrm{~s} \\
-0.663 \text { us } \\
-0.253 \mathrm{~s} \\
-0.843 \text { us } \\
1.070 \mathrm{ss} \\
0.490 \mathrm{ss} \\
-0.104 \mathrm{~s} \\
0.094 \mathrm{~s} \\
-0.452 \text { us } \\
-0.481 \text { us } \\
-0.794 \text { us } \\
-0.637 \text { us } \\
-0.408 \text { us }\end{array}$ & $\begin{array}{l}-0.042 \mathrm{~s} \\
-0.739 \text { us } \\
-0.423 \text { us } \\
-1.698 \text { us } \\
0.531 \mathrm{ss} \\
0.191 \mathrm{~s} \\
-0.156 \mathrm{~s} \\
-0.041 \mathrm{~s} \\
-0.906 \text { us } \\
-0.759 \text { us } \\
-0.825 \text { us } \\
-0.713 \text { us } \\
-0.624 \text { us }\end{array}$ & $\begin{array}{l}0.091 \mathrm{~s} \\
-0.613 \text { us } \\
-0.143 \mathrm{~s} \\
-0.544 \mathrm{us} \\
1.269 \mathrm{ss} \\
0.508 \mathrm{ss} \\
-0.051 \mathrm{~s} \\
0.079 \mathrm{~s} \\
-0.326 \mathrm{~s} \\
-0.395 \text { us } \\
-0.803 \text { us } \\
-0.605 \text { us } \\
-0.440 \text { us }\end{array}$ & $\begin{array}{l}-0.155 \mathrm{~s} \\
-0.854 \text { us } \\
-0.590 \text { us } \\
-1.200 \text { us } \\
1.453 \mathrm{ss} \\
-0.324 \mathrm{~s} \\
-0.278 \mathrm{~s} \\
-0.070 \mathrm{~s} \\
-0.603 \text { us } \\
-0.958 \text { us } \\
-0.633 \text { us } \\
-0.790 \text { us } \\
-1.026 \text { us }\end{array}$ & $\begin{array}{l}-0.068 \mathrm{~s} \\
-0.765 \text { us } \\
-0.430 \text { us } \\
-1.310 \text { us } \\
1.033 \text { ss } \\
-0.184 \mathrm{~s} \\
-0.182 \mathrm{~s} \\
-0.094 \mathrm{~s} \\
-0.674 \text { us } \\
-0.871 \text { us } \\
-0.758 \text { us } \\
-0.848 \text { us } \\
-0.974 \text { us }\end{array}$ \\
\hline & $\mathrm{OH} 23-\mathrm{h}$ & $\mathrm{OH} 26-h$ & $\mathrm{OH} 46.6$ & $\mathrm{OH}-63-d$ & & \\
\hline $\begin{array}{l}\text { anhydrite } \\
\text { bassanite } \\
\text { celestite } \\
\text { dolomite } \\
\text { fuorite } \\
\text { glauberite } \\
\text { gypsum } \\
\text { halite } \\
\text { magnesite } \\
\text { polyhalite } \\
\text { sylvite } \\
\text { syngenite } \\
\text { thenardite }\end{array}$ & $\begin{array}{l}-0.146 \mathrm{~s} \\
-0.846 \text { us } \\
-0.764 \text { us } \\
-2.059 \text { us } \\
0.792 \mathrm{ss} \\
-0.254 \mathrm{~s} \\
-0.275 \mathrm{~s} \\
-0.038 \mathrm{~s} \\
-0.999 \text { us } \\
-1.018 \text { us } \\
-0.704 \text { us } \\
-0.931 \text { us } \\
-0.966 \text { us }\end{array}$ & $\begin{array}{l}-0.087 \mathrm{~s} \\
-0.789 \text { us } \\
-0.737 \text { us } \\
-1.874 \text { us } \\
1.025 \mathrm{ss} \\
-0.157 \mathrm{~s} \\
-0.221 \mathrm{~s} \\
-0.017 \mathrm{~s} \\
-0.915 \text { us } \\
-0.859 \text { us } \\
-0.700 \text { us } \\
-0.870 \text { us } \\
-0.927 \text { us }\end{array}$ & $\begin{array}{l}-0.030 \mathrm{~s} \\
-0.732 \text { s } \\
-0.488 \text { us } \\
-1.456 \text { us } \\
1.244 \mathrm{ss} \\
-0.080 \mathrm{~s} \\
-0.165 \mathrm{~s} \\
-0.013 \mathrm{~s} \\
-0.721 \text { us } \\
-0.631 \text { us } \\
-0.662 \text { us } \\
-0.725 \text { us } \\
-0.907 \text { us }\end{array}$ & $\begin{array}{l}-0.021 \mathrm{~s} \\
-0.723 \text { us } \\
-0.257 \mathrm{~s} \\
-1.726 \text { us } \\
1.100 \mathrm{ss} \\
-0.038 \mathrm{~s} \\
-0.157 \mathrm{~s} \\
-0.002 \mathrm{~s} \\
-0.880 \mathrm{us} \\
-0.672 \text { us } \\
-0.677 \text { us } \\
-0.734 \text { us } \\
-0.873 \text { us }\end{array}$ & & \\
\hline
\end{tabular}

Letters following drill hole identification indicate orientation of hole as up (u), down (d), or subhorizontal (h). Letters following the SI number indicate undersaturation (us), saturation (s), or supersaturation (ss).

${ }^{a} S \mid=[\log$ (ion-activity product/solubility product)].

${ }^{b}$ Mineral SI obtained with the Pitzer thermodynamic database; all others with the Harvie-Moller-Weare database. 


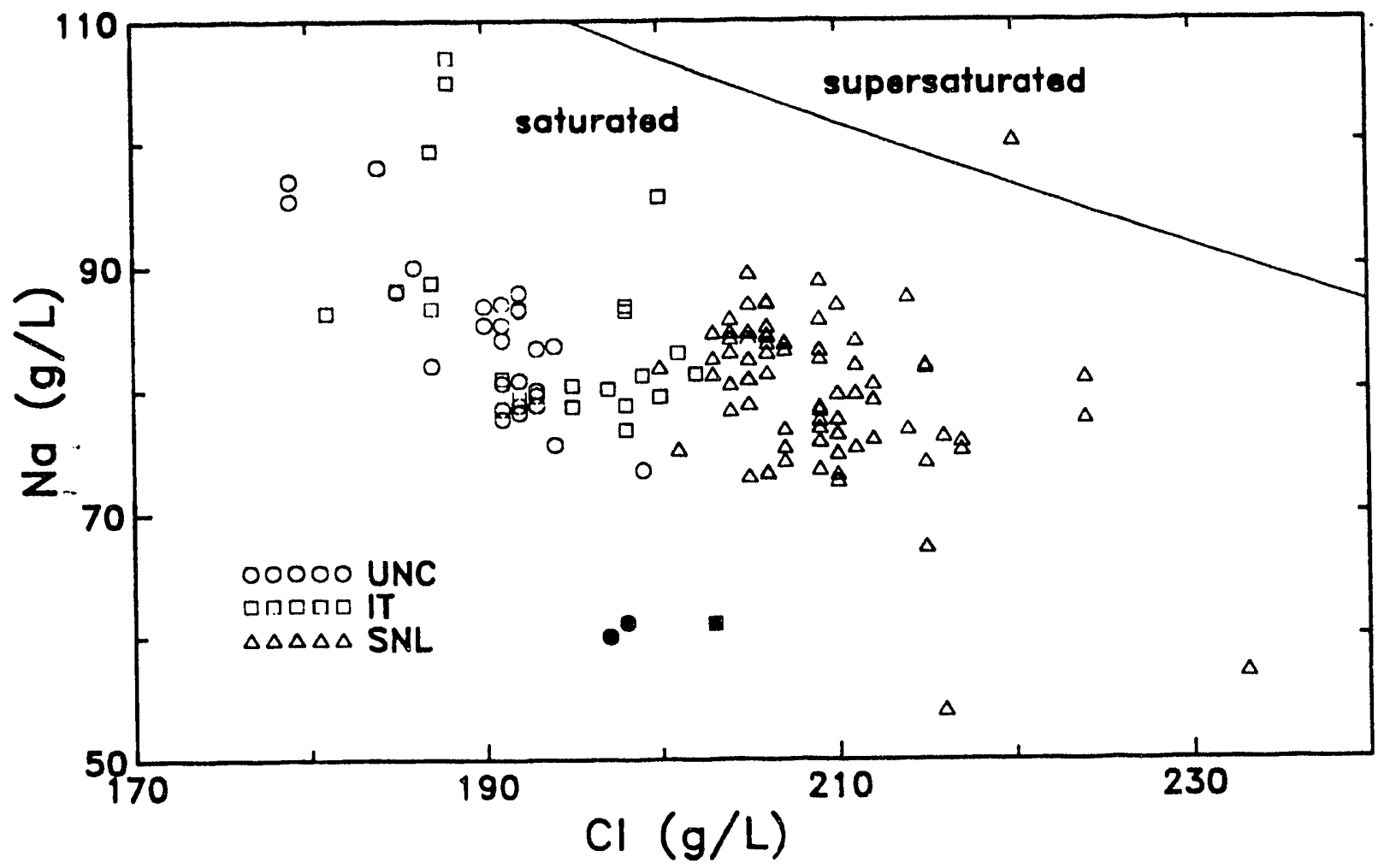

Figure 3-31

Variation of $\mathrm{Na}$ and $\mathrm{Cl}$ in Salado Formation brines recovered from underground locations at the WIPP. Filled symbols indicate upholes. Halite saturation field determined with the EQ3NR geochemical code using brine compositions. 
larger mass fraction of the initial sodium concentration is removed relative to chloride.

Anhydrite-Data displayed on the anhydrite saturation diagram (Figure 3-32) display two strikingly different trends. UNC and IT data have similar calcium concentrations and variable sulfate values, which places this data in the saturated field. SNL/NM data have similar sulfate values and variable calcium concentrations, placing the data in all three fields. The SNL/NM data are inconsistent with UNC and IT data because trends in Figure 3-32 should parallel the saturated field (similar to UNC and IT data), rather than cross cut the field boundary between the saturated and supersaturated fields. SNL/NM calcium data in the supersaturated field probably represent values with a large positive bias. This uncertainty may have been introduced from large dilution factors (Krumhansl and others, 1991), which decrease the detection-limit sensitivity and accuracy of the analytical technique.

Celestite - The saturation diagram for celestite (Figure 3-33) shows a fairly complex trend for the UNC and IT data. Strontium and sulfate concentrations appear to correlate positively until they cross into the saturated field. Within the saturated field, increases in sulfate concentrations may result in decreasing strontium values to maintain solubility constraints, or a limited amount of strontium may substitute into anhydrite. Data for upholes (filled circles and square) suggest evaporation drives the initial strontium and sulfate concentrations into the saturated field, where further evaporation can continue to concentrate sulfate, but strontium will decrease to maintain solubility constraints. This inverse behavior arises because the sulfate concentration is nearly four-orders of magnitude greater than the strontium concentration.

Downholes lying in the saturated field may indicate some brine evaporation has occurred prior to collection. Alternatively, these holes may have received a component of Culebra water (about $30 \mathrm{mg} / \mathrm{L}$ strontium) that was spread on the drift floor for road consolidation. There is some evidence for the latter hypothesis for holes OH66 and OH67 (downholes with highest strontium concentrations), as their relatively low bromide and boron concentrations (Appendix D) suggest mixing with a diluted solution has taken place.

Magnesite-Magnesite saturation has been evaluated at a pH of 6.0, 6.1, and 6.2 (Figure 3-34). The unsaturated/saturated boundary in Figure 3-34 shifts to the right at lower $\mathrm{pH}$ values and to the left for higher $\mathrm{pH}$ values. Half-filled symbols represent downholes that are calculated to be saturated with magnesite (Tables 3-3 and 3-4), and the filled symbols represent upholes. The half-filled symbols lying in the unsaturated field have $\mathrm{pH}$ values 


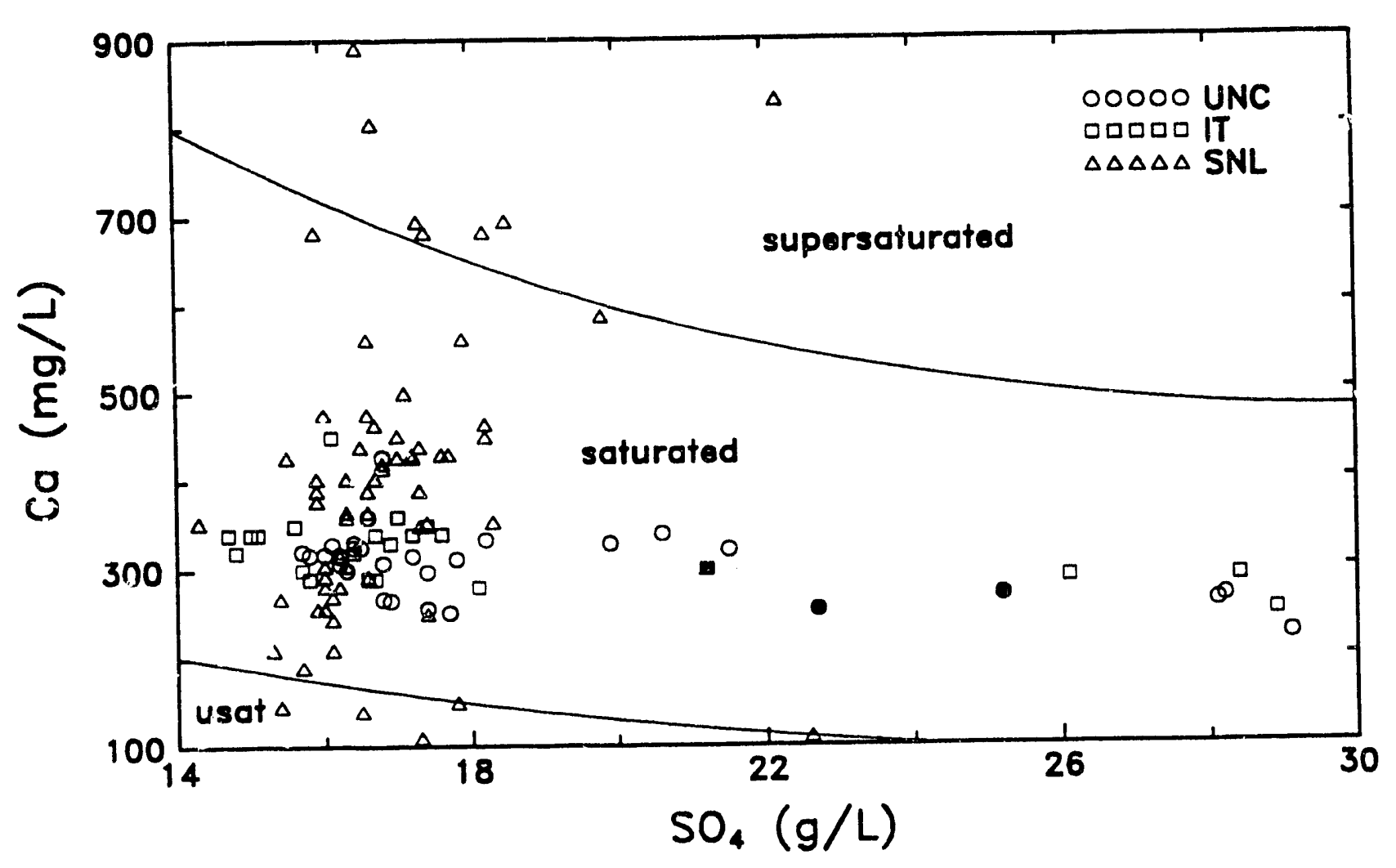

Figure 3-32

Variation of $\mathrm{Ca}$ and $\mathrm{SO}_{4}$ in Salado Formation brines recovered from underground locations at the WIPP. Filled symbols indicate upholes. Anhydrite saturation field determined with the EQ3NR geochemical code using brine compositions. 


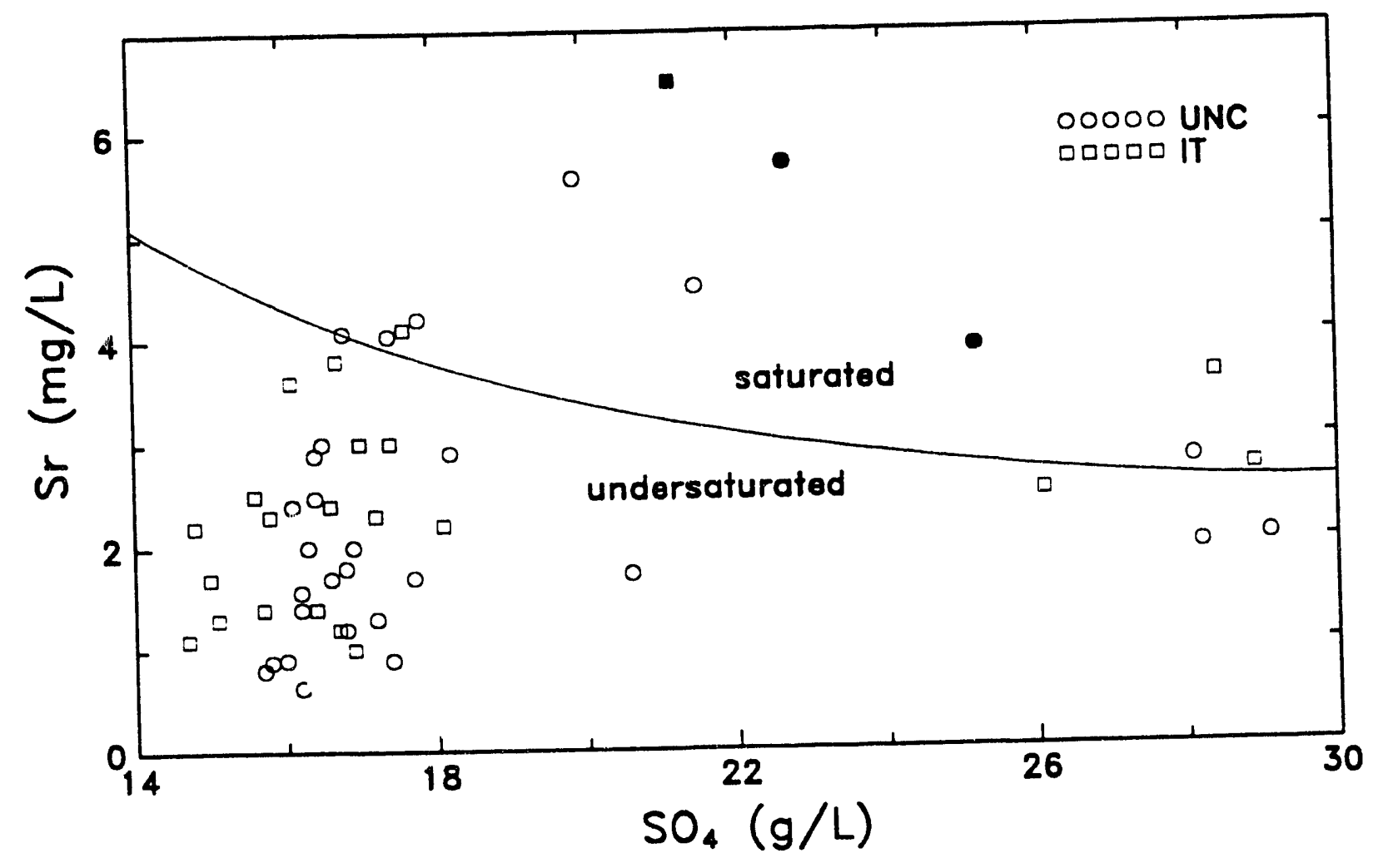

Figure 3-33

Variation of $\mathrm{Sr}$ and $\mathrm{SO}_{4}$ in Salado Formation brines recovered from underground locations at the WIPP. Filled symbols indicate upholes. Celestite saturation field determined with the EQ3NR geochemical code using brine compositions. 


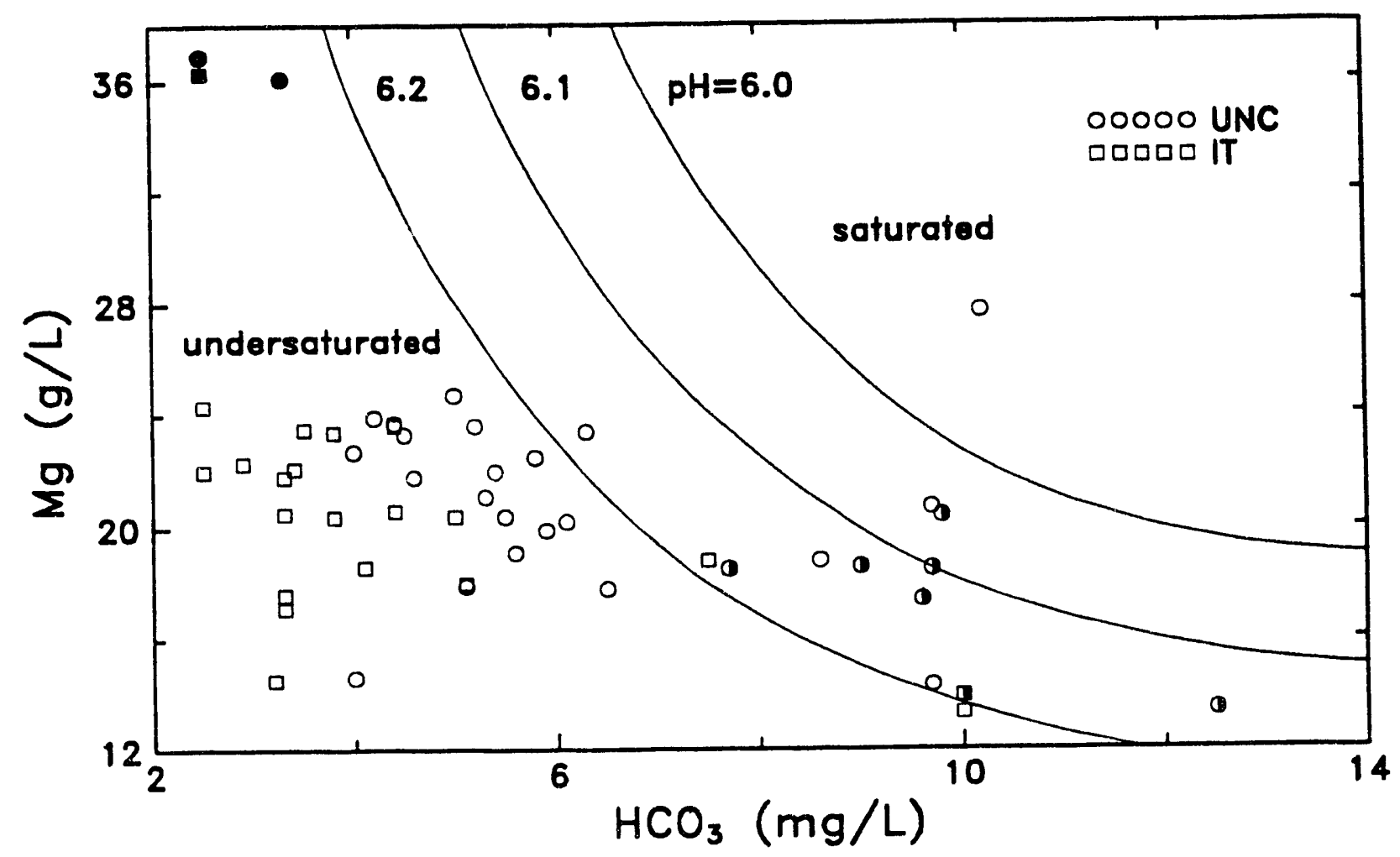

Figure 3-34

Variation of $\mathrm{Mg}$ and $\mathrm{HCO}_{3}$ in Salado Formation brines recovered from underground locations at the WIPP. Filled symbols indicate upholes. Half-filled symbols indicate samples that are saturated with magnesite.

Magnesite saturation field determined at a pH of 6.0,6.1, and 6.2 with the EQ3NR geochemical code using brine compositions.

See text for discussion of $\mathrm{pH}$ boundaries. 
greater than 6.1, and the open symbols in the saturated field have $\mathrm{pH}$ values less than 6.1; consistent with the boundary shifts noted above. The point in the upper right, just below the word saturated, is from $\mathrm{L} 1 \mathrm{X00}$ and has a pH of 5.7 to 5.8. At that low $\mathrm{pH}$, the brine is undersaturated with magnesite.

\subsection{Evaluation of the Migration of Synthetic Brine to the GSEEP Location}

Deal and others (1989) questioned whether synthetic brine migrated out of a pit in Room J along MB 139 to GSEEP. Room J is the site of the SNL/NM Drum Durability Tests (DDT), where different grades of steel drums are placed in an excavated pit filled with artificial brine to evaluate corrosicn. As part of the tests in Room J, SNL/NM had spiked the synthetic brine used in the corrosion experiments with elevated levels of iodide and cesium. The levels of iodide and cesium in the synthetic brine were, respectively, one to three orders of magnitude greater than the average concentrations observed in BSEP brines, making them excellent tracers to monitor the flow of this synthetic brine out of the Room J DDT pit and into GSEEP. Data on brine obtained from GSEEP and Room J are reported in Table 3-5. A brief analysis of this data shows that GSEEP brine does not contain a detectable amount of the synthetic brine introduced into the Room J pit.

Brine has been recovered and analyzed from GSEEP since September 1987 and continues to be sampled on a quarterly basis as part of the WIPP BSEP monitoring. All BSEP analyses of the GSEEP chemistry for 1989 are presented in Deal and others (1991), and 1990 analytical results are given in Appendix $\mathrm{C}$ of this report. These analyses provide results from two independent laboratories (IT and UNC). Table 3-5 shows the results from the March 1989 BSEP sampling of synthetic brine in the Room J pit and SNL/NM analyses of the synthetic brine (May 1986 to October 1986).

Whien comparing Appendix C (Deal and others, 1991) and Table 3-5 in this report, several observations should be noted:

- The concentrations of bromide and iodide reported by the IT laboratory for the September 14, 1989, sampling round are anomalously low and high relative to historical analytical results on the GSEEP brine, respectively.

- The IT results for bromide are anomalously high for one sample analyzed from the December 12, 1989, round and the March 21, 1990, round. These anomalous results have been traced to analytical difficulties in the IT laboratory 
Table 3-5

Composition of Brines Recovered from Room $J$ and GSEEP

\begin{tabular}{|c|c|c|c|c|c|c|c|c|c|}
\hline Sample ID/Date & $\underset{(\mathrm{ppm})^{\mathrm{a}}}{\mathrm{Br}}$ & $\underset{(p p t)^{b}}{\mathrm{Cl}^{-}}$ & $\begin{array}{c}\Gamma \\
\text { (ppm) }\end{array}$ & $\mathrm{SO}_{4}^{-2}$ & $\begin{array}{l}\mathrm{Ca}^{+2} \\
\text { (ppt) }\end{array}$ & $\begin{array}{c}\text { Cs } \\
\text { (ppm) }\end{array}$ & $\underset{\text { (ppt) }}{\mathrm{K}^{+}}$ & $\begin{array}{c}\mathrm{Mg}^{+2} \\
\text { (ppt) }\end{array}$ & $\begin{array}{l}\mathrm{Na}^{+} \\
\text {(ppt) }\end{array}$ \\
\hline$J B 1^{C}(05 / 28 / 86)$ & 21.2 & 134 & 195 & 2.2 & 0.51 & 75 & 0.50 & 0.35 & 100 \\
\hline JB2 $(06 / 10 / 86)^{d}$ & 25.9 & 129 & 175 & 2.4 & 0.58 & $\pi 7$ & 0.57 & 0.39 & 97 \\
\hline JB3 $(08 / 21 / 86)$ & 55.4 & 136 & 244 & 2.5 & 1.06 & 106 & 1.28 & 0.82 & 98 \\
\hline JB8 (10/07/86) & 80.6 & 133 & 277 & 5.2 & 0.96 & 110 & 1.70 & 1.15 & 100 \\
\hline JRM $(03 / 14 / 89)^{\circ}$ & 396 & 156 & 423 & 8.0 & 0.36 & 115 & 5.52 & 5.49 & 89 \\
\hline GSEEP $^{d}$ & 1,110 & 150 & 13.8 & 22.9 & 0.22 & 0.17 & 11.0 & 11.9 & 79.7 \\
\hline
\end{tabular}

Qppm = parts per million.

bpt = parts per thousand.

cJB samples taken from Krumhansl and Stockman (1987).

'Heaters turned on after collection of JB2.

-Average values for UNC analytical results (Appendix C in Deal and others, 1990) converted to ppt and ppm using a density of $1.22 \mathrm{~kg} / \mathrm{L}$.

dStatistical results for UNC analyses (Appendix D) converted to ppt and ppm using a density of $1.23 \mathrm{~kg} / \mathrm{L}$. 
and occur for all brine samples analyzed by IT on the above indicated sampling dates.

- Cesium analysis of brine samples was initiated in March of 1989 to support the investigation into contamination of GSEEP brine by synthetic brine introduced in the Room J pit. However, cesium analysis was discontinued after March 1989 for samples sent to the IT laboratory because they could not achieve a low enough detection limit to be useful to the objectives of this investigation.

BSEP analytical results on brine obtained from the Room J pit are available from the March 1989 sampling round. Results are fairly consistent between the IT and UNC laboratories, except for bromide and iodide. The concentrations reported by IT for these two halogens are greater than and less than UNC results, respectively. Because bromide and iodide have been traced to analytical problems in the IT laboratory in the past, the UNC values are taken as more representative of the bromide and iodide concentrations in the Room J pit. Limited data on the chemical constituents in the Room J pit are available from SNL/NM for the period May 1986 to October 1986, and these have been tabulated with the average UNC analytical results for March 1989 in Table 3-5. Note that the UNC data in Table 3-5 is not identical to the data reported in Appendix $\mathrm{C}$, because $\mathrm{mg} / \mathrm{L}$ concentrations in the Appendix have been converted to $\mathrm{mg} / \mathrm{kg}$ or $\mathrm{g} / \mathrm{kg}$ (ppm or $\mathrm{ppt}$ ) to allow comparison with the SNL/NM data on the Room J brine.

Focusing on the UNC laboratory results (Table 3-5), the average concentration of iodide and cesium in the synthetic brine is 423 ppm and 115 ppm, respectively; while 1989 and 1990 data for GSEEP are $13.8 \mathrm{ppm}$ and $0.17 \mathrm{ppm}$, respectively. The average iodide and cesium concentrations of $423 \mathrm{ppm}$ and $115 \mathrm{ppm}$ in the synthetic brine would increase the iodide and cesium concentrations in GSEEP brine by about $4.2 \mathrm{ppm}$ and $1.2 \mathrm{ppm}$ for every 1 percent of synthetic brine present in GSEEP. Since the analytical precision for iodide and cesium is about \pm 10 percent (i.e., $13.8 \pm 1.4 \mathrm{ppm}$ and $0.17 \pm 0.02 \mathrm{ppm}$ ), an increase of $4.2 \mathrm{ppm}$ iodide and 1.2 ppm cesium (i.e., 1 percent synthetic brine) in GSEEP brine would be readily detectable and significant. Since March 1989, reported iodide and cesium concentrations from UNC analyses have never exceeded $16.6 \mathrm{ppm}(20.2 \mathrm{mg} / \mathrm{L})$ and $0.19 \mathrm{ppm}(0.23 \mathrm{mg} / \mathrm{L})$ in the GSEEP brine (Appendix C in Deal and others, 1990; and this report), indicating that if a component of Room $\mathrm{J}$ brine is present, it is less than 1 percent of the brine sampled at GSEEP.

Turning to the data reported by SNL/NM on Room J brine (Table 3-5) and UNC data on GSEEP brine prior to March 1989 (Deal and others, 1989), an analysis of the data similar to 
that above can be made with iodide (cesium data is not available for GSEEP brine prior to March 1989). However, in this analysis, the lower iodide concentrations reported by SNL/NM for Room J brine (195 to 277 ppm) and slightly higher concentrations for iodide in GSEEP brine prior to March 1989 (average $14.7 \mathrm{ppm}$ for 14 samples) indicate that at least 2 percent of the synthetic brine would have to be present in the GSEEP brine for detection.

The geochemical analysis presented above cannot unequivocally rule out the presence of synthetic brine from Room $J$ in GSEEP brine. However, based on the iodide and cesium concentrations, it shows that the volume percent of synthetic brine in GSEEP would have to be less than 2 percent. At the present time, this uncertainty is the best that can be obtained. To achieve a lower uncertainty, tracer tests would have to be performed to evaluate the dilution of synthetic brine as it enters MB 139 and the flow of the resulting mixed brine through MB 139. Quarterly sampling and analysis of brine from the GSEEP locality will continue as part of the BSEP; and if a component of synthetic brine is detected, the possibility of movement of brine through hundreds of feet of fractured rock beneath the floor should be reevaluated.

The evidence presented in Section 3.2.1 shows that three brine sampling locations-GSEEP, G090, and H090 - have probably experienced mixing with an artificial brine because their compositions plot on the mixing line on the element-ratio diagrams (Figures 3-29 and 3-30). A probable source of the artificial brine component is known for $\mathrm{G} 090$ and H090. A similar component is indicated for GSEEP, and since it does not appear that the Room $\mathrm{J}$ brines are the source, the next most likely source are brines spread for floor consolidation in the G Access drift, just east of GSEEP, that flowed westward down the slope of the floor, possibly through unconsolidated muck on the drift floor, to the GSEEP location.

\subsection{Conc/usions}

Simple statistics have been presented for analytical data obtained on brines collected in 1989 and 1990. Histograms were constructed to summarize the parameter variation and compare data obtained on BSEP drill holes to SNLNM data obtained from weep arrays. In general, the SNL/NM analytical values for brine weeps were greater than data on BSEP drill holes for all compared parameters except sulfate. Additionally, statistics on archived DHP402A brine samples showed no significant difference in major-element chemistry of recently collected and archived brine samples. 
Variation diagrams of $\mathrm{Na} / \mathrm{Cl}$ versus $\mathrm{Ca} / \mathrm{SO}_{4}$ and $\mathrm{Na} / \mathrm{Cl}$ versus $\mathrm{K} / \mathrm{Mg}$ examined the evaporation and mixing trends displayed by BSEP and SNL/NM weep-array brines. Trends exhibited by BSEP data in $\mathrm{Na} / \mathrm{Cl}-\mathrm{Ca} / \mathrm{SO}_{4}$ space were attributed to precipitation of halite and anhydrite as brine evaporated prior to collection and possible mixing between a solution saturated with halite and indigenous brine. SNL/NM data also followed the SNL/NM Room $Q$ brine evaporation trend, and about half of the data points plotted along a mixing line with a solution saturated with halite and anhydrite. The evaporation trend in the $\mathrm{Na} / \mathrm{Cl}-\mathrm{K} / \mathrm{Mg}$ plot was not followed by BSEP data, and few SNL/NM data plotted along the trend. Some BSEP data points plotted along a hypothetical mixing line with a saturated solution derived from dissolution of halite with $\mathrm{Na} / \mathrm{Cl}$ and $\mathrm{K} / \mathrm{Mg}$ ratios of 0.65 and 1.2 , respectively.

Solubility calculations were conducted with the EQ3NR geochemical code, and all BSEP brines were found to be saturated or supersaturated with halite, anhydrite, gypsum, glauberite, fluorite, and barite. Some samples were also saturated with celestite, magnesite, and polyhalite. Solubility diagrams were constructed for halite, anhydrite, celestite, and magnesite, and SNL/NM weep-array data were plotted with BSEP results for halite and anhydrite. The SNL.NM and BSEP data all plotted in the halite saturation field, but only BSEP data were entirely constrained to the anhydrite saturation field. SNL/NM data plotted in the undersaturated, saturated, and supersaturated fields for anhydrite, which is attributed to analytical errors introduced by large dilution factors prior to analysis of weep-array brines.

Mixing between a synthetic brine in Room $\mathrm{J}$ and brine collected at GSEEP was investigated using analyses on iodide and cesium. The results of this analysis show that less than 1 percent, if any, of the synthetic brine in Room $\mathrm{J}$ is present in GSEEP samples collected during 1989 and 1990; and less than 2 percent, if any, in GSEEP samples collected prior to 1989. The unusual composition of the GSEEP brines is probably the result of mixing with artificial brines spread on the floor for dust control in the $G$ Access drift upslope from GSEEP, with subsequent modification by evaporation. 


\subsection{Modeling and Analysis-Long Horizontal Drill Holes}

\subsection{Introduction}

This chapter presents a preliminary analysis of predicted brine seepage into hypothetical 46-m subhorizontal drill holes excavated in salt at the WIPP repository horizon. The near-field and far-field analyses presented in this chapter are designed to assist in determining the relative importance of near-field redistribution of brine and possible far-field flow to the repository. One of the more important questions in assessing the brine seepage into the WIPP is to determine whether there is any component contributed by the far field.

Near an excavation or drill hole, the processes of salt creep and fluid flow are coupled in a complex manner (Deal and others, 1989; Deal and Roggenthen, 1991). As brine flows into the rooms or drill holes, the rock salt around these openings creeps into the excavation. The creep of the intact salt will modify the permeability and porosity of the salt and resuits in changes in fluid pressure. The change in fluid pressure in the rock pores then affects stresses in the rock and, consequently, the salt creep rate. Because detailed experimental data on these coupling effects are not available at the present time, the relative importance of each mechanism is not completely understood.

Previous work (Deal and Case, 1987; Deal and others, 1987; Deal and others, 1989; Deal and others, 1991; Deal and Roggenthen, 1991) developed the following technical approach. Salt deformation and fluid flow are modeled simultaneously using the following assumptions:

- The Salado Formation, predominantly halite with minor amounts of clay, anhydrite, and polyhalite, is modeled as a continuous media.

- The salt is modeled as an elastoviscoplastic material exhibiting time-dependent deformation, where the presence of brine does not affect the creep rate or the elastic deformation of the rock; i.e., the effective stress is nearly identical to the total stress, as evidenced by low-porosity measurements (.0156) (Deal and others, 1988; see discussion Section 4.2.3).

- The permeability and porosity of the rock are affected by salt creep, where stresses are redistributed around the opening.

- The brine is uniformly distributed through the salt and flows according to Darcy's Law under saturated conditions as fluid pressure is reduced at the opening due to development of brine seepage. 
- Nitrogen in the brine is assumed to exsolve rapidly following excavation. The precise gas content is unknown, though estimates based on the solubility of nitrogen in sea water yield volumetric changes of 20 percent for a saturated brine that is depressurized (Roggenthen, 1988).

Previous analyses of a shaft-sized excavation (Deal and others, 1989) used identical assumptions. The assumption of modeling the salt as a continuous media is perhaps more appropriate for the small (less than $0.5 \mathrm{~m}$ in diameter) horizontal drill hole than the larger 3.6-m-diameter shaft due to a smaller disturbed zone $(0.27 \mathrm{~m}$ versus $12.0 \mathrm{~m})$ and since the presence of large fractures associated with clay seam separation and pillar deformation are absent near the drill hole scale excavations. Since the modeling was done, physical measurements of the permeability and hydraulic conductivity of various stratigraphic units in and near the WIPP workings show large variations between the effective impermeable clear halite, the argillaceous halite, and the anhydrite interbeds (refer to Section 2.3), suggesting preferential flow of brine parallel to bedding. The assumption that the salt is an isotropic, continuous, and uniform media may not be as appropriate as previously thought, but does allow comparison between models of a small (7.6-cm-diameter) drill hole (this report) and a 3.6-m-diameter shaft (Deal and others, 1989).

\subsection{Model Descriptions}

In these analyses, several models were used to simulate far-field and near-field effects. These models included a detailed finite-element model (VISCOT/BISCITS) used to perform stress and fluid-flow analyses and a less detailed finite-difference model used to evaluate boundary conditions.

\subsubsection{VISCOT/BISCITS Analysis}

The detailed finite-element model was evaluated using the computer codes VISCOT (Intera, 1983) for salt-creep analysis and the BISCITS program, which is a modified version of the program SUTRA (Voss, 1984) for the fluid-flow analysis (Deal and others, 1988; Wallace and others, 1990).

Other than the smaller drill hole geometry, the physical aspects of modeling salt creep and brine inflow into the long horizontal drill holes are the same as in the previous $3.6-\mathrm{m}$ diameter shaft model. The analysis ignores the effects of surrounding excavations. The finite-element models consist of one quadrant with boundary conditions identical to those for the shaft model, as illustrated in Figure 4-1. For stress analysis, the far-field boundaries were fixed, and the lateral boundaries were constrained. The BISCITS model is a far-field model 


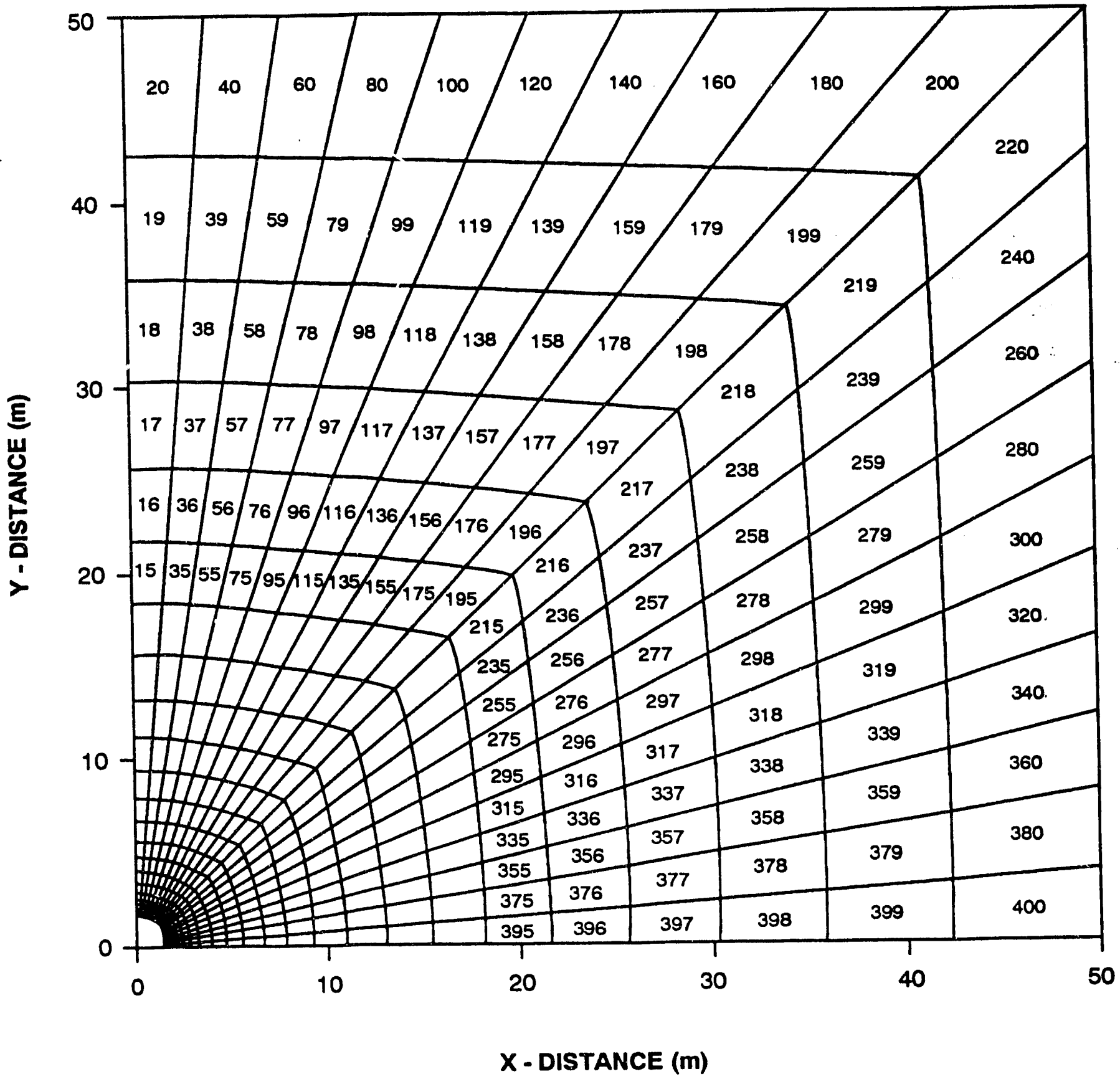

Figure 4-1

Finite-Element Mesh for a 7.6-cm-Diameter Subhorizontal Borehole Model 
that takes into account the increase in porosity and permeability, as described subsequently, in the DRZ close to the drill hole. A question of concern is whether far-field flow occurs or if flow only occurs within the DRZ. Evaluation of the near-field flow model of a 3.6-mdiameter shaft indicated a 30-year observation period would be necessary before a distinction between near-field and far-field flow could be developed (Deal and others, 1989, Section 5).

\subsubsection{Simplified Finite-Difference Analysis}

To assess the 7.6-cm-diameter drill hole, a radial, one-dimensional finite-difference model was used to evaluate alternate boundary conditions. In this model, the second-order diffusion equation with radial symmetry was solved using the explicit finite-difference method. For the far-field model, the pressure boundaries were fixed at the inner and outer boundaries that correspond to the boundary conditions for the more detailed finite-element model. For the near-field model, the inner-pressure boundary was set to zero, and the outer boundary corresponding to the edge of the DRZ was treated as a no-flow boundary.

\subsubsection{Model Input Properties}

The material properties for performing the coupled analysis include the elastic and secondary creep properties of the salt, the compressibility of the brine, and the best estimate for permeability (more precisely, intrinsic permeability) of the undisturbed rock salt. These properties are summarized in Table 4-1.

Two properties were modified from the previous shaft analysis (Deal and others, 1989, Section 5, hereafter referred to as the previous analysis). A determination was made of the moisture content of the Salado salt at the WIPP (Deal and others, 1989) that showed that the facility horizon is about 1.56 percent brine by volume ( 0.6 percent by weight), which must occupy that much pore space. The value is higher than the previously estimated value of 0.001 ( 0.1 percent), which was assumed by Peterson and others (1985) in curve-fitting gas flow data. Predictions using the stress-permeability relations developed by Lai (1971) have been made based upon the revised porosity. The porosity-permeability relationship presented by Lai was written in logarithmic form as:

$$
\log \left[\frac{\phi^{3}}{(1-\phi)^{2}}\right]=a \log k-\log b
$$


Table 4-1

Salt/Brine Material Constitutive Properties

\begin{tabular}{|c|c|c|}
\hline Parameter & $\begin{array}{c}\text { Base } \\
\text { Case Value }\end{array}$ & Units \\
\hline $\begin{array}{l}\text { Salt } \\
\text { Activation Energy, } \mathrm{Q} \\
\text { Stress Exponent, } \mathrm{n} \\
\text { Empirical Constant, A } \\
\text { Universal Gas Constant, R } \\
\text { Salt Temperature, T } \\
\text { Young's modulus, E } \\
\text { Poisson's Ratio, v }\end{array}$ & $\begin{array}{c}12,000 \\
4.9 \\
0.126 \\
1.987 \\
300 \\
31,000 \\
0.25 \\
\end{array}$ & $\begin{array}{c}\text { Calories/mole } \\
\mathrm{MPa}^{-4.9} / \text { day } \\
\text { Calories/(mole K) } \\
{ }^{\circ \mathrm{K}} \\
\mathrm{MPa}\end{array}$ \\
\hline Salt Far-Field Stress, $\mathrm{P}_{0}$ & 15 & $\mathrm{MPa}$ \\
\hline Brine Compressibility, $\beta$ & $5 \times 10^{-10}$ & $1 / \mathrm{Pa}$ \\
\hline Salt Porosity, $\phi$ & 0.0156 & \\
\hline Brine Viscosity, $\mu$ & 1.6 & Centipois \\
\hline Intact Salt-Intrinsic Permeability, $k$ & $0.1-1.0$ & Nanodarcy \\
\hline Hydraulic Conductivity, $\mathrm{K}$ & $10^{-15}-10^{-14}$ & $\mathrm{~m} / \mathrm{s}$ \\
\hline
\end{tabular}


where

$$
\begin{array}{ll}
\phi & =\text { porosity } \\
\mathbf{k} & =\text { intrinsic permeability } \\
\mathbf{a} \text { and } \mathbf{b} & =\text { empirical constants. }
\end{array}
$$

The empirical constant " $a$ " is related to the relative shanges in permeability with respect to porosity and represents the slope in the above relationship. This linear relationship with the selected constant "a" from Lai presented above may be used with the measured porosity of 1.56 percent to predict changes in permeability.

Lappin (1988) and Lappin and others (1989) have noted the difficulty in measuring in situ permeabilities in halite. In cases cited by Lappin and others (1989), the undisturbed salt permeability could have been lower than the limitations of various equipment used in the tests. The lowest permeability calculated from Peterson and others (1987) is 1 nanodarcy $\left(1 \times 10^{-21} \mathrm{~m}^{2}\right)$. In this discussion, the units are reported in nanodarcies for intrinsic permeability. The conversion to hydraulic conductivity for brine is equivalent to $10^{-14} \mathrm{~m} / \mathrm{s}$. Calculations from brine-flow experiments and more direct in situ permeability measurements show that the far-field permeability of the Salado Formation may be several orders of magnitude smaller than previously estimated (Lappin and others, 1989).

\subsection{Results of VISCOT Analysis}

The results of the VISCOT analysis for radial-tangential stress development are similar to the results of previous analysis. At the excavation, the boundary or tangential stress increases to approximately twice the value of the in situ stress, while the radial stress is reduced to zero. In the absence of creep, this stress would be maintained throughout time. However, in response to the high deviatoric stress, the salt will creep inward, and the radial and tangential stresses will relax with time.

As in the previous analyses (Deal and others, 1989), the stress relaxation is essentially complete after approximately 1,100 days. There is no change in porosity or permeability immediately after excavation (Figure 4-2). As boundary stresses relax and the stress abutment zone moves outward into the salt, a distinct zone of enhanced porosity develops. The maximum increase in porosity around the $7.6-\mathrm{cm}$ drill hole (approximately 2 percent) is much smaller than the relative increase of 40 percent in the previous analysis of the DRZ for a 3.6-m-diameter shaft. The development of permeability with time is illustrated in 
Figure 4-3. At the earliest time shown, there is very little permeahility enhancement over 1 nanodarcy. This result follows from the Kirsch solution in that the sum of normal strains (the first strain invariant) is dependent on the first stress invariant, which enters into the porosity calculation described previously. As in the case of porosity, the sum of normal strains also does not change immediately after excavation.

As salt creep relaxes the built-up stresses, the sum of the strains is no longer constant, and porosity and permeability increase with time. Because only the tangential stresses relax significantly over time, the changes in permeability in the model may be attributed chiefly to reductions in ingential stress. The results of the analysis suggest that the DRZ extends only two-tenths of a meter from the drill ho'e after 1,100 days (as compared to about $12 \mathrm{~m}$ for the shaft model) and that the maximum increase in permeability is about 3 percent from 1 nanodarcy (as compared to about 40 percent for the shaft model).

\subsection{BISCITS Analysis}

Flow rates and cumulative outflow for the far-field model are determined from the BISCITS analysis and are presented in Figures 4-4 and 4-5. When this counled model was previously used to estimate flow into a shaft (Deal and others, 1989), the porosity in tr. ${ }^{-}$far-field model increased in the disturbed zone arouncl the shaft faster than brine could be supplied from the surrounding salt. This analysis prerlicts the development of a small DRZ around the drill hole with a smaller relative change in predicted porosity that remains saturated in the far-field flow model. The results predict that a maximum flow rate $\left(10^{-5}\right.$ liters per second [L/s]) occurs immediately after excavation and declines to $10^{-6} \mathrm{~L} / \mathrm{s}$ after a year (Figure 4-4). The cumulative brine inflow predicted for one year is about $10 \mathrm{~L}$ (Figure 4-5).

\subsection{One-Dimensional Finite-Difference Analysis}

The simple finite-difference models were used to evaluate near-field versus far-field effects and variations in the intrinsic permeability of salt. The results of the far-field model for two intrinsic permeabilities ( 1 nanodarcy and 0.1 nanodarcy) are presented in Figures 4-6 through 4-11 as the radial hydraulic potential distribution, flow rate versus time, and cumulative flow versus time, respectively. The results using a higher intrinsic permeability (1 nanodarcy or $10^{-21} \mathrm{~m}^{2}$ ) are comparable to the more detailed finite-element model presented in Section 4.4, which also used an intrinsic permeability of $10^{-21} \mathrm{~m}^{2}$ and indicate that near steady-state flow is established within about 100 days at $0.08 \mathrm{~L}$ per day. For the lower intrinsic permeability ( 0.1 uanodarcy or $10^{-22} \mathrm{~m}^{2}$ ), the results indicate that steady-state flow is established after about 400 days at $0.01 \mathrm{~L}$ per day. 


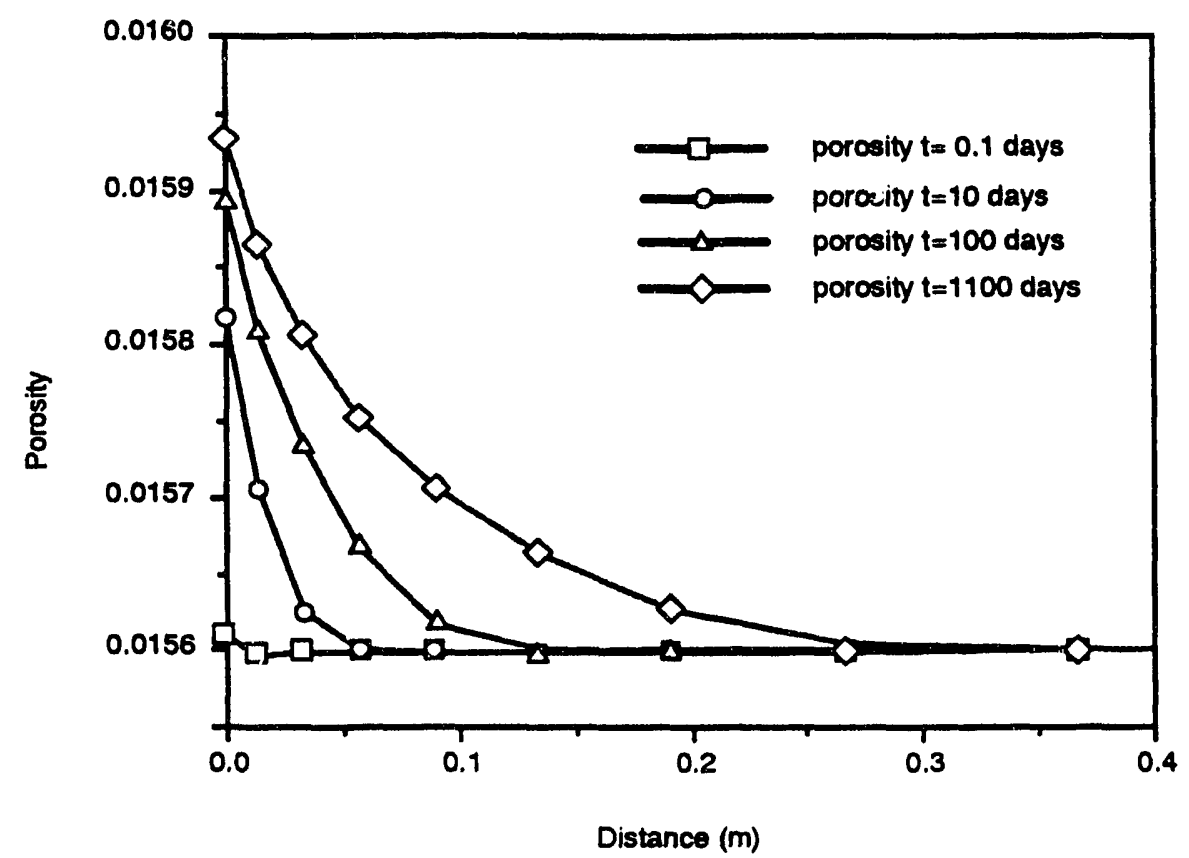

Figure 4-2

Porcsit; Versus Radial Distance of a 7.6-cm. Diameter Drill Hole

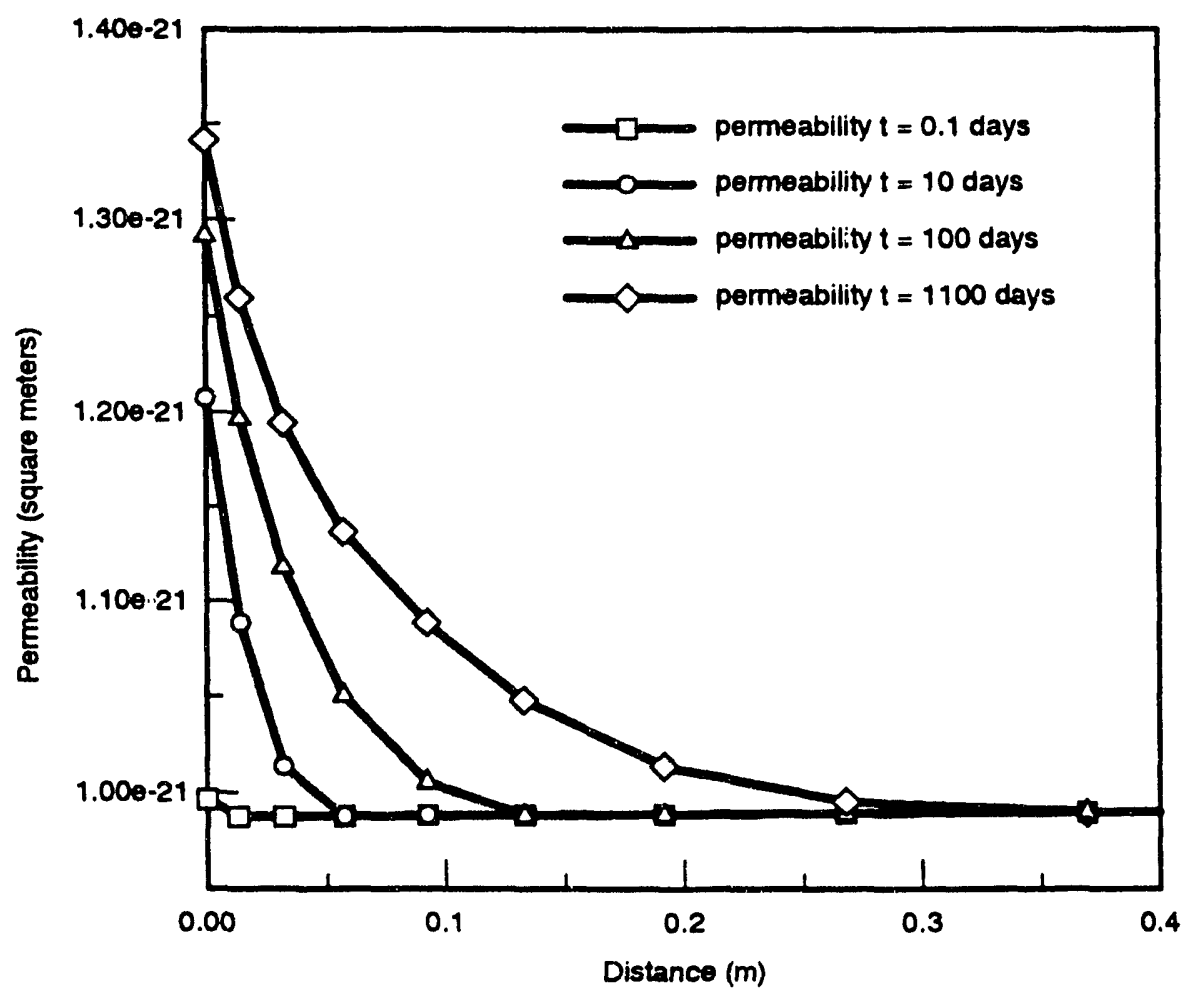

Figure 4-3

Permeability Versus Radial Distance of a 7.6-cm-Diameter Drill Hole 


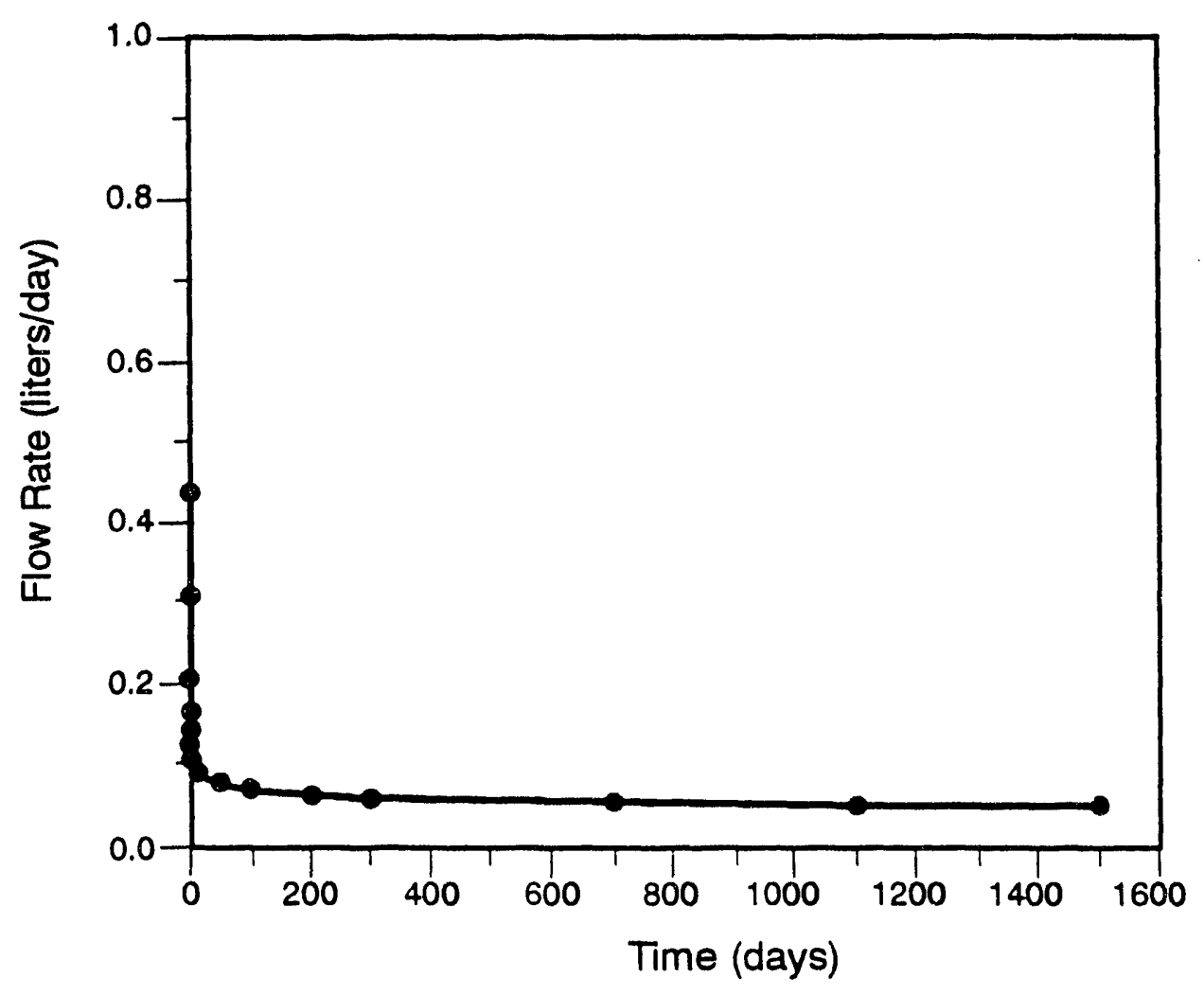

Figure 4-4

Flow Rate Versus Time for the BISCITS Model for a 7.6-cm-Diameter Drill Hole for Far-Field Flow 


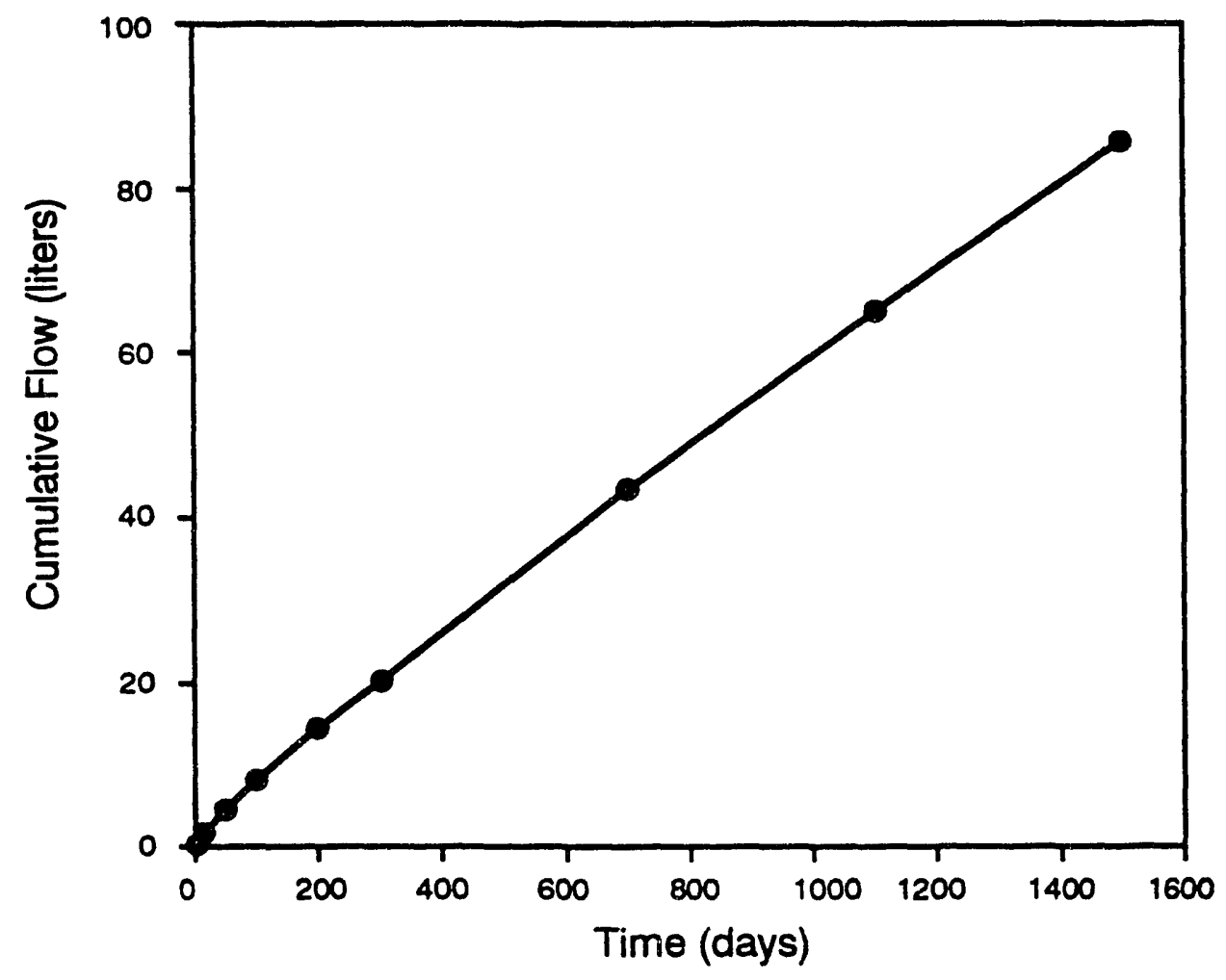

Figure 4-5

Cumulative Flow Versus Time for the BISCITS

Model for a 7.6-cm-Diameter Drill Hole for Far-Field Flow 
BRINE SAMPUNG AND EVALUATION PROGRAM REPORT 1990

MODELiNG AND ANALYSIS -LONG HORIZONTAL DRILL HOLES

$\frac{8}{5}$
0
$\frac{8}{8}$
$\frac{8}{8}$

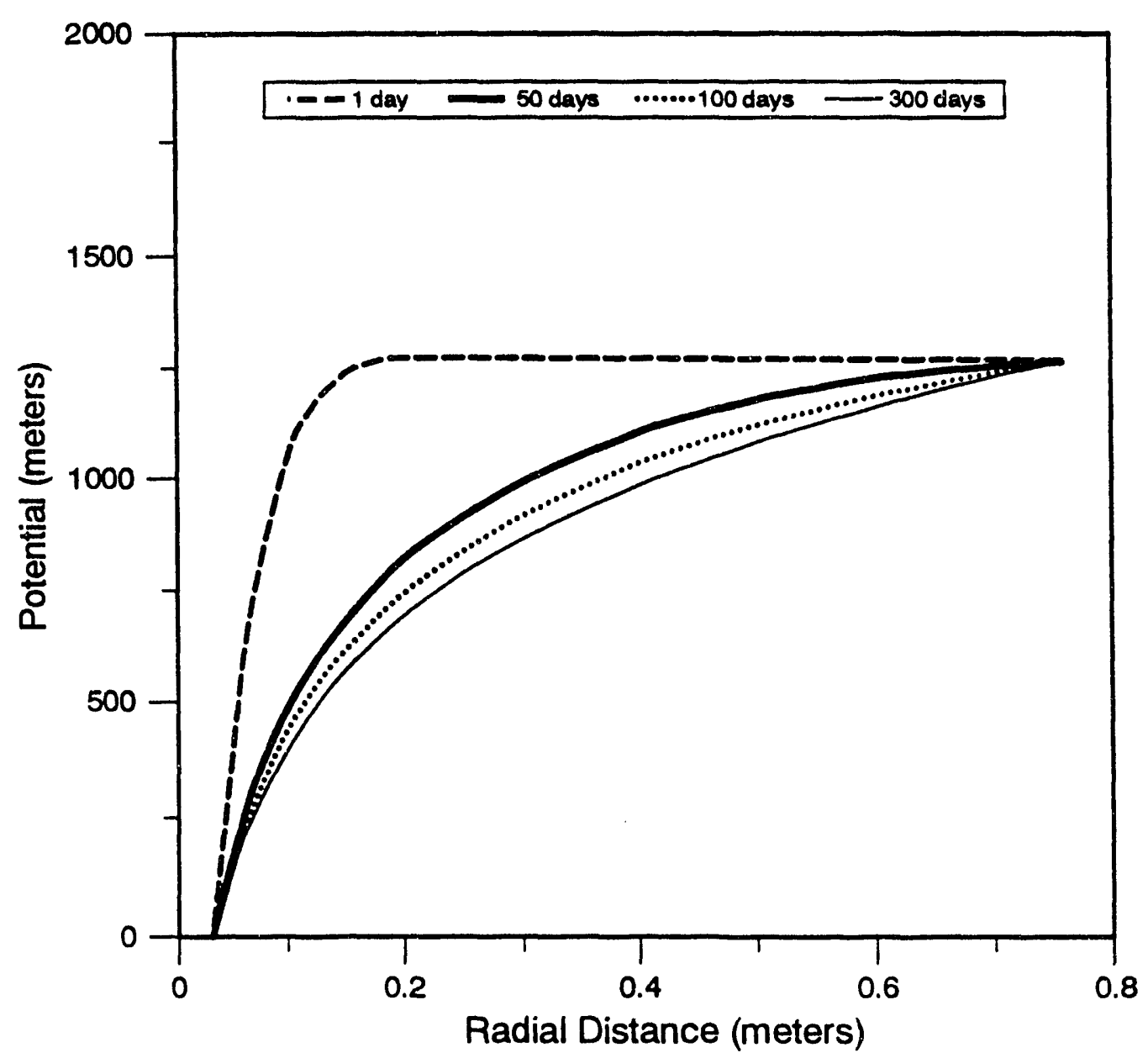

Figure 4-6

Potential Distribution for the Far-Field, High-Intrinsic Permeability (1 nanodarcy, $10^{-21} \mathrm{~m}^{2}$ ), Finite-Difference Model for a 7.6-cm-Diameter Drill Hole

4-11 


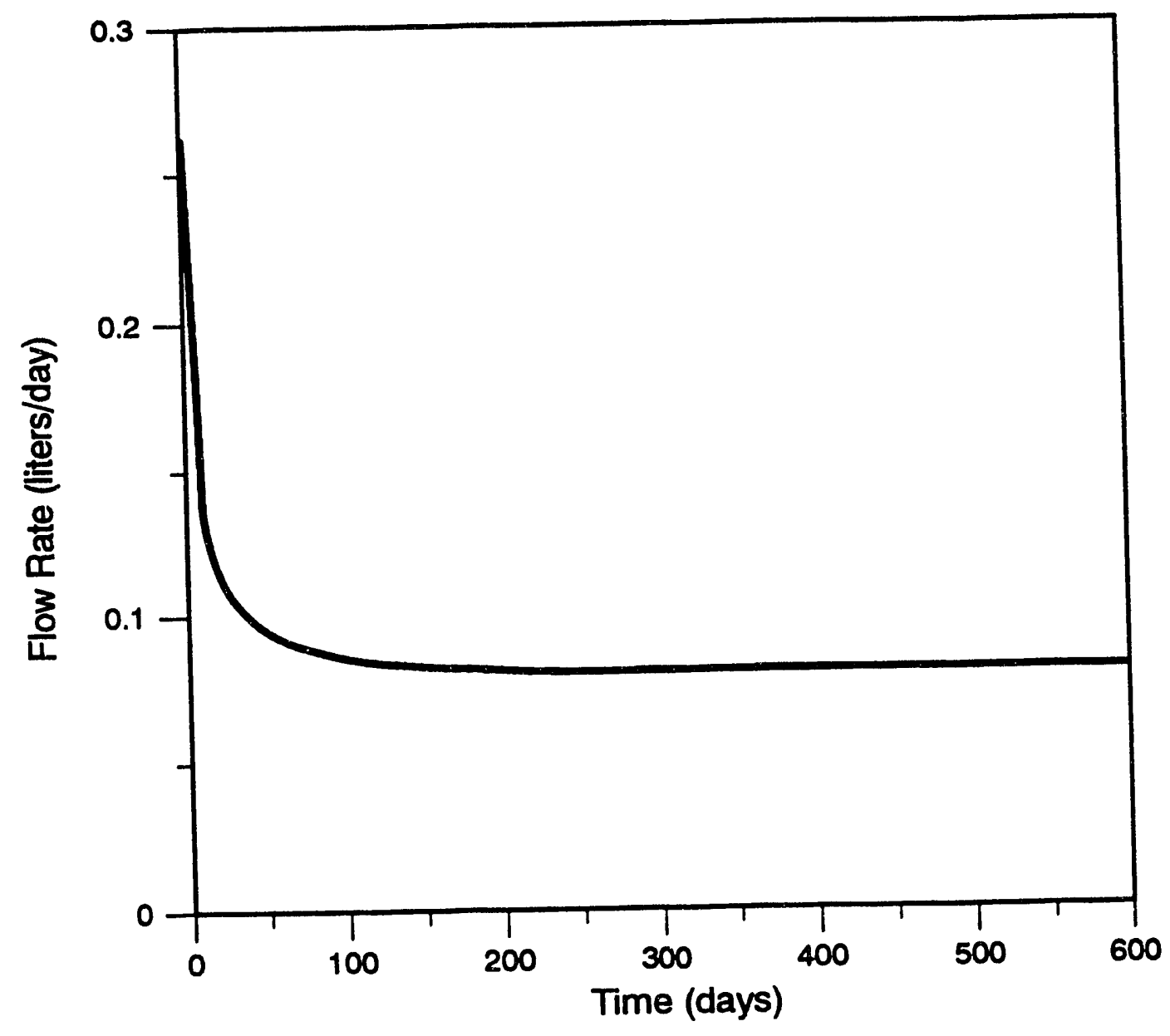

Figure 4-7

Fow Rate Versus Time for the Far-Field, High-Intrinsic Permeability (1 nanodarcy, $10^{-21} \mathrm{~m}^{2}$ ), Finite-Difference Model for a 7.6-cm-Diameter Drill Hole 


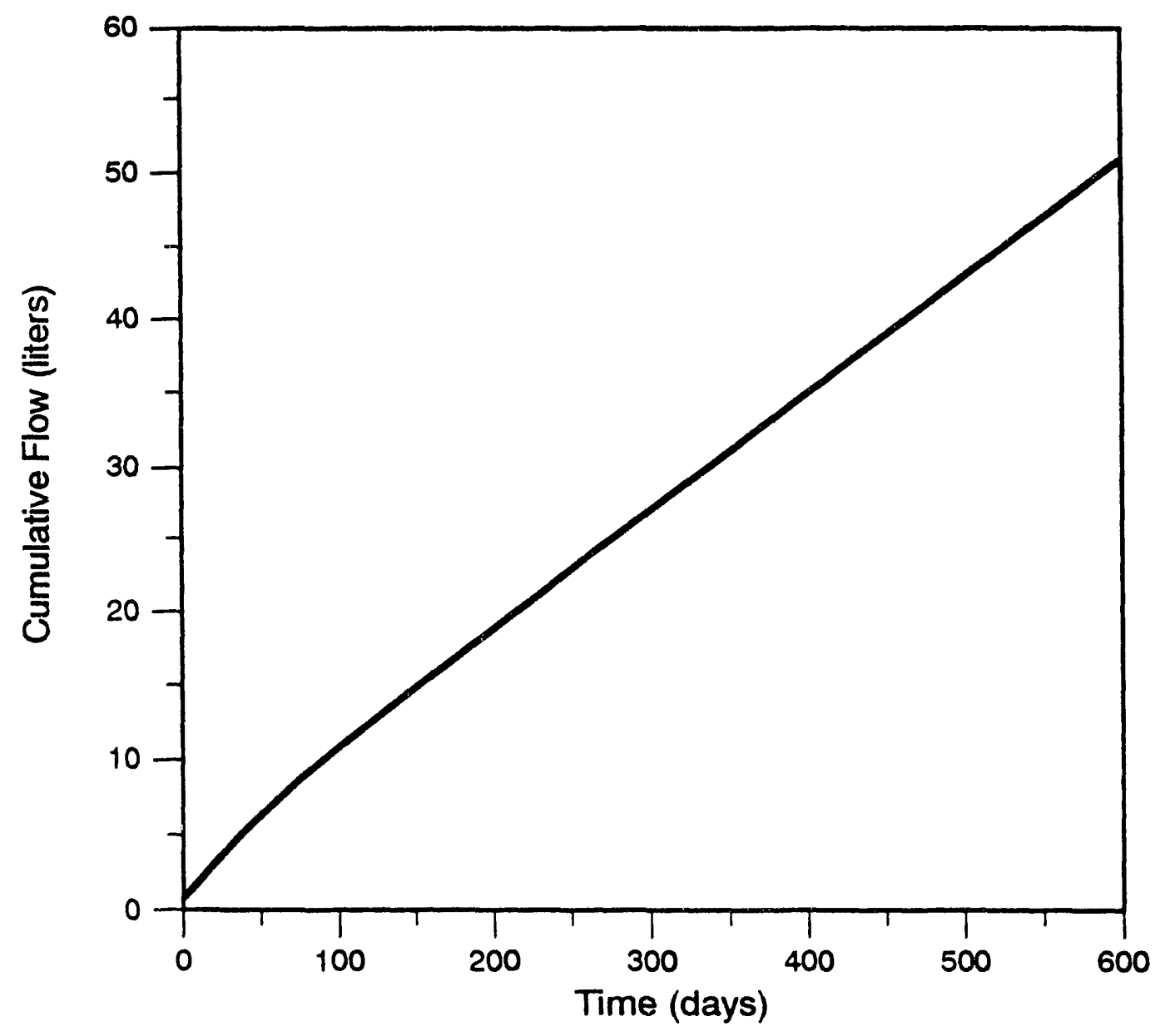

Figure 4-8

Cumulative Flow Versus Time for the Far-Field, High-Intrinsic Permeability (1 nanodarcy, $10^{-21} \mathrm{~m}^{2}$ ), Finite-Difference Model for a 7.6-cm-Diameter Drill Hole 


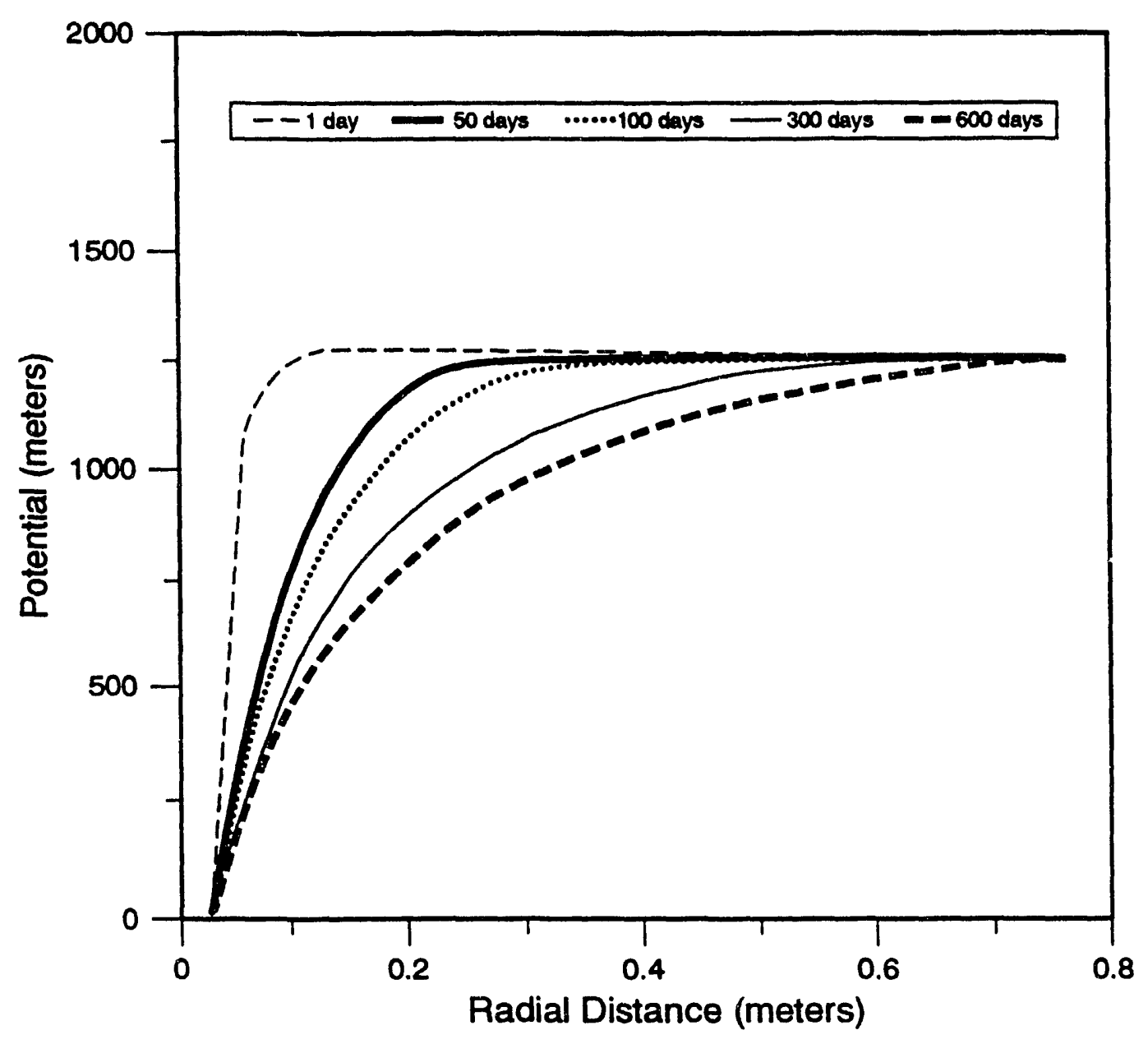

Figure 4-9

Potential Distribution for the Far-Field, Low-Intrinsic Permeability $\left(0.1\right.$ nanodarcy, $\left.10^{-22} \mathrm{~m}^{2}\right)$, Finite-Difference Model for a 7.6-cm-Diameter Drill Hole 


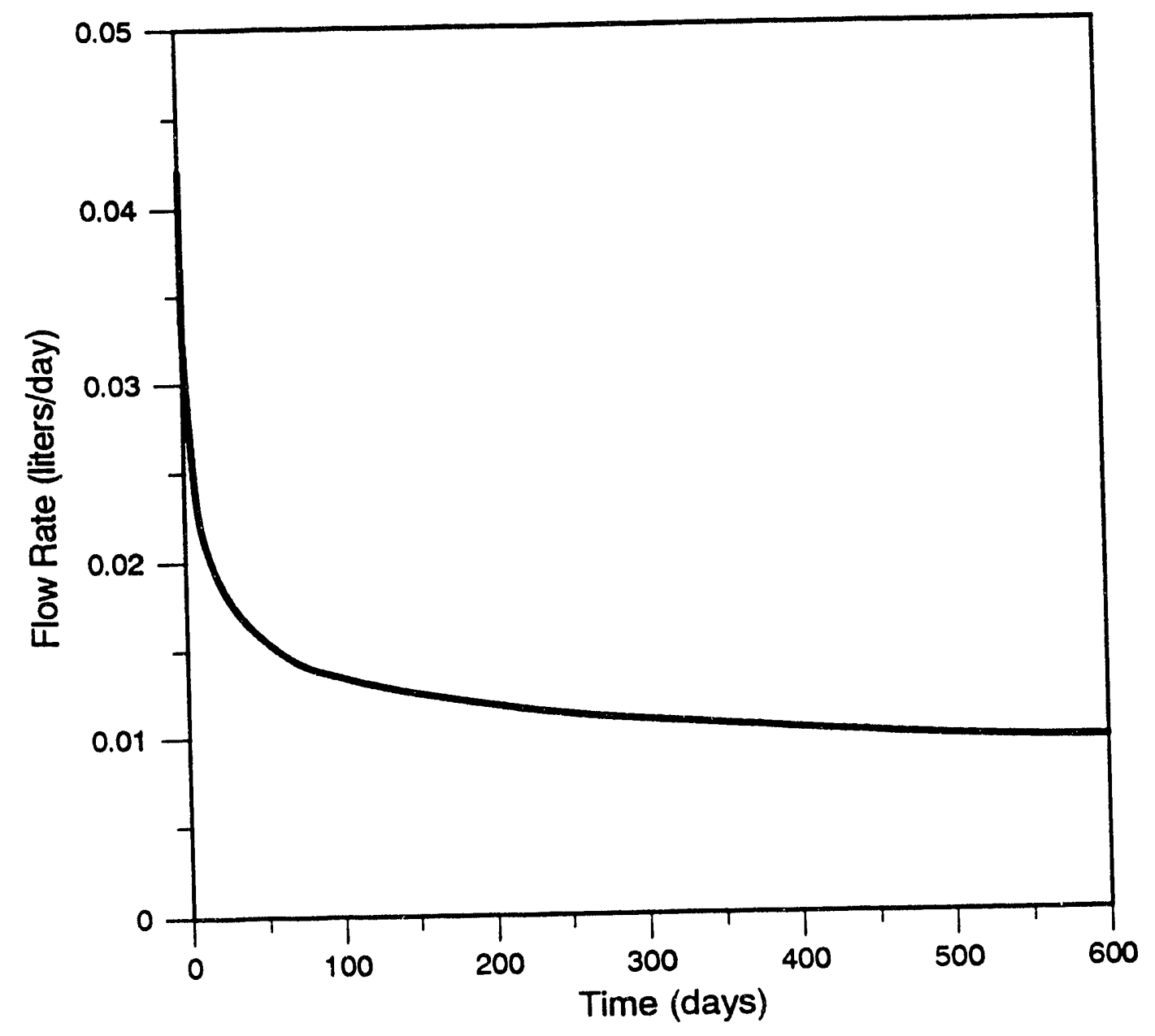

Figure 4-10

Flow Rate Versus Time for the Far-Field, Low Intrinsic Permeability (0.1 nanodarcy, $10^{-22} \mathrm{~m}^{2}$ ) Finite-Difference Model for a 7.6-cm-Diameter Drill Hole 
BRINE SAMPUNG AND EVALUATON PROCRAM REPORT 1990

MODELNG AND ANALYSIS-LONG HORIZONTAL DAIL HOLES

$\frac{8}{8}$

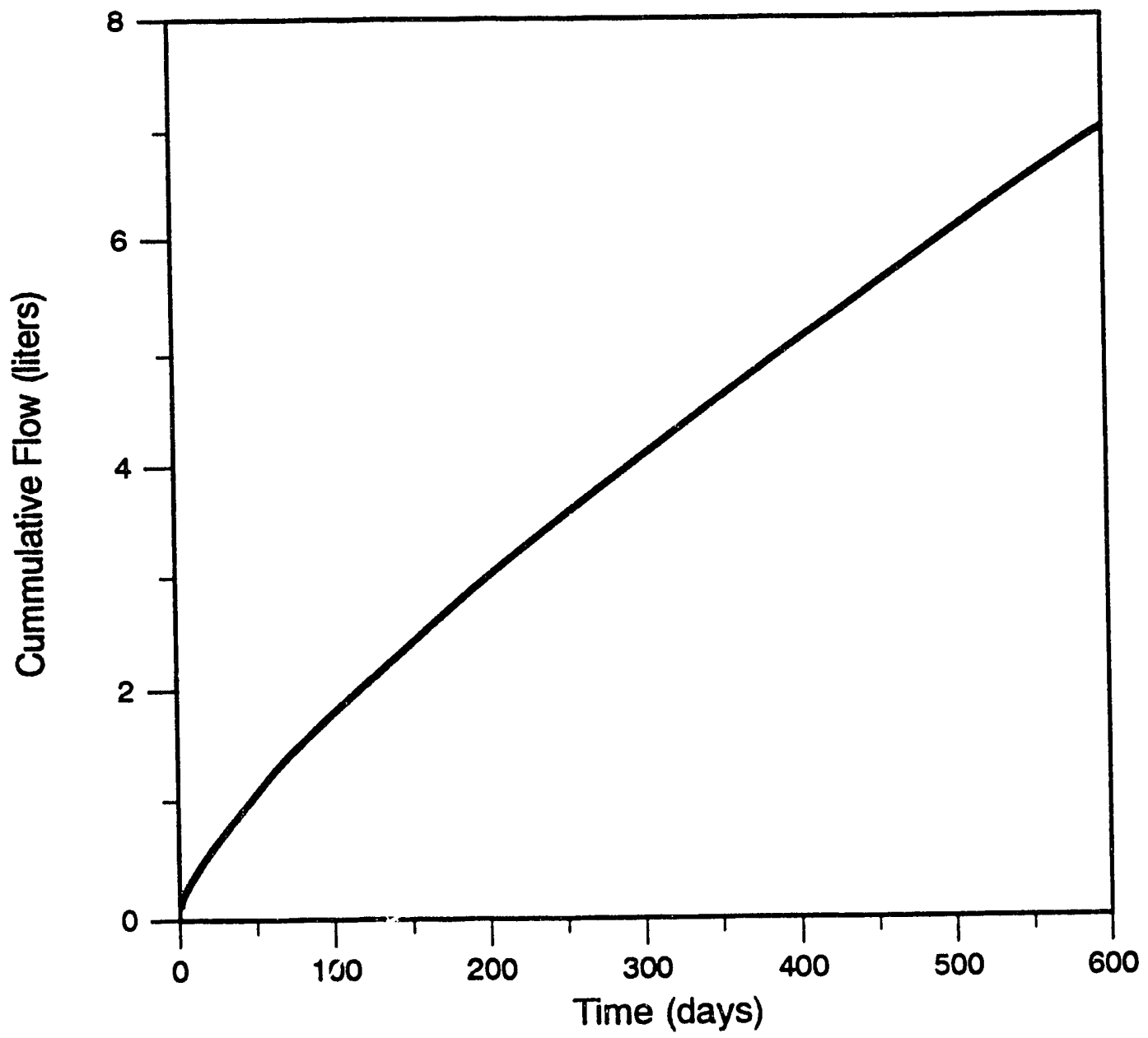

Figure 4-11

Cumulative Rate Versus Time for the Far-Field, Low-Intrinsic Permeablity ( 0.1 nanodarcy,10-22, Finite-Difference Model for a 7.6-cm-Diameter Drill Hole

4-16 
The results of the near-field model for two intrinsic permeabilities ( 1 nanodarcy and 0.1 nanodarcy) are presented in Figures 4-12 through 4-17 as the radial hydraulic potential distribution, flow rate versus time, and cumulative flow versus time, respectively. For the higher intrinsic permeability ( 1 nanodarcy), there is a rapid depressurization of the D.RZ in about 150 days with about $6 \mathrm{~L}$ of brine released. For the lower intrinsic permeability (0.1 nanodarcy), the depressurization occurs less rapidly, and the flow rates are still decreasing after 600 days (Figure 4-16). The lower the intrinsic permeability, the more slowly the brine will be released but the total amount of brine will be the same $(5 \mathrm{~L}$; Figures 4-14 and 4-17).

In comparing the near-field versus far-field models, there is little difference in flow rates for a period of 50 to 150 days; thereafter, the inflow rates are smaller for the near-field models, as expected. Previous analyses indicated that tens of years would be required for a room-scale (Room Q) or shaft-scale excavation to show a distinction between near- and far-field effects. This suggests the utility of smaller drill hole scale experiments to address the far-field flow versus near-field flow question. The selection of a lower intrinsic permeability is consistent with discussions made by Lappin (1988) and Lappin and others (1989) on salt permeability measurements and on the permeability data for the clear halite at the WIPP, which is immeasurably low (see the discussion in Section 2.3).

However, the current model provides a crude estimate of the extent of the DRZ around a drill hole. A larger DRZ would result in a proportionately greater amount of brine release due to depressurization (Figure 4-17). The following discussion evaluates variation in the size (radius) of the DRZ.

\subsection{Release of Brine from the DRZ Due to Depressurization}

Several processes may be contributing to the flow of brine into the excavation. These processes include:

- Expansion of the brine as it experiences a decrease in pressure. This process will tend to push brine into the excavation and is controlled by brine compressibility.

- Exsolution of dissolved gases as the brine experiences a decrease in pressure. This process will provide an extra gas drive that will tend to push brine into the excavation and is controlled by the amount of dissolved gases in the brine. 


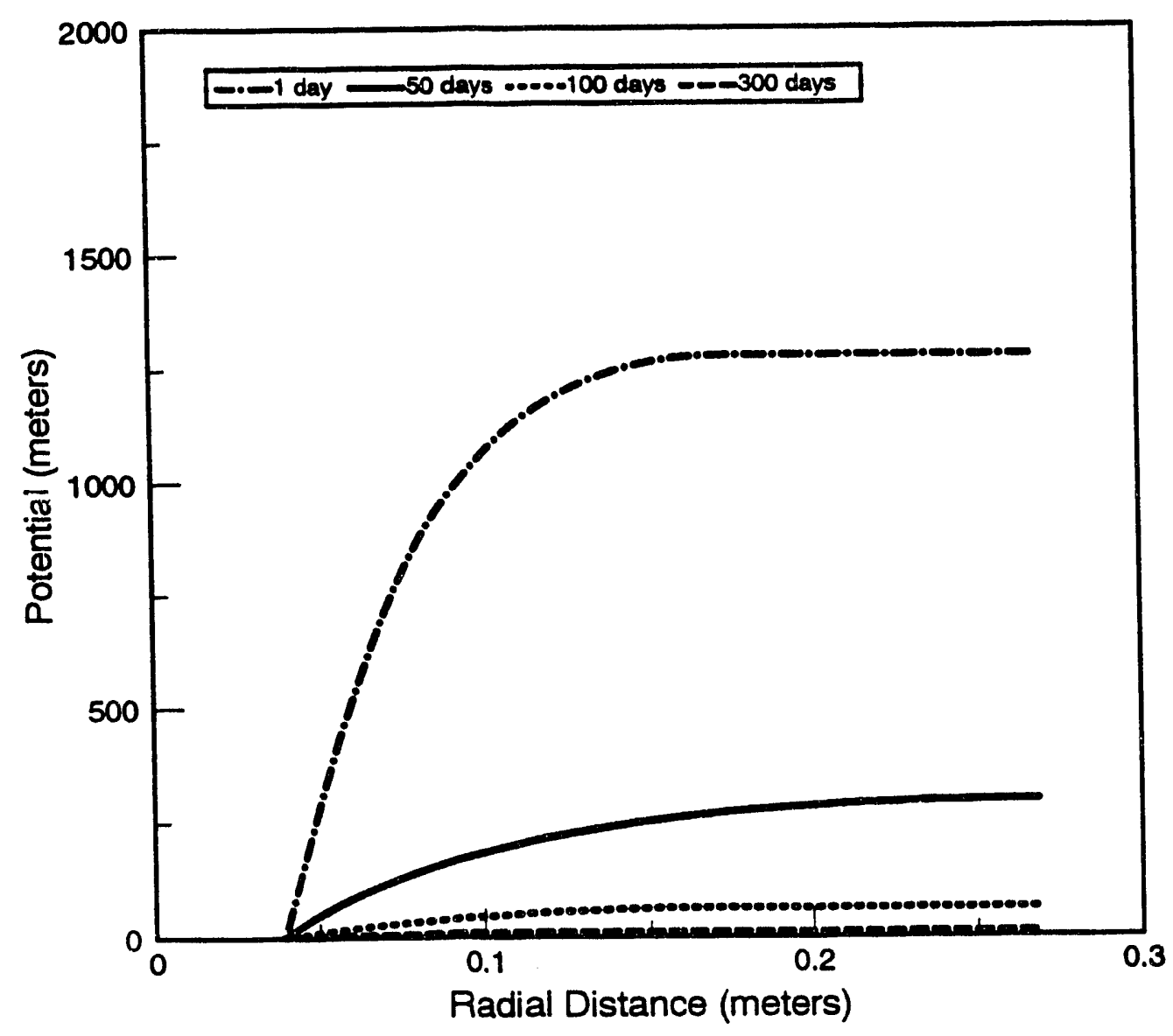

Figure 4-12

Potential Distribution for the Near-Field, High-Intrinsic Permeability (1 nanodarcy, $10^{-21} \mathrm{~m}^{2}$ ), Finite-Difference Model for a 7.6-cm-Diameter Drill Hole 


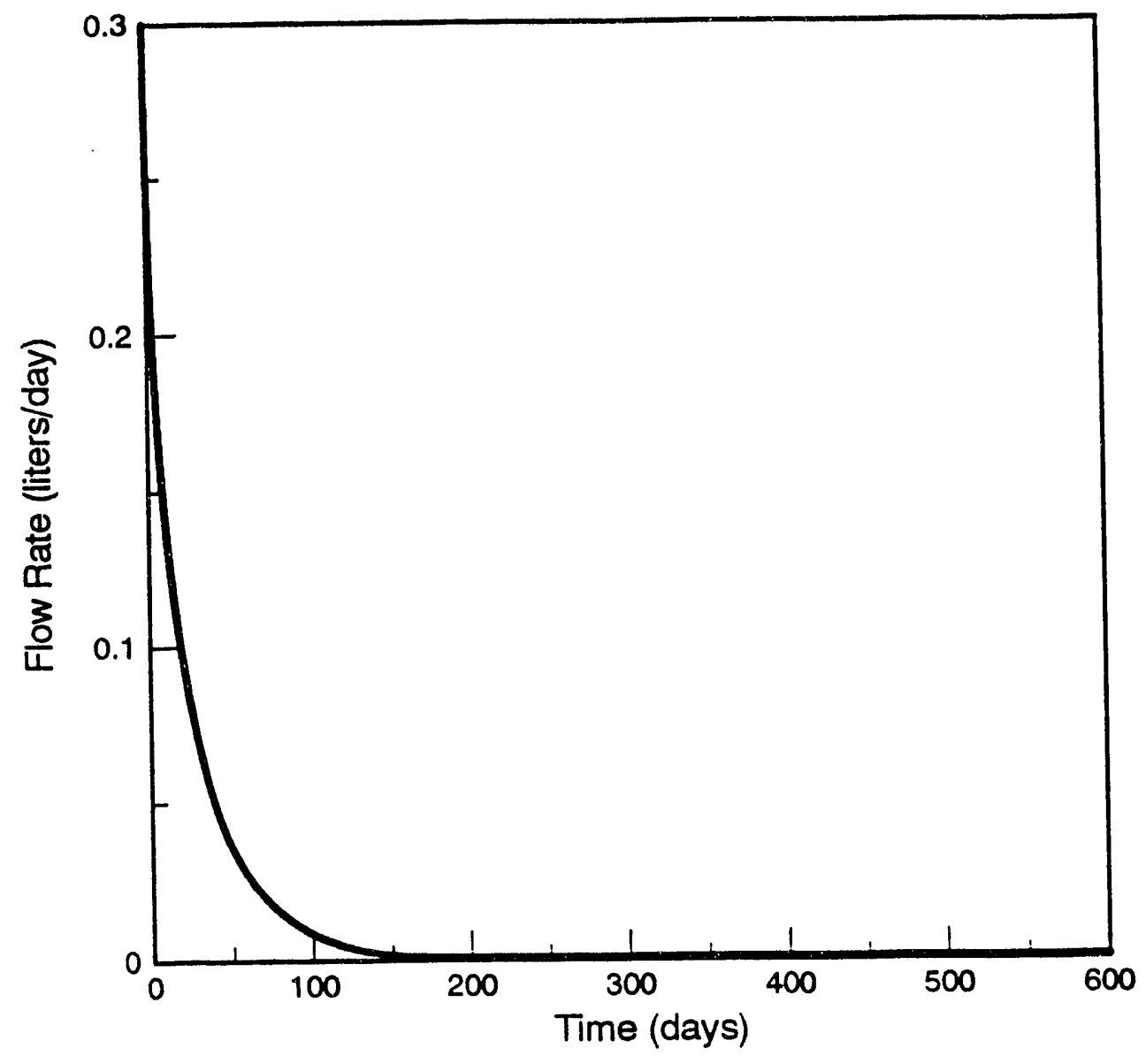

Figure 4-13

Fow Rate Versus Time for the Near-Field, High-Intrinsic Permeability (1 nanodarcy, $10^{-21} \mathrm{~m}^{2}$ ), Finite-Difference Model for a 7.6-cm-Diameter Drill Hole 


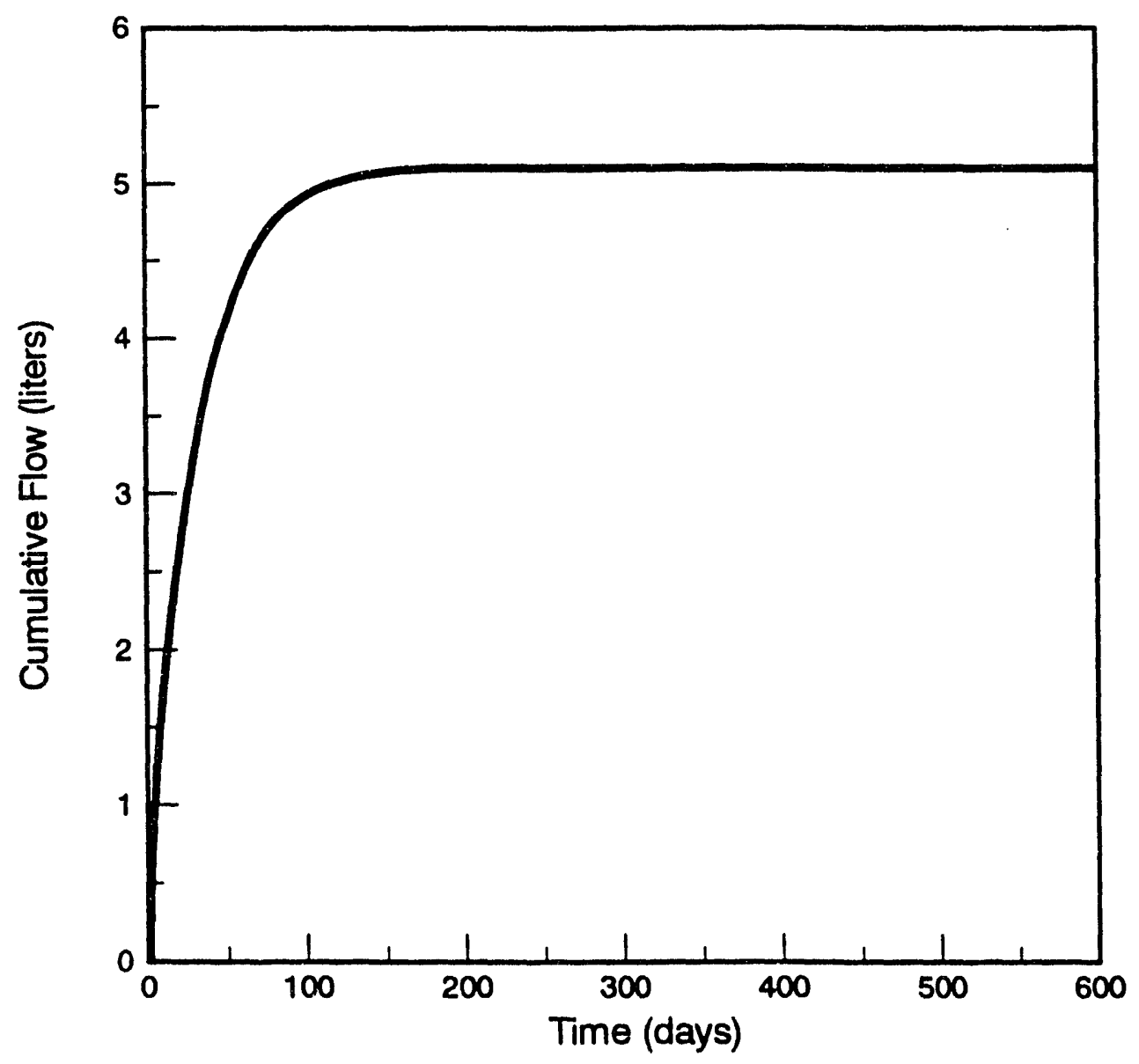

Figure 4-14

Cumulative Flow Versus Time for the Near-Field, High-Intrinsic Permeability (1 nanodarcy, $10^{-21} \mathrm{~m}$ Finite-Difference Model for a 7.6-cm-Diameter Drill Hole 


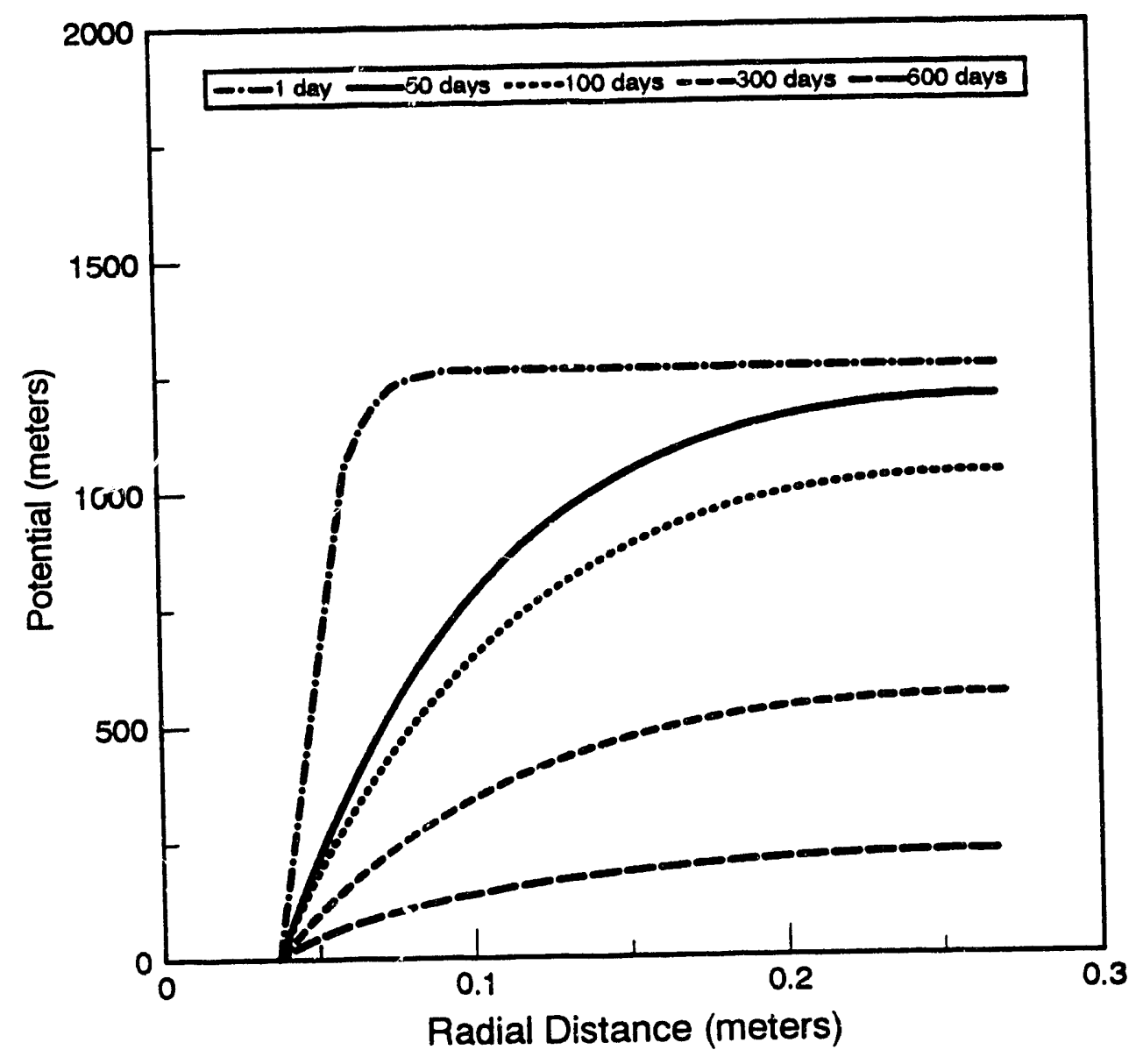

Figure 4-15

Potential Distribution for the Near-Field, Low-Intri nsic Permeability $\left(0.1 \mathrm{n}\right.$. ' 1odarcy, $\left.10^{-22} \mathrm{~m}^{2}\right)$, Finite-Difference Model for a 7.6-cm-Diameter Drill Hole 


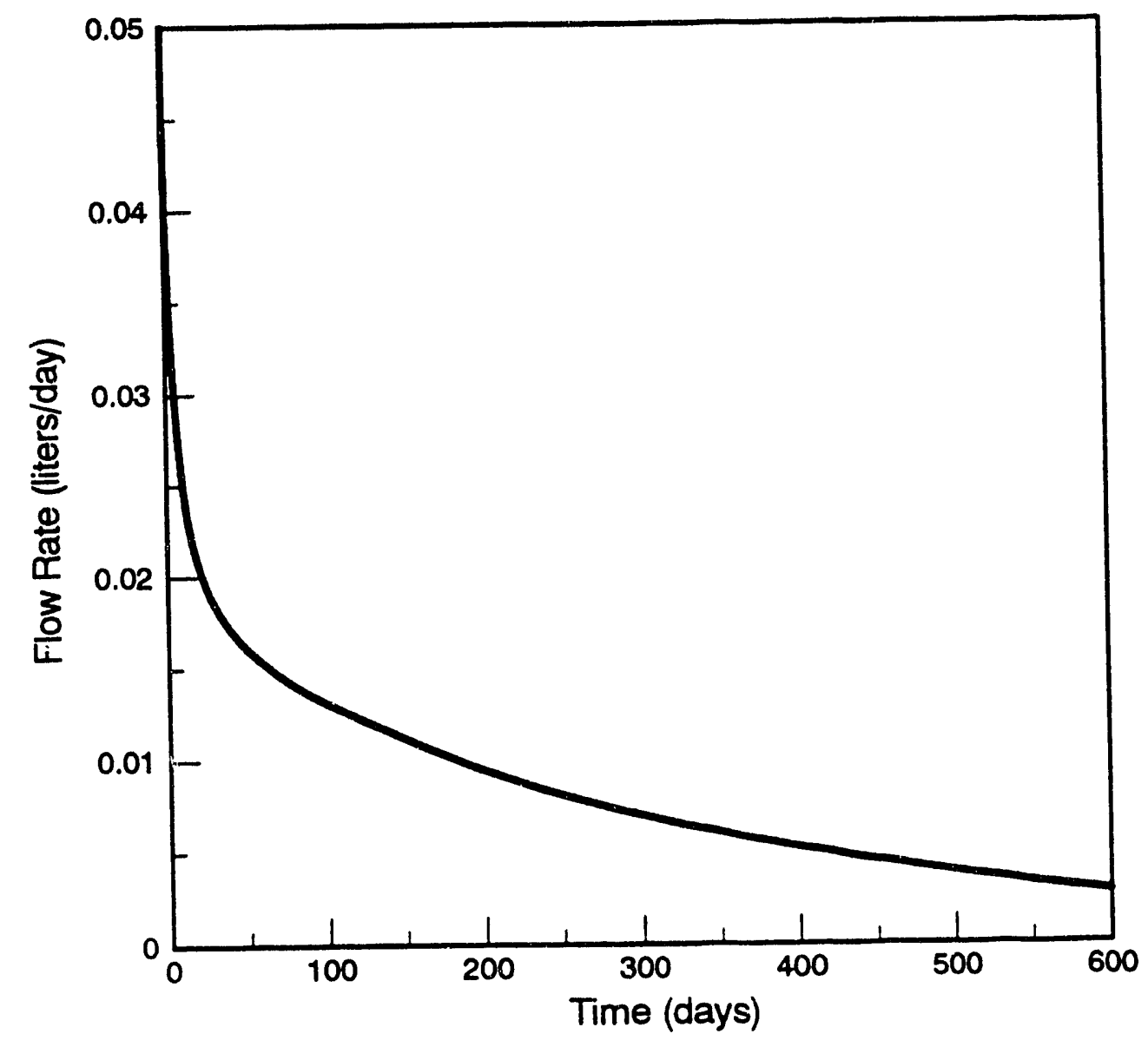

Figure 4-16

Fow Rate Versus Time for the Near-Field, Low-Intrinsic Permeability (0.1 nanodarcy, $\left.10^{-22} \mathrm{~m}^{2}\right)$, Finite-Difference Model for a 7.6-cm-Diameter Drill Hole 


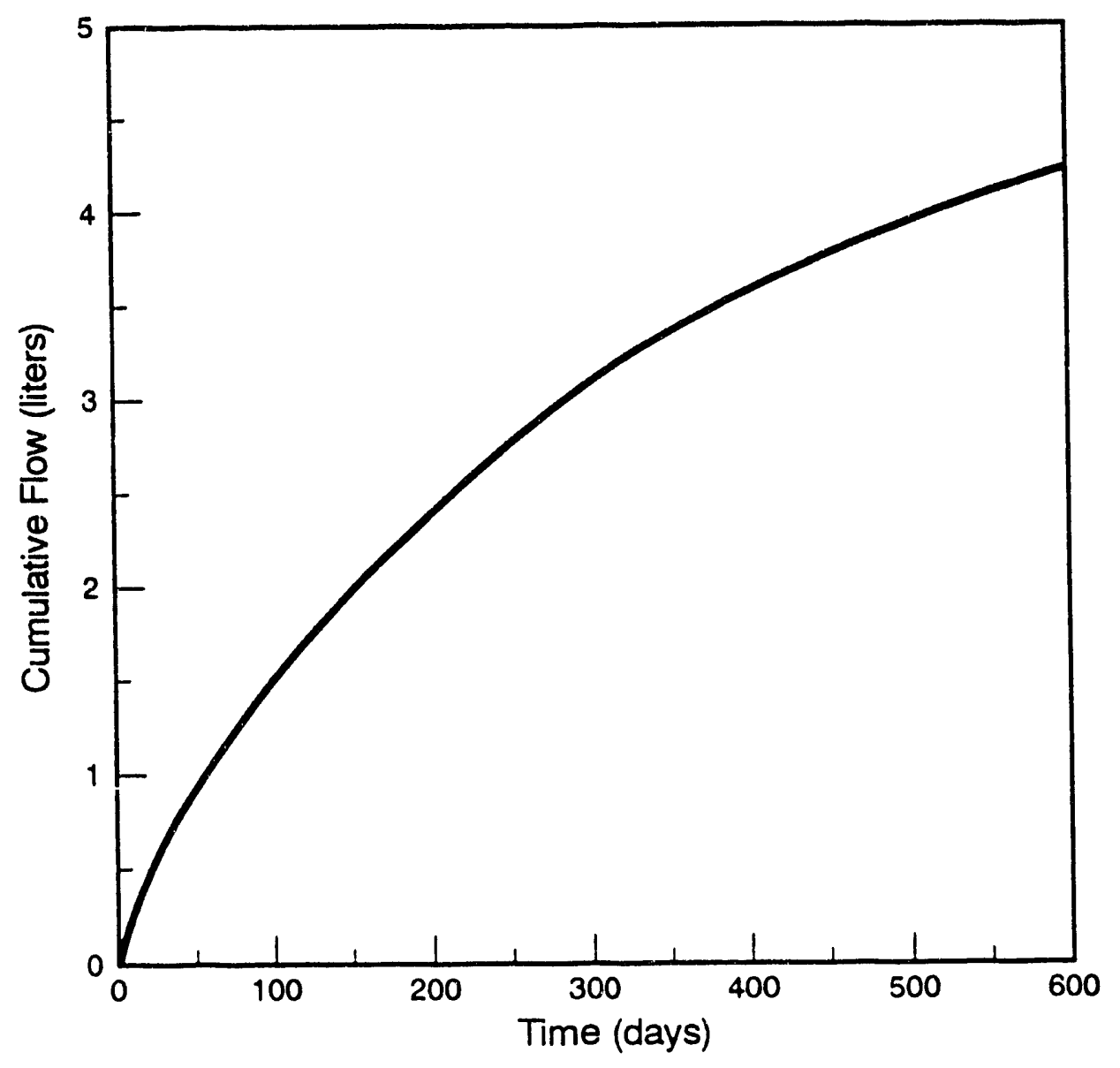

Figure 4-17

Cumulative Flow Versus Time for the Near-Field, Low-Intrinsic Permeability $\left(0.1\right.$ nanodarcy, $\left.10^{-22} \mathrm{~m}^{2}\right)$, Finite-Difference Model for a 7.6-cm-Diameter Drill Hole 
- Development of enhanced porosity within the DRZ. If the porosity increases at a greater rate than the rate at which the brine can fill the voids, then brine will tend to stay within the DRZ and flow into the excavation will be inhibited.

Assuming that expansion of brine is the dominant driving force for flow into the excavation, the amount of brine released from a homogeneous DRZ for various size DRZs may be calculated by applying the relationship (Freeze and Cherry, 1979):

$$
\frac{\Delta V}{V_{0}}=\rho g(\alpha+\phi \beta) \Delta h
$$

where

$$
\begin{aligned}
\Delta V & =\text { Change in fluid volume } \\
V_{0} & =\text { Rock volume of the DRZ } \\
\rho & =\text { Fluid mass density } \\
\mathrm{g} & =\text { Gravitational acceleration } \\
\alpha & =\text { Solid compressibility } \\
\phi & =\text { Porosity } \\
\beta & =\text { Fluid compressibility } \\
\Delta \mathrm{h} & =\text { Change in potential. }
\end{aligned}
$$

The above relationship predicts the total amount of brine to be released from a given DRZ, assuming no contribution from the far-field, without regard to the depressurization rate. The depressurization rate depends on the flow rate, which in turn depends on permeability (see previous section), but the cumulative amount of brine released due to depressurization is independent of flow rate. After depressurization is essentially complete, brine may flow downward under gravity drive and accumulate below the floor of the drill hole or drift. The above relationship provides an approximate value for the volume of brine released to a drill hole at WIPP, assuming a homogeneous medium with the specified compressibility properties and that those properties apply for the entire length of the drill hole.

The volume of the DRZ varies with excavation size. For a 7.6-cm-diameter drill hole, the VISCOT analysis predicts that the DRZ is essentially mature after about 1,100 days at a radius of $0.27 \mathrm{~m}$ (Figure 4-3). From Figure 4-18, a $0.27-\mathrm{m} \mathrm{DRZ}$ along a length of $46 \mathrm{~m}$ will release about $10 \mathrm{~L}$ of brine. For a 3.6-m-diameter shaft (or Room $\mathrm{Q}$ ), the previous VISCOT analysis predicts that the DRZ would mature at a radius of about $12 \mathrm{~m}$ after 1,000 days (Deal and others, 1989, Figure 5-7). From Figure 4-19, a 12-m DRZ along a length of $91.4 \mathrm{~m}(300 \mathrm{ft})$ will release about $30,000 \mathrm{~L}$ of brine. An equivalent $46-\mathrm{m}$ segment would therefore release about $15,000 \mathrm{~L}$ of brine. 


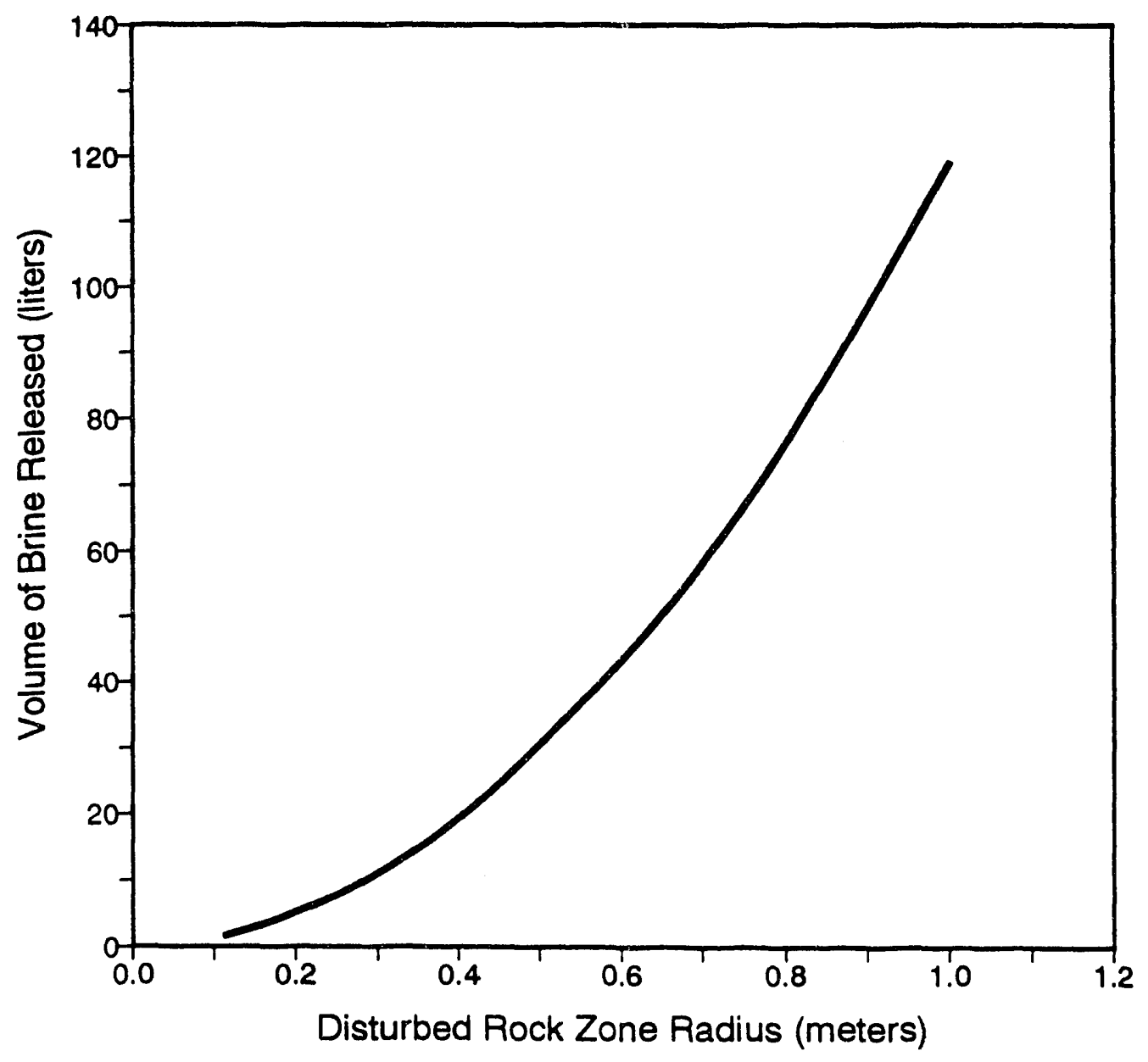

Figure 4-18

Volume of Brine Released from the DRZ for a Borehole-Sized Excavation $46 \mathrm{~m}$ Long 


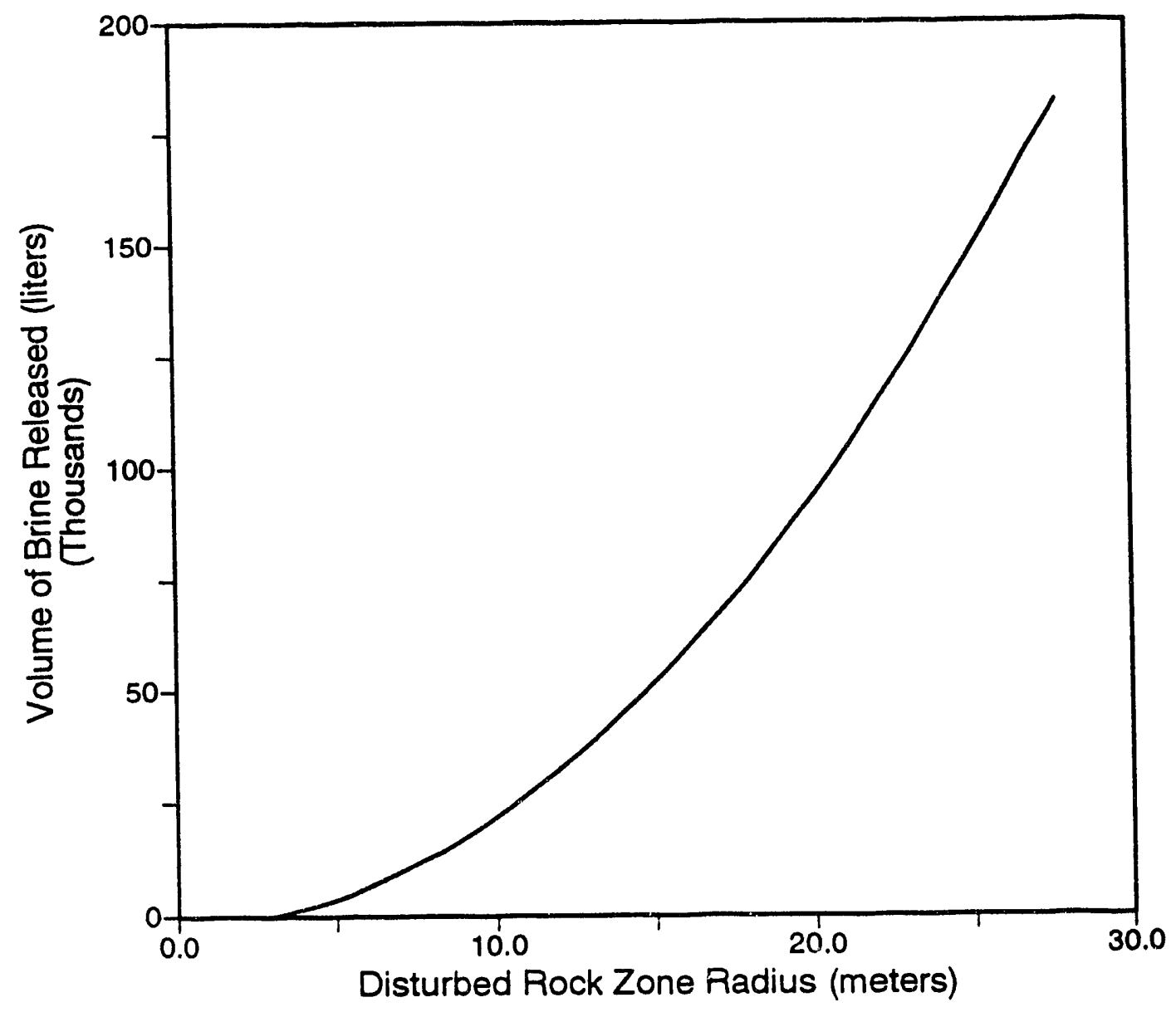

Figure 4-19

Volume of Brine Released from the DRZ for a Shaft-Sized or a Room-Sized Excavation $91.4 \mathrm{~m}(300 \mathrm{ft}$ ) Long 
For a WIPP waste storage room with a $4-\mathrm{m}$-high by $10-\mathrm{m}$-wide rectangular cross section, the equivalent radius is about $5.4 \mathrm{~m}$. If the $\mathrm{DRZ}$ is five times the radius of the excavation, the DRZ around a typical waste storage room would have a radius of about $27 \mathrm{~m}$ and a length of $91.4 \mathrm{~m}$ (300 ft). From Figure 4-19, a 27-m DRZ will release about 150,000 L of brine.

The WIPP EATF postulated that the corrosion of iron, steel, and aluminum alloys requires and consumes brine and if sufficient brine is present, represents a potential source of gas in the repository after closure (DOE, 1991). An analysis was performed for this report (Myers, 1991) of the amount of brine necessary to corrode all of the iron, steel, and aluminum alloys in the drums and waste to be stored in a typical WIPP waste storage room. Assuming that amakinite $\left(\mathrm{Fe}[\mathrm{OH}]_{2}\right)$ is the corrosion product, approximately $220,000 \mathrm{~L}$ of brine will be necessary to completely corrode all of the susceptible metal emplaced in each waste storage room.

The analysis presented above suggests that there may be insufficient brine to corrode all the susceptible metal in the storage rooms or, more specifically, that the available brine limits corrosion, which in turn limits hydrogen product. The EATF analysis (DOE, 1991) shows that the rate-controlling factor for the generation of hydrogen is the availability of the brine, not the rate of the corrosion reaction. This means that the brine is consumed as soon as it contacts the metal and gas pressures build up, further reducing brine seepage.

\subsection{Comparison of Predicted Seepage and Field Observations}

The modeling was initiated in 1987 (Deal and others, 1989) and extended to consider long drill holes in the fall of 1989, when the long drill holes were drilled. Much has been learned since 1987 about the occurrence of brine in the Salado salt and the possible mechanisms that might be driving brine seepage at the WIPP. As a result, some of the assumptions that underlie the modeling may be less appropriate than originally thought. Those assumptions include:

- Flow may be constrained to a relatively few, fairly discrete, bedding planes and radial flow in a vertical plane toward an excavation or drill hole may not occur (Sections 2.3, 2.8, and 4.1).

- Brine preferentially occurs in the more argillaceous beds and is not uniformly distributed throughout the salt (Deal and others, 1989). 
- The undisturbed porosity of the salt is much greater than initially thought (Section 4.2.3).

- The overall permeability of the Salado Formation may be much lower than initially thought (Lappin, 1988; Lappin and others, 1989).

- The permeability of the Salado Formation varies significantly from unit to unit, and the clear halite units may have no measurable intrinsic permeability (Beauheim and Holt, 1990; Beauheim and Howarth, 1991).

- The pore spaces in some of the units may be so small that surface tension forces become significant and Darcy's Law may have to be applied in a modified form (Deal and others, 1989, Figure J-2) or may not hold at all.

- Some previously unsuspected flow mechanism may be acting, such as compaction in the pillars driving brine out of the clays (Deal and Roggenthen, 1991).

One of the more important questions in assessing the brine seepage into the WIPP is to determine what, if any, is the component of brine from the far-field. Two sets of calculations were made using a finite-difference model (refer to Section 4.3). One set of calculations considered far-field flow only (Figures 4-6 through 4-11), and the other set considered nearfield flow only (Figure 4-12 through 4-17). For each case, two different permeabilities were selected, a higher intrinsic permeability $\left(1.0\right.$ nanodarcy, $\left.10^{-21} \mathrm{~m}^{2}\right)$ and a lower intrinsic permeability $\left(0.1\right.$ nanodarcy, $\left.10^{-22} \mathrm{~m}^{2}\right)$.

For far-field flow only, a steady-state inflow rate is eventually reached. This can be seen as a constant inflow rate on the graphs of flow rate versus time (Figure 4-7 and 4-10) and as a uniform slope on the cumulative brine inflow graphs (Figure 4-8 and 4-11). The effect of changing the permeability an order of magnitude is to change the steady-state flow rate an order of magnitude; from $0.1 \mathrm{~L}$ per day for the higher intrinsic permeability to $0.01 \mathrm{~L}$ per day for the lower intrinsic permeability.

For near-field flow only, brine inflow would eventually cease entirely. The same total amount of brine (about $5 \mathrm{~L}$ ) is produced from the DRZ (refer to Section 4.5), as shown in Figures 4-14 and 4-17, which is probably too low a value. Using a more accurate method (Section 4.6), the predicted value is about $10 \mathrm{~L}$. The higher the permeability, the quicker the DRZ drains. For the higher permeability, inflow ceases after about 200 days (Figure 4-13), while for the lower permeability, flow is still occurring after 600 days (Figure 4-16). 


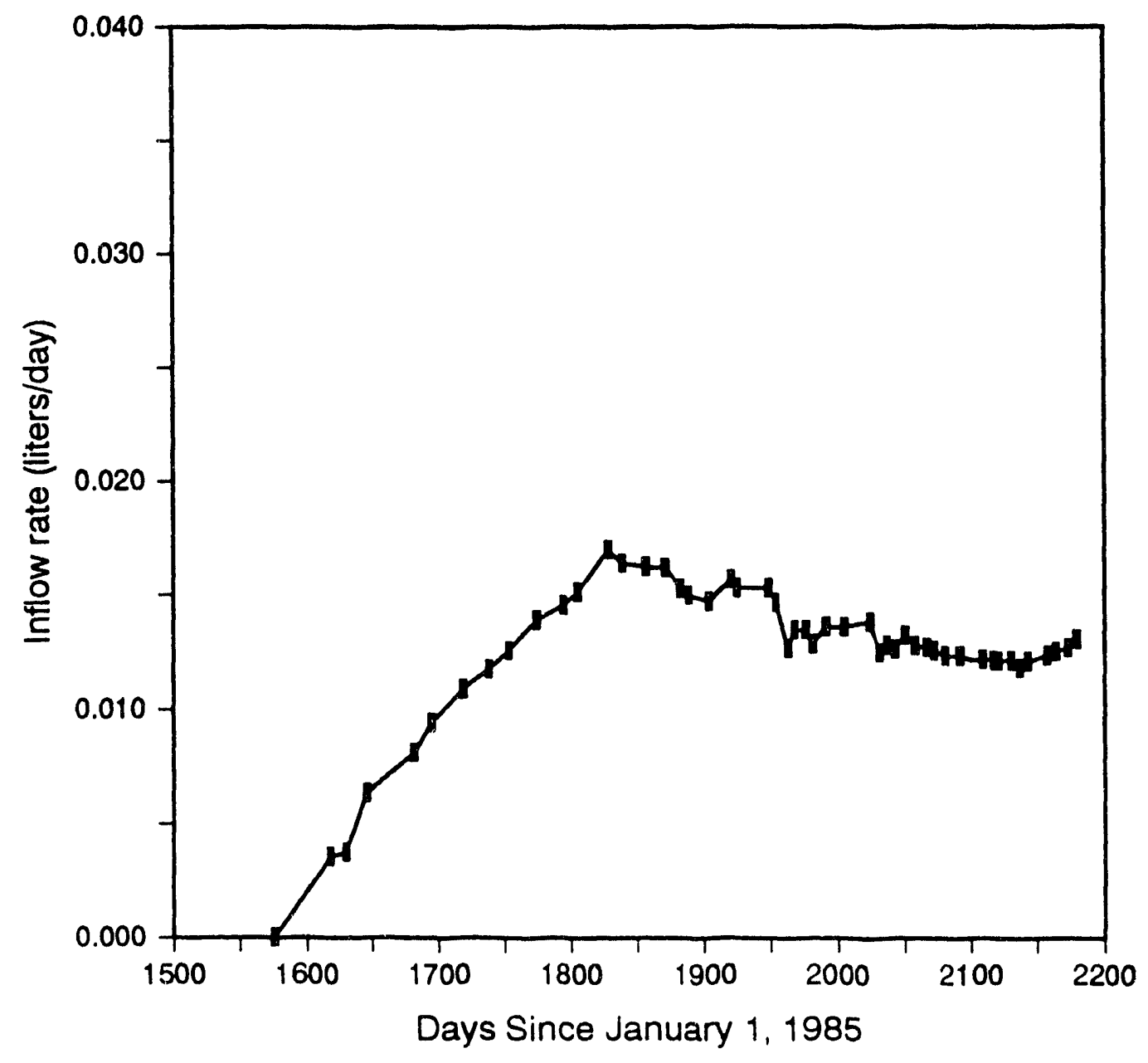

Figure 4-20

Horizontal Drill Hole OH2O

Brine Inflow Rate

Simple 11-Point Moving Average 


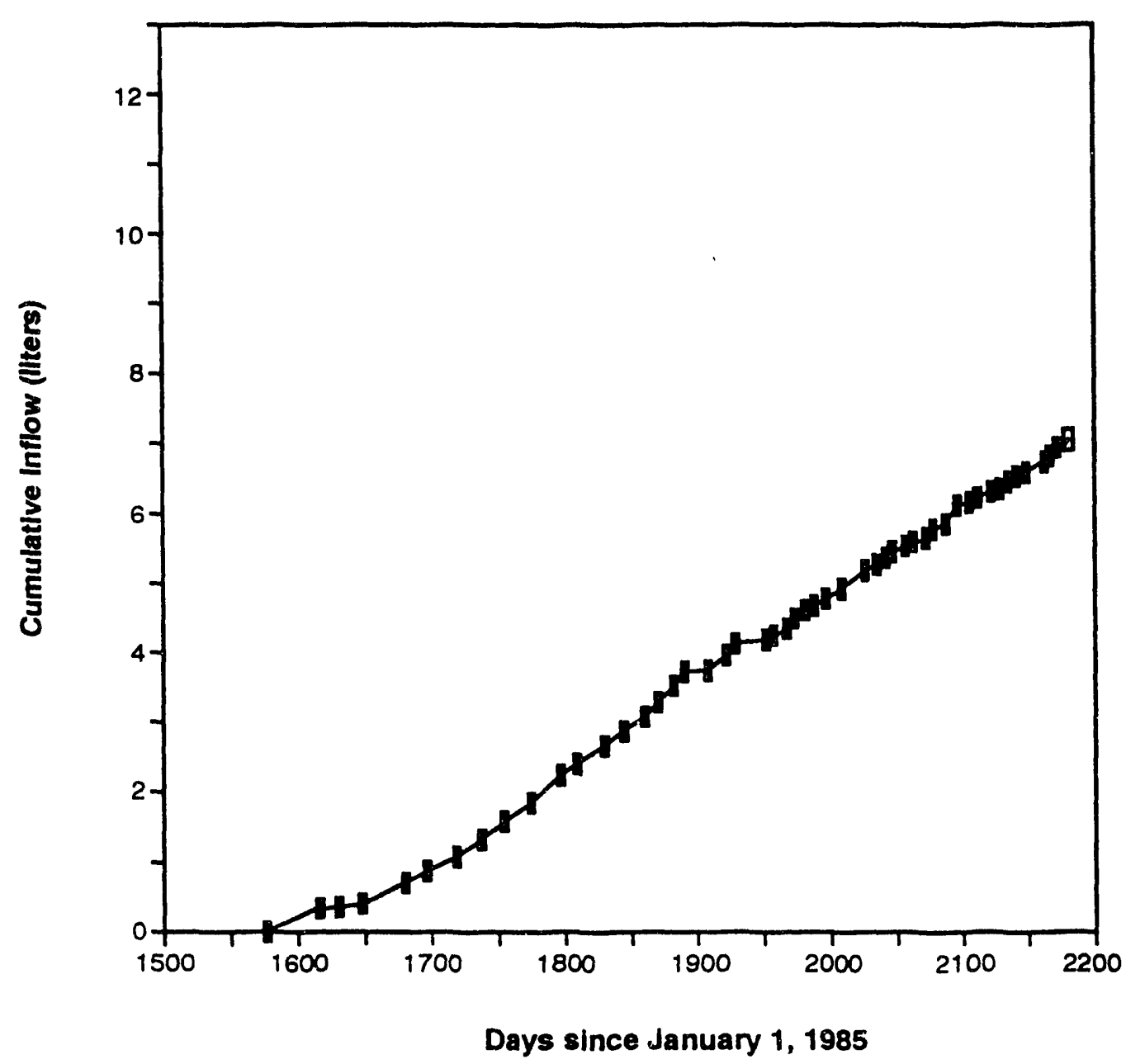

Figure 4-21

Horizontal Drill Hole OH2O

Cumulative Brine Inflow 


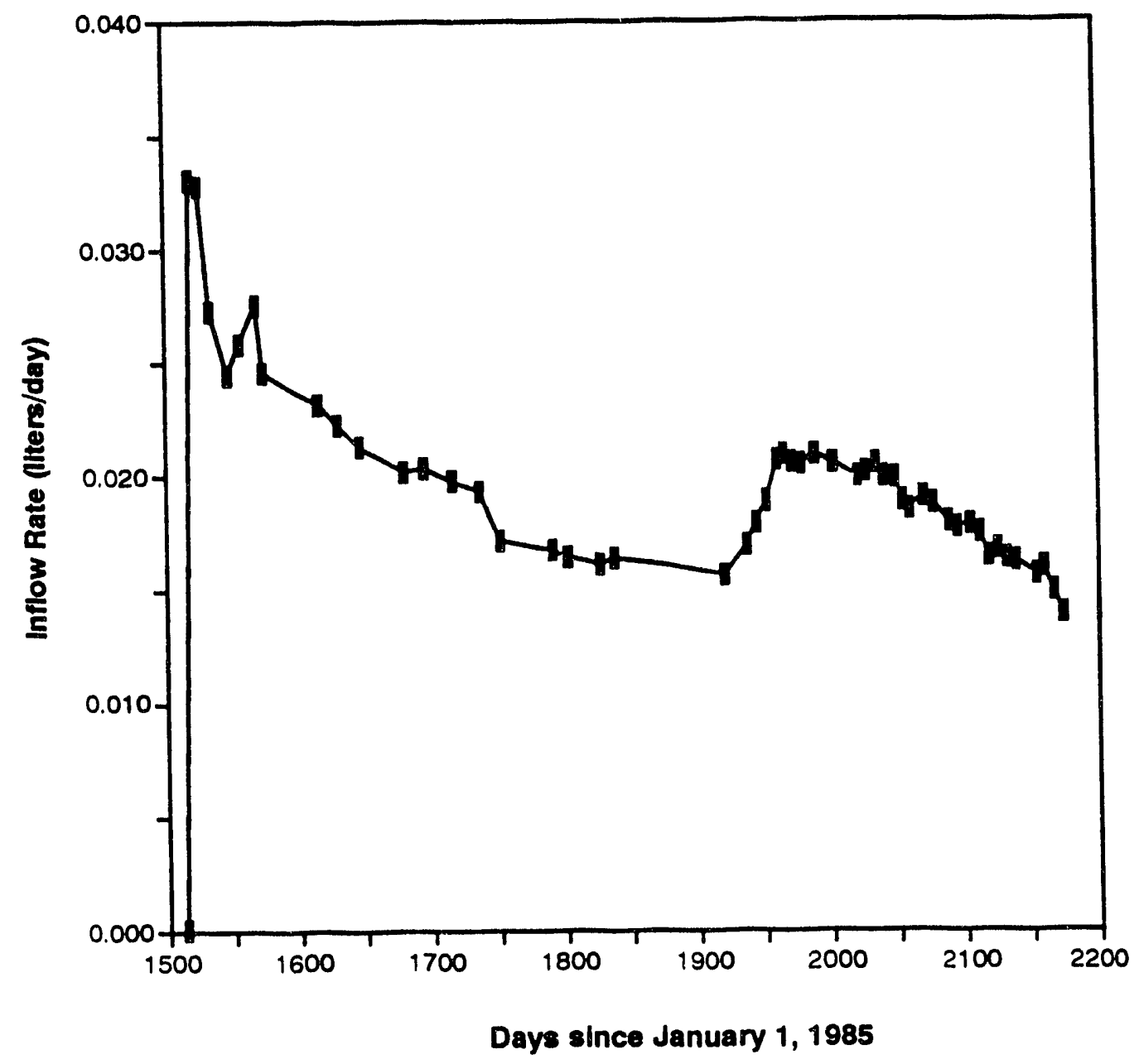

Figure 4-22

Horizontal Drill Hole OH23

Brine Inflow Rate

Simple 11-Point Moving Average 


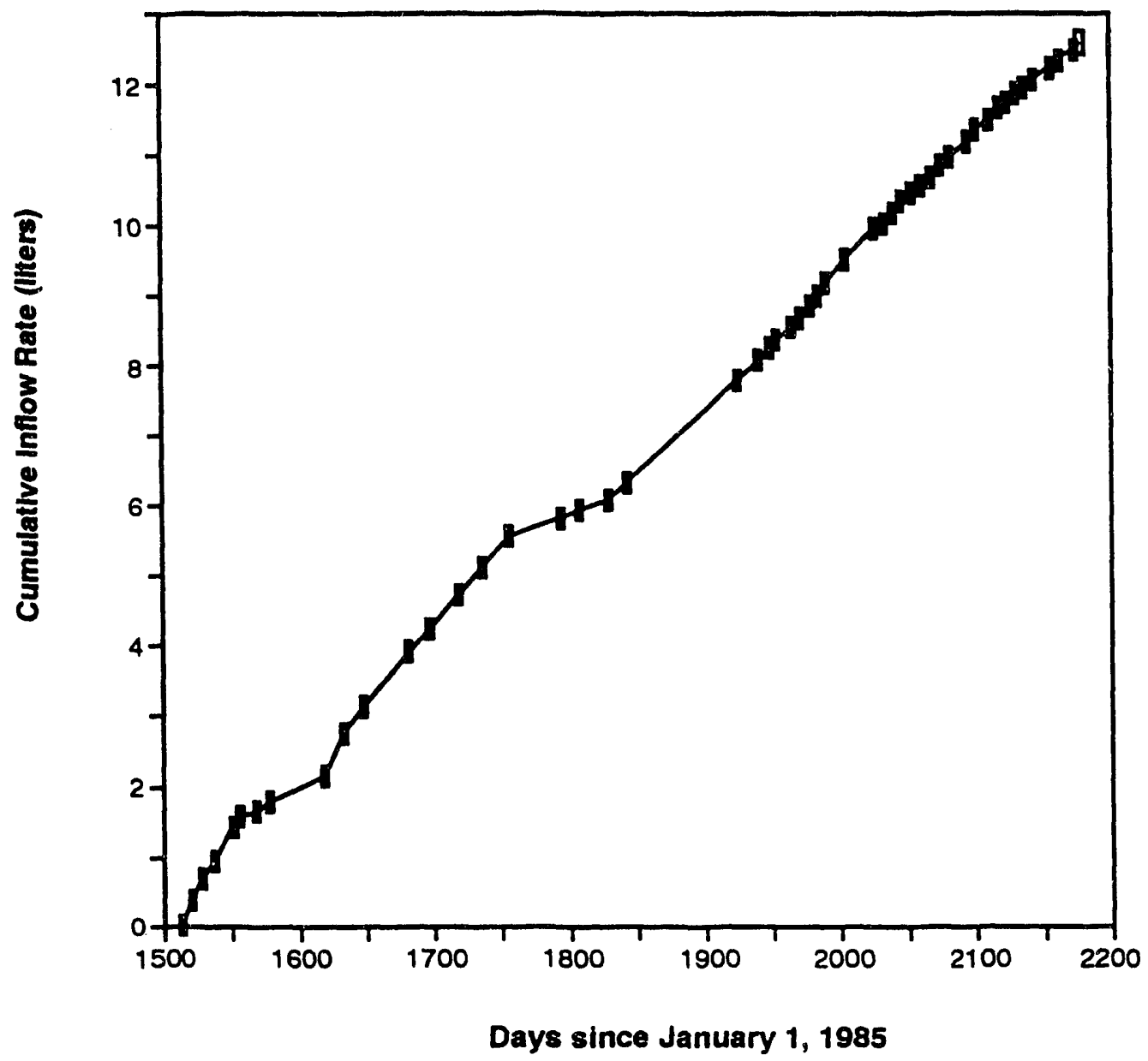

Figure 4-23

Horizontal Drill Hole OH23

Cumulative Brine inflow 


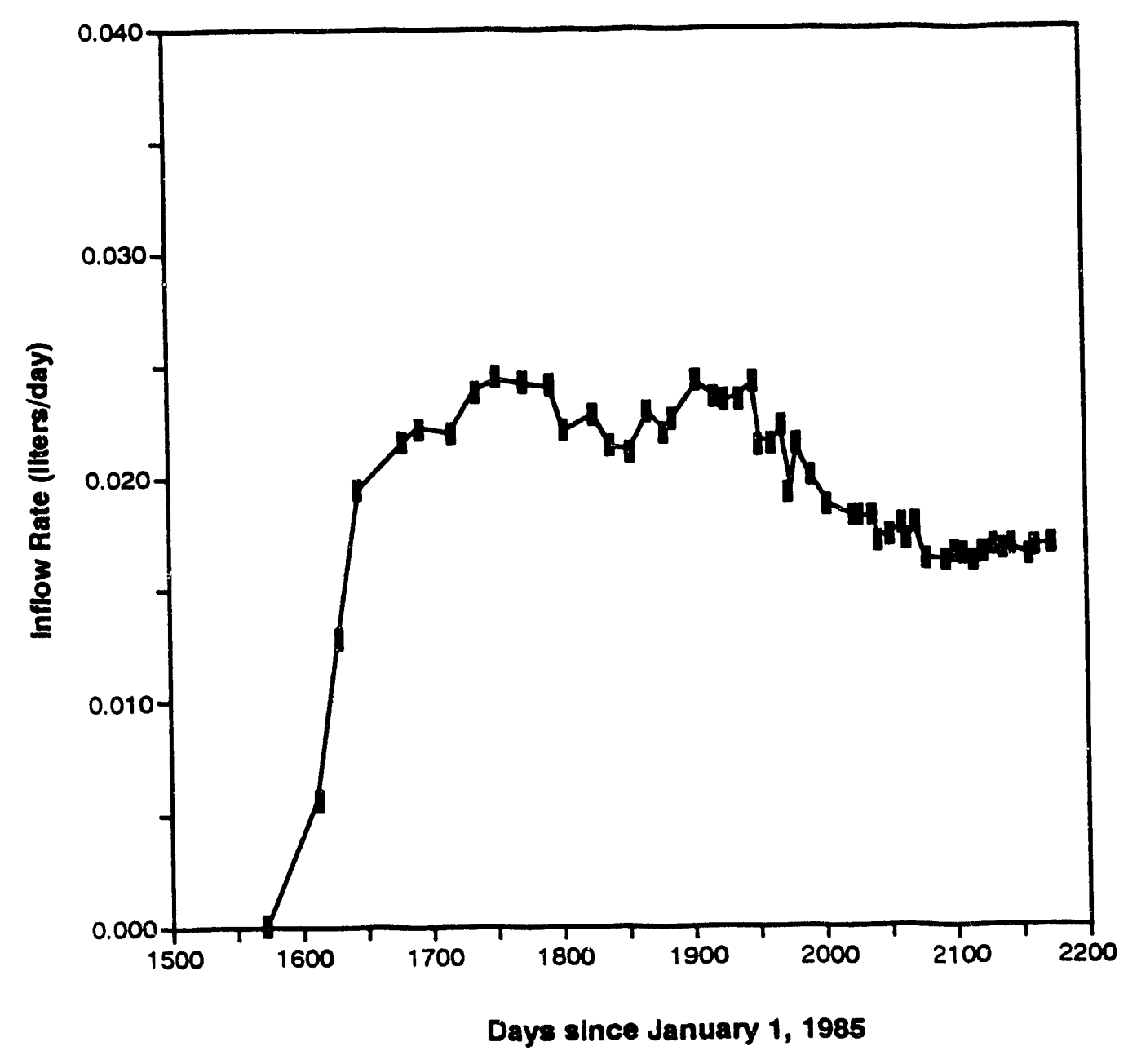

Figure 4-24

Horizontal Drill Hole OH26

Brine Inflow Rate

Simple 11-Point Moving Average 


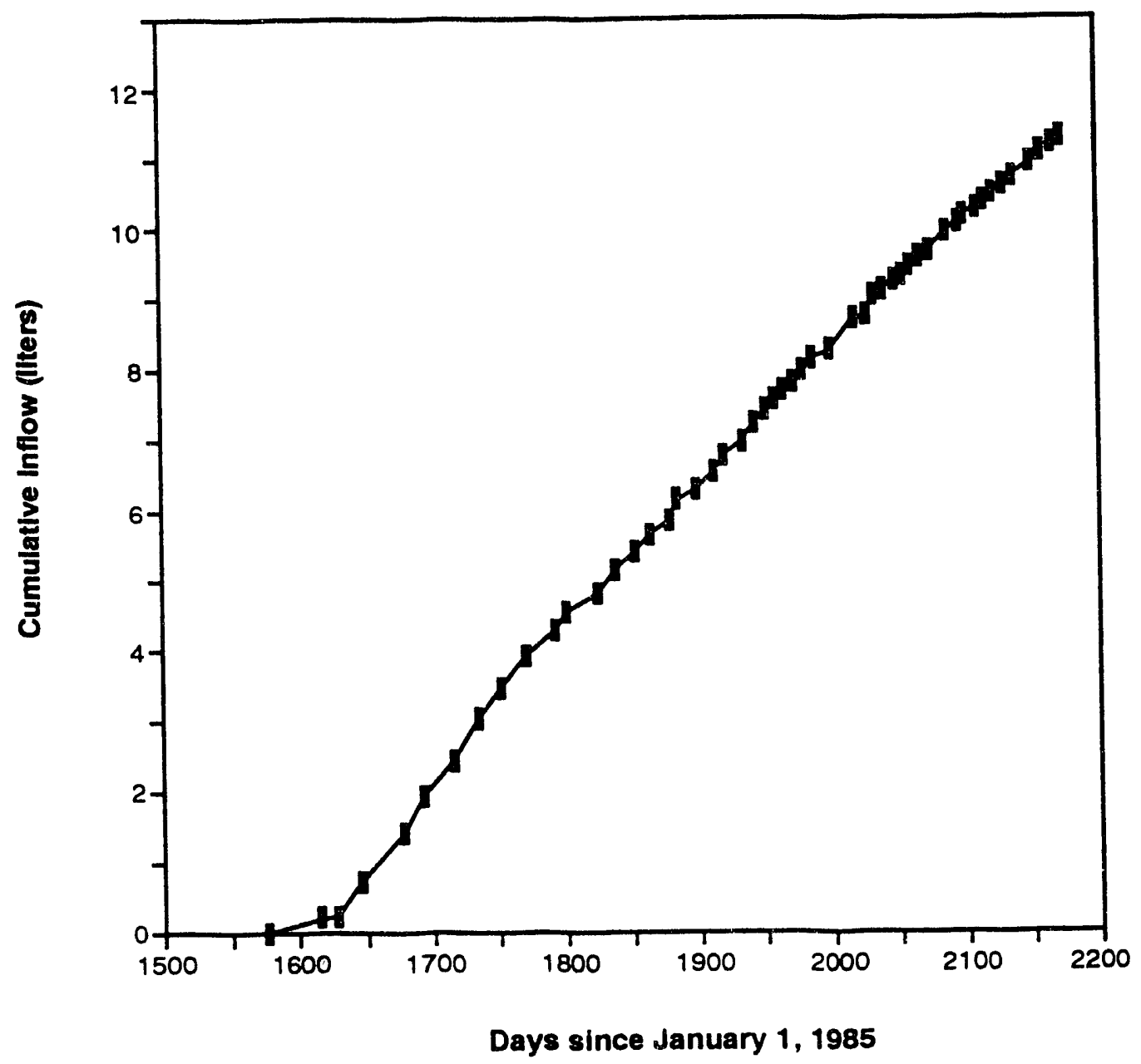

Figure 4-25

Horizontal Dril! Hole OH26

Cumulative Brine Inflow 
Inflow data for the three 46-m drill noles are presented in Appendices A and B. Inflow rate versus time and cumulative brine izflow are shown on an enlarged scale for $\mathrm{OH} 20$

(Figures 4-20 and 4-21), OH23 (Figures 4-22 and 4-23), and OH26 (Figures 4-24 and 4-25). Data span more than 600 days but remain inconclusive. The irregularity shown between day 1,753 ?7d 1,925 on the graphs of OH23 (aromalously low values on Figures 4-22 and 4-23) are the result of incomplete brine collection followed by collection of the residual brine that remained in the hole (refer to OH23 data in Appendix A).

It is clear that in ${ }^{\mathrm{f}} \mathrm{ow}$ is not dropping off as rapidly as predicted by the modeling, even in the case of near-fielc flow only at the lower permeability (Figure 4-16), and that the total volume of brine is greater than expected for near-field flow only. It is possible that even the lowest permeability value used in the modeling is still too high to reasonably represent the conditions at the WIPP. In addition to the fact that the flow mechanisms are more complicated than initially expected, these holes angle downward through several stratigraphic units and the geological complications discussed in Section 2.9 undoubtedly affect the data. Realistically, seepage into the holes may be restricted to only that length of the hole that intersects the orange marker and the thin clay layers above and below it. This thin unit may be more compressibie and porous than the values that were used in modeling.

Data will continue to be collected from these locations as a routine part of the BSEP. If there is a far-field component to the brine seepage, then the inflow to these holes should eventually reach steady-state. If there is no far-field component, then seepage should eventually cease. Additional observation holes have been proposed to resolve some of the remaining uncertainties and to consider various relevant aspects separately (Appendix E).

\subsection{Conclusions}

Several models have been developed for evaluating brine seepage into long subhorizontal drill holes to provide assistance in interpreting brine flow mechanisms. The measurements from the three 46-m subhorizontal drill holes provide the most uniform and comparable set of measurements yet obtained in the BSEP. The VISCOT modeling results suggest a DRZ extending several tenths of a meter from the drill hole, with only slight increases in porosity and permeability. The BISCITS and simple finite-difference modeling results suggest that flow occurs from the near-field over a period of about 50 to 150 days, after which flow is dominant from tre far-field. The estimated time period necessary to distinguish between farfield only and near-field only flow is of the order of years at the drill hole scale rather than tens of years at the room scale. 
Since a period of about 600 days has elapsed and flow rates are becoming relatively constant, comparisons between predicted and measured flow rates suggest that the far-field model with a lower permeability may be appropriate. It is premature to conclude this, however, as the extent of the DRZ is estimated, and a larger DRZ would require a greater amount of time before flow was dominant from the far field. It is also possible that even the lowest fermeability value used in the modeling is too high to reasonably represent the conditions at the WIPP. Using a lower permeability value would result in lower inflow rates and a longer time needed to distinguish between far-field and near-field flow. Additionally, there are enough concerns about the appropriateness of some of the modeling assumptions, so that the observed discrepancies between the observed data and the modeling predictions may fall within the modeling error. As better data become available from ongoing experiments at the WIPP, the modeling predictions will become more accurate. 


\subsection{Summary and Conclusions}

After more than eight years of observations (1982-1990), no credible evidence exists to indicate that enough naturally occurring brine will seep into the WIPP excavations to be of practical concern. The detailed observations and analyses summarized herein and in previous BSEP reports confirm the evidence apparent during casual visits to the underground workings-that the excavations are remarkably dry.

\subsection{Brine Observations}

There are traces of brine within the host rock that seep into new excavations, but all evidence iridicates that such seeps are most active in the first year or two after excavation of a new opening (refer to Section 2.2). After the drifts and rooms have been open for a few years, very little brine, if any, continues to seep into them. Most of the brine on the surfaces is evaporated into the air circulated for ventilation. This fact is documented by the lack of evidence of significant moisture in the south exploratory drift (refer to Section 2.6), the cessation of both brine weeps and growth of salt encrustations on vertical surfaces (refer to Sections 2.2 and 2.3), and the overall evidence of general dryness throughout the workings. Modeling of a shaft-sized opening (or a horizontal tunnel the size of Room Q) predicts that the porosity of the salt increases in the DRZ faster than brine can flow in to fill the pores (Deal and others, 1989, Section 5.11), that much visible brine inflow is unlikely, that brine can accumulate in the expanded pores beneath drift floors, and that it is impossible to distinguish between far-field and near-field flow until more than 30 years of inflow observations have been made. The modeling predicts that close to the walls of the shaft or Room $\mathrm{Q}$, the relative increase in porosity is about 40 percent. Fracturing around the WIPP excavations (Figure 2-8) further increases the pore spaces in the DRZ available to store brine (the so-called hidden brine beneath the floor) (refer to Section 2.7.1). Chemical evidence, however, indicates that much of the brine observed in downholes beneath the floor of the repository has been introduced during construction activities to control the salt dust for health and human safety considerations (Deal and others, 1989; Deal and Roggenthen, 1991) and is not brine that has seeped out of the host rocks. There is one location in Roum G (refer to Section 2.5) where a brine seep has occurred, but this brine has probably been diluted by artificial brine spread to control salt dust in the $G$ Access drift and has been modified by partial evaporation.

Small amounts of brine continue to seep into downholes where no water has been spread for dust contiol (iefer to Section 2.7). Seepage rates into these locations, especially the larger 
producers, are declining. Seepage rates into downholes may be misleadingly high when compared to expected seepage into waste storage rooms, because downholes cut stratigraphic units that are more moist than the units exposed at the facility horizon (refer to Section 2.7.2).

Fractures are common in the WIPP underground, and fracture systems locally connect brinefilled drill holes at some drift intersections (Deal and others, 1991, Section 4.4.1); however, extensive, large-scale hydrologically interconnected fracture systems apparently do not exist under much of the WIPP excavation, as evidenced by the fact that brine stands at different levels in closely spaced drill holes in the floor (Morse and Hassinger, 1985; Deal and Case, 1987, Appendix D, Section 3.5; Deal and others, 1989, Section 2.1.2.6) and that brine is not seeping out of fractures observed in the Salt Handling Shaft and Waste Handling Shaft sumps (refer to Section 2.7.1). Most of the north end of the workings (the experimental area) slopes down toward these two sumps, and considerable brine (thousands of liters) has been spread over that area (with the exception of Rooms A1, A2, A3, B, D, and G) for salt-dust control and floor consolidation. This obs'rvation that no brine is seeping out of the fractures observed in the sumps also confirms that little brine has seeped out of the host rock into the fracture system under the experimental part of the excavations. That fracture system has, on occasion, been filled to the level of the floor by construction water. No brine is draining out of the downslope fractures, and there is little evidence of brine in the E0 drift north of the Salt Handling Shaft. If additional brine seeped out of the host rock, it would be expected that some of that brine would come to the surface of the EO drift to form more wet areas and salt crusts than exist. The implication that little brine seeps out of the host rock is corroborated by the fact that there is practically no evidence of moisture in the south exploratory drift (refer to Section 2.6).

\subsection{Origin of the Brine}

Brine is present in the host rocks between crystals (both salt and clay), within fractures and pores, as fluid inclusions inside crystals, and as bound water of hydration. A fundamental question is whether these brines originated as residual, connate water or as infiltrating groundwater. Major-element composition (Stein and Krumhansl, 1986, 1988; Deal and others, 1989; Abitz and others, 1990; Deal and Roggenthen, 1991) of the WIPP brines indicates an origin from evaporating sea water that had precipitated salts (largely gypsum, anhydrite, and halite). The residual fluids were then modified over geologic time by digenetic reactions with rock-forming minerals (mostly gypsum, hydrous magnesium salts, and polyhalite) and by ion-exchange with clay minerals. High magnesium and bromine content argue persuasively that these brines originated as residual fluids, not as infiltrating 
groundwater that subsequently dissolved salt. If Salado sait is dissolved in fresh water, the resultant brine is low in magnesium and bromine because there are essentially none of those compounds in the salt; those ions remained behind in the Permian sea as the halite was precipitated.

The major-element composition of brines recovered from downholes is distinct from that of fluid inclusions in WIPP halite (Stein and Krumhansi, 1986 and 1988), suggesting no mixing and little movement of the brines. This observation also indicates that the brine recovered in downholes is largely intergranular fluid, and not intragranular fluid released by migration of fluid inclusions to grain boundaries by stress relief. This interpretation is supported by the field observations that the fluid inclusion brines remain stationary, except in the very rare case when macrofracturing intersects an inclusion. Estimates of the amount of fluid-inclusion brine range from 0.22 weight percent (Black and others, 1983) to 0.6 weight percent (Stein, 1985) and are clearly a minor portion of the WIPP host rocks. Macrofractures generally occur as discrete and fairly wide-spaced fractures (refer to Section 2.7.1; Bechtel, 1986) and intersect relatively few fluid inclusions. The total volume of brine expected to be released from fluid inclusions by fracturing when compared to the volume of the excavations appears minuscule.

Water is also present in the WIPP host rocks as bound water of hydration, especially in clay and hydrous magnesium salts. The contact-handled transuranic (CH-TRU) waste that will be emplaced at the WIPP will produce only very small amounts of heat and will not raise the ambient temperature high enough to liberate water of hydration or cause significant thermally driven migration of brine inclusions toward the storage rooms. No significant heat sources presently exist at the WIPP, so neither of these two processes are sources for the moisture in the WIPP brine seeps.

Water is also present within the clays between individual crystals. The clays within the Salado Formation are underconsolidated (Deal and Roggenthen, 1991) and may contain over 20 percent moisture by volume. The compositional difference between the brine seeps and the fluid-inclusion brines support the interpretation that the two different brines have been in contact with different geologic materials. This is consistent with the concept that the brine that seeps into the excavations is squeezed out of the underconsolidated clays in the host rocks (Deal and Roggenthen, 1991). 
Some clear halite units with no clay produce at least some brine when the confining pressure is reduced. Deal and Case (1987, Appendix D, Section 3.3.7) describe a core from Room B where a clear halite unit below MB 139 was visibly wet when removed from the core barrel. Brine then dripped from the fresh core. This brine was not associated with clays and was probably intergranular brine residing in spaces between salt crystals or was from microfractures within crystals. The release of this brine was probably gas-driven and not simply due to depressurization of the salt and brine. This observation indicates that some brine not associated with clay can seep into the excavations.

\subsection{Hydrologic Systems}

Possible brine inflow systems have been discussed in previous BSEP re'urts and in Chapter 1 of this report. There are basically two systems: one in which far-field flow occurs through undisturbed rock outside of the zone of rock deformation (DRZ) and a local near-field system where brine is redistributed within the DRZ. Additional effects-such as gas exsolution, development of enhanced porosity and permeability within the DRZ, and preferential flow along bedding planes-may modify brine inflow, but it is fundamentally important to distinguish between far-field sources and local, relatively limited redistribution of brine in the immediate vicinity of the WIPP excavations (refer to Chapter 1). In both cases, the driving mechanism is the pressure gradient caused by the excavation of the underground openings. Flow pathways are through permeable interbeds, along stratigraphic discontinuities, or through fractures.

There is no evidence for far-field flow toward the WIPP repository. Not only is it unlikely due to the plastic nature of the salt (Deal and Roggenthen, 1991), but the chemistry of the brine seeps shows that they could not originate from infiltrating fresh water (refer to Section 5.1). If there is no far-field component of flow, then the volume of brine available to seep into the WIPP is finite, and seepage is limited. It has long been recognized that in finegrained materials with low permeability, Darcy's Law (a linear, empirical relationship) no longer holds (Swartzendruber, 1962; Bolt and Groenevelt, 1969). WIPP host rocks have very low permeability, which are below detection limits in the clear halite units. It has also been suggested that there may be a threshold hydraulic gradient below which flow is not possible in low permeability materials (Freeze and Cherry, 1979; Deal and Roggenthen, 1991). The driving gradients around a newly excavated opening decrease rapidly with time (Deal and others, 1989, Chapter 4) and may reach values below the threshold within a few years, limiting brine seepage to the operational phase. Ventilation of the underground openings during operations will remove most of that brine by evaporation. 
Observations to date suggest that the WIPP brine seeps are part of a system dominated by near-field effects and involving compaction of underconsolidated clays. The clear halite beds in the WIPP host rocks are effectively impermeable (refer to Section 2.3; Beauheim and Holt, 1990; Beauheim and Howarth, 1991). Deal and Roggenthen (1991) suggested that because the clay minerals in the Salado Formation were quickly sealed within impermeable halite beds, normal compaction as a result of increased lithostatic pressure with continued burial was limited until the excavations were created. Deformation due to salt-creep dilation enhanced permeability and allowed the underconsolidated clay to lose water to the excavations. This hypothesis assumes that stress redistribution as a result of excavation increases vertical loading (which may exceed twice lithostatic) in the pillars between the excavated rooms and drives brine out of the clays. The brine then moves along generally horizontal flow paths to the openings at atmospheric pressure.

\subsection{Development of the Deformational Environment}

At repository depth, salt deforms plastically. Studies undertaken during the BSEP (Deal and Case, 1987; Deal and others, 1987; Deal, 1988; Deal and others, 1989; Deal and Roggenthen, 1989; Deal and others, 1991; and Chapter 4 of this report) were directed primarily toward the environment in and directly adjacent to the underground excavations. These studies and others (Bechtel, 1986; Borns and Stormont, 1988; Francke and others, 1989; Francke and others, 1990) show that the rock immediately surrounding the excavation has been significantly altered from its original state due to the deformation induced by the excavation and the movement of salt toward the excavation. There is no evidence that flow has occurred prior to the excavation of the WIPP openings. The excellent exposures in the WIPP underground show delicate sedimentary structures in near-horizontal beds, essentially undisturbed since Permian time. If deviatoric stress (necessary to move fluids laterally through these beds) had existed any time since burial, the salt itself would have deformed laterally under that same deviatoric stress because the salt is plastic. This has not occurred; therefore, no fluid migration has occurred prior to the development of deviatoric stress accompanying excavation.

The deviatoric stress causes the salt to creep into the new excavations and for a halo of deformation to form around them, whether they are rectangular or circular in cross section. Borns and Stormont (1988) and Deal and Roggenthen (1991) discuss how this halo of deformation develops around underground excavations at the WIPP. The deformation is commonly described as the DRZ. Deal and Roggenthen (1991) indicate that there are generally two parts to the deformational envelope around underground excavations in salt: an 
outer zone with plastic deformation, dilatency, microfracturing, and pore pressures above atmospheric (zone $\mathrm{C}$ in Figure 5-1), and an inner zone characterized by elastic deformation, macrofracturing, and pore spaces where the pressures are at or close to atmospheric (zone B in Figure 5-1). Some authors treat the inner zone, which includes the volume of rock that has separated (decoupled) from the host rock, as simply a growing part of the excavation comprising the active opening (or actual opening) (Mraz, 1980). A transition from plastic to elastic deformation occurs (Karman, 1911; Jaeger and Cook, 1969) at the C-B boundary, and brittle failure occurs in zone B. This is analogous to glaciers with plastic flow at a depth and a brittle surface skin where crevasses form. Brine moving toward the excavation behaves differently in the $\mathrm{B}$ and $\mathrm{C}$ zones, and it is important to consider both of them when discussing brine seepage into the WIPP excavations.

The deformational pattern is complicated by the effects of geometry and stratigraphy. The salt at the WIPP originated as a stratified and bedded sedimentary rock and consists of alternating sequences of halite, argillaceous halite, polyhalitic halite, clay layers, and thin anhydrite beds (Figure 2-4). As a result of this depositional history, there are numerous stratigraphic discontinuities. There are clay partings and thin $(1$ to $3 \mathrm{~cm})$ clay beds, as well as beds of anhydrite ranging from a few millimeters to 1 meter or so in thickness. The anhydrite beds are brittle and do not deform plastically at repository depths. Typical storage rooms are $4 \mathrm{~m}(13 \mathrm{ft})$ high and $10 \mathrm{~m}(33 \mathrm{ft})$ wide.

There is clear evidence that the excavation geometry around the openings at the WIPP is modified during deformation by these discontinuities and inhomogeneities. Roof and floors fail by heaving, separation along clay seams, and the development of macrofractures in ribs (Bechtel, 1986; Francke and others, 1990; Deal and Roggenthen, 1991). The pattern of fracturing and deformation observed at the WIPP is shown in Figure 2-8, and the effect on the development of zones B and C is shown in Figure 5-2.

\subsection{Flow Conditions}

As indicated in Section 2.3, the unfractured clear halite beds are essentially impermeable. State-of-the-art permeability testing (Beauheim and Holt, 1990; Beauheim and Howarth, 1991) was unable to measure any permeability, indicating that if it exists at all, intrinsic permeability of the clear halite units is less than $1 \times 10^{-23} \mathrm{~m}^{2}(0.01$ nanodarcy). Those halite units that contain a small percentage of clay are more permeable, typically less than $1 \times 10^{-20} \mathrm{~m}^{2}$ (10 nanodarcies). The permeability of the interbedded anhydrite units is several orders of magnitude greater, typically between $1 \times 10^{-19}$ and $1 \times 10^{-18} \mathrm{~m}^{2}$. 


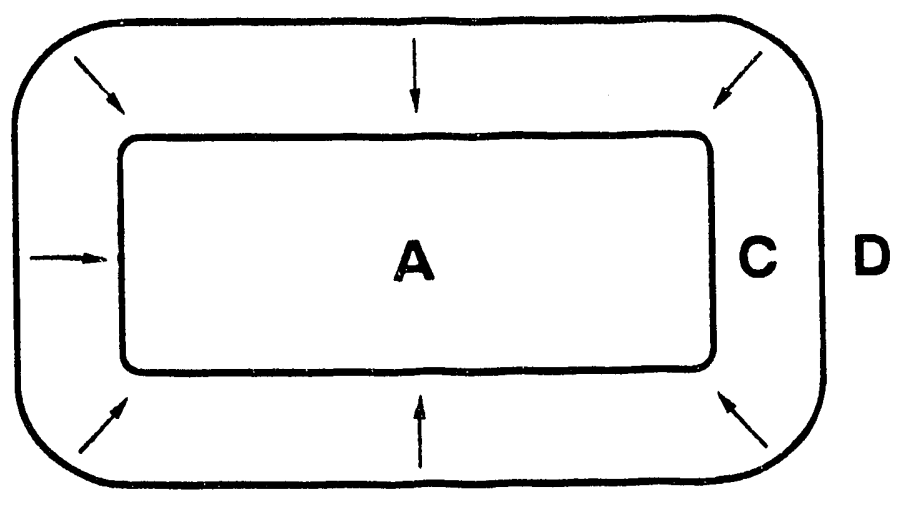

After One Day

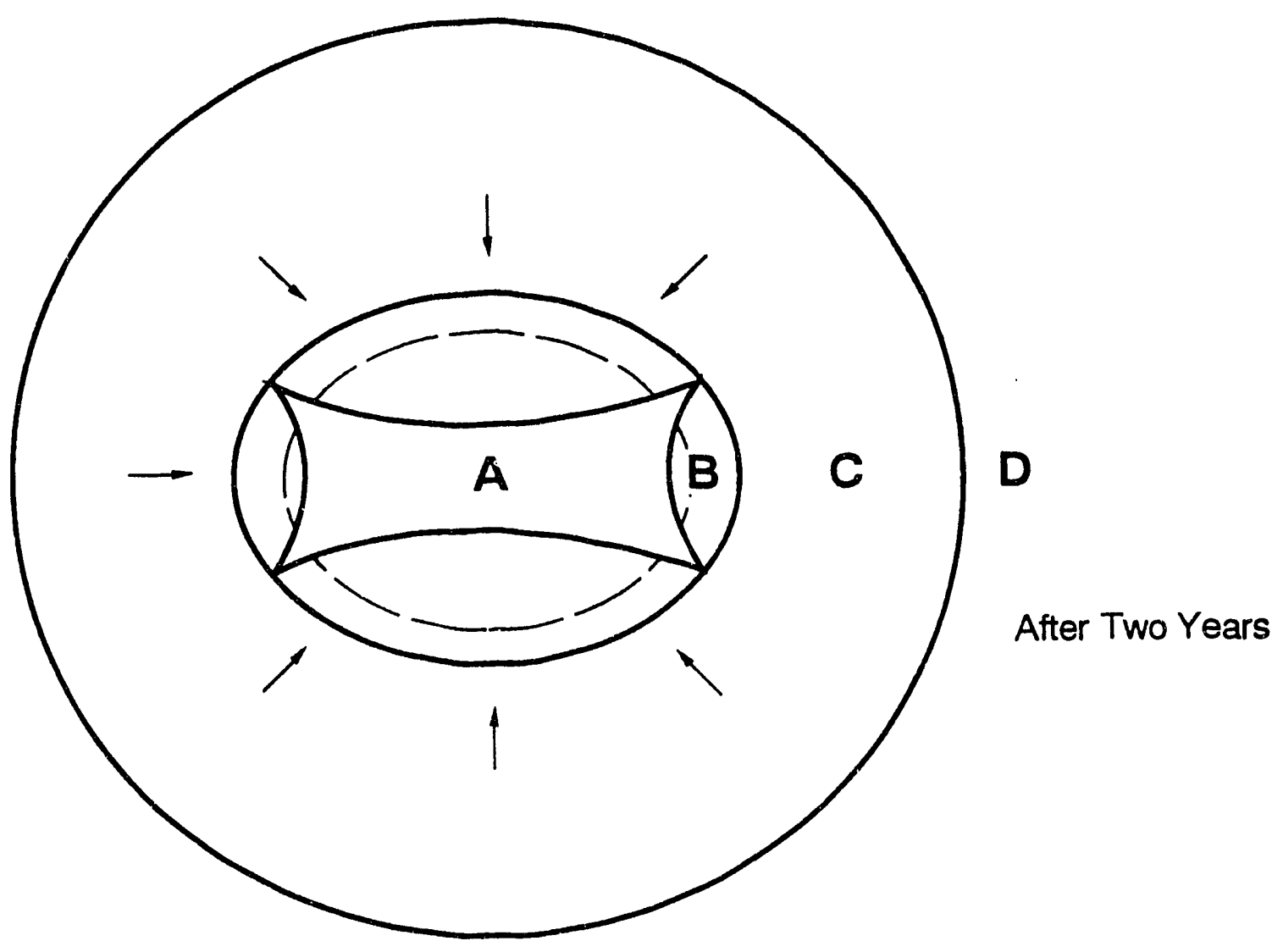

Figure 5-1

Diagrammatic vertical cross sections of a rectangular excavation in homogeneous salt one day and two years after mining. Zone $A$ is the mined opening, zone $B$ is the zone of elastic deformation, brittle failure, and macrofracturing with atmospheric pore pressures, zone $C$ is the zone of plastic deformation and dilatency with pore pressures increasing from atmospheric to lithostatic, and zone $D$ is undisturbed salt with lithostatic pore pressures. The DRZ is composed of both zone B and zone C. 


\section{A WIPP STORAGE ROOM IN BEDDED SALT}

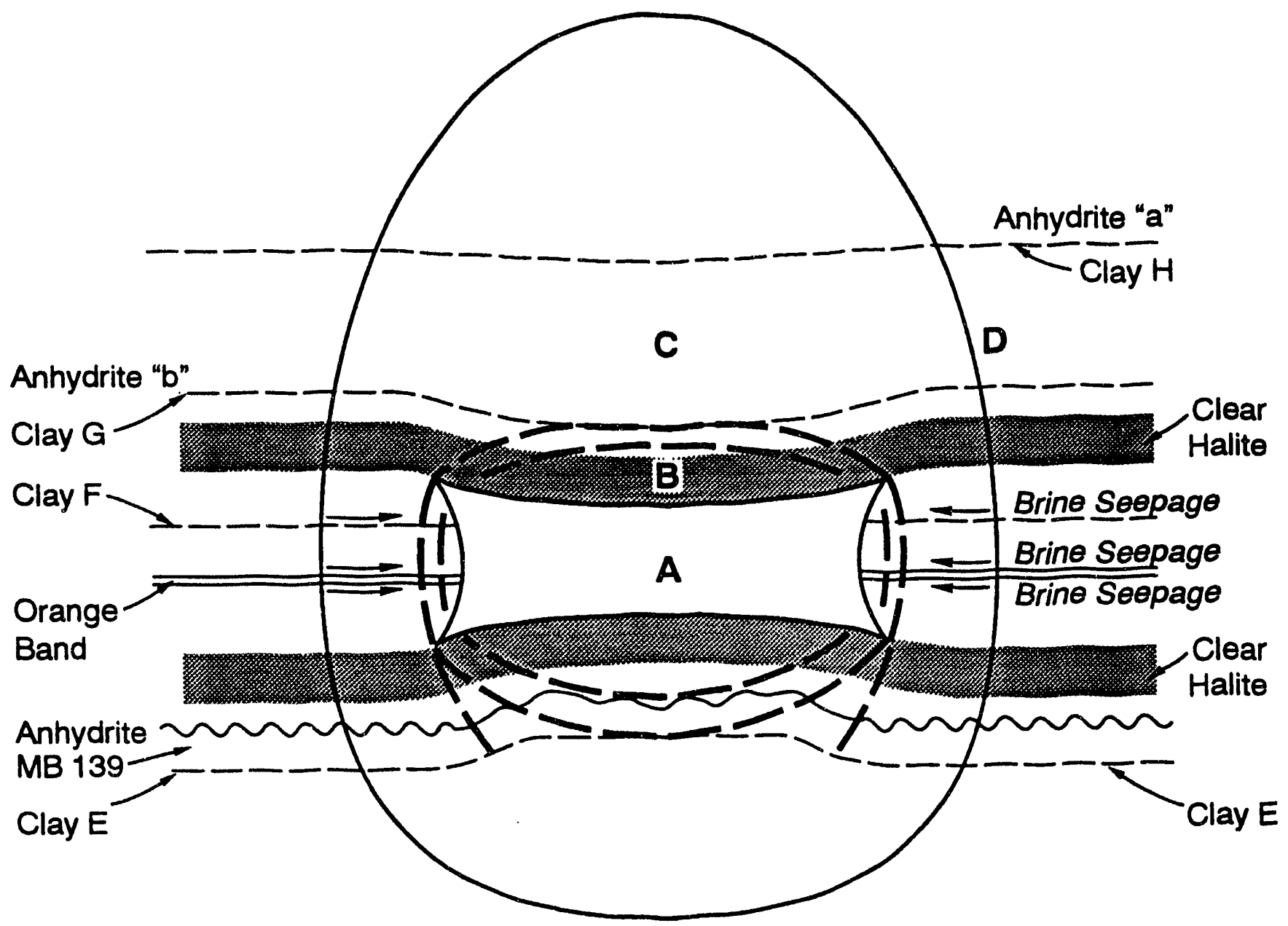

Figure 5-2

Diagrammatic vertical cross-section of a WIPP storage room in bedded salt, approximately six years after mining. Zones $A, B, C$ and $D$ are the same as in Figure 5-1. Arrows indicate brine seepage as a result of compaction of clays at clay $F$ and above and below the orange band. 
The details of flow in these very low-permeability units are quite complex, have very low velocities, involve small volumes of brine, and require testing over long periods of time during which the very properties being tested change; they are, therefore, difficult to quantify. Vertical drill holes yield inconsistent inflow data, even when closely spaced, but horizontal drill holes provide consistent and comparable data sets (refer to Section 2.9). Flow may be constrained to a relatively few, fairly discrete bedding planes, and radial flow (in a vertical plane), as assumed in most modeling, toward a horizontal excavation or drill hole may not occur. Fluid is preferentially stored in the more argillaceous beds and is not uniformly distributed throughout the salt (Deal and others, 1989). The pore spaces in some units may be so small that surface tension forces become significant and Darcy's Law may not hold at all or may have to be applied in a modified form, such as the piece-wise method suggested by Deal and others (1989). Additionaily, some previously unsuspected flow mechanism may be acting, such as compaction in the pillars driving brine out of poorly compacted clays (Deal and others, 1989). The brine contains dissolved gas (mostly nitrogen) that exsolves as the confining pressure is lowered. This gas is an additional driving mechanism for brine movement, especially in the first few days and weeks following mining, and it may locally modify flow.

A number of modeling efforts have been attempted to predict seepage into the WIPP excavations. Seepage into a horizontal drill hole $7.6 \mathrm{~cm}$ (3 in.) in diameter and $46 \mathrm{~m}$ (150 ft) long is predicted to be on the order of $0.01 \mathrm{~L}$ per day if a permeability of $1 \times 10^{-22} \mathrm{~m}^{2}$ (0.1 nanodarcy) is used for the undisturbed salt. Three drill holes of that dimension have been monitored for over two years, and all three accumulate fluids at seepage rates of 0.01 to $0.02 \mathrm{~L}$ per day. For reasons discussed in Section 2.9 , the holes have not been monitored long enough to provide definitive data.

The brine seeps at the WIPP are consistent with redistribution of brine in the DRZ as a result of the mining activities. Far-field flow, however unnecessary, has not been disproved. The way in which the flow rate varies with time is important. If the flow rate eventually reaches a steady rate, then there may be some far-field brine that flows through the body of the undisturbed rocks to reach the repository excavations. If the flow rate continues to decrease and eventually ceases, then no significant amount of brine can be derived from the far field, and only brine released from the DRZ due to depressurization will enter the repository excavations. Studies are currently being conducted or are being planned at the WIPP to 
determine which of these conditions exist and include the three drill holes mentioned above, which have not yet provided definitive data (refer to Section 2.9 and Appendix E).

The WIPP EATF proposed that the corrosion of iron, steel, and aluminum alloys requires and consumes brine, and if sufficient brine is present, the corrosion represents a potential source of gas in the repository after closure (DOE, 1991). Calculations (refer to Section 4.6) indicate that it will take approximately $220,000 \mathrm{~L}$ of brine to corrode all of the metals contained in the waste and waste drums emplaced in each waste storage room.

If no far-field flow exists, and radial flow occurs in a vertical plane toward a waste storage room, then release of brine from the DRZ around the excavations due to depressurization (Figure 5-3a) is estimated to produce about $150,000 \mathrm{~L}$ of brine (refer to Section 4.6). This volume is on the same order of magnitude as the volume of brine $(220,000 \mathrm{~L})$ necessary to corrode all the metal in the waste and waste storage drums in a waste storage room. Anoxic corrosion will consume brine and produce metal oxides and hydrogen. If the volume of brine entering the repository is less than that required to completely corrode the metal, then all of the brine that comes in contact with metal will be consumed.

There is good evidence that the assumption of radial flow in a vertical plane does not hold for the WIPP. The unfractured clear halite units have such low permeability (or none at all) that flow is probably constrained and occurs only horizontally, parallel to bedding. Brine may only be able to corain from that part of the DRZ horizontally adjacent to the storage room (Figure 5-3b). The volume of rock involved is about 7 percent of that involved in the estimate above (Figure 5-3a). Assuming that the growth of fractures in zone B will tap a slightly thicker stratigraphic interval, including some strata above and below the 4-m-high storage room, an estimate of about 10 percent seems reasonable. In that case, less than onetenth of the $150,000 \mathrm{~L}$ estimated above may enter the repository to react with the metal emplaced there and produce hydrogen gas by corrosion. As brine reacts with the metal and gas pressure builds up, brine inflow will be additionally retarded.

If compaction of the clays is the major source of the brine rather than release of brine from the DRZ due to depressurization, then even less brine may enter the repository. This situation is shown in Figure 5-2 by the brine-flow arrows shown restricted to clay $F$ and the thin clay units immediately above and below the orange band. 


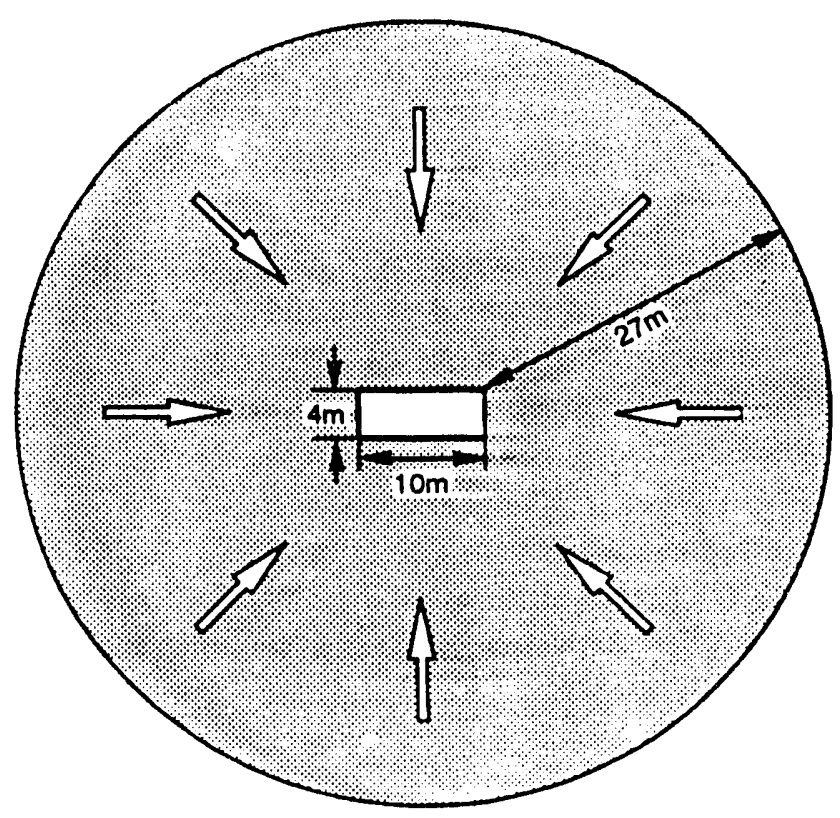

A. Radial Flow Dewatering a Cross Section Approximately $3258 \mathrm{~m}^{2}$ in Area

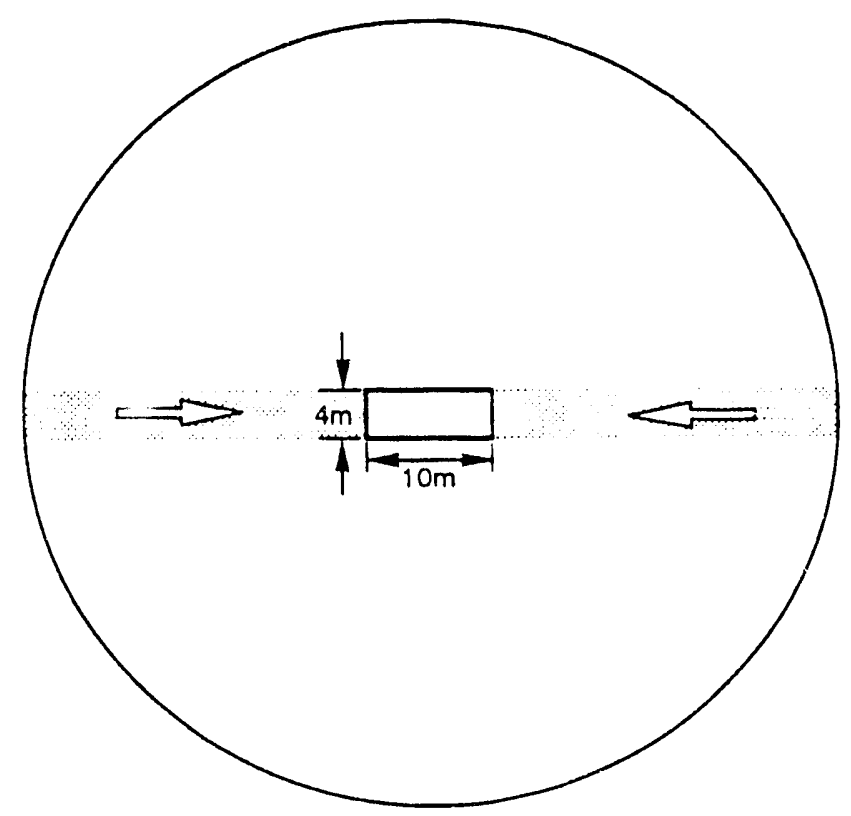

B. Horizontal Flow Dewatering Facility Horizon Strata Approximately $220 \mathrm{~m}^{2}$ in Area

Figure 5.3

Vertical Cross Section Through a Mature DRZ Around a WIPP Waste Storage Room $4 \mathrm{~m}$-High and $10 \mathrm{~m}$-Wide 


\subsection{Implications}

The relative importance of far-field flow versus local redistribution of brine in the DRZ needs to be determined (refer to Chapter 1). For example, if there is sufficient far-field flow into the repository, then enough brine may come into the excavations to completely corrode the metal in the waste and the waste drums; therefore, the potential for hydrogen generation due to corrosion will be limited by the total metal inventory. If brine seepage is a purely local phenomena due to redistribution of brine in the immediate vicinity of the excavations, there may be insufficient brine available to cause much corrosion after closure. In the latter case, gas generation will be limited by brine availability and may not be a problem.

The predicted consequences of human intrusion events, the fate of the waste-generated gases, and the migration of the hazardous constituents during undisturbed performance are all sensitive to brine inflow assumptions, even if both of the proposed systems yield similar volumes of brine during the pressurization phase after sealing and closure. If the far-field model is valid, a human intrusion event (drilling into the sealed repository at some future date) will lower fluid pressure in the waste storage rooms, create pressure gradients toward the rooms, and reinstate far-field flow. This will lead to a greater release of radionuclides from the repository as the inflowing brine infiltrates through the waste and flows up the drill hole. Alternatively, if the near-field model is valid, the only brine available for transport of radionuclides is the volume of brine that is trapped in the room at the time of sealing.

Predicting the fate of waste-generated gases is also dependent upon the hydrologic systems assumed to be operational. If brine can flow through the far field, excess gas pressure can probably be dissipated through the host rock; but if far-field flow is not a viable concept, gas generation from microbial or radiolytic decomposition of organic materials may yield very high local pressures. Analyses by the WIPP EATF have shown that predicted peak pressures are highly dependent upon the assumed mechanisms by which fluids can flow through the undisturbed host rock (DOE, 1991).

Another long-term performance concern is the migration of RCRA-listed hazardous constituents from the repository. If far-field flow is valid, the generation of excess gas pressure within the repository may force gas, possibly contaminated with VOCs, across the RCRA unit boundary. However, if far-field flow does not occur, there will be less of a potential for VOC migration. 


\subsection{Further Investigations}

Although much is known about the brine seepages at the WIPP, there are still areas that need further examination. As stated above, the idea of far-field flow seems unlikely or impossible but remains an important modeling concept that has not been disproved. The relative importance of near-field versus far-field flow remains an item of significant importance and should be resolved.

The following questions nc.

- Does the clay contain enoug!'s brine that can be squeezed out by vertical loading to explain all of the brine seepage observed at the WIPP?

- Is there enough volume present in void spaces and fractures in the DRZ beneath the floors of the excavations to hold large quantities of brine out of sight, and are those fractures connected well enough to allow brine (or gas) to flow downgradient and beneath potential seals?

- Does any far-field component of flow exist?

The following activities are proposed to address these questions:

- Clay samples have been collected from the WIPP underground and are being subjected to laboratory testing. Preliminary results indicate that the clay is quite wet and may contain 20 percent or more brine by volume. After quantification, this work will be reported in the BSEP 1991 annual report. If available brine volumes seem to be in the right order of magnitude to explain the brine seepages, additional testing will be needed to assess the rate of seepage and volumes that might realistica'ly enter a waste storage room.

- Plans for additional testing to determine the hydrologic characteristics of fracture porosity developing in the DRZ beneath the floor of the workings have been approved. This is an extension of the work reported in Deal and others (1991, Section 4) and will include testing in the E0 drift north of the Salt Harkling Shaft, which may shed light on why no brine has been observed seeping out of open fractises in the Salt Handling Shaft sump. Additional tests need to be devised to address the issue of total fracture volume.

- A testing program to drill additional horizontal and subhorizontal brine seepage observation holes has been proposed (Appendix E). This program has three phases and will answer questions about the stratigraphic variability of brine seepage and the e. fect it has had on past brine inflow observations, the effect of the DRZ on past brine inflow observations, and whether there is any detectable compo «ent of far-fieid tiow. 


\subsection{References}

Abitz, R. J., J. Myers, P. E. Drez, and D. E. Deal, 1990, "Geochemistry of Salado Formation Brines Recovered from the Waste Isolation Pilot Plant (WIPP) Repository," Proceedings of Waste Management '90, Waste Processing, Transportation, Storage and Disposal, Technical Programs and Public Education, R. G. Post, ed., Vol. 2, pp. 881-891, Tucson, Arizona.

Alcorn, S. R., 1983, Memo, Occurrence of Brine Weeps in the WIPP Facility: Memo to D.K. Shukla, October 3, 1983, WD:83:02910 1.02.00, transmitted to J. M. McGough, U.S. Department of Energy from TSC-D’Appolonia Consulting Engineers, Albuquerque, New Mexico.

Beauheim, R. L., and S. Howarth, 1991, "Status of Room Q Experiments and Salado Permeability Tests," Presentation to the WIPP Review Panel, National Academy of Sciences and Board of Radioactive Waste Management, Albuquerque, New Mexico.

Beauheim, R. L., and R. M. Holt, 1990, "Hydrogeology of the WIPP Site," in Powers, D., N. Rempe, R. Holt, and R. L. Beauheim, 1990, "Geological and Hydrological Studies of Evaporites in the Northern Delaware Basin for the Waste Isolation Pilot Plant (WIPP), New Mexico," Field Trip No. 14 Guidebook, Geological Society of America 1990 Annual Meeting, Dallas, Texas.

Bechtel National, Inc. (Bechtel), 1986, "Interim Geotechnical Field Data Report," DOE/WIPP 86-012, prepared for the U.S. Department of Energy by Bechtel National, Inc., San Francisco, California.

Bechtel National, Inc. (Bechtel), 1985, "Quarterly Geotechnical Field Data Report," WIPP-DOE-213, Bechtel Naticnal, Inc., San Francisco, California.

Bechtel National, Inc. (Bechtel), 1983, "Waste Isolation Pilot Plant Preliminary Design Validation Report," Prepared for the U.S. Department of Energy by Bechtel National, Inc., San Francisco, California.

Black, S. R., R. S. Newton, and D. K. Shukla, eds., 1983, "Results of Site Validation Experiments, Waste Isolation Pilot Plant," DOE-TME-3177, TSC-D’Appolonia Consulting Engineers, Albuquerque, New Mexico.

Bolt, G. H., and P. H. Groenevelt, 1969, "Coupling Phenomena as a Possible Cause for NonDarcian Behaviour of Water in Soil," Bulletin of the International Association of Science and Hydrology, Vol. 14, No. 2, pp. 17-26.

Borns, D. J., and J. C. Stormont, 1988, "An Interim Report on Excavation Effect Studies at the Waste Isolation Pilot Plant: The Delineation of the Disturbed Rock Zone," SAND87-1375, a report prepared for the U.S. Department of Energy by Sandia National Laboratories, Albuquerque, New Mexico, 30 pp. 
Deal, D. E., 1988, "Brine Seepage into the Waste Isolation Pilot Plant (WIPP) Excavation," in Waste Management '88, Waste Processing, Transportation, Storage and Disposal, Technical Programs and Public Education, R.G. Post, ed., Vol. 2, pp. 649-657.

Deal, D. E., and J. B. Case, 1987, "Brine Sampling and Evaluation Program, Phase I Report," DOE/WIPP 87-008, prepared for the U.S. Department of Energy by IT Corporation and Westinghouse Electric Corporation, Carisbad, New Mexico, 163 pp.

Deal, D. E., and R. M. Roggenthen, 1991, "Evolution of Hydrologic Systems and Brine Geochemistry in a Deforming Salt Medium: Data from WIPP Brine Seeps", Waste Management '91, Waste Processing, Transportation, Storage and Disposal, Technical Programs and Public Education, R. G. Post, ed., Vol. 2, pp. 507-516.

Deal, D. E., and W. M. Roggenthen, 1989, "The Brine Sampling and Evaluation Program (BSEP) at WIPP: Results of Four Years of Brine Seepage Data," in Waste Management '89, Waste Processing, Transportation, Storage and Disposal, Technical Programs and Public Education, R. G. Post, ed., Vol. 1, pp. 405-406.

Deal, D. E., R. J. Abitz, D. S. Belski, J. B. Clark, M. E. Crawley, and M. L. Martin, 1991, "Brine Sampling and Evaluation Program, 1989 Report," DOE-WIPP-91-009, prepared for U.S. Department of Energy by IT Corporation and Westinghouse Electric Corporation, Albuquerque, New Mexico.

Deal, D. E., R. J. Abitz, J. B. Case, M. E. Crawley, R. M. Deshler, P. E. Drez, C. A. Givens, R. B. King, B. A. Lauctes, J. Myers, S. Niou, J. M. Pietz, W. M. Roggenthen, J. R. Tybursk;, M. G. Wallace, and D. S. Belski, 1989, "Brine Sampling and Evaluation Program, 1988 Report," DOE/WIPP-89-015, prepared for the U.S. Department of Energy by IT Corporation and Westinghouse Electric Corporation, Carlsbad, New Mexico.

Deal, D. E., J. B. Case, R. M. Deshler, P. E. Drez, J. Myers, and J. A. Tyburski, 1987, "Brine Sampling and Evaluation Program, Phase II Report," DOE/WIPP 87-010, prepared for the U.S. Department of Energy by IT Corporation and Westinghouse Electric Corporation, Carlsbad, New Mexico, 193 pp.

Dean, W. E., 1978, "Trace and Minor Elements in Evaporites," in Marine Evaporites, W. E. Dean and B. C. Schreiber, eds., SEPM Short Course No. 4, pp. 86-104, Oklahoma City, Oklahoma.

Francke, C., S. Carlisle, E. Lewis, and N. Rempe, 1990, "Geotechnical Field Data and Analysis Report, July 1988-June 1989," DOE/WIPP 90-006, Vols. I and II, prepared for the U.S. Department of Energy by Westinghouse Electric Corporation and IT Corporation, Carlsbad, New Mexico.

Francke, C., R. Carrasco, R. Cook, D. Deal, R. Deshler, and R. Williams, 1989, "Geotec'inical Field Data and Analysis Report, July 1987-June 1988," DOE/WIPP 80-009, Vols. I and II, prepared for the U.S. Department of Energy by Westinghouse Electric Corporation and IT Corporation, Carlsbad, New Mexico. 
Freeze, R. A., and J. A. Cherry, 1979, Groundwater, Prentice-Hall, Inc., Englewood Cliffs, New Jersey, 604 pp.

Gallerani, J., 1985, Field Notes, BSEP Files, Bechtel National, Inc., San Francisco, California.

Intera Environmental Consultants, Inc., 1983, "VISCOT: A Two-Dimensional and Axisymmetric Nonlinear Transient Thermoviscoelastic and Thermoviscoplastic Finite Element Code for Modeling Time-Dependent Viscous Mechanical Behavior of a Rock Mass,"

ONWI-437, Office of Nuclear Waste Isolation, Battelle Memorial Institute, Columbus, Ohio.

Jaeger, J. C., and N. G. W. Cook, 1969, Fundamentals of Rock Mechanics, Halsted Press, New York, New York, 585 pp.

Karman, T. von, 1911, Festigkeitsversuche unter Allseitigem Druk, Z. Ver. de Ing., Vol. 55, pp. 1749-57.

Krieg, R. D., 1984, "Reference Stratigraphy and Rock Properties for the Waste Isolation Pilot Plant," SAND83-1908, Sandia National Laboratories, Albuquerque, New Mexico.

Krumhansl, J. L., and H. W. Stockman, 1987, "Test Progress Report-Room J," Memo dated January 27 to M. A. Molecke, Sandia National Laboratories, Albuquerque, New Mexico.

Krumhansl, J. L., G. D. Jarrel, V. S. McConnell, Sandia National Laboratories, "Further Documentation of WIPP Field Test Related Analyses," 1987, Personal Communication to M. A. Molecke, Sandia National Laboratories, Albuquerque, New Mexico.

Krumhansl, J. L., K. M. Kimball, and C. L. Stein, 1991, "Intergranular Fluid Compositions from the Waste Isolation Pilot Plant (WIPP), Southeastern New Mexico," Sandia National Laboratories, SAND90-0584, Albuquerque, New Mexico.

Lai, C. S., 1971, "Fluid Flow Through Rock Salt Under Various Stress States," Ph.D. Dissertation, Michigan State University, East Lansing, Michigan.

Lappin, A. R., 1988, "Summary of Site-Characterization Studies Conducted from 1983 Through 1987 at the Waste Isolation Pilot Plant (WIPP) Site, Southeastern New Mexico," SAND88-0157, Sandia National Laboratories, Albuquerque, New Mexico.

Lappin, A. R., R. L. Hunter, D. P. Garber, and P. B. Davies, 1989, "System Analysis, LongTerm Radionuclide Transport, and Dose Assessments, Waste Isolation Pilot Plant (WIFP), Southeastern New Mexico," SAND89-0462, Sandia National Laboratories, Albuquerque, New Mexico.

Morse, J. G. and B. W. Hassinger, 1985, "Brine Testing Program Plan: Waste Isolation Pilot Plant (WIPP) Project, Carlsbad, New Mexico, Revision 2," Internal Document WD:85:01214; transmitted as a letter from W.R. Cooper to R.H. Neill, WIPP, AEH 85:086, April 11, 1985. 
Mraz, D., 1980, Plastic Behavior of Salt Rock Utilized in Designing a Mining Method," CIM Bulletin, Vol. 73, pp. 11-123.

Myers, J., 1991, Calculation Briefs, WIPP Brine Sampling Evaluation Program, 1990 Report Files, IT Corporation, Albuquerque, New Mexico.

Peterson, W. E., P. L. Lagus, and K. Lie, 1987, "WIPP Horizon Free Field Fluid Transport Characteristics," SAND87-7164, Sandia National Laboratories, Albuquerque, New Mexico.

Peterson, W. E., P. L. Lagus, and K. Lie, 1985, "WIPP Horizon In-Situ Permeability Measurements Final Report," SAND85-7166, Sandia National Laboratories, Albuquerque, New Mexico.

Powers, D. W., S. J. Lambert, S-E. Shaffer, I. R. Hill, and W. D. Weart, eds., 1978, "Geological Characterization Report, Waste Isolation Pilot Plant (WIPP) Site, Southeastern New Mexico," SAND78-1596, Vol. I and II, Sandia Laboratories, Albuquerque, New Mexico.

Roggenthen, W. M., 1988, "Solubility of Nitrogen in WIPP Brines," Memorandum, IT Corporation, Albuquerque, New Mexico.

Stein, C. L., 1985, "Preliminary Report on Fluid Inclusions from Halites in the Castile and Lower Salado Formations of the Delaware Basin, Southeastern New Mexico," SAND83-0451, Sandia National Laboratories, Albuquerque, New Mexico.

Stein, C. L., and J. L. Krumhansl, 1988 "A Model for the Evolution of Brines in Salt from the Lower Salado Formation, Southeastern New Mexico," Geochimica et Cosmochimica Acta. Vol. 52, pp. 1037-1046.

Stein, C. L., and J. L. Krumhansl, 1986, "Chemistry of Brines in Salt From the Waste Isolation Pilot Plant (WIPP), Southeastern New Mexico: A Preliminary Investigation," SAND-85-0897, Sandia National Laboratories, Albuquerque, New Mexico, 38 pp.

Swartzendruber, D., 1962, "Non-Darcy Flow Behavior in Liquid-Saturated Porous Media," Journal of Geophysical Research, Vol. 67, pp. 5205-5213.

TSC-D'Appolonia, 1983a, "Quarterly Geotechnical Field Data Report-July 1983," WIPP-DOE-163, Compiled for the U.S. Department of Energy by TSC-D'Appolonia, Albuquerque, New Mexico.

TSC-D'Appolonia, 1983b, "Quarterly Geotechnical Field Data Report-October 1983," WPP-DOE-163, Compiled for the U.S. Department of Energy by TSC-D'Appolonia, Albuquerque, New Mexico.

U.S. Department of Energy (DOE), 1991, "Evaluation of the Effectiveness and Feasibility of the Waste Isolation Pilot Plant Engineered Alternatives: Final Report of the Engineered Altematives Task Force," DOE/WIPP 91-007, Rev. 0, Vol. I, U.S. Department of Energy, Carlsbad, New Mexico. 
Voss, C. I., 1984, "SUTRA Saturated-Unsaturated Transport, A Finite-Element Simulation Model for Saturated-Unsaturated, Fluid-Density-Dependent Ground-Water Flow with Energy Transport or Chemically-Reactive Single-Species Solute Transport," in U.S. Geological Survey Water-Resources Investigation Report 84-4369, Tyndall Air Force Base, Florida.

Wallace, M., J. Pietz, J. Case, D. Deal, and B. Lauctes, 1990, "Coupled Fluidi-Flow Modeling of Brines Through Deforming Salt Around the Excavations for the Waste Isolation Pilot Plant (WIPP) in the Permian Salado Formation," in Waste Management '90, Waste Processing, Transportation, Storage and Disposal, Technical Programs and Public Education, R.G. Post, ed., Vol. 2, pp. 873-880.

Wolery, T. J., 1983, "EQ3NR, A Computer Program for Geochemical Aqueous SpeciationSolubility Calculations: User's Guide and Documentation," UCRL-53414, Lawrence Livermore National Laboratory, Livermore, California. 


\section{APPENDIX A BRINE ACCUMULATION}

PART —LIST OF UNDERGROUND LOCATIONS WHERE BRINE
OCCURRENCES WERE OBSERVED AND MONITORED 


\section{APPENDIX A \\ BRINE ACCUMULATION}

PART $1-$ LIST OF UNDERGROUND LOCATIONS WHERE BRINE
OCCURRENCES WERE OBSERVED ANC MONITORED

PART I- BRINE ACCUMULATION DATA TABLES 
This page left intentionally blank 


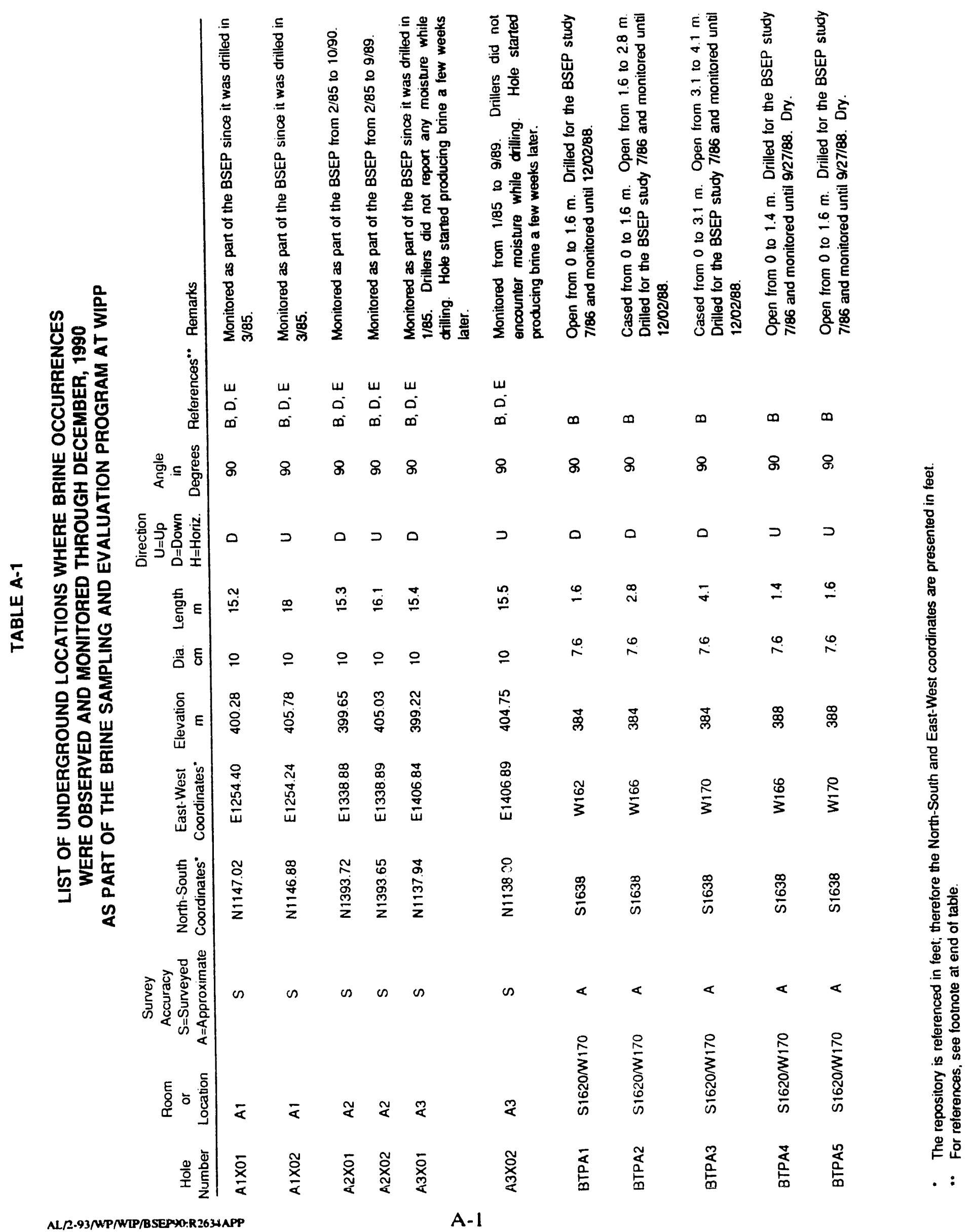




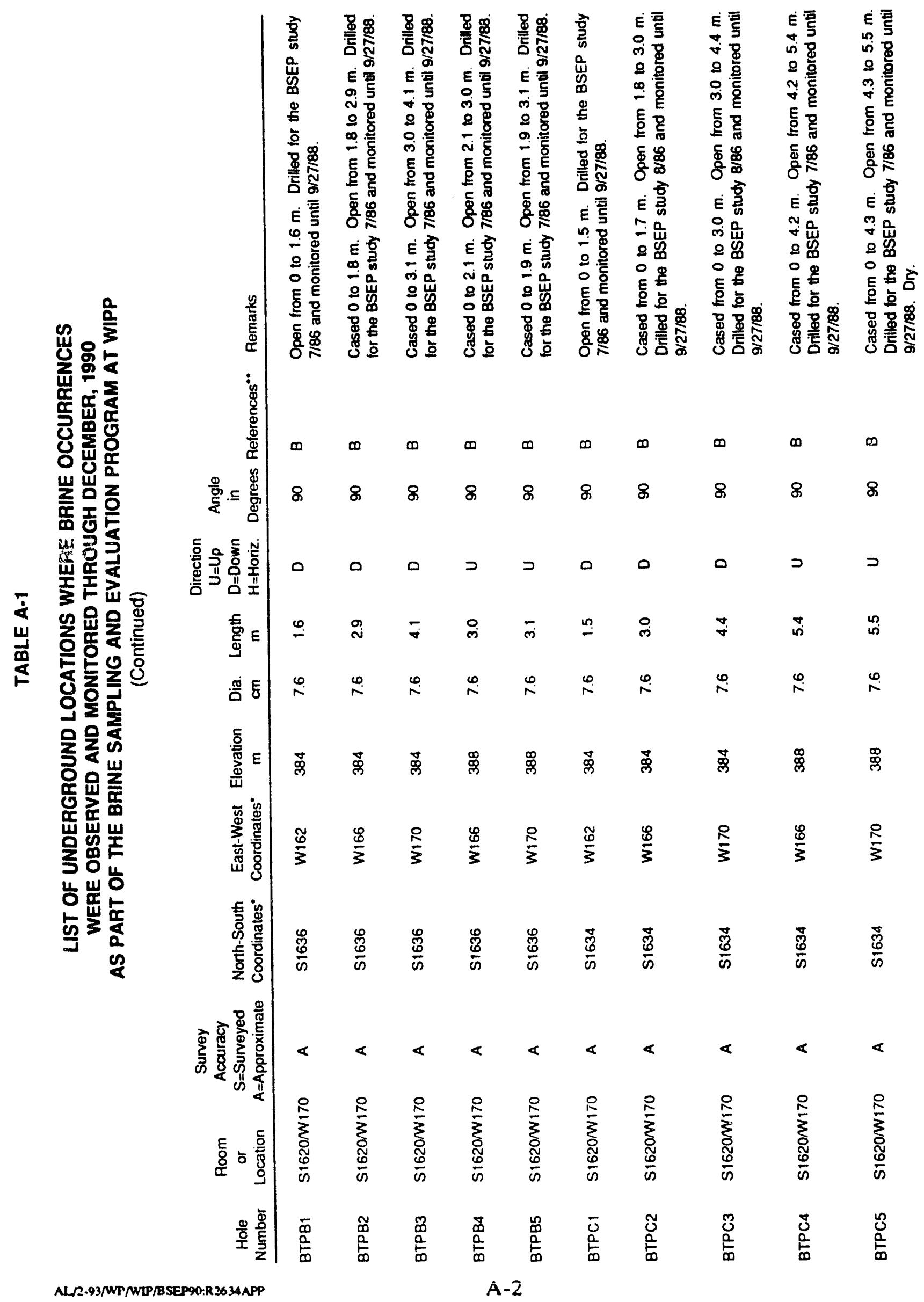




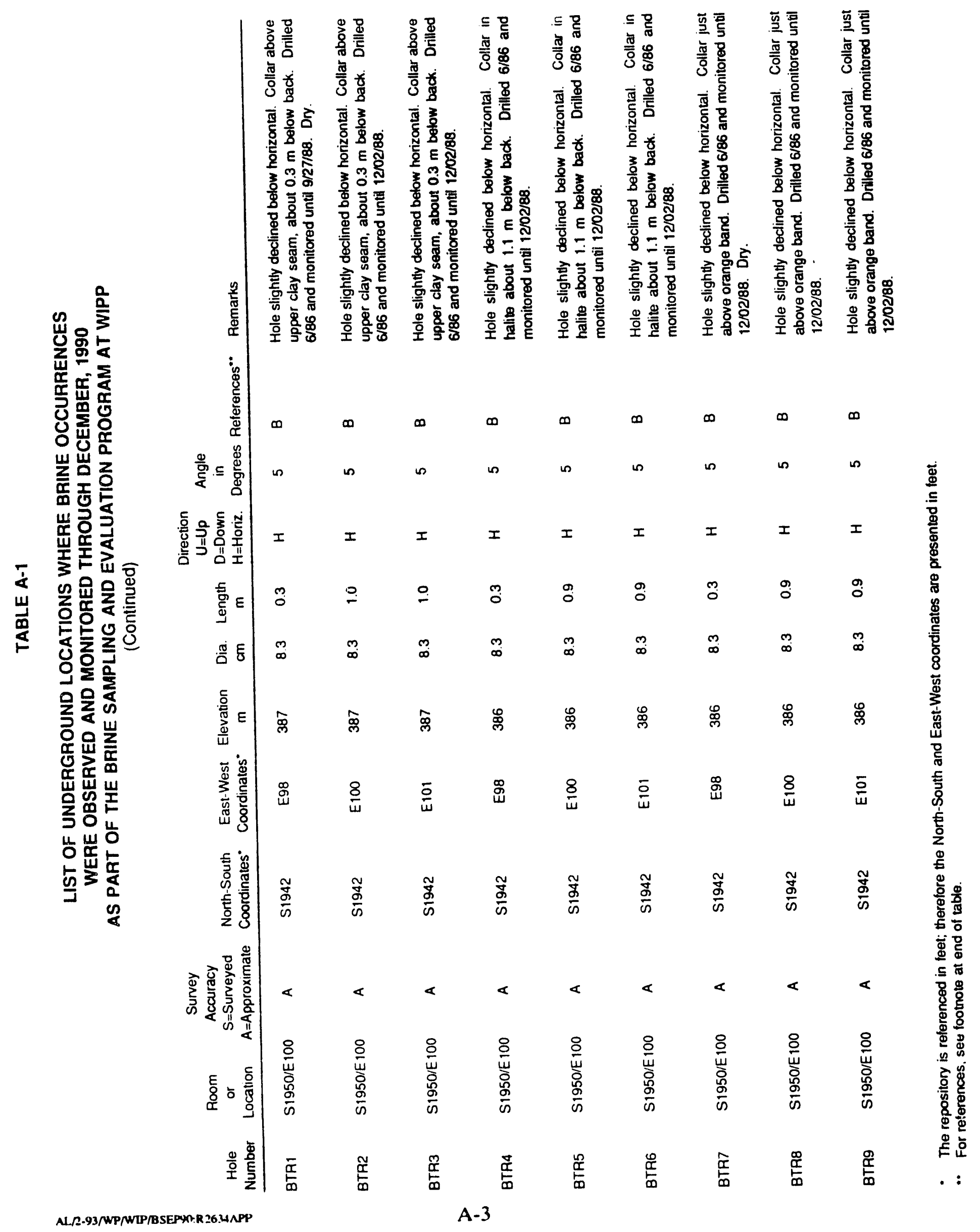




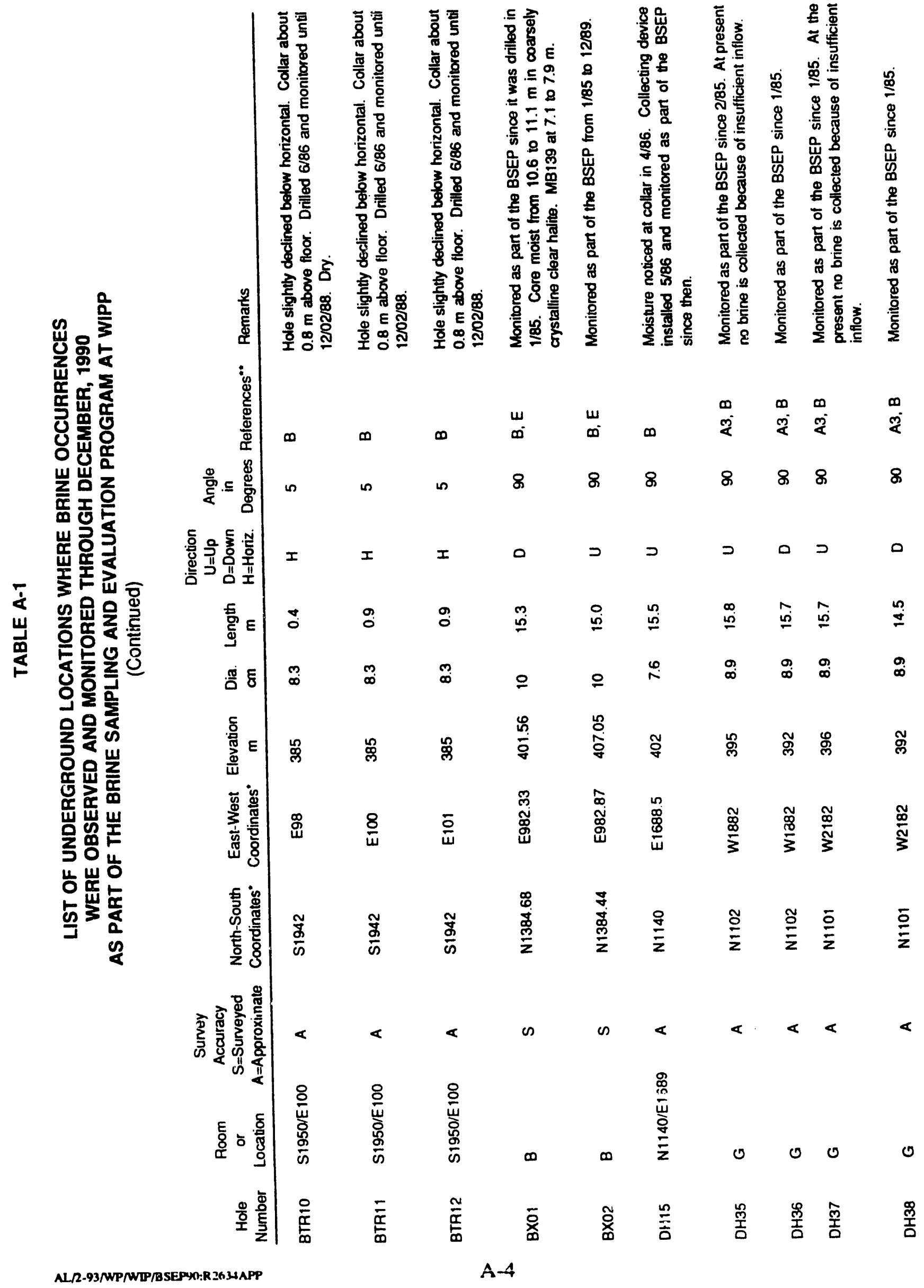




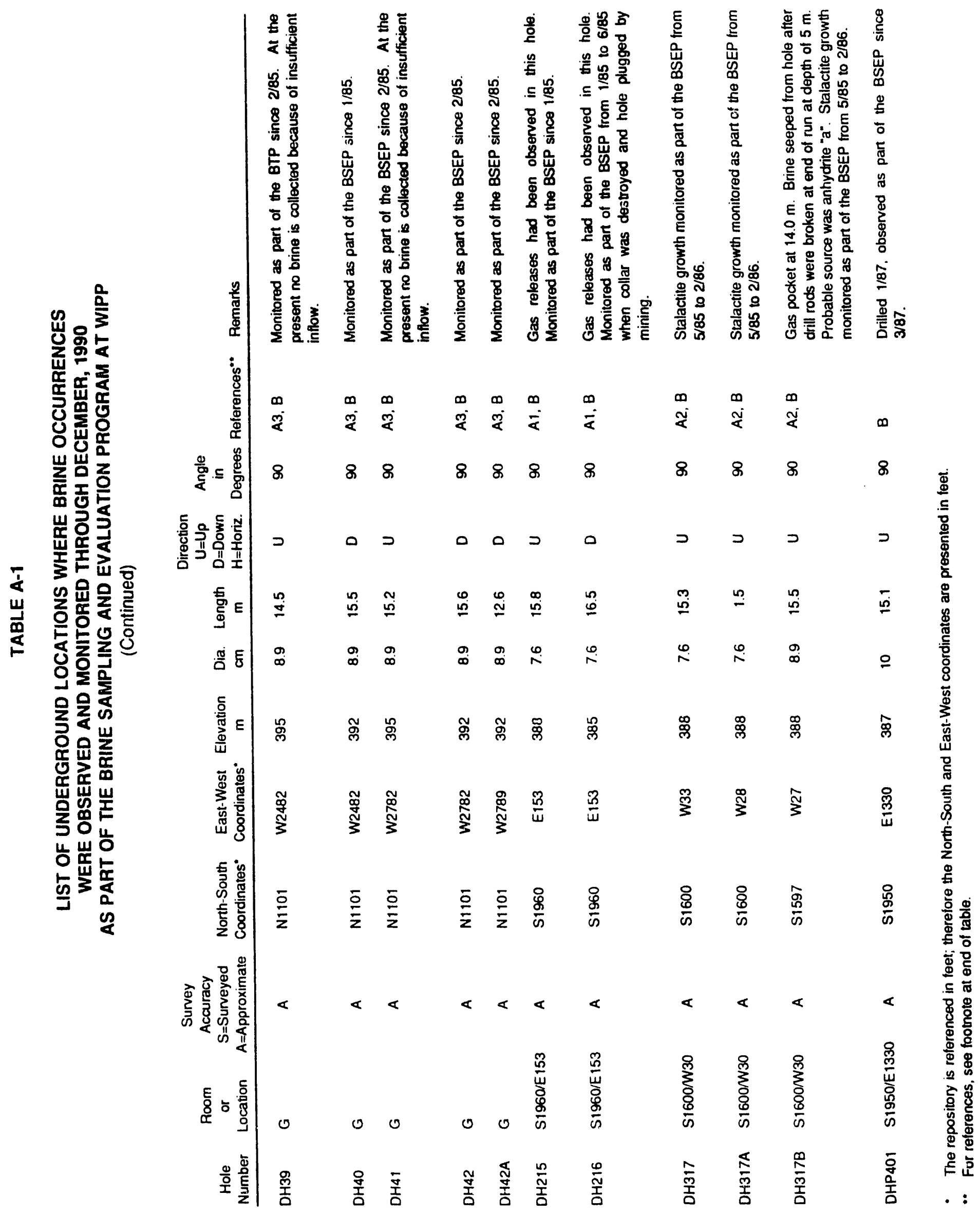




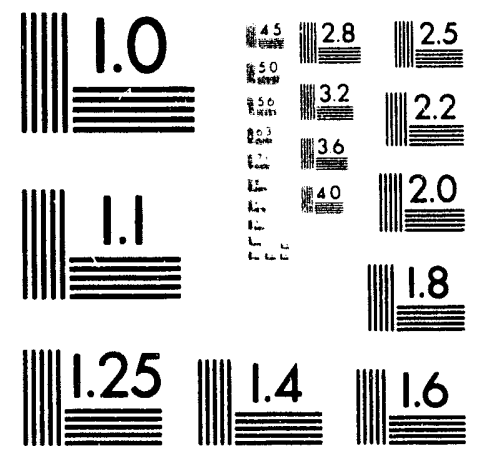



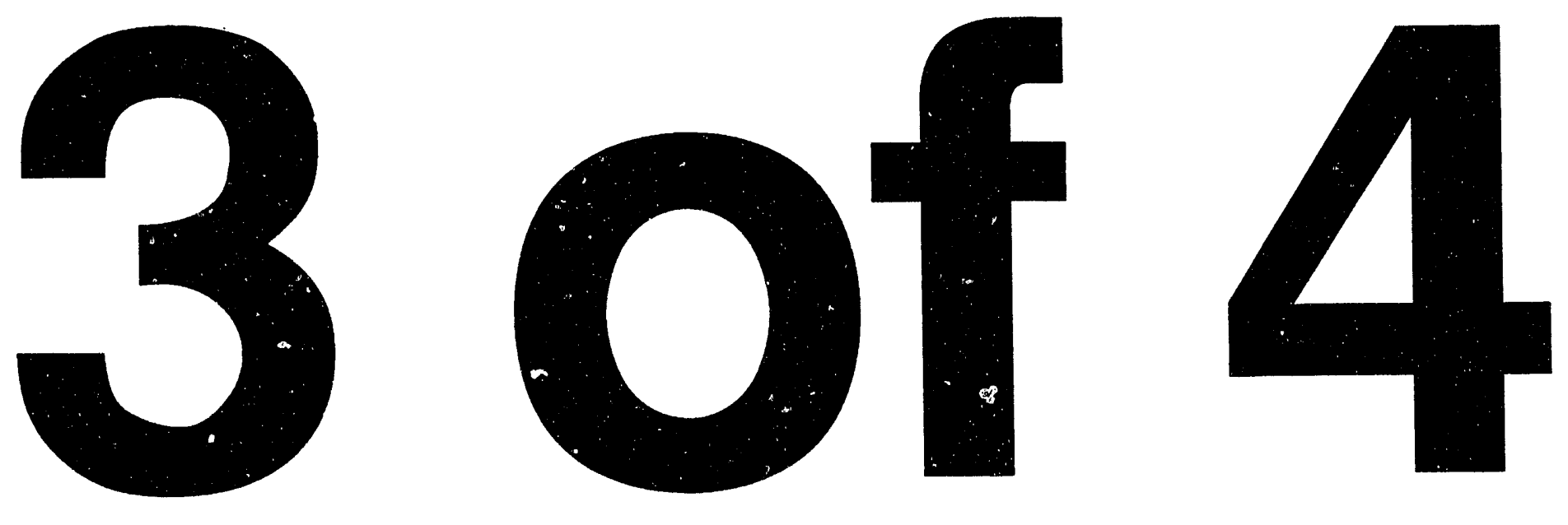


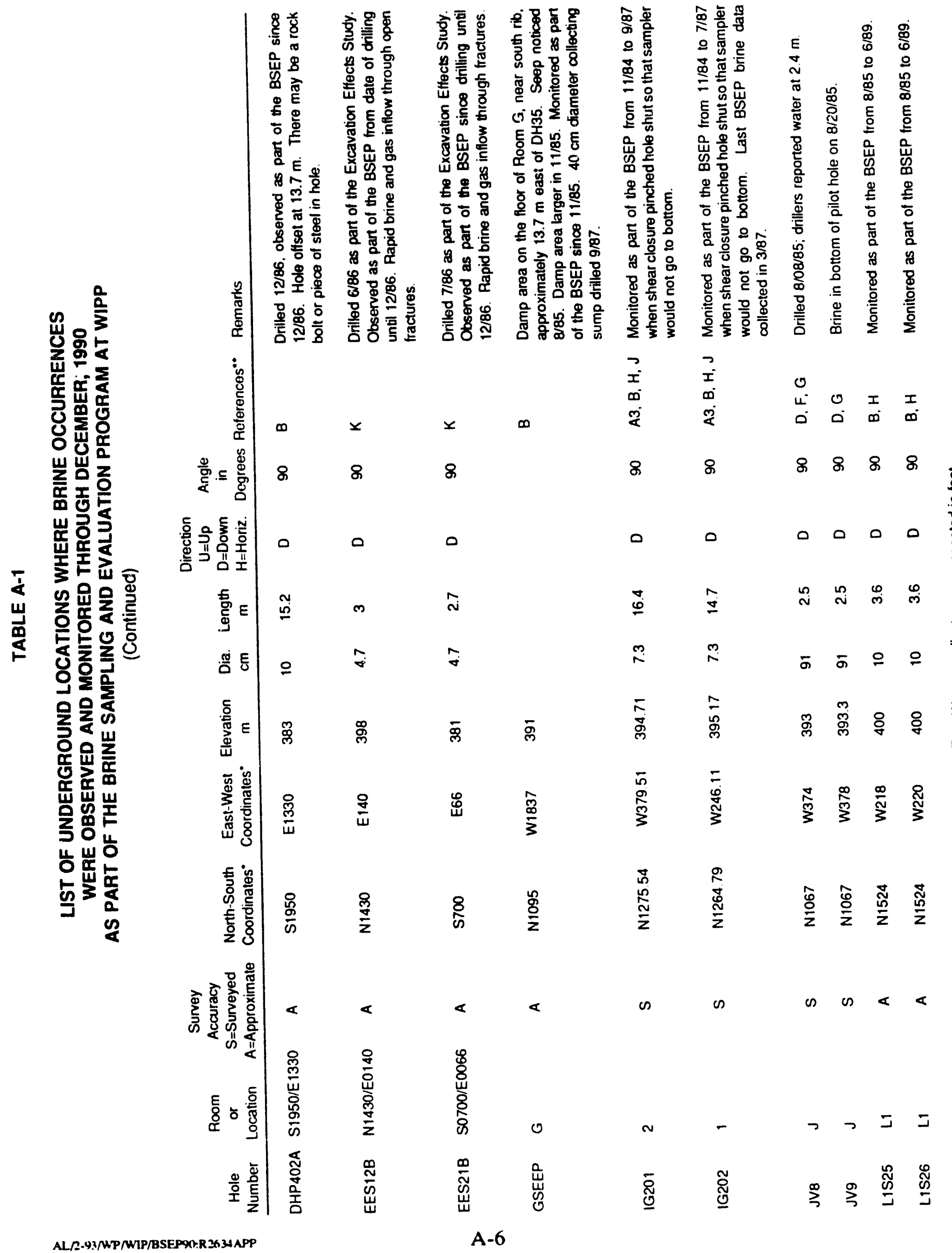



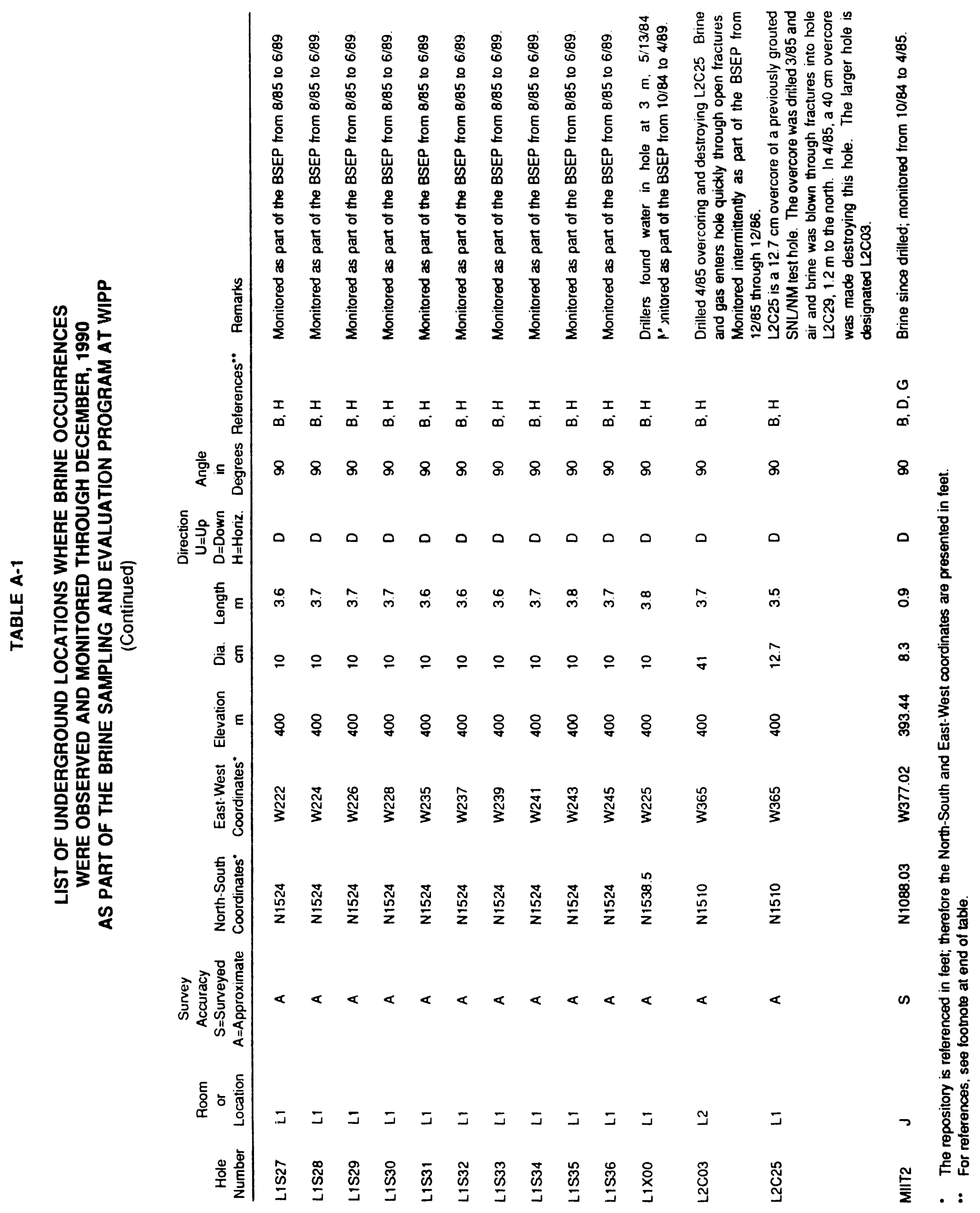


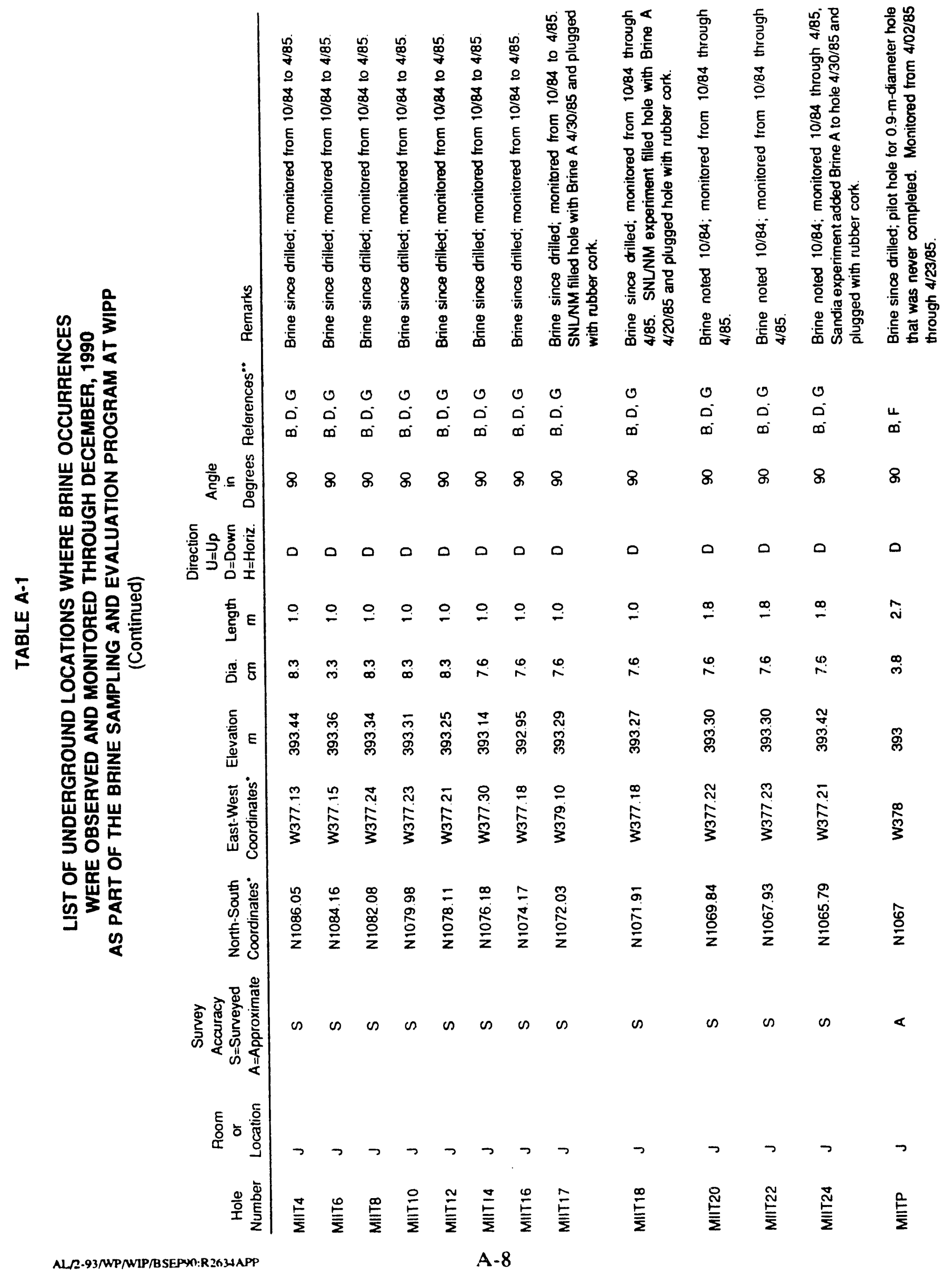




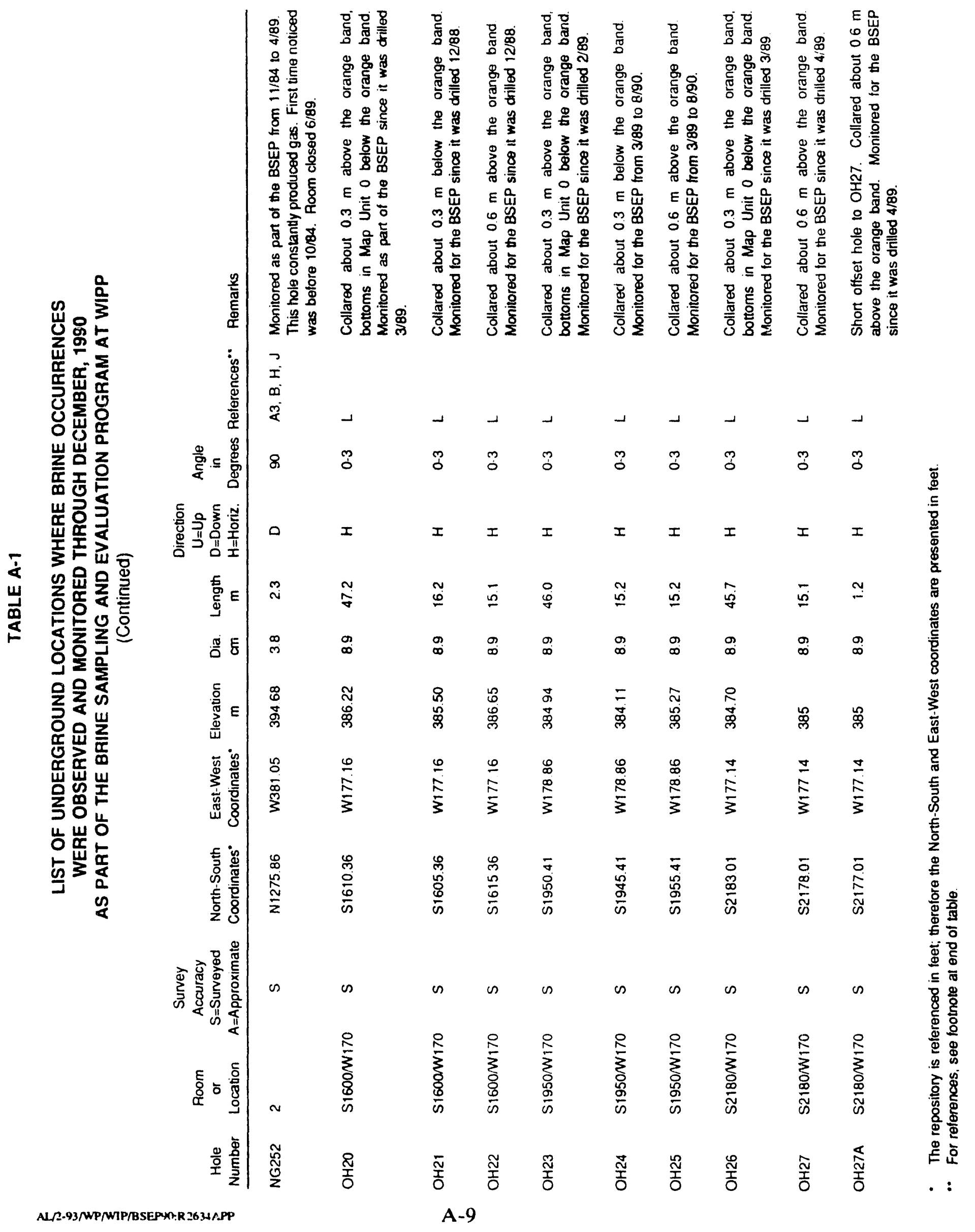



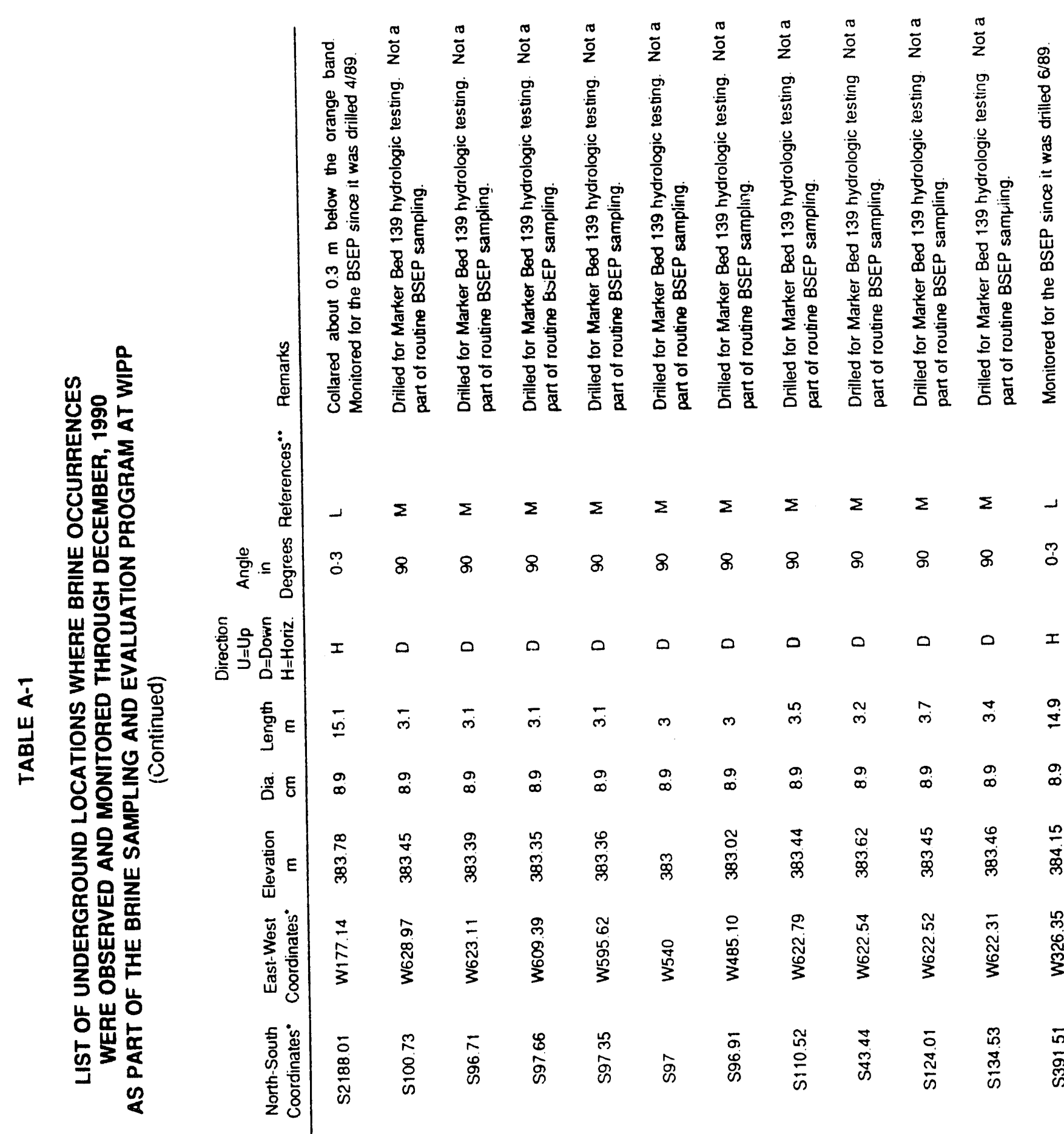


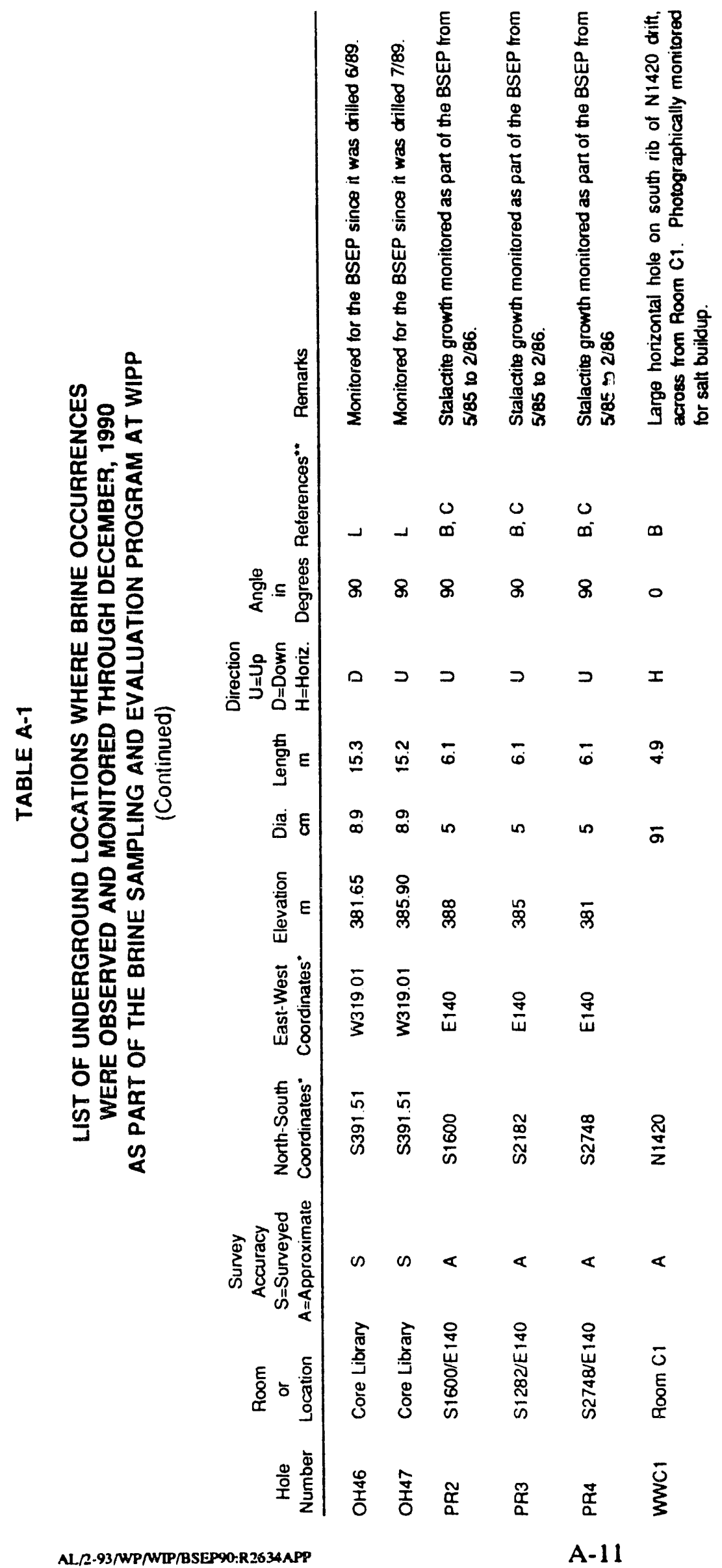




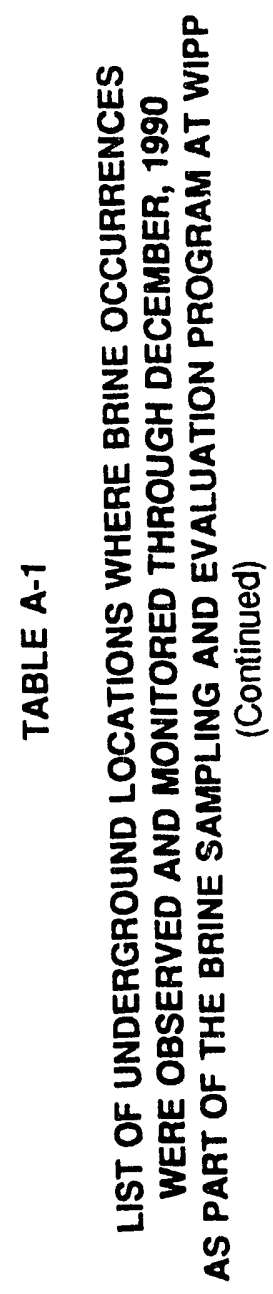

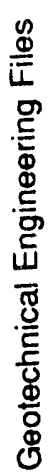

$\frac{n}{3}$

迹

$\stackrel{9}{8}$

든

U.

迥

인

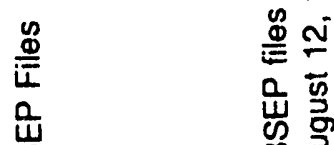

嵌 戛

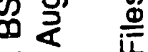

$\ddot{\mathscr{\infty}}$

ㄷำ

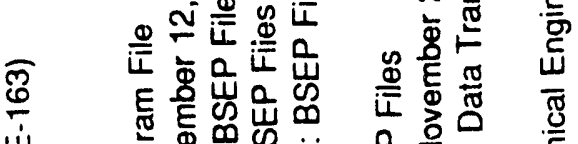

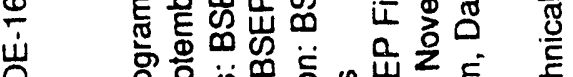

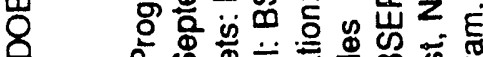

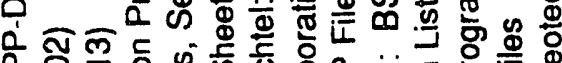

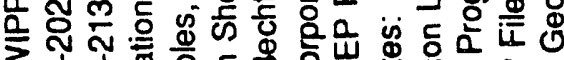

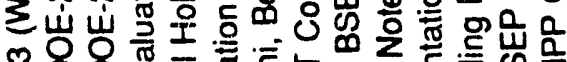

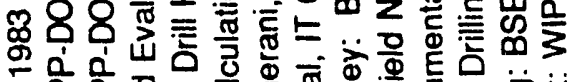

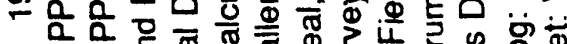
๙ क人

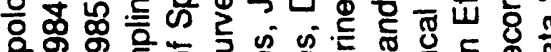

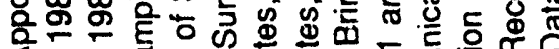

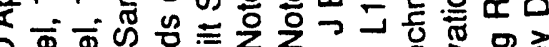

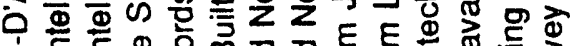

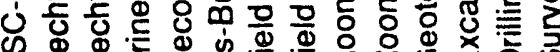

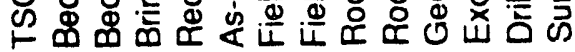

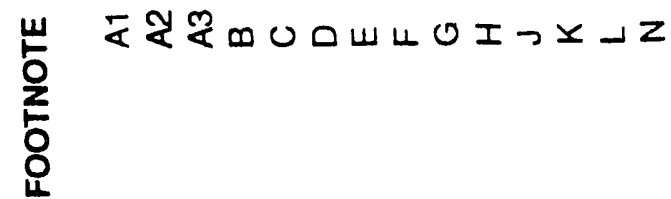


This page left intentionally blank 
This page left intentionally blank 


\section{APPENDIX A \\ BRINE ACCUMULATION}

PART I-BRINE ACCUMULATION DATA TABLES 
This page left intentionally blank 
BRINE ACCUMULATION DATA TABLE Data through December 31, 1990

\begin{tabular}{|c|c|c|c|c|c|c|c|c|}
\hline Location & Date & Time & $\begin{array}{l}\text { Liters } \\
\text { removed }\end{array}$ & $\begin{array}{c}\text { Days } \\
\text { since } \\
1 / 1 / 85 \\
\end{array}$ & $\begin{array}{c}\text { Days } \\
\text { used for } \\
\text { cale. }\end{array}$ & $\begin{array}{l}\text { Liters } \\
\text { per } \\
\text { day }\end{array}$ & $\begin{array}{c}\text { Cumulative } \\
\text { liters. } \\
\text { collected }\end{array}$ & Remarks \\
\hline $\begin{array}{l}\text { A1X01 } \\
\text { A1X01 } \\
\text { A1X01 } \\
\text { A1X01 } \\
\text { A1X01 }\end{array}$ & $\begin{array}{l}1984-10-10 \\
1985-02-26 \\
1985-03-12 \\
1985-03-20 \\
1985-03-26\end{array}$ & $\begin{array}{l}00: 00 \\
00: 00 \\
12: 20 \\
13: 30 \\
11: 25\end{array}$ & $\begin{array}{l}\text { NA } \\
\text { NA } \\
00.08 \\
00.38 \\
00.23\end{array}$ & $\begin{array}{r}0.000 \\
0.000 \\
70.514 \\
78.562 \\
84.476\end{array}$ & $\begin{array}{l}0.000 \\
0.000 \\
1.000 \\
8.048 \\
5.914\end{array}$ & $\begin{array}{l}0.000 \\
0.000 \\
0.000 \\
0.047 \\
0.008\end{array}$ & $\begin{array}{l}0.00 \\
0.00 \\
0.08 \\
0.46 \\
0.69\end{array}$ & $\begin{array}{l}\text { Room A1 completed. } \\
\text { Downhole drilled 2/21/85 to 2/26/85. } \\
\text { First time collected. } \\
\text { Brine plus some muck. } \\
\text { Muck in hole, valve leaked, some brine } \\
\text { drained back down hole. }\end{array}$ \\
\hline $\begin{array}{l}\text { A1X01 } \\
\text { A1X01 }\end{array}$ & $\begin{array}{l}1985-04-17 \\
1985-04-23\end{array}$ & $\begin{array}{l}11: 30 \\
10: 50\end{array}$ & $\begin{array}{l}00.28 \\
00.23\end{array}$ & $\begin{array}{l}106.479 \\
112.451\end{array}$ & $\begin{array}{l}6.965 \\
5.972\end{array}$ & $\begin{array}{l}0.040 \\
0.039\end{array}$ & $\begin{array}{l}1.69 \\
1.92\end{array}$ & \\
\hline A1X01 & $196 \%-04-30$ & 13:26 & 00.26 & 119.560 & 7.100 & 0.037 & 2.18 & \\
\hline $\begin{array}{l}\text { A1X01 } \\
\text { A1X01 }\end{array}$ & 1985-05-07 & $09: 10$ & 00.25 & 126.382 & 6.822 & 0.037 & 2.43 & \\
\hline $\begin{array}{l}\text { A1X0i } \\
\text { A1X01 }\end{array}$ & $\begin{array}{l}1985-05-14 \\
1985-05-21\end{array}$ & $\begin{array}{l}10: 06 \\
11: 40\end{array}$ & $\begin{array}{l}00.24 \\
00.26\end{array}$ & $\begin{array}{l}133.421 \\
140.486\end{array}$ & $\begin{array}{l}i .039 \\
7.085\end{array}$ & $\begin{array}{l}0.034 \\
0.037\end{array}$ & $\begin{array}{l}2.67 \\
2.83\end{array}$ & \\
\hline A1X01 & $1985-05-29$ & $10: \infty 0$ & $\infty 0.27$ & 148.417 & 7.931 & 0.034 & 3.20 & \\
\hline A1X01 & 1985-06-04 & $10: 20$ & 00.20 & 154.431 & 6.014 & 0.033 & 3.40 & \\
\hline $\begin{array}{l}\text { A1X01 } \\
\text { A1X01 }\end{array}$ & 1985-06-11 & $09: 40$ & 00.23 & 161.403 & 6.972 & 0.033 & 3.63 & \\
\hline $\begin{array}{l}\text { A1X01 } \\
\text { A1X01 }\end{array}$ & $\begin{array}{l}1985-06-18 \\
1985-06-25\end{array}$ & $\begin{array}{l}09: 34 \\
09: 40\end{array}$ & 00.23 & 168.399 & 6.996 & 0.033 & 3.86 & \\
\hline & $\begin{array}{l}1985-06-25 \\
1985-07-02\end{array}$ & $\begin{array}{l}09: 40 \\
11: 00\end{array}$ & 00.22 & 175.403 & 7.004 & 0.031 & 4.08 & \\
\hline A1X01 & $\begin{array}{l}1985-07-02 \\
1985-07-09\end{array}$ & $\begin{array}{l}11: 00 \\
10: 00\end{array}$ & $\begin{array}{l}00.23 \\
00.23\end{array}$ & 182.458 & 7.055 & 0.033 & 4.31 & \\
\hline A1X01 & $1985-07-16$ & $10: 55$ & $\begin{array}{l}00.23 \\
00.23\end{array}$ & 189.417 & 6.959 & 0.033 & 4.54 & \\
\hline A1X01 & $1985-07-24$ & $10: 00$ & $\begin{array}{l}00.23 \\
00.25\end{array}$ & 196.455 & 7.038 & 0.033 & 4.7 & \\
\hline $11 \times 01$ & $1985-07-30$ & $09: 32$ & $\begin{array}{l}00.25 \\
00.19\end{array}$ & 204.417 & 7.962 & 0.031 & 5.02 & \\
\hline A1X01 & $1985-08-06$ & 03:37 & $\begin{array}{l}00.19 \\
00.21\end{array}$ & 210.397 & 5.880 & 0.032 & 5.21 & \\
\hline A1X01 & $1985: 3-14$ & $09: 48$ & 00.23 & $\begin{array}{l}217.401 \\
225.408\end{array}$ & 7.004 & 0.030 & 5.42 & \\
\hline A1X01 & $1985-08-20$ & $10: 18$ & 00.19 & $\begin{array}{l}225.408 \\
231.429\end{array}$ & 8.007 & 0.029 & 5.65 & \\
\hline A1 Y01 & $1985-08-28$ & $09: 13$ & 00.23 & $\begin{array}{l}231.429 \\
239.384\end{array}$ & 6.021 & 0.032 & 5.84 & \\
\hline A1X01 & $1985-09-04$ & $09: 46$ & Ou. 19 & $\begin{array}{l}239.384 \\
246.407\end{array}$ & 7.955 & 0.029 & 6.07 & \\
\hline A1X01 & $1985-09-10$ & $09: 30$ & 00.18 & $\begin{array}{l}246.407 \\
252.396\end{array}$ & 7.023 & 0.027 & 6.26 & \\
\hline A1X01 & $1985-09-17$ & $09: 10$ & 00.18 & $\begin{array}{l}252.396 \\
259.382\end{array}$ & 5.989 & 0.030 & 6.44 & \\
\hline A1X01 & $1985-09-24$ & $09: 11$ & 00.21 & $\begin{array}{l}259.382 \\
266.383\end{array}$ & 6.986 & 0.027 & 6.63 & \\
\hline A1X01 & $1985-10-01$ & $09: 23$ & 00.21 & $\begin{array}{l}266.383 \\
273.391\end{array}$ & 7.001 & 0.030 & 6.84 & \\
\hline A1X01 & $1985-10-08$ & $12: 24$ & $\infty .20$ & $\begin{array}{l}273.391 \\
280.517\end{array}$ & 7.008 & 0.030 & 7.05 & \\
\hline A1X0i & $1985-10-15$ & $09: 43$ & 00.19 & $\begin{array}{l}280.517 \\
287.405\end{array}$ & 7.126 & 0.028 & 7.25 & Room A1 heaters turned on 10/02/85. \\
\hline A1X01 & $1985-10-23$ & $09: 55$ & 00.20 & $\begin{array}{l}287.405 \\
295.413\end{array}$ & 6.888 & 0.028 & 7.44 & \\
\hline A1X01 & $1985-10-29$ & $11: 05$ & 00.17 & $\begin{array}{l}295.413 \\
301.462\end{array}$ & 8.008 & 0.025 & 7.64 & \\
\hline A1X01 & $1985-11-05$ & $08: 50$ & 00.19 & $\begin{array}{l}301.462 \\
308.368\end{array}$ & 6.049 & 0.028 & 7.81 & \\
\hline A1X01 & $1985-11-13$ & $09: 15$ & 00.22 & $\begin{array}{l}308.368 \\
316.385\end{array}$ & 6.906 & 0.028 & 8.00 & \\
\hline A1X01 & $1985-11-21$ & $10: 40$ & 00.21 & $\begin{array}{l}316.385 \\
324.444\end{array}$ & 8.017 & 0.027 & 8.22 & \\
\hline A1X01 & $1985-11-26$ & $10: 10$ & 00.14 & $\begin{array}{l}324.444 \\
329.424\end{array}$ & 8.059 & 0.026 & 8.43 & \\
\hline A1X01 & $1985-12-04$ & $14: 13$ & 00.20 & $\begin{array}{l}329.424 \\
337.592\end{array}$ & 4.980 & 0.028 & 8.57 & \\
\hline A1X01 & $1985-12-10$ & $10: 40$ & 00.15 & $\begin{array}{l}337.592 \\
343.444\end{array}$ & 8.168 & 0.024 & 8.77 & \\
\hline A1X01 & $1985-12-17$ & $13: 59$ & 00.19 & $\begin{array}{l}343.444 \\
350.583\end{array}$ & 5.852 & 0.026 & 8.92 & \\
\hline A1Xor & $1986-01-03$ & $09: 40$ & 00.41 & $\begin{array}{l}350.583 \\
367.403\end{array}$ & 7.139 & 0.027 & 9.11 & \\
\hline A1X01 & $1986-01-08$ & $10: 20$ & 00.00 & $\begin{array}{l}367.403 \\
372.431\end{array}$ & 16.820 & 0.024 & 9.52 & \\
\hline A1X01 & $1986-01-16$ & $09: 50$ & or.25 & $\begin{array}{l}372.431 \\
380.410\end{array}$ & 5.028 & 0.018 & 9.61 & \\
\hline A1X01 & $1986-01-23$ & $10: 10$ & 00.18 & $\begin{array}{l}380.410 \\
387.424\end{array}$ & 7.979 & 0.031 & 9.86 & \\
\hline A1X01 & $1986-01-31$ & $11: 05$ & 00.21 & $\begin{array}{l}387.424 \\
395.462\end{array}$ & 7.014 & 0.026 & 10.04 & \\
\hline A1X01 & $1986-02-12$ & $10: 10$ & 00.30 & $\begin{array}{l}395.462 \\
407.424\end{array}$ & 8.038 & 0.026 & 10.25 & \\
\hline A1X01 & $1986-02-19$ & $10: 55$ & 00.18 & $\begin{array}{l}407.424 \\
414.455\end{array}$ & 11.962 & 0.025 & 10.55 & \\
\hline A1X01 & $1986-02-28$ & $14: 05$ & 00.23 & $\begin{array}{l}414.455 \\
423.587\end{array}$ & 7.031 & 0.026 & 10.73 & \\
\hline A1X01 & $1986-03-06$ & $10: 00$ & 00.15 & & 9.132 & 0.025 & 10.96 & \\
\hline A1X01 & $1986-03-13$ & $09: 30$ & 00.18 & $\begin{array}{l}429.417 \\
436.396\end{array}$ & 5.830 & 0.026 & 11.11 & \\
\hline A1X01 & $1986-03-26$ & $09: 20$ & 00.33 & $\begin{array}{l}436.396 \\
449.389\end{array}$ & 6.979 & 0.026 & 11.29 & \\
\hline A1X01 & $1986-04-02$ & 09:00 & 00.18 & $\begin{array}{l}449.389 \\
456.375\end{array}$ & 12.993 & 0.025 & 11.62 & \\
\hline A1X01 & $1986-04-08$ & $09: 09$ & 00.15 & $\begin{array}{l}456.375 \\
462.381\end{array}$ & 6.886 & 0.026 & 11.80 & \\
\hline A1X01 & $1986-04-16$ & $11: 30$ & 00.20 & $\begin{array}{l}462.381 \\
470.479\end{array}$ & 6.006 & 0.025 & 11.95 & \\
\hline A1X01 & $1986-04-24$ & $09: 35$ & 00.20 & $\begin{array}{l}470.479 \\
478.399\end{array}$ & 8.098 & 0.025 & 12.15 & \\
\hline A1X01 & $1986-04-30$ & $10: 13$ & 00.15 & $\begin{array}{l}478.399 \\
484.426\end{array}$ & 7.920 & 0.025 & 12.35 & \\
\hline
\end{tabular}


BRINE ACCUMULATION DATA TABLE (Continued) Data through December 31, 1990

\begin{tabular}{|c|c|c|c|c|c|c|c|c|}
\hline Location & Date & Time & $\begin{array}{l}\text { Liters } \\
\text { removed }\end{array}$ & $\begin{array}{c}\text { Days } \\
\text { since } \\
1 / 1 / 85 \\
\end{array}$ & $\begin{array}{l}\text { Days } \\
\text { used for } \\
\text { calc. }\end{array}$ & $\begin{array}{l}\text { Liters } \\
\text { per } \\
\text { day }\end{array}$ & $\begin{array}{c}\text { Cumulative } \\
\text { liters } \\
\text { collected } \\
\end{array}$ & Remarks \\
\hline A1X01 & $1986-05-06$ & $09: 40$ & $\infty .12$ & 490.403 & 5.977 & 0.020 & 12.62 & \\
\hline A1X01 & $1986-05-13$ & $09: 25$ & 00.19 & 497.392 & 6.989 & 0.027 & 12.81 & \\
\hline A1X01 & $1986-05-20$ & $10: 16$ & 00.18 & 504.428 & 7.036 & 0.026 & 12.99 & \\
\hline$A 1 \times 01$ & $1986-05-27$ & $15: 05$ & 00.18 & 511.628 & 7.200 & 0.025 & 13.17 & \\
\hline A1X01 & $1986-06-03$ & $09: 28$ & 00.17 & 518.394 & 6.766 & 0.025 & 13.34 & \\
\hline A1X01 & $1986-06-10$ & $10: 50$ & 00.15 & 525.451 & 7.057 & 0.021 & 13.49 & \\
\hline A1X01 & $1986-06-17$ & $09: 59$ & 00.19 & 532.416 & 6.865 & 0.027 & 13.68 & \\
\hline A1X01 & $1986-06-24$ & $10: 10$ & 00.18 & 539.424 & 7.008 & 0.026 & 13.86 & \\
\hline A1X01 & $1986-07-01$ & $12: 46$ & 00.19 & 546.532 & 7.108 & 0.027 & 14.05 & \\
\hline A1X01 & $1986-07-08$ & $10: 05$ & 00.16 & 553.420 & 6.888 & 0.023 & 14.21 & \\
\hline A1X01 & $1986-07-16$ & $09: 57$ & 00.20 & 561.415 & 7.995 & 0.025 & 14.41 & \\
\hline A1X01 & 1986-07-22 & 09:26 & 00.16 & 567.393 & 5.978 & 0.027 & 14.57 & \\
\hline A1X01 & $1986-07-29$ & $10: 05$ & $\infty .17$ & 574.420 & 7.027 & 0.024 & 14.74 & \\
\hline A1X01 & $1986-08-05$ & $10: 21$ & 00.19 & 581.431 & 7.011 & 0027 & 14.93 & \\
\hline A1X01 & $1986-08-12$ & $09: 58$ & 00.18 & 588.415 & 6.984 & 0.026 & 15.11 & \\
\hline f $1 \times 01$ & $1986-08-19$ & $10: 40$ & 00.18 & 595.444 & 7.029 & 0.026 & 15.29 & \\
\hline A1X01 & $1986-08-26$ & $10: 07$ & 00.18 & 602.422 & 6.978 & 0.026 & 15.47 & \\
\hline A1X01 & $1986-09-04$ & $10: 02$ & 00.20 & 611.418 & 8.996 & 0.022 & 15.67 & \\
\hline A1X01 & $1986-09-09$ & $10: 30$ & 00.15 & 616.438 & 5.020 & 0.030 & 15.82 & \\
\hline A1X01 & $1986-09-16$ & 09:36 & 00.18 & 623.400 & 6.962 & 0.026 & 16.00 & \\
\hline A1X01 & $1986-09-23$ & $09: 41$ & 00.18 & 630.403 & 7.003 & 0.026 & 16.18 & \\
\hline A $1 \times 01$ & $1986-10-01$ & $11: 40$ & 00.19 & 638.486 & 8.083 & 0.024 & 16.37 & \\
\hline A1X01 & $1986-10-08$ & $10: 34$ & 00.17 & 645.440 & 6.954 & 0.024 & 16.54 & \\
\hline A1X01 & $1986-10-14$ & $10: 57$ & 00.15 & 651.456 & 6.016 & 0.025 & 16.69 & \\
\hline A1X01 & $1986-11-05$ & $10: 30$ & 0.55 & 673.438 & 21.982 & 0.025 & 17.24 & \\
\hline A1X01 & $1986-11-20$ & $11: 45$ & 00.38 & 688.490 & 15.052 & 0.025 & 17.62 & \\
\hline A1X01 & $1986-12-31$ & $12: 05$ & 00.96 & 729.503 & 41.013 & 0.023 & 18.58 & \\
\hline A1X01 & 1987.02 .03 & $12: 15$ & 00.80 & 763.510 & 34.007 & 0.024 & 19.38 & \\
\hline A1X01 & $1987.03-06$ & $11: 55$ & 0.79 & 794.497 & 30.987 & 0.025 & 20.17 & \\
\hline A1X01 & $1987-03-30$ & $11: 58$ & 0.59 & 818.499 & 24.002 & 0.025 & 20.76 & \\
\hline A1X01 & 1987.05 .07 & $10: 50$ & 0.98 & 856.451 & 37.952 & 0.026 & 21.74 & \\
\hline A1X01 & $1987-06-17$ & $11: 40$ & 1.04 & 897.486 & 41.035 & 0.025 & 22.78 & \\
\hline A1X01 & $1987-07-28$ & $11: 45$ & 1.17 & 938.490 & 41.004 & 0.029 & 23.95 & \\
\hline A1X01 & $1987-09-01$ & $11: 55$ & 0.79 & 973.497 & 35.007 & 0.023 & 24.74 & $\begin{array}{l}\text { Hose came loose and some brine may have } \\
\text { drained back down hole. Trase of diesel/oil } \\
\text { in brine. }\end{array}$ \\
\hline A $1 \times 01$ & $1987-10-20$ & $11: 08$ & 1.39 & 1022.460 & 48.963 & 0.028 & 26.13 & \\
\hline A1X01 & $1987-11-19$ & $10: 30$ & 0.77 & 1052.440 & 29.980 & 0.026 & 26.90 & \\
\hline A1X01 & 1988.01 .04 & $11: 10$ & 1.20 & 1098.470 & 46.030 & 0.026 & 28.10 & \\
\hline A1X01 & $1988-02-08$ & 13:25 & 0.68 & 1133.560 & 35.090 & 0.019 & 28.78 & Lost some brine back down into hole. \\
\hline A1X01 & $1988-03-30$ & $12: 10$ & 2.25 & 1184.510 & 50.950 & 0.044 & 31.03 & $\begin{array}{l}\text { Volume high due to lack of complete } \\
\text { evacuation on } 2 / 08 / 88 \text {. }\end{array}$ \\
\hline A1X01 & 1988-05-12 & $10: 10$ & 1.09 & 1227.420 & 42.910 & 0.025 & 32.12 & \\
\hline A1X01 & $1988-07-12$ & $09: 30$ & 1.56 & 1288.400 & 60.980 & 0.026 & 33.68 & \\
\hline A1X01 & $1988-09 \cdot 27$ & $08: 25$ & 1.82 & 1365.350 & 76.950 & 0.024 & 35.50 & \\
\hline A1X01 & $1988-12-13$ & $09: 30$ & 2.35 & 1442.400 & 77.050 & 0.030 & 37.85 & \\
\hline A1X01 & $1989-03-14$ & 09:30 & 2.54 & 1533.400 & 91.000 & 0.028 & 40.39 & Check valve and hook in hole. \\
\hline A1X01 & $1989-04-06$ & $11: 55$ & NA & 1556.500 & 0.000 & 0.000 & 40.39 & Room locked. \\
\hline A1X01 & $1989-04-20$ & $10: 00$ & NA & 1570.420 & 0.000 & 0.000 & 40.39 & Room locked. \\
\hline A1X01 & $1989-05-17$ & $11: 55$ & 1.94 & 1597.500 & 64.101 & 0.030 & 42.33 & \\
\hline A1X01 & $1989-07-11$ & 10:10 & 1.30 & 1652.420 & 54.927 & 0.024 & 43.63 & \\
\hline A1X01 & $1989-09-12$ & $11: 40$ & 2.25 & 1715.490 & 63.062 & 0.036 & 45.88 & \\
\hline A1X01 & $1989-10-10$ & $09: 40$ & NA & 743.400 & 0.000 & 0.000 & 45.88 & $\begin{array}{l}\text { Installed collection device. Collection point for } \\
\text { brine located outside room. }\end{array}$ \\
\hline A1 $\times 01$ & $1989-10-20$ & $10: 42$ & 0.74 & 1753.450 & 37.960 & 0.019 & 46.62 & Some brine may have been left in hole. \\
\hline A1X01 & $1989-11-10$ & $09: 56$ & 0.72 & 1774.410 & 20.968 & 0.034 & 47.34 & \\
\hline A1X01 & $1989-11-29$ & $12: 10$ & 0.65 & 1793.510 & 19.093 & 0.034 & 47.99 & \\
\hline A1 $\times 01$ & $1989-12-12$ & $09: 10$ & 0.50 & 1806.380 & 12.875 & 0.039 & 48.49 & \\
\hline A1X01 & $1990-01-04$ & $10: 11$ & 0.63 & 1829.424 & 23.042 & 0.027 & 49.12 & \\
\hline A1X01 & $1990-01-17$ & $11: 29$ & 0.30 & 1842.478 & 13.054 & 0.023 & 49.42 & \\
\hline
\end{tabular}


BRINE ACCUMULATION DATA TABLE (Continued)

Data through December 31, 1990

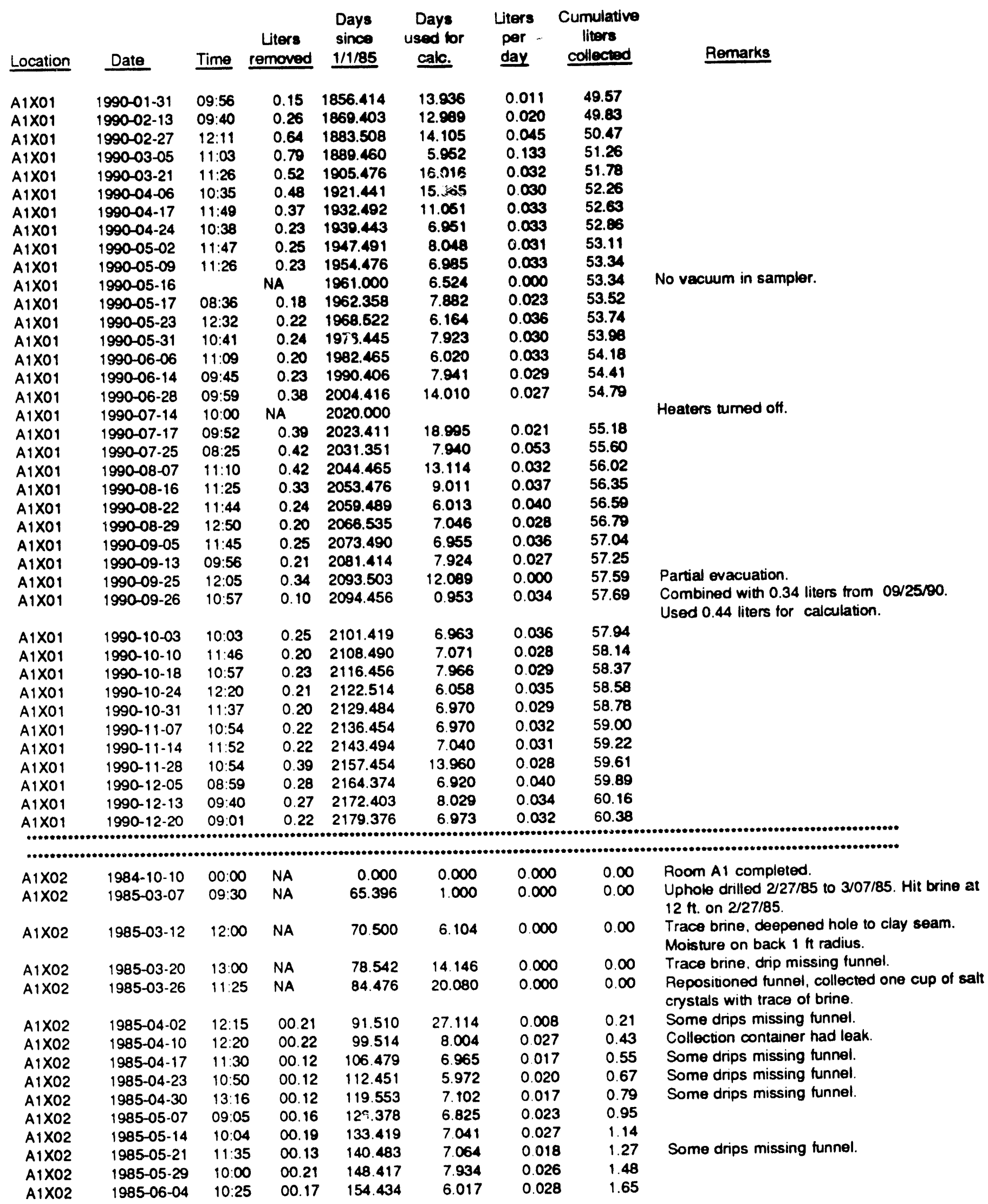


BRINE ACCUMULATION DATA TABLE (Continued) Data through December 31, 1990

\begin{tabular}{|c|c|c|c|c|c|c|c|c|}
\hline Location & Date & Time & $\begin{array}{c}\text { Liters } \\
\text { removed } \\
\end{array}$ & $\begin{array}{c}\text { Days } \\
\text { since } \\
1 / 1 / 85 \\
\end{array}$ & $\begin{array}{l}\text { Days } \\
\text { used for } \\
\text { calc. }\end{array}$ & $\begin{array}{c}\text { Liters } \\
\text { per } \\
\text { day }\end{array}$ & $\begin{array}{c}\text { Cumulative } \\
\text { liters } \\
\text { collected }\end{array}$ & Remarks \\
\hline $\mathrm{A} 1 \times 02$ & $1985-06-11$ & $09: 40$ & 00.05 & 161.403 & 6.969 & 0.007 & 1.70 & \\
\hline A $1 \times 02$ & $1985-06-18$ & 09:30 & 00.08 & 168.396 & 6.993 & 0.011 & 1.78 & $\begin{array}{l}\text { Some drips missing tunnel, big stalactite } \\
\text { formed. }\end{array}$ \\
\hline $\mathrm{A}_{1} \times 02$ & $1985-06-25$ & $09: 45$ & 00.16 & 175.406 & 7.010 & 0.023 & 1.94 & \\
\hline A $1 \times 02$ & $1985-07-02$ & $11: 00$ & 00.10 & 182.458 & 7.052 & 0.014 & 2.04 & \\
\hline A $1 \times 02$ & $1985-07-09$ & $09: 58$ & 00.15 & 189.415 & 6.957 & 0.022 & 2.19 & \\
\hline A $1 \times 02$ & $1985-07-16$ & $10: 53$ & 00.24 & 196.453 & 7.038 & 0.034 & 2.43 & \\
\hline $\mathrm{A} 1 \times 02$ & $1985-07-24$ & $09: 49$ & 00.24 & 204.409 & 7.956 & 0.030 & 2.67 & \\
\hline A $1 \times 02$ & $1985-07-30$ & $09: 30$ & 00.15 & 210.396 & 5.987 & 0.025 & 2.82 & \\
\hline $\mathrm{A} 1 \times 02$ & $1985-08-06$ & $09: 35$ & 00.14 & 217.399 & 7.003 & 0.020 & 2.96 & \\
\hline A $1 \times 02$ & $1985-08-14$ & $09: 26$ & 00.05 & 225.393 & 7.994 & 0.006 & 3.01 & \\
\hline $\mathrm{A} 1 \times 02$ & $1985-08-20$ & $10: 13$ & 00.09 & 231.426 & 6.033 & 0.015 & 3.10 & \\
\hline A1X02 & $1985-08-28$ & 09:08 & 00.06 & 239.381 & 7.955 & 0.008 & 3.16 & \\
\hline $\mathrm{A} 1 \times 02$ & $1985-09-04$ & $09: 44$ & 00.07 & 246.406 & 7.025 & 0.010 & 3.23 & \\
\hline A1X02 & $1985-09-10$ & $09: 24$ & 00.12 & 252.392 & 5.986 & 0.020 & 3.35 & \\
\hline $\mathrm{A} 1 \times 02$ & $1985-09-17$ & $09: 08$ & 00.13 & 259.381 & 6.989 & 0.019 & 3.48 & Some drips missing tunnel. \\
\hline $\mathrm{A} 1 \times 02$ & $1985-09-24$ & $09: 07$ & 00.17 & 266.380 & 6.999 & 0.024 & 3.65 & \\
\hline A1X02 & $1985-10-01$ & $09: 21$ & 00.14 & 273.390 & 7.010 & 0.020 & 3.79 & \\
\hline A1X02 & $1985-10-08$ & $12: 19$ & 00.16 & 280.513 & 7.123 & 0.022 & 3.95 & Room A1 heaters turned on 10/02/85. \\
\hline $\mathrm{A} 1 \times 02$ & $1985-10-15$ & $09: 41$ & 00.12 & 287.403 & 6.890 & 0.017 & 4.07 & \\
\hline $\mathrm{A} 1 \times 02$ & $1985-10-23$ & $09: 43$ & 00.19 & 295.405 & 8.002 & 0.024 & 4.26 & \\
\hline $\mathrm{A} 1 \times 02$ & $1985-10-29$ & $11: 02$ & 00.12 & 301.460 & 6.055 & 0.020 & 4.38 & \\
\hline A1X02 & $1985-11-05$ & $08: 46$ & 00.12 & 308.365 & 6.905 & 0.017 & 4.50 & \\
\hline A1X02 & $1985-11-13$ & $09: 16$ & 00.13 & 316.386 & 8.021 & 0.016 & 4.63 & Some drips missing funnel. \\
\hline A1X02 & $1985-11-21$ & $10: 45$ & 00.13 & 324.448 & 8.062 & 0.016 & 4.76 & Some drips missing tunnel. \\
\hline A $1 \times 02$ & $1985-12-04$ & $14: 07$ & 00.14 & 337.588 & 13.140 & 0.011 & 4.90 & \\
\hline A $1 \times 02$ & $1985-12-10$ & $10: 31$ & 00.08 & 343.438 & 5.850 & 0.014 & 4.98 & \\
\hline A1X02 & $1985-12-17$ & $13: 56$ & 00.03 & 350.581 & 7.143 & 0.004 & 5.01 & \\
\hline $\mathrm{A} 1 \times 02$ & $1986-01-03$ & $09: 40$ & 00.01 & 367.403 & 16.822 & 0.001 & 5.02 & Some drips missing funnel. \\
\hline A1X02 & $1986-01-23$ & $10: 10$ & 00.06 & 387.424 & 20.021 & 0.003 & 5.08 & New, larger funnel since $01 / 17$. \\
\hline A1X02 & $1986-01-31$ & $11: 05$ & 00.23 & 395.462 & 8.038 & 0.029 & 5.31 & \\
\hline A1X02 & $1986-02-12$ & $10: 10$ & 00.22 & 407.424 & 11.962 & 0.018 & 5.53 & \\
\hline $\mathrm{A} 1 \times 02$ & $1986-02-19$ & $10: 50$ & 00.07 & 414.451 & 7.027 & 0.010 & 5.60 & \\
\hline A1X02 & $1986-02-28$ & $14: 00$ & 00.02 & 423.583 & 9.132 & 0.002 & 5.62 & \\
\hline $\mathrm{A} 1 \times 02$ & $1986-03-13$ & $09: 30$ & 00.05 & 436.396 & 12.813 & 0.004 & 5.67 & \\
\hline A $1 \times 02$ & $1986-03-26$ & $09: 20$ & 00.05 & 449.389 & 12.993 & 0.004 & 5.72 & \\
\hline A $1 \times 02$ & $1986-04-02$ & $09: 00$ & 00.08 & 456.375 & 6.986 & 0.011 & 5.80 & \\
\hline $\mathrm{A} 1 \times 02$ & $1986-04-16$ & $11: 30$ & 00.10 & 470.479 & 14.104 & 0.007 & 5.90 & \\
\hline $\mathrm{A} 1 \times 02$ & $1986-04-24$ & 09:35 & 00.05 & 478.399 & 7.920 & 0.006 & 5.95 & \\
\hline $\mathrm{A} 1 \times 02$ & $1986-04-30$ & $10: 10$ & 00.07 & 484.424 & 6.0 .25 & 0.012 & 6.02 & \\
\hline A1X02 & $1986-05-06$ & $09: 40$ & 00.16 & 490.403 & 5.979 & 0.027 & 6.18 & \\
\hline A $1 \times 02$ & $1986-05-13$ & $09: 25$ & 00.02 & 497.392 & 6.989 & 0.003 & 6.20 & \\
\hline A $1 \times 02$ & $1986-05-20$ & $10: 16$ & 00.64 & 504.428 & 7.036 & 0.006 & 6.24 & \\
\hline A $1 \times 02$ & $1986-05-27$ & $15: 05$ & 00.15 & 511.628 & 7.200 & 0.021 & 6.39 & \\
\hline A $1 \times 02$ & $1986-06-03$ & $09: 28$ & 00.13 & 518.394 & 6.766 & 0.019 & 6.52 & \\
\hline A $1 \times 02$ & $1986-06-10$ & $10: 50$ & 00.10 & 525.451 & 7.057 & 0.014 & 6.62 & \\
\hline A $1 \times 02$ & $1986-06-17$ & $09: 59$ & 00.12 & 532.416 & 6.965 & 0.017 & 6.74 & \\
\hline A1X02 & $1986-06-24$ & $10: 10$ & 00.25 & 539.424 & 7.008 & 0.036 & 6.99 & \\
\hline $\mathrm{A} 1 \times 02$ & $1986-07-01$ & $12: 44$ & 00.23 & 546.531 & 7.107 & 0.032 & 7.22 & \\
\hline A $1 \times 02$ & $1986-07-08$ & $10: 05$ & 00.11 & 553.420 & 6.889 & 0.016 & 7.33 & \\
\hline A1X02 & $1986-07-16$ & $09: 54$ & 00.25 & 561.413 & 7.993 & 0.031 & 7.58 & \\
\hline A $1 \times 02$ & $1986-07-22$ & $09: 26$ & 00.16 & 567.393 & 5.980 & 0.027 & 7.74 & \\
\hline A $1 \times 02$ & $1986-07-29$ & $10: 05$ & 00.26 & 574.420 & 7.027 & 0.037 & 8.00 & \\
\hline A $1 \times 02$ & $1986-08-05$ & $10: 19$ & 00.22 & 581.430 & 7.010 & 0.031 & 8.22 & \\
\hline A $1 \times 02$ & $1986-08-12$ & $09: 58$ & 00.28 & 588.415 & 6.985 & 0.040 & 8.50 & \\
\hline A1 $\times 02$ & $1986-08-19$ & $10: 38$ & 00.26 & 595.443 & 7.028 & 0.037 & 8.76 & \\
\hline A $1 \times 02$ & $1986-08-26$ & $10: 07$ & 00.24 & 602.422 & 6.979 & 0.034 & 9.00 & \\
\hline $\mathrm{A} 1 \times 02$ & $1986-09-04$ & $10: 01$ & 00.35 & 611.417 & 8.995 & 0.039 & 9.35 & \\
\hline $\mathrm{A} 1 \times 02$ & $1986-09-09$ & $10: 25$ & 00.17 & 616.434 & 5.017 & 0.034 & 9.52 & \\
\hline A1 $\times 02$ & $1986-09-16$ & $09: 35$ & 00.27 & 623.399 & 6.965 & 0.039 & 9.79 & \\
\hline
\end{tabular}


BRINE ACCUMULATION DATA TABLE (Continued) Data through December 31, 1990

\begin{tabular}{|c|c|c|c|c|c|c|c|c|}
\hline Location & Date & Time & $\begin{array}{l}\text { Liters } \\
\text { removed }\end{array}$ & $\begin{array}{l}\text { Days } \\
\text { since } \\
1 / 1 / 85 \\
\end{array}$ & $\begin{array}{l}\text { Days } \\
\text { used for } \\
\text { calc. }\end{array}$ & $\begin{array}{l}\text { Liters } \\
\text { per } \\
\text { day }\end{array}$ & $\begin{array}{l}\text { Cumulative } \\
\text { liters } \\
\text { collected }\end{array}$ & Remarks \\
\hline A1X02 & $1986-09-23$ & 09:39 & 00.26 & 630.402 & 7.003 & 0.037 & 10.05 & \\
\hline $\begin{array}{l}\text { A } 1 \times 02 \\
\text { A1X02 }\end{array}$ & $\begin{array}{l}1986-10-01 \\
1986-10-08\end{array}$ & $\begin{array}{l}11: 39 \\
10: 32\end{array}$ & $\begin{array}{l}00.24 \\
00.17\end{array}$ & 638.485 & 8.083 & 0.030 & 10.29 & \\
\hline A1X02 & $1986-11-05$ & $\begin{array}{l}10: 53 \\
10: 30\end{array}$ & $\begin{array}{r}00.13 \\
0.30\end{array}$ & 651.453 & 6.014 & 0.022 & 10.59 & \\
\hline A1X02 & $1986-11-20$ & & & $\begin{array}{l}673.438 \\
688.488\end{array}$ & 21.885 & 0.014 & 10.89 & \\
\hline A1X02 & $1986-12-31$ & $\begin{array}{l}11: 43 \\
12: 10\end{array}$ & $\begin{array}{l}00.11 \\
00.14\end{array}$ & $\begin{array}{l}688.488 \\
729.507\end{array}$ & $\begin{array}{l}15.050 \\
41.019\end{array}$ & $\begin{array}{l}0.007 \\
0.003\end{array}$ & $\begin{array}{l}11.00 \\
11.14\end{array}$ & $\begin{array}{l}\text { Low readings from } 11 / 20 / 86 \text { to } 6 / 20 / 87 \text { may } \\
\text { be due to blockage in collection system. }\end{array}$ \\
\hline A1 $\times 02$ & $1987-02-03$ & $12: 16$ & NA & 763.000 & 33.493 & 0.000 & 11.14 & \\
\hline A1 $\times 02$ & $1987-03-06$ & $11: 55$ & 0.05 & 794.497 & 64.980 & 0.001 & 11.19 & \\
\hline A1X02 & $1987-03-30$ & $11: 55$ & 0.01 & 818.497 & 24.000 & 0.000 & 11.20 & Tubing plugged, unable to open. \\
\hline A1X02 & $1987-05-07$ & $10: 45$ & 0.01 & 856.448 & 1.000 & 0.000 & 11.21 & Tubing plugged, unable to open. \\
\hline A1X02 & $1987-06-30$ & $12: 00$ & 1.58 & 910.500 & 92.003 & 0.017 & 12.79 & $\begin{array}{l}\text { Removed metal tunnel, which was plugged. } \\
\text { Most of the brine collected was in the funnel. } \\
\text { Installed a large plastic funnel. }\end{array}$ \\
\hline A1 $\times 02$ & $1987-07-28$ & $11: 45$ & 0.85 & 938.490 & 27.990 & 0.030 & 13.64 & \\
\hline A1 $\times 02$ ? & $1987-09-01$ & $11: 55$ & 0.94 & 973.497 & 35.007 & 0.027 & 14.58 & \\
\hline A1X0:? & $1987-10-20$ & $10: 59$ & 1.84 & 1022.460 & 48.863 & 0.038 & 16.42 & \\
\hline A $1 \times 02$ & $1987-19-19$ & $10: 30$ & 1.09 & 1052.440 & 29.980 & 0.036 & 17.51 & \\
\hline A1X02 & $1988-01-04$ & $11: 05$ & 3.73 & 1098.460 & 46.020 & 0.081 & 21.24 & \\
\hline$A 1 \times 02$ & $1988-02-08$ & $13: 17$ & 1.65 & 1133.550 & 35.090 & 0.047 & 22.89 & \\
\hline A1X02 & $1988-03-30$ & $12: 20$ & 4.86 & 1184.510 & 50.860 & 0.095 & 27.75 & \\
\hline A1X02 & $1988-06-14$ & $09: 00$ & 5.15 & 1260.380 & 75.870 & 0.068 & 32.90 & $\begin{array}{l}\text { Removed to provide room for further } \\
\text { collection. }\end{array}$ \\
\hline A1X02 & $1988-07-12$ & $09: 30$ & 1.11 & 1288.400 & 28.020 & 0.040 & 34.01 & \\
\hline A1X02 & $1988-09-15$ & $11: 00$ & 0.18 & 1353.460 & 0.000 & 0.000 & 34.19 & $\begin{array}{l}\text { Not fully evacuated. Do not use for } \\
\text { calculation. }\end{array}$ \\
\hline A1X02 & $1988-09-27$ & $08: 30$ & 3.00 & 1365.350 & 76.950 & 0.000 & 37.19 & $\begin{array}{l}\text { Used } 3.18 \text { liters for calculation }(0.18 \text { on } 8 / 15 \\
+3.00 \text { on } 9 / 27) \text {. }\end{array}$ \\
\hline$A 1 \times 02$ & $1988-12-13$ & 09:30 & 2.50 & 1442.400 & 77.050 & 0.032 & 39.69 & \\
\hline A1X02 & $1989-03-14$ & $09: 30$ & 2.90 & 1533.400 & 90.996 & 0.033 & 42.65 & \\
\hline A $1 \times 02$ & $1989-04-06$ & $11: 55$ & NA & 1556.500 & 0.000 & 0.000 & 42.65 & Room locked. \\
\hline A $1 \times 02$ & $1989-04-20$ & $10: 00$ & NA & 570.420 & 0.000 & 0.000 & 42.65 & Room locked. \\
\hline A $1 \times 02$ & $1989-05-17$ & $12: 05$ & 4.47 & 1597.500 & 155.107 & 0.029 & 47.12 & \\
\hline$A 1 \times 02$ & $1989-07-11$ & $10: 05$ & 2.32 & 1652.420 & 54.917 & 0.042 & 49.44 & \\
\hline A1X02 & $1989-09-12$ & $11: 35$ & 2.77 & 1715.480 & 63.063 & 0.044 & 52.21 & \\
\hline A1X02 & $1989-10-10$ & $09: 25$ & 1.57 & 1743.390 & 27.909 & 0.056 & 53.78 & \\
\hline A1X02 & $1989-10-10$ & $10: 00$ & NA & 1743.420 & 0.000 & 0.000 & 53.78 & $\begin{array}{l}\text { Repositioned collection tube from funnel. } \\
\text { Collection point for brine located outside } \\
\text { room. }\end{array}$ \\
\hline A1X02 & $1989-10-20$ & $10: 44$ & NA & 1753.450 & 0.000 & 0.000 & 53.78 & No sample. \\
\hline A1X02 & $1989-11-10$ & $10: 08$ & 1.90 & 1774.420 & 31.030 & 0.061 & 55.68 & \\
\hline A1X02 & $1989-11-29$ & $12: 10$ & 0.53 & 1793.510 & 19.085 & 0.028 & 56.21 & \\
\hline A1X02 & $1989-12-12$ & $09: 20$ & 0.05 & 1806.390 & 12.882 & 0.004 & 56.26 & \\
\hline A1 $\times 02$ & $1990-01-04$ & $10: 50$ & 0.22 & 1828.451 & 23.062 & 0.010 & 56.48 & $\begin{array}{l}\text { Hose broken, some brine leaked to floor. } \\
\text { Fixed hose. funnel full of brine. }\end{array}$ \\
\hline A1X02 & $1990-01-17$ & $11: 35$ & 1.20 & 1842.483 & 13.032 & 0.092 & 57.68 & \\
\hline A1X02 & $1990-01-31$ & $10: 27$ & 0.53 & 1856.435 & 13.952 & 0.038 & 58.21 & \\
\hline A1 $\times 02$ & $1990-02-13$ & $09: 53$ & 0.29 & 1869.412 & 12.977 & 0.022 & 58.50 & \\
\hline A1X02 & $1990-02-27$ & $12: 17$ & 0.45 & 1883.512 & 14.100 & 0.032 & 58.95 & \\
\hline A1X02 & 1990-03-05 & $11: 11$ & 0.58 & 1889.466 & 5.954 & 0.097 & 59.53 & \\
\hline A1X02 & $1990-03-21$ & $11: 26$ & 0.18 & 1905.476 & 16.010 & 0.011 & 59.71 & \\
\hline A1X02 & $1990-04-06$ & $10: 40$ & 0.34 & 1921.444 & 15.968 & 0.021 & 60.05 & \\
\hline $\mathrm{A} 1 \times 02$ & $1990-04-17$ & $11: 53$ & 0.17 & 1932.495 & 11.051 & 0.015 & 60.22 & \\
\hline $\mathrm{A} 1 \times 02$ & $1990-04-24$ & $10: 40$ & 0.01 & 1939.444 & 6.949 & 0.001 & 60.23 & \\
\hline A1X02 & $1990-05-02$ & $11: 49$ & 0.23 & 1947.492 & 8.048 & 0.029 & 60.46 & \\
\hline A $1 \times 02$ & $1990-05-09$ & $11: 13$ & 0.19 & 1954.467 & 6.975 & 0.027 & 60.65 & \\
\hline A $1 \times 02$ & $1990-05-16$ & $10: 49$ & 0.23 & 1961.451 & 6.984 & 0.033 & 60.88 & \\
\hline A $1 \times 02$ & $1990-05-23$ & $12: 32$ & 0.20 & 1968.522 & 7.071 & 0.028 & 61.08 & \\
\hline A1X02 & $1990-05-31$ & $10: 29$ & 0.25 & 1976.437 & 7.915 & 0.032 & 61.33 & \\
\hline
\end{tabular}


BRINE ACCUMULATION DATA TABLE (Continued)

Data through December 31, 1990

\begin{tabular}{|c|c|c|c|c|c|c|c|}
\hline Location & Date & Time & $\begin{array}{l}\text { Liters } \\
\text { removed } \\
\end{array}$ & $\begin{array}{l}\text { Days } \\
\text { since } \\
1 / 1 / 85 \\
\end{array}$ & $\begin{array}{l}\text { Days } \\
\text { used tor } \\
\text { calc. }\end{array}$ & $\begin{array}{l}\text { Liters } \\
\text { per } \\
\text { day }\end{array}$ & $\begin{array}{c}\text { Cumulati } \\
\text { liters } \\
\text { collecte }\end{array}$ \\
\hline$A_{1} \times 02$ & $1990-06-06$ & $11: 20$ & 0.13 & 1982.472 & 6.035 & 0.022 & \\
\hline $\mathrm{A} 1 \times 02$ & $1990-06-14$ & $09: 51$ & 0.11 & 1990.410 & 7.938 & 0.014 & \\
\hline A1X02 & $1990-06-28$ & $10: 08$ & 0.24 & 2004.422 & 14.012 & 0.017 & 61.8 \\
\hline A1X02 & $1990-07-14$ & $10: 00$ & NA & 2020.000 & & & \\
\hline $\mathrm{A} 1 \times 02$ & $1990-07-17$ & $09: 51$ & 0.23 & 2023.410 & 18.988 & 0.012 & 62. \\
\hline A1X02 & $1990-07-25$ & 08:30 & 0.15 & 2031.354 & 7.944 & 0.019 & \\
\hline A1X02 & $1990-08-07$ & $10: 53$ & 0.32 & 2044.453 & 13.099 & 0.024 & 62. \\
\hline A1X02 & $1990-08-16$ & $11: 30$ & 0.11 & 2053.479 & 9.026 & 0.012 & \\
\hline A1X02 & $1990-08-22$ & $11: 52$ & 0.25 & 2059.494 & 6.015 & 0.042 & 62. \\
\hline $\mathrm{A} 1 \times 02$ & $1990-08-29$ & $12: 52$ & 0.32 & 2066.536 & 7.042 & 0.045 & \\
\hline A1X02 & $1990-09-05$ & $11: 50$ & 0.27 & 2073.493 & 6.957 & 0.039 & \\
\hline A1X02 & $1990-09-13$ & 09:58 & 0.33 & 2081.415 & 7.822 & 0.042 & \\
\hline A1X02 & $1990-09-25$ & $12: 15$ & 0.46 & 2093.510 & 12.095 & 0.038 & \\
\hline A1X02 & $1990-10-03$ & $10: 03$ & 0.28 & 2101.419 & 7.909 & 0.035 & \\
\hline A1X02 & $1990-10-10$ & $11: 43$ & 0.25 & 2108.488 & 7.069 & 0.035 & \\
\hline A1X02 & $1990-10-18$ & $11: 04$ & 0.31 & 2116.461 & 7.973 & 0.039 & \\
\hline A1X02 & $1990-10-24$ & 12:22 & 0.20 & 2122.515 & 6.054 & 0.033 & \\
\hline A1X02 & $1990-10-31$ & $11: 50$ & 0.22 & 2129.493 & 6.978 & 0.032 & \\
\hline A1X02 & $1990-11-07$ & $10: 56$ & 0.23 & 2136.456 & 6.963 & 0.033 & \\
\hline A $1 \times 02$ & $1990-11-14$ & $11: 54$ & 0.20 & 2143.496 & 7.040 & 0.028 & \\
\hline $\mathrm{A} 1 \times 02$ & $1990-11-28$ & $10: 56$ & 0.47 & 2157.456 & 13.960 & 0.034 & \\
\hline $\mathrm{A} 1 \times 02$ & $1990-12-05$ & 09:02 & 0.21 & 2164.376 & 6.920 & 0.030 & \\
\hline $\begin{array}{l}\mathrm{A} 1 \times 02 \\
\mathrm{~A} 1 \mathrm{X} 02\end{array}$ & $\begin{array}{l}1990-12-13 \\
1990-12-20\end{array}$ & $\begin{array}{l}09: 45 \\
09: 04\end{array}$ & $\begin{array}{l}0.27 \\
0.24\end{array}$ & $\begin{array}{l}2172.406 \\
2179.378\end{array}$ & $\begin{array}{l}8.030 \\
6.972\end{array}$ & $\begin{array}{l}0.034 \\
0.034\end{array}$ & \\
\hline
\end{tabular}

Heaters tumed off.

\begin{tabular}{|c|c|c|c|c|c|c|c|c|}
\hline A2X01 & $1984-07-25$ & $00: 00$ & NA & 0.000 & 0.000 & 0.000 & 0.00 & Room A2 completed. \\
\hline A2X01 & $1985-02-09$ & $00: 00$ & NA & 0.000 & 0.000 & 0.000 & 0.00 & Downhole drilled 2/04/85 to 2/09/85. \\
\hline A2X01 & $1985-02-19$ & $13: 20$ & NA & 49.556 & 1.000 & 0.000 & 0.00 & Moist muck. First entry. \\
\hline A2X01 & 1985-03-07 & $09: 30$ & 00.29 & 65.396 & 16.840 & 0.017 & 0.29 & Lots of muck, some oil. \\
\hline A2X01 & 1985-03-12 & $11: 30$ & 00.62 & 70.479 & 5.083 & 0.122 & 0.91 & Brine and muck. \\
\hline A2X01 & $1985-03-20$ & $13: 04$ & 00.52 & 78.544 & 8.065 & 0.064 & 1.43 & \\
\hline A2X01 & $1985-03-26$ & $11: 02$ & 00.38 & 84.460 & 5.916 & 0.064 & 1.81 & \\
\hline A2X01 & 1985-04-02 & $11: 58$ & 00.36 & 91.499 & 7.039 & 0.051 & 2.17 & \\
\hline A2X01 & $1985-04-10$ & $11: 53$ & 00.36 & 99.495 & 7.996 & 0.045 & 2.53 & Some muck included. \\
\hline A2X01 & 1985-04-17 & $11: 10$ & 00.27 & 106.465 & 6.970 & 0.039 & 2.80 & \\
\hline A2X01 & $1985-04-23$ & $10: 30$ & 00.24 & 112.438 & 5.973 & 0.040 & 3.04 & \\
\hline A2X01 & $1985-04-30$ & $13: 50$ & 00.29 & 119.576 & 7.138 & 0.041 & 3.33 & \\
\hline A2X01 & $1985-05-07$ & $08: 45$ & 00.25 & 126.365 & 6.789 & 0.037 & 3.58 & \\
\hline A2X01 & 1985-05-14 & $09: 40$ & 00.24 & 133.403 & 7.038 & 0.034 & 3.82 & \\
\hline A2X01 & $1985-05-21$ & $12: 08$ & 00.24 & 140.506 & 7.103 & 0.034 & 4.06 & \\
\hline A2X01 & $1985-05-29$ & $09: 00$ & 00.26 & 148.375 & 7.869 & 0.033 & 4.32 & \\
\hline A2X01 & $1985-06-04$ & 09:35 & 00.20 & 154.399 & 6.024 & 0.033 & 4.52 & \\
\hline A $2 \times 01$ & $1985-06-11$ & $09: 15$ & 00.23 & 161.385 & 6.986 & 0.033 & 4.75 & \\
\hline A2X01 & $1985-06-18$ & $09: 15$ & 00.23 & 168.385 & 7.000 & 0.033 & 4.98 & \\
\hline A2X01 & $1985-06-25$ & $09: 15$ & 00.23 & 175.385 & 7.000 & 0.033 & 5.21 & \\
\hline A2X01 & 1985-07-02 & 11.00 & 00.23 & 182.458 & 7.073 & 0.033 & 5.44 & \\
\hline A2X01 & 1985-07-09 & 09:29 & 00.22 & 189.395 & 6.937 & 0.032 & 5.66 & \\
\hline A2X01 & 1985-07-16 & $10: 30$ & 00.23 & 196.438 & 7.043 & 0.033 & 5.89 & Brine eftervesces. \\
\hline A2X01 & $1985-07-24$ & 09:39 & 00.24 & 204.402 & 7.964 & 0.030 & 6.13 & \\
\hline A2X01 & $1985-07-30$ & $08: 55$ & 00.19 & 210.372 & 5.970 & 0.032 & 6.32 & \\
\hline A2X01 & $1985-08-06$ & $09: 21$ & 00.21 & 217.390 & 7.018 & 0.030 & 6.53 & \\
\hline A2X01 & $1985-08-14$ & 09:05 & 00.25 & 225.378 & 7.988 & 0.031 & 6.78 & \\
\hline A2X01 & $1985-08-20$ & $09 \cdot 50$ & 00.19 & 231.410 & 6.032 & 0.031 & 6.97 & \\
\hline A2X01 & $1985-08-28$ & $08: 45$ & 00.21 & 239.365 & 7.955 & 0.026 & 7.18 & $\begin{array}{l}\text { Valve leaked, some brine drained back down } \\
\text { hole. }\end{array}$ \\
\hline A2X01 & $1985-09-04$ & $09: 21$ & 00.25 & 246.390 & 7.025 & 0.036 & 7.43 & \\
\hline A2X01 & $1985-09-10$ & 09:09 & 00.18 & 252.381 & 5.991 & 0.030 & 7.61 & \\
\hline A2X01 & $1985-09-17$ & $08: 50$ & 00.21 & 259.368 & 6.987 & 0.030 & 7.82 & \\
\hline
\end{tabular}


BRINE ACCUMULATION DATA TABLE (Continued)

Data through December 31, 1990

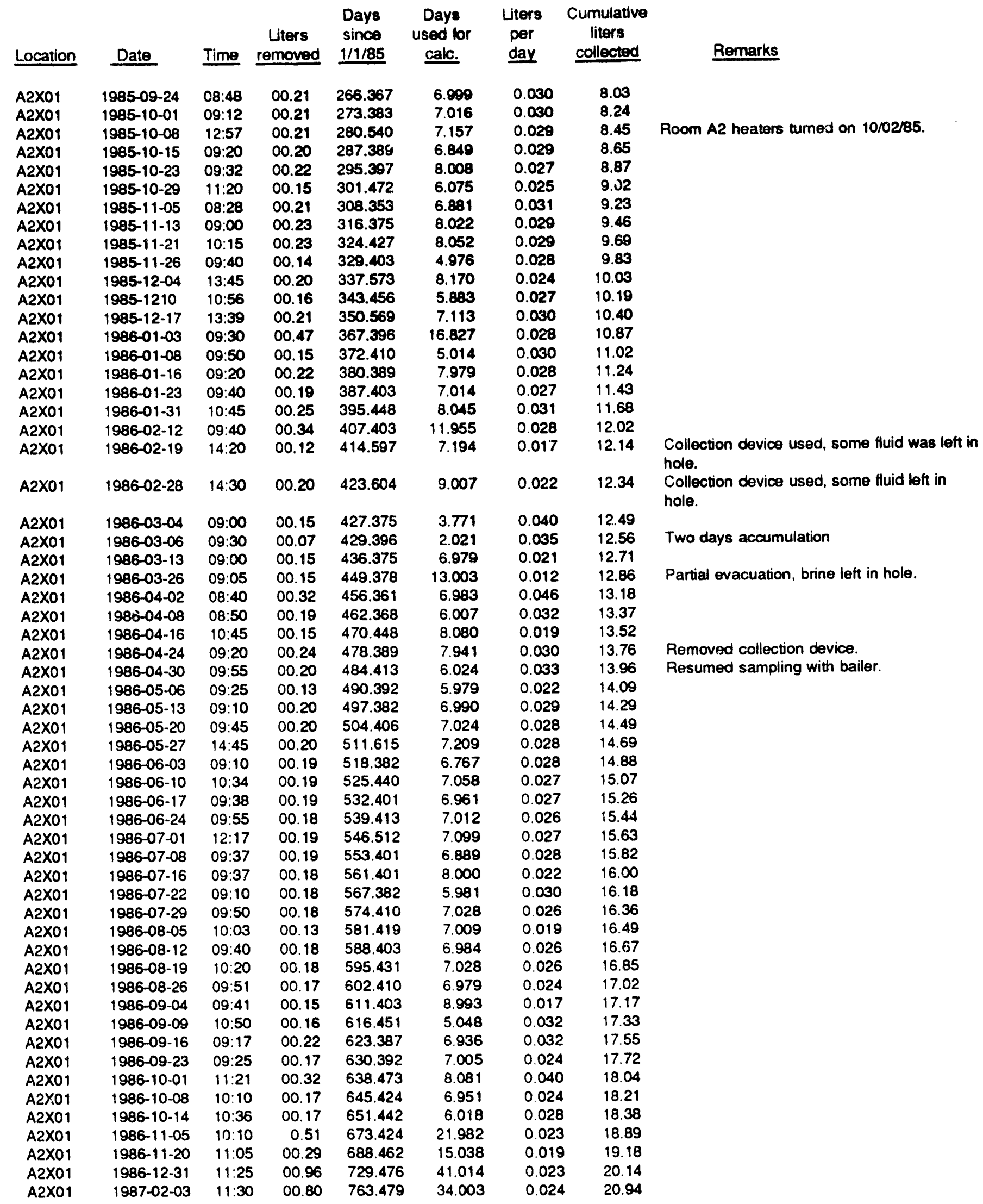


BRINE ACCUMULATION DATA TABLE (Continued) Data through December 31, 1990

\begin{tabular}{|c|c|c|c|c|c|c|c|c|}
\hline Location & Date & Time & $\begin{array}{l}\text { Liters } \\
\text { removed }\end{array}$ & $\begin{array}{l}\text { Days } \\
\text { since } \\
1 / 1 / 85 \\
\end{array}$ & $\begin{array}{l}\text { Days } \\
\text { used for } \\
\text { calc. }\end{array}$ & $\begin{array}{l}\text { Liters } \\
\text { per } \\
\text { day }\end{array}$ & $\begin{array}{l}\text { Cumulative } \\
\text { liters } \\
\text { collocted }\end{array}$ & Bemarks \\
\hline$A 2 \times 01$ & $1987-03-06$ & $11: 50$ & 0.77 & 794.493 & 31.014 & 0.025 & 21.71 & \\
\hline A2X01 & $1987-03-30$ & $11: 55$ & 0.62 & 818.503 & 24.010 & 0.026 & 22.33 & \\
\hline A2X01 & $1987-05-07$ & $10: 06$ & 0.90 & 856.421 & 37.918 & 0.024 & 23.23 & \\
\hline A2X01 & $1987-06-17$ & $11: 15$ & 1.05 & 897.469 & 41.048 & 0.026 & 24.28 & \\
\hline A2XOi & $1987-07-28$ & $12: 15$ & 1.10 & 938.510 & 41.041 & 0.027 & 25.38 & \\
\hline A2X01 & $1987-09-01$ & $11: 30$ & 0.87 & 973.479 & 34.869 & 0.025 & 26.25 & \\
\hline A2X01 & $1987-10-20$ & $10: 34$ & 1.14 & 1022.440 & 48.961 & 0.023 & 27.39 & \\
\hline A2X01 & $1987-11-19$ & $10: 10$ & 0.70 & 1052.420 & 29.880 & 0.023 & 28.09 & \\
\hline A2X01 & $1988-01-04$ & $10: 45$ & 1.43 & 1098.450 & 46.030 & 0.031 & 29.52 & \\
\hline A2X01 & $1988-02-08$ & $12: 45$ & 0.96 & 1133.530 & 35.080 & 0.027 & 30.48 & \\
\hline A2X01 & $1988-03-30$ & $12: 00$ & 1.23 & 1184.500 & 50.970 & 0.024 & 31.71 & \\
\hline A2X01 & $1988-05-12$ & $10: 30$ & 0.83 & 1227.440 & 42.940 & 0.019 & 32.54 & \\
\hline A2X01 & $1988-07-12$ & $10: 00$ & 1.51 & 1288.420 & 60.980 & 0.025 & 34.05 & \\
\hline A2X01 & $1988-09-27$ & $08: 15$ & 1.56 & 1365.340 & 76.920 & 0.020 & 35.61 & $\begin{array}{l}\text { Suction hose came off, some brine drained } \\
\text { back down hole. }\end{array}$ \\
\hline A2X01 & $1988-12-13$ & $09: 10$ & 1.61 & 1442.380 & 77.040 & 0.021 & 37.22 & Orange color. \\
\hline A2X01 & $1989-03-14$ & 08:55 & 4.04 & 1533.370 & 90.990 & 0.044 & 41.26 & \\
\hline A2X01 & $1989-04-06$ & $11: 59$ & NA & 1556.500 & 0.000 & 0.000 & 41.26 & Room locked. \\
\hline A2X01 & $1989-04-20$ & $10: 00$ & NA & 1570.420 & 0.000 & 0.000 & 41.26 & Room locked. \\
\hline A2X01 & $1989-05-17$ & $11: 20$ & 2.82 & 1597.470 & 64.100 & 0.044 & 44.08 & \\
\hline A2X01 & $1989-07-11$ & $09: 40$ & $1 . \infty$ & 1652.400 & 54.931 & 0.018 & 45.08 & \\
\hline A2X01 & $1989-09-12$ & $11: 15$ & 1.60 & 1715.470 & 63.066 & 0.025 & 46.68 & \\
\hline A2X01 & $1989-10-11$ & $10: 00$ & NA & 1744.420 & 0.000 & 0.000 & 46.68 & $\begin{array}{l}\text { Installed collection device. Collection point for } \\
\text { brine located outside heated room. }\end{array}$ \\
\hline A2X01 & $1989-10-20$ & $10: 35$ & 0.66 & 1753.440 & 37.972 & 0.017 & 47.34 & \\
\hline A2X01 & $1989-11-10$ & $09: 10$ & 0.64 & 1774.380 & 20.941 & 0.031 & 47.98 & \\
\hline A2X01 & $1989-11-29$ & $11: 19$ & 0.50 & 1793.470 & 19.090 & 0.026 & 48.48 & \\
\hline A2X01 & $1989-12-12$ & $08: 55$ & 0.33 & 1806.370 & 12.900 & 0.026 & 48.81 & \\
\hline A2X01 & $1990-01-04$ & $09: 21$ & 0.49 & 1829.390 & 23.018 & 0.021 & 49.30 & \\
\hline A2X0 9 & $1990-01-17$ & $10: 19$ & 0.30 & 1842.430 & 13.040 & 0.023 & 49.60 & \\
\hline A2X01 & $1990-01-31$ & $09: 29$ & 0.28 & 1856.395 & 13.965 & 0.020 & 49.88 & \\
\hline A2X01 & $1990-02-13$ & $10: 00$ & 0.31 & 1869.417 & 13.022 & 0.024 & 50.19 & \\
\hline A2X01 & $1990-02-27$ & $11: 35$ & 0.34 & 1883.483 & 14.066 & 0.024 & 50.53 & \\
\hline A2X01 & $1990-03-05$ & $10: 30$ & 0.30 & 1889.438 & 5.955 & 0.050 & 50.83 & \\
\hline$A 2 \times 01$ & $1990-03-21$ & $11: 00$ & 0.18 & 1905.458 & 16.020 & 0.011 & 51.01 & \\
\hline A2X01 & $1990-04-06$ & $10: 16$ & 0.36 & 1921.428 & 15.970 & 0.023 & 51.37 & \\
\hline A2X01 & $1990-04-17$ & $11: 00$ & 0.28 & 1932.458 & 11.030 & 0.025 & 51.65 & \\
\hline A2X01 & $1990-04-24$ & $09: 35$ & 0.20 & 1939.399 & 6.941 & 0.029 & 51.85 & \\
\hline A2X01 & $1990-05-02$ & $11: 08$ & 0.21 & 1947.464 & 8.065 & 0.026 & 52.06 & \\
\hline$A 2 \times 01$ & $1990-05-09$ & $10: 49$ & 0.17 & 1954.451 & 6.987 & 0.024 & 52.23 & \\
\hline A2X01 & $1990-05-16$ & $10: 08$ & 0.20 & 1961.422 & 6.971 & 0.029 & 52.43 & \\
\hline A2X01 & $1990-05-23$ & $12: 43$ & 0.21 & 1968.530 & 7.108 & 0.030 & 52.64 & \\
\hline A2X01 & $1990-06-01$ & $10: 20$ & 0.20 & 1977.431 & 8.901 & 0.022 & 52.84 & Replaced sampler. \\
\hline A2X01 & $1990-06-06$ & $10: 58$ & 0.16 & 1982.457 & 5.026 & 0.032 & 53.00 & \\
\hline A2X01 & $1990-06-14$ & $09: 20$ & 0.05 & 1990.389 & 7.932 & 0.006 & 53.05 & \\
\hline A2X01 & $1990-06-19$ & $10: 00$ & NA & 1995.000 & & & & Roof fall. Heaters turned off. \\
\hline A2X01 & $1990-06-28$ & $09: 46$ & 0.07 & 2004.407 & 14.018 & 0.005 & 53.12 & \\
\hline A2X01 & $1990-07-17$ & $10: 40$ & 0.16 & 2023.444 & 19.037 & 0.008 & 53.28 & \\
\hline A2X01 & $1990-07-25$ & $08: 22$ & NA & 2031.349 & & & 53.28 & Could not evacuate, would not hold vacusum. \\
\hline A2X01 & $1990-09-26$ & NA & & & & & & Collection device repaired. \\
\hline A2X01 & $1990-09-27$ & $10: 30$ & 0.09 & 2095.438 & 71.994 & 0.000 & 53.37 & \\
\hline A2X01 & $1990-09-28$ & $09: 40$ & 0.03 & 2096.403 & 0.965 & 0.002 & 53.40 & $\begin{array}{l}\text { Combined with } 0.09 \text { liters from } 9 / 27 / 90 \text {. Used } \\
0.12 \text { liters for calculation. }\end{array}$ \\
\hline A2X01 & $1990-10-03$ & $09: 35$ & 0.15 & 2101.399 & 4.996 & 0.030 & 53.55 & \\
\hline A2X01 & $1990-10-10$ & $11: 25$ & NA & 2108.476 & & & 53.55 & $\begin{array}{l}\text { Trace. Could not sample. Sampler does not } \\
\text { hold vacuum. Last time sampled for BSEP. }\end{array}$ \\
\hline \multirow{2}{*}{\multicolumn{9}{|c|}{ A2X02 $1984-07-25 \quad 00: 00$ NA $\quad 0.000 \quad 0.000 \quad 0.000 \quad 0.00$ Room A2 completed. }} \\
\hline & & & & & & & & Room A2 completed. \\
\hline
\end{tabular}




\section{BRINE ACCUMULATION DATA TABLE (Continued) Data through December 31, 1990}

\begin{tabular}{|c|c|c|c|c|c|c|c|c|}
\hline Location & Date & Time & $\begin{array}{c}\text { Liters } \\
\text { removed }\end{array}$ & $\begin{array}{r}\text { Days } \\
\text { since } \\
1 / 1 / 85 \\
\end{array}$ & $\begin{array}{l}\text { Days } \\
\text { used for } \\
\text { calc. }\end{array}$ & $\begin{array}{l}\text { Lters } \\
\text { per } \\
\text { day. }\end{array}$ & $\begin{array}{l}\text { Cumulative } \\
\text { liters } \\
\text { collected }\end{array}$ & Remarks \\
\hline $\mathrm{A} 2 \times 02$ & $1985-02-19$ & $13: 20$ & NA & 49.556 & 1.000 & 0.000 & 0.00 & $\begin{array}{l}\text { Uphole drilled } 2 / 11 / 85 \text { to 2/20/85, installed } \\
\text { collection device. }\end{array}$ \\
\hline $\mathrm{A} 2 \times 02$ & $1985-03-07$ & $09: 30$ & 00.34 & 65.396 & 16.840 & 0.020 & 0.34 & Moist area $1.5 \mathrm{ft}$. around the collar. \\
\hline A2X02 & $1985-03-12$ & $11: 30$ & 00.21 & 70.479 & 5.083 & 0.041 & 0.55 & Back wet, 5 ft diameter. \\
\hline $\begin{array}{l}\text { A2X02 } \\
\text { A2X02 }\end{array}$ & $1985-03-20$ & $13: 04$ & 00.31 & 78.544 & 8.065 & 0.038 & 0.86 & \\
\hline $\begin{array}{l}\mathrm{A} 2 \times 02 \\
\mathrm{~A} 2 \times 02\end{array}$ & $\begin{array}{l}1985-03-26 \\
1985-04-02\end{array}$ & $\begin{array}{l}11: 02 \\
11: 58\end{array}$ & $\begin{array}{l}00.14 \\
00.12\end{array}$ & $\begin{array}{l}84.460 \\
91.498\end{array}$ & $\begin{array}{l}5.916 \\
7.039\end{array}$ & $\begin{array}{l}0.024 \\
0.017\end{array}$ & $\begin{array}{l}1.00 \\
1.12\end{array}$ & Significant salt buildup. $4^{\prime}$ dia. wet spot on \\
\hline A2X02 & $1985-05-14$ & $09: 40$ & NA & $\begin{array}{l}126.362 \\
133.403\end{array}$ & $\begin{array}{l}13.924 \\
20.865\end{array}$ & 0.000 & 1.24 & Some drips missing funnel. \\
\hline$A 2 \times 02$ & $1985-07-09$ & $09: 25$ & 00.05 & 189.392 & $\begin{array}{l}20.865 \\
76.954\end{array}$ & $\begin{array}{l}0.000 \\
0.001\end{array}$ & $\begin{array}{l}1.24 \\
1.29\end{array}$ & Some drips missing funnel. \\
\hline $\mathrm{A} 2 \times 02$ & $1985-07-16$ & $10: 23$ & 00.06 & 196.433 & $\begin{array}{r}76.804 \\
7.041\end{array}$ & $\begin{array}{l}0.001 \\
0.009\end{array}$ & 1.35 & \\
\hline A2X02 & $1985-07-24$ & $09: 33$ & 00.02 & 204.398 & 7.965 & 0.003 & 1.37 & \\
\hline $\mathrm{A} 2 \times 02$ & $1985-08-06$ & $09: 22$ & 00.01 & 217.390 & 12.992 & 0.001 & 1.38 & \\
\hline $\mathrm{A} 2 \times 02$ & $1985-08-28$ & $08: 35$ & 00.01 & 239.358 & 21.968 & 0.000 & 1.39 & Some drips missing tunnel. \\
\hline $\mathrm{A} 2 \times 02$ & $1985-09-04$ & $09: 18$ & 00.08 & 246.387 & 7.029 & 0.011 & 1.47 & \\
\hline A2X02 & $1985-09-10$ & 09:04 & 00.02 & 252.378 & 5.991 & 0.003 & 1.49 & \\
\hline A2X02 & $1985-09-17$ & $08: 55$ & 00.02 & 259.372 & 6.994 & 0.003 & 1.51 & \\
\hline $\mathrm{A} 2 \times 02$ & $1985-10-15$ & $09: 17$ & 00.02 & 287.387 & 28.015 & 0.001 & 1.53 & Room A2 heaters tumed on 10/02/85. \\
\hline $\mathrm{A} 2 \times 02$ & $1986-01-31$ & $10: 40$ & 00.05 & 395.444 & 108.057 & 0.000 & 1.58 & \\
\hline A2X02 & $1986-02-12$ & $09: 40$ & 00.02 & 407.403 & 11.959 & 0.002 & 1.60 & \\
\hline $\mathrm{A} 2 \times 02$ & $1986-03-13$ & 09:00 & 00.01 & 436.375 & 28.972 & 0.000 & 1.61 & \\
\hline A2X02 & $1986-03-26$ & $09: 05$ & 00.07 & 449.378 & 13.003 & 0.005 & 1.68 & \\
\hline A2X02 & $1986-04-02$ & $08: 40$ & 00.10 & 456.361 & 6.883 & 0.014 & 1.78 & $\begin{array}{l}\text { High reading probably due to unplugging } \\
\text { temporary blockage in collection tube on } \\
3 / 26 / 86 \text {. }\end{array}$ \\
\hline $\mathrm{A} 2 \times 02$ & $1986-04-16$ & $10: 45$ & 00.09 & 470.448 & 14.087 & 0.006 & 1.87 & \\
\hline $\mathrm{A} 2 \times 02$ & $1986-04-24$ & $09: 20$ & 00.02 & 478.389 & 7.941 & 0.003 & 1.89 & \\
\hline $\mathrm{A} 2 \times 02$ & $1986-04-30$ & $09: 55$ & 00.02 & 484.413 & 6.024 & 0.003 & 1.91 & \\
\hline A2X02 & $1986-05-06$ & $09: 25$ & 00.02 & 490.392 & 5.979 & 0.003 & 1.93 & \\
\hline $\mathrm{A} 2 \times 02$ & $1986-05-13$ & $09: 10$ & NA & 497.382 & 6.990 & 0.000 & 1.93 & Trace collected. \\
\hline A2X02 & $1986-05-20$ & $09: 45$ & NA & 504.406 & 7.024 & 0.000 & 1.93 & Trace collected. \\
\hline A $2 \times 02$ & $1986-06-03$ & $09: 10$ & NA & 518.382 & 21.000 & 0.000 & 1.93 & Trace collected. \\
\hline A2X02 & $1986-06-10$ & $10: 34$ & NA & 525.440 & 28.058 & 0.000 & 1.93 & Trace collected. \\
\hline $\mathrm{A} 2 \times 02$ & $1986-06-17$ & $09: 38$ & 00.01 & 532.401 & 35.019 & 0.000 & 1.94 & \\
\hline A2X02 & $1986-06-24$ & $09: 50$ & 00.35 & 539.410 & 7.009 & 0.050 & 2.29 & $\begin{array}{l}\text { Very humid air. High reading probably due to } \\
\text { unplugging of temporary blockage in } \\
\text { collection tube on } 6 / 17 / 86 \text {. }\end{array}$ \\
\hline $\mathrm{A} 2 \times 02$ & $1986-07-01$ & $12: 15$ & 00.28 & 546.510 & 7.100 & 0.039 & 2.57 & \\
\hline A2X02 & $1986-07-08$ & $09: 27$ & 00.17 & 553.394 & 6.884 & 0.025 & 2.74 & \\
\hline $\mathrm{A} 2 \times 02$ & $1986-07-16$ & $09: 33$ & 00.14 & 561.398 & 8.004 & 0.017 & 2.88 & \\
\hline A2X02 & $1986-07-22$ & $09: 09$ & 00.05 & 567.381 & 5.983 & 0.008 & 2.93 & \\
\hline A2X02 & $1986-07-29$ & $09: 50$ & 00.12 & 574.410 & 7.029 & 0017 & 3.05 & \\
\hline A2X02 & 1986-08-05 & $09: 59$ & 00.07 & 581.416 & 7.006 & 0.010 & 3.12 & \\
\hline A2X02 & $1986-08-12$ & $09: 40$ & 00.12 & 588.403 & 6.987 & 0.017 & 3.24 & \\
\hline $\mathrm{A} 2 \mathrm{X} \mathrm{O} 2$ & $1986-08-19$ & $10: 20$ & 00.11 & 595.431 & 7.028 & 0.016 & 3.35 & \\
\hline A2X02 & $1986-08-26$ & $09: 50$ & 00.07 & 602.410 & 6.979 & 0.010 & 3.42 & \\
\hline A2X02 & $1986-09-04$ & $09: 40$ & 00.11 & 611.403 & 8.993 & 0.012 & 3.53 & \\
\hline $\mathrm{A} 2 \times 02$ & $1986-09-09$ & $10: 48$ & 00.06 & 616.450 & 5.047 & 0.012 & 3.59 & \\
\hline $\mathrm{A} 2 \times 02$ & $1986-09-16$ & $09: 15$ & 00.08 & 623.385 & 6.935 & 0.012 & 3.67 & \\
\hline$A 2 \times 02$ & $1986-09-23$ & $09: 23$ & 00.07 & 630.391 & 7.006 & 0.010 & 3.74 & \\
\hline A2X02 & $1986-10-01$ & $11: 10$ & 00.09 & 638.465 & 8.074 & 0.011 & 3.83 & \\
\hline A2X02 & $1986-10-08$ & $10: 08$ & 00.05 & 645.422 & 6.957 & 0.007 & 3.88 & \\
\hline A2X02 & $1986-10-14$ & $10: 35$ & 00.03 & 651.441 & 6.019 & 0.005 & 3.91 & \\
\hline A2X02 & $1986-11-05$ & $10: 08$ & 0.10 & 673.422 & 21.981 & 0.005 & 4.01 & \\
\hline A2X02 & $1986-11-20$ & $11: 03$ & 00.10 & 688.460 & 15.038 & 0.007 & 4.11 & \\
\hline A2X02 & $1986-12-31$ & $11: 20$ & 00.40 & 729.472 & 41.012 & 0.010 & 4.51 & \\
\hline A2X02 & $1987-02-03$ & $11: 25$ & 00.11 & 763.476 & 34.004 & 0.003 & 4.62 & \\
\hline
\end{tabular}


BRINE ACCUMULATION DATA TABLE (Continued)

Data through December 31, 1990

\begin{tabular}{|c|c|c|c|c|c|c|c|c|}
\hline Location & Date & Time & $\begin{array}{c}\text { Liters } \\
\text { removed }\end{array}$ & $\begin{array}{l}\text { Days } \\
\text { since } \\
1 / 1 / 85 \\
\end{array}$ & $\begin{array}{l}\text { Days } \\
\text { used for } \\
\text { calc. }\end{array}$ & $\begin{array}{l}\text { Liters } \\
\text { per } \\
\text { day }\end{array}$ & $\begin{array}{c}\text { Cumulative } \\
\text { liters } \\
\text { collected } \\
\end{array}$ & Remarks \\
\hline $\mathrm{A} 2 \times 02$ & $1987-03-06$ & $11: 50$ & 0.05 & 794.49 & 331.017 & 0.002 & 4.67 & \\
\hline $\mathrm{A} 2 \times 02$ & $1987-03-30$ & $12: 02$ & 0.03 & 818.50 & 124.008 & 0.001 & 4.70 & \\
\hline $\mathrm{A} 2 \times 02$ & $1987-05-07$ & $10: 04$ & 0.50 & 856.419 & 37.918 & 0.013 & 5.20 & \\
\hline $\mathrm{A} 2 \times 02$ & $1987-07-28$ & $12: 15$ & 0.12 & 938.510 & 82.091 & 0.001 & 5.32 & \\
\hline $\mathrm{A} 2 \times 02$ & $1987-09-01$ & $11: 30$ & 0.00 & 973.479 & 34.969 & 0.000 & 5.32 & Dry. \\
\hline A2X02 & $1987-10-20$ & $10: 34$ & 0.00 & 1022.440 & 48.961 & 0.000 & 5.32 & Dry. \\
\hline $\mathrm{A} 2 \times 02$ & $1987-11-19$ & $10: 00$ & 0.00 & 1052.420 & 29.980 & 0.000 & 5.32 & Dry. \\
\hline A2X02 & $1988-01-04$ & $10: 45$ & 0.00 & 1098.450 & 46.030 & 0.000 & 5.32 & Dry. \\
\hline $\mathrm{A} 2 \times 02$ & $1988-02-08$ & $12: 45$ & 0.00 & 1133.530 & 35.080 & 0.000 & 5.32 & Dry. \\
\hline $\mathrm{A} 2 \times 02$ & $1988-03-30$ & $12: 00$ & 0.00 & 1184.500 & 50.970 & 0.000 & 5.32 & Dry. \\
\hline $\mathrm{A} 2 \times 02$ & $1988-07-12$ & $10: 00$ & 0.00 & 1288.420 & 103.920 & 0.000 & 5.32 & Dry. \\
\hline$A 2 \times 02$ & $1988-09-27$ & $08: 15$ & 0.00 & 1365.340 & 76.930 & 0.001 & 5.36 & \\
\hline $\mathrm{A} 2 \times 02$ & $1988-12-13$ & $09: 10$ & 0 & 1442.380 & 77.040 & 0.000 & 5.36 & Dry. \\
\hline $\mathrm{A} 2 \times 02$ & $1989-04-06$ & $11: 59$ & NA & 1556.500 & 0.000 & 0.000 & 5.36 & Room locked. \\
\hline $\mathrm{A} 2 \times 02$ & $1989-04-20$ & $10: \infty 0$ & NA & 1570.420 & 0.000 & 0.000 & 5.36 & Room locked. \\
\hline $\mathrm{A} 2 \times 02$ & $1989-05-17$ & $11: 20$ & 0 & 1597.470 & 0.000 & 0.000 & 5.36 & Hole dry. \\
\hline $\mathrm{A} 2 \times 02$ & $1989-09-12$ & $11: 15$ & 0.08 & 1715.470 & 117.997 & 0.001 & 5.44 & $\begin{array}{l}\text { First sample in a long time, dry two weeks } \\
\text { ago. }\end{array}$ \\
\hline \multicolumn{9}{|c|}{ (1) } \\
\hline A3X01 & $1984-11-06$ & $00: 00$ & NA & 0.000 & 0.000 & 0.000 & 0.00 & Room A3 completed. \\
\hline A3X01 & $1985-01-14$ & $00: 00$ & NA & 0.000 & 0.000 & 0.000 & 0.00 & Downhole drilled $12 / 20 / 85$ to $1 / 14 / 85$. \\
\hline A3X01 & $1985-02-05$ & $11: 10$ & NA & 35.465 & 1.000 & 0.000 & 0.00 & Moist muck at the bottom. \\
\hline A3X01 & $1985-02-19$ & $13: 40$ & 00.30 & 49.569 & 15.104 & 0.020 & 0.30 & Some oil. First time collected. \\
\hline A3X01 & $1985-02-26$ & $13: 20$ & 00.23 & 56.556 & 6987 & 0.033 & 0.53 & Brine and oil. \\
\hline$A 3 \times 01$ & $1985-03-07$ & $09: 45$ & 00.26 & 65.406 & 8.850 & 0.029 & 0.79 & \\
\hline A3X01 & $1985-03-12$ & $11: 45$ & 00.17 & 70.490 & 5.084 & 0.033 & 0.96 & \\
\hline A3X01 & $1985-03-20$ & $13: 14$ & 00.19 & 78.551 & 8.061 & 0.024 & 1.15 & $\begin{array}{l}\text { Valve leaked, some brine drained back down } \\
\text { hole. }\end{array}$ \\
\hline$A 3 \times 01$ & $1985-03-26$ & $11: 12$ & 00.22 & 84.467 & 5.916 & 0.037 & 1.37 & \\
\hline A3X01 & $1985-04-02$ & $12: 00$ & 00.21 & 91.500 & 7.033 & 0.030 & 1.58 & \\
\hline$A 3 \times 01$ & $1985-04-10$ & $12: 00$ & 00.23 & 99.500 & 8.000 & 0.029 & 1.81 & \\
\hline A3X01 & $1985-04-17$ & $11: 20$ & 00.20 & 106.472 & 6.972 & 0.029 & 2.01 & \\
\hline A3X01 & $1985-04-23$ & $10: 41$ & 00.16 & 112.445 & 5.973 & 0.027 & 2.17 & \\
\hline A3X01 & $1985-04-30$ & $13: 35$ & 00.20 & 119.566 & 7.121 & 0.028 & 2.37 & \\
\hline A3X01 & $1985-05-07$ & $08: 55$ & 00.20 & 126.372 & 6.806 & 0.029 & 2.57 & \\
\hline A3X01 & $1985-05-14$ & $09: 56$ & 00.17 & 133.414 & 7.042 & 0.024 & 2.74 & \\
\hline A3X01 & $1985-05-21$ & $12: 00$ & 00.20 & 140.500 & 7.085 & 0.028 & 2.94 & \\
\hline A3X01 & $1985-05-29$ & $09: 25$ & 00.21 & 148.392 & 7.892 & 0.027 & 3.15 & \\
\hline A3X01 & $1985-06-04$ & $09: 55$ & 00.16 & 154.413 & 6.021 & 0.027 & 3.31 & \\
\hline A3X01 & $1985-06-11$ & $09: 25$ & 00.18 & 161.392 & 6.979 & 0.026 & 3.49 & \\
\hline A3X01 & $1985-06-18$ & $09: 27$ & 00.18 & 168.394 & 7.002 & 0.026 & 3.67 & \\
\hline A3X01 & $1985-06-25$ & $09: 30$ & 00.19 & 175.396 & 7.002 & 0.027 & 3.86 & \\
\hline A3X01 & $1985-07-02$ & $11: 00$ & 00.19 & 182.458 & 7.062 & 0.027 & 4.05 & \\
\hline A3X01 & $1985-07-09$ & $09: 50$ & 00.17 & 189.410 & 6.952 & 0.024 & 4.22 & \\
\hline A3X01 & $1985-07-16$ & $10: 50$ & 00.18 & 196.451 & 7.041 & 0.026 & 4.40 & Brine eftervesces. \\
\hline A3X01 & $1985-07-24$ & $09: 47$ & 00.21 & 204.408 & 7.957 & 0.026 & 4.61 & \\
\hline A3X01 & $1985-07-30$ & 09:30 & 00.15 & 210.396 & 5.988 & 0.025 & 4.76 & \\
\hline$A 3 \times 01$ & $1985-08-06$ & $09: 30$ & 00.17 & 217.396 & 7000 & 0.024 & 4.93 & \\
\hline$A 3 \times 01$ & $1985-08-14$ & $09: 21$ & 00.20 & 225.390 & 7.994 & 0.025 & 5.13 & \\
\hline A3X01 & $1985-08-20$ & $10: 08$ & 00.16 & 231.422 & 6.032 & 0.027 & 5.29 & \\
\hline$A 3 \times 01$ & $1985-08-28$ & $09: 05$ & 00.21 & 239.378 & 7.956 & 0.026 & 5.50 & \\
\hline$A 3 \times 01$ & $1985-09-04$ & $09: 29$ & 00.17 & 246.395 & 7017 & 0.024 & 5.67 & \\
\hline A3X01 & $1985-09-10$ & $09: 20$ & 00.15 & 252.389 & 5994 & 0.025 & 5.82 & \\
\hline A3X01 & $1985-09-17$ & $09: 06$ & 00.16 & 259.379 & 6990 & 0.023 & 5.98 & \\
\hline$A 3 \times 01$ & $1985-09-24$ & $09: 03$ & 00.17 & 266.377 & 6.998 & 0.024 & 6.15 & \\
\hline$A 3 \times 01$ & $1985-10-01$ & $09: 18$ & 00.18 & 273.387 & 7010 & 0.026 & 6.33 & \\
\hline A3X01 & $1985-10-08$ & $12: 35$ & 00.18 & 280.524 & 7.137 & 0.025 & 6.51 & Room A3 heaters turned on 10/02/85. \\
\hline A3X01 & $1985-10-15$ & $09: 35$ & 00.16 & 287.399 & 6.875 & 0.023 & 6.67 & \\
\hline A3X01 & $1985-10-23$ & $09: 40$ & 00.19 & 295.403 & 8004 & 0.024 & 6.86 & \\
\hline
\end{tabular}


BRINE ACCUMULATION DATA TABLE (Continued) Data through December 31. 1990

\begin{tabular}{|c|c|c|c|c|c|c|c|}
\hline Location & Date & Time & $\begin{array}{c}\text { Liters } \\
\text { removed }\end{array}$ & $\begin{array}{c}\text { Days } \\
\text { since } \\
1 / 1 / 85 \\
\end{array}$ & $\begin{array}{l}\text { Days } \\
\text { used for } \\
\text { calc. }\end{array}$ & $\begin{array}{l}\text { Liters } \\
\text { per } \\
\text { day }\end{array}$ & $\begin{array}{l}\text { Cumulative } \\
\text { liters } \\
\text { collected } \\
\end{array}$ \\
\hline A3X01 & $1985-10-29$ & $11: 19$ & 00.14 & 301.466 & 6.063 & 0.023 & 7.00 \\
\hline$A 3 \times 01$ & $1985-11-05$ & $08: 42$ & 00.16 & 308.362 & 6.896 & 0.023 & 7.16 \\
\hline A3X01 & $1985-11-13$ & $09: 30$ & 00.19 & 316.396 & 8.034 & 0.024 & 7.35 \\
\hline A3X01 & $1985-11-21$ & $10: 30$ & 00.19 & 324.438 & 8.042 & 0.024 & 7.54 \\
\hline A3X01 & $1985-11-26$ & $09: 55$ & 00.10 & 329.413 & 4.875 & 0.020 & 7.64 \\
\hline$A 3 \times 01$ & $1985-12-04$ & $14: 03$ & 00.18 & 337.585 & 8.172 & 0.022 & 7.82 \\
\hline A3X01 & $1985-12-10$ & $10: 46$ & 00.14 & 343.449 & 5.864 & 0.024 & 7.96 \\
\hline$A 3 \times 01$ & $12-17$ & $13: 55$ & 00.14 & 350.580 & 7.131 & 0.020 & 8.10 \\
\hline$A 3 \times 01$ & $1986-01-03$ & $10: 00$ & 00.39 & 367.417 & 16.837 & 0.023 & 8.49 \\
\hline$A 3 \times 01$ & $1986-01-08$ & $10: 10$ & 00.11 & 372.424 & 5.007 & 0.022 & 8.60 \\
\hline A3X01 & $1986-01-16$ & $09: 35$ & 00.18 & 380.399 & 7.975 & 0.023 & 8.78 \\
\hline A3X01 & $1986-01-23$ & $10: 00$ & 00.15 & 387.417 & 7.018 & 0.021 & 8.93 \\
\hline A3X01 & $1986-01-31$ & $10: 55$ & 00.18 & 395.455 & 8.038 & 0.022 & 9.11 \\
\hline$A 3 \times 01$ & $1986-02-12$ & $10: 00$ & 00.27 & 407.417 & 11.962 & 0.023 & 9.38 \\
\hline A3X01 & $1986-02-19$ & $10: 40$ & 00.15 & 414.444 & 7.027 & 0.021 & 9.53 \\
\hline A3X01 & $1986-02-28$ & $14: 20$ & 00.22 & 423.597 & 9.153 & 0.024 & 9.75 \\
\hline$A 3 \times 01$ & $1986-03-06$ & $09: 50$ & 00.14 & 429.410 & 5.813 & 0.024 & 9.89 \\
\hline$A 3 \times 01$ & $1986-03-13$ & $09: 20$ & 00.15 & 436.389 & 6.979 & 0.021 & 10.04 \\
\hline A3X01 & $1986-03-26$ & $09: 15$ & 00.30 & 449.385 & 12.996 & 0.023 & 10.34 \\
\hline A3X01 & $1986-04-02$ & $08: 50$ & 00.16 & 456.368 & 6.983 & 0.023 & 10.50 \\
\hline$A 3 \times 01$ & $1986-04-08$ & 09:05 & 00.14 & 462.378 & 6.010 & 0.023 & 10.64 \\
\hline A3X01 & $1986-04-16$ & $11: 25$ & 00.18 & 470.476 & 8.098 & 0.022 & 10.82 \\
\hline A3X01 & $1986-04-24$ & 09:30 & 00.18 & 478.396 & 7.920 & 0.023 & 11.00 \\
\hline A3X01 & $1986-04-30$ & $10: 00$ & 00.14 & 484.417 & 6.021 & 0.023 & 11.14 \\
\hline A3X01 & $1986-05-06$ & $09: 35$ & 00.14 & 490.399 & 5.982 & 0.023 & 11.28 \\
\hline A3X01 & $1986-05-13$ & $09: 20$ & 00.15 & 497.389 & 6.990 & 0.021 & 11.43 \\
\hline A3X01 & $1986-05-20$ & 10:10 & 00.15 & 504.424 & 7.035 & 0.021 & 11.58 \\
\hline A3X01 & $1986-05-27$ & $15: 00$ & 00.16 & 511.625 & 7201 & 0.022 & 11.74 \\
\hline A3X01 & $1986-06-03$ & $09: 20$ & 00.15 & 518.389 & 6.764 & 0.022 & 11.89 \\
\hline A3X01 & $1986-06-10$ & $10: 42$ & 00.16 & 525.446 & 7.057 & 0.023 & 12.05 \\
\hline A3X01 & 1986-06-17 & $09: 51$ & 00.12 & 532.410 & 6.964 & 0.017 & 12.17 \\
\hline A3X01 & $1986-06-24$ & $10: 05$ & 00.16 & 539.420 & 7.010 & 0.023 & 12.33 \\
\hline A3X01 & $1986-07-01$ & $12: 35$ & 00.16 & 546.524 & 7.104 & 0.023 & 12.49 \\
\hline$A 3 \times 01$ & $1986-07-08$ & $09: 57$ & 00.15 & 553.415 & 6.891 & 0.022 & 12.64 \\
\hline$A 3 \times 01$ & $1986-07-16$ & $09: 47$ & 0.19 & 561.408 & 7.993 & 0.024 & 12.83 \\
\hline$A 3 \times 01$ & $1986-07-22$ & $09: 23$ & 0.14 & 567.391 & 5.983 & 0.023 & 12.97 \\
\hline$A 3 \times 01$ & 1986 & $10: 00$ & 0.14 & 574.417 & 7.026 & 0.020 & 13.11 \\
\hline $\mathrm{A} 3 \times 01$ & $1986-08-05$ & $10: 15$ & 0.18 & 581.427 & 7.010 & 0.026 & 13.29 \\
\hline $\mathrm{A} 3 \times 01$ & $1986-08-12$ & $09: 50$ & 00.16 & 588.410 & 6.983 & 0.023 & 13.45 \\
\hline $\mathrm{A} 3 \times 01$ & $1986-08-19$ & $10: 35$ & 00.16 & 595.441 & 7.031 & 0.023 & 13.61 \\
\hline A3X01 & $1986-08-26$ & $10: 00$ & 00.15 & 602.417 & 6.976 & 0.022 & 13.76 \\
\hline A3X01 & $1986-09-04$ & $09: 52$ & 00.20 & 611.411 & 8.994 & 0.022 & 13.96 \\
\hline A3X01 & $1986-09-09$ & $10: 35$ & 00.12 & 616.441 & 5.030 & 0.024 & 14.08 \\
\hline A3X01 & $1986-09-16$ & $09 \cdot 29$ & 00.14 & 623.395 & 6.954 & 0.020 & 14.22 \\
\hline A3X01 & $1986-09-23$ & $09: 36$ & 00.18 & 630.400 & 7.005 & 0.026 & 14.40 \\
\hline A3X01 & $1986-10-01$ & $11: 30$ & 00.19 & 638.479 & 8.079 & 0.024 & 14.59 \\
\hline$A 3 \times 01$ & $1986-10-08$ & 10.24 & 00.14 & 645.433 & 6.954 & 0.020 & 14.73 \\
\hline A3X01 & $1986-10-14$ & $10: 47$ & 00.12 & 651.449 & 6.016 & 0.020 & 14.85 \\
\hline A3X01 & $1986-11-05$ & $10: 20$ & 0.52 & 673.431 & 21.982 & 0.024 & 15.37 \\
\hline A3X01 & $1986-11-20$ & $11: 33$ & 00.33 & 688.481 & 15.050 & 0.022 & 15.70 \\
\hline$A 3 \times 01$ & $1986-12-31$ & $11: 45$ & 00.88 & 729.490 & 41.009 & 0.021 & 16.58 \\
\hline A3X01 & $1987-02-03$ & 12.00 & 00.73 & 763.500 & 34.010 & 0.021 & 17.31 \\
\hline A3X01 & 1987-03-06 & $11: 45$ & 0.68 & 794.490 & 30.990 & 0.022 & 17.99 \\
\hline A3X01 & 1987-03-30 & $12: 00$ & 0.55 & 818.500 & 24.010 & 0.023 & 18.54 \\
\hline $\mathrm{A} 3 \times 01$ & $1987-05-07$ & $10: 39$ & 0.80 & 856.444 & 37.944 & 0021 & 19.34 \\
\hline A3X01 & $1987-06-17$ & $11: 25$ & 0.89 & 897.476 & 41.032 & 0.022 & 20.23 \\
\hline A3X01 & $1987-07-28$ & $12: 02$ & 0.92 & 938.501 & 41.025 & 0.022 & 21.15 \\
\hline$A 3 \times 01$ & $1987-09-01$ & $11: 45$ & 0.77 & 973.490 & 34.989 & 0.022 & 21.92 \\
\hline$A 3 \times 01$ & $1987-10-20$ & $10: 55$ & 1.10 & 1022.450 & 48.960 & 0.022 & 23.02 \\
\hline $\mathrm{A} 3 \times 01$ & $1987-11-19$ & $10: 20$ & 0.66 & 1052.430 & 29.980 & 0.022 & 23.68 \\
\hline
\end{tabular}


BRINE ACCUMULATION DATA TABLE (Continued)

Data through December 31, 1990

\begin{tabular}{|c|c|c|c|c|c|c|c|c|}
\hline Location & Date & Time & $\begin{array}{c}\text { Liters } \\
\text { removed }\end{array}$ & $\begin{array}{c}\text { Days } \\
\text { since } \\
1 / 1 / 85 \\
\end{array}$ & $\begin{array}{l}\text { Days } \\
\text { used tor } \\
\text { calc. }\end{array}$ & $\begin{array}{l}\text { Liters } \\
\text { per } \\
\text { tay } \\
\end{array}$ & $\begin{array}{c}\text { Cumulative } \\
\text { liters } \\
\text { collected } \\
\end{array}$ & Remarks \\
\hline A3X01 & $1988-01-04$ & $11: 00$ & 1.01 & 1098.460 & 46.030 & 0.022 & 24.69 & \\
\hline A3X01 & $1988-02-08$ & $13: 30$ & 0.67 & 1133.560 & 35.100 & 0.019 & 25.36 & \\
\hline A3X01 & $1988-03-30$ & $12: 10$ & 1.02 & 1184.510 & 50.950 & 0.020 & 26.38 & \\
\hline A3X01 & $1988-05-12$ & $10: 20$ & 0.88 & 1227.430 & 42.920 & 0.021 & 27.26 & \\
\hline A3X01 & $1988-07-12$ & $09: 40$ & 1.28 & 1288.400 & 60.970 & 0.021 & 28.54 & \\
\hline A3X01 & $1988-09-27$ & $08: 20$ & & 1365.350 & 0.000 & 0.000 & 28.54 & Cannot be sampled. Room has bad back. \\
\hline A3X01 & $1988-12-13$ & $09: 25$ & 3.35 & 1442.390 & 153.980 & 0.022 & 31.89 & \\
\hline$A 3 \times 01$ & $1989-03-14$ & $09: 15$ & 1.90 & 1533.380 & 90.993 & 0.021 & 33.79 & \\
\hline$A 3 \times 01$ & $1989-04-06$ & $12: 04$ & NA & 1556.500 & 0.000 & 0.000 & 33.79 & Room locked. \\
\hline$A 3 \times 01$ & $1989-04-20$ & $10: 00$ & NA & 1570.420 & 0.000 & 0.000 & 33.79 & Room locked. \\
\hline$A 3 \times 01$ & $1989-05-17$ & $11: 45$ & 1.42 & 1597.490 & 64.105 & 0.022 & 35.21 & \\
\hline$A 3 \times 01$ & $1989-07-11$ & $09: 55$ & 0.93 & 1652.410 & 54.923 & 0.017 & 36.14 & \\
\hline$A 3 \times 01$ & $1989-09-12$ & $11: 26$ & 1.51 & 1715.480 & 63.063 & 0.024 & 37.65 & \\
\hline A3X01 & $1989-10-10$ & $09: 43$ & NA & 1743.400 & 0.000 & 0.000 & 37.65 & $\begin{array}{l}\text { Installed collection device. Collection point for } \\
\text { brine located outside room. }\end{array}$ \\
\hline A3X01 & $1989-10-20$ & $10: 39$ & 0.36 & 1753.440 & 37.968 & 0.009 & 38.01 & \\
\hline A3X01 & $1989-11-10$ & $09: 40$ & 0.50 & 1774.400 & 20.959 & 0.024 & 38.51 & \\
\hline A3X01 & $1989-11-29$ & $11: 56$ & 0.63 & 1793.500 & 13.094 & 0.033 & 39.14 & \\
\hline A3X01 & $1989-12-12$ & $09: 00$ & 0.43 & 1806.380 & 12.878 & 0.033 & 39.57 & \\
\hline $\mathrm{A} 3 \times 01$ & $1990-01-04$ & $10: 00$ & 0.50 & 1829.417 & 23.042 & 0.022 & 40.07 & \\
\hline A3X01 & $1990-01-17$ & $11: 24$ & 0.25 & 1842.475 & 13.058 & 0.019 & 40.32 & \\
\hline$A 3 \times 01$ & $1990-01-31$ & $09: 40$ & 0.24 & 1856.403 & 13.928 & 0.017 & 40.56 & \\
\hline$A 3 \times 01$ & $1990-02-13$ & $09: 21$ & 0.31 & 1869.390 & 12.987 & 0.024 & 40.87 & \\
\hline A3X01 & $1990-02-27$ & $11: 43$ & 0.32 & 1883.488 & 14.098 & 0.023 & 41.19 & \\
\hline A3X01 & $1980-03-05$ & $10: 45$ & 0.30 & 1889.450 & 5.860 & 0.050 & 41.49 & \\
\hline A3X01 & 1990-03-21 & $11: 15$ & 0.15 & 1905.470 & 16.021 & 0.009 & 41.64 & Brine probably left in hole. \\
\hline A3X01 & $1990-04-06$ & $10: 29$ & 0.35 & 1921.440 & 15.968 & 0.022 & 41.99 & \\
\hline A3X01 & $1990-04-17$ & $11: 13$ & 0.13 & 1932.470 & 11.030 & 0.012 & 42.12 & \\
\hline A3X01 & $1990-04-24$ & $10: 26$ & 0.02 & 1939.430 & 6.968 & 0.000 & 42.14 & \\
\hline A3X01 & $1990-04-25$ & $09: 35$ & 0.15 & 1940.400 & 0.964 & 0.021 & 42.29 & $\begin{array}{l}\text { Reinstalled sampler. Combined with } 0.02 \\
\text { liters from } 04 / 24 / 90 \text {. Used } 0.17 \text { liters for } \\
\text { calculation. }\end{array}$ \\
\hline A3X01 & 1990-05-02 & $11: 20$ & 0 & 1947.470 & 7.073 & 0.000 & 42.29 & Could not sample. \\
\hline A3X01 & $1990-05-16$ & $10: 26$ & NA & 1961.430 & 0.000 & 0.000 & 42.29 & Sampler malfunction. \\
\hline A3X01 & $1990-05-23$ & $12: 35$ & 0.08 & 1968.524 & 21.052 & 0.004 & 42.37 & \\
\hline A3X01 & 1990-05-31 & $10: 51$ & 0.14 & 1976.452 & 7.928 & 0.018 & 42.51 & \\
\hline A3X01 & $1990-06-01$ & $10: 25$ & NA & 1977.434 & & & 42.51 & Replaced sampler. \\
\hline A3X01 & $1990-06-06$ & $11: 06$ & 0.49 & 1982.462 & 6.010 & 0.082 & 43.00 & \\
\hline A3X01 & $1990-06-14$ & $08: 38$ & 0.17 & 1990.360 & 7.898 & 0.022 & 43.17 & \\
\hline A3X01 & $1990-07-17$ & $10: 18$ & 0.60 & 2023.429 & 33.069 & 0.000 & 43.77 & \\
\hline A3X01 & $1990-07-18$ & $10: 11$ & 0.09 & 2024.424 & 0.995 & 0.020 & 43.86 & $\begin{array}{l}\text { Combined with } 0.60 \text { liters from } 07 / 17 / 90 \text {. } \\
\text { Used } 0.69 \text { liters for calculation. }\end{array}$ \\
\hline A3X01 & $1990-07-25$ & $08: 20$ & 0.70 & 2031.347 & 6.923 & 0.000 & 44.56 & \\
\hline A3X01 & $1990-08-07$ & $11: 21$ & 0.24 & 2044.473 & 13.126 & 0.047 & 44.80 & $\begin{array}{l}\text { Combined with } 0.7 \text { liters from } 07 / 25 / 90 \text {. Used } \\
0.94 \text { liters for calculation. }\end{array}$ \\
\hline A3X01 & $1990-08-16$ & $11 \cdot 11$ & 0.27 & 2053.466 & 8.993 & 0.030 & 45.07 & \\
\hline A3X01 & 1990-08-22 & $11: 42$ & 0.15 & 2059.488 & 6.022 & 0.025 & 45.22 & \\
\hline A3X01 & 1990-08-23 & $10: 00$ & NA & 2060.000 & & & & Heaters turned off. \\
\hline $\mathrm{A} 3 \times 01$ & 1990-08-29 & $12: 44$ & 0.16 & 2066.531 & 7.043 & 0.023 & 45.38 & \\
\hline A3X01 & 1990-09-05 & $11: 35$ & 0.15 & 2073.483 & 6.952 & 0.022 & 45.53 & \\
\hline A3X01 & $1990-09-13$ & $09: 56$ & 0.18 & 2081.414 & 7.931 & 0.023 & 45.71 & \\
\hline A3X01 & $1990-09-25$ & $12: 34$ & 0.25 & 2093.524 & 12.110 & 0.021 & 45.96 & \\
\hline A3X01 & $1990-09-26$ & $11: 09$ & 0.02 & 2094.465 & 0.941 & 0.021 & 45.98 & \\
\hline A3X01 & $1990-10-03$ & $09: 50$ & 0.16 & 2101.410 & 6.945 & 0.023 & 46.14 & \\
\hline$A 3 \times 01$ & $1990-10-10$ & $11 \cdot 40$ & 0.15 & 2108.486 & 7.076 & 0.021 & 46.29 & \\
\hline $\mathrm{A} 3 \times 01$ & $1990-10-18$ & $10: 53$ & 0.16 & 2116.453 & 7.967 & 0.020 & 46.45 & \\
\hline A3X01 & $1990-10-24$ & $12: 08$ & 0.14 & 2122.506 & 6.053 & 0.023 & 46.59 & \\
\hline A3X01 & $1990-10-31$ & $11: 35$ & 0.16 & 2129.483 & 6.977 & 0.023 & 46.75 & \\
\hline A3XO1 & $1990-11-07$ & $10: 52$ & 0.15 & 2136.453 & 6.970 & 0.022 & 46.90 & \\
\hline$A 3 \times 01$ & $1990-11-14$ & $11: 50$ & 0.15 & 2143.493 & 7.040 & 0.021 & 47.05 & \\
\hline
\end{tabular}


BRINE ACCUMULATION DATA TABLE (Continued) Data through December 31, 1990

\begin{tabular}{|c|c|c|c|c|c|c|c|c|}
\hline Location & Date & Time & $\begin{array}{c}\text { Liters } \\
\text { removed }\end{array}$ & $\begin{array}{c}\text { Days } \\
\text { since } \\
1 / 1 / 85 \\
\end{array}$ & $\begin{array}{l}\text { Days } \\
\text { used for } \\
\text { calc. }\end{array}$ & $\begin{array}{l}\text { Liters } \\
\text { per } \\
\text { day }\end{array}$ & $\begin{array}{c}\text { Cumulative } \\
\text { liters } \\
\text { collected }\end{array}$ & Remarks \\
\hline A3X01 & $1990-11-28$ & $10: 51$ & 0.30 & 2157.452 & 13.959 & 0.021 & 47.35 & \\
\hline$A 3 \times 01$ & $1990-12-05$ & $08: 55$ & 0.15 & 2164.372 & 6.920 & 0.022 & 47.50 & \\
\hline A3X01 & $1990-12-13$ & $09: 35$ & 0.17 & 2172.399 & 8.027 & 0.021 & 47.67 & \\
\hline A3X01 & $1990-12-20$ & $08: 56$ & 0.18 & 2179.372 & 6.973 & 0.026 & 47.85 & \\
\hline \multicolumn{9}{|c|}{ | } \\
\hline $\mathrm{A} 3 \times 02$ & $1984-11-06$ & $00: 00$ & NA & 0.000 & 0.000 & 0.000 & 0.00 & Room A3 completed. \\
\hline $\mathrm{A} 3 \times 02$ & $1985-01-22$ & $00: 00$ & NA & 0.000 & 0.000 & 0.000 & 0.00 & Uphole drilled $1 / 15 / 85$ to $1 / 22 / 85$. \\
\hline $\mathrm{A} 3 \times 02$ & $1985-02-05$ & $11: 10$ & NA & 35.465 & 1.000 & 0.000 & 0.00 & No drips noticed. \\
\hline $\mathrm{A} 3 \times 02$ & $1985-02-19$ & $13: 40$ & 00.11 & 49.569 & 15.104 & 0.007 & 0.11 & First time collected. \\
\hline $\mathrm{A} 3 \times 02$ & $1985-02-26$ & $13: 20$ & 00.11 & 56.556 & 6.987 & 0.016 & 0.22 & Wet spot within $1.5 \mathrm{ft}$. radius. \\
\hline $\mathrm{A} 3 \times 02$ & $1985-03-07$ & $09: 45$ & 00.21 & 65.406 & 8.850 & 0.024 & 0.43 & Moist area on back, approximately $1 \mathrm{ft}$ radius. \\
\hline $\mathrm{A} 3 \times 02$ & $1985-03-12$ & $11: 45$ & 00.11 & 70.490 & 5.084 & 0.022 & 0.54 & Wet spot on back 3 it diameter. \\
\hline $\mathrm{A} 3 \times 02$ & $1985-03-20$ & $13: 14$ & 00.01 & 78.551 & 8.061 & 0.001 & 0.55 & \\
\hline $\mathrm{A} 3 \times 02$ & $1985-03-26$ & $11: 12$ & 00.28 & 84.467 & 5.916 & 0.047 & 0.83 & Tube found plugged. Brine in tubing. \\
\hline$A 3 \times 02$ & $1985-04-02$ & $12: 00$ & 00.08 & 91.500 & 7.033 & 0.011 & 0.91 & \\
\hline $\mathrm{A} 3 \times 02$ & $1985-04-10$ & $12: 02$ & 00.05 & 99.501 & 8.001 & 0.006 & 0.96 & Tube plugged. \\
\hline $\mathrm{A} 3 \times 02$ & $1985-04-17$ & $11: 20$ & 00.11 & 106.472 & 6.971 & 0.016 & 1.07 & \\
\hline $\mathrm{A} 3 \times 02$ & $1985-04-23$ & $10: 40$ & 00.09 & 112.444 & 5.972 & 0.015 & 1.16 & \\
\hline $\mathrm{A} 3 \times 02$ & $1985-04-30$ & $13: 29$ & 00.12 & 119.562 & 7.118 & 0.017 & 1.28 & \\
\hline $\mathrm{A} 3 \times 02$ & $1985-05-07$ & $08: 50$ & 00.13 & 126.368 & 6.806 & 0.019 & 1.41 & \\
\hline $\mathrm{A} 3 \times 02$ & $1985-05-14$ & $09: 53$ & 00.13 & 133.412 & 7.044 & 0.018 & 1.54 & \\
\hline $\mathrm{A} 3 \times 02$ & $1985-05-21$ & $11: 55$ & 00.13 & 140.497 & 7.085 & 0.018 & 1.67 & \\
\hline $\mathrm{A} 3 \times 02$ & $1985-05-29$ & $09: 20$ & 00.14 & 148.389 & 7.892 & 0.018 & 1.81 & \\
\hline $\mathrm{A} 3 \times 02$ & $1985-06-04$ & $09: 50$ & 00.10 & 154.410 & 6.021 & 0.017 & 1.91 & \\
\hline $\mathrm{A} 3 \times 02$ & $1985-06-11$ & $09: 20$ & 00.13 & 161.389 & 6.979 & 0.019 & 2.04 & \\
\hline $\mathrm{A} 3 \times 02$ & $1985-06-18$ & $09: 25$ & 00.12 & 168.392 & 7.003 & 0.017 & 2.16 & \\
\hline $\mathrm{A} 3 \times 02$ & $1985-06-25$ & $09: 25$ & 00.13 & 175.392 & 7.000 & 0.019 & 2.29 & \\
\hline$A 3 \times 02$ & 1985-07-02 & $11: 00$ & 00.10 & 182.458 & 7.066 & 0.014 & 2.39 & \\
\hline $\mathrm{A} 3 \times 02$ & $1985-07-09$ & $09: 44$ & 00.02 & 189.406 & 6.948 & 0.003 & 2.41 & \\
\hline $\mathrm{A} 3 \times 02$ & $1985-07-16$ & $10: 46$ & 00.02 & 196.449 & 7.043 & 0.003 & 2.43 & \\
\hline $\mathrm{A} 3 \times 02$ & $1985-07-24$ & $09: 45$ & 00.19 & 204.406 & 7.957 & 0.024 & 2.62 & $\begin{array}{l}\text { High volume probably due to unplugging } \\
\text { temporary blockage in collection tube on } \\
7 / 16 / 85 \text {. }\end{array}$ \\
\hline $\mathrm{A} 3 \times 02$ & $1985-07-30$ & $09: 25$ & 00.08 & 210.392 & 5.986 & 0.013 & 2.70 & \\
\hline $\mathrm{A} 3 \times 02$ & $1985-08-06$ & $09: 28$ & 00.08 & 217.394 & 7.002 & 0.011 & 2.78 & \\
\hline $\mathrm{A} 3 \times 02$ & 1985-08-14 & $09: 10$ & 00.10 & 225.382 & 7.988 & 0.013 & 2.88 & \\
\hline $\mathrm{A} 3 \times 02$ & $1985-08-20$ & $10: 00$ & 00.08 & 231.417 & 6.035 & 0.013 & 2.96 & \\
\hline $\mathrm{A} 3 \times 02$ & $1985-08-28$ & $08: 58$ & 00.09 & 239.374 & 7.957 & 0.011 & 3.05 & \\
\hline $\mathrm{A} 3 \times 02$ & $1985-09-04$ & $09: 26$ & 00.09 & 246.393 & 7.019 & 0.013 & 3.14 & \\
\hline $\mathrm{A} 3 \times 02$ & $1985-n 9-10$ & $09: 14$ & 00.08 & 252.385 & 5.992 & 0.013 & 3.22 & \\
\hline $\mathrm{A} 3 \times 02$ & $1985-09-17$ & $09: 05$ & 00.09 & 259.378 & 6.993 & 0.013 & 3.31 & \\
\hline $\mathrm{A3} \times 02$ & $1985-09-24$ & $09: 03$ & 00.08 & 266.377 & 6.999 & 0.011 & 3.39 & \\
\hline A3X02 & $1985-10-01$ & $09: 15$ & 00.07 & 273.385 & 7.008 & 0.010 & 3.46 & \\
\hline A3X02 & $1985-10-08$ & $12: 33$ & 00.09 & 280.523 & 7.138 & 0.013 & 3.55 & Room A3 heaters turned on 10/02/85. \\
\hline $\mathrm{A} 3 \times 02$ & $1985-10-15$ & $09: 31$ & 00.06 & 287.397 & 6.874 & 0.009 & 3.61 & \\
\hline $\mathrm{A} 3 \times 02$ & $1985-10-23$ & 0937 & 00.07 & 295.401 & 8.004 & 0.009 & 3.68 & \\
\hline $\mathrm{A} 3 \times 02$ & $1985-10-29$ & $11: 09$ & 00.08 & 301.465 & 6.064 & 0.013 & 3.76 & \\
\hline $\mathrm{A} 3 \times 02$ & $1985-11-05$ & $08: 39$ & 00.04 & 308.360 & 6.895 & 0.006 & 3.80 & \\
\hline $\mathrm{A} 3 \times 02$ & $1985-11-13$ & $09: 28$ & 00.08 & 316.394 & 8.034 & 0.010 & 3.88 & \\
\hline $\mathrm{A} 3 \times 02$ & $1985-11-21$ & $10: 25$ & 00.05 & 324.434 & 8.040 & 0.006 & 3.93 & \\
\hline $\mathrm{A} 3 \times 02$ & $1985-12-04$ & $13: 56$ & 00.10 & 337.581 & 13.147 & 0.008 & 4.03 & \\
\hline $\mathrm{A} 3 \times 02$ & $1985-12 \cdot 10$ & $10: 42$ & 00.05 & 343.446 & 5.865 & 0.009 & 4.08 & \\
\hline A3 $\times 02$ & $1985-12-17$ & $13: 50$ & 00.03 & 350.576 & 7.130 & 0.004 & 4.11 & \\
\hline $\mathrm{A} 3 \times 02$ & $1986-01-03$ & $10: 20$ & 00.13 & 367.417 & 16.841 & 0.008 & 4.24 & \\
\hline A3X02 & $1986-01.08$ & $10: 10$ & 00.03 & 372.424 & 5.007 & 0.006 & 4.27 & \\
\hline A3X02 & $1986-01-16$ & 09:35 & 00.05 & 380.399 & 7.975 & 0.006 & 4.32 & \\
\hline A3X02 & $1986-01-31$ & $10: 55$ & 00.01 & 385.455 & 15.056 & 0.001 & 4.33 & Trace $<0.01$ liters of brine. \\
\hline $\mathrm{A} 3 \times 02$ & $1986-04-24$ & $09: 30$ & 00.01 & 478.396 & 82.941 & 0.000 & 4.34 & \\
\hline A3X02 & $1986-05-06$ & $09: 35$ & 00.02 & 490.399 & 12.003 & 0.002 & 4.36 & \\
\hline
\end{tabular}


BRINE ACCUMULATION DATA TABLE (Continued)

Data through December 31, 1990

\begin{tabular}{|c|c|c|c|c|c|c|c|c|}
\hline Location & Date & Time & $\begin{array}{l}\text { Liters } \\
\text { removed }\end{array}$ & $\begin{array}{c}\text { Days } \\
\text { since } \\
1 / 1 / 85 \\
\end{array}$ & $\begin{array}{l}\text { Days } \\
\text { used for } \\
\text { calc. }\end{array}$ & $\begin{array}{l}\text { Liters } \\
\text { per } \\
\text { day }\end{array}$ & $\begin{array}{c}\text { Cumulative } \\
\text { liters } \\
\text { collected }\end{array}$ & Remarks \\
\hline $\begin{array}{l}\mathrm{A} 3 \times 02 \\
\mathrm{~A} 3 \times 02\end{array}$ & $\begin{array}{l}1986-05-27 \\
1986-06-03\end{array}$ & $\begin{array}{l}15: 00 \\
09: 20\end{array}$ & $\begin{array}{l}\text { NA } \\
00.03\end{array}$ & $\begin{array}{l}511.625 \\
518.389\end{array}$ & $\begin{array}{l}21.226 \\
27.990\end{array}$ & $\begin{array}{l}0.000 \\
0.001\end{array}$ & $\begin{array}{l}4.36 \\
4.39\end{array}$ & Trace. \\
\hline$A 3 \times 02$ & $1986-06-10$ & $10: 42$ & NA & 525.446 & 7.057 & 0.000 & 4.39 & Trace. \\
\hline A3X02 & $1986-06-17$ & $09: 51$ & NA & 532.410 & 14.021 & 0.000 & 4.39 & Trace. \\
\hline $\mathrm{A} 3 \times 02$ & $1986-07-01$ & $12: 32$ & 00.03 & 546.522 & 28.133 & 0.001 & 4.42 & \\
\hline $\mathrm{A} 3 \times 02$ & $1986-07-08$ & $09: 57$ & 00.01 & 553.415 & 6.893 & 0.001 & 4.43 & \\
\hline $\mathrm{A} 3 \times 02$ & $1986-07-29$ & $10: 00$ & NA & 574.417 & 21.002 & 0.000 & 4.43 & Trace. \\
\hline $\mathrm{A} 3 \times 02$ & $1986-08-12$ & $09: 50$ & NA & 588.410 & 34.895 & 0.000 & 4.43 & Dry. \\
\hline $\mathrm{A} 3 \times 02$ & $1986-08-19$ & $10: 33$ & NA & 595.440 & 42.025 & 0.000 & 4.43 & Dry. \\
\hline $\mathrm{A} 3 \times \mathrm{O} 2$ & $1986-09-04$ & 09:50 & NA & 611.410 & 57.995 & 0.000 & 4.43 & Trace. \\
\hline $\mathrm{A} 3 \times 02$ & $1986-09-23$ & $09: 33$ & 00.00 & 630.398 & 76.883 & 0.000 & 4.43 & Dry. \\
\hline $\mathrm{A} 3 \times 02$ & $1986-10-01$ & $11: 28$ & NA & 638.478 & 8.080 & 0.000 & 4.43 & Dry. \\
\hline $\mathrm{A} 3 \times 02$ & $1986-10-08$ & $10: 22$ & NA & 645.432 & 6.954 & 0.000 & 4.43 & Dry. \\
\hline $\mathrm{A} 3 \times 02$ & $1986-10-14$ & $10: 44$ & 00.00 & 651.447 & 6.015 & 0.000 & 4.43 & Dry. \\
\hline $\mathrm{A} 3 \times 02$ & $1986-11-05$ & $10: 25$ & NA & 673.431 & 27.999 & 0.000 & 4.43 & Dry. \\
\hline $\mathrm{A} 3 \times \mathrm{O} 2$ & $1986-11-20$ & $11: 30$ & NA & 688.479 & 43.047 & 0.000 & 4.43 & Dry. \\
\hline $\mathrm{A} 3 \times 02$ & $1986-12-31$ & $11: 45$ & NA & 729.490 & 84.058 & 0.000 & 4.43 & Dry. \\
\hline $\mathrm{A} 3 \times 02$ & $1987-02-03$ & $12: 02$ & NA & 763.000 & 117.568 & 0.000 & 4.43 & Dry. \\
\hline $\mathrm{A} 3 \times 02$ & $1987-03-06$ & $11: 45$ & NA & 794.490 & 149.058 & 0.000 & 4.43 & Dry. \\
\hline $\mathrm{A} 3 \times 02$ & $1987-03-30$ & $12: 00$ & 0.00 & 818.500 & 24.010 & 0.000 & 4.43 & Ory. \\
\hline $\mathrm{A} 3 \times 02$ & $1987-05-07$ & $10: 39$ & 0.00 & 856.444 & 61.954 & 0.000 & 4.43 & Dry. \\
\hline $\mathrm{A} 3 \times 02$ & $1987-07-28$ & 12:02 & 0.00 & 938.501 & 144.011 & 0.000 & 4.43 & Dry. \\
\hline $\mathrm{A} 3 \times \mathrm{O} 2$ & $1987-09-01$ & $11: 48$ & 0.00 & 973.492 & 34.991 & 0.000 & 4.43 & Dry. \\
\hline A3X02 & $1987-10-20$ & $10: 50$ & 0.00 & 1022.450 & 48.958 & 0.000 & 4.43 & Dry. \\
\hline $\mathrm{A} 3 \times 02$ & $1987-11-19$ & $10: 20$ & 0.00 & 1052.430 & 29.980 & 0.000 & 4.43 & Dry. \\
\hline $\mathrm{A} 3 \times 02$ & $1988-01-04$ & $11: 00$ & 0.00 & 1098.460 & 46.030 & 0.000 & 4.43 & Dry. \\
\hline $\mathrm{A} 3 \times 02$ & $1988-02-08$ & 13:30 & 0.00 & 1133.560 & 35.100 & 0.000 & 4.43 & Dry. \\
\hline A3X02 & $1988-03-30$ & 12:10 & 0.00 & 1184.510 & 50.950 & 0.000 & 4.43 & Dry. \\
\hline $\mathrm{A} 3 \times 02$ & 1988-07-12 & 09:40 & 0.00 & 1288.400 & 103.890 & 0.000 & 4.43 & Dry. \\
\hline $\mathrm{A} 3 \times 02$ & $1988-09-27$ & 08:25 & 0.00 & 1365.350 & 76.950 & 0.000 & 4.43 & Dry. \\
\hline A3X02 & $1988-12-13$ & 09:25 & 0 & 1442.390 & 77.040 & 0.000 & 4.43 & Dry. \\
\hline $\mathrm{A} 3 \times 02$ & $1989-04-06$ & $12: 04$ & NA & 1556.500 & 0.000 & 0.000 & 4.43 & Room locked. \\
\hline $\mathrm{A} 3 \times 02$ & 1989-04-20 & $10: 00$ & NA & 1570.420 & 0.000 & 0.000 & 4.43 & Room locked. \\
\hline A3X02 & 1989-05-17 & $11: 45$ & 0 & 1597.490 & 155.098 & 0.000 & 4.43 & Hole dry. \\
\hline A3X02 & $\begin{array}{l}1989-09-12 \\
198 \ldots\end{array}$ & $\begin{array}{l}11: 20 \\
1 \ldots \ldots . . .\end{array}$ & 0 & 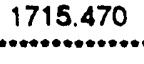 & $\begin{array}{l}117.982 \\
\ldots\end{array}$ & 0.000 & 4.43 & Hole dry. \\
\hline \multicolumn{9}{|c|}{ 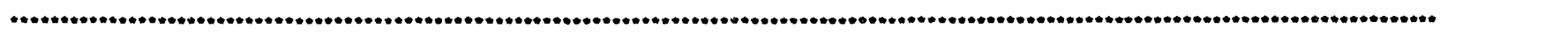 } \\
\hline BX01 & 1984-06-02 & $00: 00$ & NA & 0.000 & 0.000 & 0.000 & 0.00 & Room B completed. \\
\hline BX01 & $1985-01-27$ & $00: 00$ & NA & 0.000 & 1.000 & 0.000 & 0.00 & $\begin{array}{l}\text { Downhole drilled } 1 / 24 / 85 \text { to } 1 / 27 / 85 \text {. Wet } \\
\text { core and brine encountered } 1 / 26 / 85 \text { at } 35 \text { to } \\
36.5 \text { teet. }\end{array}$ \\
\hline BX01 & $1985-02-05$ & $11: 00$ & $\infty 0.39$ & 35.458 & 11.041 & 0.035 & 0.39 & First ume collected. \\
\hline BX01 & $1985-02-11$ & $12: 00$ & 00.72 & 41.500 & 6.042 & 0.119 & 1.11 & \\
\hline BX01 & $1985-02-19$ & $13: 00$ & 00.70 & 49.542 & 8.042 & 0.087 & 1.81 & \\
\hline BX01 & $1985-02-26$ & $12: 45$ & 00.61 & 56.531 & 6.989 & 0.087 & 2.42 & \\
\hline BX01 & $1985-03-07$ & $09: 15$ & 00.70 & 65.385 & 8.854 & 0.079 & 3.12 & \\
\hline BX01 & $1985-03-12$ & $11: 45$ & 00.41 & 70.490 & 5.105 & 0.080 & 3.53 & \\
\hline BX01 & $1985-03-20$ & $12: 50$ & 00.61 & 78.535 & 8.045 & 0.076 & 4.14 & \\
\hline BX01 & $1985-03-26$ & $10: 45$ & 00.45 & 84.448 & 5.913 & 0.076 & 4.59 & \\
\hline BX01 & 1985-04-02 & $11: 44$ & 00.51 & 91.489 & 7.041 & 0.072 & 5.10 & \\
\hline BX01 & $1985-04-10$ & $11: 38$ & 00.55 & 99.485 & 7.996 & $0.06 !$ & 5.65 & \\
\hline BX01 & $1985-04-17$ & $11: 00$ & 00.45 & 106.458 & 6.973 & 0.065 & 6.10 & \\
\hline BX01 & $1985-04-23$ & $10: 05$ & 00.38 & 112.420 & 5.962 & 0.064 & 6.48 & Room B heaters tumed on $4 / 23 / 85$. \\
\hline BX01 & $1985-05-01$ & $11: 40$ & 00.46 & 120.486 & 8.066 & 0.057 & 6.94 & \\
\hline BX01 & $1985-06-04$ & $09: 30$ & 02.00 & 154.396 & 33.910 & 0.059 & 8.94 & First check in several weeks. \\
\hline BX01 & $1985-07-16$ & $10: 15$ & 02.34 & 196.427 & 42.031 & 0.056 & 11.28 & Brine effervesces. \\
\hline BX01 & $1985-08-26$ & 13:56 & 02.38 & 237.581 & 41.154 & 0.058 & 13.66 & $\begin{array}{l}\text { Room temp. } 98 \text { degrees } F \text {. at collar, } 103 \mathrm{~F} \text { in } \\
\text { center of room. }\end{array}$ \\
\hline BX01 & $1985-10-08$ & $12: 00$ & 02.27 & 280.500 & 42.919 & 0.053 & 15.93 & \\
\hline BX01 & $1985-11-21$ & 10:05 & 02.42 & 324.420 & 43.920 & 0.055 & 18.35 & \\
\hline
\end{tabular}


BRINE ACCUMULATION DATA TABLE (Continued)

Data through December 31, 1990

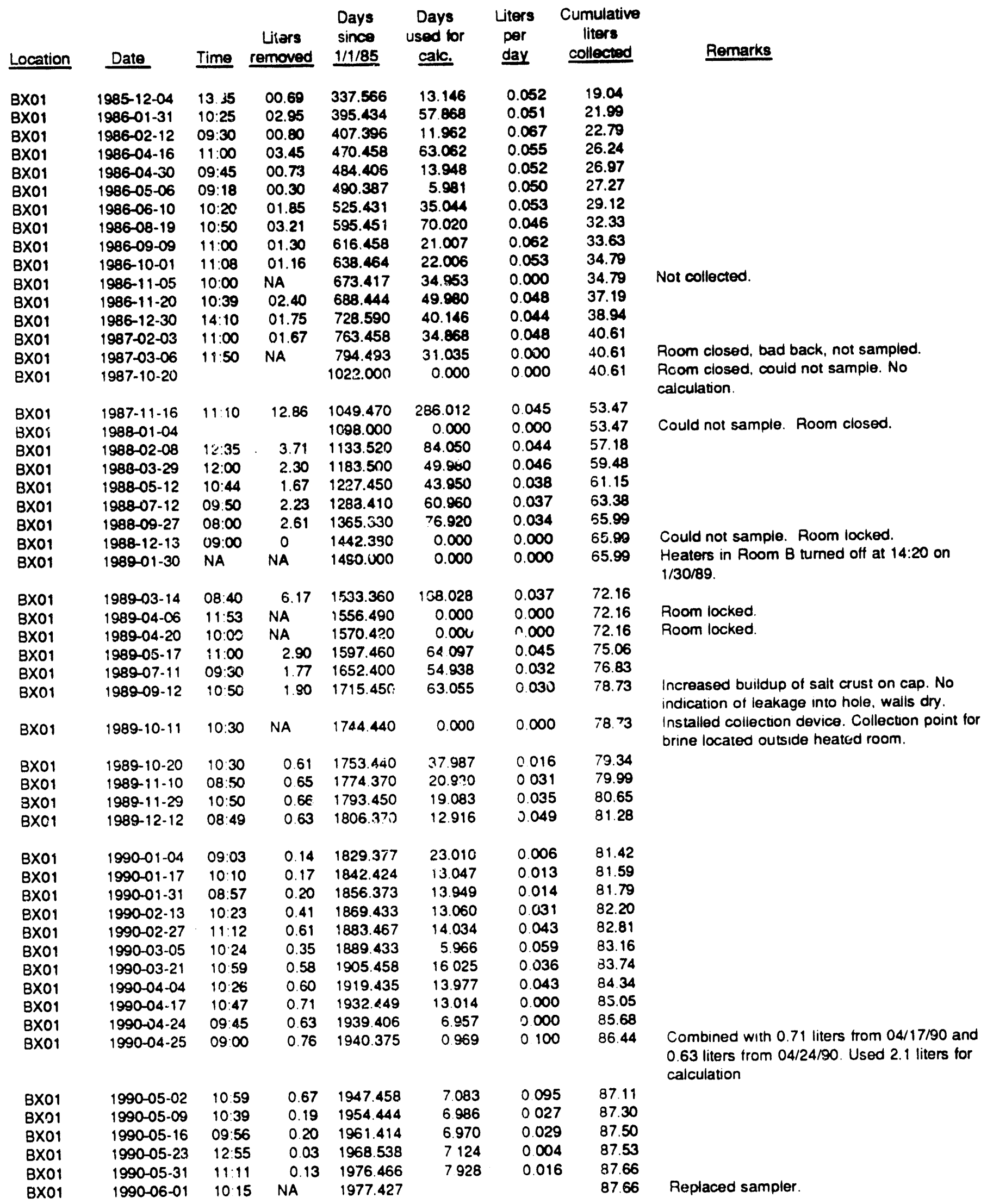


BRINE ACCUMULATION DATA TABLE (Continued) Data through December 31, 1990

\begin{tabular}{|c|c|c|c|c|c|c|c|c|}
\hline Location & Date & Time & $\begin{array}{l}\text { Liters } \\
\text { removed }\end{array}$ & $\begin{array}{c}\text { Days } \\
\text { since } \\
1 / 1 / 85 \\
\end{array}$ & $\begin{array}{l}\text { Days } \\
\text { used for } \\
\text { calc. }\end{array}$ & $\begin{array}{c}\text { Liters } \\
\text { per } \\
\text { day }\end{array}$ & $\begin{array}{c}\text { Cumulative } \\
\text { liters } \\
\text { collected }\end{array}$ & Remarks \\
\hline BX01 & $1990-06-06$ & $10: 53$ & 0.41 & 1982.453 & 5.887 & 0.068 & 88.07 & \\
\hline BX01 & $1990-06-14$ & $09: 14$ & 0.28 & 1990.385 & 7.932 & 0.035 & 88.35 & \\
\hline BX01 & $1990-06-20$ & 08:42 & 0.05 & 1996.362 & 5.977 & 0.008 & 88.40 & \\
\hline BX01 & $1990-06-28$ & 09:35 & 0.40 & 2004.399 & 8.037 & 0.050 & 88.80 & \\
\hline BX01 & $1990-07-17$ & $10: 20$ & 0.12 & 2023.431 & 19.032 & 0.000 & 88.92 & Partial evacuation. \\
\hline BX01 & $1990-07-18$ & $09: 54$ & 0.47 & 2024.412 & 0.981 & 0.029 & 89.39 & $\begin{array}{l}\text { Combined with } 0.12 \text { liters from } 07 / 17 / 90 \text {. } \\
\text { Used } 0.59 \text { liters for calculation. }\end{array}$ \\
\hline BX01 & $1990-07-25$ & $08: 10$ & 0.38 & 2031.340 & 6.928 & 0.055 & 89.77 & \\
\hline BX01 & $1990-08-07$ & $11: 40$ & 0.40 & 2044.486 & 13.146 & 0.030 & 90.17 & \\
\hline BX01 & $1990-08-16$ & $10: 52$ & 0.31 & 2053.453 & 8.967 & 0.035 & 90.48 & \\
\hline BX01 & $1990-08-22$ & $11: 40$ & 0.21 & 2059.486 & 6.033 & 0.035 & 90.69 & \\
\hline BX01 & $1990-08-29$ & $12: 27$ & 0.09 & 2066.519 & 7.033 & 0.013 & 90.78 & \\
\hline BX01 & $1990-09-05$ & $11: 10$ & 0.12 & 2073.465 & 6.946 & 0.017 & 90.90 & \\
\hline BX01 & $1890-09-13$ & $09: 27$ & 0.30 & 2081.394 & 7.929 & 0.038 & 91.20 & \\
\hline BX01 & $1990-09-25$ & $12: 51$ & 0.48 & 2093.535 & 12.141 & 0.000 & 91.68 & Brine probably left in hole. \\
\hline BX01 & $1990-09-26$ & $11: 18$ & 0.02 & 2094.471 & 0.936 & 0.038 & 91.70 & $\begin{array}{l}\text { Combined with } 0.48 \text { liters from } 09 / 25 / 90 \text {. } \\
\text { Used } 0.50 \text { liters for calculation. }\end{array}$ \\
\hline BX01 & $1990-10-03$ & $09: 25$ & 0.21 & 2101.392 & 6.921 & 0.030 & 91.91 & \\
\hline BX01 & $1990-10-10$ & $11: 10$ & 0.23 & 2108.465 & 7.073 & 0.033 & 92.14 & \\
\hline BX01 & $1990-10-18$ & $10: 46$ & 0.23 & 2116.449 & 7.984 & 0.029 & 92.37 & \\
\hline BX01 & $1990-10-24$ & $12: 02$ & 0.20 & 2122.501 & 6.052 & 0.033 & 92.57 & \\
\hline BX01 & 1990-10-31 & $11: 26$ & 0.22 & 2129.476 & 6.975 & 0.032 & 92.79 & \\
\hline BX01 & $1990-11-07$ & $10: 49$ & 0.15 & 2136.451 & 6.975 & 0.022 & 92.94 & \\
\hline BX01 & $1990-11-14$ & 12:01 & 0.26 & 2143.501 & 7.050 & 0.037 & 93.20 & \\
\hline BX01 & $1990-11-28$ & $10: 41$ & 0.49 & 2157.445 & 13.844 & 0.035 & 93.69 & \\
\hline BX01 & $1990-12-05$ & $08: 53$ & 0.21 & 2164.370 & 6.925 & 0.030 & 93.90 & \\
\hline BX01 & $1990-12-13$ & 09:30 & 0.10 & 2172.396 & 8.026 & 0.012 & 94.00 & \\
\hline BX01 & $1990-12-20$ & $08: 47$ & 0.38 & 2179.366 & 6.970 & 0.055 & 94.38 & \\
\hline \multicolumn{9}{|c|}{ 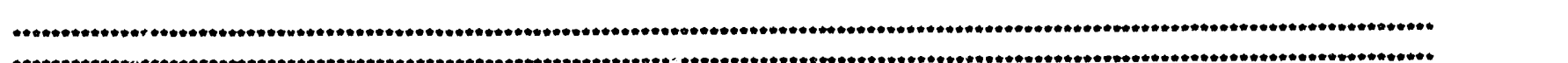 } \\
\hline & 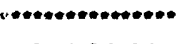 & 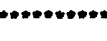 & & & & & 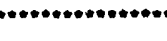 & \\
\hline $\mathrm{BX02}$ & $1984-06-02$ & $00: 00$ & NA & 0.000 & 0.000 & 0.000 & 0.00 & Room B completed. \\
\hline $\mathrm{BX02}$ & $1985-02-01$ & $00: 00$ & NA & 0.000 & 0.000 & 0.000 & 0.00 & Uphole drilled 1/29/85 to 2/01/85. \\
\hline BX02 & $1985-02-05$ & $11: 00$ & NA & 35.458 & 1.000 & 0.000 & 0.00 & No drips noticed. \\
\hline $\mathrm{B} \times 02$ & $1985-02-19$ & $13: 00$ & NA & 49.542 & 15.084 & 0.000 & 0.00 & Tubing plugged. \\
\hline $\mathrm{BX02}$ & $1985-03-12$ & $11: 45$ & NA & 70.490 & 36.032 & 0.000 & 0.00 & Trace, tew drops in jug. \\
\hline $\mathrm{BX02}$ & $1985-03-20$ & $12: 50$ & 00.10 & 78.535 & 44.077 & 0.002 & 0.10 & \\
\hline $\mathrm{BX02}$ & $1985-03-26$ & $10: 45$ & 00.12 & 84.448 & 5.913 & 0.020 & 0.22 & \\
\hline $\mathrm{BX02}$ & $1985-04-02$ & $11: 44$ & 00.10 & 91.489 & 7.041 & 0.014 & 0.32 & \\
\hline BX02 & $1985-04-10$ & $11: 38$ & $0 n .21$ & 99.465 & 7.996 & 0.026 & 0.53 & \\
\hline $\mathrm{BXO2}$ & $1985-04-17$ & $11: 00$ & 00.13 & 106.458 & 6.973 & 0.019 & 0.66 & \\
\hline BX02 & $1985-04-23$ & $10: 05$ & 00.01 & 112.420 & 5.962 & 0.002 & 0.67 & $\begin{array}{l}\text { Room } B \text { heaters turned on } 4 / 23 / 85 \text {. Low } \\
\text { reading probably due to partial blockage of } \\
\text { collection tube. }\end{array}$ \\
\hline $\mathrm{BXO2}$ & $1985-05-01$ & $11: 31$ & 00.12 & 120.480 & 8.060 & 0.015 & 0.79 & \\
\hline BX02 & $1985-06-04$ & $09: 25$ & 00.50 & 154.392 & 33.912 & 0.015 & 1.29 & First check in several weeks. \\
\hline $\mathrm{BX02}$ & $1985-07-16$ & $10: 00$ & 00.16 & 196.417 & 42.025 & 0.004 & 1.45 & Changed funnel. \\
\hline $\mathrm{BX02}$ & $1985-10-08$ & $12: 00$ & 00.04 & 280.500 & 84.083 & 0.000 & 1.49 & \\
\hline $\mathrm{BX02}$ & $1986-01-17$ & $09: 00$ & 00.26 & 381.375 & 100.875 & 0.003 & 1.75 & Changed tunnel. \\
\hline $8 \times 0 ?$ & $1986-01-31$ & $10: 15$ & NA & 395.427 & 14.052 & 0.000 & $1-5$ & \\
\hline $\mathrm{BXO2}$ & $1986-04-16$ & $11: 00$ & NA & 470.458 & 89.083 & 0.000 & 1.75 & $\begin{array}{l}\text { Trace in plastic tube, salt buildup in tube and } \\
\text { container. }\end{array}$ \\
\hline $\mathrm{BX02}$ & $1986-08-19$ & $10: 50$ & NA & 595.451 & 214.076 & 0.000 & 1.75 & Dry. \\
\hline $\mathrm{BX} 02$ & $1986-10-01$ & $11: 05$ & 00.00 & 638.462 & 257.087 & 0.000 & 1.75 & Dry. \\
\hline BX02 & $1986-11-05$ & $10: 00$ & NA & 673.417 & 34.955 & 0.000 & 1.75 & Dry. \\
\hline $\mathrm{BX02}$ & $1986-11-20$ & $10: 37$ & NA & 688.442 & 49.980 & 0.000 & 1.75 & Dry. \\
\hline $\mathrm{BX02}$ & $1986-12-30$ & $14: 05$ & NA & 728.587 & 90.125 & 0.000 & 1.75 & Dry. \\
\hline $\mathrm{BXO2}$ & $1987-02-03$ & NA: & NA & 763.000 & 125.538 & 0.000 & 1.75 & \\
\hline $\mathrm{BX02}$ & $1987-03-06$ & $11: 50$ & NA & 794.493 & 156.031 & 0.000 & 1.75 & Room locked, bad back. \\
\hline
\end{tabular}


BRINE ACCUMULATION DATA TABLE (Continued) Data through December 31, 1990

\begin{tabular}{|c|c|c|c|c|c|c|c|c|}
\hline Location & Date & Time & $\begin{array}{c}\text { Liters } \\
\text { removed }\end{array}$ & $\begin{array}{c}\text { Days } \\
\text { since } \\
1 / 1 / 85 \\
\end{array}$ & $\begin{array}{l}\text { Days } \\
\text { used for } \\
\text { calc. }\end{array}$ & $\begin{array}{l}\text { Liters } \\
\text { per } \\
\text { day }\end{array}$ & $\begin{array}{c}\text { Cumulative } \\
\text { liters } \\
\text { collected }\end{array}$ & Remarks \\
\hline BX02 & $1987-10-20$ & & & 1022.000 & 0.000 & 0.000 & 1.75 & $\begin{array}{l}\text { Room locked, could not sample. No } \\
\text { calculation. }\end{array}$ \\
\hline $\mathrm{BXO2}$ & $1987-11-16$ & $11: 10$ & & 1049.470 & 0.000 & 0.000 & 1.75 & $\begin{array}{l}\text { Funnel not hooked up. No collection, no } \\
\text { calculation. }\end{array}$ \\
\hline $\mathrm{BXO2}$ & $1988-01-04$ & & & 1098.000 & 0.000 & 0.000 & 1.75 & Could not sample. Room locked. \\
\hline $\mathrm{BXO2}$ & $1988-02-08$ & $12: 35$ & 0.00 & 1133.520 & 370.520 & 0.000 & 1.75 & Dry. \\
\hline $8 \times 02$ & $1988-03-30$ & $12: 00$ & 0.00 & 1184.500 & 50.980 & 0.000 & 1.75 & Dry. \\
\hline $\mathrm{BX02}$ & $1988-07-12$ & $09: 55$ & 0.00 & 1288.410 & 103.910 & 0.000 & 1.75 & Dry. \\
\hline $\mathrm{BXO2}$ & $1988-09-27$ & 08:10 & 0.00 & 1365.340 & 76.230 & 0.000 & 1.75 & Dry. \\
\hline $\mathrm{BXO2}$ & $1988-12-13$ & $09: 00$ & 0 & 1442.380 & 0.000 & 0.000 & 1.75 & Could not sample. Foom locked. \\
\hline $\mathrm{BXO2}$ & $1989-01-30$ & NA & NA & 1490.000 & 0.000 & 0.000 & 1.75 & $\begin{array}{l}\text { Heaters in Room B turned off at } 14: 20 \text { on } \\
1 / 30 / 89 .\end{array}$ \\
\hline $\begin{array}{l}\mathrm{B} \times 02 \\
\mathrm{BXO2}\end{array}$ & $\begin{array}{l}1989-04-06 \\
1989-04-20\end{array}$ & $\begin{array}{l}11: 53 \\
\text { NA }\end{array}$ & $\begin{array}{l}\text { NA } \\
\text { NA }\end{array}$ & $\begin{array}{l}1556.490 \\
1570.000\end{array}$ & $\begin{array}{l}0.000 \\
0.000\end{array}$ & $\begin{array}{l}0.000 \\
0.000\end{array}$ & $\begin{array}{l}1.75 \\
1.75\end{array}$ & $\begin{array}{l}\text { Room locked. } \\
\text { Room locked. }\end{array}$ \\
\hline $\mathrm{B} \times \mathrm{O} 2$ & $1989-05-17$ & $11: 00$ & 0 & 1597.460 & 232.118 & 0.000 & 1.75 & Hole dry. \\
\hline $\mathrm{BXO2}$ & $1989-09-12$ & $10: 45$ & NA & 1715.450 & 0.000 & 0.000 & 1.75 & $\begin{array}{l}\text { No collection device. Stalactites forming. Last } \\
\text { time sampled for BSEP. }\end{array}$ \\
\hline \multirow{2}{*}{\multicolumn{9}{|c|}{ 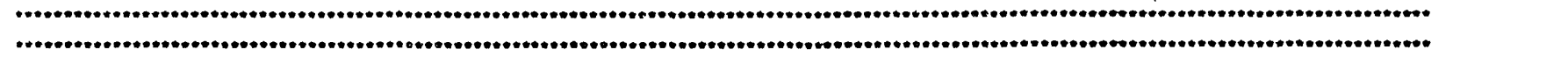 }} \\
\hline & & & & & & & & \\
\hline $\mathrm{DH} 15$ & $1984-03-13$ & $00: 00$ & NA & 0.000 & 0.000 & 0.000 & 0.00 & Dritt excavated at N1104/E 1688.5 . \\
\hline $\mathrm{DH} 15$ & $1984-03-21$ & $00: 00$ & NA & 0.000 & 0.000 & 0.000 & 0.00 & Uphole drilled $3 / 20 / 84$ to $3 / 21 / 84$. \\
\hline $\mathrm{DH} 15$ & $1986-05-20$ & $00: 00$ & NA & 0.000 & 0.000 & 0.000 & 0.00 & Collection tunnel and container installed. \\
\hline $\mathrm{DH} 15$ & $1986-05-27$ & $15: 00$ & NA & 511.625 & 1.000 & 0.000 & 0.00 & Trace of brine. First time collected. \\
\hline $\mathrm{DH} 15$ & $1986-06-03$ & $09: 15$ & 00.02 & 518.385 & 7.760 & 0.003 & 0.02 & \\
\hline $\mathrm{DH} 15$ & $1986-06-10$ & $10: 40$ & 00.04 & 525.444 & 7.059 & 0.006 & 0.06 & \\
\hline $\mathrm{DH} 15$ & $1986-06-17$ & $09: 45$ & $\infty 0.03$ & 532.406 & 6.962 & 0.004 & 0.09 & \\
\hline $\mathrm{DH} 15$ & $1986-06-24$ & $10: 00$ & 00.05 & 539.417 & 7.011 & 0.007 & 0.14 & $\begin{array}{l}\text { Lots of clay has fallen down hole and } \\
\text { accumulated in collection container. }\end{array}$ \\
\hline $\begin{array}{l}\mathrm{DH} 15 \\
\mathrm{DH} 15\end{array}$ & $\begin{array}{l}1986-07-01 \\
1986-07-08\end{array}$ & $\begin{array}{l}12: 30 \\
09: 50\end{array}$ & $\begin{array}{l}00.05 \\
00.05\end{array}$ & $\begin{array}{l}546.521 \\
553.410\end{array}$ & $\begin{array}{l}7.104 \\
6.889\end{array}$ & $\begin{array}{l}0.007 \\
0.007\end{array}$ & $\begin{array}{l}0.19 \\
0.24\end{array}$ & \\
\hline $\mathrm{DH} 15$ & $1986-07-16$ & $09: 40$ & 00.06 & 561.403 & 7.993 & 0.008 & 0.30 & \\
\hline $\mathrm{DH} 15$ & $1986-07-22$ & $09: 15$ & 00.05 & 567.385 & 5.982 & 0.008 & 0.35 & Clay in collection container. \\
\hline $\mathrm{DH} 15$ & $1986-07-29$ & $09: 55$ & 00.05 & 574.413 & 7.028 & 0.007 & 0.40 & \\
\hline $\mathrm{OH} 15$ & $1986-08-05$ & $10: 20$ & 00.05 & 581.431 & 7.018 & 0.007 & 0.45 & \\
\hline $\mathrm{DH} 15$ & $1986-08-12$ & $09: 45$ & 00.05 & 588.406 & 6.975 & 0.007 & 0.50 & \\
\hline DH15 & $1986-08-19$ & $10: 20$ & 00.05 & 595.431 & 7.025 & 0.007 & 0.55 & \\
\hline $\mathrm{DH} 15$ & $1986-08-26$ & $10: 00$ & 00.05 & 602.417 & 6.986 & 0.007 & 0.60 & \\
\hline DH15 & $1986-09-04$ & $09: 50$ & 00.06 & 611.410 & 8.993 & 0.007 & 0.66 & \\
\hline DH15 & $1986-09-09$ & $11: 00$ & 00.03 & 616.458 & 5.048 & 0.006 & 0.69 & \\
\hline DH15 & $1986-09-16$ & $09: 25$ & 00.05 & 623.392 & 6.234 & 0.007 & 0.74 & \\
\hline DH15 & $1986-09-23$ & $09: 30$ & 00.06 & 630.396 & 7.004 & 0.009 & 0.80 & \\
\hline $\mathrm{DH} 15$ & $1986-10-01$ & $11: 29$ & 00.06 & 638.478 & 8.082 & 0.007 & 0.86 & \\
\hline $\mathrm{DH} 15$ & $1986-11-05$ & $10: 15$ & 0.22 & 673.427 & 34.249 & 0006 & 1.08 & \\
\hline $\mathrm{DH} 15$ & $1986-11-20$ & $11: 28$ & 00.07 & 688.478 & 15.051 & 0.005 & 1.15 & \\
\hline DH15 & $1986-12-31$ & $11: 37$ & 00.18 & 729.484 & 41006 & 0.004 & 1.33 & \\
\hline DH15 & $1987-03-30$ & $12: 02$ & 0.41 & 818.501 & 89.017 & 0.005 & 1.74 & \\
\hline DH15 & $1987-05-07$ & $10: 22$ & 0.17 & 856.432 & 37.931 & 0.004 & 1.91 & \\
\hline DH15 & $1987-06-17$ & $11: 20$ & 0.21 & 897.472 & 41.040 & 0,005 & 2.12 & \\
\hline DH15 & $1987-07-28$ & $12: 07$ & 0.14 & 938.505 & 41.033 & 0.003 & 2.26 & \\
\hline DH15 & $1987-09-01$ & $11: 35$ & 0.13 & 973.483 & 34.978 & 0.004 & 2.39 & \\
\hline $\mathrm{DH} 15$ & $1987-09-16$ & $10: 00$ & & 988.417 & 0.000 & 0.000 & 2.39 & 0.05 liter in jar not removed. No calculation. \\
\hline $\mathrm{DH} 15$ & $1987-10-20$ & $10: 45$ & 0.29 & 1022.450 & 48.967 & 0.006 & 2.68 & \\
\hline $\mathrm{DH} 15$ & $1987-11-19$ & $10: 15$ & 0.15 & 1052.430 & 29.980 & 0.005 & 2.83 & \\
\hline DH15 & $1988-01-04$ & 1100 & 0.23 & 1098.460 & 46.030 & 0.005 & 3.06 & \\
\hline $\mathrm{DH} 15$ & $1988-02-08$ & $12: 40$ & 0.09 & 1133.530 & 35.070 & 0.003 & 3.15 & \\
\hline DH15 & $1588-03-30$ & $12: 10$ & 0.15 & 1184.510 & 50.880 & 0.003 & 3.30 & \\
\hline $\mathrm{DH} 15$ & $1988-07-12$ & $09: 50$ & 0.21 & 1288.410 & 103.900 & 0.002 & 3.51 & \\
\hline $\mathrm{DH} 15$ & $1988-09-27$ & $08: 20$ & 0.00 & 1365.350 & 76.940 & 0.000 & 3.51 & Dry. \\
\hline $\mathrm{DH} 15$ & $1988-12-13$ & $09: 20$ & 0 & 1442.390 & 77.040 & 0.000 & 3.51 & Dry. \\
\hline DH15 & $1989-03-14$ & $09: 12$ & 0 & 1533.380 & 90.994 & 0.000 & 3.51 & Hole ary, funnel loose. \\
\hline
\end{tabular}


BRINE ACCUMULATION DATA TABLE (Continued) Data through December 31, 1990

\begin{tabular}{|c|c|c|c|c|c|c|c|c|}
\hline Location & Date & Time & $\begin{array}{c}\text { Liters } \\
\text { removed }\end{array}$ & $\begin{array}{l}\text { Days } \\
\text { since } \\
1 / 1 / 85 \\
\end{array}$ & $\begin{array}{l}\text { Days } \\
\text { used for } \\
\text { calc. }\end{array}$ & $\begin{array}{l}\text { Liters } \\
\text { per } \\
\text { day }\end{array}$ & $\begin{array}{l}\text { Cumulative } \\
\text { liters } \\
\text { collected }\end{array}$ & Remarks \\
\hline DH15 & $1989-04-06$ & $11: 55$ & 0 & 1556.500 & 23.114 & 0.000 & 3.51 & Hole dry. \\
\hline DH15 & $1989-04-20$ & $10: 05$ & 0.04 & 1570.420 & 13.923 & 0.003 & 3.55 & \\
\hline $\begin{array}{l}\mathrm{DH} 15 \\
\mathrm{DH} 15\end{array}$ & $1989-05-17$ & $11: 40$ & 0 & 1597.490 & 27.066 & 0.000 & 3.55 & Hole dry. \\
\hline $\begin{array}{l}\text { DH15 } \\
\text { DH15 }\end{array}$ & $1989-06-29$ & $10: 55$ & 0 & 1640.450 & 42.969 & 0.000 & 3.55 & Hole dry. \\
\hline & $\begin{array}{l}1989-07-25 \\
1989-08-16\end{array}$ & $11: 30$ & 0 & 1666.480 & 26.024 & 0.000 & 3.55 & Hole ory. \\
\hline DH15 & $\begin{array}{l}1989-08-16 \\
1989-09-12\end{array}$ & $10: 10$ & 0 & 1688.420 & 21.945 & 0.000 & 3.55 & Hole dry. \\
\hline $\mathrm{DH} 15$ & $\begin{array}{l}1989-09-12 \\
1989-10-20\end{array}$ & $\begin{array}{l}12: 00 \\
10: 39\end{array}$ & 0 & 1715.500 & 27.076 & 0.000 & 3.55 & Hole diy. \\
\hline $\mathrm{DH} 15$ & $\begin{array}{l}1989-10-20 \\
1989-11-10\end{array}$ & $\begin{array}{l}10: 39 \\
09: 30\end{array}$ & 0 & 1753.440 & 37.944 & 0.000 & 3.55 & Hole ary. \\
\hline $\mathrm{DH} 15$ & $\begin{array}{l}1989-11-10 \\
1989-11-29\end{array}$ & $\begin{array}{l}09: 30 \\
11: 40\end{array}$ & 0 & 1774.400 & 20.952 & 0.000 & 3.55 & Hole dry. \\
\hline $\mathrm{DH} 15$ & $\begin{array}{l}1989-11-29 \\
1989-12-12\end{array}$ & $\begin{array}{l}11: 40 \\
08: 56\end{array}$ & 0 & 1793.490 & 19.090 & 0.000 & 3.55 & Hole dry. \\
\hline $\mathrm{DH} 15$ & & $\begin{array}{l}08: 56 \\
09: 30\end{array}$ & 0 & 1806.370 & 12.886 & 0.000 & 3.55 & Hole dry. \\
\hline $\mathrm{DH} 15$ & & $\begin{array}{l}09: 30 \\
11: 28\end{array}$ & 0.0 & 1829.396 & 23.024 & 0.000 & 3.55 & Dry. \\
\hline $\mathrm{DH} 15$ & $\begin{array}{l}1990-01-17 \\
1990-01-31\end{array}$ & $\begin{array}{l}11: 28 \\
09: 35\end{array}$ & 0.0 & 1842.478 & 13.082 & 0.000 & 3.55 & Dry. \\
\hline $\mathrm{DH} 15$ & & $\begin{array}{l}09: 35 \\
09: 58\end{array}$ & 0.0 & 1856.399 & 13.921 & 0.000 & 3.55 & Dry. \\
\hline $\mathrm{DH} 15$ & $1990-02-27$ & $\begin{array}{l}09: 58 \\
11: 41\end{array}$ & 0.0 & 1869.415 & 13.016 & 0.000 & 3.55 & Dry. \\
\hline $\mathrm{DH} 15$ & $1990-03-05$ & $\begin{array}{l}11: 41 \\
10: 32\end{array}$ & $\begin{array}{l}0.0 \\
0.0\end{array}$ & 1883.487 & 14.072 & 0.000 & 3.55 & Dry. \\
\hline $\mathrm{DH} 15$ & $1990-03-21$ & $11: 03$ & $\begin{array}{l}0.0 \\
0.0\end{array}$ & 1889.439 & 5.952 & 0.000 & 3.55 & Dry. \\
\hline $\mathrm{DH} 15$ & $1990-04-04$ & $11: 00$ & $\begin{array}{l}0.0 \\
0.0\end{array}$ & 1905.460 & 16.021 & 0.000 & 3.55 & Dry. \\
\hline $\mathrm{DH} 15$ & $1990-04-06$ & $10: 22$ & & 1919.458 & 13.998 & 0.000 & 3.55 & Dry. \\
\hline DH15 & $1990-04-17$ & $11: 04$ & $\begin{array}{l}0.0 \\
0.0\end{array}$ & 1921.432 & 1.974 & 0.000 & 3.55 & Dry. \\
\hline DH15 & $1990-04-24$ & $10: 25$ & $\begin{array}{l}0.0 \\
0.0\end{array}$ & 1932.461 & 11.029 & 0.000 & 3.55 & Dry. \\
\hline DH15 & $1990-05-02$ & $11: 20$ & $\begin{array}{l}0.0 \\
0.0\end{array}$ & 1939.434 & 6.973 & 0.000 & 3.55 & Dry. \\
\hline DH15 & $1990-05-09$ & $10: 36$ & $\begin{array}{l}0.0 \\
0.0\end{array}$ & $\begin{array}{l}1947.472 \\
1954.42\end{array}$ & 8.038 & 0.000 & 3.55 & Dry. \\
\hline DH15 & $1990-05-16$ & $10: 04$ & $\begin{array}{l}0.0 \\
0.0\end{array}$ & $\begin{array}{l}1954.442 \\
1961.419\end{array}$ & 6.970 & 0.000 & 3.55 & Dry. \\
\hline DH15 & $1990-05-23$ & $12: 40$ & $\begin{array}{l}0.0 \\
0.0\end{array}$ & $\begin{array}{l}1961.419 \\
1968.528\end{array}$ & 6.977 & 0.000 & 3.55 & Dry. \\
\hline DH15 & $1990-05-31$ & $10: 54$ & $\begin{array}{l}0.0 \\
0.0\end{array}$ & $\begin{array}{l}1968.528 \\
1976.454\end{array}$ & 7.109 & 0.000 & 3.55 & Dry. \\
\hline DH15 & $1990-06-06$ & $11: 00$ & $\begin{array}{l}0.0 \\
0.0\end{array}$ & $\begin{array}{l}1976.454 \\
1982.458\end{array}$ & 7.926 & 0.000 & 3.55 & Dry. \\
\hline DH15 & $1990-06-14$ & $09: 36$ & $\begin{array}{l}0.0 \\
0.0\end{array}$ & $\begin{array}{l}1982.458 \\
1990.400\end{array}$ & 6.004 & 0.000 & 3.55 & Dry. \\
\hline DH15 & $1990-06-20$ & $08: 40$ & $\begin{array}{l}0.0 \\
0.0\end{array}$ & $\begin{array}{l}1990.400 \\
1996.361\end{array}$ & 7.942 & 0.000 & 3.55 & Dry. \\
\hline DH15 & $1990-06-28$ & $09: 56$ & $\begin{array}{l}0.0 \\
0.0\end{array}$ & $\begin{array}{l}1996.361 \\
2004.414\end{array}$ & 5.961 & 0.000 & 3.55 & Dry. \\
\hline DH15 & $1990-07-25$ & $08: 15$ & $\begin{array}{l}0.0 \\
0.0\end{array}$ & $\begin{array}{l}2004.414 \\
2031.344\end{array}$ & 8.053 & 0.000 & 3.55 & Dry. \\
\hline DH15 & $1990-08-16$ & $10: 58$ & $\begin{array}{l}0.0 \\
0.0\end{array}$ & $\begin{array}{l}2031.344 \\
2053.457\end{array}$ & 26.830 & 0.000 & 3.55 & Dry. \\
\hline DH15 & $1990-08-22$ & $11: 45$ & $\begin{array}{l}0.0 \\
0.0\end{array}$ & $\begin{array}{l}2053.457 \\
2059.490\end{array}$ & 22.113 & 0.000 & 3.55 & Dry. \\
\hline DH15 & $1990-08-29$ & $12: 30$ & $\begin{array}{l}0.0 \\
0.0\end{array}$ & $\begin{array}{l}2059.490 \\
2066.521\end{array}$ & 6.033 & 0.000 & 3.55 & Dry. \\
\hline $\mathrm{DH} 15$ & $1990-09-05$ & $11: 40$ & $\begin{array}{l}0.0 \\
0.0\end{array}$ & $\begin{array}{l}2066.521 \\
2073.486\end{array}$ & 7.031 & 0.000 & 3.55 & Dry. \\
\hline DH15 & $1990-09-13$ & $09: 44$ & $\begin{array}{l}0.0 \\
0.0\end{array}$ & $\begin{array}{l}2073.486 \\
2081.406\end{array}$ & 6.965 & 0.000 & 3.55 & Dry. \\
\hline $\mathrm{DH} 15$ & $1990-09-25$ & $12: 20$ & $\begin{array}{l}0.0 \\
0.0\end{array}$ & $\begin{array}{l}2081.406 \\
2093.514\end{array}$ & 7.920 & 0.000 & 3.55 & Dry. \\
\hline DH15 & $1990-09-26$ & $11: 20$ & $\begin{array}{l}0.0 \\
0.0\end{array}$ & $\begin{array}{l}2093.514 \\
2094.472\end{array}$ & 12.108 & 0.000 & 3.55 & Dry. \\
\hline DH15 & $1990-10-03$ & $09: 40$ & $\begin{array}{l}0.0 \\
0.0\end{array}$ & $\begin{array}{l}2094.472 \\
2101.403\end{array}$ & 0.958 & 0.000 & 3.55 & Dry. \\
\hline DH15 & $1990-10-10$ & $11: 30$ & $\begin{array}{l}0.0 \\
0.0\end{array}$ & $\begin{array}{l}2101.403 \\
2108.479\end{array}$ & 6.931 & 0.000 & 3.55 & Dry. \\
\hline DH15 & $1990-10-18$ & $10: 15$ & $\begin{array}{l}0.0 \\
0.0\end{array}$ & $\begin{array}{l}2108.479 \\
2116.427\end{array}$ & 7.076 & 0.000 & 3.55 & Dry. \\
\hline DHi15 & $1990-10-24$ & $12: 06$ & $\begin{array}{l}1.0 \\
(1.0\end{array}$ & $\begin{array}{l}2116.427 \\
2122.504\end{array}$ & 7.948 & 0.000 & 3.55 & Dry. \\
\hline $\mathrm{DH} 15$ & $1990-10-31$ & $11: 32$ & $\begin{array}{l}(1.0 \\
0.0\end{array}$ & $\begin{array}{l}2122.504 \\
2129.481\end{array}$ & 6.077 & 0.000 & 3.55 & Dry. \\
\hline $\mathrm{DH} 15$ & $1990-11-14$ & $11: 48$ & $\begin{array}{l}0.0 \\
0.0\end{array}$ & $\begin{array}{l}2129.481 \\
2143.492\end{array}$ & 6.977 & 0.000 & 3.55 & Dry. \\
\hline $\mathrm{DH} 15$ & $1990-11-28$ & $10: 50$ & $\begin{array}{l}0.0 \\
0.0\end{array}$ & $\begin{array}{l}2143.492 \\
2157.451\end{array}$ & 14.011 & 0.000 & 3.55 & Dry. \\
\hline $\mathrm{DH} 15$ & $1990-12-05$ & $08: 54$ & $\begin{array}{l}0.0 \\
0.0\end{array}$ & $\begin{array}{l}2157.451 \\
2164.371\end{array}$ & 13.959 & 0.000 & 3.55 & Dry. \\
\hline $\mathrm{DH} 15$ & $1990-12-13$ & $09: 32$ & $\begin{array}{l}0.0 \\
0.0\end{array}$ & $\begin{array}{l}2164.371 \\
2172.397\end{array}$ & 6.920 & 0.000 & 3.55 & Dry. \\
\hline & -.................. & & & $\begin{array}{l}2172.397 \\
\ldots\end{array}$ & 8.026 & 0.000 & 3.55 & Dry. \\
\hline \multirow{2}{*}{\multicolumn{9}{|c|}{ ( }} \\
\hline DH35 & $1984-11-21$ & $00: 00$ & NA & & & & & \\
\hline & & & & 0.000 & 0.000 & 0.000 & 0.0 & excavated. \\
\hline DH35 & $1985-01-27$ & $00: 00$ & NA & 0.000 & 0.000 & 0.000 & 0.00 & Uphole drilled $1 / 26 / 85$ to $1 / 27 / 85$ \\
\hline DH35 & $1985-02-05$ & $11: 15$ & NA & 35.469 & 1.000 & 0.000 & 0.00 & Started to drip. \\
\hline DH35 & 1985-03-05 & $10: 00$ & 00.19 & 63.417 & 28.848 & 0.007 & 0.19 & Salt crystals in container. First time collected. \\
\hline DH35 & $1985-03-12$ & $10: 00$ & 00.17 & 70.417 & 7.000 & 0.024 & 0.36 & Salt crystals in container. \\
\hline DH35 & $1985-03-20$ & $10: 26$ & 00.18 & 78.435 & 8.018 & 0.024 & 0.55 & \\
\hline DH35 & $1985-03-26$ & $09: 45$ & 00.13 & 84.406 & 5.971 & 0.022 & 0.68 & \\
\hline DH35 & $1985-04-02$ & $10: 15$ & 00.15 & 91.427 & 7.021 & 0.021 & 0.83 & Salt crystals in container. \\
\hline DH35 & $1985-04-10$ & $10: 14$ & 00.19 & 99.426 & 7.999 & 0.024 & 1.02 & \\
\hline
\end{tabular}


BRINE ACCUMULATION DATA TABLE (Continued) Data through December 31, 1990

\begin{tabular}{|c|c|c|c|c|c|c|c|c|}
\hline Location & Date & Time & $\begin{array}{l}\text { Liters } \\
\text { removed }\end{array}$ & $\begin{array}{l}\text { Days } \\
\text { since } \\
1 / 1 / 85 \\
\end{array}$ & $\begin{array}{l}\text { Days } \\
\text { used tor } \\
\text { calc. }\end{array}$ & $\begin{array}{l}\text { Liters } \\
\text { per } \\
\text { day }\end{array}$ & $\begin{array}{c}\text { Cumulative } \\
\text { liters } \\
\text { collected } \\
\end{array}$ & Remarks \\
\hline DH35 & $1985-04-23$ & $11: 46$ & 00.12 & 112.490 & 13.064 & 0.009 & 1.14 & \\
\hline $\mathrm{DH} 35$ & $1985-04-30$ & $11: 09$ & 00.16 & 119.465 & 6.975 & 0.023 & 1.30 & Clay in container. \\
\hline DH35 & $1985-05-07$ & $09: 53$ & 00.14 & 126.412 & 6.947 & 0.020 & 1.44 & \\
\hline $\mathrm{DH} 35$ & $1985-05-14$ & $10: 48$ & 00.16 & 133.450 & 7.038 & 0.023 & 1.60 & \\
\hline DH35 & $1985-05-21$ & $10: 42$ & 00.15 & 140.446 & 6.996 & 0.021 & 1.75 & \\
\hline DH35 & $1985-05-29$ & $10: 00$ & 00.15 & 148.417 & 7.971 & 0.019 & 1.90 & \\
\hline DH35 & $1985-06-11$ & $10: 10$ & 00.02 & 161.424 & 13.007 & 0.002 & 1.92 & \\
\hline DH35 & $1985-07-09$ & $11: 10$ & 00.06 & 189.465 & 28.041 & 0.002 & 1.98 & \\
\hline DH35 & $1985-07-16$ & $11: 48$ & 00.13 & 196.492 & 7.027 & 0.019 & 2.11 & \\
\hline DH35 & $1985-07-24$ & $10: 37$ & 00.12 & 204.442 & 7.950 & 0.015 & 2.23 & \\
\hline DH35 & $1985-07-30$ & $10: 17$ & 00.08 & 210.428 & 5.986 & 0.013 & 2.31 & Clay in container. \\
\hline DH35 & $1985-08-06$ & $10: 37$ & 00.08 & 217.442 & 7.014 & 0.011 & 2.39 & Clay chunks in container. \\
\hline DH35 & $1985-08-14$ & $10: 53$ & 00.11 & 225.453 & 8.011 & 0.014 & 2.50 & \\
\hline DH35 & $1995-08-20$ & $11: 05$ & 00.09 & 231.462 & 6.009 & 0.015 & 2.59 & \\
\hline DH35 & $1985-08-28$ & $10: 00$ & 00.14 & 239.417 & 7.955 & 0.018 & 2.73 & \\
\hline DH35 & $1985-09-04$ & $10: 30$ & 00.11 & 246.438 & 7.021 & 0.016 & 2.84 & \\
\hline DH35 & $1985-09-10$ & $10: 38$ & 00.11 & 252.443 & 6.005 & 0.018 & 2.95 & \\
\hline DH35 & $1985-09-17$ & $09: 40$ & 00.12 & 259.403 & 6.960 & 0.017 & 3.07 & \\
\hline DH35 & $1985-09-24$ & $09: 48$ & 00.07 & 266.408 & 7.005 & 0.010 & 3.14 & \\
\hline DH35 & $1985-10-08$ & $10: 44$ & 00.08 & 280.447 & 14.038 & 0.006 & 3.22 & \\
\hline DH35 & $1985-10-15$ & $10: 17$ & 00.06 & 287.428 & 6.981 & 0.009 & 3.28 & \\
\hline DH35 & $1985-10-29$ & $09: 42$ & 00.06 & 301.404 & 13.976 & 0.004 & 3.34 & \\
\hline DH35 & $1985-11-05$ & $09: 24$ & 00.08 & 308.392 & 6.988 & 0.011 & 3.42 & \\
\hline DH35 & $1985-11-13$ & $10: 06$ & 00.11 & 316.421 & 8.029 & 0.014 & 3.53 & \\
\hline DH35 & $1985-11-21$ & $11: 32$ & 00.07 & 324.481 & 8.060 & 0.009 & 3.60 & \\
\hline DH35 & $1985-11-26$ & $11: 25$ & 00.05 & 329.476 & 4.995 & 0.010 & 3.65 & Changed collection container. \\
\hline DH35 & $1986-01 \cdot 23$ & $10: 40$ & 00.06 & 387.444 & 57.968 & 0.001 & 3.71 & $\begin{array}{l}\text { Clay in collection container. Entry has beem } \\
\text { restricted since } 12 / 10 / 85 \text { due to mining } \\
\text { activities. }\end{array}$ \\
\hline DH35 & $1986-01-31$ & $12: 16$ & 00.06 & 395.511 & 8.067 & 0.007 & 3.77 & \\
\hline $\mathrm{DH} 35$ & $1986-02-12$ & $10: 55$ & 00.09 & 407.455 & 11.944 & 0.008 & 3.86 & \\
\hline DH35 & $1986-02-19$ & $11: 45$ & 00.07 & 414.490 & 7.035 & 0.010 & 3.93 & \\
\hline DH35 & $1986-02-28$ & $13: 20$ & 00.06 & 423.556 & 9.066 & 0.007 & 3.99 & \\
\hline DH35 & $1986-03-06$ & $10: 45$ & 00.03 & 429.448 & 5.892 & 0.005 & 4.02 & \\
\hline DH35 & $1986-03-13$ & $10: 10$ & 00.07 & 436.424 & 6.976 & 0.010 & 4.09 & \\
\hline DH35 & $1986-03-26$ & $10: 20$ & NA & 449.431 & 13.007 & 0.000 & 409 & $\begin{array}{l}\text { Funnel broken, } 5 \text { inch stalactite formed from } \\
\text { collar. }\end{array}$ \\
\hline $\mathrm{DH} 35$ & $1986-04-02$ & $09: 40$ & NA & 456.403 & 19.979 & 0.000 & 4.09 & Installed new funnel. \\
\hline $\mathrm{DH} 35$ & $1986-05-27$ & $15: 45$ & NA & 511.656 & 75.232 & 0.000 & 4.09 & Trace of brine. \\
\hline DH35 & $1986-06-03$ & $10: 08$ & 00.01 & 518.422 & 81.998 & 0.000 & 4.10 & \\
\hline $\mathrm{DH} 35$ & $1986-06-10$ & $11: 35$ & 00.02 & 525.483 & 7.061 & 0.003 & 412 & \\
\hline DH35 & $1986-06-17$ & $10: 58$ & 00.01 & 532.457 & 6.974 & 0.001 & 4.13 & \\
\hline DH35 & $1986-06-24$ & $10: 57$ & 00.02 & 539.456 & 6.999 & 0.003 & 4. 15 & \\
\hline DH35 & $1986-07-01$ & $14: 03$ & 00.02 & 546.585 & 7.129 & 0.003 & 4.17 & \\
\hline $\mathrm{DH} 35$ & $1986-07-08$ & $10: 37$ & 00.02 & 553.442 & 6.857 & 0.003 & 4.19 & \\
\hline DH35 & $1986-07-16$ & 10:36 & 00.03 & 561,442 & 8.000 & 0.004 & 4.22 & \\
\hline DH35 & $1986-07-22$ & $10: 05$ & NA & 567.420 & 5.978 & 0.000 & 422 & $\begin{array}{l}\text { Trace of brine. Cleaned sott clay out of } \\
\text { funnel. }\end{array}$ \\
\hline DH35 & $1986-07-29$ & $10: 35$ & 00.01 & 574.441 & 12.999 & 0.001 & 4.23 & \\
\hline DH35 & 1986-08-05 & $11: 13$ & 00.03 & 581.467 & 7.026 & 0.004 & 4.26 & \\
\hline DH35 & $1986-08-12$ & $10: 35$ & 00.03 & 588.441 & 6.974 & 0.004 & 4.29 & \\
\hline DH35 & $1986-08-19$ & $11: 35$ & $\infty 0.01$ & 595.483 & 7.042 & 0.001 & 4.30 & \\
\hline DH35 & $1986-08-26$ & $10: 38$ & NA & 602.443 & 6.960 & 0.000 & 4.30 & Trace collected. \\
\hline $\mathrm{DH} 35$ & $1986-09-04$ & $10: 40$ & 00.01 & 611.444 & 15.961 & 0.001 & 431 & \\
\hline DH35 & $1986-09-09$ & $10: 10$ & NA & 616.424 & 4.980 & 0.000 & 431 & Trace collected. \\
\hline DH35 & $1986-09-16$ & $10: 13$ & NA & 623.426 & 11.982 & 0.000 & 431 & Trace collected. \\
\hline $\mathrm{DH} 35$ & $1986-09-23$ & $10: 11$ & NA & 630.424 & 18.980 & 0.000 & 4.31 & Trace. \\
\hline DH35 & $1986-10-01$ & $12: 16$ & 0.00 & 638.511 & 27.067 & 0.000 & 4.31 & Trace, none collected. \\
\hline DH35 & $1986-10-08$ & $11: 08$ & NA & 645.464 & 6.953 & 0.000 & 4.31 & Small amount not collected. \\
\hline DH35 & $1986-11-05$ & $11: 28$ & NA & 673.478 & 28.014 & 0.000 & 4.31 & Damp, not collected. \\
\hline
\end{tabular}


BRINE ACCUMULATION DATA TABLE (Continued) Data through December 31, 1990

\begin{tabular}{|c|c|c|c|c|c|c|c|c|}
\hline Location & Date & Time & $\begin{array}{l}\text { Liters } \\
\text { removed }\end{array}$ & $\begin{array}{c}\text { Days } \\
\text { since } \\
1 / 1 / 85 \\
\end{array}$ & $\begin{array}{l}\text { Days } \\
\text { used tor } \\
\text { calc. }\end{array}$ & $\begin{array}{l}\text { Liters } \\
\text { per } \\
\text { day }\end{array}$ & $\begin{array}{c}\text { Cumulative } \\
\text { liters } \\
\text { collected }\end{array}$ & Remarks \\
\hline DH35 & $1986-11-20$ & NA & NA & 688.000 & 42.536 & 0.000 & 4.31 & Not sampled, looked dry. \\
\hline DH35 & $1986-12-30$ & $12: 15$ & NA & 728.510 & 83.046 & 0.000 & 4.31 & \\
\hline DH35 & $1987-02-03$ & NA & NA & 763.000 & 117.536 & 0.000 & 4.31 & \\
\hline DH35 & $1887-03-06$ & $11: 25$ & NA & 794.476 & 149.012 & 0.000 & 4.31 & Dry. \\
\hline DH35 & $1987-03-30$ & $11: 20$ & 0.00 & 818.472 & 23.996 & 0.000 & 4.31 & Dry. \\
\hline DH35 & $1987-05-07$ & $11: 35$ & 0.00 & 856.483 & 62.007 & 0.000 & 4.31 & Dry. \\
\hline DH35 & $1887-06-18$ & $12: 10$ & 0.00 & 898.507 & 104.031 & 0.000 & 4.31 & Dry. \\
\hline DH35 & $1887-07-28$ & $11: 15$ & 0.00 & 938.469 & 143.993 & 0.000 & 4.31 & Dry. \\
\hline DH35 & $1987-09-01$ & $10: 50$ & 0.00 & 973.451 & 34.982 & 0.000 & 4.31 & Dry. \\
\hline DH35 & $1987-10-20$ & $11: 56$ & 0.00 & 1022.500 & 49.048 & 0.000 & 4.31 & Dry. \\
\hline DH35 & $1987-11-19$ & $11: 30$ & 0.00 & 1052.480 & 29.980 & 0.000 & 4.31 & Dry. \\
\hline DH35 & $1888-01-04$ & $12: 00$ & 0.00 & 1098.500 & 46.020 & 0.000 & 4.31 & Dry. \\
\hline DH35 & $1988-02-08$ & $11: 55$ & 0.00 & 1133.500 & 35.000 & 0.000 & 4.31 & Dry. \\
\hline DH35 & $1988-03-29$ & $11: 40$ & 0.00 & 1183.490 & 49.990 & 0.000 & 4.31 & Dry. \\
\hline DH35 & $1988-07-12$ & $08: 50$ & 0.00 & 1288.370 & 104.880 & 0.000 & 4.31 & Dry. \\
\hline DH35 & $1988-09-27$ & $10: 50$ & 0.00 & 1365.450 & 77.080 & 0.000 & 4.31 & Dry. \\
\hline DH35 & 1989-03-15 & $10: 50$ & 0 & 1534.450 & 169.000 & 0.000 & 4.31 & Hole dry. \\
\hline DH35 & $1989-04-06$ & $09: 40$ & 0 & 1556.400 & 21.952 & 0.000 & 4.31 & Hole dry. \\
\hline DH35 & $1989-04-20$ & $09: 40$ & 0 & 1570.400 & 14.000 & 0.000 & 4.31 & Hole dry. \\
\hline DH35 & $1989-06-06$ & $10: 15$ & 0 & 1617.430 & 47.024 & 0.000 & 4.31 & \\
\hline DH35 & $1989-06-29$ & $10: 35$ & 0 & 1640.440 & 23.014 & 0.000 & 4.31 & Hole dry. \\
\hline DH35 & $1989-07-25$ & 09:55 & 0 & 1666.410 & 25.972 & 0.000 & 4.31 & Hole dry. \\
\hline DH35 & $1989-08-16$ & $09: 55$ & 0 & 1688.410 & 22.000 & 0.000 & 4.31 & Hole dry. \\
\hline DH35 & $1989-08-28$ & $10: 20$ & 0 & 1700.430 & 12.018 & 0.000 & 4.31 & Collection device removed. \\
\hline DH35 & $1889-12-13$ & $11: 20$ & 0 & 1807.470 & 107.041 & 0.000 & 4.31 & Hole dry. \\
\hline DH35 & $1990-01-24$ & $10: 00$ & 0.0 & 1849.417 & 41.845 & 0.000 & 4.31 & Dry. \\
\hline DH35 & $1990-02-07$ & $10: 30$ & 0.0 & 1863.438 & 14.021 & 0.000 & 4.31 & Dry. \\
\hline Dit35 & $1990-02-21$ & $09: 48$ & 0.0 & 1877.408 & 13.970 & 0.000 & 4.31 & Dry. \\
\hline DH35 & 1990-03-05 & 09:35 & 0.0 & 1889.399 & 11.991 & 0.000 & 4.31 & Dry. \\
\hline DH35 & 1990-03-19 & $10: 36$ & 0.0 & 1903.442 & 14.043 & 0.000 & 4.31 & Dry. \\
\hline $\begin{array}{l}\text { DH35 } \\
\text { DH35 }\end{array}$ & $\begin{array}{l}1990-03-21 \\
1990-04-04\end{array}$ & $\begin{array}{l}10: 30 \\
09: 56\end{array}$ & $\begin{array}{l}0.0 \\
0.0\end{array}$ & $\begin{array}{l}1905.438 \\
1919.414\end{array}$ & 1.996 & $\begin{array}{l}0.000 \\
0.000\end{array}$ & $\begin{array}{l}4.31 \\
4.31\end{array}$ & $\begin{array}{l}\text { Dry. } \\
\text { Dry. }\end{array}$ \\
\hline $\begin{array}{l}\text { DH35 } \\
\text { DH35 }\end{array}$ & $\begin{array}{l}1990-04-04 \\
1990-04-10\end{array}$ & $09: 36$ & $\begin{array}{l}0.0 \\
0.0\end{array}$ & $\begin{array}{l}1919.414 \\
1925.357\end{array}$ & $\begin{array}{r}13.976 \\
50.2\end{array}$ & $\begin{array}{l}0.000 \\
0.000\end{array}$ & $\begin{array}{l}4.31 \\
4.31\end{array}$ & $\begin{array}{l}\text { Dry. } \\
\text { Dry. }\end{array}$ \\
\hline $\begin{array}{l}\text { DH35 } \\
\text { DH35 }\end{array}$ & $1990-04-17$ & $10: 17$ & 0.0 & $\begin{array}{l}1925.357 \\
1932.428\end{array}$ & $\begin{array}{l}5.943 \\
7.071\end{array}$ & $\begin{array}{l}0.000 \\
0.000\end{array}$ & $\begin{array}{l}4.31 \\
4.31\end{array}$ & $\begin{array}{l}\text { Dry. } \\
\text { Dry. }\end{array}$ \\
\hline $\begin{array}{l}\text { DH35 } \\
\text { DH35 }\end{array}$ & $1990-04-24$ & $09: 35$ & 0.0 & $\begin{array}{l}1932.428 \\
1939.399\end{array}$ & 7.071 & $\begin{array}{l}0.000 \\
0.000\end{array}$ & 4.31 & $\begin{array}{l}\text { Dry. } \\
\text { Dry. }\end{array}$ \\
\hline $\begin{array}{l}\text { DH35 } \\
\text { DH35 }\end{array}$ & $1990-05-02$ & $10: 30$ & 0.0 & $\begin{array}{l}1939.399 \\
1947.438\end{array}$ & 6.971 & $\begin{array}{l}0.000 \\
0.000\end{array}$ & 4.31 & $\begin{array}{l}\text { Dry. } \\
\text { Dry. }\end{array}$ \\
\hline $\begin{array}{l}\text { DH35 } \\
\text { DH35 }\end{array}$ & $1990-05-09$ & $08: 42$ & 0.0 & $\begin{array}{l}1947.438 \\
1954.362\end{array}$ & 8.039 & $\begin{array}{l}0.000 \\
0.000\end{array}$ & 4.31 & $\begin{array}{l}\text { Dry. } \\
\text { Dry. }\end{array}$ \\
\hline $\begin{array}{l}\text { DH35 } \\
\text { DH35 }\end{array}$ & $1990-05-16$ & $08: 45$ & 0.0 & $\begin{array}{l}1954.362 \\
1961.365\end{array}$ & 6.924 & $\begin{array}{l}0.000 \\
0.000\end{array}$ & 4.31 & $\begin{array}{l}\text { Dry. } \\
\text { Dry. }\end{array}$ \\
\hline $\begin{array}{l}\text { DH35 } \\
\text { DH35 }\end{array}$ & $1990-05-23$ & $12: 03$ & 0.0 & $\begin{array}{l}1961.365 \\
1968.502\end{array}$ & 7.003 & $\begin{array}{l}0.000 \\
0.000\end{array}$ & 4.31 & $\begin{array}{l}\text { Dry. } \\
\text { Dry. }\end{array}$ \\
\hline $\begin{array}{l}\text { DH35 } \\
\text { DH35 }\end{array}$ & $1990-05-31$ & $08: 40$ & 0.0 & $\begin{array}{l}1968.502 \\
1976.361\end{array}$ & $\begin{array}{l}7.137 \\
7.950\end{array}$ & $\begin{array}{l}0.000 \\
0.000\end{array}$ & 4.31 & $\begin{array}{l}\text { Dry. } \\
\text { Dry. }\end{array}$ \\
\hline $\begin{array}{l}\text { DH35 } \\
\text { DH35 }\end{array}$ & $1990-06-06$ & $08: 43$ & 0.0 & $\begin{array}{l}1976.361 \\
1982.363\end{array}$ & 7.859 & 0.000 & 4.31 & $\begin{array}{l}\text { Dry. } \\
\text { Dry. }\end{array}$ \\
\hline $\begin{array}{l}\text { DH35 } \\
\text { DH35 }\end{array}$ & $1990-06-14$ & $08: 32$ & 0.0 & $\begin{array}{l}1982.363 \\
1990.356\end{array}$ & $\begin{array}{l}6.002 \\
7.993\end{array}$ & 0.000 & 4.31 & $\begin{array}{l}\text { Dry. } \\
\text { Dry. }\end{array}$ \\
\hline DH35 & $1990-06-20$ & $09: 53$ & 0.0 & 1996.412 & 6.056 & 0.000 & 4.31 & Dry. \\
\hline DH35 & $1990-06-28$ & $08: 38$ & 0.0 & 2004.360 & 7.948 & 0.000 & 4.31 & Dry. \\
\hline DH35 & $1990-07-17$ & $10: 50$ & 0.0 & 2023.451 & 19.091 & 0.000 & 4.31 & Dry. \\
\hline DH35 & $1990-07-25$ & $09: 32$ & 0.0 & 2031.397 & 7.246 & 0.000 & 4.31 & Dry. \\
\hline DH35 & $1990-08-01$ & $10: 38$ & 0.0 & 2038.443 & 7.046 & 0.000 & 4.31 & Dry. \\
\hline DH35 & $1990-12-13$ & $08: 50$ & 0.0 & 2172.368 & 133.925 & 0.000 & 4.31 & Dry. \\
\hline \multicolumn{9}{|c|}{ 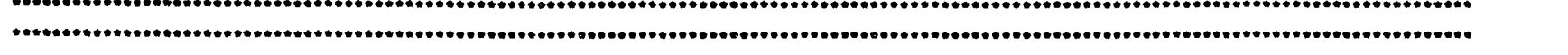 } \\
\hline DH36 & $1984-11-21$ & $00: 00$ & NA & 0.000 & 0.000 & 0.000 & $0 \infty$ & $\begin{array}{l}\text { Approximate date this part of Room G } \\
\text { excavated. }\end{array}$ \\
\hline DH36 & $1985-01-26$ & $00: 00$ & NA & 0.000 & 0.000 & 0.000 & 0.00 & Downhole drilled 1/26/85 \\
\hline DH36 & $1985-01-28$ & $09: 00$ & NA & 27.375 & 1.000 & 0.000 & 0.00 & Moist muck at the bottom. \\
\hline DH36 & $1985-02-05$ & $11: 15$ & 02.50 & 35.469 & 9.094 & 0.275 & 2.50 & $\begin{array}{l}\text { About } 1 \mathrm{ft} \text {. muck, brine and hydraulic fluid. } \\
\text { First time bailed. }\end{array}$ \\
\hline DH36 & $1935-02-11$ & $11: 00$ & 01.51 & 41.458 & 5.989 & 0.252 & 4.01 & Brine, muck, hydraulic fluid. \\
\hline DH36 & $1985-02-19$ & $12: 10$ & 01.78 & 49.507 & 8.049 & 0.221 & 5.79 & Some muck. \\
\hline DH36 & $1985-02-26$ & $10: 45$ & 01.48 & 56.448 & 6.941 & 0.213 & 7.27 & Brine and muck. \\
\hline DH36 & 1985-03-05 & $10: 00$ & 01.76 & 63.417 & 6.969 & 0.253 & 9.03 & \\
\hline
\end{tabular}


BRINE ACCUMULATION DATA TABLE (Continued)

Data through December 31, 1990

\begin{tabular}{|c|c|c|c|c|c|c|c|c|}
\hline Location & Date & Time & $\begin{array}{l}\text { Liters } \\
\text { removed }\end{array}$ & $\begin{array}{c}\text { Days } \\
\text { since } \\
1 / 1 / 85 \\
\end{array}$ & $\begin{array}{l}\text { Days } \\
\text { used for } \\
\text { calc. }\end{array}$ & $\begin{array}{c}\text { Liters } \\
\text { per } \\
\text { day }\end{array}$ & $\begin{array}{c}\text { Cumulative } \\
\text { liters } \\
\text { collected }\end{array}$ & Remarks \\
\hline DH36 & $1985-03-12$ & $10: 00$ & 01.55 & 70.447 & 7.000 & 0.221 & 10.58 & \\
\hline DH36 & $1985-03-20$ & $10: 26$ & 01.59 & 78.435 & 8.018 & 0.198 & 12.17 & \\
\hline DH36 & $1985-03-26$ & $09: 45$ & 01.35 & 84.406 & 5.971 & 0.226 & 13.52 & \\
\hline DH36 & $1985-04-02$ & $10: 15$ & 01.58 & 91.427 & 7.021 & 0.225 & 15.10 & \\
\hline DH36 & $1985-04-10$ & $10: 25$ & 01.71 & 99.434 & 8.007 & 0.214 & 16.81 & \\
\hline DH36 & $1985-04-17$ & $13: 30$ & 01.49 & 106.562 & 7.128 & 0.209 & 18.30 & \\
\hline DH36 & $1985-04-23$ & $11: 46$ & 01.45 & 112.490 & 5.928 & 0.245 & 19.75 & \\
\hline DH36 & $1985-04-30$ & $11: 21$ & 01.49 & 119.473 & 6.983 & 0.213 & 21.24 & \\
\hline DH36 & $1985-05-07$ & $09: 58$ & 01.55 & 126.415 & 6.942 & 0.223 & 22.79 & \\
\hline DH36 & $1985-05-14$ & $10: 54$ & 01.77 & 133.454 & 7.039 & 0.251 & 24.56 & \\
\hline DH36 & $1985-05-21$ & $10: 45$ & 01.61 & 140.448 & 6.994 & 0.230 & 26.17 & \\
\hline DH36 & $1985-05-29$ & $10: 00$ & 01.50 & 148.417 & 7.969 & 0.188 & 27.67 & \\
\hline DH36 & $1985-06-04$ & $11: 33$ & 01.40 & 154.481 & 6.064 & 0.231 & 29.07 & \\
\hline DH36 & $1985-06-11$ & $11: 15$ & 01.55 & 161.469 & 6.988 & 0.222 & 30.62 & 冫 \\
\hline DH36 & $1985-06-18$ & $10: 17$ & 01.58 & 168.428 & 6.959 & 0.227 & 32.20 & \\
\hline DH36 & $1985-06-25$ & $10: 40$ & 01.43 & 175.444 & 7.016 & 0.204 & 33.63 & \\
\hline DH36 & $1985-07-02$ & $11: 00$ & 01.59 & 182.458 & 7.014 & 0.227 & 35.22 & \\
\hline DH36 & $1985-07-09$ & $11: 15$ & 01.54 & 189.469 & 7011 & 0.220 & 36.76 & \\
\hline DH36 & $1985-07-16$ & $11: 50$ & 01.58 & 196.493 & 7.024 & 0.225 & 38.34 & Brine eftervesces. \\
\hline $\mathrm{DH} 36$ & $1985-07-24$ & $10: 46$ & 01.78 & 204.449 & 7.956 & 0.224 & 40.12 & \\
\hline DH36 & $1985-07-30$ & $10: 20$ & 01.39 & 210.431 & 5.982 & 0.232 & 41.51 & \\
\hline DH36 & $1985-08-06$ & $10: 43$ & 01.70 & 217.447 & 7.016 & 0.242 & 43.21 & \\
\hline DH36 & $1985-08-14$ & $11: 02$ & 01.58 & 225.460 & 8.013 & 0.197 & 44.79 & $\begin{array}{l}\text { Valve leaked. Some brine drained back down } \\
\text { hole. }\end{array}$ \\
\hline DH36 & $1985-08-20$ & $11: 11$ & 01.42 & 231.466 & 6.006 & 0.236 & 46.21 & \\
\hline DH36 & $1985-08-28$ & $10: 00$ & 01.94 & 239.417 & 7.951 & 0.244 & 48.15 & \\
\hline DH36 & $1985-09-04$ & $10: 32$ & 01.69 & 246.439 & 7.022 & 0.241 & 49.84 & \\
\hline $\mathrm{DH} 36$ & $1985-09-10$ & $10: 35$ & 01.41 & 252.441 & 6.002 & 0.235 & 51.25 & \\
\hline DH36 & $1985-09-17$ & $09: 42$ & 01.53 & 259.404 & 6.963 & 0.220 & 52.78 & \\
\hline $\mathrm{DH} 36$ & $1985-09-24$ & $09: 50$ & 01.53 & 266.410 & 7.006 & 0.218 & 54.31 & \\
\hline DH36 & $1985-10-01$ & $09: 55$ & 01.58 & 273.413 & 7.003 & 0.226 & 55.89 & \\
\hline $\mathrm{DH} 36$ & $1985-10-08$ & $10: 52$ & 01.63 & 280.453 & 7.040 & 0.232 & 57.52 & \\
\hline DH36 & $1985-10-15$ & $10: 30$ & 01.58 & 287.438 & 6.985 & 0.226 & 59.10 & \\
\hline DH36 & $1985-10-23$ & $10: 23$ & 01.82 & 295.433 & 7.995 & 0.228 & 60.92 & \\
\hline DH36 & $1985-10-29$ & $09: 51$ & 01.36 & 301.410 & 5.977 & 0.228 & 62.28 & \\
\hline DH36 & $1985-11.05$ & $09: 27$ & 01.63 & 308.394 & 6984 & 0.233 & 63.91 & \\
\hline DH36 & $1985-11-13$ & $10: 14$ & 01.79 & 316.426 & 8.032 & 0.223 & 65.70 & \\
\hline DH36 & $1985-11-21$ & $11: 36$ & 01.91 & 324.483 & 8.057 & 0.237 & 67.61 & \\
\hline DH36 & $1985-11-26$ & $11: 30$ & 01.01 & 329.479 & 4.996 & 0.202 & 68 62 & \\
\hline DH36 & $1985-12-03$ & $13: 35$ & 01.50 & 336.566 & 7.087 & 0.212 & 70.12 & \\
\hline DH36 & $1985-12 \cdot 10$ & $12: 15$ & 01.52 & 343.510 & 6.944 & 0.219 & 71.64 & \\
\hline $\mathrm{DH} 36$ & $1986-01-23$ & $11: 00$ & 09.30 & 387.458 & 43.948 & 0.212 & 80.94 & $\begin{array}{l}\text { Entry restricted since } 12 / 10 / 85 \text { due to mining } \\
\text { activities. }\end{array}$ \\
\hline DH36 & $1986-01-31$ & $12: 20$ & 01.38 & 395.514 & 8.056 & 0.171 & 82.32 & \\
\hline DH36 & $1986-02-12$ & $11: 00$ & 03.02 & 407.458 & 11.944 & 0.253 & 85.34 & \\
\hline DH36 & $1986-02-19$ & $11 \cdot 45$ & 01.55 & 414.490 & 7.032 & 0.220 & 86.89 & \\
\hline DH36 & $1986-02-28$ & $13: 20$ & 01.85 & 423.556 & 9.066 & 0.204 & 88.74 & \\
\hline DH36 & $1986-03-06$ & $10: 45$ & 01.30 & 429.448 & 5.892 & 0.221 & 90.04 & Volume was estımated. \\
\hline DH36 & $1986-03-13$ & $10: 10$ & 01.50 & 436.424 & 6.976 & 0.215 & 91.54 & \\
\hline DH36 & $1986-03-26$ & $10: 20$ & 02.56 & 449.431 & 13.007 & 0.197 & 94.10 & \\
\hline DH36 & $1986-04-02$ & $09: 40$ & 01.75 & 456.403 & 6.972 & 0.251 & 95.85 & \\
\hline $\mathrm{DH} 36$ & $1986-04-08$ & 09.45 & 00.97 & 462.406 & 6.003 & 0.162 & 96.82 & \\
\hline DH36 & $1986-04-16$ & $12: 25$ & 01.65 & 470.517 & 8.111 & 0.203 & 98.47 & \\
\hline DH36 & $1986-04-24$ & $10: 20$ & 02.00 & 478.431 & 7.914 & 0.253 & 100.47 & \\
\hline DH36 & $1986-04-30$ & $10: 55$ & 01.21 & 484.455 & 6.024 & 0.201 & 101.68 & \\
\hline DH36 & $1986-05-06$ & $10: 14$ & 01.20 & 490.426 & 5.971 & 0.201 & 102.88 & \\
\hline $\mathrm{DH} 36$ & $1986-05-13$ & $11: 13$ & 01.42 & 497.467 & 7.041 & 0.202 & 104.30 & \\
\hline $\mathrm{DH} 36$ & $1986-05-20$ & $11: 10$ & 01.50 & 504.465 & 6.998 & 0.214 & 105.80 & \\
\hline DH36 & $1986-05-27$ & $15: 45$ & 01.40 & 511.656 & 7.191 & 0.195 & 107.20 & \\
\hline DH36 & $1986-06-03$ & $10: 10$ & 01.38 & 518.424 & 6.768 & 0.204 & 108.58 & \\
\hline
\end{tabular}


BRINE ACCUMULATION DATA TABLE (Continued)

Data through December 31, 1990

\begin{tabular}{|c|c|c|c|c|c|c|c|c|}
\hline Location & Date & Time & $\begin{array}{c}\text { Liters } \\
\text { removed } \\
\end{array}$ & $\begin{array}{l}\text { Days } \\
\text { since } \\
1 / 1 / 85 \\
\end{array}$ & $\begin{array}{l}\text { Days } \\
\text { used for } \\
\text { calc. }\end{array}$ & $\begin{array}{l}\text { Liters } \\
\text { per } \\
\text { day }\end{array}$ & $\begin{array}{c}\text { Cumulative } \\
\text { liters } \\
\text { collected }\end{array}$ & Remarks \\
\hline DH36 & $1986-06-10$ & $11: 35$ & 01.24 & 525.483 & 7.059 & 0.176 & 100.82 & $\begin{array}{l}\text { Valve leaked. Some brine drained back down } \\
\text { hole. }\end{array}$ \\
\hline DH36 & $1986-06-17$ & $11: 00$ & 01.65 & 532.458 & 6.975 & 0.237 & 111.47 & \\
\hline DH36 & $1986-06-24$ & $11: 00$ & 01.45 & 539.458 & 7.000 & 0.207 & 112.92 & \\
\hline DH36 & $1986-07-01$ & $14: 05$ & 01.55 & 546.587 & 7.129 & 0.217 & 114.47 & \\
\hline DH36 & $1986-07-08$ & $10: 45$ & 01.40 & 553.448 & 6.861 & 0.204 & 115.87 & \\
\hline DHบ6 & $1986-07-16$ & $10: 45$ & 01.76 & 561.448 & 8.000 & 0.220 & 117.63 & \\
\hline DH36 & $1986-07-22$ & $10: 07$ & 01.29 & 567.422 & 5.974 & 0.216 & 118.92 & \\
\hline DH36 & $1986-07-29$ & $10: 40$ & 01.45 & 574.444 & 7.022 & 0.206 & 120.37 & \\
\hline DH36 & $1986-08-05$ & $11: 20$ & 01.46 & 581.472 & 7.028 & 0.208 & 121.83 & \\
\hline DH36 & $1986-08-12$ & $10: 37$ & 01.50 & 588.442 & 6.970 & 0.215 & 123.33 & \\
\hline DH36 & $1986-08-19$ & $11: 35$ & 01.38 & 595.483 & 7.041 & 0.196 & 124.71 & \\
\hline DH36 & $1986-08-26$ & $10: 38$ & 01.49 & 602.443 & 6.960 & 0.214 & 126.20 & Static level not measured. \\
\hline DH36 & $1986-09-04$ & $10: 41$ & 01.70 & 611.445 & 9.002 & 0.189 & 127.80 & \\
\hline DH36 & $1986-09-09$ & $10: 15$ & 01.20 & 616.427 & 4.982 & 0.241 & 129.10 & \\
\hline DH36 & $1986-09-16$ & $10: 20$ & 01.37 & 623.431 & 7.004 & 0.196 & 130.47 & \\
\hline DH36 & $1986-09-23$ & $10: 18$ & 01.40 & 630.429 & 6.998 & 0.200 & 131.87 & \\
\hline DH36 & $1986-10-01$ & $12: 18$ & 01.76 & 638.513 & 8.084 & 0.218 & 133.63 & \\
\hline DH36 & $1986-10-08$ & $11: 10$ & 01.44 & 645.465 & 6.952 & 0.207 & 135.07 & Brine efferveces as it is poured into beaker. \\
\hline DH36 & $1986-10-14$ & $11: 57$ & 01.21 & 651.498 & 6.033 & 0.201 & 136.28 & Static level not measured. \\
\hline $\mathrm{DH} 36$ & $1986-11-05$ & $11: 38$ & 4.28 & 673.485 & 21.987 & 0.195 & 140.56 & \\
\hline DH36 & $1986-11-20$ & $12: 35$ & 03.12 & 688.524 & 15.039 & 0.207 & 143.68 & \\
\hline DHЗ6 & $1986-12-30$ & $12: 25$ & 01.72 & 728.517 & 0.000 & 0.000 & 143.68 & $\begin{array}{l}\text { Partial evacuation. No calculation. Do not plot } \\
\text { or use zero value. }\end{array}$ \\
\hline DH36 & $1986-12-31$ & $12: 38$ & 6.54 & 729.526 & 41.002 & 0.201 & 151.94 & $\begin{array}{l}\text { Calculated using } 8.26 \text { liters in } 41.002 \text { days } \\
(1.72 \mid 12 / 30 / 86 \text { plus } 6.54 \mid 12 / 31 / 86) \text {. }\end{array}$ \\
\hline $\begin{array}{l}\text { DH36 } \\
\text { DH36 }\end{array}$ & $\begin{array}{l}1987-02-03 \\
1987-03-06\end{array}$ & $\begin{array}{l}13: 35 \\
11: 20\end{array}$ & $\begin{array}{r}06.84 \\
5.84\end{array}$ & $\begin{array}{l}763.566 \\
794.472\end{array}$ & $\begin{array}{l}34.040 \\
30.906\end{array}$ & $\begin{array}{l}0.201 \\
0.189\end{array}$ & $\begin{array}{l}158.78 \\
164.62\end{array}$ & \\
\hline DH36 & $1987-03-30$ & $11: 27$ & 4.95 & 818.477 & 24.005 & 0.206 & 169.57 & \\
\hline DH36 & $1987-05-07$ & $11: 33$ & 6.62 & 856.481 & 38.004 & 0.174 & 176.19 & \\
\hline $\mathrm{DH} 36$ & $1987-06-17$ & $10: 45$ & 7.25 & 897.448 & 0.000 & 0.000 & 183.44 & Some brine left in hole; no calculation. \\
\hline DH36 & $1987-06-18$ & $12: 10$ & 0.49 & 898.507 & 42.026 & 0.184 & 183.93 & $\begin{array}{l}\text { Original Vday calculation too high due to } \\
\text { resicual brine lett in hole. Recalculated using } \\
7.741(7.25 \text { | } 6 / 17 / 87 \text { plus } 0.49 \text { | } 6 / 18 / 87) \text {. }\end{array}$ \\
\hline $\mathrm{DH} 36$ & $1987-07-28$ & $11: 27$ & 7.76 & 938.477 & 39.970 & 0.194 & 191.69 & \\
\hline $\mathrm{DH} 36$ & $1987-09-01$ & $10: 50$ & 6.99 & 973.451 & 34.974 & 0.200 & 998.68 & \\
\hline $\mathrm{DH} 36$ & $1987-10-20$ & $11: 56$ & 8.58 & 1022.500 & 48.049 & 0.175 & 207.26 & \\
\hline DH36 & $1987-11-19$ & $11: 30$ & 4.19 & 1052.480 & 29.980 & 0.140 & 211.45 & \\
\hline $\mathrm{DH} 36$ & $1988-01-04$ & $11: 50$ & 6.74 & 1098.490 & 46.010 & 0.146 & 218.19 & \\
\hline DH36 & $1988-02-08$ & $11: 50$ & 4.90 & 1133.490 & 35.000 & 0.140 & 223.09 & \\
\hline DH36 & $1988-03-29$ & 11:35 & 7.25 & 1183.480 & 49.990 & 0.145 & 230.34 & \\
\hline DH36 & $1988-05-05$ & $09: 45$ & 5.01 & 1220.410 & 36.930 & 0.136 & 235.35 & \\
\hline DH36 & $1988-05-12$ & $09: 50$ & 1.30 & 1227.410 & 7.000 & 0.186 & 236.65 & \\
\hline DH36 & $1988-07-12$ & $08: 50$ & 7.90 & 1288.370 & 60.860 & 0.130 & 244.55 & \\
\hline DH36 & $1988-07-28$ & $10: 25$ & 1.50 & 1304.430 & 16.060 & 0.093 & 246.05 & \\
\hline DH36 & $1988-08-11$ & $10: 30$ & 3.66 & 1318.440 & 14.010 & 0.261 & 249.71 & \\
\hline DH36 & $1988-08-25$ & $09: 24$ & 2.05 & 1332.390 & 13.950 & 0.147 & 251.76 & \\
\hline DH36 & $1988-09-08$ & $14: 50$ & & 1346.620 & 0.000 & 0.000 & 251.76 & Did not sample. \\
\hline DH36 & $1988-09-14$ & $08: 40$ & 2.36 & 1352.360 & 19.970 & 0.118 & 254.12 & Slight orange color. \\
\hline DH36 & $1888-08-27$ & $10: 45$ & 1.30 & 1365.450 & 13.090 & 0.099 & 255.42 & \\
\hline DH36 & $1988-12-13$ & $10: 00$ & 10.63 & 1442.420 & 76.970 & 0.138 & 266.05 & \\
\hline DH36 & $1989-03-14$ & $10: 10$ & 11.16 & 1533.420 & 91.007 & 0.123 & 277.21 & \\
\hline DH36 & $1989-04-06$ & $09: 31$ & 2.73 & 1556.400 & 22.973 & 0.119 & 279.94 & \\
\hline DH36 & $1989-04-20$ & $09: 40$ & 1.79 & 1570.400 & 14.006 & 0.128 & 281.73 & \\
\hline DH36 & $1989-05-17$ & $10: 20$ & 6.45 & 1597.430 & 27.028 & 0.239 & 288.18 & \\
\hline DH36 & $1989-06-06$ & $10: 10$ & 2.62 & 1617.420 & 19.993 & 0.131 & 290.80 & \\
\hline DH36 & $1989-06-29$ & $10: 35$ & 2.42 & 1640.440 & 23.017 & 0.105 & 293.22 & \\
\hline DH36 & $1989-07-06$ & $09: 10$ & 1.08 & 1647.380 & 6.941 & 0.156 & 294.30 & \\
\hline $\mathrm{DH} 36$ & $1989-07-25$ & $09: 55$ & 2.35 & 1666.410 & 19.031 & 0.123 & 296.65 & \\
\hline DH36 & $1989-08-16$ & $09: 27$ & 2.75 & 1688.390 & 21.981 & 0.125 & 299.40 & \\
\hline
\end{tabular}


BRINE ACCUMULATION DATA TABLE (Continued) Data through December 31, 1990

\begin{tabular}{|c|c|c|c|c|c|c|c|c|}
\hline Location & Date & Time & $\begin{array}{c}\text { Liters } \\
\text { removed } \\
\end{array}$ & $\begin{array}{l}\text { Days } \\
\text { since } \\
1 / 1 / 85 \\
\end{array}$ & $\begin{array}{l}\text { Days } \\
\text { used for } \\
\text { calc. }\end{array}$ & $\begin{array}{l}\text { Liters } \\
\text { per } \\
\text { day }\end{array}$ & $\begin{array}{l}\text { Cumulative } \\
\text { liters } \\
\text { collected } \\
\end{array}$ & Remarks \\
\hline DH36 & $1989-09-12$ & $09: 30$ & 3.81 & 1715.400 & 27.002 & 0.141 & 303.21 & \\
\hline DH36 & $1989-12-13$ & $11: 10$ & 11.07 & 1807.460 & 92.069 & 0.120 & 314.28 & \\
\hline DH36 & $1990-01-10$ & $10: 18$ & 2.48 & 1835.429 & 27.964 & 0.089 & 316.76 & \\
\hline DH36 & $1990-01-24$ & $09: 37$ & 2.0 & 1849.401 & 13.972 & 0.143 & 318.76 & \\
\hline DH36 & $1990-02-07$ & $10: 17$ & 1.53 & 1863.428 & 14.027 & 0.109 & 320.29 & \\
\hline DH36 & $1990-02-21$ & $09: 50$ & 1.75 & 1877.410 & 13.982 & 0.125 & 322.04 & \\
\hline DH36 & $1990-03-05$ & $09: 25$ & 1.10 & 1889.392 & 11.982 & 0.092 & 323.14 & \\
\hline DH36 & $1990-03-14$ & $12: 30$ & NA & 1898.521 & & & 323.14 & Installed sampler. \\
\hline DH36 & $1990-03-19$ & $10: 36$ & 0.80 & 1903.442 & 14.050 & 0.000 & 323.94 & Brine probably left in hole. \\
\hline DH36 & $1990-03-21$ & $10: 16$ & 0.57 & 1905.428 & 1.986 & 0.085 & 324.51 & $\begin{array}{l}\text { Combined with } 0.80 \text { liters from } 03 / 19 / 90 \text {. } \\
\text { Used } 1.37 \text { liters for calculation. }\end{array}$ \\
\hline DH36 & $1990-04-04$ & $09: 09$ & 1.08 & 1919.381 & 13.953 & 0.077 & 325.59 & \\
\hline DH36 & $1990-04-10$ & $08: 34$ & 0.97 & 1925.357 & 5.976 & 0.162 & 326.56 & \\
\hline DH36 & $1990-04-17$ & $10: 17$ & 0.85 & 1932.428 & 7.071 & 0.120 & 327.41 & \\
\hline DH36 & $1990-04-24$ & $09: 14$ & 0.86 & 1939.385 & 6.957 & 0.000 & 328.27 & \\
\hline DH36 & $1990-04-25$ & $08: 45$ & 0.57 & 1940.365 & 0.980 & 0.180 & 328.84 & $\begin{array}{l}\text { Combined with } 0.86 \text { liters from } 04 / 27 / 90 \text {. } \\
\text { Used } 1.43 \text { liters for calculation. }\end{array}$ \\
\hline DH36 & $1990-05.02$ & $10: 24$ & 1.37 & 1947.433 & 7.068 & 0.194 & 330.21 & \\
\hline $\mathrm{DH} 36$ & $1990-05-09$ & $08: 35$ & 0.68 & 1954.358 & 6.925 & 0.098 & 330.89 & \\
\hline DH36 & $1990-05-16$ & $08: 45$ & 0.78 & 1961.365 & 7.007 & 0.111 & 331.67 & \\
\hline DH36 & $1990-05-17$ & $07: 50$ & 0.17 & 1962.326 & 0.961 & 0.177 & 331.84 & \\
\hline DH36 & $1990-05-23$ & $12: 02$ & 0.68 & 1968.501 & 6.175 & 0.110 & 332.52 & \\
\hline DH36 & $1990-05-31$ & $08: 38$ & 0.85 & 1976.360 & 7.859 & 0.108 & 333.37 & \\
\hline DH36 & $1990-06-01$ & $11: 00$ & 0.15 & 1977.458 & 1.098 & 0.137 & 333.52 & Repaired sampler, evacuated hole. \\
\hline DH36 & $1990-06-06$ & $08: 47$ & 0.45 & 1982.366 & 4.908 & 0.092 & 333.97 & \\
\hline DH36 & $1990-06-14$ & $08: 38$ & 0.82 & 1990.360 & 7.994 & 0.103 & 334.79 & \\
\hline DH36 & $1990-06-20$ & $09: 53$ & 0.59 & 1996.412 & 6.052 & 0.097 & 335.38 & \\
\hline DH36 & $1990-06-28$ & $08: 38$ & 0.88 & 2004.360 & 7.948 & 0.111 & 336.26 & \\
\hline DH36 & $1990-07-17$ & $10: 52$ & 0.41 & 2023.453 & 19.093 & 0.000 & 336.67 & \\
\hline DH36 & $1990-07-18$ & $10: 20$ & 0.62 & 2024.431 & 0.978 & 0.051 & 337.29 & $\begin{array}{l}\text { Combined with } 0.41 \text { liters from } 07 / 17 / 90 \text {. } \\
\text { Used } 1.03 \text { liters for calculation. }\end{array}$ \\
\hline DH36 & $1990-07-25$ & $09: 45$ & 0.61 & 2031.406 & 6.975 & 0.087 & 337.90 & \\
\hline DH36 & $1990-08-01$ & $10: 38$ & 0.61 & 2038.443 & 7.037 & 0.087 & 338.51 & \\
\hline DH36 & $1990-12-12$ & $09: 47$ & 11.54 & 2171.408 & 132.965 & 0.087 & 350.05 & First evacuation since $08 / 07 / 90$ \\
\hline DH36 & $1990-12 \cdot 19$ & $11: 22$ & 3.61 & 2178.474 & 7066 & 0.511 & 353.66 & $\begin{array}{l}\text { Brine stored in fractures may have drained } \\
\text { into hole atter evacuation of } 11.5 \text { liters on } \\
12 / 12 / 90\end{array}$ \\
\hline & & & & & $\cdots$ & & & ............................................. \\
\hline $\mathrm{DH} 37$ & $1984-12-05$ & $00: 00$ & NA & 0.000 & 0.000 & 0.000 & 0.00 & $\begin{array}{l}\text { Approximate date this part of Room G } \\
\text { excavated. }\end{array}$ \\
\hline DH37 & $1985-01-26$ & $00: 00$ & NA & 0.000 & 0.000 & 0.000 & 0.00 & Uphole drilled $1 / 25 / 85$ to $1 / 26 / 85$ \\
\hline DH37 & $1985-02-05$ & $11: 15$ & NA & 35.469 & 1.000 & 0.000 & 0.00 & Started to drip. \\
\hline DH37 & $1985-03-05$ & $10: 10$ & 00.06 & 63.424 & 28.955 & 0.002 & 0.06 & Stalactute in collection container. \\
\hline DH37 & $1985-03-12$ & $10: 00$ & 00.06 & 70.417 & 6.993 & 0.009 & 012 & Salt crystals in collection container. \\
\hline DH37 & $1985-03-26$ & $09: 50$ & NA & 84.410 & 13993 & 0.000 & 0.12 & Trace, none collected. \\
\hline DH37 & $1985-04-17$ & $13: 30$ & 00.06 & 106.562 & 36.145 & 0.002 & 0.18 & \\
\hline DH37 & $1985-04-23$ & $11: 41$ & 00.04 & 112.487 & 5.925 & 0.007 & 022 & \\
\hline DH37 & $1985-04-30$ & $10: 50$ & 00.03 & 119.451 & 6.964 & 0004 & 0.25 & \\
\hline DH37 & $1985-05-07$ & $09: 45$ & 00.06 & 126.406 & 6.955 & 0.009 & 0.31 & \\
\hline DH37 & $1985-05-14$ & $10: 37$ & 00.07 & 133.442 & 7.036 & 0.010 & 0.38 & \\
\hline DH37 & $1985-05-21$ & $10: 31$ & 00.06 & 140.438 & 6.996 & 0.009 & 0.44 & \\
\hline DH37 & $1985-05-29$ & $10: 00$ & 00.06 & 148.417 & 7.979 & 0.008 & 0.50 & \\
\hline $\mathrm{DH} 37$ & $1985-06-04$ & $11: 22$ & 00.05 & 154.474 & 6.057 & 0.008 & 0.55 & \\
\hline DH37 & $1985-06-11$ & $10: 32$ & 00.05 & 161.439 & 6.965 & 0.007 & 0.60 & \\
\hline DH37 & $1985-06-18$ & $10: 05$ & 00.08 & 168.420 & 6.981 & 0.011 & 0.68 & Stalactites in collection container. \\
\hline $\mathrm{DH} 37$ & $1985-06-25$ & $10: 44$ & 00.05 & 175.447 & 7.027 & 0.007 & 0.73 & \\
\hline DH37 & $1985-07-02$ & $11: 00$ & 00.04 & 182.458 & 7.011 & 0.006 & 0.77 & \\
\hline DH37 & $1985-07-09$ & $11: 00$ & 00.03 & 189.458 & 7.000 & 0.004 & 0.80 & \\
\hline
\end{tabular}


BRINE ACCUMULATION DATA TABLE (Continued) Data through December 31, 1990

\begin{tabular}{|c|c|c|c|c|c|c|c|c|}
\hline Location & Date & Time & $\begin{array}{c}\text { Liters } \\
\text { removed }\end{array}$ & $\begin{array}{l}\text { Days } \\
\text { since } \\
1 / 1 / 85 \\
\end{array}$ & $\begin{array}{l}\text { Days } \\
\text { used for } \\
\text { calc. }\end{array}$ & $\begin{array}{c}\text { Liters } \\
\text { per } \\
\text { day }\end{array}$ & $\begin{array}{c}\text { Cumulative } \\
\text { liters } \\
\text { collected } \\
\end{array}$ & Remarks \\
\hline DH37 & $1985-07-16$ & $11: 40$ & 00.06 & 196.486 & 7.028 & 0.009 & 0.86 & \\
\hline $\mathrm{DH} 37$ & $1985-07-24$ & $10: 33$ & 00.06 & 204.440 & 7.954 & 0.008 & 0.92 & \\
\hline DH37 & $1985-07-30$ & $10: 11$ & 00.02 & 210.424 & 5.984 & 0.003 & 0.94 & \\
\hline $\mathrm{DH} 37$ & $1985-08-06$ & $10: 32$ & 00.01 & 217.439 & 7.015 & 0.001 & 0.95 & \\
\hline $\mathrm{DH} 37$ & $1985-08-14$ & $10: 49$ & 00.02 & 225.451 & 8.012 & 0.002 & 0.97 & \\
\hline DH37 & $1985-08-20$ & $10: 56$ & 00.03 & 231.456 & 6.005 & 0.005 & 1.00 & \\
\hline DH37 & $1985-08-28$ & $09: 55$ & 00.04 & 239.413 & 7.957 & 0.005 & 1.04 & \\
\hline $\mathrm{DH} 37$ & $1985-09-04$ & $10: 21$ & 00.02 & 246.431 & 7.018 & 0.003 & 1.06 & \\
\hline DH37 & $1985-09-10$ & $10: 14$ & 00.03 & 252.426 & 5.995 & 0.005 & 1.09 & \\
\hline DH37 & $1985-09-17$ & $09: 35$ & 00.02 & 259.399 & 6.973 & 0.003 & 1.11 & \\
\hline DH37 & $1985-09-24$ & $09: 45$ & 00.02 & 266.406 & 7.007 & 0.003 & 1.13 & \\
\hline $\mathrm{DH} 37$ & $1985-10-01$ & $09: 50$ & 00.01 & 273.410 & 7.004 & 0.001 & 1.14 & \\
\hline $\mathrm{DH} 37$ & $1985-10-15$ & $10: 10$ & 00.01 & 287.424 & 14.014 & 0.001 & 1.15 & \\
\hline $\mathrm{DH} 37$ & $1985-10-23$ & $10: 17$ & 00.02 & 295.428 & 8.004 & 0.002 & 1.17 & \\
\hline $\mathrm{DH} 37$ & $1985-10-29$ & $09: 35$ & 00.02 & 301.399 & 5.971 & 0.003 & 1.19 & \\
\hline DH37 & 1986-07-01 & $14: 00$ & 00.02 & 546.583 & 245.184 & 0.000 & 1.21 & \\
\hline DH37 & $1986-11-05$ & $11: 22$ & NA & 673.474 & 126.891 & 0.000 & 1.21 & Dry. \\
\hline DH37 & $1986-11-20$ & $12: 25$ & NA & 688.517 & 141.934 & 0.000 & 1.21 & Dry, not collected. \\
\hline $\mathrm{DH} 37$ & $1986-12-30$ & $12: 00$ & NA & 728.500 & 181.917 & 0.000 & 1.21 & \\
\hline $\mathrm{DH} 37$ & $1987-02-03$ & NA: & NA & 763.000 & 216.417 & 0.000 & 1.21 & \\
\hline DH37 & $1987-03-06$ & $11: 05$ & NA & 794.462 & 247.879 & 0.000 & 1.21 & Dry. \\
\hline DH37 & $1987-03-30$ & $11: 10$ & 0.00 & 818.465 & 24.003 & 0.000 & 1.21 & Dry. \\
\hline DH37 & $1987-05-07$ & $11: 27$ & 0.00 & 856.477 & 62.015 & 0.000 & 1.21 & Dry. \\
\hline $\mathrm{DH} 37$ & $1987-06-18$ & $12: 05$ & 0.00 & 898.503 & 104.041 & 0.000 & 1.21 & Dry. \\
\hline DH37 & $1987-07-28$ & $10: 53$ & 0.00 & 938.453 & 143.991 & 0.000 & 1.21 & Dry. \\
\hline $\mathrm{DH} 37$ & $1987-09-01$ & $10: 45$ & 0.00 & 973.448 & 34.995 & 0.000 & 1.21 & Dry. \\
\hline DH37 & $1987-10-20$ & $11: 35$ & 0.00 & 1022.480 & 49.032 & 0.000 & 1.21 & Dry. \\
\hline DH37 & $1987-11-19$ & $11: 05$ & 0.00 & 1052.460 & 29.980 & 0.000 & 1.21 & Dry. \\
\hline DH37 & $1988-01-04$ & $11: 35$ & 0.00 & 1098.480 & 46.020 & 0.000 & 1.21 & Dry. \\
\hline DH37 & $1988-02-08$ & $11: 40$ & 0.00 & 1133.490 & 35.010 & 0.000 & 1.21 & Dry. \\
\hline DH37 & $1988-03-29$ & $11: 35$ & 0.00 & 1183.480 & 49.990 & 0.000 & 1.21 & Dry. \\
\hline $\mathrm{DH} 37$ & $1988-07-12$ & $08: 50$ & 0.00 & 1288.370 & 104.890 & 0.000 & 1.21 & Dry. \\
\hline $\mathrm{DH} 37$ & $1988-09-27$ & $10: 45$ & 0.00 & 1365.450 & 77.080 & 0.000 & 1.21 & Dry. \\
\hline $\mathrm{DH} 37$ & $1988-12-13$ & $09: 55$ & 0 & 1442.410 & 76.960 & 0.000 & 1.21 & Dry. \\
\hline $\mathrm{DH} 37$ & 1989-03-14 & $10: 00$ & 0 & 1533.420 & 91.004 & 0.000 & 1.21 & Hole dry. \\
\hline $\mathrm{DH} 37$ & $1989-04-06$ & $09: 45$ & 0 & 1556.410 & 22.989 & 0.000 & 1.21 & Hole dry. \\
\hline $\mathrm{DH} 37$ & $1989-04-20$ & $09: 35$ & 0 & 1570.400 & 13.993 & 0.000 & 1.21 & Hole dry. \\
\hline $\mathrm{DH} 37$ & $1989-05-17$ & $10: 20$ & 0 & 1597.430 & 27.032 & 0.000 & 1.21 & Hole dry. \\
\hline DH37 & $1989-06-06$ & $10: 10$ & 0 & 1617.420 & 19.993 & 0.000 & 1.21 & Hole dry. \\
\hline $\mathrm{DH} 37$ & $1988-06-29$ & $10: 30$ & 0 & 1640.440 & 23.014 & 0.000 & 1.21 & Hole dry. \\
\hline $\mathrm{DH} 37$ & $1989-07-25$ & $09: 55$ & 0 & 1666.410 & 25.975 & 0.000 & 1.21 & Hole dry. \\
\hline $\mathrm{DH} 37$ & $1989-08-16$ & $09: 55$ & 0 & 1688.410 & 22.000 & 0.000 & 1.21 & Hole dry. \\
\hline $\mathrm{DH} 37$ & $1989-08-28$ & $10: 20$ & 0 & 1700.430 & 12.018 & 0.000 & 1.21 & Collection device removed. \\
\hline $\mathrm{DH} 37$ & $1989-12-13$ & $11: 00$ & 0 & 1807.460 & 107.027 & 0.000 & 1.21 & Hole dry. \\
\hline $\mathrm{DH} 37$ & $1990-01-10$ & $10: 09$ & 0.0 & 1835.423 & 27.965 & 0.000 & 1.21 & Dry. \\
\hline $\mathrm{DH} 37$ & $1990-01-24$ & $10: 00$ & 0.0 & 1849.417 & 13.994 & 0.000 & 1.21 & Dry. \\
\hline $\mathrm{DH} 37$ & $1990-02-07$ & $10: 30$ & 0.0 & 1863.438 & 14.021 & 0.000 & 1.21 & Dry. \\
\hline $\mathrm{DH} 37$ & $1990-02-21$ & $09: 47$ & 0.0 & 1877.408 & 13.970 & 0.000 & 1.21 & Dry. \\
\hline $\mathrm{DH} 37$ & $1990-03-05$ & $09: 25$ & 0.0 & 1889.392 & 11.984 & 0.000 & 1.21 & Dry. \\
\hline $\mathrm{DH} 37$ & $1990-03-19$ & $11: 30$ & 0.0 & 1903.479 & 14.087 & 0.000 & 1.21 & Dry. \\
\hline $\mathrm{DH} 37$ & $1990-03-21$ & $10: 30$ & 0.0 & 1905.438 & 1.959 & 0.000 & 1.21 & Dry. \\
\hline $\mathrm{DH} 37$ & $1990-04-04$ & $09: 37$ & 0.0 & 1919.401 & 13.963 & 0.000 & 1.21 & Dry. \\
\hline $\mathrm{DH} 37$ & $1990-04-10$ & $08: 36$ & 0.0 & 1925.358 & 5.957 & 0.000 & 1.21 & Dry. \\
\hline $\mathrm{DH} 37$ & $1990-04-17$ & $10: 17$ & 0.0 & 1932.428 & 7.070 & 0.000 & 1.21 & Dry. \\
\hline $\mathrm{DH} 37$ & $1990-04-24$ & $09: 30$ & 0.0 & 1939.396 & 6.968 & 0.000 & 1.21 & Dry. \\
\hline $\mathrm{DH} 37$ & $1990-05-02$ & $10: 30$ & 0.0 & 1947.438 & 8.042 & 0.000 & 1.21 & Dry. \\
\hline $\mathrm{DH} 37$ & $1990-05-09$ & $08: 43$ & 0.0 & 1954.363 & 6.925 & 0.000 & 1.21 & Dry. \\
\hline $\mathrm{DH} 37$ & $1990-05-16$ & $08: 45$ & 0.0 & 1961.365 & 7.002 & 0.000 & 1.21 & Dry. \\
\hline $\mathrm{DH} 37$ & $1990-05-23$ & $12: 03$ & 0.0 & 1968.502 & 7.137 & 0.000 & 1.21 & Dry. \\
\hline $\mathrm{DH} 37$ & $1990-05-31$ & $08: 40$ & 0.0 & 1976.361 & 7.859 & 0.000 & 1.21 & Dry. \\
\hline
\end{tabular}


BRINE ACCUMULATION DATA TABLE (Continued)

Data through December 31, 1990

\begin{tabular}{|c|c|c|c|c|c|c|c|c|}
\hline Location & Date & Time & $\begin{array}{l}\text { Litors } \\
\text { removed }\end{array}$ & $\begin{array}{l}\text { Days } \\
\text { since } \\
1 / 1 / 85 \\
\end{array}$ & $\begin{array}{l}\text { Days } \\
\text { used tor } \\
\text { calc. }\end{array}$ & $\begin{array}{l}\text { Liters } \\
\text { per } \\
\text { day }\end{array}$ & $\begin{array}{c}\text { Cumulative } \\
\text { liters } \\
\text { collected }\end{array}$ & Remarks \\
\hline $\mathrm{DH} 37$ & 1990.06-06 & 0940 & 00 & 1982.403 & 6.042 & 0.000 & 121 & Dry. \\
\hline DH37 & $1990-06-14$ & $08: 35$ & 0.0 & 1990.358 & 7.055 & 0.000 & 1.21 & Dry \\
\hline DH37 & $1990-06 \cdot 20$ & $09: 35$ & 0.0 & 1996.399 & 6.041 & 0.000 & 121 & Dry. \\
\hline DH37 & $1990-06 \cdot 28$ & $08: 38$ & 0.0 & 2004.360 & 7.961 & 0.000 & 121 & Dry \\
\hline DH37 & $1990-07.17$ & $10: 59$ & 0.0 & 2023.458 & 19.098 & 0.000 & $1<1$ & Dry. \\
\hline $\mathrm{DH} 37$ & $1990-07-25$ & $09: 33$ & 00 & 2031.398 & 7.240 & 0.000 & 1.21 & Dry \\
\hline $\mathrm{OH} 37$ & $1990-08-01$ & $10: 38$ & 0.0 & 2038.443 & 7.045 & 0.000 & 1.21 & Dry. \\
\hline 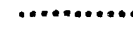 & & & & 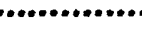 & 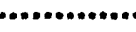 & 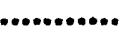 & ....... & 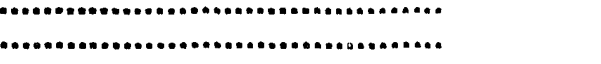 \\
\hline DH38 & $1984-12 \cdot 05$ & $00: 00$ & NA & 0.000 & 0.000 & 0000 & .00 & $\begin{array}{l}\text { Approximate date this part of floom G } \\
\text { excavated. }\end{array}$ \\
\hline DH38 & $1985-01.26$ & 00.00 & NA & 0.000 & 0.000 & 0.000 & 000 & Downhole drilled $1 / 25 / 85$ to $1 / 26 / 85$ \\
\hline DH38 & $1985-01-28$ & 09.00 & NA & 27.375 & 1.000 & 0.000 & 0.00 & Dry. \\
\hline DH38 & $1985-02.05$ & 1115 & NA & 35.469 & 9.094 & 0,000 & 000 & Wet at bottom \\
\hline DH38 & 1985-02-19 & $12: 10$ & 0080 & 49.507 & 23.132 & 0035 & 0.80 & Brine and fine muck \\
\hline DH38 & $1985-02-26$ & $10: 45$ & 0126 & 56.448 & 6.941 & 0182 & 2.06 & Brine and $\operatorname{lin} \theta$ muck \\
\hline DH38 & 1985.0305 & $10: 00$ & 00.45 & 63.417 & 6.969 & 0.065 & 2.51 & \\
\hline DH38 & $1985-03 \cdot 12$ & 1000 & 0039 & 70.417 & 7000 & 0.056 & 2.90 & \\
\hline DH38 & $1985-03.20$ & 1037 & 00.45 & 78.442 & 8.025 & 0056 & 3.35 & \\
\hline $\mathrm{DH} 38$ & $1985-03-26$ & $09: 50$ & 00.36 & 84.410 & 5.968 & 0060 & 3.71 & \\
\hline DH38 & 1985-04-02 & $10: 25$ & 00.41 & 91.434 & 7.024 & 0058 & 4.12 & Some muck \\
\hline DНЗ8 & $1985-04-10$ & $10: 31$ & 00.44 & 99.438 & 8.004 & 0.055 & 456 & \\
\hline DH38 & $1985-04-17$ & $13: 30$ & 00.41 & 106.562 & 7124 & 0.058 & 497 & \\
\hline DH38 & $1985-04-23$ & $11: 41$ & 00.34 & 112.487 & 5.925 & 0.057 & 5.31 & \\
\hline DH38 & $1985-04-30$ & $11: 05$ & 00.39 & 119.462 & 6.975 & 0.056 & 5.70 & \\
\hline $\mathrm{DH} 38$ & $1985-05-07$ & $09: 50$ & 00.42 & 126.410 & 6.248 & 0.060 & 6.12 & \\
\hline DH38 & $1985-05-14$ & 10.45 & 00.41 & 133.448 & 7.038 & 0.058 & 6.53 & \\
\hline DH38 & $1985-05-21$ & $10: 35$ & 00.41 & 140.441 & 6.993 & 0.059 & 6.94 & \\
\hline DH38 & $1985-05-29$ & 1135 & 00.47 & 148.483 & 8.042 & 0.058 & 7.41 & \\
\hline $\mathrm{DH} 38$ & $1985-06-04$ & $11: 25$ & 00.35 & 154.476 & 5.993 & 0.058 & 7.76 & \\
\hline DH38 & $1985-06-11$ & $10: 35$ & 00.40 & 161.441 & 6.965 & 0.057 & 8.16 & \\
\hline DH38 & $1985-06-18$ & 10.09 & 00.39 & 168.423 & 6.982 & 0.056 & 855 & \\
\hline DH38 & $1985-06-25$ & 10.50 & 00.42 & 175.451 & 7.028 & 0.060 & 8.97 & \\
\hline DH38 & $1985-07-02$ & 1100 & 00.44 & 182.458 & 7007 & 0063 & 9.41 & \\
\hline DH38 & $1985-07-09$ & 1105 & 00.43 & 189.462 & 7004 & 0061 & 9.84 & \\
\hline $\mathrm{DH} 38$ & $1985-07-16$ & 1145 & 00.43 & 196.490 & 7.028 & 0061 & 10.27 & Brıne ettervescos \\
\hline DH38 & $1985-07-24$ & 1035 & 00.49 & 204.441 & 7951 & 0.062 & 10.76 & \\
\hline $\mathrm{DH} 38$ & $1985-07-30$ & 1014 & 00.38 & 210.426 & 5985 & 0.063 & 11.14 & \\
\hline $\mathrm{DH} 38$ & $1985-08-06$ & 10.34 & 00.42 & 217.440 & 7014 & 0.060 & 11.56 & \\
\hline $\mathrm{DH} 38$ & $1985-08-14$ & $10: 51$ & 00.49 & 225.452 & 8.012 & 0.061 & 12.05 & \\
\hline DH38 & $1985-08-20$ & 11.02 & 00.37 & 231.460 & 6.008 & 0.062 & 12.42 & \\
\hline $\mathrm{DH} 38$ & $1985-08-28$ & $10: 00$ & 00.51 & 239.417 & 7.957 & 0.064 & 12.93 & \\
\hline $\mathrm{DH} 38$ & $1985-09-04$ & $10: 23$ & 00.44 & 246.433 & 7.016 & 0.063 & 13.37 & \\
\hline DH38 & $1985-09-10$ & $10: 19$ & 00.39 & 252.430 & 5.997 & 0.065 & 13.76 & \\
\hline $\mathrm{DH} 38$ & $1985-09-17$ & 09:37 & 00.44 & 259.401 & 6.971 & 0.063 & 14.20 & \\
\hline DH38 & $1985-09-24$ & $09: 45$ & 00.44 & 266.406 & 7.005 & 0.063 & 14.64 & \\
\hline DH38 & $1985-10-01$ & $09: 53$ & 00.44 & 273.412 & 7006 & 0.063 & 15.08 & \\
\hline $\mathrm{DH} 38$ & $1985-10.08$ & 1038 & 00.46 & 280.443 & 7.031 & 0.065 & 15.54 & \\
\hline $\mathrm{OH} 38$ & $1985-10-15$ & $10: 15$ & 00.44 & 287.427 & 6.984 & 0.063 & 15.98 & \\
\hline DH38 & $1985-10-23$ & 10.20 & 00.49 & 295.431 & 8.004 & 0.061 & 16.47 & \\
\hline DH38 & $1985-10-29$ & $09: 40$ & 00.39 & 301.403 & 5.972 & 0.065 & 16.86 & \\
\hline $\mathrm{DH} 38$ & $1985-11-05$ & $09: 14$ & 00.43 & 308.385 & 6.982 & 0.062 & 17.29 & \\
\hline $\mathrm{DH} 38$ & $1985-11-13$ & $10: 00$ & 00.52 & 316.417 & 8.032 & 0.065 & 17.81 & \\
\hline DH38 & $1985-11.21$ & $11: 29$ & 00.47 & 324.478 & 8.061 & 0.058 & 18.28 & \\
\hline OH38 & $1985-11-26$ & $11: 20$ & 00.33 & 329.472 & 4.994 & 0.066 & 18.61 & \\
\hline $\mathrm{DH} 38$ & $1985-12.03$ & $13: 30$ & 00.42 & 336.562 & 7.090 & 0.059 & 19.03 & \\
\hline $\mathrm{DH} 38$ & $1985-12-10$ & $12: 30$ & 00.41 & 343.521 & 6.959 & 0.059 & 19.44 & \\
\hline $\mathrm{DH} 38$ & $1986-01-23$ & $11: 20$ & 02.70 & 387.472 & 43.951 & 0.061 & 22.14 & $\begin{array}{l}\text { Entry restricted since } 12 / 10 / 85 \text { due to mining } \\
\text { activities. }\end{array}$ \\
\hline $\mathrm{DH} 38$ & $1986-01-31$ & $12: 10$ & 00.53 & 395.507 & 8.035 & 0.066 & 22.67 & \\
\hline
\end{tabular}


BAINE ACCUMULATION DATA TABLE (Continued) Data through December 31, 1990

\begin{tabular}{|c|c|c|c|c|c|c|c|c|}
\hline Location & Date & Time & $\begin{array}{c}\text { Liters } \\
\text { removed }\end{array}$ & $\begin{array}{c}\text { Days } \\
\text { since } \\
1 / 1 / 85 \\
\end{array}$ & $\begin{array}{l}\text { Days } \\
\text { used for } \\
\text { calc. }\end{array}$ & $\begin{array}{l}\text { Liters } \\
\text { per } \\
\text { day }\end{array}$ & $\begin{array}{c}\text { Cumulative } \\
\text { liters } \\
\text { collected }\end{array}$ & Remarks \\
\hline DH38 & $1986-02-12$ & $10: 50$ & 00.75 & 407.451 & 11.944 & 0.063 & 23.42 & \\
\hline DH38 & $1986-02-19$ & $11: 40$ & 00.43 & 414.486 & 7.035 & 0.061 & 23.85 & \\
\hline DH38 & $1986-02-28$ & $13: 15$ & 00.37 & 423.552 & 9.066 & 0.041 & 24.22 & $\begin{array}{l}\text { Lost substantial volume due to break in } \\
\text { suction line. Brine flowed back down into } \\
\text { hole. }\end{array}$ \\
\hline DH38 & 1986-03-06 & $10: 35$ & 00.45 & 429.441 & 5.889 & 0.076 & 24.67 & \\
\hline DH38 & $1986-03-13$ & $10: 05$ & 00.43 & 436.420 & 6.979 & 0.062 & 25.10 & \\
\hline DH38 & $1986-03-26$ & $10: 10$ & 00.59 & 449.424 & 13.004 & 0.045 & 25.69 & \\
\hline DH38 & $1986-04-02$ & $09: 35$ & 00.58 & 456.399 & 6.975 & 0.083 & 26.27 & \\
\hline $\mathrm{DH} 38$ & $1986-04-08$ & $09: 40$ & 00.35 & 462.403 & 6.004 & 0.058 & 26.62 & \\
\hline DH38 & $1986-04-16$ & $12: 10$ & 00.50 & 470.507 & 8.104 & 0.062 & 27.12 & \\
\hline $\mathrm{DH} 38$ & $1986-04-24$ & $10: 12$ & 00.47 & 478.425 & 7.918 & 0.059 & 27.59 & \\
\hline DH38 & $1986-04-30$ & $10: 50$ & 00.35 & 484.451 & 6.026 & 0.058 & 27.84 & \\
\hline $\mathrm{DH} 38$ & $1986-05-06$ & $10: 14$ & 00.31 & 490.426 & 5.975 & 0.052 & 28.25 & \\
\hline DH38 & $1986-05-13$ & $11: 05$ & 00.41 & 497.462 & 7.036 & 0.058 & 28.66 & \\
\hline DH38 & $1986-05-20$ & $11: 05$ & $\infty .40$ & 504.462 & 7.000 & 0.057 & 29.06 & \\
\hline DH38 & $1986-05-27$ & $15: 40$ & 00.38 & 511.653 & 7.191 & 0.053 & 29.44 & \\
\hline $\mathrm{DH} 38$ & $1986-06-03$ & $10: 05$ & 00.44 & 518.420 & 6.767 & 0.065 & 29.88 & \\
\hline DH38 & $1986-06-10$ & $11: 22$ & 00.43 & 525.474 & 7.054 & 0.061 & 30.31 & \\
\hline DH38 & $1986-06-17$ & $10: 50$ & 00.37 & 532.451 & 6.977 & 0.053 & 30.68 & \\
\hline $\mathrm{DH} 38$ & $1986-06-24$ & $10: 52$ & 00.50 & 539.453 & 7.002 & 0.071 & 31.18 & \\
\hline DH38 & $1986-07-01$ & $14: 01$ & 00.40 & 546.584 & 7.131 & 0.056 & 31.58 & \\
\hline DH38 & $1986-07-08$ & $10: 30$ & 00.38 & 553.438 & 6.854 & 0.055 & 31.80 & \\
\hline DH38 & $1986-07-16$ & $10: 34$ & 00.43 & 561.440 & 8.002 & 0.054 & 32.39 & \\
\hline DH38 & $1986-07-22$ & $09: 58$ & 00.35 & 567.415 & 5.975 & 0.059 & 32.74 & \\
\hline DH38 & $1986-07-29$ & $10: 40$ & 00.38 & 574.444 & 7.029 & 0.054 & 33.12 & \\
\hline DH38 & 1986-08-05 & $11: 10$ & 00.39 & 581.465 & 7.021 & 0.056 & 33.51 & \\
\hline DH38 & $1986-08-12$ & $10: 30$ & 00.40 & 588.438 & 6.973 & 0.057 & 33.91 & \\
\hline DH38 & 1986-08-19 & $11: 30$ & 00.41 & 595.479 & 7.041 & 0.058 & 34.32 & \\
\hline DH38 & $1986-08-26$ & $10: 32$ & 00.36 & 602.439 & 6.960 & 0.052 & 34.68 & \\
\hline DH38 & $1986-09-04$ & $10: 35$ & 00.49 & 611.441 & 9.002 & 0.054 & 35.17 & \\
\hline DH38 & $1986-09-09$ & $10: 00$ & 00.30 & 616.417 & 4.976 & 0.060 & 35.47 & \\
\hline DH38 & $1986-09-16$ & $10: 11$ & 00.38 & 623.424 & 7.007 & 0.054 & 35.85 & \\
\hline DH38 & $1986-09-23$ & $10: 10$ & 00.37 & 630.424 & 7.000 & 0.053 & 36.22 & \\
\hline DH38 & $1986-10-01$ & $12: 07$ & 00.43 & 638.505 & 8.081 & 0.053 & 36.65 & \\
\hline DHз8 & $1986-10-08$ & $11: 30$ & 00.36 & 645.479 & 6.974 & 0.052 & 37.01 & \\
\hline DH38 & $1986-10-14$ & $11: 45$ & 00.35 & 651.490 & 6.011 & 0.058 & 37.36 & \\
\hline DH38 & $1986-11-05$ & $11: 26$ & 1.10 & 673.476 & 21.986 & 0.050 & 38.46 & \\
\hline DH38 & $1986-11.20$ & $12: 27$ & 00.82 & 688.519 & 15.043 & 0.055 & 39.28 & \\
\hline DH38 & $1986-12-30$ & $12: 15$ & 01.87 & 728.510 & 39.991 & 0.047 & 41.15 & \\
\hline DH38 & $1987-02-03$ & $13: 15$ & 01.72 & 763.552 & 35.042 & 0.049 & 42.87 & \\
\hline DH38 & $1987-03-06$ & $11: 05$ & 1.58 & 794.462 & 30.910 & 0.051 & 44.45 & \\
\hline DH38 & $1987-03-30$ & $11: 13$ & 1.17 & 818.467 & 24.005 & 0.049 & 45.62 & \\
\hline DH38 & $1987-05-07$ & $11: 20$ & 1.89 & 856.472 & 38.005 & 0.050 & 47.51 & \\
\hline $\begin{array}{l}\text { DH38 } \\
\text { DH38 }\end{array}$ & $\begin{array}{l}1987-06-17 \\
1987-06-18\end{array}$ & $\begin{array}{l}10: 45 \\
12: 05\end{array}$ & $\begin{array}{l}1.91 \\
0.16\end{array}$ & $\begin{array}{l}897.448 \\
898.503\end{array}$ & $\begin{array}{r}0.000 \\
42.031\end{array}$ & $\begin{array}{l}0.000 \\
0.049\end{array}$ & $\begin{array}{l}49.42 \\
49.58\end{array}$ & $\begin{array}{l}\text { Some brine left in hole; no calculation. } \\
\text { Calculated using } 2.07 \text { liters (1.91 I. } 6 / 17 / 87 \\
\text { plus } 0.16 \mid 6 / 18 / 87) \text {. }\end{array}$ \\
\hline DH38 & $1987-07-28$ & $10: 53$ & 1.88 & 938.453 & 39.950 & 0.047 & 51.46 & \\
\hline DH38 & $1987-09-01$ & $10: 45$ & 1.70 & 973.448 & 34.995 & 0.049 & 53.16 & \\
\hline DH38 & $1987-10-20$ & $11: 40$ & 2.29 & 1022.490 & 49.042 & 0.047 & 55.45 & \\
\hline DH38 & $1987-11-19$ & $11: 05$ & 1.42 & 1052.460 & 29.970 & 0.047 & 56.87 & \\
\hline DH38 & $1988-01-04$ & $11: 35$ & 2.05 & 1098.480 & 46.020 & 0.045 & 58.92 & \\
\hline DH38 & $1988-02-08$ & $11: 40$ & 1.48 & 1133.490 & 35.010 & 0.042 & 60.40 & \\
\hline DH38 & $1988-03-29$ & $11: 30$ & 2.10 & 1183.480 & 49.990 & 0.042 & 62.50 & \\
\hline DH38 & $1988-05-05$ & $09: 55$ & 1.70 & 1220.410 & 36.930 & 0.046 & 64.20 & \\
\hline $\mathrm{DH} 38$ & $1988-05-12$ & $11: 20$ & 0.31 & 1227.470 & 7.060 & 0.044 & 64.51 & \\
\hline DH38 & $1988-07-12$ & $08: 45$ & 2.44 & 1288.360 & 60.890 & 0.040 & 66.95 & \\
\hline DH38 & $1988-07-28$ & $10: 20$ & 0.88 & 1304.430 & 16.070 & 0.055 & 67.83 & \\
\hline DH38 & $1988-09-27$ & $10: 30$ & 1.92 & 1365.440 & 61.010 & 0.031 & 69.75 & \\
\hline DH38 & $1988-12-13$ & $09: 55$ & 3.45 & 1442.410 & 76.970 & 0.045 & 73.20 & \\
\hline
\end{tabular}


BRINE ACCUMULATION DATA TABLE (Continued) Data through December 31, 1990

\begin{tabular}{|c|c|c|c|c|c|c|c|c|}
\hline Location & Date & Time & $\begin{array}{l}\text { Liters } \\
\text { removed }\end{array}$ & $\begin{array}{l}\text { Days } \\
\text { since } \\
1 / 1 / 85 \\
\end{array}$ & $\begin{array}{l}\text { Days } \\
\text { used for } \\
\text { calc. }\end{array}$ & $\begin{array}{l}\text { Liters } \\
\text { per } \\
\text { day }\end{array}$ & $\begin{array}{c}\text { Cumulative } \\
\text { liters } \\
\text { collected }\end{array}$ & Remarks \\
\hline DH38 & $1989-03-14$ & $09: 55$ & 3.25 & 1533.410 & 91.000 & 0.036 & 76.45 & \\
\hline $\mathrm{DH} 38$ & $1989-04-06$ & $09: 45$ & 1.03 & 1556.410 & 22.993 & 0.045 & 77.48 & \\
\hline $\mathrm{OH} 38$ & $1989-04-20$ & $09: 35$ & 0.75 & 1570.400 & 13.993 & 0.054 & 78.23 & \\
\hline $\mathrm{DH} 38$ & $1989-05-17$ & $10: 05$ & 1.11 & 1597.420 & 27.021 & 0.041 & 79.34 & \\
\hline $\mathrm{DH} 38$ & $1989-06-06$ & $10: 00$ & 0.70 & 1617.420 & 19.907 & 0.035 & 80.04 & \\
\hline $\mathrm{DH} 38$ & $1989-06-29$ & $10: 30$ & 0.64 & 1640.440 & 23.021 & 0.028 & 80.68 & \\
\hline DH38 & $1989-07-25$ & $10: 27$ & 0.92 & 1666.430 & 25.097 & 0.035 & 81.60 & \\
\hline DH38 & $1980-08-16$ & $09: 57$ & 0.81 & 1688.410 & 21.880 & 0.037 & 82.41 & \\
\hline DH38 & $1989-09-12$ & $09: 20$ & 1.16 & 1715.390 & 26.974 & 0.043 & 83.57 & \\
\hline $\mathrm{DH} 38$ & $1989-12-13$ & $10: 55$ & 3.20 & 1807.450 & 92.066 & 0.035 & 86.77 & \\
\hline $\mathrm{DH} 38$ & $1990-01-10$ & $10: 03$ & 1.00 & 1835.419 & 27.864 & 0.036 & 87.77 & \\
\hline DH38 & $1990-01-24$ & $10: 10$ & 0.21 & 1849.424 & 14.005 & 0.015 & 87.98 & \\
\hline DH38 & $1990-02-07$ & $10: 30$ & 0.48 & 1863.438 & 14.014 & 0.034 & 88.46 & \\
\hline $\mathrm{DH} 38$ & $1990-03-05$ & $09: 18$ & 0.53 & 1889.388 & 25.950 & 0.020 & 88.99 & \\
\hline DH38 & $1990-03-13$ & $14: 00$ & NA & 1897.583 & & & 88.99 & Installed sampler. \\
\hline DH38 & $1990-03-19$ & $11: 30$ & 0.61 & 1903.479 & 14.091 & 0.000 & 89.60 & Hole not completely evacuated. \\
\hline DH38 & $1990-03-21$ & $10: 30$ & 0.57 & 1905.438 & 1.959 & 0.073 & 90.17 & $\begin{array}{l}\text { Combined with } 0.61 \text { from } 03 / 19 / 90 \text {. Used } \\
1.18 \text { liters for calculation. }\end{array}$ \\
\hline DH38 & $1990-04-04$ & $09: 37$ & 0.62 & 1919.401 & 13.963 & 0.044 & 90.79 & \\
\hline $\mathrm{DH} 38$ & $1990-04-10$ & $08: 56$ & 0.34 & 1925.372 & 5.971 & 0.057 & 91.13 & \\
\hline $\mathrm{DH} 38$ & $1990-04-17$ & $10: 39$ & 0.23 & 1932.444 & 7.072 & 0.033 & 91.36 & \\
\hline $\mathrm{DH} 38$ & $1990-04-24$ & $09: 30$ & 0.27 & 1939.396 & 6.952 & 0.039 & 91.63 & \\
\hline $\mathrm{DH} 38$ & $1990-05-02$ & $10: 47$ & 0.32 & 1947.449 & 8.053 & 0.040 & 91.95 & \\
\hline $\mathrm{DH} 38$ & $1990-05.09$ & $09: 08$ & 0.23 & 1954.381 & 6.932 & 0.033 & 92.18 & \\
\hline DH38 & $1990-05-16$ & $09: 35$ & 0.25 & 1961.399 & 7.018 & 0.036 & 92.43 & \\
\hline $\mathrm{DH} 38$ & $1990-05-23$ & $12: 03$ & 0.25 & 1968.502 & 7.103 & 0.035 & 92.68 & \\
\hline $\mathrm{DH} 38$ & $1990-05-31$ & $09: 04$ & 0.28 & 1976.378 & 7.876 & 0.036 & 92.96 & \\
\hline $\mathrm{DH} 38$ & $1990-06-06$ & $09: 40$ & 0.22 & 1982.403 & 6.025 & 0.037 & 93.18 & \\
\hline $\mathrm{DH} 38$ & $1990-06-14$ & $08: 53$ & 0.27 & 1990.370 & 7.967 & 0.034 & 93.45 & \\
\hline DH38 & $1990-06-20$ & $09: 49$ & 0.22 & 1996.409 & 6.039 & 0.036 & 93.67 & \\
\hline $\mathrm{DH} 38$ & $1990-06-28$ & $09: 15$ & 0.29 & 2004.385 & 7.976 & 0.036 & 93.96 & \\
\hline $\mathrm{DH} 38$ & $1990-07-17$ & $11: 30$ & 0.50 & 2023.479 & 19.094 & 0.000 & 94.46 & \\
\hline DH38 & $1990-07-18$ & $10: 40$ & 0.20 & 2024.444 & 0.965 & 0.035 & 94.66 & $\begin{array}{l}\text { Combined with } 0.50 \text { liters from } 07 / 17 / 90 \text {. } \\
\text { Used } 0.70 \text { liters for calculation. }\end{array}$ \\
\hline DH38 & $1990-07-25$ & $09: 42$ & 0.30 & 2031.404 & 6.960 & 0.043 & 94.96 & \\
\hline $\mathrm{DH} 38$ & $1990-08-01$ & $10: 30$ & 0.14 & 2038.438 & 7.034 & 0.020 & 95.10 & \\
\hline \multicolumn{9}{|c|}{ 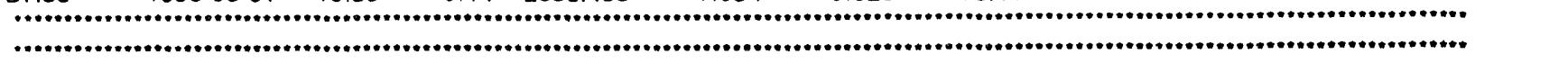 } \\
\hline DH39 & $1984-12-13$ & $00: 00$ & NA & 0.000 & 0.000 & 0.000 & 0.00 & $\begin{array}{l}\text { Approximate date that part of Room G was } \\
\text { excavated. }\end{array}$ \\
\hline DH39 & $1985-01-24$ & $00: 00$ & NA & 0.000 & 0.000 & 0.000 & 0.00 & Uphole drilled. \\
\hline DH39 & $1985-02-05$ & $11: 15$ & NA & 35.469 & 1.000 & 0.000 & 0.00 & Moist, no stalactites. \\
\hline $\mathrm{DH} 39$ & $1985-02-26$ & $10: 25$ & NA & 56.434 & 21.965 & 0.000 & 0.00 & Wet, back wet in $1.5 \mathrm{ft}$ circle. \\
\hline DH39 & $1985-03-12$ & $10: 00$ & NA & 70.417 & 35.948 & 0.000 & 0.00 & Trace, salt crystals in container. \\
\hline DH39 & $1985-03-26$ & $09: 55$ & NA & 84.413 & 49.944 & 0.000 & 0.00 & Trace. \\
\hline $\mathrm{DH} 39$ & $1985-05-07$ & $09: 37$ & 00.01 & 126.401 & 91.932 & 0.000 & 0.01 & \\
\hline $\mathrm{DH} 39$ & $1985-05-29$ & $1: 30$ & 00.03 & 148.479 & 22.078 & 0.001 & 0.04 & Stalactites in sample. \\
\hline DH39 & $1986-11-05$ & $11: 10$ & NA & 673.465 & 524.986 & 0.000 & 0.04 & Dry. \\
\hline $\mathrm{DH} 39$ & $1986-11.20$ & NA & NA & 688.000 & 539.521 & 0.000 & 0.04 & Dry. \\
\hline DH39 & $1986-12-30$ & $11: 45$ & NA & 728.490 & 580.011 & 0.000 & 0.04 & \\
\hline DH39 & $1987-02-03$ & NA & NA & 763.000 & 614.521 & 0.000 & 0.04 & \\
\hline DH39 & $1987-03-06$ & $11: 00$ & NA & 794.458 & 645.979 & 0.000 & 0.04 & Dry. \\
\hline $\mathrm{DH} 39$ & $1987-03-30$ & $11: 05$ & 0.00 & 818.462 & 24.004 & 0.000 & 0.04 & Dry. \\
\hline DH39 & $1987-05-07$ & $11: 20$ & 0.00 & 856.472 & 62.014 & 0.000 & 0.04 & Dry. \\
\hline DH39 & $1987-06-18$ & $12: 00$ & 0.00 & 898.500 & 104.042 & 0.000 & 0.04 & Dry. \\
\hline DH39 & $1987-07-28$ & $11: 03$ & 0.00 & 938.460 & 144.002 & 0.000 & 0.04 & Dry. \\
\hline DH39 & $1987-09-01$ & $10: 21$ & 0.00 & 973.431 & 34.971 & 0.000 & 0.04 & Dry. \\
\hline $\mathrm{DH} 39$ & $1987-10-20$ & $11: 33$ & 0.00 & 1022.480 & 49.049 & 0.000 & 0.04 & Dry. \\
\hline $\mathrm{DH} 39$ & $1987-11-19$ & $11: 00$ & 0.00 & 1052.460 & 29.980 & 0.000 & 0.04 & Dry. \\
\hline $\mathrm{DH} 39$ & $1988-01-04$ & $11: 35$ & 0.00 & 1098.480 & 46.020 & 0.000 & 0.04 & Dry. \\
\hline
\end{tabular}


BRINE ACCUMULATION DATA TABLE (Continued) Data through December 31, 1990

\begin{tabular}{|c|c|c|c|c|c|c|c|c|}
\hline Location & Date & Time & $\begin{array}{l}\text { Liters } \\
\text { removed } \\
\end{array}$ & $\begin{array}{c}\text { Days } \\
\text { since } \\
1 / 1 / 85 \\
\end{array}$ & $\begin{array}{l}\text { Days } \\
\text { used for } \\
\text { calc. }\end{array}$ & $\begin{array}{l}\text { Liters } \\
\text { per } \\
\text { day }\end{array}$ & $\begin{array}{c}\text { Cumulative } \\
\text { liters } \\
\text { collected } \\
\end{array}$ & Remarks \\
\hline DH39 & $1988-02-08$ & $11: 35$ & 0.00 & 1133.480 & 35.000 & 0.000 & 0.04 & Dry. \\
\hline DH39 & $1988-03-29$ & $11: 30$ & 0.00 & 1183.480 & 50.000 & 0.000 & 0.04 & Dry. \\
\hline DH39 & $1988-07-12$ & $08: 45$ & 0.00 & 1288.360 & 104.880 & 0.000 & 0.04 & Dry. \\
\hline DH39 & $1988-09-27$ & $10: 30$ & 0.00 & 1365.440 & 77.080 & 0.000 & 0.04 & Dry. \\
\hline DH39 & $1888-12-13$ & $09: 50$ & 0 & 1442.410 & 76.970 & 0.000 & 0.04 & Dry. \\
\hline DH39 & $1989-03-14$ & $09: 50$ & 0 & 1533.410 & 91.000 & 0.000 & 0.04 & Hole dry. \\
\hline DH39 & $1989-04-06$ & $09: 50$ & 0 & 1556.410 & 23.000 & 0.000 & 0.04 & Hole dry. \\
\hline DH39 & $1989-04-20$ & $09: 20$ & 0 & 1570.390 & 13.979 & 0.000 & 0.04 & Hole dry. \\
\hline DH39 & $1989-05-17$ & $10: 05$ & 0 & 1597.420 & 27.031 & 0.000 & 0.04 & Hole dry. \\
\hline DH39 & $1989-06-06$ & $10: 00$ & 0 & 1617.420 & 19.997 & 0.000 & 0.04 & Hole dry. \\
\hline DH39 & $1989-06-29$ & $10: 25$ & 0 & 1640.430 & 23.017 & 0.000 & 0.04 & Hole dry. \\
\hline DH39 & $1989-07-25$ & $09: 55$ & 0 & 1666.410 & 25.979 & 0.000 & 0.04 & Hole dry. \\
\hline DH39 & $1989-08-16$ & $09: 55$ & 0 & 1688.410 & 22.000 & 0.000 & 0.04 & Hole dry. \\
\hline DH39 & $1989-08-28$ & $10: 15$ & 0 & 1700.430 & 12.014 & 0.000 & 0.04 & Collection device removed. \\
\hline DH39 & $1989-12-13$ & $10: 25$ & 0 & 1807.430 & 107.007 & 0.000 & 0.04 & Hole dry. \\
\hline DH39 & $1990-01-10$ & $10: 00$ & 0.0 & 1835.417 & 27.983 & 0.000 & 0.00 & Dry. \\
\hline DH39 & $1990-01-24$ & $10: 00$ & 0.0 & 1849.417 & 14.000 & 0.000 & 0.00 & Dry. \\
\hline DH39 & $1990-02-07$ & $10: 30$ & 0.0 & 1863.438 & 14.021 & 0.000 & 0.00 & Dry. \\
\hline DH39 & $1990-02-21$ & $09: 46$ & 0.0 & 1877.407 & 13.969 & 0.000 & 0.00 & Dry. \\
\hline DH39 & $1990-03-05$ & $09: 18$ & 0.0 & 1889.388 & 11.981 & 0.000 & 0.00 & Dry. \\
\hline DH39 & $1990-03-19$ & $11: 25$ & 0.0 & 1903.476 & 14.088 & 0.000 & 0.00 & Dry. \\
\hline DH39 & $1990-03-21$ & $10: 25$ & 0.0 & 1905.434 & 1.958 & 0.000 & 0.00 & Dry. \\
\hline DH39 & $1990-04-04$ & $09: 31$ & 0.0 & 1919.397 & 13.963 & 0.000 & 0.00 & Dry. \\
\hline DH39 & $1990-04-10$ & $08: 36$ & 0.0 & 1925.358 & 5.961 & 0.000 & 0.00 & Dry. \\
\hline DH39 & $1990-04-17$ & $10: 39$ & 0.0 & 1932.444 & 7.086 & 0.000 & 0.00 & Dry. \\
\hline DH39 & $1990-04-24$ & $09: 30$ & 0.0 & 1939.396 & 6.952 & 0.000 & 0.00 & Dry. \\
\hline DH39 & $1990-05-02$ & $10: 30$ & 0.0 & 1947.438 & 8.042 & 0.000 & 0.00 & Dry. \\
\hline DH39 & $1990-05-09$ & $08: 44$ & 0.0 & 1954.364 & 6.926 & 0.000 & 0.00 & Dry. \\
\hline DH39 & $1990-05-16$ & $09: 25$ & 0.0 & 1961.392 & 7.028 & 0.000 & 0.00 & Dry. \\
\hline DH39 & $1990-05-23$ & $12: 06$ & 0.0 & 1968.504 & 7.112 & 0.000 & 0.00 & Dry. \\
\hline DH39 & $1990-05-31$ & $09: 02$ & 0.0 & 1976.376 & 7.872 & 0.000 & 0.00 & Dry. \\
\hline DH39 & $1990-06-06$ & $09: 39$ & 0.0 & 1982.402 & 6.026 & 0.000 & 0.00 & Dry. \\
\hline DH39 & $1990-06-14$ & $08: 51$ & 0.0 & 1990.369 & 7.967 & 0.000 & 0.00 & Dry. \\
\hline DH39 & $1990-06-20$ & $09: 33$ & 0.0 & 1996.398 & 6.029 & 0.000 & 0.00 & Dry. \\
\hline DH39 & $1990-06-28$ & $08: 38$ & 0.0 & 2004.360 & 7.962 & 0.000 & 0.00 & Dry. \\
\hline DH39 & $1990-07-17$ & $11: 00$ & 0.0 & 2023.458 & 19.098 & 0.000 & 0.00 & Dry. \\
\hline DH39 & $1990-07-25$ & $09: 34$ & 0.0 & 2031.399 & 7.941 & 0.000 & 0.00 & Dry. \\
\hline DH39 & $1990-08-01$ & $10: 30$ & 0.0 & 2038.438 & 7.039 & 0.000 & 0.00 & Dry. \\
\hline \multicolumn{9}{|c|}{ 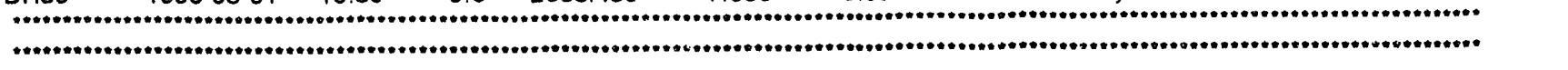 } \\
\hline $\mathrm{DH} 40$ & $1984-12-13$ & $00: 00$ & NA & 0.000 & 0.000 & 0.000 & 0.00 & $\begin{array}{l}\text { Approximate date this part of Roum G } \\
\text { excavated. }\end{array}$ \\
\hline $\mathrm{DH} 40$ & $1985-01-25$ & $00: 00$ & NA & 0.000 & 0.000 & 0.000 & $0 . \infty$ & Downhole drilled $1 / 24 / 85$ to $1 / 25 / 85$. \\
\hline $\mathrm{DH} 40$ & $1985-01-28$ & $09: 00$ & NA & 27.375 & 1.000 & 0.000 & 0.00 & Dry. \\
\hline $\mathrm{DH} 40$ & $1985-02-05$ & $11: 15$ & NA & 35.469 & 9.094 & 0.000 & 0.00 & Moist at bottom. \\
\hline $\mathrm{DH} 40$ & $1985-03-12$ & $10: 10$ & NA & 70.424 & 44.049 & 0.000 & 0.00 & Moist muck. \\
\hline $\mathrm{DH} 40$ & $1985-03-26$ & $09: 55$ & NA & 84.413 & 58.038 & 0.000 & 0.00 & Moist muck. \\
\hline $\mathrm{DH} 40$ & $1985-04-17$ & $13: 30$ & 00.98 & 106.562 & 80.187 & 0.012 & 0.98 & Brine, muck, and oil \\
\hline $\mathrm{DH} 40$ & $1985-04-23$ & $11: 33$ & 00.26 & 112.481 & 5.919 & 0.044 & 1.24 & Brine and muck. \\
\hline $\mathrm{DH} 40$ & $1985-04-30$ & $10: 49$ & 00.11 & 119.451 & 6.970 & 0.016 & 1.35 & Feel something spongy in bottom of hole \\
\hline $\mathrm{DH} 4 \mathrm{C}$ & $1985-05-07$ & $09: 42$ & 00.10 & 126.404 & 6.953 & 0.014 & 1.45 & \\
\hline $\mathrm{DH} 4 \mathrm{C}$ & $1985-05-14$ & $10: 40$ & 00.09 & 133.444 & 7.040 & 0.013 & 1.54 & . \\
\hline $\mathrm{OH} 4 \mathrm{O}$ & $1985-05-21$ & $10: 26$ & 00.07 & 140.435 & 6.991 & 0.010 & 1.61 & \\
\hline $\mathrm{DH} 40$ & $1985-05-29$ & $11: 30$ & 00.08 & 148.479 & 8.044 & 0.010 & 1.69 & \\
\hline $\mathrm{DH} 4 \mathrm{O}$ & $1985.06-04$ & $11: 15$ & 00.10 & 154.469 & 5.990 & 0.017 & 1.79 & Contained a lot of salt muck. \\
\hline $\mathrm{DH} 4 \mathrm{O}$ & $1985-06-11$ & $10: 30$ & 00.05 & 161.438 & 6.969 & 0.007 & 1.84 & \\
\hline $\mathrm{DH} 40$ & $1985-06-18$ & $10: 01$ & 00.09 & 168.417 & 6.979 & 0.013 & 1.93 & \\
\hline $\mathrm{DH} 40$ & $1985-06-25$ & $11: 00$ & 00.08 & 175.458 & 7.041 & 0.011 & 2.01 & \\
\hline $\mathrm{DH} 40$ & $1985-07-02$ & $11: 00$ & 00.09 & 182.458 & 7.000 & 0.013 & 2.10 & \\
\hline $\mathrm{DH} 40$ & $1985-07-09$ & $10: 45$ & 00.12 & 189.448 & 6.990 & 0.017 & 2.22 & \\
\hline
\end{tabular}


BRINE ACCUMULATION DATA TABLE (Continued) Data through December 31, 1990

\begin{tabular}{|c|c|c|c|c|c|c|c|c|}
\hline Location & Date & Time & $\begin{array}{l}\text { Liters } \\
\text { removiset }\end{array}$ & $\begin{array}{c}\text { Days } \\
\text { since } \\
1 / 1 / 85 \\
\end{array}$ & $\begin{array}{l}\text { Days } \\
\text { used for } \\
\text { calc. }\end{array}$ & $\begin{array}{l}\text { Liters } \\
\text { per } \\
\text { day }\end{array}$ & $\begin{array}{c}\text { Cumulative } \\
\text { liters } \\
\text { collected } \\
\end{array}$ & Remarks \\
\hline $\begin{array}{l}\mathrm{DH} 40 \\
\mathrm{DH} 40\end{array}$ & $\begin{array}{l}1985-07-16 \\
1985-07-24\end{array}$ & $\begin{array}{l}11: 38 \\
10: 31\end{array}$ & $\begin{array}{l}00.09 \\
00.07\end{array}$ & $\begin{array}{l}196.485 \\
204.438\end{array}$ & 7.037 & 0.013 & $\begin{array}{l}2.31 \\
2.38\end{array}$ & \\
\hline $\mathrm{DH} 40$ & $1985-08-06$ & $10: 20$ & 00.06 & 217.431 & 7.000 & $0.00 \%$ & 2.51 & \\
\hline DH40 & $1985-08-14$ & $10: 43$ & 00.07 & 225.447 & 8.016 & 0.000 & 2.58 & \\
\hline DH 40 & $1985-08-20$ & $10: 50$ & 00.05 & 231.451 & 6.004 & 0.008 & 2.63 & \\
\hline $\mathrm{DH} 4 \mathrm{O}$ & $1985-08-28$ & $09: 53$ & 00.08 & 239.412 & 7.961 & 0.010 & 2.71 & \\
\hline DH4O & $1085-09-04$ & $10: 18$ & 00.03 & 246.429 & 7.017 & C.04 & 2.74 & \\
\hline DH4O & $1985-09-10$ & $10: 11$ & 00.04 & 252.424 & 5.995 & 0.007 & 2.78 & \\
\hline $\mathrm{DH} 40$ & $1985-09-17$ & $09: 31$ & 00.03 & 259.397 & 6.973 & 0.004 & 2.81 & \\
\hline $\mathrm{DH} 40$ & $1985-09-24$ & $09: 40$ & 00.06 & 266.403 & 7.006 & 0.009 & 2.87 & \\
\hline $\mathrm{OH} 40$ & $1985-10-01$ & $09: 47$ & $n 0.06$ & 273.408 & 7.005 & 0.008 & 2.93 & \\
\hline $\mathrm{DH} 40$ & $1985-10-08$ & $10: 32$ & 00.04 & 280.432 & 701 & 0.006 & 2.97 & \\
\hline $\mathrm{DH} 40$ & $1985-10-15$ & $10: 05$ & 00.09 & 287.420 & 6.981 & 0.013 & 3.06 & \\
\hline DH40 & $1985-10-23$ & $10: 13$ & 00.04 & 295.426 & 8.006 & 0.005 & 3.10 & \\
\hline CH4O & $1985-10-29$ & $09: 32$ & 00.07 & 301.397 & 5.971 & 0.012 & 3.17 & \\
\hline $\mathrm{DH} 40$ & $1985-11-05$ & $09: 10$ & 00.04 & 308.382 & 6.985 & 0.006 & 3.21 & \\
\hline DH4O & $1985-11-13$ & $09: 55$ & 00.07 & 316.413 & 8.031 & 0.009 & 3.28 & \\
\hline $\mathrm{DH} 40$ & $1985-11-21$ & $11: 24$ & 00.02 & 324.475 & 8.062 & 0.002 & 3.30 & \\
\hline $\mathrm{DH} 40$ & $1985-12-03$ & $13: 20$ & 00.08 & 336.556 & 12.081 & 0.007 & 3.38 & \\
\hline $\mathrm{DH} 40$ & $1985-12-10$ & $12: 40$ & 00.04 & 343.528 & 6.972 & 0.006 & 3.42 & \\
\hline $\mathrm{DH} 40$ & $1956-01-23$ & $11: 25$ & 00.24 & 387.476 & 43.848 & 0.005 & 3.66 & $\begin{array}{l}\text { Entry restricted sinco } 12 / 10 / 85 \text { due to mining } \\
\text { activities. }\end{array}$ \\
\hline DH4O & $1986-01-31$ & $12: 10$ & 00.02 & 395.507 & 8.031 & 0.002 & 3.68 & \\
\hline $\mathrm{DH} 40$ & $1986-02-19$ & $11: 20$ & 00.14 & 414.472 & 18.965 & 0.007 & 3.82 & \\
\hline DH4O & $1986-02-28$ & $13: 10$ & 00.05 & 423.549 & 9.077 & 0.006 & 3.87 & \\
\hline $\mathrm{DH} 40$ & $1986-03-13$ & $10: 00$ & 00.02 & 436.417 & 12.868 & $0.00 \mathrm{~L}$ & 3.89 & \\
\hline $\mathrm{DH} 40$ & $1986-04-24$ & $10: 05$ & 00.13 & 478.420 & 42.003 & 0.003 & 4.02 & \\
\hline $\mathrm{DH} 40$ & $i=86-05-20$ & $11: 05$ & 00.10 & 504.162 & 26.042 & 0.004 & 4.12 & \\
\hline $\mathrm{DH} 40$ & $1986-06-43$ & $09: 58$ & 00.20 & 518.415 & 13.953 & 0.014 & 4.32 & \\
\hline $\mathrm{DH} 40$ & $1986-09-16$ & $10: 05$ & 00.34 & 623.420 & 105.005 & 0.003 & 4.66 & Pid not collect for several months. \\
\hline $\mathrm{DH} 40$ & $1986-11-05$ & $11: 18$ & 0.27 & 673.471 & 50.051 & 0.005 & 4.90 & \\
\hline $\mathrm{CH} 40$ & $1986-11-20$ & NA & NA & 689.000 & 14.529 & 0.000 & 4.93 & \\
\hline DH40 & $1986-12-30$ & $12: 00$ & 00.25 & 728.500 & 55.029 & 0.005 & 5.18 & \\
\hline $\mathrm{DH} 40$ & $1987-02-03$ & $13: 00$ & 00.13 & 763.542 & 35.042 & 0.004 & 5.31 & \\
\hline $\mathrm{DH} 40$ & $1987-03-06$ & 10.55 & 0.09 & 794.455 & 30.913 & 0.003 & 5.40 & \\
\hline $\mathrm{DH} 40$ & $1987-03-30$ & $11: 05$ & 0.10 & 818.462 & 24.007 & 0.004 & 5.50 & \\
\hline DH40 & $1987-06-18$ & $12: 00$ & 0.19 & 898.500 & 80.038 & 0.002 & 5.69 & \\
\hline $\mathrm{DH} 40$ & $1987-09-01$ & $10: 25$ & 0.16 & 573.434 & 74.934 & 0.002 & 5.85 & \\
\hline DH4D & $1988-02-08$ & $11: 30$ & 0.55 & 1133.480 & 160.046 & 0.003 & 6.40 & \\
\hline $\mathrm{DH} 40$ & $1988-03-29$ & $11: 25$ & 0.14 & 1183.480 & 50.000 & 0.003 & 6.54 & \\
\hline $\mathrm{DH} 40$ & $1988-05-12$ & $11: 40$ & 0.20 & 1227.490 & 44.010 & 0.005 & 6.74 & \\
\hline $\mathrm{DH} 40$ & $1988-07-12$ & $03: 40$ & 0.15 & 1288.360 & 60.870 & $0.00 ?$ & 6.89 & \\
\hline $\mathrm{DH} 40$ & $1908.09-27$ & $10: 25$ & 0.21 & 1365.430 & 77.070 & 0.003 & 710 & \\
\hline $\mathrm{DH} 40$ & $198 C \cdot 2-13$ & $09: 45$ & 0.12 & 1442.410 & 76.980 & 0.002 & 7.22 & \\
\hline $\mathrm{DH} 40$ & $1389-03-15$ & $10: 35 T$ & T.ace & 1534.440 & 0.000 & 0.000 & 7.22 & Trace of brine found. \\
\hline DH40 & $1989-04-06$ & $09: 50$ & 0.27 & 1556.410 & 114.004 & 0.002 & 7.49 & \\
\hline DH4O & $1989-04-20$ & $09: 20$ & 0.09 & 1570.390 & 13.979 & 0.006 & 7.58 & \\
\hline $\mathrm{DH} 40$ & $+289-05-17$ & $10: 00$ & 0.30 & 1597.420 & 27.028 & 0.011 & 7.88 & \\
\hline UH40 & 989-06-06 & 09.55 & 0.12 & 1617.410 & 19.926 & 0.006 & 8.00 & \\
\hline $\mathrm{DH} 40$ & $1989-06-29$ & $10: 25 T$ & Trace & 1640.430 & 0000 & 0.000 & 8.00 & Trace of brine found. \\
\hline $\mathrm{DH} 40$ & $1989-07 \cdot 25$ & $10: 18$ & 0.07 & 1666.430 & $\therefore 3.016$ & 0.001 & 8.07 & \\
\hline $\mathrm{DH} 40$ & $1989-08-16$ & $09: 49$ & 0.06 & 1688.410 & 21.980 & 0.003 & 8.13 & \\
\hline DH40 & $1989-09-12$ & $09: 10 \mathrm{i}$ & Trace & 1715.380 & 0.000 & 0.000 & 813 & Trace of fluid in hole. \\
\hline $\mathrm{DH} 40$ & $1989-12-13$ & $10: 25$ & 0.20 & 1807.430 & 119.025 & $0.00 i$ & 8.33 & \\
\hline DH4O & $1990-01-10$ & $09: 50$ & 0.08 & 1835.410 & 27.976 & 0.003 & $8.4 !$ & \\
\hline $\mathrm{DH} 40$ & 1990-03-05 & $09: 10$ & 0.50 & 1889.382 & 53.972 & 0.009 & 8.91 & \\
\hline DH40 & $1990-03-+?$ & $13: 30$ & NA & .397. .52? & & & 8.9 & Installed sampier. \\
\hline DH40 & $1990-C-13$ & $11: 25$ & 0.09 & 1903.476 & 14.094 & 0.000 & 9.00 & Brine probably left in hole. \\
\hline
\end{tabular}


BRINE ACCUMULATION DATA TABLE (Continued) Data through December 31, 1990

\begin{tabular}{|c|c|c|c|c|c|c|c|c|}
\hline Location & Date & Time & $\begin{array}{c}\text { Liters } \\
\text { removed } \\
\end{array}$ & $\begin{array}{c}\text { Days } \\
\text { since } \\
1 / 1 / 85 \\
\end{array}$ & $\begin{array}{l}\text { Days } \\
\text { used for } \\
\text { calc. }\end{array}$ & $\begin{array}{l}\text { Liters } \\
\text { per } \\
\text { day }\end{array}$ & $\begin{array}{c}\text { Cumulative } \\
\text { liters } \\
\text { collected } \\
\end{array}$ & Remarks \\
\hline $\mathrm{DH} 40$ & $1990-03-21$ & $10: 25$ & 0.02 & 1905.434 & 1.958 & 0.007 & 9.02 & $\begin{array}{l}\text { Combined with } 0.09 \text { liters trom } 03 / 19 / 90 \text {. } \\
\text { Used } 0.11 \text { liters for calculation. }\end{array}$ \\
\hline $\mathrm{DH} 40$ & 1990-04-04 & $09: 31$ & 0.03 & 1919.397 & $\begin{array}{l}13.963 \\
28.0 .8\end{array}$ & 0.002 & 9.05 & \\
\hline DH4O & 1990-05-02 & $10: 41$ & 0.09 & 1947.445 & 28.048 & 0.003 & 9.14 & \\
\hline DH40 & $1990-05-16$ & $09: 26$ & 0.07 & 1961.393 & 13.948 & 0.005 & 9.21 & \\
\hline DH40 & $1990-06-14$ & $11: 19$ & 0.13 & 1990.472 & 29.079 & 0.004 & 9.34 & \\
\hline $\mathrm{DH} 40$ & $1990-06-20$ & 09:40 & 0.02 & 1996.403 & 5.231 & 0.003 & 9.36 & \\
\hline DH40 & $1990-06-28$ & 09:00 & 0.03 & 2004.375 & 7.872 & 0.004 & 9.39 & \\
\hline DH40 & $1990-07 \cdot 17$ & $11: 17$ & 0.10 & 2023.470 & 19.095 & 0.005 & $\begin{array}{c}9.49 \\
0.00\end{array}$ & \\
\hline $\mathrm{DH} 41$ & $1984-12-30$ & $00: 00$ & NA & 0.000 & 0.000 & 0.000 & 0.00 & Approximate date this part of Room $\mathbf{G}$ \\
\hline & & & & 0.000 & & & & excavated. \\
\hline DH41 & $1985-01-24$ & $00: 00$ & NA & 0.000 & 0.000 & 0.000 & 0.00 & Uphole drilled 1/23/85 to 1/24/85. \\
\hline DH41 & $1985-02-05$ & $11: 15$ & NA & 35.469 & 1.000 & 0.000 & 0.00 & Moist, no stalactites. \\
\hline DH41 & $1985-03-26$ & $10: 05$ & NA & 84.420 & $\$ 9.951$ & 0.000 & 0.00 & Trace. \\
\hline DH41 & $1985-05-07$ & $09: 21$ & 00.01 & 126.390 & 91.921 & 0.000 & 0.01 & \\
\hline $\mathrm{DH} 41$ & $1985-05-29$ & $10: 00$ & 00.01 & 148.417 & .2 .027 & 0.000 & 0.02 & Trace. \\
\hline DH41 & $1985-07-24$ & $10: 13$ & 00.01 & 204.426 & 56.009 & 0.000 & 0.03 & \\
\hline DH41 & $1985-08-20$ & $12: 00$ & 00.01 & 231.500 & 27.074 & 0.000 & 0.04 & Trace. \\
\hline DH41 & $1985-08-28$ & $09: 35$ & liu.02 & 239.399 & 7.899 & 0.003 & 0.06 & \\
\hline DH41 & $1985-09-17$ & $09: 20$ & 00.01 & 259.389 & 19.990 & 0.001 & 0.07 & \\
\hline $\mathrm{DH} 41$ & $1986-02-19$ & $11: 20$ & $\infty .05$ & 414.472 & 155.083 & 0.000 & 0.12 & $\begin{array}{l}\text { Lots of salt crystais and lumps of clay in } \\
\text { container. }\end{array}$ \\
\hline DH41 & $1986-11-05$ & $11: 00$ & NA & 673.458 & 258.986 & 0.000 & 0.12 & $\begin{array}{l}\text { Dry. Funnel has been removed, sa: crust on } \\
\text { collar. }\end{array}$ \\
\hline $\begin{array}{l}\mathrm{DH} 41 \\
\mathrm{DH} 41\end{array}$ & $\begin{array}{l}1986-11-20 \\
1986-12-30\end{array}$ & $\begin{array}{l}12: 07 \\
12: 50\end{array}$ & $\begin{array}{l}\text { NA } \\
\text { NA }\end{array}$ & $\begin{array}{l}688.505 \\
728.535\end{array}$ & $\begin{array}{l}274.033 \\
314.063\end{array}$ & $\begin{array}{l}0.000 \\
0.000\end{array}$ & $\begin{array}{l}0.12 \\
0.12\end{array}$ & Dry. \\
\hline DH41 & $1987-02-03$ & NA & NA & 763.000 & 348.528 & 0.000 & 0.12 & \\
\hline $\mathrm{DH} 41$ & $1987-03-05$ & $10: 55$ & NA & 793.455 & 378.983 & 0.000 & 0.12 & Crusty. \\
\hline $\mathrm{DH} 41$ & $1987-03-30$ & $11: 00$ & 0.00 & 818.458 & 25.003 & 0.000 & 0.12 & Dry. \\
\hline $\mathrm{DH} 41$ & $1987-05-07$ & $11: 09$ & 0.00 & 856.465 & 63.010 & 0.000 & 0.12 & Dry. \\
\hline $\mathrm{DH} 41$ & $1987-06-18$ & $11: 56$ & 0.00 & 898.497 & 105.042 & 0.000 & 0.12 & Dry. \\
\hline $\mathrm{DH} 41$ & $1987-07-28$ & $11: 03$ & 0.00 & 938.460 & 145.005 & 0.000 & 0.12 & Dry. \\
\hline $\mathrm{DH} 41$ & $1987-09-01$ & $10: 15$ & 0.00 & 973.427 & 34.967 & 0.000 & 0.12 & nry. \\
\hline $\mathrm{DH} 41$ & $1987-10-20$ & $11: 28$ & 0.00 & 1022.480 & 49.053 & 0.000 & 0.12 & Dry. \\
\hline $\mathrm{DH} 41$ & $1987-11-19$ & $10: 55$ & 0.00 & 1052.450 & 29.970 & 0.000 & 0.12 & Dry. \\
\hline $\mathrm{DH} 41$ & $1988-01-04$ & $11: 35$ & $0 . \infty$ & 1098.480 & 46.030 & 0.000 & 0.12 & Dry. \\
\hline $\mathrm{DH} 11$ & $1988-02-08$ & $11: 20$ & 0.00 & 1133.470 & 34.990 & 0.000 & 0.12 & Dry. \\
\hline $\mathrm{DH} 41$ & $1988-03-29$ & $11: 20$ & 0.00 & 1183.470 & 50.000 & 0.000 & 0.12 & Dry. \\
\hline $\mathrm{DH} 41$ & $1988-07-12$ & $08: 40$ & 0.00 & 1288.360 & 104.890 & 0.000 & 0.12 & Dry. \\
\hline DH41 & $1988-09-27$ & $10: 20$ & 0.00 & 1365.430 & 77.070 & 0.000 & 0.12 & Dry. \\
\hline DH41 & $1988-12-13$ & $09: 45$ & 0 & 1442.410 & 76.980 & .0 .000 & 0.12 & Dry. \\
\hline $\mathrm{DH} 41$ & $1989-04-06$ & $09: 55$ & 0 & 1556.410 & 114.007 & 0.000 & 0.12 & Hole dry. \\
\hline $\mathrm{DH} 41$ & $1989-04-20$ & $09: 10$ & 0 & 1570.380 & 13.969 & 0.000 & 0.12 & Hole dry. \\
\hline DH41 & $1989-05-17$ & $10: 00$ & 0 & 1597.420 & 27.035 & 0.000 & 0.12 & Hole dry. \\
\hline DH41 & $1989-06-06$ & $09: 55$ & 0 & 1617.410 & 18.996 & 0.000 & 0.12 & Hole dry. \\
\hline DH41 & $1989-06-29$ & $10: 15$ & 0 & 1640.430 & $23.0,4$ & 0.000 & 0.12 & Hole dry. \\
\hline DH41 & $1989-07-25$ & 09:55 & 0 & 1666.410 & 25.986 & 0.000 & 0.12 & Hole dry. \\
\hline $\mathrm{DH} 41$ & $1989-08-16$ & 09:55 & 0 & 1688.410 & 22.000 & 0.000 & 0.12 & Hole dry. \\
\hline $\mathrm{DH} 41$ & $1989-08-28$ & $10: 15$ & 0 & 1700.430 & 12.014 & 0.000 & 0.12 & Collection device removed. \\
\hline DH41 & $1989-12-13$ & $10: 03$ & 0 & 1807.420 & 106.992 & 0.000 & 0.12 & Hole dry. \\
\hline DH41 & $1990-01-10$ & $09: 45$ & 0.0 & 1835.406 & 27.987 & 0.000 & 0.12 & Dry. \\
\hline $\mathrm{DH} 41$ & $1990-01-24$ & $10: 00$ & 0.0 & 1849.417 & 14.011 & 0.000 & 0.12 & Dry. \\
\hline $\mathrm{DH} 41$ & $1990-02-07$ & $10: 30$ & 0.0 & 1863.438 & 14.021 & 0.000 & 0.12 & Dry. \\
\hline $\mathrm{DH} 41$ & $1990-02-21$ & $09: 45$ & 0.0 & 1877.406 & 13.968 & 0.000 & 0.12 & Dry. \\
\hline $\mathrm{DH} 41$ & $1990-03-05$ & $09: 08$ & 0.0 & 1889.381 & 1.975 & 0.000 & 0.12 & Dry. \\
\hline DH41 & 1990-03-19 & $11: 12$ & 0.0 & 1903.467 & 14.086 & 0.000 & 0.12 & Dry. \\
\hline $\mathrm{DH} 41$ & $1990-03-21$ & $10: 23$ & 0.0 & 1905.433 & 1.966 & 0.000 & 0.12 & Dry. \\
\hline $\mathrm{DH} 41$ & $1990-04-04$ & $09: 14$ & 0.0 & 1919.385 & 13.952 & 0.000 & 0.12 & Dry. \\
\hline
\end{tabular}


BRINE ACCUMULATION DATA TABLE (Continued)

Data through December 31, 1990

\begin{tabular}{|c|c|c|c|c|c|c|c|c|}
\hline Location & Date & Time & $\begin{array}{l}\text { Liters } \\
\text { removed }\end{array}$ & $\begin{array}{c}\text { Days } \\
\text { since } \\
1 / 1 / 85 \\
\end{array}$ & $\begin{array}{l}\text { Days } \\
\text { used for } \\
\text { catc. }\end{array}$ & $\begin{array}{l}\text { Liters } \\
\text { per } \\
\text { day }\end{array}$ & $\begin{array}{c}\text { Cumulative } \\
\text { liters } \\
\text { collected }\end{array}$ & Remarks \\
\hline DH41 & $1990-04-10$ & $08: 36$ & 0.0 & 1925.358 & 5.873 & 0.000 & 0.12 & Dry. \\
\hline $\mathrm{DH} 41$ & $1990-04-17$ & $10: 29$ & 0.0 & 1932.437 & 7.079 & 0.000 & 0.12 & Dry. \\
\hline $\mathrm{DH} 41$ & $1990-04-24$ & $09: 26$ & 0.0 & 1939.393 & 6.956 & 0.000 & 0.12 & Dry. \\
\hline $\mathrm{DH} 41$ & $1990-05-02$ & $10: 30$ & 0.0 & 1947.438 & 8.045 & 0.000 & 0.12 & Dry. \\
\hline $\mathrm{DH} 41$ & $1990-05-09$ & $09: 45$ & 0.0 & 1954.406 & 6.968 & 0.000 & 0.12 & Dry. \\
\hline $\mathrm{DH} 41$ & $1990-05-16$ & $09: 11$ & 0.0 & 1961.383 & 6.977 & 0.000 & 0.12 & Dry. \\
\hline DH41 & $1990-05-23$ & $12: 06$ & 0.0 & 1968.504 & 7.121 & 0.000 & 0.12 & Dry. \\
\hline $\mathrm{DH} 41$ & $1990-05-31$ & 09:01 & 0.0 & 1976.376 & 7.872 & 0.000 & 0.12 & Dry. \\
\hline DH41 & $1990-06-06$ & $09: 30$ & 0.0 & 1882.396 & 6.020 & 0.000 & 0.12 & Dry. \\
\hline DH41 & $1990-06-14$ & $08: 48$ & 0.0 & 1990.367 & 7.971 & 0.000 & 0.12 & Dry. \\
\hline DH41 & $1990-06-20$ & $09: 35$ & 0.0 & 1996.399 & 6.032 & 0.000 & 0.12 & Dry. \\
\hline DH41 & $1990-06-28$ & $08: 38$ & 0.0 & 2004.360 & 7.961 & 0.000 & 0.12 & Dry. \\
\hline DH41 & $1990-07-17$ & $11: 02$ & 0.0 & 2023.460 & 19.100 & 0.000 & 0.12 & Dry. \\
\hline DH41 & $1990-07-25$ & $09: 43$ & 0.0 & 2031.405 & 7.945 & 0.000 & 0.12 & Dry. \\
\hline DH41 & $1990-08-01$ & $10: 25$ & 0.0 & 2038.434 & $\begin{array}{r}7.029 \\
\ldots . . .6 \ldots . . .\end{array}$ & 0.000 & 0.12 & Dry. \\
\hline مHU? & & 00.00 & & & & & ma..." & \\
\hline $\mathrm{DH} 42$ & $1984-12-30$ & 00:00 & NA & 0.000 & 0.000 & 0.000 & 0.00 & $\begin{array}{l}\text { Approximate date this pan of hoom G } \\
\text { excavated. }\end{array}$ \\
\hline DH42 & $1985-01-23$ & $00: 00$ & NA & 0.000 & 0.000 & 0.000 & 0.00 & Downhole drilled. \\
\hline $\mathrm{DH} 42$ & $1985-01-28$ & $09: 00$ & NA & 27.375 & 1.000 & 0.000 & 0.00 & Moist muck at the bottom. \\
\hline $\mathrm{DH} 42$ & $1985-02-05$ & $11: 15$ & 00.27 & 35.469 & 9.094 & 0.030 & 0.27 & First time collected. \\
\hline $\mathrm{DH} 42$ & $1985-02-11$ & $11: 00$ & 00.30 & 41.458 & 5.989 & 0.050 & 0.57 & \\
\hline DH42 & $1985-02-19$ & $13: 10$ & 00.33 & 49.549 & 8.091 & 0.041 & 0.90 & \\
\hline $\mathrm{DH} 42$ & $1985-02-26$ & $10: 45$ & 00.26 & 56.448 & 6.899 & 0.038 & 1.16 & \\
\hline $\mathrm{DH} 42$ & 1985-03-05 & $10: 00$ & 00.28 & 63.417 & 6.969 & 0.040 & 1.44 & \\
\hline $\mathrm{DH} 42$ & $1985-03-12$ & $10: 20$ & 00.25 & 70.431 & 7.014 & 0.036 & 1.69 & \\
\hline $\mathrm{DH} 42$ & $1985-03-20$ & 10.54 & 00.25 & 78.454 & 8.023 & 0.031 & 1.94 & $\begin{array}{l}\text { Valve leaked, some brine drained back } \\
\text { downhole. }\end{array}$ \\
\hline $\mathrm{DH} 42$ & $1985-03-26$ & $10: 06$ & 00.28 & 84.421 & 5.967 & 0.047 & 2.22 & \\
\hline $\mathrm{DH} 42$ & $1985-04-02$ & $10: 45$ & 00.26 & 91.448 & 7.027 & 0.037 & 2.48 & \\
\hline $\mathrm{DH} 42$ & $1985-04-10$ & $10: 45$ & 00.29 & 99.448 & 8.000 & 0.036 & 2.77 & \\
\hline $\mathrm{DH} 42$ & $1985-04-17$ & $13: 30$ & 00.24 & 106.562 & 7.114 & 0.034 & 3.01 & \\
\hline $\mathrm{DH} 42$ & $1985-04-23$ & $13: 23$ & 00.04 & 112.558 & 5.996 & 0.007 & 3.05 & $\begin{array}{l}\text { Significant volume of brine drained back } \\
\text { down hole. }\end{array}$ \\
\hline $\mathrm{DH} 42$ & $1985-04-30$ & $10: 31$ & 00.38 & 119.438 & 6.880 & 0.055 & 3.43 & \\
\hline $\mathrm{DH} 42$ & $1985-05-07$ & $09: 25$ & 00.33 & 126.392 & 6.954 & 0.047 & 3.76 & \\
\hline $\mathrm{DH} 42$ & $1985-05-14$ & $10: 30$ & 00.25 & 133.438 & 7.046 & 0.035 & 4.01 & \\
\hline $\mathrm{DH} 42$ & $1985-05-21$ & $10: 17$ & 00.26 & 140.428 & 6.990 & 0.037 & 4.27 & \\
\hline $\mathrm{DH} 42$ & $1985-05-29$ & $10: 10$ & 00.30 & 148.424 & 7.996 & 0.038 & 4.57 & \\
\hline $\mathrm{OH} 42$ & $1985-06-04$ & $10: 45$ & 00.22 & 154.448 & 6.024 & 0.037 & 4.79 & \\
\hline $\mathrm{DH} 42$ & $1985-06-11$ & $10: 10$ & 00.25 & 161.424 & 6.976 & 0.036 & 5.04 & \\
\hline $\mathrm{DH} 42$ & $1985-06-18$ & $09: 53$ & 00.25 & 168.412 & 6.988 & 0.036 & 5.29 & \\
\hline DH42 & $1985-06-25$ & $11: 15$ & 00.25 & 175.469 & 7.057 & 0.035 & 5.54 & \\
\hline $\mathrm{DH} 42$ & $1985-07-02$ & $11: 00$ & 00.24 & 182.458 & 6.989 & 0.034 & 5.78 & \\
\hline $\mathrm{OH} 42$ & $1985-07-09$ & $10: 30$ & 00.25 & 189.438 & 6.980 & 0.036 & 6.03 & \\
\hline $\mathrm{DH} 42$ & $1985-07-16$ & $11: 08$ & 00.25 & 196.464 & 7.026 & 0.036 & 6.28 & Brine effervesces. \\
\hline $\mathrm{DH} 42$ & $1985-07-24$ & $10 \cdot 19$ & 00.28 & 204.430 & 7.966 & 0.035 & 6.56 & \\
\hline DH42 & $1985-07-30$ & $09: 57$ & 00.22 & 210.415 & 5.985 & 0.037 & 6.78 & \\
\hline $\mathrm{DH} 42$ & 1985-08-06 & $10: 13$ & 00.26 & 217.426 & 7.011 & 0.037 & 7.04 & \\
\hline DH42 & $1985-08-14$ & $10: 59$ & 00.27 & 225.458 & 8.032 & 0.034 & 731 & \\
\hline $\mathrm{DH} 42$ & $1985-08-20$ & $10: 45$ & 00.21 & 231.448 & 5.990 & 0.035 & 7.52 & \\
\hline DH42 & $1985-08-28$ & $09: 45$ & 00.29 & 239.406 & 7.958 & 0.036 & 7.81 & \\
\hline DH42 & $1985-09-04$ & $10: 12$ & 00.25 & 246.425 & 7019 & 0.036 & 8.06 & \\
\hline $\mathrm{DH} 42$ & $1985-09-10$ & $09: 56$ & 00.21 & 252.414 & 5.989 & 0.035 & 8.27 & \\
\hline $\mathrm{DH} 42$ & $1985-09-17$ & $09: 26$ & 00.28 & 259.393 & 6.979 & 0.040 & 8.55 & \\
\hline $\mathrm{DH} 42$ & $1985-09-24$ & $09: 37$ & 00.24 & 266.401 & 7.008 & 0.034 & 8.79 & \\
\hline $\mathrm{OH} 42$ & $1985-10-01$ & $09: 44$ & 00.24 & 273.406 & 7.005 & 0.034 & 9.03 & \\
\hline $\mathrm{DH} 42$ & $1985-10-08$ & $10: 25$ & 00.23 & 280.434 & 7.028 & 0.033 & 9.26 & \\
\hline DH42 & $1985-10-15$ & $10: 00$ & 00.23 & 287.417 & 6.983 & 0.033 & 9.49 & \\
\hline
\end{tabular}


BRINE ACCUMULATION DATA TABLE (Continued) Data through December 31, 1990

\begin{tabular}{|c|c|c|c|c|c|c|c|c|}
\hline Location & Date & Time & $\begin{array}{l}\text { Liters } \\
\text { removed } \\
\end{array}$ & $\begin{array}{l}\text { Days } \\
\text { since } \\
1 / 1 / 85 \\
\end{array}$ & $\begin{array}{l}\text { Days } \\
\text { used tor } \\
\text { calc. }\end{array}$ & $\begin{array}{l}\text { Liters } \\
\text { per } \\
\text { day }\end{array}$ & $\begin{array}{c}\text { Cumulative } \\
\text { liters } \\
\text { collected } \\
\end{array}$ & Remarks \\
\hline $\mathrm{DH} 42$ & $1985-10-23$ & $10: 07$ & 00.26 & 295.422 & 8.005 & 0.032 & 9.75 & \\
\hline $\mathrm{DH} 42$ & $1985-10-29$ & $09: 16$ & 00.24 & 301.386 & 5.964 & 0.040 & 9.99 & \\
\hline $\mathrm{DH} 42$ & $1985-11-05$ & 09:05 & 00.22 & 308.378 & 6.992 & 0.031 & 10.21 & \\
\hline $\mathrm{DH} 42$ & $1985-11-13$ & $09: 46$ & 00.26 & 316.407 & 8.029 & 0.032 & 10.47 & \\
\hline $\mathrm{DH} 42$ & $1985-11-21$ & $10: 53$ & 00.26 & 324.453 & 8.046 & 0.032 & 10.73 & \\
\hline DH42 & $1985-11-26$ & $10: 59$ & 00.16 & 329.458 & 5.005 & 0.032 & 10.89 & \\
\hline $\mathrm{DH} 42$ & $1985-12-03$ & $13: 10$ & 00.20 & 336.549 & 7.001 & 0.028 & 11.09 & \\
\hline $\mathrm{DH} 42$ & $1985-12-10$ & $12: 50$ & 00.22 & 343.535 & 6.886 & 0.031 & 11.31 & \\
\hline $\mathrm{DH} 42$ & $1986-01-23$ & $11: 30$ & 01.32 & 387.479 & 43.944 & 0.030 & 12.63 & $\begin{array}{l}\text { Entry restricted since } 12 / 10 / 85 \text { due to mining } \\
\text { activities. }\end{array}$ \\
\hline DH42 & $1986-01-31$ & $12: 05$ & 00.30 & 395.503 & 8.024 & 0.037 & 12.93 & \\
\hline $\mathrm{DH} 42$ & $1986-02-12$ & $10: 35$ & 00.38 & 407.441 & 11.833 & 0.032 & 13.31 & \\
\hline $\mathrm{DH} 42$ & $1986-02-19$ & $11: 10$ & 00.22 & 414.465 & 7.024 & 0.031 & 13.53 & \\
\hline $\mathrm{DH} 42$ & $1986-02-28$ & $13: 00$ & 00.31 & 423.542 & 9.077 & 0.034 & 13.84 & \\
\hline $\mathrm{DH} 42$ & $1986-03-06$ & $10: 30$ & 00.17 & 429.438 & 5.896 & 0.029 & 14.01 & \\
\hline $\mathrm{DH} 42$ & $1986-03-13$ & $09: 53$ & 00.21 & 436.412 & 6.974 & 0.030 & 14.22 & \\
\hline $\mathrm{DH} 42$ & $1986-03-26$ & $10: 00$ & 00.39 & 449.417 & 13.005 & 0.030 & 14.61 & \\
\hline $\mathrm{DH} 42$ & 1986-04-02 & $09: 25$ & 00.20 & 456.392 & 6.975 & 0.029 & 14.81 & \\
\hline $\mathrm{DH} 42$ & $1986-04-08$ & $09: 30$ & 00.20 & 462.396 & 6.004 & 0.033 & 15.01 & \\
\hline $\mathrm{DH} 42$ & $1986-04-16$ & $11: 55$ & 00.24 & 470.497 & 8.101 & 0.030 & 15.25 & \\
\hline $\mathrm{DH} 42$ & $1986-04-24$ & $09: 55$ & 00.21 & 478.413 & 7.916 & 0.027 & 15.46 & \\
\hline $\mathrm{DH} 42$ & $1986-04-30$ & $10: 41$ & 00.17 & 484.445 & 6.032 & 0.028 & 15.63 & \\
\hline $\mathrm{DH} 42$ & $1986-05-06$ & $10: 10$ & 00.19 & 490.424 & 5.979 & 0.032 & 15.82 & \\
\hline $\mathrm{DH} 42$ & $1986-05-13$ & $10: 00$ & 00.20 & 497.417 & 6.993 & 0.029 & 16.02 & \\
\hline $\mathrm{DH} 42$ & $1986-05-20$ & $11: 00$ & 00.20 & 504.458 & 7.041 & 0.028 & 16.22 & \\
\hline $\mathrm{DH} 42$ & $1986-05-27$ & $15: 35$ & 00.20 & 511.649 & 7.191 & 0.028 & 16.42 & \\
\hline $\mathrm{DH} 42$ & $1986-06-03$ & $09: 50$ & 00.20 & 518.410 & 6.761 & 0.030 & 16.62 & \\
\hline $\mathrm{OH} 42$ & $1986-06-10$ & $11: 13$ & 00.17 & 525.467 & 7.057 & 0.024 & 16.79 & \\
\hline $\mathrm{DH} 42$ & $1986-06-17$ & $10: 40$ & 00.20 & 532.444 & 6.977 & 0.029 & 16.99 & \\
\hline $\mathrm{DH} 42$ & $1986-06-24$ & $10: 40$ & 00.18 & 539.444 & 7.000 & 0.026 & 17.17 & \\
\hline $\mathrm{DH} 42$ & $1986-07-01$ & $13: 45$ & 00.20 & 546.573 & 7.129 & 0.028 & 17.37 & \\
\hline $\mathrm{DH} 42$ & $1986-07-08$ & $10: 22$ & 00.20 & 553.432 & 6.859 & 0.029 & 17.57 & \\
\hline $\mathrm{DH} 42$ & $1986-07-16$ & $10: 15$ & 00.30 & 561.427 & 7.995 & 0.038 & 17.87 & \\
\hline $\mathrm{DH} 42$ & $1986-07-22$ & $09: 50$ & 00.16 & 567.410 & 5.983 & 0.027 & 18.03 & \\
\hline $\mathrm{DH} 42$ & $1986-07-29$ & $10: 25$ & 00.20 & 574.434 & 7.024 & 0.028 & 18.23 & \\
\hline $\mathrm{DH} 42$ & $1986-08-05$ & $11: 00$ & 00.22 & 581.458 & 7.024 & 0.031 & 18.45 & \\
\hline $\mathrm{DH} 42$ & $1986-08-12$ & $10: 20$ & 00.20 & 588.431 & 6.973 & 0.029 & 18.65 & \\
\hline $\mathrm{DH} 42$ & $1986-08-19$ & $11: 20$ & 00.18 & 595.472 & 7.041 & 0.026 & 18.83 & \\
\hline $\mathrm{DH} 42$ & $1986-08-26$ & $10: 25$ & 00.20 & 602.434 & 6.962 & 0.029 & 19.03 & \\
\hline DH42 & $1986-09-04$ & $10: 20$ & 00.25 & 611.431 & 8.997 & 0.028 & 19.28 & \\
\hline $\mathrm{DH} 42$ & $1986-09-09$ & $09: 46$ & 00.14 & 616.407 & 4.976 & 0.028 & 19.42 & \\
\hline $\mathrm{DH} 42$ & $1986-09-16$ & $09: 52$ & 00.20 & 623.411 & 7.004 & 0.029 & 19.62 & \\
\hline DH42 & $1986-09-23$ & $09: 58$ & 00.15 & 630.415 & 7.004 & 0.021 & 19.77 & \\
\hline $\mathrm{DH} 42$ & $1986-10-01$ & $12: 03$ & 00.36 & 638.502 & 8.087 & 0.045 & 20.13 & \\
\hline $\mathrm{DH} 42$ & $1986-10-08$ & $10: 55$ & 00.15 & 645.455 & 6.953 & 0.022 & 20.28 & \\
\hline DH42 & $1986-10-14$ & $11: 19$ & 00.15 & 651.472 & 6.017 & 0.025 & 20.43 & \\
\hline $\mathrm{DH} 42$ & $1986-11-05$ & $11: 07$ & 0.52 & 673.463 & 21.991 & 0.024 & 20.95 & \\
\hline $\mathrm{DH} 42$ & $1986-11-20$ & $12: 10$ & 00.33 & 688.507 & 15.044 & 0.022 & 21.28 & \\
\hline $\mathrm{DH} 42$ & $1986-12-30$ & $11: 45$ & 00.78 & 728.490 & 39.983 & 0.020 & 22.06 & \\
\hline $\mathrm{DH} 42$ & $1987-02-03$ & $12: 50$ & 00.85 & 763.535 & 35.045 & 0.024 & 22.91 & \\
\hline $\mathrm{DH} 42$ & $1987-03-06$ & $10: 45$ & 0.68 & 794.448 & 30.913 & 0.022 & 23.59 & \\
\hline $\mathrm{DH} 42$ & $1987-03-30$ & $11: 00$ & 0.53 & 818.458 & 24.010 & 0.022 & 24.12 & \\
\hline DH42 & $1987-05-07$ & $11: 15$ & 0.90 & 856.469 & 38.011 & 0.024 & 25.02 & Brine effervesces. \\
\hline $\mathrm{DH} 42$ & $1987-06-17$ & $10: 35$ & 0.91 & 897.441 & 0.000 & 0.000 & 25.93 & $\begin{array}{l}\text { Wood fragments in hole. Some brine left in } \\
\text { hole, no calculation. }\end{array}$ \\
\hline DH42 & $1987-06-18$ & $11: 56$ & 0.10 & 898.497 & 42.028 & 0.024 & 26.03 & $\begin{array}{l}\text { Calculated using } 1.01 \text { liters }(0.91 \text { I. } 6 / 17 / 87 \\
\text { plus } 0.10(6 / 18 / 87) \text {. }\end{array}$ \\
\hline DH42 & $1987-07-28$ & $11: 10$ & 0.94 & 938.465 & 39.968 & 0.024 & 26.97 & \\
\hline $\mathrm{DH} 42$ & $1987-09-01$ & $10: 15$ & 0.79 & 973.427 & 34.962 & 0.023 & 27.76 & \\
\hline $\mathrm{DH} 42$ & $1987-10-20$ & $11: 31$ & 1.29 & 1022.480 & 49.053 & 0.026 & 29.05 & \\
\hline
\end{tabular}


BRINE ACCUMULATION DATA TABLE (Continued) Data through December 31, 1990

\begin{tabular}{|c|c|c|c|c|c|c|c|c|}
\hline Location & Date & Time & $\begin{array}{l}\text { Liters } \\
\text { removed }\end{array}$ & $\begin{array}{l}\text { Days } \\
\text { since } \\
1 / 1 / 85 \\
\end{array}$ & $\begin{array}{l}\text { Days } \\
\text { used for } \\
\text { calc. }\end{array}$ & $\begin{array}{l}\text { Liters } \\
\text { per } \\
\text { day }\end{array}$ & $\begin{array}{c}\text { Cumulative } \\
\text { liters } \\
\text { collected }\end{array}$ & Remarks \\
\hline DH42 & $1987-11-19$ & $10: 55$ & 0.75 & 1052.450 & 29.970 & 0.025 & 29.80 & \\
\hline $\mathrm{DH} 42$ & $1988-01-04$ & $11: 30$ & 1.13 & 1098.480 & 46.030 & 0.025 & 30.93 & \\
\hline $\mathrm{DH} 42$ & $1988-02-08$ & $11: 20$ & 0.75 & 1133.470 & 34.000 & 0.021 & 31.68 & \\
\hline $\mathrm{DH} 42$ & $1988-03-29$ & $11: 20$ & 1.10 & 1183.470 & 50.000 & 0.022 & 32.78 & \\
\hline $\mathrm{DH} 42$ & $1988-05-05$ & $09: 30$ & 0.75 & 1220.400 & 36.830 & 0.020 & 33.53 & \\
\hline $\mathrm{DH} 42$ & $1988-05-12$ & $09: 45$ & 0.13 & 1227.410 & 7.010 & 0.019 & 33.66 & \\
\hline $\mathrm{DH} 42$ & $1988-07-12$ & OB:35 & 1.15 & 1288.360 & 60.050 & 0.018 & 34.81 & \\
\hline $\mathrm{DH} 42$ & $1988-07-28$ & $10: 10$ & 0.34 & 1304.420 & 16.060 & 0.021 & 35.15 & \\
\hline $\mathrm{DH} 42$ & $1988-09-27$ & $10: 20$ & 0.66 & 1365.430 & 61.010 & 0.011 & 35.81 & \\
\hline $\mathrm{DH} 42$ & $1988-12-13$ & $09: 38$ & 1.71 & 1442.400 & 76.870 & 0.022 & 37.52 & \\
\hline $\mathrm{DH} 42$ & 1989-03-15 & $10: 30$ & 1.50 & 1534.440 & 92.037 & 0.016 & 39.02 & \\
\hline $\mathrm{DH} 42$ & $1989-04-06$ & $10: 10$ & 0.54 & 1556.420 & 21.886 & 0.025 & 39.56 & \\
\hline $\mathrm{DH} 42$ & $1989-04-20$ & $09: 10$ & 0.50 & 1570.380 & 13.958 & 0.036 & 40.06 & \\
\hline $\mathrm{DH} 42$ & $1989-05-17$ & $09: 45$ & 0.66 & 1597.410 & 27.024 & 0.024 & 40.72 & \\
\hline $\mathrm{OH} 42$ & $1989-06-06$ & $09: 50$ & 0.41 & 1617.410 & 20.004 & 0.020 & 41.13 & \\
\hline $\mathrm{DH} 42$ & $1989-06-29$ & $10: 20$ & 0.35 & 1640.430 & 23.021 & 0.015 & 41.48 & \\
\hline $\mathrm{DH} 42$ & $1989-07-25$ & $10: 10$ & 0.55 & 1666.420 & 25.993 & 0.021 & 42.03 & \\
\hline $\mathrm{DH} 42$ & $1989-08-16$ & $09: 40$ & 0.36 & 1688.400 & 21.979 & 0.016 & 42.39 & \\
\hline $\mathrm{DH} 42$ & $1989-09-12$ & 09:00 & 0.35 & 1715.380 & 26.972 & 0.013 & 42.74 & \\
\hline DH42 & $1989-12-13$ & $10: 03$ & 1.50 & 1807.420 & 92.044 & 0.016 & 44.24 & \\
\hline $\mathrm{DH} 42$ & $1990-01-10$ & $09: 45$ & 0.70 & 1835.406 & 27.987 & 0.025 & 44.94 & \\
\hline $\mathrm{DH} 42$ & $1990-01-24$ & $09: 57$ & 0.27 & 1849.415 & 14.009 & 0.019 & 45.21 & \\
\hline $\mathrm{DH} 42$ & $1990-02-07$ & $10: 23$ & 0.34 & 1863.433 & 14.018 & 0.024 & 45.55 & \\
\hline DH42 & $1990-02-21$ & $10: 19$ & 0.32 & 1877.430 & 13.997 & 0.023 & 45.87 & \\
\hline $\mathrm{DH} 42$ & 1990-03-05 & $09: 00$ & 0.36 & 1889.375 & 11.945 & 0.030 & 46.23 & \\
\hline $\mathrm{DH} 42$ & $1990-03-13$ & $12: 00$ & NA & 1897.500 & & & 46.23 & Installed sampler. \\
\hline DH42 & 1990-03-19 & $11: 12$ & 0.06 & 1903.467 & 14.092 & 0.000 & 46.29 & Brine probably left in hole. \\
\hline $\mathrm{DH} 42$ & $1990-03-21$ & $10: 23$ & 0.08 & 1905.433 & 1.966 & 0.008 & 46.37 & $\begin{array}{l}\text { Combined with } 0.06 \text { liters from } 03 / 19 / 90 \text {. } \\
\text { Used } 0.14 \text { liters for calculation. }\end{array}$ \\
\hline $\mathrm{DH} 42$ & $1990-04-04$ & $09: 24$ & 0.24 & 1919.392 & 13.959 & 0.017 & 46.61 & \\
\hline $\mathrm{DH} 42$ & $1990-04-10$ & $08: 43$ & 0.14 & 1925.363 & 5.971 & 0.023 & 46.75 & \\
\hline $\mathrm{DH} 42$ & $1990-04-17$ & $10: 29$ & 0.14 & 1932.437 & 7.074 & 0.020 & 46.89 & \\
\hline $\mathrm{DH} 42$ & $1990-04-24$ & $09: 26$ & 0.13 & 1939.393 & 6.956 & 0.019 & 47.02 & \\
\hline $\mathrm{DH} 42$ & $1990-05-02$ & $10: 39$ & 0.15 & 1947.444 & 8.051 & 0.019 & 47.17 & \\
\hline $\mathrm{DH} 42$ & $1990-05-09$ & $09: 01$ & 0.13 & 1954.376 & 6.932 & 0.019 & 47.30 & \\
\hline $\mathrm{DH} 42$ & $1990-05-16$ & $09: 11$ & 0.13 & 1961.383 & 7.007 & 0.018 & 47.43 & \\
\hline $\mathrm{DH} 42$ & $1990-05-23$ & $12: 08$ & 0.14 & 1968.506 & 7.123 & 0.020 & 47.57 & \\
\hline $\mathrm{DH} 42$ & $1990-05-31$ & $08: 59$ & 0.13 & 1976.374 & 7.868 & 0.017 & 47.70 & \\
\hline $\mathrm{DH} 42$ & $1990-06-06$ & $09: 37$ & 0.13 & 1982.401 & 6.027 & Q.022 & 47.83 & \\
\hline $\mathrm{DH} 42$ & $1990-06-14$ & $08: 46$ & 0.16 & 1990.365 & 7.964 & 0.020 & 47.99 & \\
\hline $\mathrm{DH} 42$ & $1990-06-20$ & $09: 35$ & 0.12 & 1996.399 & 6.034 & 0.020 & 48.11 & \\
\hline $\mathrm{DH} 42$ & $1990-06-28$ & $08: 55$ & 0.15 & 2004.372 & 7.973 & 0.019 & 48.26 & \\
\hline $\mathrm{DH} 42$ & $1990-07-17$ & $11: 08$ & 0.31 & 2023.464 & 19.092 & 0.016 & 48.57 & \\
\hline $\mathrm{DH} 42$ & $1990-07-25$ & $09: 40$ & 0.20 & 2031.403 & 7.939 & 0.025 & 48.77 & \\
\hline $\mathrm{DH} 42$ & 1990-08-01 & $10: 20$ & 0.15 & 2038.431 & 7.028 & 0.021 & 48.92 & \\
\hline \multicolumn{9}{|c|}{ 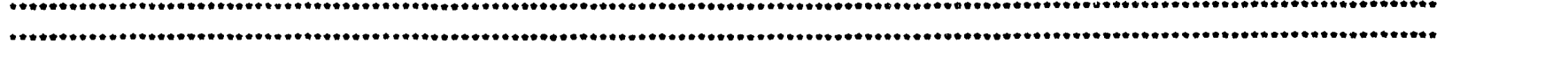 } \\
\hline $\mathrm{DH} 42 \mathrm{~A}$ & $1984-12-30$ & $00: 00$ & NA & 0.000 & 0.000 & 0.000 & 0.00 & $\begin{array}{l}\text { Approximate date this part of Room } G \\
\text { excavated. }\end{array}$ \\
\hline DH42A & $1985-01-25$ & $00: 00$ & NA & 0.000 & 0.000 & 0.000 & 0.00 & $\begin{array}{l}\text { Downhole drilled (redrill of DH42) to recover } \\
\text { core trom } 20 \text { to } 40 \mathrm{ft} \text {. }\end{array}$ \\
\hline $\mathrm{DH} 42 \mathrm{~A}$ & $1985-01-28$ & $09: 00$ & NA & 27.375 & 1.000 & 0.000 & 0.00 & Brine in hole. \\
\hline DH42A & $1985-02-05$ & $11: 15$ & 00.85 & 35.469 & 9.094 & 0.093 & 0.85 & First time collected. \\
\hline DH42A & $1985-02-11$ & $11: 00$ & 00.99 & 41.458 & 5.989 & 0.165 & 1.84 & \\
\hline DH42A & $1985-02-19$ & $12: 10$ & 01.45 & 49.507 & 8.049 & 0.180 & 3.29 & \\
\hline DH42A & $1985-02-26$ & $10: 45$ & 01.18 & 56.448 & 6.941 & 0.170 & 4.47 & \\
\hline DH42A & $1985-03-05$ & $10: 00$ & 01.24 & 63.417 & 6.969 & 0.178 & 5.71 & \\
\hline DH42A & $1985-03-12$ & $10: 20$ & 01.29 & 70.431 & 7.014 & 0.184 & 7.00 & \\
\hline $\mathrm{DH} 42 \mathrm{~A}$ & $1985-03-20$ & $11: 00$ & 01.45 & 78.458 & 8.027 & 0.181 & 8.45 & \\
\hline
\end{tabular}


BRINE ACCUMULATION DATA TABLE (Continued)

Data through December 31, 1990

\begin{tabular}{|c|c|c|c|c|c|c|c|c|}
\hline Location & Date & Time & $\begin{array}{l}\text { Liters } \\
\text { removed }\end{array}$ & $\begin{array}{c}\text { Days } \\
\text { since } \\
1 / 1 / 85 \\
\end{array}$ & $\begin{array}{l}\text { Days } \\
\text { used for } \\
\text { calc. }\end{array}$ & $\begin{array}{l}\text { Liters } \\
\text { per } \\
\text { day }\end{array}$ & $\begin{array}{c}\text { Cumulative } \\
\text { liters } \\
\text { collected }\end{array}$ & Rernarks \\
\hline DH42A & $1985-03-26$ & $10: 10$ & 01.07 & 84.424 & 5.966 & 0.179 & 9.52 & \\
\hline DH42A & $1985-04-02$ & $10: 45$ & 01.15 & 91.448 & 7.024 & 0.164 & 10.67 & \\
\hline DH42A & $1985-04-10$ & $10: 45$ & 01.45 & 99.448 & 8.000 & 0.181 & 12.12 & \\
\hline $\mathrm{DH} 42 \mathrm{~A}$ & $1985-04-17$ & $13: 30$ & 01.32 & 106.562 & 7.114 & 0.186 & 13.44 & \\
\hline $\mathrm{DH} 42 \mathrm{~A}$ & $1985-04-23$ & $13: 23$ & 01.07 & 112.558 & 5.986 & 0.178 & 14.51 & \\
\hline DH42A & $1985-04-30$ & $10: 23$ & 01.35 & 118.433 & 6.875 & 0.186 & 15.86 & \\
\hline DH42A & $1985-05-07$ & $09: 23$ & 01.39 & 126.391 & 6.958 & 0.200 & 17.25 & \\
\hline $\mathrm{DH} 42 \mathrm{~A}$ & $1985-05-14$ & $10: 25$ & 01.34 & 133.434 & 7.043 & 0.180 & 18.59 & \\
\hline $\mathrm{DH} 42 \mathrm{~A}$ & $1985-05-21$ & $10: 14$ & 01.29 & 140.426 & 6.992 & 0.184 & 19.88 & \\
\hline $\mathrm{DH} 42 \mathrm{~A}$ & $1985-05-29$ & $10: 30$ & 01.28 & 148.438 & 8.012 & 0.160 & 21.16 & \\
\hline $\mathrm{DH} 42 \mathrm{~A}$ & $1985-06-04$ & $10: 50$ & 01.03 & 154.451 & 6.013 & 0.171 & 22.19 & \\
\hline $\mathrm{DH} 42 \mathrm{~A}$ & $1985-06-11$ & $10: 15$ & 01.19 & 161.427 & 6.976 & 0.171 & 23.38 & \\
\hline $\mathrm{DH} 42 \mathrm{~A}$ & $1985-06-18$ & $09: 51$ & 01.18 & 168.410 & 6.983 & 0.169 & 24.56 & \\
\hline DH42A & $1985-06-25$ & $11: 05$ & 01.16 & 175.462 & 7.052 & 0.164 & 25.72 & \\
\hline $\mathrm{DH} 42 \mathrm{~A}$ & $1985-07-02$ & $11: 00$ & 01.12 & 182.458 & 6.996 & 0.160 & 26.84 & \\
\hline DH42A & $1985-07-09$ & $10: 25$ & 01.12 & 189.434 & 6.976 & 0.161 & 27.96 & Gas effervescing from sample. \\
\hline DH42A & $1985-07-16$ & $11: 10$ & 01.11 & 196.465 & 7.031 & 0.158 & 29.07 & Brine eftervesces. \\
\hline $\mathrm{DH} 42 \mathrm{~A}$ & $1985-07-24$ & $10: 25$ & 01.23 & 204.434 & 7.969 & 0.154 & 30.30 & \\
\hline $\mathrm{DH} 42 \mathrm{~A}$ & $1985-07-30$ & $09: 54$ & 00.94 & 210.412 & 5.978 & 0.157 & 31.24 & \\
\hline DH42A & $1985-08-06$ & $10: 10$ & 01.05 & 217.424 & 7.012 & 0.150 & 32.29 & \\
\hline $\mathrm{DH} 42 \mathrm{~A}$ & $1985-08-14$ & $10: 33$ & 01.11 & 225.440 & 8.016 & 0.138 & 33.40 & \\
\hline $\mathrm{DH} 42 \mathrm{~A}$ & $1985-08-20$ & $10: 14$ & 00.92 & 231.426 & 5.986 & 0.154 & 34.32 & \\
\hline DH42A & $1985-08-28$ & $09: 40$ & 01.17 & 239.403 & 7.977 & 0.147 & 35.49 & \\
\hline $\mathrm{DH} 42 \mathrm{~A}$ & $1985-09-04$ & $10: 10$ & 00.99 & 246.424 & 7.021 & 0.141 & 36.48 & \\
\hline $\mathrm{DH} 42 \mathrm{~A}$ & $1985-09-10$ & $09: 55$ & 00.83 & 252.413 & 5.989 & 0.139 & 37.31 & \\
\hline $\mathrm{DH} 42 \mathrm{~A}$ & $1985-09-17$ & $09: 25$ & 00.92 & 259.392 & 6.979 & 0.132 & 38.23 & \\
\hline $\mathrm{DH} 42 \mathrm{~A}$ & $1985-09-24$ & $09: 25$ & 00.94 & 266.392 & 7.000 & 0.134 & 39.17 & \\
\hline $\mathrm{DH} 42 \mathrm{~A}$ & $1985-10-01$ & $09: 40$ & 00.93 & 273.403 & 7.011 & 0.133 & 40.10 & \\
\hline DH42A & $1985-10-08$ & $10: 24$ & 00.96 & 280.433 & 7.030 & 0.137 & 41.06 & \\
\hline $\mathrm{DH} 42 \mathrm{~A}$ & $1985-10-15$ & $10: 15$ & 00.81 & 287.427 & 6.994 & 0.116 & 41.87 & \\
\hline DH42A & $1985-10-23$ & $10: 10$ & 01.02 & 295.424 & 7.997 & 0.128 & 42.89 & \\
\hline $\mathrm{DH} 42 \mathrm{~A}$ & $1985-10-29$ & $09: 20$ & 00.75 & 301.389 & 5.965 & 0.126 & 43.64 & \\
\hline $\mathrm{DH} 42 \mathrm{~A}$ & $1985-11-05$ & $09: 00$ & 00.86 & 308.375 & 6.986 & 0.123 & 44.50 & \\
\hline DH42A & $1985-11-13$ & $09: 44$ & 01.03 & 316.406 & 8.031 & 0.128 & 45.53 & \\
\hline $\mathrm{DH} 42 \mathrm{~A}$ & $1985-11-21$ & $10: 50$ & 00.94 & 324.451 & 8.045 & 0.117 & 46.47 & \\
\hline $\mathrm{DH} 42 \mathrm{~A}$ & $1985-11-26$ & $10: 55$ & 00.61 & 329.455 & 5004 & 0.122 & 47.08 & \\
\hline $\mathrm{DH} 42 \mathrm{~A}$ & $1985-12.03$ & $13: 05$ & 00.78 & 336.545 & 7.090 & 0.110 & 47.86 & \\
\hline DH42A & $1985-12-10$ & $12: 50$ & 00.86 & 343.535 & 6.990 & 0.123 & 48.72 & \\
\hline $\mathrm{DH} 42 \mathrm{~A}$ & $1986-01-23$ & $11: 40$ & 05.13 & 387.486 & 43.951 & 0.117 & 53.85 & $\begin{array}{l}\text { Entry restricted since } 12 / 10 / 85 \text { due to mining } \\
\text { activities. }\end{array}$ \\
\hline DH42A & 1986-01-31 & $12: 00$ & 00.92 & 395.500 & 8.014 & 0.115 & 54.77 & \\
\hline DH42A & $1986-02-12$ & $10: 40$ & 01.36 & 407.444 & 11.944 & 0.114 & 56.13 & \\
\hline DH42A & $1986-02-19$ & $11: 15$ & 00.80 & 414.469 & 7.025 & 0.114 & 56.93 & \\
\hline DH42A & $1986-02-28$ & $12: 55$ & 00.90 & 423.538 & 9.069 & 0.099 & 57.83 & \\
\hline $\mathrm{DH} 42 \mathrm{~A}$ & $1986-03-06$ & $10: 25$ & 00.70 & 429.434 & 5.896 & 0.119 & 58.53 & \\
\hline $\mathrm{DH} 42 \mathrm{~A}$ & $1986-03-13$ & $09: 48$ & 00.73 & 436.408 & 6.974 & 0.105 & 59.26 & \\
\hline DH42A & $1986-03-26$ & $09: 40$ & 01.39 & 449.403 & 12.995 & 0.107 & 60.65 & \\
\hline $\mathrm{DH} 42 \mathrm{~A}$ & $1986-04-02$ & $09: 20$ & 00.80 & 456.389 & 6.986 & 0.115 & 61.45 & \\
\hline $\mathrm{DH} 42 \mathrm{~A}$ & $1986-04-08$ & $09: 28$ & 00.63 & 462.394 & 6.005 & 0.105 & 62.08 & \\
\hline $\mathrm{DH} 42 \mathrm{~A}$ & $1986-04-16$ & $11: 50$ & 00.89 & 470.493 & 8.099 & 0.110 & 62.97 & \\
\hline $\mathrm{DH} 42 \mathrm{~A}$ & $1986-04-24$ & $09: 50$ & 00.67 & 478.410 & 7.917 & 0.085 & 63.64 & \\
\hline $\mathrm{DH} 42 \mathrm{~A}$ & $1986-04-30$ & $10: 36$ & 00.76 & 484.442 & 6.032 & 0.126 & 64.40 & \\
\hline $\mathrm{DH} 42 \mathrm{~A}$ & $1986-05-06$ & $10: 00$ & 00.55 & 490.417 & 5.975 & 0.092 & 64.95 & \\
\hline $\mathrm{DH} 42 \mathrm{~A}$ & $1986-05-13$ & $10: 00$ & 00.73 & 497.417 & 7.000 & 0.104 & 65.68 & \\
\hline $\mathrm{OH} 42 \mathrm{~A}$ & $1986-05-20$ & $11: 00$ & 00.70 & 504.458 & 7.041 & 0.099 & 66.38 & \\
\hline DH42A & $1986-05-27$ & 15.35 & 00.65 & 511.649 & 7.191 & 0.090 & 67.03 & \\
\hline DH42A & $1986-06-03$ & $09: 50$ & 00.66 & 518.410 & 6.761 & 0.098 & 67.69 & \\
\hline $\mathrm{DH} 42 \mathrm{~A}$ & $1986-06-10$ & $11: 15$ & 00.54 & 525.469 & 7.059 & 0.076 & 68.23 & \\
\hline $\mathrm{DH} 42 \mathrm{~A}$ & $1986-06-17$ & $10: 31$ & 00.65 & 532.438 & 6.969 & 0.093 & 68.88 & \\
\hline $\mathrm{DH} 42 \mathrm{~A}$ & $1986-06-24$ & $10: 45$ & 00.63 & 539.448 & 7.010 & 0.090 & 69.51 & \\
\hline
\end{tabular}


BRINE ACCUMULATION DATA TABLE (Continued) Data through December 31, 1990

\begin{tabular}{|c|c|c|c|c|c|c|c|c|}
\hline Location & Date & Time & $\begin{array}{l}\text { Liters } \\
\text { removed }\end{array}$ & $\begin{array}{l}\text { Days } \\
\text { since } \\
1 / 1 / 85 \\
\end{array}$ & $\begin{array}{l}\text { Days } \\
\text { used for } \\
\text { calc. }\end{array}$ & $\begin{array}{l}\text { Liters } \\
\text { per } \\
\text { day }\end{array}$ & $\begin{array}{c}\text { Cumulative } \\
\text { liters } \\
\text { collected }\end{array}$ & Remarks \\
\hline DH42A & $1986-07-01$ & $13: 50$ & 00.71 & 546.576 & 7.128 & 0.100 & 70.22 & \\
\hline $\mathrm{DH} 42 \mathrm{~A}$ & $1986-07-08$ & $10: 25$ & 00.63 & 553.434 & 6.858 & 0.092 & 70.85 & \\
\hline $\mathrm{DH} 42 \mathrm{~A}$ & $1986-07-16$ & $10: 00$ & 00.66 & 561.417 & 7.983 & 0.083 & 71.51 & \\
\hline $\mathrm{DH} 42 \mathrm{~A}$ & $1986-07-22$ & $09: 48$ & 00.61 & 567.408 & 5.891 & 0.102 & 72.12 & \\
\hline $\mathrm{DH} 42 \mathrm{~A}$ & $1986-07-29$ & $10: 25$ & 00.71 & 574.434 & 7.026 & 0.101 & 72.83 & \\
\hline $\mathrm{DH} 42 \mathrm{~A}$ & $1986-08-05$ & $10: 55$ & 00.66 & 581.455 & 7.021 & 0.094 & 73.49 & \\
\hline DH42A & $1986-08-12$ & $10: 23$ & 00.63 & 588.433 & 6.978 & 0.090 & 74.12 & \\
\hline DH42A & $1986-08-19$ & $11: 22$ & 00.68 & 595.474 & 7.041 & 0.097 & 74.80 & \\
\hline DH42A & $1986-08-26$ & $10: 28$ & 00.68 & 602.436 & 6.862 & 0.098 & 75.48 & Static level not measured. \\
\hline $\mathrm{OH} 42 \mathrm{~A}$ & $1986-09-04$ & $10: 25$ & 00.71 & 611.434 & 8.998 & 0.079 & 76.19 & $\begin{array}{l}\text { Valve broke off and left in hole after } \\
\text { collecting most of brine. Some brine left in } \\
\text { hole. }\end{array}$ \\
\hline DH42A & $1986-09-09$ & $09: 40$ & 00.07 & 616.403 & 4.969 & 0.014 & 76.26 & Bottom obstructed by object in hole. \\
\hline $\mathrm{DH} 42 \mathrm{~A}$ & $1986-09-16$ & $09: 59$ & 00.95 & 623.416 & 7.013 & 0.135 & 77.21 & \\
\hline $\mathrm{DH} 42 \mathrm{~A}$ & $1986-09-23$ & $10: 02$ & 00.60 & 630.418 & 7.002 & 0.086 & 77.81 & \\
\hline $\mathrm{DH} 42 \mathrm{~A}$ & $1986-10-01$ & $11: 57$ & 00.43 & 638.498 & 8.080 & 0.053 & 78.24 & \\
\hline $\mathrm{DH} 42 \mathrm{~A}$ & $1986-10-08$ & $10: 55$ & 00.81 & 645.455 & 6.957 & 0.116 & 79.05 & \\
\hline $\mathrm{DH} 42 \mathrm{~A}$ & $1986-10-14$ & $11: 24$ & 00.56 & 651.475 & 6.020 & 0.093 & 79.61 & \\
\hline DH42A & $1986-11-05$ & $11: 04$ & 1.94 & 673.461 & 21.986 & 0.088 & 81.55 & \\
\hline DH42A & $1986-11-20$ & $12: 08$ & 01.40 & 688.506 & 15.045 & 0.093 & 82.95 & \\
\hline $\mathrm{OH} 42 \mathrm{~A}$ & $1986-12-31$ & $11: 30$ & 02.91 & 729.479 & 40.973 & 0.071 & 85.86 & \\
\hline DH42A & $1987-02-03$ & $12: 35$ & 03.15 & 763.524 & 34.045 & 0.093 & 89.01 & \\
\hline DH42A & $1987-03-06$ & $10: 45$ & 2.61 & 794.448 & 30.924 & 0.084 & 91.62 & \\
\hline DH42A & $1987-03-30$ & $10: 56$ & 2.52 & 818.456 & 24.008 & 0.101 & 94.14 & \\
\hline DH42A & $1987-05-07$ & $11: 10$ & 3.17 & 856.465 & 38.009 & 0.083 & 97.31 & \\
\hline $\mathrm{DH} 42 \mathrm{~A}$ & $1987-06-17$ & $10: 30$ & 2.94 & 897.438 & 0.000 & 0.000 & 100.25 & $\begin{array}{l}\text { Approx. } 0.01 \text { liter spilled. Some brine left in } \\
\text { hole; no calc. }\end{array}$ \\
\hline DH42A & $1987-06-18$ & $11: 54$ & 0.11 & 898.496 & 42.031 & 0.073 & 100.36 & $\begin{array}{l}\text { Calculated using } 3.05 \text { liters }(2.94 / 6 / 17 / 87 \\
\text { plus } 0.11 \mid 6 / 18 / 87) \text {. }\end{array}$ \\
\hline DH42A & $1987-07-28$ & $11: 03$ & 3.07 & 938.460 & 39.964 & 0.077 & 103.43 & \\
\hline DH42A & $1987-09-01$ & $10: 08$ & 2.69 & 973.422 & 34.962 & 0.077 & 106.12 & Samples effervesce. \\
\hline DH42A & $1987-10-20$ & $11: 28$ & 3.73 & 1022.480 & 49.058 & 0.076 & 109.85 & \\
\hline $\mathrm{DH} 42 \mathrm{~A}$ & $1987-11-19$ & $10: 55$ & 2.17 & 1052.450 & 29.970 & 0.072 & 112.02 & \\
\hline DH42A & $1988-01-04$ & $11: 25$ & 3.28 & 1098.480 & 46.030 & 0.071 & 115.30 & \\
\hline DH42A & $1988-02-08$ & $11: 10$ & 2.47 & 1133.470 & 34.990 & 0.071 & 117.77 & \\
\hline DH42A & $1988-03-29$ & $11: 15$ & 3.57 & 1183.470 & 50.000 & 0.071 & 121.34 & \\
\hline DH42A & $1988-05-05$ & $09: 00$ & 2.38 & 1220.380 & 36.910 & 0.064 & 123.72 & \\
\hline DH42A & $1988-05-12$ & $09: 40$ & 0.50 & $1227.4 \mathrm{CO}$ & 7.020 & 0.071 & 124.22 & \\
\hline DH42A & $1988-07-12$ & $08: 30$ & 4.06 & 1288.350 & 60.950 & 0.067 & 128.28 & \\
\hline $\mathrm{DH} 42 \mathrm{~A}$ & $1988-07-28$ & $10: 15$ & 1.25 & 1304.430 & 16.080 & 0.078 & 129.53 & \\
\hline $\mathrm{DH} 42 \mathrm{~A}$ & $1988-09-14$ & $08: 45$ & 3.00 & 1352.360 & 47.930 & 0.063 & 132.53 & \\
\hline $\mathrm{DH} 42 \mathrm{~A}$ & $1988-09-27$ & $10: 10$ & 1.07 & 1365.420 & 13.060 & 0.082 & 133.60 & \\
\hline DH42A & $1988-12-13$ & 09:35 & 7.95 & 1442.400 & 76.980 & 0.103 & 141.55 & \\
\hline $\mathrm{DH} 42 \mathrm{~A}$ & 1989-03-15 & $10: 00$ & 5.82 & 1534.420 & 92.018 & 0.063 & 147.37 & \\
\hline DH42A & $1989-04-06$ & $10: 15$ & 1.44 & 1556.430 & 22.010 & 0.065 & 148.81 & \\
\hline DH42A & $1989-04-20$ & $09: 00$ & 0.75 & 1570.380 & 13.948 & 0054 & 149.56 & \\
\hline $\mathrm{OH} 42 \mathrm{~A}$ & $\begin{array}{r}1989-05-17 \\
1989-06-06\end{array}$ & $\begin{array}{l}09: 45 \\
09 \cdot 45\end{array}$ & $\begin{array}{l}1.91 \\
1.30\end{array}$ & $\begin{array}{l}1597.410 \\
1617.410\end{array}$ & 27.031 & 0.071 & $\begin{array}{l}151.47 \\
152.77\end{array}$ & \\
\hline $\mathrm{DH} 42 \mathrm{~A}$ & $\begin{array}{l}1989-06-06 \\
1989-06-29\end{array}$ & $\begin{array}{l}09: 45 \\
10: 15\end{array}$ & $\begin{array}{l}1.30 \\
1.35\end{array}$ & $\begin{array}{l}1617.410 \\
1640.430\end{array}$ & 20.000 & 0.065 & $\begin{array}{l}152.77 \\
154.12\end{array}$ & \\
\hline DH42A & $\begin{array}{l}1989-06-29 \\
1989-07-25\end{array}$ & $\begin{array}{l}10: 15 \\
10: 05\end{array}$ & $\begin{array}{l}1.35 \\
1.51\end{array}$ & $\begin{array}{l}1640.430 \\
1666.420\end{array}$ & 23.021 & 0.059 & $\begin{array}{l}154.12 \\
155.63\end{array}$ & \\
\hline DH42A & $\begin{array}{l}1989-07-25 \\
1989-08-16\end{array}$ & $\begin{array}{l}10: 05 \\
09: 31\end{array}$ & $\begin{array}{l}1.21 \\
1.48\end{array}$ & $\begin{array}{l}1666.420 \\
1688.400\end{array}$ & 25.993 & $\begin{array}{l}0058 \\
0067\end{array}$ & $\begin{array}{l}150.63 \\
157.11\end{array}$ & \\
\hline DH42A & $\begin{array}{c}1989-08-16 \\
1989-09-12\end{array}$ & $08: 50$ & 1.63 & $\begin{array}{l}1688.400 \\
1715.370\end{array}$ & $\begin{array}{l}21.977 \\
26.971\end{array}$ & $\begin{array}{l}0.067 \\
0.060\end{array}$ & 158.74 & \\
\hline DH42A & & $09: 20$ & 5.28 & 1807.390 & $\begin{array}{l}26.971 \\
92.021\end{array}$ & $\begin{array}{l}0.060 \\
0.057\end{array}$ & 164.02 & \\
\hline DH42A & & $09: 36$ & 1.95 & 1835.400 & $\begin{array}{l}92.021 \\
28.011\end{array}$ & $\begin{array}{l}0.057 \\
0.070\end{array}$ & 165.97 & \\
\hline DH42A & $\begin{array}{l}1990-01-10 \\
1990-01-24\end{array}$ & $09: 52$ & 0.75 & 1849.411 & $\begin{array}{l}28.011 \\
14.011\end{array}$ & 0.054 & 166.72 & \\
\hline $\mathrm{DH} 42 \mathrm{~A}$ & & $10: 20$ & 0.95 & 1863.431 & 14.020 & 0.068 & 16767 & \\
\hline $\begin{array}{l}\mathrm{DH} 42 \mathrm{~A} \\
\mathrm{OH} 42 \mathrm{~A}\end{array}$ & $1990-02-21$ & $09: 56$ & 0.81 & 1877.414 & 13.983 & 0058 & 168.48 & \\
\hline $\begin{array}{l}\text { DH42A } \\
\text { DH42A }\end{array}$ & $1990-03-05$ & $08: 47$ & 0.68 & 1889.366 & 11.952 & 0.057 & 169.16 & \\
\hline $\begin{array}{l}\text { DH42A } \\
\text { DH42A }\end{array}$ & $1990-03-13$ & $11: 36$ & NA & 1897.483 & & & 169.16 & Installed sampler. \\
\hline $\begin{array}{l}\text { DH42A } \\
\text { DH42A }\end{array}$ & $1990-03-19$ & $11: 07$ & 0.51 & 1903463 & 14.097 & 0.000 & 169.67 & Partial evacuation. \\
\hline
\end{tabular}


BRINE ACCUMULATION DATA TABLE (Continued) Data through December 31, 1990

\begin{tabular}{|c|c|c|c|c|c|c|c|c|}
\hline Location & Date & Time & $\begin{array}{l}\text { Liters } \\
\text { removed }\end{array}$ & $\begin{array}{l}\text { Days } \\
\text { since } \\
1 / 1 / 85 \\
\end{array}$ & $\begin{array}{l}\text { Days } \\
\text { used for } \\
\text { calc. }\end{array}$ & $\begin{array}{l}\text { Liters } \\
\text { per } \\
\text { day }\end{array}$ & $\begin{array}{l}\text { Cumulative } \\
\text { liters } \\
\text { collected }\end{array}$ & Remarks \\
\hline DH42A & $1990-03-21$ & $10: 21$ & 0.28 & 1905.431 & 1.968 & 0.049 & 169.95 & $\begin{array}{l}\text { Combined with } 0.51 \text { liters from } 03 / 19 / 90 \text {. } \\
\text { Used } 0.79 \text { liters for calculation. }\end{array}$ \\
\hline DH42A & $1990-04-04$ & $09: 14$ & 0.60 & 1919.385 & 13.854 & 0.043 & 170.55 & \\
\hline DH42A & $1990-04-10$ & $08: 40$ & 0.58 & 1925.361 & 5.976 & 0.097 & 171.13 & \\
\hline $\mathrm{DH} 42 \mathrm{~A}$ & $1990-04-17$ & $10: 19$ & 0.38 & 1932.430 & 7.069 & 0.054 & 171.51 & \\
\hline DH42A & $1990-04-24$ & $09: 18$ & 0.42 & 1939.388 & 5.858 & 0.060 & 171.93 & \\
\hline DH42A & $1990-05-02$ & $10: 32$ & 0.51 & 1947.439 & 8.051 & 0.063 & 172.44 & \\
\hline DH42A & $1990-05-09$ & $08: 48$ & 0.39 & 1954.367 & 6.928 & 0.056 & 172.83 & \\
\hline $\mathrm{DH} 42 \mathrm{~A}$ & $1990-05-16$ & $09: 07$ & 0.43 & 1961.380 & 7.013 & 0.061 & 173.26 & \\
\hline $\mathrm{DH} 42 \mathrm{~A}$ & $1990-05-23$ & $12: 08$ & 0.40 & 1968.506 & 7.126 & 0.056 & 173.66 & \\
\hline $\mathrm{DH} 42 \mathrm{~A}$ & $1990-05-31$ & $08: 47$ & 0.46 & 1976.366 & 7.860 & 0.059 & 174.12 & \\
\hline $\mathrm{DH} 42 \mathrm{~A}$ & $1990-06-06$ & $09: 30$ & 0.34 & 1982.396 & 6.030 & 0.056 & 174.46 & \\
\hline DH42A & $1990-06-14$ & 08:38 & 0.39 & 1980.360 & 7.964 & 0.048 & 174.85 & \\
\hline DH42A & $1990-06-20$ & $09: 33$ & 0.45 & 1996.398 & 6.038 & 0.075 & 175.30 & \\
\hline $\mathrm{DH} 42 \mathrm{~A}$ & $1990-06-28$ & $08: 50$ & 0.45 & 2004.368 & 7.970 & 0.056 & 175.75 & \\
\hline $\mathrm{DH} 42 \mathrm{~A}$ & $1990-07-17$ & $11: 04$ & 0.56 & 2023.461 & 19.093 & 0.000 & 176.31 & Partial evacuation. \\
\hline $\mathrm{DH} 42 \mathrm{~A}$ & $1990-07-18$ & $10: 30$ & 0.48 & 2024.438 & 0.977 & 0.052 & 176.79 & $\begin{array}{l}\text { Combined with } 0.56 \text { liters from } 07 / 17 / 90 \text {. } \\
\text { Used } 1.04 \text { liters for calculation. }\end{array}$ \\
\hline DH42A & $1990-07-25$ & $09: 37$ & 0.43 & 2031.401 & 6.963 & 0.062 & 177.22 & \\
\hline DH42A & $1990-08-01$ & $10: 18$ & 0.50 & 2038.429 & 7.028 & 0.071 & 177.72 & \\
\hline \multicolumn{9}{|c|}{ (n) } \\
\hline DH215 & $1989-04-06$ & $11: 00$ & 0 & 1556.458 & 114.010 & 0.000 & 17.45 & Hole dry. \\
\hline DH215 & $1989-04-20$ & 13:10 & 0.11 & 1570.549 & 14.091 & 0.008 & 17.56 & \\
\hline DH215 & $1989-05-17$ & $09: 00$ & 0 & 1597.375 & 26.826 & 0.000 & 17.56 & Hole dry. \\
\hline DH215 & $1980-06-29$ & $08: 50$ & 0 & 1640.368 & 42.993 & 0.000 & 17.56 & Hole dry. \\
\hline $\mathrm{DH} 215$ & $1989-07-25$ & $11: 00$ & 0.25 & 1666.458 & 26.090 & 0.010 & 17.81 & \\
\hline $\mathrm{DH} 215$ & $1989-08-16$ & $09: 10$ & 0 & 1688.382 & 21.824 & 0.000 & 17.81 & Hole dry. \\
\hline DH215 & $1989-09-12$ & $12: 00$ & 0 & 1715.500 & 27.118 & 0.000 & 17.81 & Hole dry. \\
\hline $\mathrm{DH} 215$ & $1989-12-12$ & $12: 25$ & 0 & 1806.517 & 91.017 & 0.000 & 17.81 & Hole dry. \\
\hline $\mathrm{DH} 215$ & $1990-02-07$ & $11: 00$ & 0.0 & 1863.458 & 56.841 & 0.000 & 17.81 & Dry. \\
\hline $\mathrm{DH} 215$ & $1990-02-21$ & $09: 00$ & 0.0 & 1877.375 & 13.917 & 0.000 & 17.81 & Dry. \\
\hline $\mathrm{DH} 215$ & $1990-03-05$ & $12: 04$ & 0.0 & 1889.503 & 12.128 & 0.000 & 17.81 & Dry. \\
\hline $\mathrm{DH} 215$ & $1990-03-21$ & $09: 00$ & 0.0 & 1905.375 & 15.872 & 0.000 & 17.81 & Dry. \\
\hline $\mathrm{DH} 215$ & $1990-04-11$ & $10: 21$ & 00 & 1926.431 & 21.056 & 0.000 & 17.81 & Dry. \\
\hline DH215 & $1990-05-02$ & $09: 35$ & 0.0 & 1947.399 & 20.968 & 0.000 & 17.81 & Dry. \\
\hline DH215 & $1990-05-08$ & $10: 07$ & 0.0 & 1953.422 & 6.023 & 0.000 & 17.81 & Dry. \\
\hline $\mathrm{DH} 215$ & $1990-05-17$ & $09: 11$ & 0.0 & 1962.383 & 8.961 & 0.000 & 17.81 & Dry. Prepared collector. \\
\hline $\mathrm{DH} 215$ & $1990-05-23$ & $13: 35$ & 0.0 & 1968.566 & 6.183 & 0.000 & 17.81 & Dry. \\
\hline $\mathrm{DH} 215$ & $1990-05-31$ & $10: 00$ & 0.01 & 1976.417 & 7.851 & 0.001 & 17.82 & Did not save. \\
\hline $\mathrm{DH} 215$ & $1990-06-06$ & $08: 45$ & 0.0 & 1982.365 & 5.948 & 0.000 & 17.82 & Dry. \\
\hline $\mathrm{DH} 215$ & $1990-06-14$ & $10: 57$ & 0.07 & 1990.456 & 8.091 & 0.009 & 17.89 & \\
\hline DH215 & $1990-06-20$ & $10: 20$ & NA & 1996.431 & & & 17.89 & Trace. Did not remove. \\
\hline $\mathrm{DH} 215$ & $1990-06-28$ & $11: 00$ & NA & 2004.458 & & & 17.89 & Trace. Did not remove \\
\hline $\mathrm{DH} 215$ & $1990-07-17$ & $09: 33$ & NA & 2023.398 & & & 17.89 & Trace. Did not remove. \\
\hline $\mathrm{DH} 215$ & $1990-07-25$ & $11: 00$ & 0.0 & 2031.458 & 41.002 & 0.000 & 17.89 & Dry. \\
\hline $\mathrm{DH} 215$ & $1990-08-07$ & $09: 10$ & 0.04 & 2044.382 & 12.924 & 0.003 & 17.93 & \\
\hline $\mathrm{DH} 215$ & $1990-08-22$ & $11: 15$ & 0.03 & 2059.469 & 15.087 & 0.002 & 17.96 & \\
\hline $\mathrm{DH} 215$ & $1990-08-29$ & $11: 30$ & NA & 2066.479 & & & 17.96 & Trace. Did not sample. \\
\hline $\mathrm{DH} 215$ & $1990-09-05$ & $10: 30$ & NA & 2073.438 & & & 17.96 & Trace. Did not collect. \\
\hline $\mathrm{DH} 215$ & $1990-09-12$ & $08: 37$ & 0.02 & 2080.359 & 20.890 & 0.001 & 17.98 & \\
\hline $\mathrm{DH} 215$ & $1990-11-08$ & $10: 01$ & 0.05 & 2137.417 & 57.058 & 0.001 & 18.03 & \\
\hline \multirow{3}{*}{\multicolumn{9}{|c|}{ 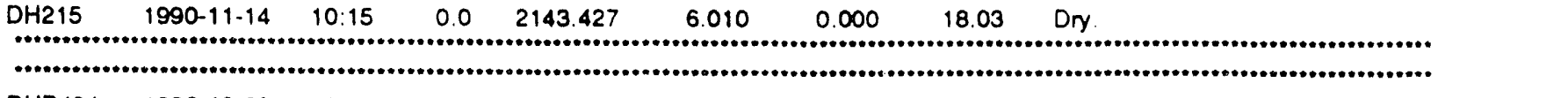 }} \\
\hline & & & & & & & & \\
\hline & & & & & & & & \\
\hline $\begin{array}{l}\text { DHP401 } \\
\text { DHP401 }\end{array}$ & $\begin{array}{l}1986-10-29 \\
1987-01-06\end{array}$ & $\begin{array}{l}00: 00 \\
00: 00\end{array}$ & $\begin{array}{l}\text { NA } \\
\text { NA }\end{array}$ & $\begin{array}{l}0.000 \\
0.000\end{array}$ & $\begin{array}{l}0.000 \\
0.000\end{array}$ & $\begin{array}{l}0.000 \\
0.000\end{array}$ & $\begin{array}{l}0.00 \\
0.00\end{array}$ & $\begin{array}{l}\text { Drift excavated at } S 1950 / E 1320 \text {. } \\
\text { Uphole drilling initiated } 12 / 08 / 86 \text {, stopped on } \\
12 / 09 / 86 \text { at } 27.9 \mathrm{th} \text {. Drilling resumed } 1 / 02 / 87 \\
\text { and completed } 1 / 06 / 87 \text {. }\end{array}$ \\
\hline
\end{tabular}


BRINE ACCUMULATION DATA TABLE (Continued)

Data through December 31, 1990

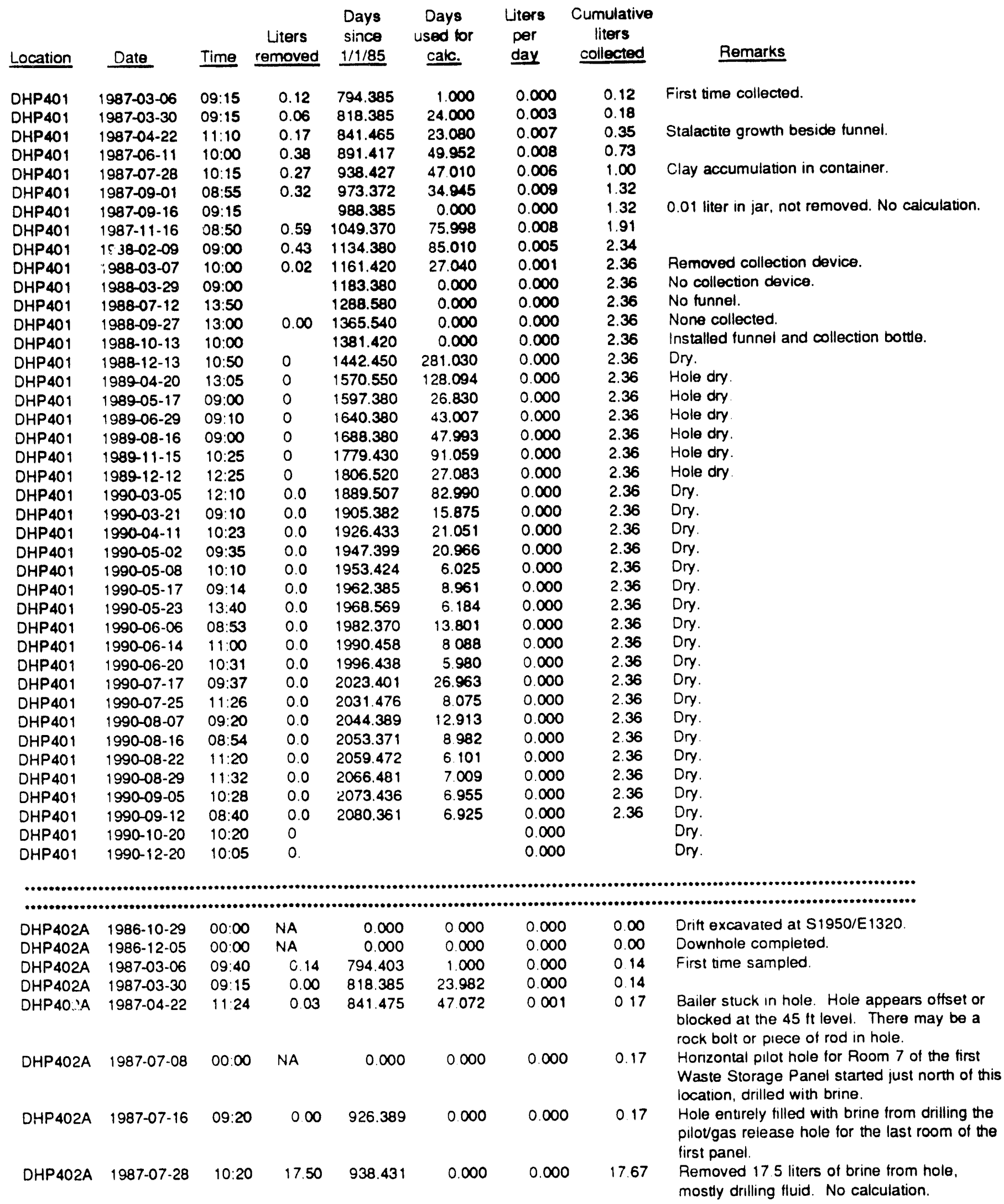




\section{BRINE ACCUMULATION DATA TABLE (Continued) Data through December 31, 1990}

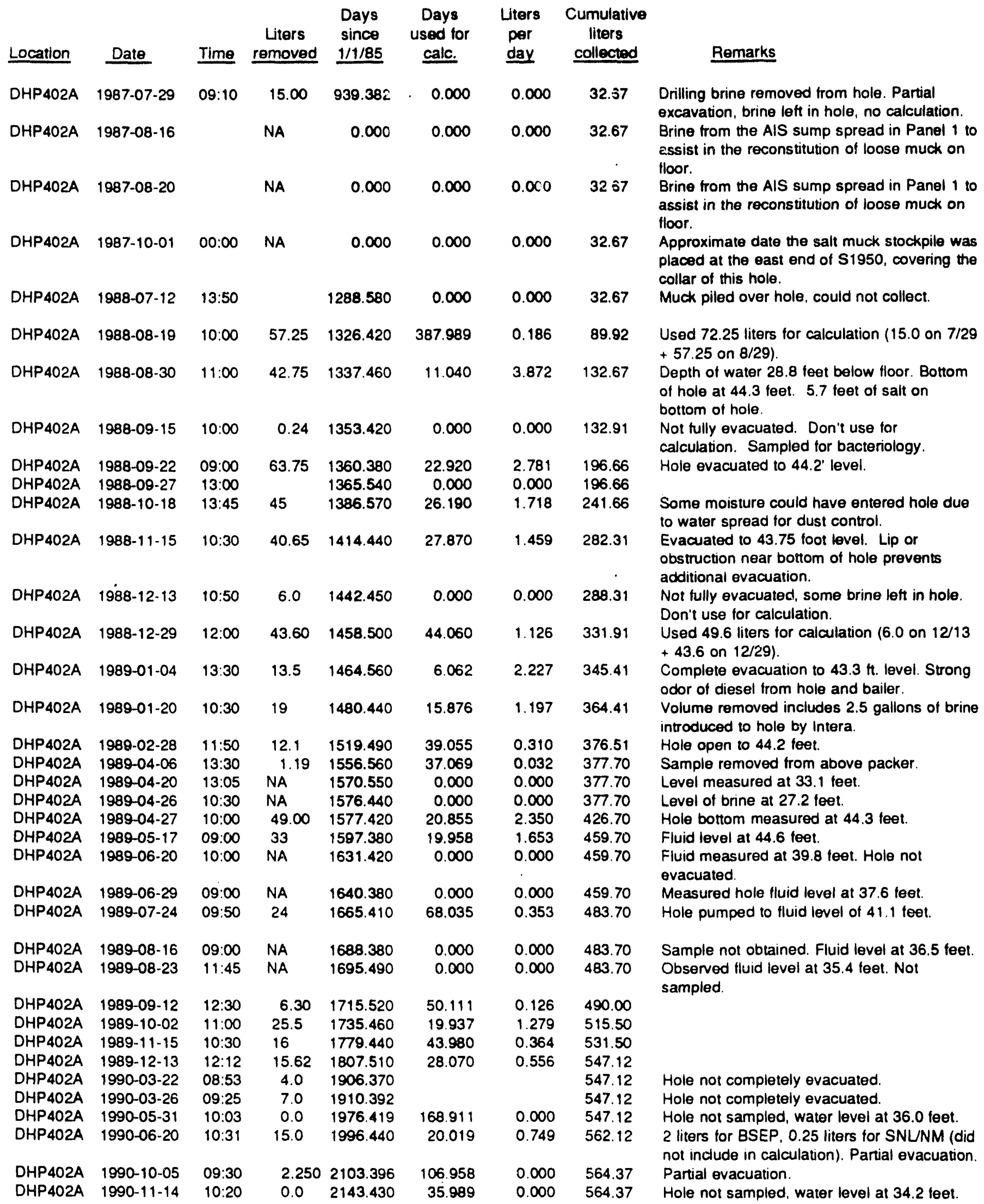


BRINE ACCUMULATION DATA TABLE (Continued)

Data through December 31, 1990

\begin{tabular}{|c|c|c|c|c|c|c|c|c|}
\hline -ocation & Date & Time & $\begin{array}{l}\text { Liters } \\
\text { removed }\end{array}$ & $\begin{array}{c}\text { Days } \\
\text { since } \\
1 / 1 / 85\end{array}$ & $\begin{array}{l}\text { Days } \\
\text { used tor } \\
\text { calc. }\end{array}$ & $\begin{array}{l}\text { Liters } \\
\text { per } \\
\text { day }\end{array}$ & $\begin{array}{c}\text { Cumulative } \\
\text { liters } \\
\text { collected }\end{array}$ & Remarks \\
\hline
\end{tabular}

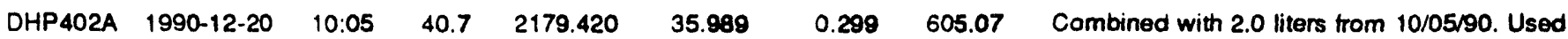
42.7 liters for calculation.

$\begin{array}{llllll}\text { GSEEP } & 1984-11-21 & 0.000 & 0.000 & 0.000 & 0.00 \\ \text { GSEEP } & 1985-08-28 & 0.000 & 0.000 & 0.000 & 0.00 \\ \text { GSEEP } & 1985-11-12 & 0.000 & 0.000 & 0.000 & 0.00\end{array}$

Approximate date this part of Room $G$ excavated.

Noticed damp area on floor at this location.

Damp area on floor near S. rib appiux. E1140 (45 ft E. of DH35) and at E1149. Crusted moist area is about $4 \mathrm{ft}$ by $4 \mathrm{th}$, has increased noticeably in size over last two months. Damp area covers $16 \mathrm{ft} E-W, 13 \mathrm{~h}$ N-S across width of Room G. Many weeps on lower $3 \mathrm{ft}$ of $S \mathrm{rib}$. Brine is seeping out of air pipe support hole.

First time collection. Dug out salt.

Partial removal.

\begin{tabular}{|c|c|c|c|c|c|c|c|}
\hline & & & & & & & \\
\hline GSEEP & $1985-12-03$ & 12:00 & 01.50 & 336.500 & 7.000 & 0.214 & \\
\hline GSEEP & $1985-12-04$ & $12: 00$ & 01.13 & 337.500 & 1.000 & 1.130 & \\
\hline GSEEP & $1985-12-10$ & $12: 00$ & 01.80 & 343.500 & 6.000 & 0.300 & \\
\hline GSEEP & $1986-01-23$ & $12: 00$ & 00.50 & 387.500 & 44.000 & 0.011 & \\
\hline GSEEP & $1986-01-31$ & $12: 00$ & 00.94 & 395.500 & 8.000 & 0.117 & \\
\hline GSEEP & $1986-02-12$ & $12: 00$ & 02.23 & 407.500 & 12.000 & 0.186 & \\
\hline GSEEP & $1986-02-19$ & $12: 00$ & 02.14 & 414.500 & 7.000 & 0.306 & \\
\hline GSEEP & $1986-02-28$ & $12: 00$ & 01.95 & 423.500 & 9.000 & 0.217 & \\
\hline SEEP & $1986-03-04$ & $11: 20$ & 02.62 & 427.472 & 3.972 & 0.660 & \\
\hline GSEEP & $1986-03-06$ & $10: 50$ & 02.07 & 429.451 & 1.979 & 1.046 & \\
\hline GSEEP & $1986-03-13$ & $11: 46$ & 03.23 & 436.490 & 7.039 & 0.459 & \\
\hline GSEEP & $1986-03-26$ & $10: 20$ & 03.00 & 449.431 & 12.941 & 0.232 & \\
\hline GSEEP & $1986-04-02$ & $10: 00$ & 02.68 & 456.417 & 6.986 & 0.384 & \\
\hline GSEEP & $1986-04-08$ & $10: 00$ & 02.50 & 462.417 & 6.000 & 0.417 & \\
\hline GSEEP & $1986-04-16$ & $12: 00$ & 02.24 & 470.500 & 8.083 & 0.277 & \\
\hline GSEEP & $1986-04-24$ & $10: 30$ & 02.35 & 478.438 & 7.938 & 0.296 & \\
\hline GSEEP & $1986-04-30$ & $11: 00$ & 02.40 & 484.458 & 6.020 & 0.399 & \\
\hline GSEEP & $1986-05-06$ & $10: 30$ & 02.49 & 490.438 & 5.980 & 0.416 & \\
\hline GSEEP & $1986-05-13$ & $11: 20$ & 02.66 & 497.472 & 7.034 & 0.378 & \\
\hline GSEEP & $1986-05-20$ & $11: 20$ & 02.44 & 504.472 & 7.000 & 0.349 & \\
\hline GSEEP & $1986-05-27$ & $15: 30$ & 03.11 & 511.646 & 7.174 & 0.434 & \\
\hline GSEEP & $1986-06-03$ & $10: 40$ & 03.31 & 518.444 & 6.798 & 0.487 & \\
\hline GSEEP & $1986-06-10$ & $11: 38$ & 03.21 & 525.485 & 7.041 & 0.456 & \\
\hline GSEEP & $1986-06-17$ & $11: 15$ & 03.11 & 532.469 & 6.984 & 0.445 & \\
\hline GSEEP & $1986-06-24$ & $11: 00$ & 04.60 & 539.458 & 6.989 & 0.658 & \\
\hline GSEEP & $1986-07-01$ & $14: 00$ & 05.43 & 546.583 & 7.125 & 0.762 & \\
\hline GSEEP & $1986-07-08$ & $10: 50$ & 04.14 & 553.451 & 6.868 & 0.603 & \\
\hline GSEEP & $1986-07-16$ & $10: 50$ & 03.32 & 561.451 & 8.000 & 0.415 & \\
\hline GSEEP & $1986-07-22$ & $10: 15$ & 02.29 & 567.427 & 5.976 & 0.383 & \\
\hline GSEEP & $1986-07-29$ & $10: 45$ & 02.68 & 574.448 & 7.021 & 0.382 & $81 . C$ \\
\hline GSEEP & $1986-08-05$ & $11: 20$ & 02.60 & 581.472 & 7.024 & 0.370 & \\
\hline GSEEP & $1986-08-12$ & $10: 45$ & 03.67 & 588.448 & 6.976 & 0.526 & 87. \\
\hline GSEEP & $1986-08-19$ & $11: 40$ & 03.90 & 595.486 & 7.038 & 0.554 & \\
\hline GSEEP & $1986-08-26$ & $11: 00$ & 03.73 & 602.458 & 6.972 & 0.535 & \\
\hline GSEEP & $1986-09-04$ & $10: 55$ & 05.15 & 611.455 & 8.997 & 0.572 & 100. \\
\hline GSEEP & $1986-09-09$ & $10: 00$ & 03.70 & 616.417 & 4.962 & 0.746 & 103. \\
\hline GSEEP & $1986-09-16$ & $10: 25$ & 03.82 & 623.434 & 7.017 & 0.544 & 07. \\
\hline GSEEP & $1986-09-23$ & $10: 20$ & 04.29 & 630.431 & 6.997 & 0.613 & 111. \\
\hline GSEEP & $1986-10-01$ & $12: 24$ & 03.70 & 638.517 & 8.086 & 0.458 & 15. \\
\hline GSEEP & $1986-10-08$ & $10: 45$ & 03.80 & 645.448 & 6.931 & 0.548 & 19. \\
\hline GSEEP & $1986-10-08$ & $14: 57$ & 01.87 & 645.623 & 0.175 & 10.690 & 121.5 \\
\hline & $1986-10-10$ & $09: 16$ & 01.24 & 647.386 & 1.763 & 0.703 & $1<6$ \\
\hline
\end{tabular}

Very humid air in workings

Very humid last week; rain on surface.

Last week has been humid and rainy.

Second collection for this day. Use $(3.80+$ $1.87) /(6.931+0.175)=0.798$ liter/day. 
BRINE ACCUMULATION DATA TABLE (Continued) Data through December 31, 1990

\begin{tabular}{|c|c|c|c|c|c|c|c|c|}
\hline Location & Date & Time & $\begin{array}{c}\text { Liters } \\
\text { removed }\end{array}$ & $\begin{array}{l}\text { Days } \\
\text { since } \\
1 / 1 / 85 \\
\end{array}$ & $\begin{array}{l}\text { Days } \\
\text { used for } \\
\text { calc. }\end{array}$ & $\begin{array}{l}\text { Liters } \\
\text { per } \\
\text { day }\end{array}$ & $\begin{array}{c}\text { Cumulative } \\
\text { liters } \\
\text { collected } \\
\end{array}$ & Remarks \\
\hline GSEEP & $1986-10-14$ & $11: 10$ & 02.19 & 651.465 & 4.079 & 0.537 & 124.73 & \\
\hline GSEEP & $1986-11-05$ & $10: 45$ & 4.44 & 673.448 & 21.883 & 0.202 & 129.17 & First time 3.74 liters; second time $0: 70$ liters. \\
\hline GSEEP & $1986-11-20$ & $12: 02$ & 03.84 & 688.501 & 15.053 & 0.255 & 133.01 & \\
\hline GSEEP & $1986-12-30$ & $12: 50$ & 04.44 & 728.535 & 40.034 & 0.111 & 137.45 & \\
\hline GSEEP & $1987-02-03$ & $13: 45$ & 03.45 & 763.573 & 35.038 & 0.098 & 140.80 & \\
\hline GSEEP & $1987-03-06$ & $11: 30$ & 3.0 & 794.479 & 30.906 & 0.097 & 143.90 & \\
\hline GSEEP & $1987-03-30$ & $11: 34$ & 2.51 & 818.482 & 24.003 & 0.105 & 146.41 & \\
\hline GSEEP & $1987-05-07$ & $11: 48$ & 3.31 & 856.492 & 38.010 & 0.087 & 149.72 & \\
\hline GSEEP & $1987-06-30$ & $10: 00$ & 12.24 & 910.417 & 53.925 & 0.227 & 161.96 & \\
\hline GSEEP & $1987-07-16$ & $10: 30$ & 11.66 & 926.438 & 16.021 & 0.728 & 173.62 & \\
\hline GSEEP & $1987-07-23$ & $09: 20$ & 3.87 & 933.389 & 6.951 & 0.557 & 177.49 & \\
\hline GSEEP & $1987-07-28$ & $11: 35$ & 2.36 & 938.483 & 5.084 & 0.463 & 179.85 & \\
\hline GSEEP & $1987-08-07$ & $09: 15$ & 5.33 & 948.385 & 9.902 & 0.538 & 185.18 & \\
\hline GSEEP & $1987-08-12$ & $10: 12$ & 2.80 & 953.425 & 5.040 & 0.556 & 187.98 & \\
\hline GSEEP & $1987-08-24$ & $08: 46$ & 6.53 & 965.365 & 11.940 & 0.547 & 194.51 & \\
\hline GSEEP & $1987-09-01$ & $11: 00$ & 5.26 & 973.458 & 8.093 & 0.650 & 199.77 & \\
\hline GSEEP & $1987-09-11$ & $09: 00$ & 5.03 & 983.375 & 9.917 & 0.507 & 204.80 & \\
\hline GSEEP & $1987-09-16$ & $09: 33$ & 2.42 & 988.398 & 5.023 & 0.482 & 207.22 & \\
\hline GSEEP & $1987-09-25$ & $08: 55$ & 4.12 & 997.372 & 8.974 & 0.459 & 211.34 & $\begin{array}{l}\text { Sump drilled to facilitate accumulation of } \\
\text { brine. }\end{array}$ \\
\hline GSEEP & $1987-10-01$ & $12: 15$ & 2.81 & 1003.510 & 6.138 & 0.458 & 214.15 & \\
\hline GSEEP & $1987-10-08$ & $10: 25$ & 2.97 & 1010.430 & 6.920 & 0.429 & 217.12 & \\
\hline GSEEP & $1987-10-16$ & $10: 41$ & 3.37 & 1018.450 & 8.020 & 0.420 & 220.49 & \\
\hline GSEEP & $198 \pi-10-20$ & $11: 59$ & 2.06 & 1022.500 & 4.050 & 0.509 & 222.55 & \\
\hline GSEEP & $1987-11-12$ & $10: 41$ & 10.21 & 1045.450 & 22.950 & 0.445 & 232.76 & \\
\hline GSEEP & $1987-11-19$ & $11: 35$ & 2.90 & 1052.480 & 7.030 & 0.413 & 235.66 & \\
\hline GSEEP & $1987-12-07$ & $12: 50$ & 7.02 & 1070.530 & 18.050 & 0.389 & 242.68 & \\
\hline GSEEP & $1988-01-04$ & $12: 10$ & 16.11 & 1098.510 & 27.980 & 0.576 & 258.79 & \\
\hline GSEEP & $1988-01-20$ & $11: 25$ & 8.68 & 1114.480 & 15.970 & 0.544 & 267.47 & \\
\hline GSEEP & $1988-02-08$ & $12: 15$ & 9.58 & 1133.510 & 19.030 & 0.503 & 277.05 & \\
\hline GSEEP & $1988-02-25$ & $10: 40$ & 11.87 & 1150.440 & 16.930 & 0.701 & 288.92 & \\
\hline GSEEP & $1988-03-09$ & $10: 18$ & 7.35 & 1163.430 & 12.990 & 0.566 & 296.27 & \\
\hline GSEEP & $1988-03-17$ & $11: 20$ & 4.45 & 1171.470 & 8.040 & 0.553 & 300.72 & \\
\hline GSEEP & $1988-03-29$ & $11: 45$ & 5.42 & 1183.490 & 12.020 & 0.451 & 306.14 & \\
\hline GSEEP & $1988-04-15$ & $11: 01$ & 7.43 & 1200.460 & 16.970 & 0.438 & 313.57 & \\
\hline GSEEP & $1988-05-05$ & $10: 10$ & 9.34 & 1220.420 & 19.960 & 0.468 & 322.91 & \\
\hline GSEEP & $1988-05-12$ & $09: 30$ & 3.55 & 1227.400 & 6.880 & 0.509 & 326.46 & \\
\hline GSEEP & $1988-06-09$ & $08: 45$ & 12.00 & 1255.360 & 27.960 & 0.429 & 338.46 & \\
\hline GSEEP & $1988-06-16$ & $09: 43$ & 4.13 & 1262.400 & 7.040 & 0.587 & 342.59 & \\
\hline GSEEP & $1988-06-30$ & $08: 30$ & 6.00 & 1276.350 & 13.850 & 0.430 & 348.59 & \\
\hline GSEEP & $1988-07-12$ & $09: 00$ & 6.40 & 1288.380 & 12.030 & 0.532 & 354.99 & \\
\hline GSEEP & $1988-07-28$ & $10: 30$ & 11.35 & 1304.440 & 16.060 & 0.707 & 366.34 & \\
\hline GSEEP & $1988-08-11$ & $10: 00$ & 12.02 & 1318.420 & 13.980 & 0.860 & 378.36 & \\
\hline GSEEP & $1988-08-25$ & $09: 07$ & 6.72 & 1332.380 & 13.960 & 0.481 & 385.08 & Hole covered with tight fitting brattice cloth. \\
\hline GSEEP & $1988-09-08$ & $14: 48$ & 7.31 & 1346.620 & 14.240 & 0.513 & 392.39 & \\
\hline GSEEP & $1988-09-14$ & $08: 30$ & 3.00 & 1352.350 & 5.730 & 0.524 & 395.39 & \\
\hline GSEEP & $1988-09-27$ & $10: 50$ & 6.45 & 1365.450 & 13.100 & 0.492 & 401.84 & \\
\hline GSEEP & $1988-10-18$ & $10: 22$ & 10.20 & 1386.430 & 20.880 & 0.486 & 412.04 & \\
\hline GSEEP & $1988-11-10$ & $09: 08$ & 12.62 & 1409.380 & 22.950 & 0.550 & 424.66 & $\begin{array}{l}\text { Smell of urine in sample and coming from } \\
\text { hole. }\end{array}$ \\
\hline GSEEP & $1988-12-13$ & $10: 20$ & 17.81 & 1442.430 & 33.050 & 0.539 & 442.47 & $\begin{array}{l}\text { Sample effervesces and brine feels warmer } \\
\text { than usual. }\end{array}$ \\
\hline GSEEP & $1989-01-10$ & $13: 30$ & 17.38 & 1470.560 & 28.131 & 0.618 & 459.85 & \\
\hline GSEEP & $1989-02-09$ & $10: 22$ & 19.5 & 1500.430 & 29.870 & 0.653 & 479.35 & \\
\hline GSEEP & $1989-03-01$ & $10: 00$ & 3.90 & 1520.420 & 0.000 & 0.000 & 483.25 & \\
\hline GSEEP & $1989-03-14$ & $12: 45$ & 19.57 & 1533.530 & 33.099 & 0.709 & 502.82 & $\begin{array}{l}\text { Add } 3.9 \text { I collected } 3 / 01 / 90 \text { to } 19.57 \mathrm{I} \text {. Use } \\
23.47 \text { liter for calculation. }\end{array}$ \\
\hline GSEEP & $1989-04-06$ & $08: 56$ & 16.35 & 1556.370 & 22.841 & 0.716 & 519.17 & \\
\hline GSEEP & $1989-04-20$ & $08: 45$ & 10.43 & 1570.370 & 13.993 & 0.745 & 529.60 & \\
\hline GSEEP & $1989-05-17$ & $09: 40$ & 19.72 & 1597.400 & 27.038 & 0.729 & 549.32 & \\
\hline
\end{tabular}


BRINE ACCUMULATION DATA TABLE (Continued)

Data through December 31, 1990

\begin{tabular}{|c|c|c|c|c|c|c|c|c|}
\hline Location & Date & Time & $\begin{array}{l}\text { Liters } \\
\text { removed } \\
\end{array}$ & $\begin{array}{c}\text { Days } \\
\text { since } \\
1 / 4 / 85 \\
\end{array}$ & $\begin{array}{l}\text { Days } \\
\text { used for } \\
\text { calc. }\end{array}$ & $\begin{array}{l}\text { Liters } \\
\text { per } \\
\text { day }\end{array}$ & $\begin{array}{c}\text { Cumulative } \\
\text { liters } \\
\text { collected }\end{array}$ & Remarks \\
\hline GSEEP & $1989-06-06$ & $09: 40$ & 14.52 & 1617.400 & 20.000 & 0.726 & 563.84 & \\
\hline GSEEP & $1989-06-29$ & $10: 01$ & 15.95 & 1640.420 & 23.014 & 0.693 & 579.79 & \\
\hline GSEEP & $1989-07-06$ & $09: 00$ & 4.67 & 1647.380 & 6.958 & 0.671 & 584.46 & \\
\hline GSEEP & $1989-07-25$ & $09: 30$ & 12.60 & 1666.400 & 19.021 & 0.662 & 597.06 & \\
\hline GSEEP & $1989-08-16$ & $09: 15$ & 14.73 & 1688.380 & 21.989 & 0.670 & 611.79 & \\
\hline GSEEP & $1989-09-12$ & $08: 30$ & 18.68 & 1715.350 & 26.869 & 0.693 & 630.47 & \\
\hline GSEEP & $1989-10-11$ & $09: 47$ & 17.70 & 1744.410 & 29.054 & 0.609 & 648.17 & \\
\hline GSEEP & $1989-11-15$ & $09: 30$ & 21.44 & 1779.400 & 34.988 & 0.613 & 669.61 & \\
\hline GSEEP & $1989-12-13$ & $09: 13$ & 16.30 & 1807.380 & 27.888 & 0.582 & 685.91 & \\
\hline GSEEP & $1990-01-10$ & $09: 21$ & 16.40 & 1835.390 & 28.006 & 0.586 & 702.31 & \\
\hline $\begin{array}{l}\text { GSEEP } \\
\text { GSEEP }\end{array}$ & $\begin{array}{l}1990-01-24 \\
1990-02-07\end{array}$ & $\begin{array}{l}09: 19 \\
10: 07\end{array}$ & $\begin{array}{l}9.0 \\
9.0\end{array}$ & $\begin{array}{l}1849.388 \\
1863.422\end{array}$ & $\begin{array}{l}13.998 \\
14.034\end{array}$ & $\begin{array}{l}0.643 \\
0.641\end{array}$ & $\begin{array}{l}711.31 \\
720.31\end{array}$ & \\
\hline GSEEP & $1990-02-21$ & $09: 40$ & 8.32 & 1877.403 & 13.881 & 0.595 & 728.63 & \\
\hline GSEEP & 1990-03-21 & $09: 49$ & 16.55 & 1905.409 & 28.006 & 0.591 & 745.18 & \\
\hline GSEEP & $1990-04-24$ & $11: 16$ & 20.33 & 1939.469 & 34.060 & 0.597 & 765.51 & \\
\hline GSEEP & $1990-05-23$ & $11: 51$ & 16.66 & 1968.494 & 29.025 & 0.574 & 782.17 & \\
\hline GSEEP & $1990-06-06$ & $12: 30$ & 10.50 & 1982.521 & 14.000 & 0.750 & 792.67 & \\
\hline GSEEP & $1990-06-20$ & $08: 56$ & 15.72 & 1996.372 & 27.878 & 0.564 & 808.39 & \\
\hline GSEEP & $1990-07-25$ & $08: 50$ & 15.0 & 2031.368 & 34.996 & 0.429 & 823.39 & \\
\hline GSEEP & $1990-12-11$ & $10: 30$ & 2.0 & 2170.438 & 139.070 & 0.000 & 825.39 & $\begin{array}{l}\text { Partial removal. First time sampled since } \\
07 / 25 / 90 \text {. }\end{array}$ \\
\hline GSEEP & $1990-12-13$ & $08: 56$ & 49.89 & 2172.372 & 1.230 & 0.368 & 875.28 & $\begin{array}{l}\text { Combined vith } 2.0 \text { liters from } 12 / 11 / 90 \text {. Used } \\
51.89 \text { liters for calculation. }\end{array}$ \\
\hline GSEEP & $1990-12-20$ & $08: 23$ & 0.0 & 2179.349 & 147.981 & 0.000 & 875.28 & Could not sample. \\
\hline
\end{tabular}

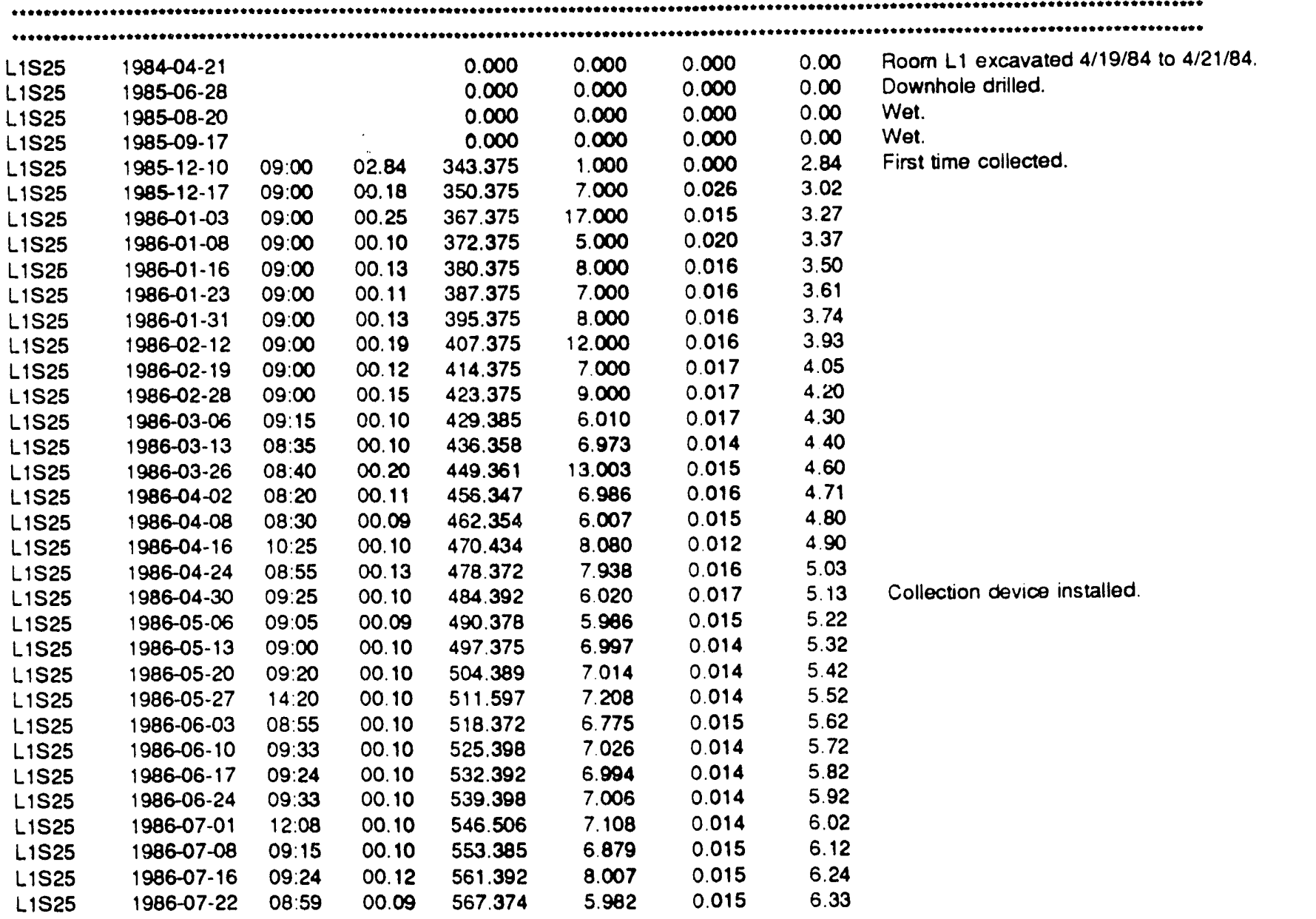


BRINE ACCUMULATION DATA TABLE (Continued)

Data through December 31, 1990

\begin{tabular}{|c|c|c|c|c|c|c|c|c|}
\hline Location & Date & Time & $\begin{array}{l}\text { Liters } \\
\text { removed }\end{array}$ & $\begin{array}{c}\text { Days } \\
\text { since } \\
1 / 1 / 85 \\
\end{array}$ & $\begin{array}{l}\text { Days } \\
\text { used for } \\
\text { calc. }\end{array}$ & $\begin{array}{l}\text { Liters } \\
\text { per } \\
\text { day }\end{array}$ & $\begin{array}{c}\text { Cumulative } \\
\text { liters } \\
\text { collected }\end{array}$ & Remarks \\
\hline L1S25 & $1986-07-29$ & $09: 27$ & 00.10 & 574.394 & 7.020 & 0.014 & 6.43 & \\
\hline L1S25 & $1986-08-05$ & $09: 51$ & 00.09 & 581.410 & 7.016 & 0.013 & 6.52 & \\
\hline L1S25 & $1986-08-12$ & $09: 20$ & 00.10 & 588.389 & 6.979 & 0.014 & 6.62 & \\
\hline L1S25 & $1986-08-19$ & $10: 03$ & 00.10 & 595.419 & 7.030 & 0.014 & 6.72 & \\
\hline L1S25 & $1986-08-26$ & $09: 36$ & 00.10 & 602.400 & 6.981 & 0.014 & 6.82 & \\
\hline L1S25 & $1986-09-04$ & $09: 15$ & 00.12 & 611.385 & 8.985 & 0.013 & 6.94 & \\
\hline L1S25 & $1986-09-09$ & $11: 38$ & 00.08 & 616.485 & 5.100 & 0.016 & 7.02 & \\
\hline L1S25 & $1986-09-16$ & 09:02 & 00.09 & 623.376 & 6.891 & 0.013 & 7.11 & \\
\hline L1S25 & $1986-09-23$ & $09: 08$ & 00.10 & 630.381 & 7.005 & 0.014 & 7.21 & \\
\hline L1S25 & $1986-10-01$ & $09: 58$ & 00.10 & 638.415 & 8.034 & 0.012 & 7.31 & \\
\hline L1S25 & $1986-10-08$ & $09: 24$ & 00.10 & 645.392 & 6.977 & 0.014 & 7.41 & \\
\hline L1S25 & $1986-10-14$ & $10: 09$ & 00.07 & 651.423 & 6.031 & 0.012 & 7.48 & \\
\hline L1S25 & $1986-11-05$ & $09: 32$ & 0.27 & 673.397 & 21.974 & 0.012 & 7.75 & \\
\hline L1S25 & $1986-11-20$ & $10: 13$ & 00.18 & 688.426 & 15.029 & 0.012 & 7.93 & \\
\hline L1S25 & $1986-12-31$ & $10: 42$ & 00.41 & 729.446 & 41.020 & 0.010 & 8.34 & Collection device removed. \\
\hline L1S25 & $1987-03-06$ & $12: 20$ & 0.61 & 794.514 & 65.068 & 0.009 & 8.95 & \\
\hline L1S25 & $1987-03-31$ & $10: 25$ & 0.00 & 819.434 & 24.920 & 0.000 & 8.95 & Dry. \\
\hline L1S25 & $1987-05-07$ & $08: 35$ & 0.33 & 856.358 & 61.844 & 0.005 & 9.28 & \\
\hline L1S25 & $1987-06-18$ & $12: 25$ & 0.42 & 898.517 & 42.159 & 0.010 & 9.70 & \\
\hline L1S25 & $1987-07-28$ & $13: 09$ & 0.44 & 938.548 & 40.031 & 0.011 & 10.14 & \\
\hline L1S25 & $1987-09-01$ & $12: 52$ & 0.34 & 973.536 & 34.988 & 0.010 & 10.48 & \\
\hline L1S25 & $1987-10-20$ & $12: 20$ & 0.38 & 1022.510 & 48.974 & 0.008 & 10.86 & \\
\hline L1S25 & $1987-11-19$ & $12: 20$ & 0.19 & 1052.510 & 30.000 & 0.006 & 11.05 & \\
\hline L.1S25 & $1988-01-04$ & $12: 33$ & 0.14 & 1098.520 & 46.010 & 0.003 & 11.19 & \\
\hline L1S25 & $1988-02-08$ & $13: 46$ & 0.13 & 1133.570 & 35.050 & 0.004 & 11.32 & \\
\hline L1S25 & $1988-03-30$ & $12: 20$ & 0.28 & 1184.510 & 50.940 & 0.005 & 11.60 & \\
\hline L1S25 & $1988-07-12$ & $11: 50$ & 0.31 & 1288.490 & 103.980 & 0.003 & 11.91 & \\
\hline L1S25 & $1988-09-27$ & $08: 50$ & 0.40 & 1365.370 & 76.880 & 0.005 & 12.31 & \\
\hline L1S25 & $1988-12-13$ & $11: 30$ & 0.55 & 1442.480 & 77.110 & 0.007 & 12.86 & \\
\hline L1S25 & 1989-03-15 & $11: 02$ & 0.21 & 1534.460 & 91.981 & 0.002 & 13.07 & \\
\hline L1S25 & $1989-04-06$ & $10: 30$ & 0.10 & 1556.440 & 21.978 & 0.005 & 13.17 & \\
\hline L1S25 & $1989-04-20$ & $12: 05$ & 0.08 & 1570.500 & 14.065 & 0.006 & 13.25 & \\
\hline L1S25 & $1989-05-17$ & NA & NA & 1597.000 & 0.000 & 0.000 & 13.25 & Not sampled, equipment in the way. \\
\hline L1S25 & $1989-06-06$ & $10: 35$ & 0.15 & 1617.440 & 46.938 & 0.003 & 13.40 & Last time sampled for BSEP. \\
\hline \multicolumn{9}{|c|}{ (n) } \\
\hline L1S26 & $1984-04-21$ & & & 0.000 & 0.000 & 0.000 & 0.00 & Room L1 excavated $4 / 19 / 84$ to $4 / 21 /$ \\
\hline L1S26 & $1985-06-28$ & & & 0.000 & 0.000 & 0.000 & 0.00 & Downhole drilled. \\
\hline L1S26 & $1985-08-20$ & & & 0.000 & 0.000 & 0.000 & 0.00 & Dry. \\
\hline L1S26 & $1985-09-17$ & & & 0.000 & 0.000 & 0.000 & 0.00 & Dry. \\
\hline L1S26 & $1985-12-10$ & & & 0.000 & 0.000 & 0.000 & 0.00 & Dry. \\
\hline L1S26 & $1985-12-17$ & & & 0.000 & 0.000 & 0.000 & 0.00 & Dry. \\
\hline L1S26 & $1986-04-02$ & $08: 20$ & 00.09 & 456.347 & 1.000 & 0.000 & 0.09 & First time collected. \\
\hline L1S26 & $1986-04-24$ & $08: 55$ & 00.05 & 478.372 & 22.025 & 0.002 & 0.14 & \\
\hline L1S26 & $1986-05-20$ & $09: 20$ & 00.05 & 504.389 & 26.017 & 0.002 & 0.19 & \\
\hline L1S26 & $1986-06-10$ & $09: 24$ & 00.05 & 525.392 & 21.003 & 0.002 & 0.24 & \\
\hline L1S26 & $1986-06-24$ & $09: 20$ & 00.05 & 539.389 & 13.997 & 0.004 & 0.29 & \\
\hline L1S26 & $1986-07-08$ & $09: 17$ & 00.04 & 553.387 & 13.998 & 0.003 & 0.33 & \\
\hline L1S26 & $1986-07-16$ & $09: 05$ & 00.02 & 561.378 & 7.991 & 0.003 & 0.35 & \\
\hline L1S26 & $1986-07-29$ & $09: 15$ & 00.04 & 574.385 & 13.007 & 0.003 & 0.39 & \\
\hline L1S26 & $1986-08-12$ & $09: 06$ & 00.04 & 588.379 & 13.994 & 0.003 & 0.43 & \\
\hline L1S26 & $1986-08-26$ & $09: 25$ & 00.04 & 602.392 & 14.013 & 0.003 & 0.47 & \\
\hline L1S26 & $1986-09-09$ & $11: 27$ & 00.05 & 616.477 & 14.085 & 0.004 & 0.52 & \\
\hline L1S26 & $1986-09-23$ & $08: 55$ & 00.03 & 630.372 & 13.895 & 0.002 & 0.55 & \\
\hline L1S26 & $1986-10-01$ & $09: 48$ & 00.03 & 638.408 & 8.036 & 0.004 & 0.58 & \\
\hline L1S26 & $1986-11-05$ & $09: 04$ & 0.03 & 673.378 & 34.970 & 0.001 & 0.61 & \\
\hline L1S26 & $1986-11-20$ & $09: 59$ & 00.03 & 688.416 & 15.038 & 0.002 & 0.64 & \\
\hline L1S26 & $1986-12-31$ & $10: 42$ & NA & 729.446 & 41.030 & 0.000 & 0.64 & Dry \\
\hline L1S26 & $1987-03-06$ & $12: 25$ & 0.05 & 794.517 & 106.101 & 0.000 & 0.69 & \\
\hline
\end{tabular}


BRINE ACCUMULATION DATA TABLE (Continued)

Data through December 31, 1990

\begin{tabular}{|c|c|c|c|c|c|c|c|c|}
\hline Location & Date & Time & $\begin{array}{l}\text { Liters } \\
\text { removed } \\
\end{array}$ & $\begin{array}{c}\text { Days } \\
\text { since } \\
1 / 1 / 85 \\
\end{array}$ & $\begin{array}{c}\text { Davs } \\
\text { used for } \\
\text { calc. }\end{array}$ & $\begin{array}{l}\text { Liters } \\
\text { per } \\
\text { day }\end{array}$ & $\begin{array}{c}\text { Cumulative } \\
\text { liters } \\
\text { collected }\end{array}$ & Remarks \\
\hline L1S26 & 1987-03-3! & $10: 28$ & 0.00 & $815 .+36$ & 24.019 & 0.000 & 0.69 & Dry. \\
\hline L1S26 & $1987-05-07$ & $08: 37$ & ก 22 & 856.359 & 61.842 & 0.000 & 0.71 & \\
\hline L1S26 & $1987-06-18$ & $12: 27$ & 0.47 & 898.519 & 42.160 & 0.002 & 0.78 & \\
\hline L1S26 & $1987-07-38$ & $13: 13$ & 0.10 & 938.551 & 40.032 & 0.002 & 0.88 & \\
\hline L1S26 & $1987-09-01$ & $12: 55$ & 0.07 & 973.538 & 34.987 & 0.002 & 0.95 & \\
\hline L1S26 & $1987-10-20$ & $12: 24$ & 0.03 & 1022.520 & 48.982 & 0.001 & 0.98 & \\
\hline L1S26 & $1987-11-19$ & $12: 21$ & 0.07 & 1052.510 & 29.990 & 0.002 & 1.05 & \\
\hline L1S26 & $1988-01-04$ & $12: 38$ & 0.03 & 1098.530 & 46.020 & 0.001 & 1.08 & \\
\hline L1S26 & $1988-02-08$ & $13: 47$ & 0.04 & 1133.570 & 35.040 & 0.001 & 1.12 & \\
\hline L1S26 & $1988-03-30$ & $12: 20$ & Trace & 1184.510 & 50.940 & 0.000 & 1.12 & \\
\hline L1S26 & $1988-07-12$ & $11: 50$ & 0.11 & 1288.480 & 103.8810 & 0.001 & 1.23 & \\
\hline L1S26 & $1988-09-27$ & $08: 52$ & 0.15 & 1365.370 & 76.880 & 0.002 & 1.38 & \\
\hline L1S26 & $1988-12-13$ & $11: 30$ & 0.13 & 1442.480 & 77.110 & 0.002 & 1.51 & \\
\hline L1S26 & $1989-03-15$ & $11: 04$ & 0 & 1534.460 & 91.982 & 0.000 & 151 & Hole dry. \\
\hline L1S26 & $1989-04-06$ & $10: 32$ & 0 & 1556.440 & 21.978 & 0.000 & 1.51 & Hole dry. \\
\hline L1S26 & $1989-04-20$ & $12: 10$ & 0 & 1570.510 & 14.068 & 0.000 & 1.51 & Hole ony. \\
\hline L1S26 & $1989-05-17$ & NA & NA & 1597.000 & 0.000 & 0.000 & 1.51 & Not sampled, equipmunt in the way. \\
\hline Lis26 & $1989-06-06$ & $10: 40$ & 0 & 1617.440 & 46.837 & 0.000 & 1.51 & Hole ory. Last time sampled ior BSEP. \\
\hline \multirow{2}{*}{\multicolumn{6}{|c|}{ 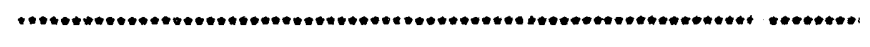 }} & \multirow{2}{*}{\multicolumn{3}{|c|}{ 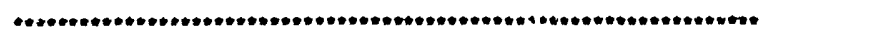 }} \\
\hline & & & & & & & & \\
\hline $\begin{array}{l}\text { L1S27 } \\
\text { L1S27 }\end{array}$ & & & & 0.000 & 0.000 & $0.00(1$ & 0.00 & Room L1 excavated $4 / 19 / 84$ to $4 / 21 / 84$. \\
\hline L1S27 & $\begin{array}{l}1985-07-01 \\
1985-08-20\end{array}$ & & & 0.000 & 0.000 & 0.000 & 0.00 & \\
\hline L1S27 & & & & 0.000 & 0.000 & 0.500 & 0.00 & Wet. \\
\hline L1S27 & $1995-09-17$ & & & 0.000 & 0.000 & $ن .000$ & 0.00 & Wet. \\
\hline L1S27 & $1985-12-10$ & $09: 00$ & 00.83 & 343.375 & 1.000 & 0.000 & 0.83 & First time collected. \\
\hline L1S27 & $1985-12-17$ & & & 0.000 & 0.000 & 0.000 & 0.83 & Wet, partial pool in bottom, none collected. \\
\hline L1S27 & $1936-01-03$ & 09:00 & 00.10 & 367.375 & 24.000 & 0.004 & 0.93 & \\
\hline L1S27 & $1986-01-16$ & $09: 00$ & 00.05 & 380.375 & 13.000 & 0.004 & 0.98 & \\
\hline L1S27 & $1986-02-12$ & $09: 00$ & 00.08 & 407.375 & 27.000 & 0.003 & 1.06 & \\
\hline L1S27 & $1986-02-19$ & $09: 00$ & 00.04 & 414.375 & 7.000 & 0.006 & 1.10 & \\
\hline L1S27 & $1986-02-28$ & $09: 00$ & 00.06 & 423.375 & 9.000 & 0.007 & 1.16 & \\
\hline L1S27 & $1986-03-13$ & 08:35 & 00.08 & 436.358 & 12.983 & 0.006 & 1.24 & Two weeks collection. \\
\hline L1S27 & $1986-03-26$ & $08: 45$ & 00.06 & 449.365 & 13.007 & 0.005 & 1.30 & \\
\hline L1S27 & $1986-04-08$ & $08: 30$ & 00.07 & 462.354 & 12.989 & 0.005 & 1.37 & \\
\hline L1S27 & $1980-2 \div 24$ & $09: 05$ & 00.08 & 478.378 & 16.024 & 0.005 & 1.45 & \\
\hline L1S27 & $1986-05-06$ & $08: 55$ & 00.05 & 490.372 & 11.994 & 0.004 & 1.50 & \\
\hline L1S27 & $1986-05-13$ & $08: 50$ & 00.04 & 497.368 & 6.996 & 0.006 & 1.54 & \\
\hline L1S27 & $1986-05-27$ & $14: 20$ & 00.07 & 511597 & 14.229 & 0.005 & 1.61 & \\
\hline L1S27 & $1986-06-10$ & $09: 25$ & 00.06 & 525.392 & 13.79.5 & 0.004 & 1.67 & \\
\hline L.S27 & $1986-06 \cdot 17$ & $09: 15$ & 00.04 & 532.385 & $6 \% 33$ & 0.006 & 1.71 & \\
\hline L1S27 & $1986-06-24$ & $09: 22$ & 00.04 & 339.390 & 7.005 & 0.006 & 1.75 & \\
\hline LiS27 & $1986-07-01$ & $19: 56$ & 00.04 & 546.497 & 7.107 & 0.006 & 1.79 & \\
\hline L1S27 & $1986-07-08$ & $09: 18$ & 00.04 & 553.388 & 6.891 & 0.006 & 1.83 & \\
\hline L1S27 & $1986-07-16$ & $09: 09$ & 00.04 & 561.381 & 7.993 & 0.005 & 1.87 & \\
\hline L1S27 & $1986-07-29$ & $09: 17$ & 00.07 & 574.387 & 13.006 & 0.005 & 1.94 & \\
\hline L1S27 & $1986-08-12$ & 09:08 & 00.06 & 588.381 & 13.994 & 0.004 & 2.00 & \\
\hline L1S27 & $1986-08-19$ & $09: 52$ & 00.05 & 595.411 & 7.030 & 0.007 & 2.05 & \\
\hline L1S27 & $1986-08-26$ & $09: 26$ & 00.04 & 602.393 & 6.982 & 0.006 & 2.09 & \\
\hline L1S27 & $1986-09-04$ & $08: 57$ & 00.05 & 611.373 & 8.980 & 0.006 & 2.14 & \\
\hline L1S27 & $1986-09-09$ & $11: 28$ & 00.04 & 616.478 & $j .105$ & 0.008 & 2.18 & \\
\hline L1S27 & $1986-09-16$ & $08: 53$ & 00.04 & 623.370 & 6.892 & 0.006 & 2.22 & \\
\hline L1S27 & $1986-09-23$ & $08: 56$ & 00.03 & 630.372 & 7002 & 0.004 & 2.25 & \\
\hline L1S27 & $1986-10-0 y$ & $09: 49$ & 00.03 & 638.409 & 8.037 & 0.004 & 2.28 & \\
\hline L1S27 & $86-11-05$ & 09:06 & 0.06 & 673.379 & 34.970 & 0.002 & 2.34 & \\
\hline L1S27 & $: 3416-11-20$ & $10: 02$ & 00.04 & 688.418 & 15.039 & 0.003 & 2.38 & \\
\hline L1S27 & $1986-12-31$ & $10: 42$ & 00.00 & 729.446 & 41.028 & 0.000 & 2.38 & Wet, but not enough to remove. \\
\hline L_1S27 & $1987-0 s-06$ & $12: 30$ & 0.13 & 794.521 & 65.075 & 0.002 & 2.51 & \\
\hline L1S27 & $1987-03-31$ & $10: 28$ & 0.00 & 819.436 & 24.915 & 0.000 & 2.51 & Dry. \\
\hline L1S27 & $1987-05-07$ & $08: 3 ?$ & 0.07 & 856.360 & 61.839 & 0.001 & 2.58 & \\
\hline L1S27 & $1987-06-1 \varepsilon$ & $12: 30$ & 0.11 & 898.521 & 42.161 & 0.003 & 2.69 & \\
\hline
\end{tabular}


BRINE ACC:UMULATION DATA TABLE (Continlied)

Data through December 31, 1990

\begin{tabular}{|c|c|c|c|c|c|c|c|c|}
\hline Location & Date & Time & $\begin{array}{l}\text { Liters } \\
\text { removed } \\
\end{array}$ & $\begin{array}{c}\text { Days } \\
\text { since } \\
1 / 1 / 85 \\
\end{array}$ & $\begin{array}{l}\text { Days } \\
\text { used for } \\
\text { calc. }\end{array}$ & $\begin{array}{l}\text { Liters } \\
\text { per } \\
\text { day }\end{array}$ & $\begin{array}{c}\text { Cumulative } \\
\text { liters } \\
\text { collected } \\
\end{array}$ & Remarks \\
\hline $\begin{array}{l}\text { L1S27 } \\
\text { L1S27 }\end{array}$ & $\begin{array}{l}1987-07-28 \\
1987-09-01\end{array}$ & $\begin{array}{l}13: 14 \\
12: 55\end{array}$ & $\begin{array}{l}0.18 \\
0.14\end{array}$ & $\begin{array}{l}938.551 \\
973.538\end{array}$ & $\begin{array}{l}40.030 \\
34.087\end{array}$ & $\begin{array}{l}0.004 \\
0.004\end{array}$ & $\begin{array}{l}2.87 \\
3.01\end{array}$ & \\
\hline $\begin{array}{l}\text { L1S27 } \\
\text { L1S27 }\end{array}$ & $\begin{array}{l}1987-10-20 \\
1987-11-19\end{array}$ & $\begin{array}{l}12: 25 \\
12: 25\end{array}$ & $\begin{array}{l}0.00 \\
0.11\end{array}$ & $\begin{array}{l}1022.520 \\
1052.520\end{array}$ & $\begin{array}{l}48.882 \\
30.000\end{array}$ & $\begin{array}{l}0.002 \\
0.004\end{array}$ & $\begin{array}{l}3.10 \\
3.21\end{array}$ & \\
\hline $\begin{array}{l}\text { L1S27 } \\
\text { L1S27 }\end{array}$ & $\begin{array}{l}1988-01-04 \\
1988-02-08\end{array}$ & $\begin{array}{l}12: 40 \\
13: 48\end{array}$ & $\begin{array}{l}0.00 \\
0.00\end{array}$ & $\begin{array}{l}1098.530 \\
1133.580\end{array}$ & $\begin{array}{l}46.010 \\
35.050\end{array}$ & $\begin{array}{l}0.000 \\
0.000\end{array}$ & $\begin{array}{l}3.21 \\
3.21\end{array}$ & $\begin{array}{l}\text { Dry. } \\
\text { Dry. }\end{array}$ \\
\hline L1S27 & $1988-03-30$ & $12: 20$ & 0.07 & 1184.510 & 50.230 & 0.001 & 3.28 & \\
\hline L1S27 & $1988-07-12$ & $11: 50$ & 0.24 & 1288.490 & 103.080 & 0.002 & 3.52 & \\
\hline L1S27 & $1888-09-27$ & $0 t \cdot 54$ & 0.53 & 1365.370 & 76.880 & 0.007 & 4.05 & \\
\hline L1S27 & $1988-12-13$ & $11: 30$ & 0.18 & 1412.480 & 77.110 & 0.002 & 4.23 & \\
\hline L1S27 & 1989-03-15 & $11: 06$ & 0.04 & 1534.460 & 91.883 & 0.000 & 4.27 & \\
\hline L1S27 & $1989-04-06$ & $10: 32$ & 0 & 1556.440 & 21.977 & 0.000 & 4.27 & Hole dry. \\
\hline L1S27 & $1989-04-20$ & $12: 10$ & 0 & 1570.510 & 14.068 & 0.000 & 4.27 & Hole ory. \\
\hline L1S27 & $1989-05-17$ & NA & NA & 1597.000 & 0.000 & 0.000 & 4.27 & Not sampled, equipment in the way. \\
\hline Lis27 & $1989-06-06$ & $\begin{array}{l}10: 45 \\
0.0\end{array}$ & 0 & $\begin{array}{l}1617.450 \\
\ldots .0 .0 .\end{array}$ & 46.841 & 0.000 & $\begin{array}{l}4.27 \\
.27+\cdots\end{array}$ & Hole dry. Last time sampled for BSEP. \\
\hline \multicolumn{9}{|r|}{ 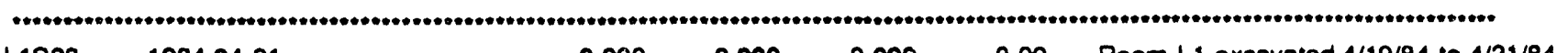 } \\
\hline $\begin{array}{l}\text { L1S28 } \\
\text { L1S28 }\end{array}$ & $\begin{array}{l}1984-04-21 \\
1985-07-12\end{array}$ & & & $\begin{array}{l}0.000 \\
0.000\end{array}$ & $\begin{array}{l}0.000 \\
0.000\end{array}$ & $\begin{array}{l}0.000 \\
0.000\end{array}$ & $\begin{array}{l}0.00 \\
0.00\end{array}$ & $\begin{array}{l}\text { Room L1 excavated 4/19/84 to 4/21/84. } \\
\text { Downhole drilled. }\end{array}$ \\
\hline L1S28 & $1985-08-20$ & & & 0.000 & 0.000 & 0.000 & $\begin{array}{l}0.00 \\
0.00\end{array}$ & Dry. \\
\hline L1S28 & $1985-09-17$ & & & 0.000 & 0.000 & 0.000 & 0.00 & Dry. \\
\hline L1S28 & $1985-12-10$ & & & 0.000 & 0.000 & 0.000 & 0.00 & Dry. \\
\hline L1S28 & $1985-12-17$ & & & 0.000 & 0.000 & 0.000 & 0.00 & Dry. \\
\hline L1S28 & $1986-11-05$ & 09:08 & 0.11 & 673.381 & $i .000$ & 0.000 & 0.11 & First time collected. \\
\hline L1S28 & $1986-11-20$ & NA & NA & 688.000 & 14.619 & 0.000 & 0.11 & Dry. \\
\hline L1S28 & $1986-12-31$ & $10: 42$ & NA & 729.446 & 41.011 & 0.000 & 0.11 & Dry. \\
\hline L1S28 & $1987-03-06$ & $12: 30$ & NA & 794.521 & 121.140 & 0.000 & 0.11 & Dry. \\
\hline L1S28 & $1987-03-31$ & $10: 31$ & 0.00 & 819.438 & 24.917 & 0.000 & 0.11 & Dry. \\
\hline L1S28 & $1987-05-07$ & $08: 39$ & 0.00 & 856.360 & 61.839 & 0.000 & 0.11 & Dry. \\
\hline L1S28 & $1987-06-18$ & $12: 35$ & 0.00 & 898.524 & 104.003 & 0.000 & 0.11 & Dry. \\
\hline L1S28 & $1987-07-28$ & $13: 24$ & 0.09 & 938.558 & 144.037 & 0.001 & 0.20 & \\
\hline L1S28 & $1987-09-01$ & $12: 55$ & 0.01 & 973.538 & 34.880 & 0.000 & 0.21 & \\
\hline L1S28 & $1987-10-20$ & 12.26 & 0.02 & 1022.520 & 48.982 & 0.000 & 0.23 & \\
\hline L1S28 & $1987-11-19$ & $12: 30$ & 0.00 & 1052.520 & 30.000 & 0.000 & 0.23 & Dry. \\
\hline L1S28 & $1988-01-04$ & $12: 42$ & 0.01 & 1098.530 & 46.010 & 0.000 & 0.24 & \\
\hline L1S28 & $1988-02-08$ & \multicolumn{2}{|c|}{ 13:49 Trace } & 1133.580 & 35.050 & 0.000 & 0.24 & \\
\hline L1S28 & 1988-03-30 & $12: 20$ & 0.00 & 1184.510 & 50.830 & 0.000 & 0.24 & Dry. \\
\hline L1S28 & $1988-07-12$ & $11: 55$ & 0.50 & 1288.500 & 103.990 & 0.005 & 0.74 & \\
\hline L1S28 & $1988-09-27$ & $08: 56$ & 0.40 & 1365.370 & 76.870 & 0.005 & 1.14 & \\
\hline L1S28 & $1988-12-13$ & $11: 30$ & 0.37 & 1442.480 & 77.110 & 0.005 & 1.51 & \\
\hline L1S28 & $1989-03-15$ & $11: 08$ & 0.48 & 1534.460 & 91.885 & 0.005 & 1.99 & \\
\hline L1S28 & $1989-04-06$ & $10: 40$ & 0.06 & 1556.440 & 21.080 & 0.003 & 2.05 & \\
\hline L1S28 & $1989-04-20$ & $12: 10$ & 0.17 & 1570.510 & 14.063 & 0.012 & 2.22 & \\
\hline L1S28 & $1989-05-17$ & NA & NA & 1597.000 & 0.000 & 0.000 & 2.22 & Not sampled; equipment in the way. \\
\hline L1S28 & $1989-06-06$ & $10: 50$ & 0.28 & 1617.450 & 46.844 & 0.006 & 2.50 & Last time sampled for BSEP. \\
\hline \multicolumn{9}{|c|}{ " } \\
\hline L1S29 & $1984-04-21$ & & & 0.000 & 0.000 & 0.000 & 0.00 & Room $L 1$ excavated $4 / 19 / 84$ to $4 / 21 / 84$. \\
\hline L1S29 & $1985-07-15$ & & & 0.000 & 0.000 & 0.000 & 0.00 & Downhole driled. \\
\hline L1S29 & $1985-08-20$ & & & 0.000 & 0.000 & 0.000 & 0.00 & Wet. \\
\hline L1S29 & $1985-09-17$ & & & 0.000 & 0.000 & 0.000 & 0.00 & Wet. \\
\hline L1S29 & $1985-12-10$ & $09: 00$ & 02.20 & 343.375 & 1.000 & 0.000 & 2.20 & First time collected. \\
\hline L1S29 & $1985-12-17$ & $09: 00$ & 00.30 & 350.375 & 7.000 & 0.043 & 2.50 & \\
\hline L1S29 & $1986-01-03$ & $09: 00$ & 00.71 & 367.375 & 17.000 & 0.042 & 3.21 & \\
\hline L1S29 & $1986-01-08$ & $09: 00$ & 00.24 & 372.375 & 5.000 & 0.048 & 3.45 & \\
\hline L1S29 & $1986-01-16$ & $09: 00$ & 00.40 & 380.375 & 8.000 & 0.050 & 3.85 & \\
\hline L1S29 & $1986-01-23$ & $09: 00$ & 00.32 & 387.375 & 7.000 & 0.046 & 4.17 & \\
\hline L1S29 & $1986-01-31$ & 09:00 & 00.34 & 395.375 & 8.000 & 0.043 & 4.51 & \\
\hline L1S29 & $1986-02-12$ & 09:00 & 00.41 & 407.375 & 12.000 & 0.034 & 4.92 & \\
\hline L1S29 & $1986-02-19$ & 09:00 & 00.25 & 414.375 & 7.000 & 0.036 & 5.17 & \\
\hline
\end{tabular}


BRINE ACCUMULATION DATA TABLE (Continued)

Data through December 31, 1990

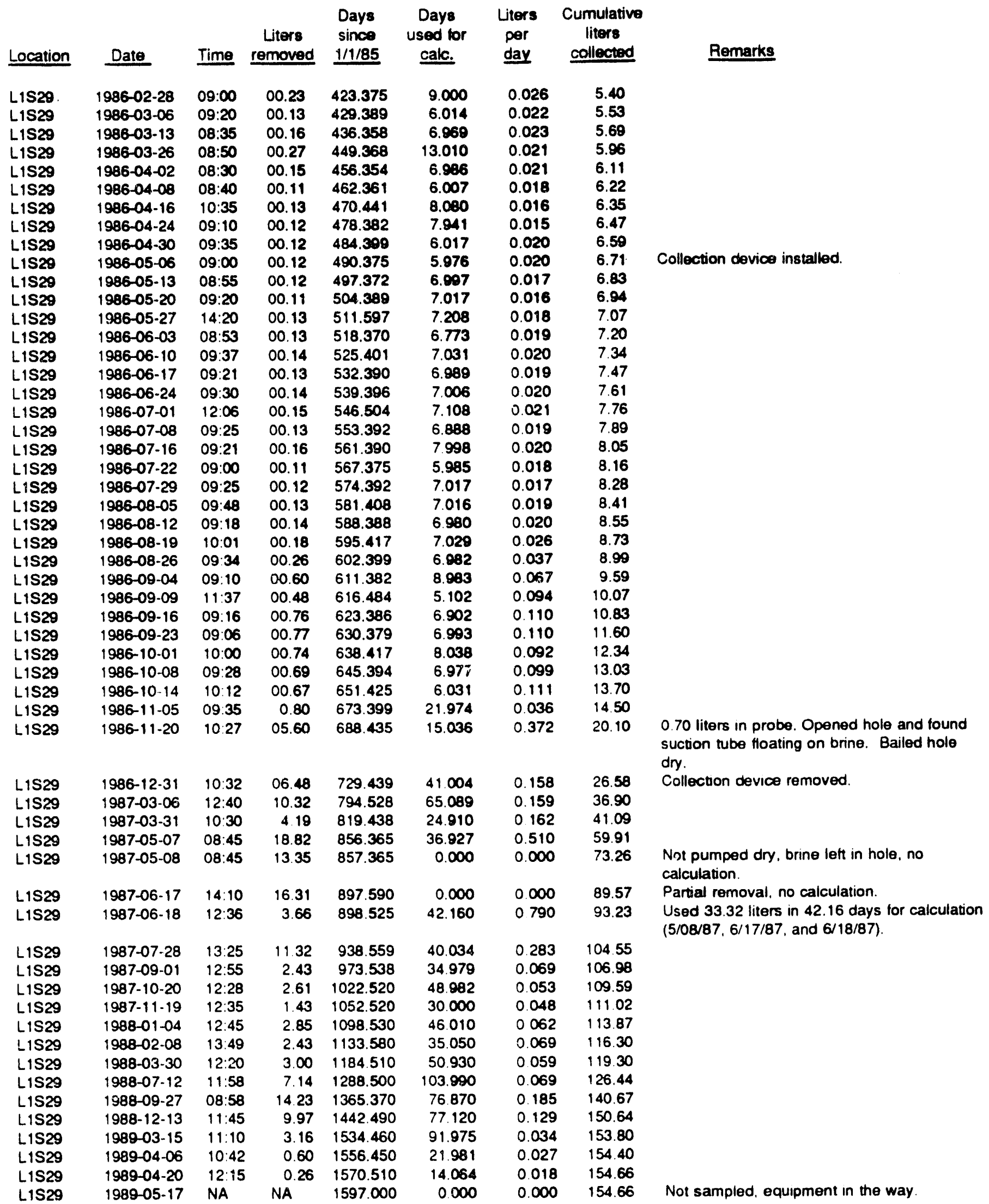


BRINE ACCUMULATION DATA TABLE (Continued)

Data through December 31, 1990

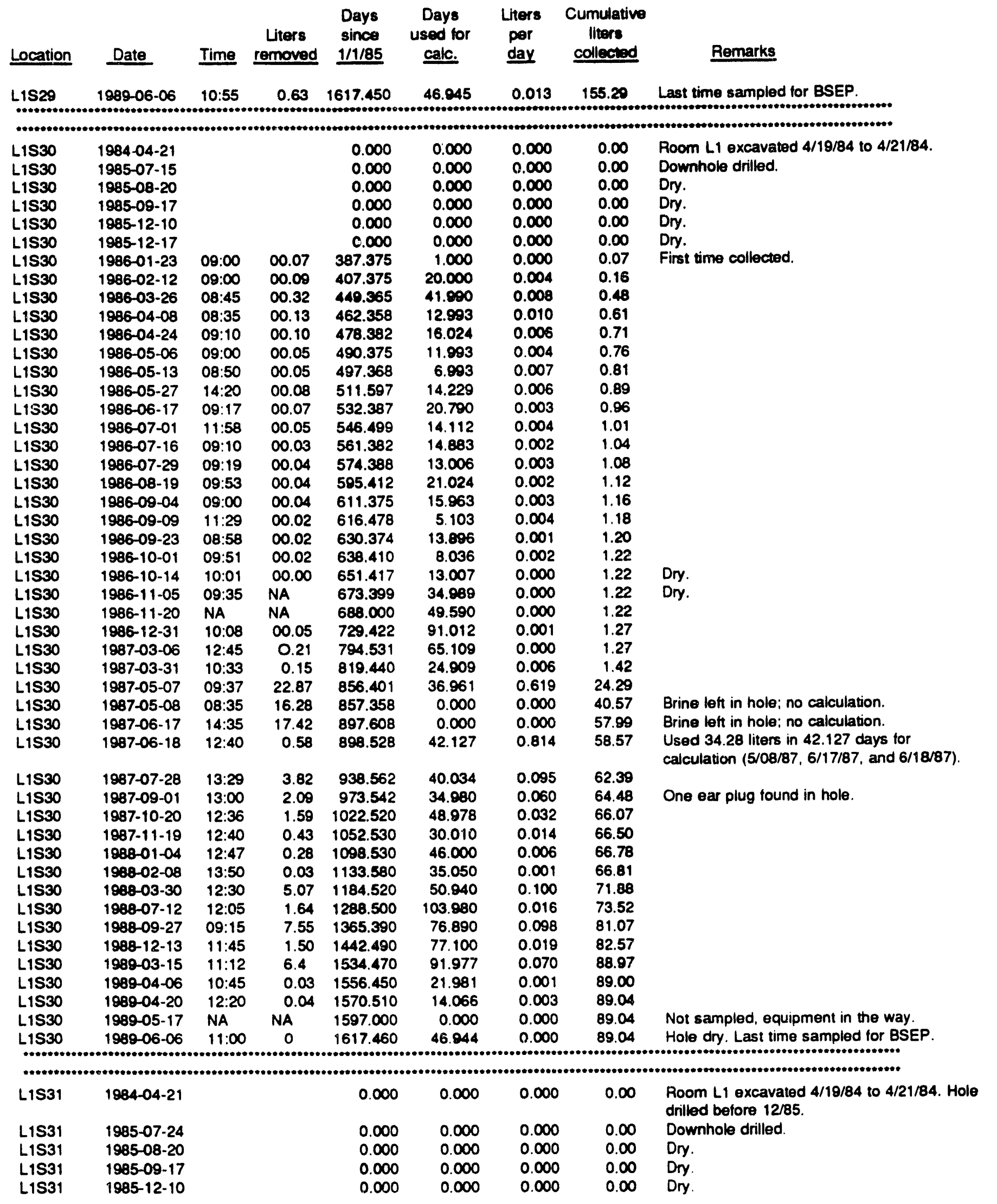


BRINE ACCUMULATION DATA TABLE (Continued)

Data through December 31, 1990

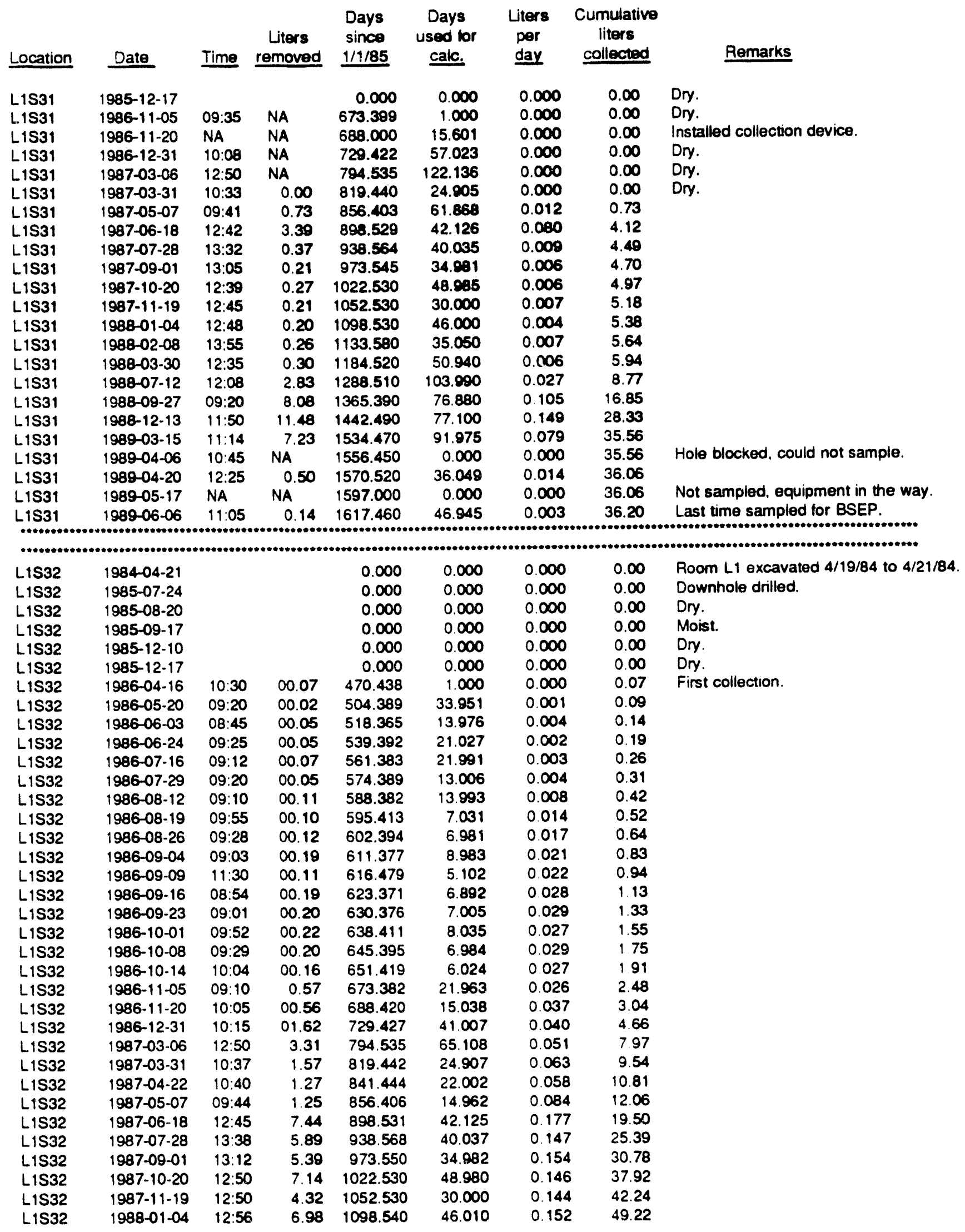


BRINE ACCUMULATION DATA TABLE (Continued)

Data through December 31, 1990

\begin{tabular}{|c|c|c|c|c|c|c|c|c|}
\hline Location & Date & Time & $\begin{array}{l}\text { Liters } \\
\text { removed }\end{array}$ & $\begin{array}{c}\text { Days } \\
\text { since } \\
1 / 1 / 85 \\
\end{array}$ & $\begin{array}{l}\text { Days } \\
\text { used for } \\
\text { calc. }\end{array}$ & $\begin{array}{l}\text { Liters } \\
\text { per } \\
\text { day }\end{array}$ & $\begin{array}{c}\text { Cumulative } \\
\text { liters } \\
\text { collected } \\
\end{array}$ & Remarks \\
\hline L1S32 & $1988-02-08$ & $14: 00$ & 6.11 & 1133.580 & 35.040 & 0.174 & 55.33 & \\
\hline L1S32 & $1988-03-30$ & $12: 40$ & 7.84 & 1184.530 & 50.850 & 0.154 & 63.17 & \\
\hline L1S32 & $1988-07-12$ & $12: 20$ & 12.64 & 1288.510 & 103.980 & 0.122 & 75.81 & \\
\hline L1S32 & $1988-09-27$ & $09: 25$ & 13.03 & 1365.390 & 76.880 & 0.169 & 88.84 & \\
\hline L1S32 & $1988-12-13$ & $11: 50$ & 12.40 & 1442.490 & 77.100 & 0.161 & 101.24 & \\
\hline L1S32 & $1989-03-15$ & $11: 16$ & 10.03 & 1534.470 & 91.076 & 0.109 & 111.27 & \\
\hline L1S32 & $1889-04-06$ & $10: 50$ & 0.18 & 1556.450 & 21.082 & 0.008 & 111.45 & \\
\hline L1S32 & $1989-04-20$ & $12: 30$ & 0.12 & 1570.520 & 14.070 & 0.009 & 111.57 & \\
\hline L1S32 & $1989-05-17$ & NA & NA & 1597.000 & 0.000 & 0.000 & 111.57 & Not sampled, equipment in the way. \\
\hline L1S32 & 1989-06-05 & $11: 10$ & 0.21 & 1617.460 & 46.944 & 0.004 & 111.78 & Last time sampled for BSEP. \\
\hline \multicolumn{9}{|c|}{ 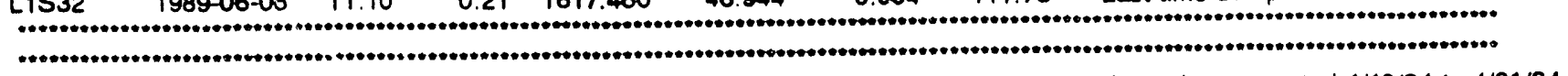 } \\
\hline L1S33 & $1984-04-21$ & & & 0.000 & 0.000 & 0.000 & 0.00 & Room $L 1$ excavated $4 / 19 / 84$ to $4 / 21 / 84$ \\
\hline L1S33 & $1985-07-23$ & & & 0.000 & 0.000 & 0.000 & 0.00 & Downhole drilled. \\
\hline L1S33 & $1985-08-20$ & & & 0.000 & 0.000 & 0.000 & 0.00 & Wet. \\
\hline L1S33 & $1985-09-17$ & & & 0.000 & 0.000 & 0.000 & 0.00 & Wet. \\
\hline L1S33 & $1985-12-10$ & $09: 00$ & 01.01 & 343.375 & 1.000 & 0.000 & 1.01 & First time collected. \\
\hline L1S33 & $1985-12-17$ & 09:00 & 00.11 & 350.375 & 7.000 & 0.016 & 1.12 & \\
\hline L1S33 & $1986-01-03$ & $09: 00$ & 00.21 & 367.375 & 17.000 & 0.012 & 1.33 & \\
\hline L1S33 & $1986-01-08$ & $09: 00$ & 00.06 & 372.375 & 5.000 & 0.012 & 1.39 & \\
\hline L1S33 & $1986-01-16$ & $09: 00$ & 00.09 & 380.375 & 8.000 & 0.011 & 1.48 & \\
\hline L1S33 & $1986-01-23$ & $09: 00$ & 00.08 & 387.375 & 7.000 & 0.011 & 1.56 & \\
\hline L1S33 & $1986-01-31$ & $09: 00$ & 00.09 & 395.375 & 8.000 & 0.011 & 1.65 & \\
\hline L1S33 & $1986-02-12$ & $09: 00$ & 00.15 & 407.375 & 12.000 & 0.012 & 1.80 & \\
\hline L.1S33 & $1986-02-19$ & $09: 00$ & 00.12 & 414.375 & 7.000 & 0.017 & 1.92 & \\
\hline L1S33 & $1986-02-28$ & $09: 00$ & 00.11 & 423.375 & 9.000 & 0.012 & 2.03 & Estimated. lost some during collection. \\
\hline L1S33 & $1986-03-06$ & $09: 20$ & 00.09 & 429.389 & 6.014 & 0.015 & 2.12 & \\
\hline L1S33 & $1986-03-13$ & $08: 40$ & 00.10 & 436.361 & 6.972 & 0.014 & 2.22 & \\
\hline L1S33 & $1986-03-26$ & $08: 50$ & 00.20 & 449.368 & 13.007 & 0.015 & 2.42 & \\
\hline L1S33 & $1986-04-02$ & $08: 30$ & 00.10 & 456.354 & 6.886 & 0.014 & 2.52 & \\
\hline L1S33 & $1986-04-08$ & 08:38 & 00.08 & 462.360 & 6.006 & 0.013 & 2.60 & \\
\hline L.1S33 & $1986-04-16$ & $10: 30$ & 00.11 & 470.438 & 8.078 & 0.014 & 2.71 & \\
\hline L1S33 & $1986-04-24$ & $09: 10$ & 00.12 & 478.382 & 7.944 & 0.015 & 2.83 & \\
\hline L1S33 & $1986-04-30$ & $09: 30$ & 00.10 & 484.396 & 6.014 & 0.017 & 2.93 & \\
\hline L1S33 & $1986-05-06$ & $09: 00$ & 00.09 & 490.375 & 5.979 & 0.015 & 3.02 & \\
\hline L1S33 & $1986-05-13$ & $08: 55$ & 00.11 & 497.372 & 6.997 & 0.016 & 3.13 & \\
\hline L1S33 & $1986-05-20$ & $09: 20$ & 00.12 & 504.389 & 7.017 & 0.017 & 3.25 & \\
\hline L1S33 & $1986-05-27$ & $14: 20$ & 00.12 & 511.597 & 7.208 & 0.017 & 3.37 & \\
\hline L1S33 & $1986-06-03$ & $08: 50$ & 00.12 & 518.368 & 6.771 & 0.018 & 3.49 & \\
\hline L1S33 & $1986-06-10$ & $09: 28$ & 00.12 & 525.394 & 7.026 & 0.017 & 3.61 & \\
\hline L1S33 & $1986-06-17$ & $09: 19$ & 00.12 & 532.388 & 6.994 & 0.017 & 3.73 & \\
\hline L1S33 & $1986-06-24$ & $09: 25$ & 00.13 & 539.392 & 7.004 & 0.019 & 3.86 & \\
\hline L1S33 & $1986-07-01$ & $12: 00$ & $\infty .11$ & 546.500 & 7.108 & 0.015 & 3.97 & \\
\hline L1S33 & $1986-07-08$ & $09: 20$ & 00.10 & 553.389 & 6.889 & 0.015 & 4.07 & \\
\hline L1S33 & $1986-07-16$ & $09: 14$ & 00.13 & 561.385 & 7.996 & 0.016 & 4.20 & \\
\hline L1S33 & $1986-07-22$ & $08: 52$ & 00.10 & 567.369 & $5.984^{\circ}$ & 0.017 & 4.30 & \\
\hline L1S33 & $1986-07-29$ & $09: 22$ & 00.15 & 574.390 & 7.021 & 0.021 & 4.45 & \\
\hline L1S33 & 1986-08-05 & $09: 43$ & 00.13 & 581.405 & 7.015 & 0.019 & 4.58 & \\
\hline L1S33 & $1986-08-12$ & $09: 13$ & 00.16 & 588.384 & 6.979 & 0.023 & 4.74 & \\
\hline L1S33 & $1986-08-19$ & $09: 56$ & 00.16 & 595.414 & 7.030 & 0.023 & 4.90 & \\
\hline Lis33 & $1986-08-26$ & $09: 29$ & 00.18 & 602.395 & 6.881 & 0.026 & 5.08 & \\
\hline Lis33 & $1986-09-04$ & $09: 04$ & 00.22 & 611.378 & 8.983 & 0.024 & 5.30 & \\
\hline L1S33 & $1986-09-09$ & $11: 31$ & 00.14 & 616.480 & 5.102 & 0.027 & 5.44 & \\
\hline L1S33 & $1986-09-16$ & $08: 55$ & 00.16 & 623.372 & 6.892 & 0.023 & 5.60 & \\
\hline L1S33 & $1986-09-23$ & $09: 02$ & 00.17 & 630.376 & 7.004 & 0.024 & 5.77 & \\
\hline L1S33 & $1986-10-01$ & $09: 54$ & 00.20 & 638.413 & 8.037 & 0.025 & 5.97 & \\
\hline LiS33 & $1986-10-08$ & $09: 29$ & 00.18 & 645.395 & 6.982 & 0.026 & 6.15 & \\
\hline L1S33 & $1986-10-14$ & $10: 06$ & 00.17 & 651.421 & 6.026 & 0.028 & 6.32 & \\
\hline L1S33 & $1986-11-05$ & $09: 15$ & 0.45 & 673.385 & 21.964 & 0.020 & 6.77 & \\
\hline L1S33 & $1986-11-20$ & $10: 07$ & 00.35 & 688.422 & 15.037 & 0.023 & 7.12 & \\
\hline
\end{tabular}


BRINE ACCUMULATION DATA TABLE (Continued)

Data through December 31, 1990

\begin{tabular}{|c|c|c|c|c|c|c|c|c|}
\hline Location & Date & Time & $\begin{array}{l}\text { Liters } \\
\text { removed }\end{array}$ & $\begin{array}{c}\text { Days } \\
\text { sinco } \\
1 / 1 / 85 \\
\end{array}$ & $\begin{array}{l}\text { Days } \\
\text { used for } \\
\text { calc. }\end{array}$ & $\begin{array}{c}\text { Liters } \\
\text { per } \\
\text { day }\end{array}$ & $\begin{array}{c}\text { Cumulative } \\
\text { liters } \\
\text { collected }\end{array}$ & Remarks \\
\hline L1S33 & $1986-12-31$ & $10: 17$ & 00.69 & 729.428 & 41.006 & 0.017 & 7.81 & \\
\hline L1S33 & $1987-03-06$ & $12: 55$ & 0.68 & 794.538 & 65.110 & 0.010 & $\begin{array}{l}8.49 \\
9.30\end{array}$ & \\
\hline $\begin{array}{l}\text { L1S33 } \\
\text { L1S33 }\end{array}$ & $\begin{array}{l}1987-03-31 \\
1987-05-07\end{array}$ & $\begin{array}{l}10: 40 \\
09: 46\end{array}$ & 0.81 & 819.444 & 24.006 & 0.033 & $\begin{array}{r}9.30 \\
10.80\end{array}$ & \\
\hline $\begin{array}{l}\text { L1S33 } \\
\text { L1S33 }\end{array}$ & $\begin{array}{l}1987-05-07 \\
1987-06-18\end{array}$ & $\begin{array}{l}09: 46 \\
12: 50\end{array}$ & $\begin{array}{l}1.50 \\
4.39\end{array}$ & $\begin{array}{l}856.407 \\
898.535\end{array}$ & $\begin{array}{l}36.863 \\
42.128\end{array}$ & $\begin{array}{l}0.041 \\
0.104\end{array}$ & $\begin{array}{l}10.80 \\
15.19\end{array}$ & \\
\hline L.1S33 & $1987-07-28$ & $13: 45$ & 2.10 & 938.573 & 40.038 & 0.052 & 17.29 & \\
\hline L1S33 & $1987-09-01$ & 13:13 & 0.27 & 973.551 & 34.078 & 0.008 & 17.56 & \\
\hline L1S33 & $1987-10-20$ & $12: 52$ & 2.20 & 1022.540 & 48.889 & 0.045 & 19.76 & \\
\hline L1S33 & $1987-11-19$ & $12: 55$ & 1.43 & 1052.540 & 30.000 & 0.048 & 21.19 & \\
\hline L1S33 & $1988-01-04$ & $12: 58$ & 2.82 & 1098.540 & 46.000 & 0.061 & 24.01 & \\
\hline L1S33 & $1988-02-08$ & $14: 10$ & 1.65 & 1133.590 & 35.050 & 0.047 & 25.66 & \\
\hline L1S33 & $1988-03-30$ & $12: 45$ & 1.96 & 1184.530 & 50.040 & 0.038 & 27.62 & \\
\hline L1S33 & $1988-07-12$ & $12: 25$ & 6.11 & 1288.520 & 103.000 & 0.059 & 33.73 & \\
\hline L1S33 & $1988-09-27$ & $09: 40$ & 7.77 & 1365.400 & 76.880 & 0.101 & 41.50 & \\
\hline L1S33 & $1988-12-13$ & $12: 00$ & 8.42 & 1442.500 & 77.100 & 0.109 & 49.92 & \\
\hline L1S33 & $1989-03-15$ & $11: 18$ & 5.58 & 1534.470 & 91.971 & 0.061 & 55.50 & \\
\hline L1S33 & $1989-04-06$ & $10: 55$ & 0.31 & 1556.450 & 21.984 & 0.014 & 55.81 & \\
\hline L1S33 & $1989-04-20$ & $12: 35$ & 0.28 & 1570.520 & 14.060 & 0.020 & 56.09 & \\
\hline L1S33 & $1989-05-17$ & NA & NA & 1597.000 & 0.000 & 0.000 & 56.09 & Not sampled, equipment in the way. \\
\hline L1S33 & $1989-06-06$ & $11: 15$ & 0.40 & 1617.470 & 46.945 & 0.009 & 56.49 & Last time sampled for BSEP. \\
\hline \multicolumn{9}{|r|}{ " } \\
\hline L1S34 & $1984-04-21$ & & & 0.000 & 0.000 & 0.000 & 0.00 & Room L1 excavated $4 / 19 / 84$ to $4 / 21 / 84$. \\
\hline L1S34 & $1985-07-18$ & & & 0.000 & 0.000 & 0.000 & 0.00 & Downhole drilled. \\
\hline L1S34 & $1985-08-20$ & & & 0.000 & 0.000 & 0.000 & 0.00 & Dry. \\
\hline L1S34 & $1985-09-17$ & & & 0.000 & 0.000 & 0.000 & 0.00 & Dry. \\
\hline L1S34 & $1985-12-10$ & & & 0.000 & 0.000 & 0.000 & 0.00 & Dry. \\
\hline L1S34 & $1985-12-17$ & & & 0.000 & 0.000 & 0.000 & 0.00 & Dry. \\
\hline L1S34 & $1986-11-05$ & $09: 15$ & NA & 673.385 & 1.000 & 0.000 & 0.00 & Dry. \\
\hline L1S34 & $1986-11-20$ & NA & NA & 688.000 & 15.615 & 0.000 & 0.00 & \\
\hline L1S34 & $1986-12-31$ & $10: 17$ & NA & 729.428 & 57.043 & 0.000 & 0.00 & Dry. \\
\hline L1S34 & $1987-03-06$ & $13: 00$ & NA & 794.542 & 122.157 & 0.000 & 0.00 & Dry. \\
\hline L1S34 & $1987-03-31$ & $10: 40$ & 0.00 & 819.444 & 24.802 & 0.000 & 0.00 & Dry. \\
\hline L1S34 & $1987-05-07$ & $09: 46$ & 0.00 & 856.407 & 61.865 & 0.000 & 0.00 & Dry. \\
\hline L1S34 & $1987-06-18$ & $12: 51$ & 0.00 & 898.535 & 103.993 & 0.000 & 0.00 & Dry. \\
\hline L1S34 & $1987-07-28$ & $13: 38$ & 0.00 & 938.568 & 144.026 & 0.000 & 0.00 & Dry. \\
\hline L1S34 & $1987-09-01$ & $13: 13$ & 0.00 & 973.551 & 34.823 & 0.000 & 0.00 & Dry. \\
\hline LiS34 & $1987-10-20$ & $12: 53$ & 0.00 & 1022.540 & 48.889 & 0.000 & 0.00 & Dry. \\
\hline L1S34 & $1987-11-19$ & $13: 00$ & 0.00 & 1052.540 & 30.000 & 0.000 & 0.00 & Dry. \\
\hline L1S34 & $1988-01-04$ & $12: 58$ & 0.00 & 1098.540 & 46.000 & 0.000 & 0.00 & Dry. \\
\hline L1S34 & $1988-02-08$ & $14: 15$ & & 1133.590 & 0.000 & 0.000 & 0.00 & Did not sample. \\
\hline L1S34 & $1988-03-30$ & $12: 45$ & 0.00 & 1184.530 & 85.990 & 0.000 & 0.00 & Dry. \\
\hline L1S34 & $1988-07-12$ & $12: 25$ & 0.00 & 1288.520 & 103.890 & 0.000 & 0.00 & Dry. \\
\hline L1S34 & $1988-09-27$ & $09: 40$ & 0.00 & 1365.400 & 76.880 & 0.000 & 0.00 & Dry. \\
\hline L1S34 & $1988-12-13$ & $12: 00$ & 0 & 1442.500 & 77.100 & 0.000 & 0.00 & Dry. \\
\hline L1S34 & $1989-03-15$ & $11: 20$ & 0 & 1534.470 & 91.972 & 0.000 & 0.00 & Hole dry. \\
\hline L1S34 & $1989-04-06$ & $10: 57$ & 0 & 1556.460 & 21.884 & 0.000 & 0.00 & Hole dry. \\
\hline L1S34 & $1989-04-20$ & $12: 40$ & 0 & 1570.530 & 14.072 & 0.000 & 0.00 & Hole dry. \\
\hline L1S34 & $1989-05-17 N A$ & & NA & 1597.000 & 0.000 & 0.000 & 0.00 & Not sampled, equipment in the way. \\
\hline L1S34 & $1989-06-06$ & $11: 20$ & 0 & 1617.470 & 46.944 & 0.000 & 0.00 & Hole dry. Last time sampled for BSEP. \\
\hline & & & & & & & & 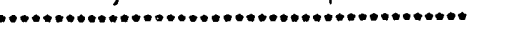 \\
\hline \multicolumn{9}{|c|}{ 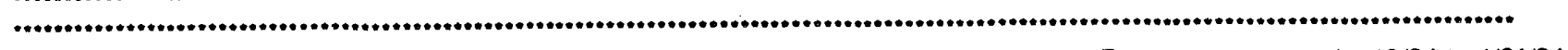 } \\
\hline L1S35 & $1984-04-21$ & & & 0.000 & 0.000 & 0.000 & 0.00 & Room L1 excavated $4 / 19 / 84$ to $4 / 21 / 84$ \\
\hline L1S35 & $1985-07-17$ & & & 0.000 & 0.000 & 0.000 & 0.00 & Downhole drilled. \\
\hline L1S35 & $1985-08-20$ & & & 0.000 & 0.000 & 0.000 & 0.00 & Dry. \\
\hline L1S35 & $1985-09-17$ & & & 0.000 & 0.000 & 0.000 & 0.00 & Dry. \\
\hline L1S35 & $1985-12-10$ & & 0.000 & 0.000 & 0.000 & 0.00 & Dry. & \\
\hline L1S35 & $1985-12-17$ & & & 0.000 & 0.000 & 0.000 & 0.00 & Dry. \\
\hline L1S35 & $1986-11-05$ & $09: 20$ & 0.09 & 673.389 & 1.000 & 0.000 & 0.09 & \\
\hline L1S35 & $1986-11-20$ & NA & NA & 688.000 & 14.611 & 0.000 & 0.09 & \\
\hline
\end{tabular}


BRINE ACCUMULATION DATA TABLE (Continued) Data through December 31, 1990

\begin{tabular}{|c|c|c|c|c|c|c|c|c|}
\hline Location & Date & Time & $\begin{array}{c}\text { Liters } \\
\text { removed }\end{array}$ & $\begin{array}{c}\text { Days } \\
\text { since } \\
1 / 1 / 85 \\
\end{array}$ & $\begin{array}{l}\text { Days } \\
\text { used for } \\
\text { calc. }\end{array}$ & $\begin{array}{l}\text { Liters } \\
\text { per } \\
\text { day }\end{array}$ & $\begin{array}{c}\text { Cumulative } \\
\text { liters } \\
\text { collected }\end{array}$ & Remarks \\
\hline L1S35 & 1986-12-31 & $10: 17$ & NA & 729.428 & 56.039 & 0.000 & 0.09 & Dry. \\
\hline $\begin{array}{l}\text { L1S35 } \\
\text { L1S35 }\end{array}$ & $1987-03-06$ & $13: 00$ & NA & 794.542 & 121.153 & 0.000 & 0.09 & Dry. \\
\hline $\begin{array}{l}\text { L1S35 } \\
\text { L1S35 }\end{array}$ & $1987-03-31$ & $10: 40$ & 0.00 & 819.444 & 24.902 & 0.000 & 0.09 & Dry. \\
\hline $\begin{array}{l}\text { L1S35 } \\
\text { L1S35 }\end{array}$ & $1987-05-07$ & $09: 46$ & 0.00 & 856.407 & 61.865 & 0.000 & 0.09 & Dry. \\
\hline $\begin{array}{l}\text { L1S35 } \\
\text { L1S35 }\end{array}$ & $1987-06-18$ & $12: 52$ & 0.00 & 898.536 & 103.994 & 0.000 & 0.09 & Dry. \\
\hline $\begin{array}{l}\text { L1S35 } \\
\text { L1S35 }\end{array}$ & $1987-07-28$ & 13:38 & 0.00 & 938.568 & 144.026 & 0.000 & 0.09 & Dry. \\
\hline $\begin{array}{l}\text { L1S355 } \\
\text { L1S35 }\end{array}$ & $1987-09-01$ & $13: 13$ & 0.00 & 973.551 & 34.983 & 0.000 & 0.09 & Dry. \\
\hline $\begin{array}{l}\text { L1S35 } \\
\text { L1S35 }\end{array}$ & $1987-10-20$ & $12: 53$ & 0.00 & 1022.540 & 48.989 & 0.000 & 0.09 & Dry. \\
\hline $\begin{array}{l}\text { L1S35 } \\
\text { L1S35 }\end{array}$ & $1987-11-19$ & $13: 05$ & 0.00 & 1052.550 & 30.010 & 0.000 & 0.09 & Dry. \\
\hline $\begin{array}{l}\text { L1S35 } \\
\text { L1S35 }\end{array}$ & $1988-01-04$ & $12: 58$ & 0.00 & 1098.540 & 45.980 & 0.000 & 0.09 & Dry. \\
\hline $\begin{array}{l}\text { L1S35 } \\
\text { L1S35 }\end{array}$ & $1988-02-08$ & $14: 25$ & & 1133.600 & 0.000 & 0.000 & 0.09 & Did not sample. \\
\hline L1S35 & $1988-03-30$ & $12: 45$ & 0.00 & 1184.530 & 85.890 & 0.000 & 0.09 & Dry. \\
\hline LiS35 & $1988-07-12$ & $12: 25$ & 0.00 & 1288.520 & 103.990 & 0.000 & 0.09 & Dry. \\
\hline L1S35 & $1988-09-27$ & $09: 40$ & 0.00 & 1365.400 & 76.880 & 0.000 & 0.09 & Dry. \\
\hline L1S35 & $1988-12-13$ & $12: 30$ & 0 & 1442.520 & 77.120 & 0.000 & 0.09 & Dry. \\
\hline L1S35 & $1989-03-15$ & $11: 22$ & 0 & 1534.470 & 91.953 & 0.000 & 0.09 & Hole dry. \\
\hline L1S35 & $1989-04-06$ & $10: 57$ & 0 & 1556.460 & 21.982 & 0.000 & 0.09 & Hole dry. \\
\hline L1S35 & $1989-04-20$ & $12: 40$ & 0 & 1570.530 & 14.072 & 0.000 & 0.09 & Hole dry. \\
\hline L1S35 & $1989-05-17$ & NA & NA & 1597.000 & 0.000 & 0.000 & 0.09 & Not sampled, equipment in the way. \\
\hline L1S35 & $1989-06-06$ & $11: 25$ & 0 & 1617.480 & 46.948 & 0.000 & 0.09 & Hole dry. Last time sampled for BSEP. \\
\hline & & & & & 年 & & & 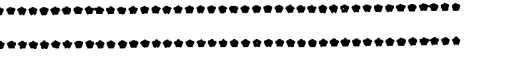 \\
\hline $\begin{array}{l}\text { L1S36 } \\
\text { L1S36 }\end{array}$ & $\begin{array}{l}1984-04-21 \\
1985-07-22\end{array}$ & & & $\begin{array}{l}0.000 \\
0.000\end{array}$ & $\begin{array}{l}0.000 \\
0.000\end{array}$ & $\begin{array}{l}0.000 \\
0.000\end{array}$ & $\begin{array}{l}0.00 \\
0.00\end{array}$ & $\begin{array}{l}\text { Room L1 excavated } 4 / 19 / 84 \text { to } 4 / 21 / 84 \text {. } \\
\text { Downhole drilled. }\end{array}$ \\
\hline L1S36 & $1985-08-2$ & & & 0.000 & 0.000 & 0.000 & 0.00 & Wet. \\
\hline L1S36 & $1985-09-17$ & & & 0.000 & 0.000 & 0.000 & 0.00 & Wet. \\
\hline L1S36 & $1985-12-10$ & $09: 00$ & 01.28 & 343.375 & 1.000 & 0.000 & 1.28 & First time collected. \\
\hline L1S36 & $1985-12-17$ & 09:00 & 00.09 & 350.375 & 7.000 & 0.013 & 1.37 & \\
\hline L1S36 & $1986-01-03$ & $09: 00$ & 00.12 & 367.375 & 17.000 & 0.007 & 1.49 & \\
\hline L1S36 & $1986-01-08$ & 09:00 & 00.05 & 372.375 & 5.000 & 0.010 & 1.54 & \\
\hline L1S36 & $1986-01-16$ & 09:00 & 00.04 & 380.375 & 8.000 & 0.005 & 1.58 & \\
\hline L1S36 & $1986-02-12$ & $09: 00$ & 00.15 & 407.375 & 27.000 & 0.006 & 1.73 & \\
\hline L1S36 & $1986-02-28$ & $09: 00$ & 00.11 & 423.375 & 16.000 & 0.007 & 1.84 & \\
\hline L1S36 & $1986-03-13$ & $08: 40$ & 00.06 & 436.361 & 12.886 & 0.005 & 1.90 & \\
\hline L1S36 & $1986-04-02$ & $08: 35$ & 00.11 & 456.358 & 19.997 & 0.006 & 2.01 & Yellow color. \\
\hline L1S36 & $1986-04-16$ & $10: 30$ & 00.08 & 470.438 & 14.080 & 0.006 & 2.09 & \\
\hline L1S36 & $1986-04-30$ & $09: 30$ & 00.09 & 484.396 & 13.858 & 0.006 & 2.18 & \\
\hline L1S36 & $1986-05-13$ & $08: 58$ & 00.08 & 497.374 & 12.978 & 0.006 & 2.26 & \\
\hline L1S36 & $1986-05-27$ & $14: 20$ & 00.09 & 511.597 & 14.223 & 0.006 & 2.35 & \\
\hline L.1S36 & $1986-06-10$ & $09: 30$ & 00.10 & 525.396 & 13.799 & 0.007 & 2.45 & \\
\hline L1S36 & $1986-06-24$ & $09: 28$ & $\infty .10$ & 539.394 & 13.998 & 0.007 & 2.55 & \\
\hline L1S36 & $1986-07-01$ & $12: 03$ & 00.05 & 546.502 & 7.108 & 0.007 & 2.60 & \\
\hline L1S36 & $1986-07-08$ & $09: 22$ & 00.05 & 553.390 & 6.888 & 0.007 & 2.65 & \\
\hline L1S36 & $1986-07-16$ & $09: 16$ & 00.06 & 561.386 & 7.906 & 0.008 & 2.71 & \\
\hline L1S36 & $1986-07-22$ & $08: 56$ & 00.05 & 567.372 & 5.886 & 0.008 & 2.76 & \\
\hline L1S36 & $1986-07-29$ & $09: 23$ & 00.05 & 574.391 & 7.019 & 0.007 & 2.81 & \\
\hline L1S36 & $1986-08-05$ & $09: 46$ & 00.05 & 581.407 & 7.016 & 0.007 & 2.86 & \\
\hline L1S36 & $1986-08-12$ & $09: 15$ & $\infty 0.05$ & 588.385 & 6.978 & 0.007 & 2.91 & \\
\hline L1S36 & $1986-08-19$ & $09: 59$ & 00.06 & 595.416 & 7.031 & 0.009 & 2.97 & \\
\hline L1S36 & $1986-08-26$ & $09: 30$ & 00.06 & 602.396 & 6.880 & 0.009 & 3.03 & \\
\hline L1S36 & $1986-09-04$ & $09: 05$ & $\infty 0.07$ & 611.378 & 8.982 & 0.008 & 3.10 & \\
\hline L1S36 & $1986-09-09$ & $11: 32$ & 00.04 & 616.481 & 5.103 & 0.008 & 3.14 & \\
\hline L1S36 & $1986-09-16$ & $08: 56$ & 00.05 & 623.372 & 6.891 & 0.007 & 3.19 & \\
\hline L1S36 & $1986-09-23$ & $09: 03$ & 00.05 & 630.377 & 7.005 & 0.007 & 3.24 & \\
\hline L1S36 & $1986-10-01$ & $09: 55$ & 0.05 & 638.413 & 8.036 & 0.006 & 3.29 & \\
\hline L1S36 & $1986-10-08$ & $09: 30$ & 00.03 & 645.396 & 6.983 & 0.004 & 3.32 & \\
\hline L1S36 & $1986-11-05$ & $09: 25$ & 0.10 & 673.392 & 27.996 & 0.004 & 3.42 & \\
\hline L1S36 & $1986-11-20$ & $10: 10$ & 00.05 & 688.424 & 15.032 & 0.003 & 3.47 & \\
\hline L1S36 & $1986-12-31$ & $10: 22$ & 00.05 & 729.432 & 41.008 & 0.001 & 3.52 & \\
\hline L1S36 & $1987-03-06$ & $13: 00$ & 0.14 & 794.542 & 65.110 & 0.002 & 3.66 & \\
\hline
\end{tabular}


BRINE ACCUMULATION DATA TABLE (Continued) Data through December 31, 1990

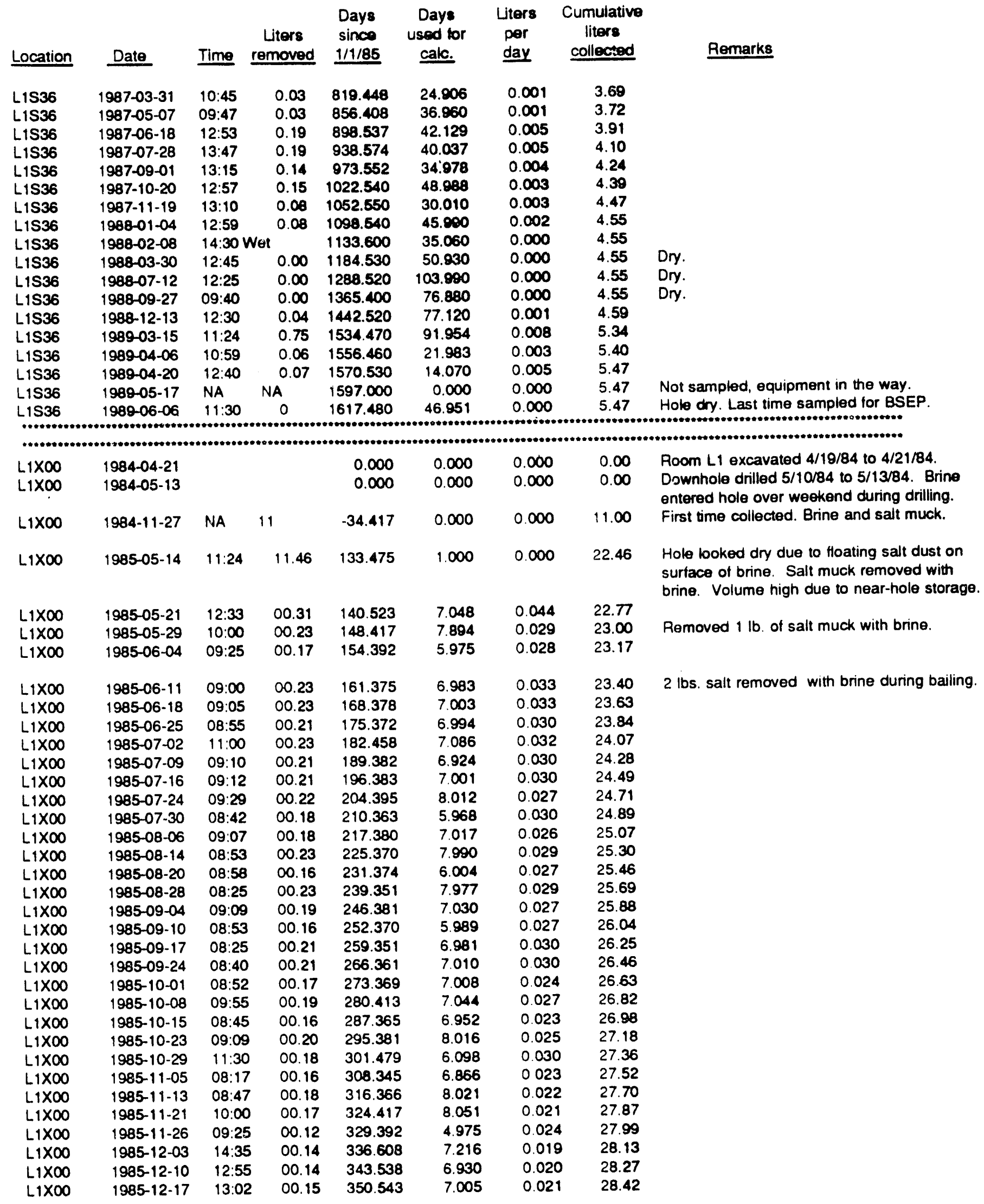


BRINE ACCUMULATION DATA TABLE (Continued)

Data through December 31, 1990

\begin{tabular}{|c|c|c|c|c|c|c|c|c|}
\hline Location & Date & Time & $\begin{array}{l}\text { Liters } \\
\text { removed } \\
\end{array}$ & $\begin{array}{l}\text { Days } \\
\text { since } \\
1 / 1 / 85 \\
\end{array}$ & $\begin{array}{l}\text { Days } \\
\text { used for } \\
\text { calc. }\end{array}$ & $\begin{array}{l}\text { Liters } \\
\text { per } \\
\text { day }\end{array}$ & $\begin{array}{c}\text { Cumulative } \\
\text { liters } \\
\text { collected } \\
\end{array}$ & Remarks \\
\hline L1X00 & $1986-01-03$ & 09:05 & 00.38 & 367.378 & 16.835 & 0.023 & 28.80 & \\
\hline L1X00 & $1986-01-08$ & $09: 25$ & 00.11 & 372.392 & 5.014 & 0.022 & 28.91 & \\
\hline L1X00 & $1986-01-16$ & $09: 00$ & 00.18 & 380.375 & 7.883 & 0.023 & 29.00 & \\
\hline L.1X00 & $1986-01-23$ & $09: 15$ & 00.14 & 387.385 & 7.010 & 0.020 & 29.23 & \\
\hline L1X00 & $1986-01-31$ & $09: 45$ & 00.18 & 385.406 & 8.021 & 0.022 & 29.41 & \\
\hline L1X00 & $1986-02-12$ & $08: 50$ & 00.30 & 407.368 & 11.862 & 0.025 & 29.71 & \\
\hline$L 1 \times 00$ & $1986-02-19$ & $09: 40$ & 00.16 & 414.403 & 7.035 & 0.023 & 29.87 & \\
\hline$L 1 \times \infty 0$ & $1986-02-28$ & $11: 20$ & 00.24 & 423.472 & 9.069 & 0.026 & 30.11 & \\
\hline L1X00 & $1986-03-06$ & $09: 10$ & 00.12 & 429.382 & 5.910 & 0.020 & 30.23 & \\
\hline$L 1 \times 00$ & $1986-03-13$ & $08: 30$ & 00.16 & 436.354 & 6.972 & 0.023 & 30.39 & \\
\hline$L 1 \times 00$ & $1986-03-26$ & $08: 35$ & 00.29 & 449.358 & 13.004 & 0.022 & 30.68 & \\
\hline L1X00 & $1986-04-02$ & $08: 15$ & 00.17 & 456.344 & 6.986 & 0.024 & 30.85 & \\
\hline L1X00 & $1986-04-08$ & $08: 26$ & 00.15 & 462.351 & 6.007 & 0.025 & 31.00 & \\
\hline$L 1 \times 00$ & $1986-04-16$ & $10: 20$ & 00.19 & 470.431 & 8.080 & 0.024 & 31.19 & \\
\hline$L 1 \times 00$ & $1986-04-24$ & $08: 50$ & 00.16 & 478.368 & 7.937 & 0.020 & 31.35 & \\
\hline$L 1 \times 00$ & $1986-04-30$ & $09: 20$ & 00.16 & 484.389 & 6.021 & 0.027 & 31.51 & \\
\hline L1X00 & $1986-05-06$ & $08: 50$ & 00.15 & 490.368 & 5.979 & 0.025 & 31.66 & \\
\hline L1X00 & $1986-05-13$ & $08: 48$ & 00.18 & 497.367 & 6.999 & 0.026 & 31.84 & \\
\hline L1X00 & $1986-05-20$ & $09: 20$ & 00.18 & 504.389 & 7.022 & 0.026 & 32.02 & \\
\hline L1X00 & $1986-05-27$ & $14: 20$ & 00.17 & 511.597 & 7.208 & 0.024 & 32.19 & \\
\hline L1X00 & $1986-06-03$ & $08: 43$ & $\infty .15$ & 518.363 & 6.766 & 0.022 & 32.34 & \\
\hline L1X00 & $1986-06-10$ & $09: 20$ & 00.21 & 525.389 & 7.026 & 0.030 & 32.55 & \\
\hline L1X00 & $1986-06-17$ & $09: 12$ & 00.14 & 532.383 & 6.994 & 0.020 & 32.69 & \\
\hline L1X00 & $1986-06-24$ & $09: 15$ & 00.22 & 539.385 & 7.002 & 0.031 & 32.91 & \\
\hline L1X00 & $1986-07-01$ & $11: 53$ & 00.22 & 546.495 & 7.110 & 0.031 & 33.13 & \\
\hline L1X00 & $1986-07-08$ & $09: 10$ & 00.22 & 553.382 & 6.887 & 0.032 & 33.35 & \\
\hline L1X00 & $1986-07-16$ & $09: 00$ & 00.21 & 561.375 & 7.993 & 0.026 & 33.56 & \\
\hline L1X00 & $1986-07-22$ & $08: 45$ & 00.17 & 567.365 & 5.990 & 0.028 & 33.73 & \\
\hline L1X00 & $1986-07-29$ & $09: 08$ & 00.18 & 574.381 & 7.016 & 0.026 & 33.91 & \\
\hline L1X00 & $1986-08-05$ & $09: 33$ & 00.20 & 581.398 & 7.017 & 0.029 & 34.11 & \\
\hline L1X00 & $1986-08-12$ & $09: 05$ & 00.20 & 588.378 & 6.980 & 0.029 & 34.31 & \\
\hline L1X00 & $1986-08-19$ & $09: 49$ & 00.20 & 595.409 & 7.031 & 0.028 & 34.51 & \\
\hline L1X00 & $1986-08-26$ & $09: 20$ & 00.19 & 602.389 & 6.980 & 0.027 & 34.70 & \\
\hline LIXOO & $1986-09-04$ & $08: 55$ & 00.25 & 611.372 & 8.983 & 0.028 & 34.95 & \\
\hline L1X00 & $1986-09-09$ & $11: 25$ & 00.16 & 616.476 & 5.104 & 0.031 & 35.11 & \\
\hline L1X00 & $1986-09-16$ & $08: 50$ & 00.19 & 623.368 & 6.892 & 0.028 & 35.30 & \\
\hline L1X00 & $1986-09-23$ & $08: 53$ & 00.20 & 630.370 & 7.002 & 0.029 & 35.50 & \\
\hline LIX00 & $1986-10-01$ & $09: 46$ & 00.22 & 638.407 & 8.037 & 0.027 & 35.72 & \\
\hline L1X00 & $1986-10-08$ & $09: 17$ & 00.18 & 645.387 & 6.980 & 0.026 & 35.90 & \\
\hline L1X00 & $1986-10-14$ & $10: \infty 0$ & 00.14 & 651.417 & 6.030 & 0.023 & 36.04 & \\
\hline L1X00 & $1986-11-05$ & 09:02 & 0.52 & 673.376 & 21.959 & 0.024 & 36.56 & \\
\hline L1X00 & $1986-11-20$ & $09: 47$ & 00.36 & 688.408 & 15.032 & 0.024 & 36.92 & \\
\hline L1X00 & $1986-12-31$ & $10: 00$ & 00.88 & 729.417 & 41.009 & 0.021 & 37.80 & \\
\hline L.1X00 & $1987-02-03$ & $10: 45$ & 00.61 & 763.448 & 34.031 & 0.018 & 38.41 & \\
\hline$L 1 X 00$ & $1987-03-06$ & $09: 45$ & 0.58 & 794.406 & 30.958 & 0.019 & 38.99 & $\begin{array}{l}\text { Hole looked dry due to floating salt dust on } \\
\text { surface of brine. }\end{array}$ \\
\hline L.1X00 & $1987-04-10$ & $09: 30$ & 0.68 & 829.396 & 34.990 & 0.019 & 39.67 & \\
\hline L1X00 & $1987-06-17$ & $14: 00$ & 0.83 & 897.583 & 0.000 & 0.000 & 40.50 & Brine left in hole; no calculation. \\
\hline L1X00 & $1987-07-28$ & $13: 07$ & 1.09 & 938.547 & 109.151 & 0.018 & 41.50 & $\begin{array}{l}\text { Calculated using } 1.92 \text { liters in } 109.151 \text { days } \\
(6 / 17 / 87 \text { and } 7 / 28 / 87) \text {. }\end{array}$ \\
\hline L1X00 & $1987-09-01$ & $12: 45$ & 0.95 & 973.531 & 34.984 & 0.027 & 42.45 & \\
\hline L1X00 & $1987-09-10$ & $10: 34$ & 0.25 & 982.440 & 8.909 & 0.028 & 42.70 & Installed collection device. \\
\hline$L 1 \times 00$ & $1987-10-20$ & $12: 18$ & 0.09 & 1022.510 & 40.070 & 0.002 & 42.79 & \\
\hline L $1 \times 00$ & $1987-11-19$ & $12: 15$ & 1.35 & 1052.510 & 30.000 & 0.045 & 44.14 & \\
\hline L1X00 & $1986-01-04$ & $12: 30$ & 0.43 & 1098.520 & 46.010 & 0.009 & 44.57 & \\
\hline$L 1 \times 00$ & $1988-02-08$ & $13: 45$ & 0.93 & 1133.570 & 35.050 & 0.027 & 45.50 & \\
\hline L.1X00 & $1988-03-30$ & $12: 20$ & 1.00 & 1184.510 & 50.940 & 0.020 & 46.50 & \\
\hline L1X00 & $1988-07-12$ & $12: 25$ & 2.33 & 1288.520 & 104.010 & 0.022 & 48.83 & \\
\hline L1X00 & $1988-09-27$ & $08: 45$ & 2.07 & 1365.360 & 76.840 & 0.027 & 50.90 & \\
\hline$L 1 \times \infty 0$ & $1988-12-13$ & $11: 30$ & 1.85 & 1442.480 & 77.120 & 0.024 & 52.75 & \\
\hline
\end{tabular}


BRINE ACCUMULATION DATA TABLE (Continued)
Data through December 31, 1990

\begin{tabular}{|c|c|c|c|c|c|c|c|c|}
\hline Location & Date & Time & $\begin{array}{l}\text { Liters } \\
\text { removed }\end{array}$ & $\begin{array}{l}\text { Days } \\
\text { since } \\
1 / 1 / 85 \\
\end{array}$ & $\begin{array}{l}\text { Days } \\
\text { used for } \\
\text { calc. }\end{array}$ & $\begin{array}{l}\text { Liters } \\
\text { per } \\
\text { day }\end{array}$ & $\begin{array}{c}\text { Cumulative } \\
\text { liters } \\
\text { collected }\end{array}$ & Remarks \\
\hline L1X00 & $1989-03-15$ & $11: 00$ & 1.58 & 1534.460 & 91.979 & 0.017 & 54.33 & $\begin{array}{l}\text { Std. will not fit in hole, collection device } \\
\text { removed. }\end{array}$ \\
\hline L1X00 & $1989-04-06$ & $10: 30$ & NA & 1556.440 & 0.000 & 0.000 & 54.33 & \\
\hline 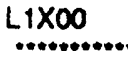 & $1989-04-20$ & $12: \infty 0$ & $\begin{array}{l}1.25 \\
\ldots .00\end{array}$ & 1570.500 & $\begin{array}{l}36.042 \\
00000000\end{array}$ & 0.035 & 55.58 & Last time sampled for BSEP. \\
\hline \multicolumn{9}{|l|}{$\cdots \cdots \cdots$} \\
\hline NG252 & $1983-03-16$ & & & 0.000 & 0.000 & 0.000 & 0.00 & $\begin{array}{l}\text { West side of SPDV Test Room } 2 \text { excavated. } \\
\text { (Room excavated 3/09/83 to } 3 / 20 / 83 \text { ). }\end{array}$ \\
\hline NG252 & $1983-03-20$ & & & 0.000 & 0.000 & 0.000 & 0.00 & Approximate date downhole drilled. \\
\hline NG252 & $1984-03-04$ & & & 0.000 & 0.000 & 0.000 & 0.00 & $\begin{array}{l}\text { Overcored nonfunctional stress meter with } 6^{*} \\
\text { hole (to } 1.5 \text { teet). }\end{array}$ \\
\hline NG252 & $1984-11-21$ & & & 0.000 & 0.000 & 0.000 & 0.00 & $\begin{array}{l}\text { Brine 7" below west edge of collar. Cleaned } \\
\text { hole. }\end{array}$ \\
\hline NG252 & $1984-11-30$ & & & 0.000 & 0.000 & 0.000 & 0.00 & Installed PVC casing for BSEP observations. \\
\hline NG252 & $1984-12-19$ & $12: 00$ & 04.60 & -12.500 & 1.000 & 0.000 & 4.60 & Partial removal. First time collected. \\
\hline NG252 & $1984-12-20$ & $09: 00$ & 04.35 & -11.625 & 0.875 & 0.000 & 8.95 & Pumped dry. Inflow rate about $2 \mathrm{cc} / \mathrm{hr}$. \\
\hline NG252 & $1935-01-08$ & $09: 43$ & 08.19 & 7.405 & 19.030 & 0.430 & 17.14 & Pumpod dry. \\
\hline NG252 & $1985-02-05$ & $09: 30$ & 08.48 & 35.396 & 27.991 & 0.303 & 25.62 & $\begin{array}{l}\text { Gas bubbles observed rising through brine in } \\
\text { hole. }\end{array}$ \\
\hline NG252 & $1985-02-14$ & $10: 33$ & 04.14 & 44.440 & 9.044 & 0.458 & 29.76 & \\
\hline NG252 & $1985-02-19$ & 10:18 & 03.92 & 49.429 & 4.989 & 0.786 & 33.68 & \\
\hline NG252 & $1985-03-07$ & $10: 57$ & 03.83 & 65.456 & 16.027 & 0.239 & 37.51 & \\
\hline NG252 & $1985-03-12$ & $09: 10$ & 03.41 & 70.382 & 4.926 & 0.692 & 40.92 & \\
\hline NG252 & $1985-03-20$ & $10: 00$ & 03.71 & 78.417 & 8.035 & 0.462 & 44.63 & \\
\hline NG252 & $1985-03-26$ & $09: 30$ & 03.24 & 84.396 & 5.979 & 0.542 & 47.87 & \\
\hline NG252 & $1985-04-02$ & $10: 00$ & 03.38 & 91.417 & 7.021 & 0.481 & 51.25 & \\
\hline NG252 & $1985-04-10$ & $10: 02$ & 03.29 & 99.418 & 8.001 & 0.411 & 54.54 & \\
\hline NG252 & $1985-04-17$ & $13: 50$ & 03.57 & 106.576 & 7.158 & 0.499 & 58.11 & \\
\hline NG252 & $1985-04-23$ & $12: 00$ & 02.58 & 112.500 & 5.924 & 0.436 & 60.69 & \\
\hline Na252 & $1985-04-30$ & $11: 39$ & 03.28 & 119.485 & 6.985 & 0.470 & 63.97 & \\
\hline NG252 & $1985-05-07$ & $10: 25$ & 02.96 & 126.434 & 6.940 & 0.426 & 66.93 & \\
\hline NG252 & $1985-05-14$ & $11: 05$ & 02.83 & 133.462 & 7.028 & 0.403 & 69.76 & \\
\hline NG252 & $1985-05-21$ & $11: 12$ & 03.01 & 140.467 & 7.005 & 0.430 & 72.77 & Brine degassing in collection container. \\
\hline NG252 & $1985-05-29$ & $10: 00$ & 03.45 & 148.417 & 7.950 & 0.434 & 76.22 & \\
\hline NG252 & $1985-06-04$ & $11: 50$ & 02.90 & 154.493 & 6.076 & 0.47 .7 & 79.12 & \\
\hline NG252 & $1985-06-11$ & $11: 35$ & 03.06 & 161.483 & 6.990 & 0.438 & 82.18 & \\
\hline NG252 & $1985-06-18$ & $10: 47$ & 02.82 & 168.449 & 6.866 & 0.405 & 85.00 & \\
\hline NG252 & $1985-06-25$ & $10: 00$ & 03.34 & 175.417 & 6.968 & 0.479 & 88.34 & \\
\hline NG252 & $1985-07-02$ & $11: 00$ & 03.50 & 182.458 & 7.041 & 0.497 & 91.84 & \\
\hline NG252 & $1985-07-09$ & $11: 30$ & 03.46 & 189.479 & 7.021 & 0.493 & 95.30 & Brine effervesces. \\
\hline NG252 & $1985-07-16$ & $12: 09$ & 03.43 & 196.506 & 7.027 & 0.488 & 98.73 & Brine effervesces. \\
\hline NG252 & $1985-07-24$ & $11: 10$ & 03.83 & 204.465 & 7.959 & 0.481 & 102.56 & \\
\hline NG252 & $1985-07-30$ & $10: 45$ & 02.79 & 210.448 & 5.983 & 0.466 & 105.35 & \\
\hline NG252 & $1985-08-06$ & $10: 58$ & 03.05 & 217.457 & 7.009 & 0.435 & 108.40 & \\
\hline NG252 & $1985-08-14$ & $12: 10$ & 03.48 & 225.507 & 8.050 & 0.432 & 111.88 & \\
\hline NG252 & $1985-08-20$ & $11: 31$ & 03.15 & 231.480 & 5.973 & 0.527 & 115.03 & \\
\hline NG252 & $1985-08-28$ & $10: 00$ & 03.11 & 239.417 & 7.937 & 0.392 & 118.14 & \\
\hline NG252 & $1985-09-04$ & $10: 58$ & 03.17 & 246.457 & 7.040 & 0.450 & 121.31 & \\
\hline NG252 & $1985-09-10$ & $11: 23$ & 03.04 & 252.474 & 6.017 & 0.505 & 124.35 & \\
\hline NG252 & $1985-09-17$ & $10: 16$ & 02.68 & 259.428 & 6.954 & 0.385 & 127.03 & \\
\hline NG252 & $1985-09-24$ & $10: 20$ & 02.98 & 266.431 & 7.003 & 0.426 & 130.01 & \\
\hline NG252 & $1985-10-01$ & $10: 25$ & 03.19 & 273.434 & 7.003 & 0.456 & 133.20 & \\
\hline NG252 & $1985-10-08$ & $11: 05$ & 03.36 & 280.462 & 7.028 & 0.478 & 136.56 & \\
\hline NG252 & $1985-10-15$ & $10: 46$ & 02.64 & 287.449 & 6.987 & 0.378 & 139.20 & \\
\hline NG252 & $1985-10-23$ & $10: 58$ & 02.93 & 295.457 & 8.008 & 0.366 & 142.13 & \\
\hline NG252 & $1985-10-29$ & $10: 45$ & 02.64 & 301.448 & 5.991 & 0.441 & 144.77 & \\
\hline NG252 & $1985-11-05$ & $09: 40$ & 02.16 & 308.403 & 6.955 & 0.311 & 146.93 & $\begin{array}{l}10 \text { days after brine was removed from 36" } \\
\text { hole in SPDV Test Room } 3 .\end{array}$ \\
\hline $\begin{array}{l}\text { NG252 } \\
\text { NG252 }\end{array}$ & $1985-11-13$ & $10: 45$ & 02.72 & 316.448 & 8.045 & 0.338 & 149.65 & \\
\hline NG252 & $1985-11-21$ & $11: 50$ & 02.88 & 324.493 & 8.045 & 0.358 & 152.53 & \\
\hline
\end{tabular}


BRINE ACCUMULATION DATA TABLE (Continued)

Data through December 31, 1990

\begin{tabular}{|c|c|c|c|c|c|c|c|c|}
\hline Location & Date & Time & $\begin{array}{l}\text { Liters } \\
\text { removed }\end{array}$ & $\begin{array}{l}\text { Days } \\
\text { since } \\
1 / 1 / 85 \\
\end{array}$ & $\begin{array}{l}\text { Days } \\
\text { used tor } \\
\text { caic. }\end{array}$ & $\begin{array}{l}\text { Liters } \\
\text { per } \\
\text { day }\end{array}$ & $\begin{array}{l}\text { Cumulative } \\
\text { liters } \\
\text { collected }\end{array}$ & Remarks \\
\hline NG252 & $1985-11-26$ & $10: 40$ & 02.28 & 329.444 & 4.951 & 0.461 & 154.81 & \\
\hline NG252 & $1985-12-03$ & $14: 15$ & 02.45 & 336.594 & 7.150 & 0.343 & 157.26 & \\
\hline NG252 & $1985-12-10$ & $13: 41$ & 02.34 & 343.570 & 6.976 & 0.335 & 159.60 & \\
\hline NG252 & $1985-12-17$ & $14: 15$ & 02.73 & 350.594 & 7.024 & 0.389 & 162.33 & \\
\hline NG252 & $1986-01-03$ & $10: 30$ & 04.03 & 367.438 & 16.844 & 0.239 & 166.36 & Partial removal only. \\
\hline NG252 & $1986-01-08$ & $10: 40$ & 03.00 & 372.444 & 5.006 & 0.599 & 169.36 & $\begin{array}{l}\text { High volume of brine due to only partial } \\
\text { removal on } 1 / 03 / 86 \text {. }\end{array}$ \\
\hline NG252 & $1986-01-16$ & $10: 10$ & 03.90 & 380.424 & 7.980 & 0.489 & 173.26 & \\
\hline NG252 & $1986-01-23$ & $10: 20$ & 02.84 & 387.431 & 7.007 & 0.405 & 176.10 & \\
\hline NG252 & $1986-01-31$ & $12: 45$ & 02.94 & 395.531 & 8.100 & 0.363 & 179.04 & \\
\hline NG252 & $1986-02-12$ & $11: 30$ & 02.87 & 407.479 & 11.848 & 0.240 & 181.91 & \\
\hline NG252 & $1986-02-19$ & $12: 13$ & 02.85 & 414.509 & 7.030 & 0.405 & 184.76 & \\
\hline NG252 & $1986-03-06$ & $11: 00$ & 04.10 & 429.458 & 14.849 & 0.274 & 188.86 & \\
\hline NG252 & $1986-03-13$ & $10: 30$ & 02.78 & 436.438 & 6.980 & 0.398 & 191.64 & \\
\hline NG252 & $1986-03-26$ & $10: 25$ & 03.50 & 449.434 & 12.996 & 0.269 & 195.14 & \\
\hline NG252 & $1986-04-02$ & $10: 10$ & 02.67 & 456.424 & 6.990 & 0.382 & 197.81 & \\
\hline NG252 & $1986-04-08$ & $10: 15$ & 02.00 & 462.427 & 6.003 & 0.333 & 199.81 & \\
\hline NG252 & $1986-04-16$ & $12: 30$ & 02.52 & 470.521 & 8.094 & 0.311 & 202.33 & \\
\hline NG252 & $1986-04-24$ & $10: 40$ & 01.93 & 478.444 & 7.923 & 0.244 & 204.26 & \\
\hline NG252 & $1986-04-30$ & $11: 20$ & 02.10 & 484.472 & 6.028 & 0.348 & 206.36 & \\
\hline NG252 & $1986-05-06$ & $10: 45$ & 01.80 & 490.448 & 5.976 & 0.301 & 208.16 & \\
\hline NG252 & $1986-05-13$ & $11: 35$ & 01.33 & 497.483 & 7.035 & 0.189 & 209.49 & \\
\hline NG252 & $1986-05-20$ & $11: 25$ & 01.22 & 504.476 & 6.993 & 0.174 & 210.71 & \\
\hline NG252 & $1986-05-27$ & $16: 10$ & 01.60 & 511.674 & 7.198 & 0.222 & 212.31 & \\
\hline NG252 & $1986-06-03$ & $10: 45$ & 01.49 & 518.448 & 6.774 & 0.220 & 213.80 & \\
\hline NG252 & $1986-06-10$ & $11: 45$ & 02.18 & 525.490 & 7.042 & 0.310 & 215.98 & \\
\hline NG252 & $1986-06-17$ & $11: 21$ & 02.65 & 532.473 & 6.983 & 0.379 & 218.63 & \\
\hline NG252 & $1986-06-24$ & $11: 15$ & 01.77 & 539.469 & 6.996 & 0.253 & 220.40 & \\
\hline NG252 & $1986-07-01$ & $14: 20$ & 01.80 & 546.597 & 7.128 & 0.253 & 222.20 & \\
\hline NG252 & $1986-07-08$ & $10: 55$ & 01.50 & 553.455 & 6.858 & 0.219 & 223.70 & \\
\hline NG252 & $1986-07-16$ & $11: \infty$ & 01.88 & 561.458 & 8.003 & 0.235 & 225.58 & \\
\hline NG252 & $1986-07-22$ & $10: 22$ & 01.94 & 567.432 & 5.974 & 0.325 & 227.52 & \\
\hline NG252 & $1986-07-29$ & $10: 55$ & 02.16 & 574.455 & 7.023 & 0.308 & 229.68 & \\
\hline NG252 & $1986-08-05$ & $11: 33$ & 01.92 & 581.481 & 7.026 & 0.273 & 231.60 & \\
\hline NG252 & $1986-08-12$ & $10: 50$ & 01.90 & 588.451 & 6.970 & 0.273 & 233.50 & \\
\hline NG252 & $1986-08-19$ & $11: 45$ & 01.82 & 595.490 & 7.039 & 0.259 & 235.32 & \\
\hline NG252 & $1986-08-26$ & $11: 05$ & 01.85 & 602.462 & 6.972 & 0.265 & 237.17 & \\
\hline NG252 & $1986-09-04$ & $11: 00$ & 02.15 & 611.458 & 8.996 & 0.239 & 239.32 & \\
\hline NG252 & $1986-09-09$ & $09: 12$ & 01.85 & 616.383 & 4.925 & 0.376 & 241.17 & \\
\hline NG252 & $1986-09-16$ & $10: 27$ & 01.81 & 623.435 & 7.052 & 0.257 & 242.98 & \\
\hline NG252 & $1586-09-23$ & $10: 30$ & 01.65 & 630.438 & 7.003 & 0.236 & 244.63 & \\
\hline NG252 & $1986-10-01$ & $12: 30$ & 02.67 & 638.521 & 8.083 & 0.330 & 247,30 & \\
\hline NG252 & $1986-10-08$ & $11: 30$ & 01.61 & 645.479 & 6.958 & 0.231 & 248.91 & \\
\hline NG252 & $1986-10-14$ & $12: 10$ & 01.72 & 651.507 & 6.028 & 0.285 & 250.63 & \\
\hline NG252 & $1986-11-05$ & $11: 57$ & 3.45 & 673.498 & 21.991 & 0.157 & 254.08 & \\
\hline NG252 & $1986-11-20$ & $12: 40$ & 03.93 & 688.528 & 15.030 & 0.261 & 258.01 & \\
\hline NG252 & $1986-12-30$ & $13: 13$ & 03.54 & 728.551 & 40.023 & 0.090 & 261.55 & \\
\hline NG252 & $1987-01-06$ & $13: 00$ & 02.38 & 735.542 & 6.991 & 0.318 & 263.93 & \\
\hline NG252 & $1987-01-12$ & $12: 15$ & 06.81 & 741.510 & 5.968 & 1.141 & 270.74 & \\
\hline NG252 & $1987-02-03$ & $09: 15$ & 03.93 & 763.385 & 21.875 & 0.180 & 274.67 & \\
\hline NG252 & $1987-03-06$ & $13: 35$ & 4.2 & 794.566 & 31.181 & 0.135 & 278.87 & \\
\hline NG252 & $1987-04-22$ & $09: 17$ & 4.83 & 841.387 & 46.821 & 0.103 & 283.70 & \\
\hline NG252 & $1987-05-07$ & $11: 59$ & 4.24 & 856.499 & 15.112 & 0.281 & 287.94 & $\begin{array}{l}\text { Low liters/day values for some periods } \\
\text { between } 11 / 05 / 86 \text { and } 6 / 16 / 87 \text { may be the } \\
\text { result in part of the long time between } \\
\text { collections. }\end{array}$ \\
\hline NG252 & $1987-06-17$ & $14: 10$ & 4.63 & 897.590 & 0.000 & 0.000 & 292.57 & Some brine left in hole; no calc. \\
\hline NG252 & $1987-06-30$ & $10: 20$ & 410 & 910.431 & 53.932 & 0.162 & 296.67 & $\begin{array}{l}\text { Calculation used } 8.73 \text { liters in } 53.932 \text { days } \\
(6 / 17 / 87 \text { and } 6 / 30 / 87) \text {. }\end{array}$ \\
\hline NG252 & $1987-07-16$ & $10: 50$ & 3.77 & 926.451 & 16.020 & 0.235 & 300.44 & \\
\hline
\end{tabular}


BRINE ACCUMULATION DATA TABLE (Continued) Data through December 31, 1990

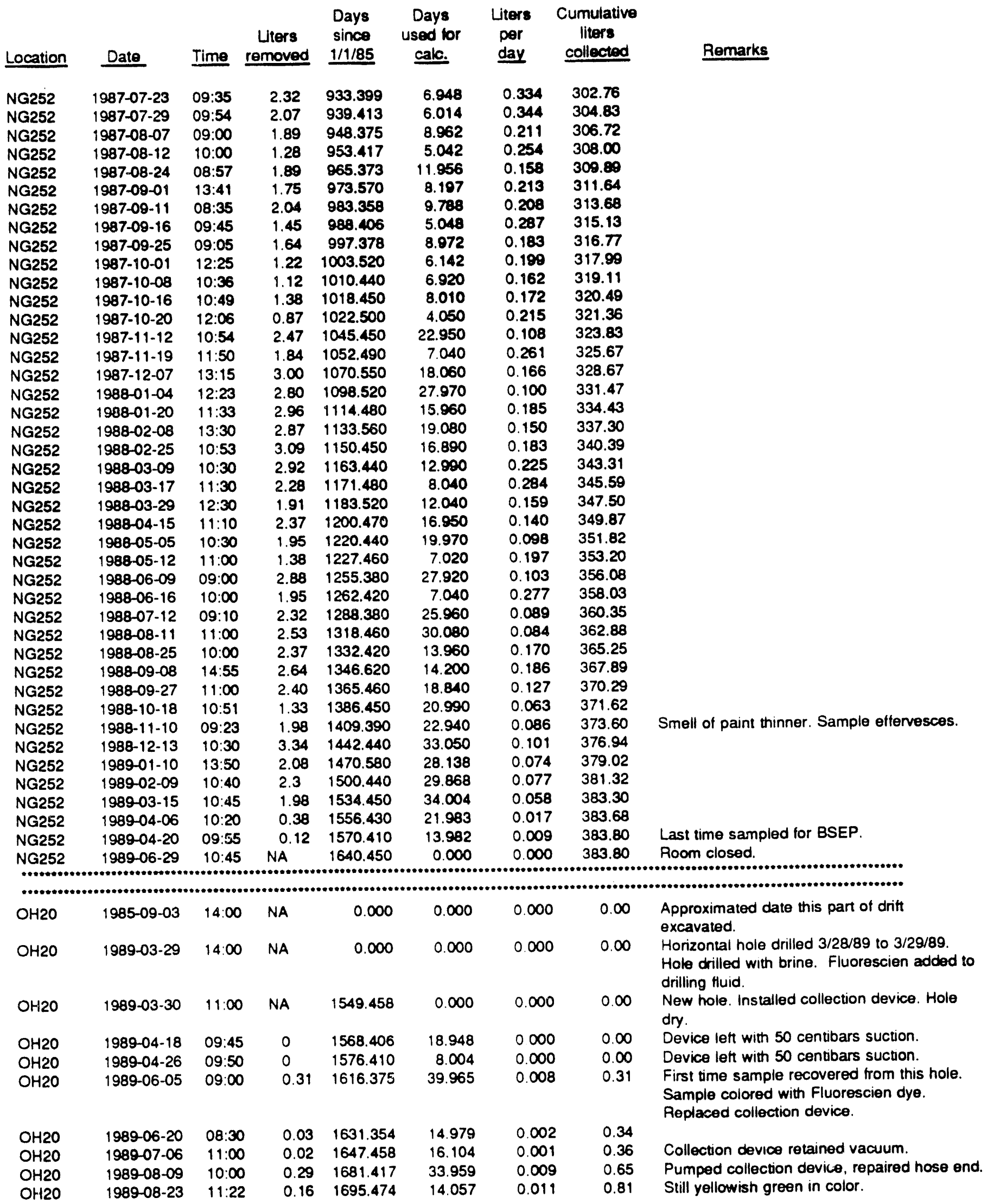


BRINE ACCUMULATION DATA TABLE (Continued) Data through December 31, 1990

\begin{tabular}{|c|c|c|c|c|c|c|c|c|}
\hline Location & Date & Time & $\begin{array}{l}\text { Liters } \\
\text { removed }\end{array}$ & $\begin{array}{l}\text { Days } \\
\text { since } \\
1 / 1 / 85 \\
\end{array}$ & $\begin{array}{l}\text { Days } \\
\text { used for } \\
\text { calc. }\end{array}$ & $\begin{array}{l}\text { Liters } \\
\text { per } \\
\text { day }\end{array}$ & $\begin{array}{l}\text { Cumulative } \\
\text { liters } \\
\text { collected }\end{array}$ & Remarks \\
\hline $\mathrm{OH} 2 \mathrm{O}$ & $1989-09-14$ & $11: 05$ & 0.21 & 1717.462 & 21.988 & 0.010 & .1 .02 & \\
\hline $\mathrm{OH} 2 \mathrm{O}$ & $1989-10-02$ & $11: 20$ & 0.27 & 1735.472 & 18.010 & 0.015 & 1.29 & \\
\hline $\mathrm{OH} 2 \mathrm{O}$ & $1989-10-20$ & $11: 25$ & 0.26 & 1753.476 & 18.004 & 0.014 & 1.55 & \\
\hline $\mathrm{OH} 2 \mathrm{O}$ & $1989-11-10$ & $10: 18$ & 0.29 & 1774.429 & 20.953 & 0.014 & 1.84 & \\
\hline $\mathrm{OH} 2 \mathrm{O}$ & $1989-11-29$ & $13: 00$ & 0.37 & 1793.542 & 19.113 & 0.019 & 2.21 & \\
\hline $\mathrm{OH} 2 \mathrm{O}$ & $1989-12-12$ & $10: 06$ & 0.20 & 1806.421 & 12.879 & 0.016 & 2.41 & \\
\hline $\mathrm{OH} 2 \mathrm{O}$ & $1990-01-04$ & $11: 52$ & 0.27 & 1829.494 & 23.073 & 0.012 & 2.68 & \\
\hline $\mathrm{OH} 2 \mathrm{O}$ & $1990-01-17$ & 09:59 & 0.21 & 1842.416 & 12.922 & 0.016 & 2.89 & \\
\hline $\mathrm{OH} 2 \mathrm{O}$ & 1990-01-31 & $10: 38$ & 0.21 & 1856.443 & 14.027 & 0.015 & 3.10 & \\
\hline $\mathrm{OH} 2 \mathrm{O}$ & $1990-02-13$ & $10: 40$ & 0.18 & 1869.444 & 13.001 & 0.014 & 3.28 & \\
\hline $\mathrm{OH} 2 \mathrm{O}$ & $1990-02-27$ & $12: 28$ & 0.24 & 1883.519 & 14.075 & 0.017 & 3.52 & \\
\hline $\mathrm{OH} 2 \mathrm{O}$ & $1990-03-05$ & $11: 12$ & 0.20 & 1889.467 & 5.248 & 0.034 & 3.72 & \\
\hline $\mathrm{OH} 2 \mathrm{O}$ & $1990-03-21$ & $09: 30$ & 0.08 & 1905.396 & 15.929 & 0.005 & 3.80 & \\
\hline OH2: & $1990-04-04$ & $12: 04$ & 0.18 & 1919.503 & 14.107 & 0.013 & 3.98 & \\
\hline $\mathrm{OH} 2 \mathrm{O}$ & $1990-04-10$ & $10: 06$ & 0.11 & 1925.421 & 5.918 & 0.019 & 4.09 & \\
\hline $\mathrm{OH} 2 \mathrm{O}$ & $1990-05-02$ & $10: 03$ & 0.10 & 1947.419 & 21.898 & 0.005 & 4.19 & \\
\hline $\mathrm{OH} 2 \mathrm{O}$ & $1990-05-09$ & $09: 24$ & 0.09 & 1954.392 & 6.973 & 0.013 & 4.28 & \\
\hline $\mathrm{OH} 2 \mathrm{O}$ & $1990-05-16$ & $11: 55$ & 0.07 & 1961.497 & 7.105 & 0.010 & 4.35 & \\
\hline $\mathrm{OH} 2 \mathrm{O}$ & $1990-05-23$ & $13: 09$ & 0.18 & 1968.548 & 7.051 & 0.026 & 4.53 & \\
\hline $\mathrm{OH} 2 \mathrm{O}$ & $1990-05-31$ & $09: 43$ & 0.09 & 1976.405 & 7.857 & 0.011 & 4.62 & \\
\hline $\mathrm{OH} 2 \mathrm{O}$ & $1990-06-06$ & $11: 45$ & 0.08 & 1982.490 & 6.085 & 0.013 & 4.70 & \\
\hline $\mathrm{OH} 2 \mathrm{O}$ & $1990-06-14$ & $10: 27$ & 0.09 & 1990.435 & 7.945 & 0.011 & 4.79 & \\
\hline $\mathrm{OH} 2 \mathrm{O}$ & $1990-06-28$ & $10: 42$ & 0.18 & 2004.446 & 14.011 & 0.013 & 4.97 & \\
\hline $\mathrm{OH} 2 \mathrm{O}$ & $1990-07-17$ & $09: 14$ & 0.24 & 2023.385 & 18.239 & 0.000 & 5.21 & \\
\hline $\mathrm{OH} 2 \mathrm{O}$ & $1990-07-18$ & $11: 10$ & 0.01 & 2024.465 & 1.080 & 0.012 & 5.22 & $\begin{array}{l}\text { Combined with } 0.24 \text { liters from } 07 / 17 / 90 \text {. } \\
\text { Used } 0.25 \text { liters for calculation. }\end{array}$ \\
\hline $\mathrm{OH} 2 \mathrm{O}$ & $\begin{array}{l}1990-07-25 \\
1990-08-01\end{array}$ & $\begin{array}{l}10: 20 \\
11: 20\end{array}$ & 0.09 & 2031.431 & 6.966 & 0.013 & 5.31 & \\
\hline $\begin{array}{l}\mathrm{OH} 2 \mathrm{O} \\
\mathrm{OH} 2 \mathrm{O}\end{array}$ & $\begin{array}{l}1990-08-01 \\
1990-08-07\end{array}$ & $\begin{array}{l}11: 20 \\
10: 13\end{array}$ & $\begin{array}{l}0.09 \\
0.08\end{array}$ & $\begin{array}{l}2038.472 \\
2044.426\end{array}$ & $\begin{array}{l}7.041 \\
5.854\end{array}$ & 0.013 & 5.40 & \\
\hline $\begin{array}{l}\mathrm{OH} 2 \mathrm{O} \\
\mathrm{OH} 2 \mathrm{O}\end{array}$ & $1990-08-16$ & $10: 13$ & $\begin{array}{l}0.18 \\
0.11\end{array}$ & $\begin{array}{l}2044.426 \\
2053.426\end{array}$ & $\begin{array}{l}5.254 \\
9.000\end{array}$ & 0.013 & 5.48 & \\
\hline $\mathrm{OH} 2 \mathrm{O}$ & $1990-08-22$ & $10: 56$ & 0.08 & 2059.456 & $\begin{array}{l}9.000 \\
6.030\end{array}$ & 0.012 & 5.59 & \\
\hline $\mathrm{OH} 2 \mathrm{O}$ & $1990-08-29$ & $10: 33$ & 0.09 & 2066.440 & $\begin{array}{l}6.030 \\
6.984\end{array}$ & $\begin{array}{l}0.013 \\
0.013\end{array}$ & $\begin{array}{l}5.67 \\
5.76\end{array}$ & \\
\hline $\mathrm{OH} 2 \mathrm{O}$ & $1990-09-05$ & $10: 44$ & 0.09 & 2073.447 & 7.007 & 0.013 & 5.85 & \\
\hline $\mathrm{OH} 2 \mathrm{O}$ & $1990-09-12$ & $09: 10$ & 0.08 & 2080.382 & 6.935 & 0.012 & 5.93 & \\
\hline $\mathrm{OH} 2 \mathrm{O}$ & $1990-09-25$ & $11: 52$ & 0.14 & 2093.494 & 13.712 & 0.000 & 6.07 & Partial evacuation. \\
\hline $\mathrm{OH} 2 \mathrm{O}$ & $1990-09-26$ & $10: 10$ & 0.09 & 2094.424 & 0.930 & $0: 016$ & 6.16 & $\begin{array}{l}\text { Combined with } 0.14 \text { liters from } 09 / 25 / 90 \text {. } \\
\text { Used } 0.23 \text { liters for calculation. }\end{array}$ \\
\hline $\mathrm{OH} 2 \mathrm{O}$ & $1990-10-03$ & $09: 10$ & 0.06 & 2101.382 & 6.958 & 0.009 & 6.22 & \\
\hline $\mathrm{OH} 2 \mathrm{O}$ & $1990-10-10$ & $10: 31$ & 0.08 & 2108.438 & 7.056 & 0.011 & 6.30 & \\
\hline $\mathrm{OH} 2 \mathrm{O}$ & $1990-10-18$ & $09: 37$ & 0.09 & 2116.401 & 7.963 & 0.011 & 6.39 & \\
\hline $\mathrm{OH} 2 \mathrm{O}$ & $1990-10-24$ & $11: 45$ & 0.07 & 2122.490 & 6.089 & 0.011 & 6.46 & \\
\hline $\mathrm{OH} 20$ & $1990-10-31$ & $11: 00$ & 0.09 & 2129.458 & 6.968 & 0.013 & 6.55 & \\
\hline $\mathrm{OH} 2 \mathrm{O}$ & $1990-11-07$ & $11: 37$ & 0.08 & 2136.484 & 7.026 & 0.011 & 6.63 & \\
\hline $\mathrm{OH} 2 \mathrm{O}$ & $1990-11-14$ & $10: 50$ & 0.09 & 2143.451 & 6.867 & 0.013 & 6.72 & \\
\hline $\mathrm{OH} 2 \mathrm{O}$ & $1990-11-28$ & $11: 37$ & 0.16 & 2157.484 & 14.033 & 0.011 & 6.88 & \\
\hline $\mathrm{OH} 2 \mathrm{O}$ & $1990-12-05$ & $09: 40$ & 0.09 & 2164.403 & 6.919 & 0.013 & 6.97 & \\
\hline $\mathrm{OH} 2 \mathrm{O}$ & $1990-12-13$ & $10: 00$ & 0.10 & 2172.417 & 8.014 & 0.012 & 7.07 & \\
\hline $\mathrm{OH} 2 \mathrm{O}$ & $1990-12-20$ & $10: 47$ & 0.09 & 2179.449 & 7.032 & 0.013 & 7.16 & \\
\hline 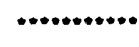 & & & & & & & & \\
\hline $\begin{array}{l}\mathrm{OH} 21 \\
\mathrm{OH} 21\end{array}$ & $\begin{array}{l}1985-09-03 \\
1988-12-12\end{array}$ & $\begin{array}{l}14: 00 \\
14: 00\end{array}$ & $\begin{array}{l}\text { NA } \\
\text { NA }\end{array}$ & $\begin{array}{l}0.000 \\
0.000\end{array}$ & $\begin{array}{l}0.000 \\
0.000\end{array}$ & $\begin{array}{l}0.000 \\
0.000\end{array}$ & $\begin{array}{l}0.00 \\
0.00\end{array}$ & $\begin{array}{l}\text { Approximate date this part of dritt excavated. } \\
\text { Horizontal hole drilled } 12 / 12 / 88 \text { to } 12 / 19 / 88 \text {. } \\
\text { Hole drilled with brine. Fluorescien added to } \\
\text { drilling fluid. }\end{array}$ \\
\hline $\mathrm{OH} 21$ & $1989-02-06$ & $10: 00$ & NA & 1497.417 & 0.000 & 0.000 & 0.00 & $\begin{array}{l}\text { New hole. Installed collection device @ 53' in } \\
\text { hole. Hole dry. }\end{array}$ \\
\hline $\mathrm{OH} 21$ & $1989-02-14$ & $09: 25$ & 0 & 1505.392 & 7.975 & 0.000 & 0.00 & $\begin{array}{l}\text { Hole plugged with foam. Hole holding } \\
\text { vacuum at approx. } 50 \text { centibars. }\end{array}$ \\
\hline $\mathrm{OH} 21$ & $1989-02-21$ & $10: 30$ & 0 & 1512.438 & 7.046 & 0.000 & 0.00 & Holding vacuum. \\
\hline
\end{tabular}




\section{BRINE ACCUMULATION DATA TABLE (Continued) Data through December 31, 1990}

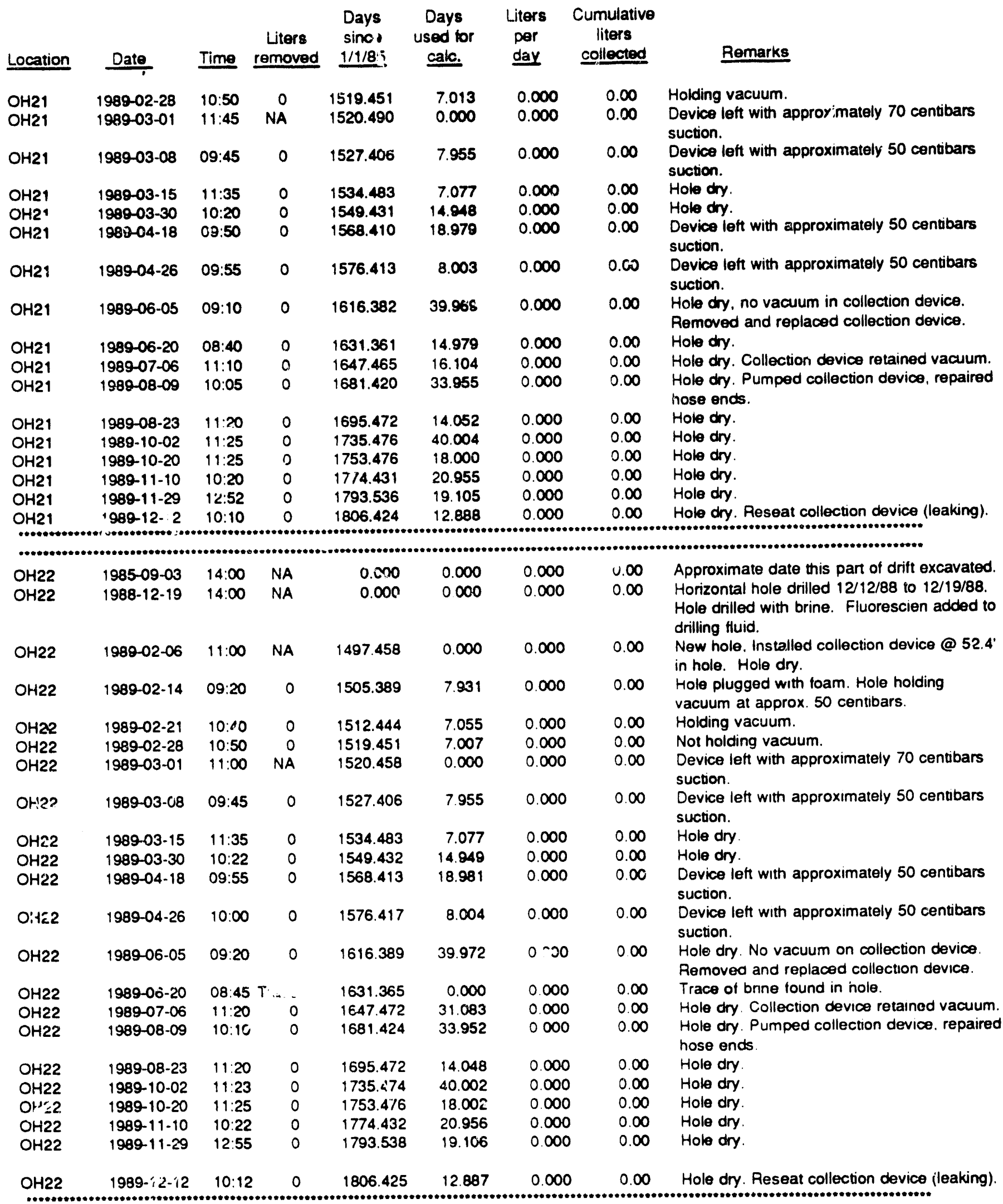




\section{BRINE ACCUMULATION DATA TABLE (Continued) Data through December 31, 1990}

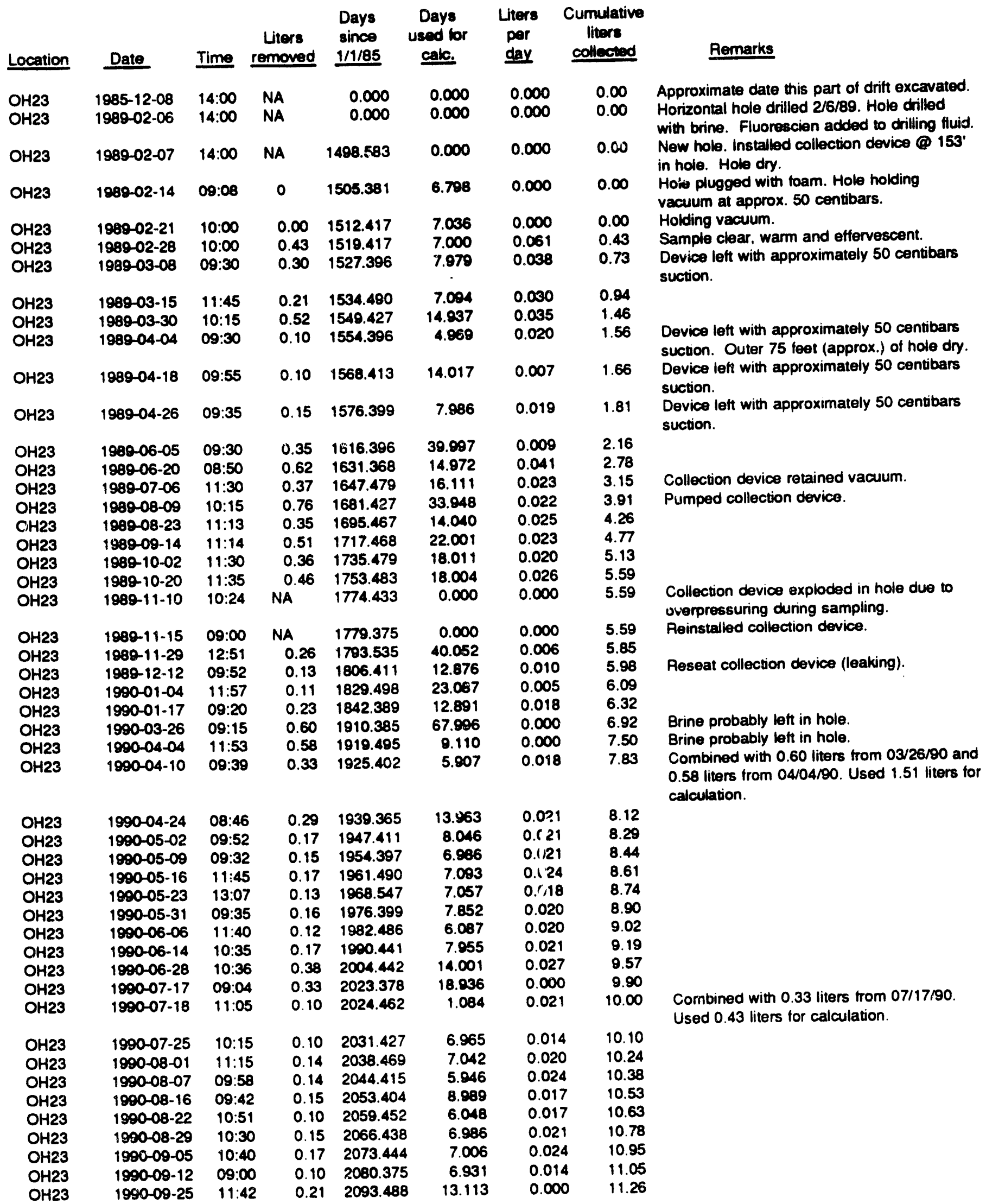


BRINE ACCUMULATION DATA TABLE (Continued) Data through December 31, 1990

\begin{tabular}{|c|c|c|c|c|c|c|c|c|}
\hline Location & Date & Time & $\begin{array}{l}\text { Liters } \\
\text { removed }\end{array}$ & $\begin{array}{r}\text { Days } \\
\text { since } \\
1 / 1 / 85 \\
\end{array}$ & $\begin{array}{l}\text { Days } \\
\text { used for } \\
\text { calc. }\end{array}$ & $\begin{array}{l}\text { Liters } \\
\text { per } \\
\text { day }\end{array}$ & $\begin{array}{l}\text { Cumulative } \\
\text { liters } \\
\text { collected }\end{array}$ & Remarks \\
\hline $\mathrm{OH} 23$ & $1990-09-26$ & $09: 53$ & 0.06 & 2094.412 & 0.924 & 0.019 & 11.32 & $\begin{array}{l}\text { Combined with } 0.21 \text { liters from 09/25/90. } \\
\text { Used } 0.27 \text { liters for calculation. }\end{array}$ \\
\hline $\mathrm{OH} 23$ & $1990-10-03$ & $09: 05$ & 0.11 & 2101.378 & 6.966 & 0.016 & 11.43 & \\
\hline $\mathrm{OH} 23$ & $1990-10-10$ & $10: 22$ & 0.13 & 2108.432 & 7.054 & 0.018 & 11.56 & \\
\hline $\mathrm{OH} 23$ & $1990-10-18$ & 09:30 & 0.15 & 2116.396 & 7.964 & 0.019 & 11.71 & \\
\hline $\mathrm{OH} 23$ & $1990-10-24$ & $11: 30$ & 0.10 & 2122.479 & 6.083 & 0.016 & 11.81 & \\
\hline $\mathrm{OH} 23$ & $1990-10-31$ & $10: 53$ & 0.11 & 2129.453 & 6.974 & 0.016 & 11.92 & \\
\hline $\mathrm{OH} 23$ & $1990-11-07$ & $11: 40$ & 0.10 & 2136.486 & 7.033 & 0.014 & 12.02 & \\
\hline $\mathrm{OH} 23$ & $1990-11-14$ & $10: 45$ & 0.13 & 2143.448 & 6.962 & 0.019 & 12.15 & \\
\hline $\mathrm{OH} 23$ & $1900-11-28$ & 11:32 & 0.22 & 2157.481 & 14.033 & 0.016 & 12.37 & \\
\hline $\mathrm{OH} 23$ & $1990-12-05$ & $09: 35$ & 010 & 2164.399 & 6.918 & 0.014 & 12.47 & \\
\hline $\mathrm{OH} 23$ & $1990-12-13$ & $10: 15$ & 0.14 & 2172.427 & 8.028 & 0.017 & 12.61 & \\
\hline $\mathrm{OH} 23$ & $1990-12-20$ & $10: 30$ & 0.10 & 2179.438 & 7.011 & 0.014 & 12.71 & \\
\hline \multicolumn{9}{|c|}{$\left[\begin{array}{lll} & 0\end{array}\right.$} \\
\hline $\mathrm{OH} 24$ & $1985-12-08$ & $14: 00$ & NA & 0.000 & 0.000 & 0.000 & 0.00 & Approximate date this part of drift excavated. \\
\hline $\mathrm{OH} 24$ & $1989-03-06$ & $14: 00$ & NA & 0.000 & 0.000 & 0.000 & $0 . \infty$ & Horizontal hole drilled $3 / 2 / 89$ to $3 / 6 / 89$. \\
\hline $\mathrm{OH} 24$ & $1989-03-08$ & 09:50 & NA & 1527.410 & 0.000 & 0.000 & 0.00 & $\begin{array}{l}\text { New hole. Installed collection device. Hole } \\
\text { dry. }\end{array}$ \\
\hline $\mathrm{OH} 24$ & 1989-03-15 & $11: 45$ & 0 & 1534.490 & 7.080 & 0.000 & 0.00 & Hole dry. \\
\hline $\mathrm{OH} 24$ & $1989-03-30$ & $10: 25$ & 0 & 1549.434 & 14.944 & 0.000 & 0.00 & Hole diry. \\
\hline $\mathrm{OH} 24$ & $1989-04-18$ & $10: 00$ & 0 & 1568.417 & 18.983 & 0.000 & 0.00 & $\begin{array}{l}\text { Device left with approximately } 50 \text { centibars } \\
\text { suction. }\end{array}$ \\
\hline $\mathrm{OH} 24$ & $1989-04-26$ & $09: 40$ & 0 & 1576.403 & 7.986 & 0.000 & 0.00 & $\begin{array}{l}\text { Device left with approximately } 50 \text { centibars } \\
\text { suction. }\end{array}$ \\
\hline $\mathrm{OH} 24$ & $1989-06-05$ & $09: 40$ & 0.05 & 1616.403 & 40.000 & 0.001 & 0.05 & $\begin{array}{l}\text { First time sample recovered. No vacuum in } \\
\text { collection device. Collection device removed } \\
\text { and replaced. }\end{array}$ \\
\hline $\mathrm{OH} 24$ & $1989-06-20$ & $09: 00$ & 0.03 & 1631.375 & 14.972 & 0.002 & 0.08 & \\
\hline $\mathrm{OH} 24$ & $1989-07-06$ & $11: 40$ & 0.01 & 1647.486 & 16.111 & 0.001 & 0.09 & Collection device retained vacuum. \\
\hline $\mathrm{OH} 24$ & $1989-08-09$ & $10: 20$ & 0 & 1681.431 & 33.945 & 0.000 & 0.09 & Hole dry. Pumped collection device. \\
\hline $\mathrm{OH} 24$ & $1989-08-23$ & $11: 18$ & 0 & 1695.471 & 14.040 & 0.000 & 0.09 & Hole dry. \\
\hline $\mathrm{OH} 24$ & $1989-10-02$ & $11: 35$ & 0 & 1735.483 & 40.012 & 0.000 & 0.09 & Hole dry. \\
\hline $\mathrm{OH} 24$ & $1989-10-20$ & $11: 35$ & 0 & 1753.483 & 18.000 & 0.000 & 0.09 & Hole dry. \\
\hline $\mathrm{OH} 24$ & $1989-11-10$ & $10: 26$ & 0 & 1774.435 & 20.952 & 0.000 & 0.09 & Hole dry. \\
\hline $\mathrm{OH} 24$ & $1989-11-29$ & $12: 58$ & 0 & 1793.540 & 19.105 & 0.000 & 0.09 & Hole ary. \\
\hline $\mathrm{OH} 24$ & $1989-12-12$ & $09: 54$ & 0 & 1806.412 & 12.872 & 0.000 & 0.09 & Hole ory. Reseat collection device (leaking). \\
\hline $\mathrm{OH} 24$ & $1990-04-10$ & $09: 46$ & 0.09 & 1925.407 & 118.995 & 0.001 & 0.18 & \\
\hline $\mathrm{OH} 24$ & $1990-04-24$ & $08: 46$ & 0.03 & 1939.365 & 13.958 & 0.002 & 0.21 & \\
\hline $\mathrm{OH} 24$ & $1990-05-02$ & $09: 55$ & NA & 1947.413 & & & 0.21 & Trace. \\
\hline $\mathrm{OH} 24$ & $1990-08-10$ & $09: 40$ & NA & 2047.403 & & & 0.21 & $\begin{array}{l}\text { Cleaned, checked, and reinstalled vacuum up } \\
\text { to } 50 \text { centloars. Checked in one hour. } \\
\text { Sampler hoiding vacuum. }\end{array}$ \\
\hline \multicolumn{9}{|c|}{ (1) } \\
\hline $\mathrm{OH} 25$ & $1985-12-08$ & $14: 00$ & NA & 0.000 & 0.000 & 0.000 & 0.00 & Approximate date this part of drift excavated. \\
\hline $\mathrm{OH} 25$ & $1989-03-27$ & $14: 00$ & NA & 0.000 & 0.000 & 0.000 & 0.00 & Honzontal hole drilled on $3 / 27 / 89$ \\
\hline $\mathrm{OH} 25$ & $1989-03-30$ & $10: 27$ & 0 & 1549.435 & 1549.430 & 0.000 & 0.00 & Hole dry. \\
\hline $\mathrm{PH} 25$ & $1989-04-18$ & $10: 05$ & 0 & 1568.420 & 18.985 & 0.000 & 0.00 & $\begin{array}{l}\text { Device left with approximately } 50 \text { centibars } \\
\text { suction. }\end{array}$ \\
\hline $\mathrm{OH} 25$ & $1989-04-26$ & $09: 45$ & 0 & 1576.406 & 7986 & 0000 & 0.00 & $\begin{array}{l}\text { Device left with approximately } 50 \text { centibars } \\
\text { suction. }\end{array}$ \\
\hline $\mathrm{OH} 25$ & $1989-06-05$ & $09: 50$ & 0 & 1616.410 & 40004 & 0.000 & $0 \infty$ & $\begin{array}{l}\text { Hole dry No vacuum on collection device. } \\
\text { Collection device removed and replaced. }\end{array}$ \\
\hline $\mathrm{OH} 25$ & $1989-06-20$ & $09: 10$ & 0 & 1631.382 & 14.972 & 0.000 & 0.00 & Hole dry. \\
\hline $\mathrm{OH} 25$ & $1989-07-06$ & $11: 40$ & 0.01 & 1647.486 & 16.104 & 0001 & 0.01 & Collection device retained vacuum. \\
\hline $\mathrm{OH} 25$ & $1989-08-09$ & $10: 25$ & 0 & 1681.434 & 33.948 & 0.000 & 0.01 & Hole dry \\
\hline $\mathrm{OH} 25$ & $1989-08-23$ & $11: 18$ & 0 & 1695.471 & 14.037 & 0.000 & 0.01 & Hole dry. \\
\hline $\mathrm{OH} 25$ & $1989-10-02$ & $11: 35$ & 0 & 1735.483 & 40.012 & 0.000 & 0.01 & Hole dry. \\
\hline 0425 & $1989-10-20$ & $11: 35$ & 0 & 1753483 & 18000 & 0.000 & 0.01 & Hole dry. \\
\hline
\end{tabular}




\section{BRINE ACCUMULATION DATA TABLE (Continued) Data through December 31, 1990}

\begin{tabular}{|c|c|c|c|c|c|c|c|c|}
\hline Location & Date & Time & $\begin{array}{c}\text { Liters } \\
\text { removed }\end{array}$ & $\begin{array}{c}\text { Days } \\
\text { since } \\
1 / 1 / 85 \\
\end{array}$ & $\begin{array}{l}\text { Days } \\
\text { used for } \\
\text { calc. }\end{array}$ & $\begin{array}{l}\text { Liters } \\
\text { per } \\
\text { day }\end{array}$ & $\begin{array}{c}\text { Cumulative } \\
\text { liters } \\
\text { collected }\end{array}$ & Remarks \\
\hline
\end{tabular}

\begin{tabular}{|c|c|c|c|c|c|c|c|c|}
\hline $\begin{array}{l}\mathrm{OH} 26 \\
\mathrm{OH} 26\end{array}$ & $\begin{array}{l}1986-08-05 \\
1989-03-27\end{array}$ & $\begin{array}{l}14: 00 \\
14: 00\end{array}$ & $\begin{array}{l}\text { NA } \\
\text { NA }\end{array}$ & $\begin{array}{l}0.000 \\
0.000\end{array}$ & $\begin{array}{l}0.000 \\
0.000\end{array}$ & $\begin{array}{l}0.000 \\
0.000\end{array}$ & $\begin{array}{l}0.00 \\
0.00\end{array}$ & $\begin{array}{l}\text { Approximate date this part of drift excavated. } \\
\text { Horizontal hole drilled on } 3 / 27 / 89 \text {. Hole drilled } \\
\text { with brine. Fluorescien added to drilling fluid. }\end{array}$ \\
\hline $\mathrm{OH} 26$ & $1989-03-30$ & $10: 00$ & NA & 1548.417 & 0.000 & 0.000 & 0.00 & $\begin{array}{l}\text { New hole. Installed collection device. Hole } \\
\text { dry. }\end{array}$ \\
\hline OH26 & $1989-04-18$ & $10: 10$ & 0 & 1568.424 & 19.007 & 0.000 & 0.00 & $\begin{array}{l}\text { Device left with approximately } 50 \text { centibars } \\
\text { suction. }\end{array}$ \\
\hline $\mathrm{OH} 26$ & $1989-04-26$ & $09: 15$ & 0 & 1576.385 & 7.961 & 0.000 & 0.00 & $\begin{array}{l}\text { Device leth with approximately } 50 \text { centibars } \\
\text { suction. }\end{array}$ \\
\hline $\mathrm{OH} 26$ & $1989-06-05$ & $10: 00$ & 0.20 & 1616.417 & 40.032 & 0.005 & 0.20 & $\begin{array}{l}\text { First time sample recovered. Collection } \\
\text { device removed and replaced. }\end{array}$ \\
\hline $\mathrm{OH} 26$ & $1989-06-20$ & $09: 15$ & 0.05 & 1631.385 & 14.868 & 0.003 & 0.25 & \\
\hline $\mathrm{OH} 26$ & $1989-07-06$ & $11: 50$ & 0.49 & 1647.493 & 16.108 & 0.030 & 0.74 & Collection device retained vacuum. \\
\hline $\mathrm{OH} 26$ & $1989-08-09$ & $10: 30$ & 0.67 & 1681.438 & 33.945 & 0.020 & 1.41 & \\
\hline $\mathrm{OH} 26$ & $1989-08-23$ & 10:30 & 0.55 & 1695.438 & 14.000 & 0.039 & 1.96 & \\
\hline $\mathrm{OH} 26$ & $1989-09-14$ & $11: 21$ & 0.51 & 1717.473 & 22.035 & 0.023 & 2.47 & \\
\hline $\begin{array}{l}\mathrm{OH} 26 \\
\mathrm{OH} 26\end{array}$ & 1989-10-02 & $11: 40$ & $\begin{array}{l}0.56 \\
0.45\end{array}$ & $\begin{array}{l}1735.486 \\
1753.490\end{array}$ & 18.013 & 0.031 & 3.03 & \\
\hline $\mathrm{OH} 26$ & $\begin{array}{l}1989-10-20 \\
1989-11-10\end{array}$ & $\begin{array}{l}11: 45 \\
11: 04\end{array}$ & $\begin{array}{l}0.45 \\
0.48\end{array}$ & $\begin{array}{l}1753.490 \\
1774.461\end{array}$ & $\begin{array}{l}18.004 \\
20.971\end{array}$ & $\begin{array}{l}0.025 \\
0.023\end{array}$ & $\begin{array}{l}3.48 \\
3.96\end{array}$ & \\
\hline $\mathrm{OH} 26$ & $1989-11-29$ & $12: 40$ & 0.32 & 1793.528 & 19.067 & 0.017 & 4.28 & \\
\hline $\mathrm{OH} 26$ & $1989-12-12$ & $09: 38$ & 0.32 & 1806.401 & 12.873 & 0.025 & 4.60 & \\
\hline $\mathrm{OH} 26$ & $1990-01-04$ & $12: 05$ & 0.23 & 1829.503 & 23.102 & 0.010 & 4.83 & \\
\hline $\mathrm{OH} 26$ & $1990-01-17$ & $08: 58$ & 0.36 & 1842.374 & 12.871 & 0.028 & 5.19 & \\
\hline $\mathrm{OH} 26$ & $1990-01-31$ & $10: 54$ & 0.26 & 1856.454 & 14.080 & 0.018 & 5.45 & \\
\hline $\mathrm{OH} 26$ & $1990-02-13$ & $11: 30$ & 0.26 & 1869.479 & 13.025 & 0.020 & 5.71 & \\
\hline $\begin{array}{l}\mathrm{OH} 26 \\
\mathrm{OH} 26\end{array}$ & $\begin{array}{l}1990-03-05 \\
1990-03-21\end{array}$ & $\begin{array}{l}11: 27 \\
09: 26\end{array}$ & $\begin{array}{l}0.26 \\
0.18\end{array}$ & $\begin{array}{l}1889.477 \\
1905.393\end{array}$ & $\begin{array}{r}5.845 \\
15.916\end{array}$ & $\begin{array}{l}0.044 \\
0.011\end{array}$ & $\begin{array}{l}6.18 \\
6.36\end{array}$ & \\
\hline $\mathrm{OH} 26$ & $1990-04-24$ & $08: 33$ & 0.19 & 1839.356 & 13.869 & $\begin{array}{l}0.037 \\
0.014\end{array}$ & $\begin{array}{l}6.86 \\
7.05\end{array}$ & \\
\hline $\mathrm{OH} 26$ & 1990-05-02 & $09: 45$ & 0.24 & 1947.406 & 8.050 & 0.030 & 7.29 & \\
\hline OH26 & $1990-05-09$ & $09: 46$ & 0.21 & 1954.407 & 7.001 & 0.030 & 7.50 & \\
\hline $\mathrm{OH} 26$ & $1990-05-16$ & $11: 30$ & 0.15 & 1961.479 & 7.072 & 0.021 & 7.65 & \\
\hline OH26 & $1990-05-23$ & $13: 03$ & 0.12 & 1968.544 & 7.065 & 0.017 & 7.77 & \\
\hline $\mathrm{OH} 26$ & 1990-05-31 & $09: 29$ & 0.14 & 1976.395 & 7.851 & 0.018 & 7.91 & \\
\hline $\mathrm{OH} 26$ & $1990-06-06$ & $11: 35$ & 0.14 & 1982.483 & 6.088 & 0.023 & 8.05 & \\
\hline $\mathrm{OH} 26$ & $1990-06-14$ & $10: 42$ & 0.14 & 1990.446 & 7.963 & 0.018 & 8.19 & \\
\hline $\mathrm{OH} 26$ & $1990-06-28$ & 10:27 & 0.16 & 2004.435 & 13.889 & 0.011 & 8.35 & \\
\hline $\mathrm{OH} 26$ & $1990-07-17$ & $08: 56$ & 0.18 & 2023.372 & 18.937 & 0.000 & 8.53 & \\
\hline $\mathrm{OH} 26$ & $1990-07-18$ & $11: 00$ & 0.28 & 2024.458 & 1.086 & 0.023 & 8.81 & $\begin{array}{l}\text { Combined with } 0.18 \text { liters } 07 / 17 / 90 \text {. Used } \\
0.46 \text { liters for calculation. }\end{array}$ \\
\hline $\mathrm{OH} 26$ & $1990-07-25$ & 10:07 & 0.05 & 2031.422 & 6.964 & 0.007 & 8.86 & Brine probably left in hole. \\
\hline $\mathrm{OH} 26$ & 1990-08-01 & $11: 05$ & 0.25 & 2038.462 & 7.040 & 0.036 & 9.11 & \\
\hline $\mathrm{OH} 26$ & $1990-08-07$ & $09: 40$ & 0.11 & 2044.403 & 5.941 & 0.019 & 9.22 & \\
\hline $\mathrm{OH} 26$ & $1990-08-16$ & $09: 18$ & 0.12 & 2053.387 & 8.984 & 0.013 & 9.34 & \\
\hline $\mathrm{OH} 26$ & $1990-08-22$ & $10: 44$ & 0.10 & 2059.447 & 6.060 & 0.017 & 9.44 & \\
\hline $\mathrm{OH} 26$ & $1990-08-29$ & $10: 23$ & 0.11 & 2066.433 & 6.986 & 0.016 & 9.55 & \\
\hline $\mathrm{OH} 26$ & $1990-09-05$ & $10: 34$ & 0.11 & 2073.440 & 7.007 & 0.016 & 9.66 & \\
\hline $\mathrm{OH} 26$ & $1990-09-12$ & $08: 45$ & 0.10 & 2080.365 & 6.925 & 0.014 & 9.76 & \\
\hline $\mathrm{OH} 26$ & $1990-09-25$ & $11: 26$ & 0.19 & 2093.476 & 13.111 & 0.000 & 9.95 & \\
\hline
\end{tabular}


BRINE ACCUMULATION DATA TABLE (Continued) Data through December 31, 1990

\begin{tabular}{|c|c|c|c|c|c|c|c|c|}
\hline Location & Date & Time & $\begin{array}{c}\text { Liters } \\
\text { removed } \\
\end{array}$ & $\begin{array}{r}\text { Days } \\
\text { since } \\
1 / 1 / 85 \\
\end{array}$ & $\begin{array}{l}\text { Days } \\
\text { used tor } \\
\text { calc. }\end{array}$ & $\begin{array}{l}\text { Liters } \\
\text { per } \\
\text { day }\end{array}$ & $\begin{array}{l}\text { Cumulative } \\
\text { liters } \\
\text { collected } \\
\end{array}$ & Remarks \\
\hline OH26 & $1990-09-26$ & $09: 48$ & 0.10 & 2094.408 & 0.932 & 0.020 & 10.05 & $\begin{array}{l}\text { Combined with } 0.19 \text { liters from } 09 / 25 / 90 \text {. } \\
\text { Used } 0.29 \text { liters for calculation. }\end{array}$ \\
\hline $\begin{array}{l}\mathrm{OH} 26 \\
\mathrm{OH} 26\end{array}$ & $\begin{array}{l}1990-10-03 \\
1990-10-10\end{array}$ & $\begin{array}{l}08: 55 \\
10: 14\end{array}$ & $\begin{array}{l}0.10 \\
0.11\end{array}$ & $\begin{array}{l}2101.372 \\
2108.426\end{array}$ & 6.864 & $\begin{array}{l}0.094 \\
0.016\end{array}$ & $\begin{array}{l}10.15 \\
10.26\end{array}$ & \\
\hline $\mathrm{OH} 26$ & $1990-10-18$ & $09: 25$ & 0.13 & 2116.392 & 7.866 & 0.016 & 10.39 & \\
\hline $\mathrm{OH} 26$ & $1990-10-24$ & $11: 16$ & 0.11 & 2122.469 & 6.077 & 0.018 & 10.50 & \\
\hline $\mathrm{OH} 26$ & $1990-10-31$ & $10: 43$ & 0.12 & 2129.447 & 6.978 & 0.017 & 10.62 & \\
\hline OH26 & $1990-11-07$ & $11: 43$ & 0.13 & 2136.488 & 7.041 & 0.018 & 10.75 & \\
\hline $\mathrm{OH} 26$ & $1990-11-14$ & $10: 40$ & 0.10 & 2143.444 & 6.956 & 0.014 & 10.85 & \\
\hline $\mathrm{OH} 26$ & $1990-11-28$ & $11: 20$ & 0.21 & 2157.472 & 14.028 & 0.015 & 11.06 & \\
\hline $\begin{array}{l}\mathrm{OH} 26 \\
\mathrm{OH} 26\end{array}$ & $\begin{array}{l}1990-12-05 \\
1990-12-13\end{array}$ & $\begin{array}{l}09: 30 \\
10: 20\end{array}$ & $\begin{array}{l}0.14 \\
0.13\end{array}$ & $\begin{array}{l}2164.396 \\
2172.431\end{array}$ & $\begin{array}{l}6.924 \\
8.035\end{array}$ & $\begin{array}{l}0.020 \\
0.016\end{array}$ & $\begin{array}{l}11.20 \\
11.33\end{array}$ & \\
\hline $\mathrm{OH} 26$ & $1990-12-20$ & $10: 20$ & 0.11 & 2179.431 & 7.000 & 0.016 & 11.44 & \\
\hline \multicolumn{9}{|c|}{ 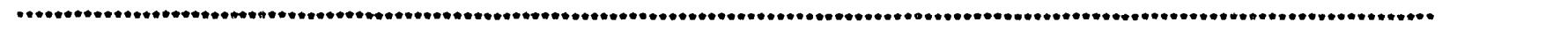 } \\
\hline $\mathrm{OH} 27$ & $1986-08-05$ & $14: 00$ & NA & 0.000 & 0.000 & 0.000 & 0.00 & Approximate date this part of drift excavated. \\
\hline $\mathrm{OH} 27$ & 1989-04-17 & $14: 00$ & NA & 0.000 & 0.000 & 0.000 & $0 . \infty$ & Horizontal hole drilled $4 / 13 / 89$ to $4 / 17 / 89$ \\
\hline $\mathrm{OH} 27$ & $1989-04-18$ & $10: 15$ & 0 & 1568.427 & 1568.430 & 0.000 & 0.00 & $\begin{array}{l}\text { Device left with approximately } 50 \text { cenubars } \\
\text { suction. }\end{array}$ \\
\hline $\mathrm{OH} 27$ & $1989-04-26$ & $09: 25$ & 0 & 1576.392 & 7.965 & 0.000 & 0.00 & $\begin{array}{l}\text { Device left with approximately } 50 \text { centibars } \\
\text { suction. }\end{array}$ \\
\hline OH27 & $1989-06-05$ & $10: 10$ & 0 & 1616.424 & 40.032 & 0.000 & 0.00 & $\begin{array}{l}\text { Hole dry. Collection device removed and } \\
\text { replaced. }\end{array}$ \\
\hline $\mathrm{OH} 27$ & $1989-06-20$ & $09: 20$ & 0 & 1631.389 & 14.965 & 0.000 & $0 . \infty$ & Hole dry. \\
\hline $\mathrm{OH} 27$ & $1989-07-06$ & 11:55 & 0.02 & 1647.497 & 16.108 & 0.001 & 0.02 & Collection device retained vacuum. \\
\hline $\mathrm{OH} 27$ & $1989-08-09$ & $10: 35$ & Trace & 1681.441 & 0.000 & 0.000 & 0.02 & Trace of brine found. \\
\hline $\mathrm{OH} 27$ & $1989-08-23$ & $10: 57$ & Trace & 1695.456 & 0.000 & 0.000 & 0.02 & Trace of fluid in hole. \\
\hline $\mathrm{OH} 27$ & $1989-10-02$ & $11: 45$ & 0 & 1735.490 & 87.993 & 0.000 & 0.02 & Hole dry. \\
\hline $\mathrm{OH} 27$ & $1989-10-20$ & $11: 45$ & 0 & 1753.490 & 18.000 & 0.000 & 0.02 & Hole dry. \\
\hline $\mathrm{OH} 27$ & $1989-11-10$ & $11: 14$ & 0 & 1774.468 & 20.978 & 0.000 & 0.02 & Hole dry. \\
\hline $\mathrm{OH} 27$ & $1989-11-29$ & $12: 45$ & 0 & 1793.531 & 19.063 & 0.000 & 0.02 & Hole dry. \\
\hline $\mathrm{OH} 27$ & $1989-12 \cdot 12$ & $09: 40$ & 0 & 1806.403 & 12.872 & 0.000 & 0.02 & Hole dry. \\
\hline $\mathrm{OH} 27$ & $1990-04-24$ & $08: 52$ & 0.17 & 1939.369 & 132.966 & 0.001 & 0.19 & \\
\hline $\mathrm{OH} 27$ & $1990-08-10$ & $09: 30$ & NA & 2047.396 & & & 0.19 & $\begin{array}{l}\text { Cleaned, checked. and reinstalled vacuum up } \\
\text { to } 50 \text { centubars. Checked in one hour. } \\
\text { Sampler holding vacuum. }\end{array}$ \\
\hline \multicolumn{9}{|c|}{$\ldots$} \\
\hline OH27A & $1986-08-05$ & $14: 00$ & NA & 0.000 & 0.000 & 0.000 & 0.00 & Approximate date this part of drift excavated. \\
\hline OH27A & 1989-04-04 & $14: 00$ & NA & 0.000 & 0.000 & 0.000 & 0.00 & Horizontal hole drilled on $4 / 4 / 89$ \\
\hline OH27A & $1989-04-18$ & $10: 20$ & 0 & 1568.431 & 1568.430 & 0.000 & $0 . \infty$ & $\begin{array}{l}\text { Devico left with approximately } 50 \text { centibars } \\
\text { suction. }\end{array}$ \\
\hline OH27A & 1989-04-26 & 09:20 & 0.21 & 1576.389 & 7.958 & 0.026 & 0.21 & $\begin{array}{l}\text { Device left with approximately } 50 \text { centubars } \\
\text { suction. }\end{array}$ \\
\hline OH27A & $1989-05-17$ & 09:10 & 0.08 & 1597.382 & 20.993 & 0.004 & 0.29 & \\
\hline OH27A & $1989-06-05$ & $10: 20$ & 0 & 1616.431 & 19.049 & 0.000 & 0.29 & $\begin{array}{l}\text { Hole dry. Collection device removed and } \\
\text { replaced. }\end{array}$ \\
\hline OH27A & 1989-06-20 & 09:25 & 0 & 1631.392 & 14.961 & 0.000 & 0.29 & Hole dry. \\
\hline OH27A & 1989-07-06 & $11: 55$ & 0 & 1647.497 & 16.105 & 0.000 & 0.29 & Hole dry. Collection device retained vacuum. \\
\hline OH27A & $1989-08-09$ & $10: 40$ & 0 & 1681.444 & 33.947 & 0.000 & 0.29 & Hole dry. \\
\hline OH27A & $1989-08-23$ & $10: 50$ & 0 & 1695.451 & 14.007 & 0.000 & 0.29 & Hole dry. \\
\hline OH27A & $1989-10-02$ & $11: 45$ & 0 & 1735.490 & 40.039 & 0.000 & 0.29 & Hole dry. \\
\hline OH27A & $1989-10-20$ & $11: 45$ & 0 & 1753.490 & 18.000 & 0.000 & 0.29 & Hole dry. \\
\hline OH27A & $1989-11-10$ & $11: 14$ & 0 & 1774.468 & 20.978 & 0.000 & 0.29 & Hole dry. \\
\hline OH27A & $1989-11-29$ & $12: 48$ & 0 & 1793.533 & 19.065 & 0.000 & 0.29 & Hole dry. \\
\hline OH27A & $1989-12-12$ & $09: 40$ & 0 & 1806.403 & 12.870 & 0.000 & 029 & Hole dry. \\
\hline \multicolumn{9}{|c|}{ 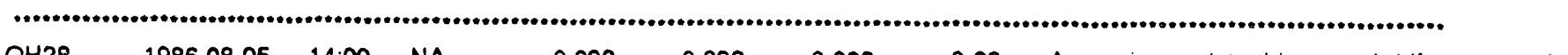 } \\
\hline $\begin{array}{l}\mathrm{OH} 28 \\
\mathrm{OH} 28\end{array}$ & $\begin{array}{l}1986-08-05 \\
1989-04-12\end{array}$ & $\begin{array}{l}14: 00 \\
14: 00\end{array}$ & $\begin{array}{l}\text { NA } \\
\text { NA }\end{array}$ & $\begin{array}{l}0.000 \\
0.000\end{array}$ & $\begin{array}{l}0.000 \\
0.000\end{array}$ & $\begin{array}{l}0.000 \\
0.000\end{array}$ & $\begin{array}{l}0.00 \\
0.00\end{array}$ & $\begin{array}{l}\text { Approximate date this part of drift excavate } \\
\text { Honzontal hole drilled } 4 / 11 / 89 \text { to } 4 / 12 / 89 \text {. }\end{array}$ \\
\hline
\end{tabular}


BRINE ACCUMULATION DATA TABLE (Continued) Data through December 31, 1990

\begin{tabular}{|c|c|c|c|c|c|c|c|c|}
\hline Location & Dato & Time & $\begin{array}{l}\text { Liters } \\
\text { removed }\end{array}$ & $\begin{array}{c}\text { Days } \\
\text { sinco } \\
1 / 1 / 85 \\
\end{array}$ & $\begin{array}{l}\text { Days } \\
\text { used tor } \\
\text { calc. }\end{array}$ & $\begin{array}{l}\text { Liters } \\
\text { por } \\
\text { day }\end{array}$ & $\begin{array}{c}\text { Cumulative } \\
\text { litere } \\
\text { collected }\end{array}$ & Remarks \\
\hline OH28 & $1989-04-18$ & 10:25 & 0 & 1568.434 & 1568.430 & 0.000 & 0.00 & $\begin{array}{l}\text { Device lett with approximately } 50 \text { centibars } \\
\text { suction. }\end{array}$ \\
\hline OH28 & $1980-04-26$ & $09: 30$ & 0 & 1576.396 & $7: 962$ & 0.000 & 0.00 & $\begin{array}{l}\text { Device left with approximately } 50 \text { centibars } \\
\text { suction. }\end{array}$ \\
\hline $\mathrm{OH} 28$ & $1989-06-05$ & $10: 30$ & 0.08 & 1616.438 & 40.042 & 0.002 & 0.08 & $\begin{array}{l}\text { First time sample recovered. Collection } \\
\text { device removed and replaced. }\end{array}$ \\
\hline $\begin{array}{l}\mathrm{OH} 28 \\
\mathrm{OH} 28\end{array}$ & $\begin{array}{l}1989-06-20 \\
1989-07-06\end{array}$ & $\begin{array}{l}09: 30 \\
12: 00\end{array}$ & $\begin{array}{l}0.03 \\
0\end{array}$ & $\begin{array}{l}1631.396 \\
1647.500\end{array}$ & $\begin{array}{l}14.958 \\
16.104\end{array}$ & $\begin{array}{l}0.002 \\
0.000\end{array}$ & $\begin{array}{l}0.11 \\
0.11\end{array}$ & Hole dry. Collection device retained vacuum. \\
\hline $\mathrm{OH} 28$ & $1989-08-09$ & $10: 45$ & 0 & 1681.448 & 33.848 & 0.000 & 0.11 & Hole dry. \\
\hline $\mathrm{OH} 28$ & $1989-08-23$ & $10: 46$ & 0 & 1695.449 & 14.001 & 0.000 & 0.11 & Hole dry. \\
\hline OH28 & $1989-10-02$ & $11: 50$ & 0.05 & 1735.483 & 40.044 & 0.001 & 0.16 & \\
\hline OH28 & $1989-10-20$ & $11: 45$ & 0 & 1753.490 & 17.007 & 0.000 & 0.16 & Hole dry. \\
\hline OH28 & $1989-11-10$ & $11: 10$ & 0.07 & 1774.465 & 20.975 & 0.003 & 0.23 & \\
\hline $\mathrm{OH} 28$ & $1989-11-29$ & $12: 48$ & 0 & 1793.533 & 19.068 & 0.000 & 0.23 & Hole dy. \\
\hline $\mathrm{OH} 28$ & $1989-12-12$ & $09: 48$ & 0.10 & 1806.408 & 12.875 & 0.008 & 0.33 & \\
\hline $\mathrm{OH} 28$ & $1990-04-10$ & $09: 36$ & 0.14 & 1925.400 & 118.992 & 0.001 & 0.47 & \\
\hline $\mathrm{OH} 28$ & $1990-04-24$ & 08:36 & 0.18 & 1939.358 & 13.858 & 0.013 & 0.65 & \\
\hline $\mathrm{OH} 28$ & $1990-05-02$ & 09:35 & 0.01 & 1947.399 & 8.041 & 0.001 & 0.66 & \\
\hline $\mathrm{OH} 28$ & $1990-05-09$ & $09: 40$ & NA & 1954.403 & & & 0.66 & Trace. \\
\hline $\mathrm{OH} 28$ & $1990-05-16$ & $11: 38$ & 0.02 & 1961.485 & 14.086 & 0.001 & 0.68 & \\
\hline $\begin{array}{l}\mathrm{OH} 28 \\
\mathrm{OH} 28\end{array}$ & $\begin{array}{l}1990-05-31 \\
1990-08-07\end{array}$ & $\begin{array}{l}09: 33 \\
09: 42\end{array}$ & $\begin{array}{l}0.01 \\
0.10\end{array}$ & $\begin{array}{l}1976.398 \\
2044.404\end{array}$ & $\begin{array}{l}14.913 \\
68.006\end{array}$ & $\begin{array}{l}0.001 \\
0.001\end{array}$ & $\begin{array}{l}0.69 \\
0.79\end{array}$ & \\
\hline $\mathrm{OH} 28$ & $1990-08-10$ & $09: 10$ & NA & 2047.382 & & ( & 0.79 & $\begin{array}{l}\text { Cleaned, checked, and reinstalled vacuum up } \\
\text { to } 50 \text { centbars. Checked in one hour. } \\
\text { Sampler holding vacuum. }\end{array}$ \\
\hline $\mathrm{OH} 28$ & $1990-09-12$ & 08:40 & 0.04 & 2080.361 & 35.957 & 0.001 & 0.83 & 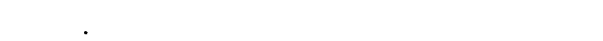 \\
\hline $\mathrm{OH} 28$ & $1990-09-26$ & $09: 50$ & 0.05 & 2094.410 & 14.049 & 0.004 & 0.88 & \\
\hline $\mathrm{OH} 28$ & $1990-11-28$ & $11: 28$ & 0.08 & 2157.478 & 63.068 & 0.001 & 0.96 & \\
\hline $\mathrm{OH} 28$ & $1990-12-20$ & $10: 27$ & 0.07 & 2179.435 & 21.957 & 0.003 & 1.03 & \\
\hline \multicolumn{9}{|c|}{ ". } \\
\hline $\mathrm{OH} 45$ & $1989-05-08$ & $14: 00$ & NA & 0.000 & 0.000 & 0.000 & 0.00 & $\begin{array}{l}\text { Approximate date this part of underground } \\
\text { core storage room excavated. }\end{array}$ \\
\hline $\begin{array}{l}\mathrm{OH} 45 \\
\mathrm{OH} 45\end{array}$ & $\begin{array}{l}1889-06-15 \\
1889-06-23\end{array}$ & $\begin{array}{l}14: 00 \\
11: 00\end{array}$ & $\begin{array}{l}\text { NA } \\
\text { NA }\end{array}$ & $\begin{array}{r}0.000 \\
1634.458\end{array}$ & $\begin{array}{l}0.000 \\
0.000\end{array}$ & $\begin{array}{l}0.000 \\
0.000\end{array}$ & $\begin{array}{l}0 . \infty 0 \\
0.00\end{array}$ & $\begin{array}{l}\text { Horizontal hole drilled } 6 / 9 / 89 \text { to } 6 / 15 / 89 \text {. } \\
\text { New hole. Installed collection device. }\end{array}$ \\
\hline OH45 & $1889-08-09$ & $14: 00$ & 0 & 1681.583 & 47.125 & 0.000 & 0.00 & $\begin{array}{l}\text { No vacuum, reinstalled collection device. } \\
\text { Hole dry. }\end{array}$ \\
\hline $\begin{array}{l}\mathrm{OH} 45 \\
\mathrm{OH} 45\end{array}$ & $\begin{array}{l}1980-08-23 \\
1982-09-12\end{array}$ & $\begin{array}{l}11: 30 \\
12: 35\end{array}$ & $\begin{array}{l}0.45 \\
0.15\end{array}$ & $\begin{array}{l}1695.479 \\
1715.524\end{array}$ & $\begin{array}{l}13.896 \\
20.045\end{array}$ & $\begin{array}{l}0.032 \\
0.007\end{array}$ & $\begin{array}{l}0.45 \\
0.60\end{array}$ & First time hole sampled. \\
\hline $\mathrm{OH} 45$ & $1889-10-02$ & $12: 15$ & 0.13 & 1735.510 & 19.986 & 0.007 & 0.73 & \\
\hline OH45 & $1989-10-20$ & $11: 10$ & 0.11 & 1753.465 & 17.955 & 0.006 & 0.84 & \\
\hline OH45 & $1889-11-10$ & 10:20 & 0.13 & 1774.431 & 20.966 & 0.006 & 0.97 & \\
\hline $\mathrm{OH} 45$ & $1889-11-29$ & $13: 11$ & 0.11 & 1793.549 & 18.118 & 0.006 & 1.08 & \\
\hline OH45 & $1989-12-12$ & $10: 19$ & 0.08 & 1806.430 & 12.881 & 0.006 & 1.16 & Sample bubbling. \\
\hline $\mathrm{OH} 45$ & $1990-01-04$ & $11: 41$ & 0.14 & 1829.487 & 23.057 & 0.006 & 1.30 & \\
\hline $\mathrm{OH} 45$ & $1990-01-17$ & $11: 54$ & 0.08 & 1842.496 & 13.009 & 0.006 & 1.38 & \\
\hline $\mathrm{OH} 45$ & $1990-01-31$ & $11: 08$ & 0.01 & 1856.464 & 13.968 & 0.001 & 1.39 & \\
\hline $\mathrm{OH} 45$ & $1990-02-13$ & $10: 54$ & 0.01 & 1869.454 & 12.990 & 0.001 & 1.40 & \\
\hline $\mathrm{OH} 45$ & $1930-02-27$ & $12: 56$ & 0.11 & 1883.539 & 14.085 & 0.008 & 1.51 & Removed arid replaced sampler. \\
\hline $\mathrm{OH} 45$ & $1990-03-05$ & $11: 45$ & 0.08 & 1889.490 & 5.951 & 0.013 & 1.59 & \\
\hline $\mathrm{OH} 45$ & $1990-03-21$ & $11: 34$ & NA & 1905.482 & & & 0.43 & Trace. \\
\hline $\begin{array}{l}\mathrm{OH} 45 \\
\mathrm{OH} 45\end{array}$ & $\begin{array}{l}1990-04-10 \\
1990-05-02\end{array}$ & $\begin{array}{l}10: 28 \\
09: 12\end{array}$ & $\begin{array}{l}\text { NA } \\
0.06\end{array}$ & $\begin{array}{l}1925.436 \\
1947.383\end{array}$ & 57.893 & 0.001 & $\begin{array}{l}0.43 \\
1.65\end{array}$ & Trace. \\
\hline $\mathrm{OH} 45$ & $1990-05-09$ & $10: 03$ & NA & 1954.419 & & & 0.49 & Trace. \\
\hline $\mathrm{OH} 45$ & $1890-05-17$ & $09: 20$ & 0.05 & 1962.389 & 15.006 & 0.003 & 1.70 & \\
\hline $\mathrm{OH} 45$ & $1990-05-23$ & 13:10 & 0.01 & 1968.549 & 6.160 & 0.002 & 1.71 & \\
\hline $\mathrm{OH} 45$ & $1990-06-14$ & $10: 15$ & 0.01 & 1990.427 & 21.878 & 0.000 & 1.72 & Brine probably left in hole. \\
\hline $\mathrm{OH} 45$ & $1990-07-17$ & $11: 58$ & 0.46 & 2023.499 & 33.072 & 0.014 & 2.18 & \\
\hline
\end{tabular}



BRINE ACCUMULATION DATA TABLE (Continued)
Data through December 31, 1990

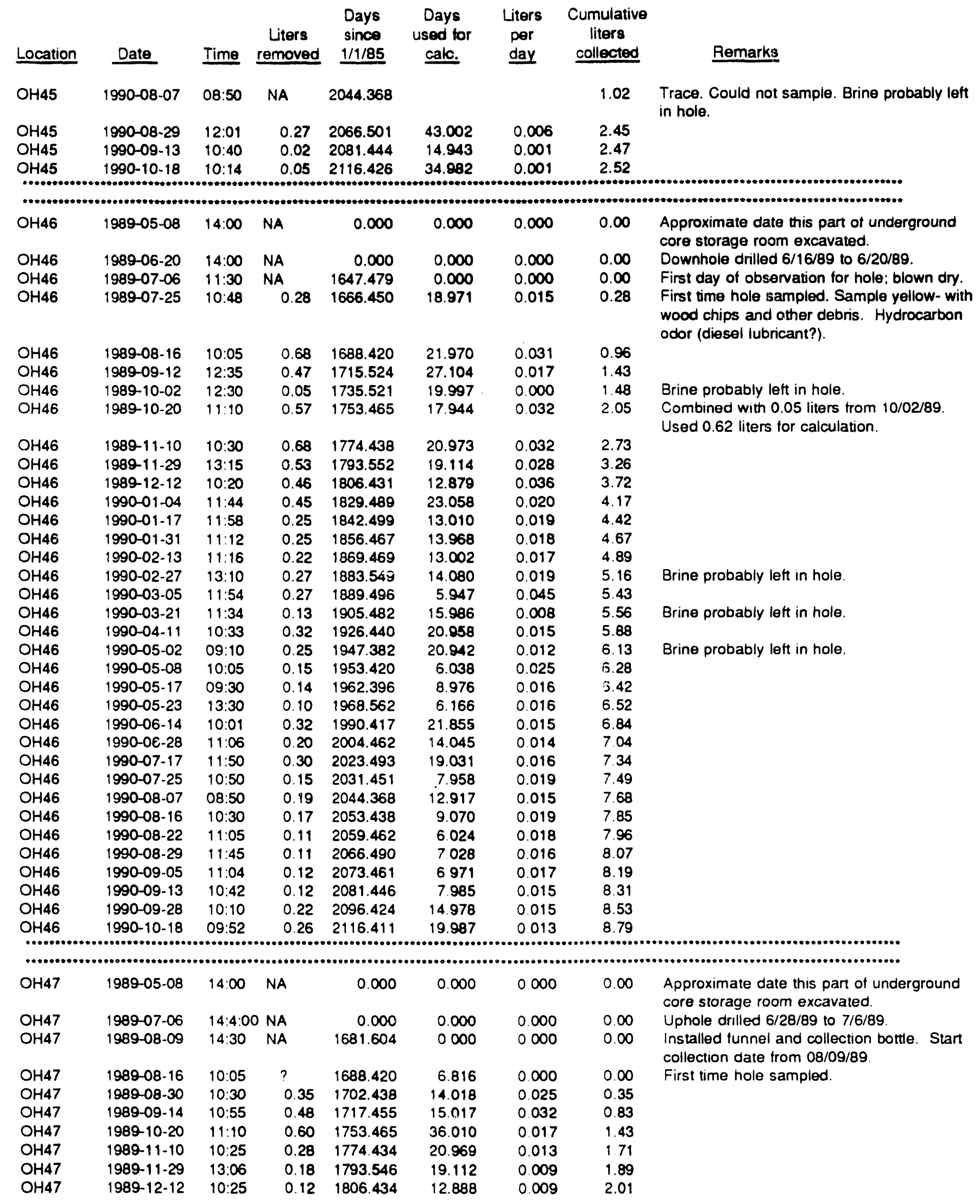


BRINE ACCUMULATION DATA TABLE (Continued)

Data through December 31, 1990

\begin{tabular}{|c|c|c|c|c|c|c|c|c|}
\hline Location & Date & Time & $\begin{array}{l}\text { Liters } \\
\text { removed } \\
\end{array}$ & $\begin{array}{l}\text { Days } \\
\text { since } \\
1 / 1 / 85 \\
\end{array}$ & $\begin{array}{l}\text { Days } \\
\text { used for } \\
\text { calc. }\end{array}$ & $\begin{array}{l}\text { Liters } \\
\text { per } \\
\text { day }\end{array}$ & $\begin{array}{c}\text { Cumulative } \\
\text { liters } \\
\text { collected } \\
\end{array}$ & Remarks \\
\hline $\mathrm{OH} 47$ & $1990-01-04$ & $11: 40$ & 0.24 & 1829.486 & 23.052 & 0.010 & 2.25 & \\
\hline $\mathrm{OH} 47$ & $1990-01-17$ & $11: 59$ & 0.13 & 1842.499 & 13.013 & 0.010 & 2.38 & \\
\hline $\mathrm{OH} 47$ & $1990-01-31$ & $11: 15$ & 0.11 & 1856.469 & 13.970 & 0.008 & 2.49 & \\
\hline $\mathrm{OH} 47$ & $1990-02-13$ & $11: 20$ & 0.09 & 1869.472 & 13.003 & 0.007 & 2.58 & \\
\hline $\mathrm{OH} 47$ & $1990-02-27$ & $13: 30$ & 0.12 & 1883.562 & 14.090 & 0.009 & 2.70 & \\
\hline $\mathrm{OH} 47$ & 1990-03-05 & $11: 57$ & 0.09 & 1889.498 & 5.936 & 0.015 & 2.79 & \\
\hline $\mathrm{OH} 47$ & $1990-03-21$ & $11: 41$ & 0.11 & 1905.487 & 15.989 & 0.007 & 2.90 & \\
\hline $\mathrm{OH} 47$ & $1990-04-11$ & $10: 30$ & 0.05 & 1926.438 & 20.851 & 0.002 & 2.95 & \\
\hline $\mathrm{OH} 47$ & $1990-05-02$ & $08: 55$ & 0.08 & 1947.372 & 20.934 & 0.004 & 3.03 & \\
\hline $\mathrm{OH} 47$ & $1990-05-08$ & $10: 07$ & 0.09 & 1953.422 & 6.050 & 0.015 & 3.12 & \\
\hline $\mathrm{OH} 47$ & $1990-05-17$ & $09: 25$ & 0.02 & 1962.392 & 8.970 & 0.002 & 3.14 & \\
\hline $\mathrm{OH} 47$ & $1990-05-23$ & $13: 30$ & 0.01 & 1968.562 & 6.170 & 0.002 & 3.15 & \\
\hline $\mathrm{OH} 47$ & $1990-06-14$ & $10: 08$ & 0.13 & 1990.422 & 21.860 & 0.006 & 3.28 & \\
\hline $\mathrm{OH} 47$ & $1990-07-17$ & $11: 42$ & 0.08 & 2023.487 & 33.065 & 0.002 & 3.36 & \\
\hline $\mathrm{OH} 47$ & $1990-08-07$ & $08: 56$ & 0.05 & 2044.372 & 20.885 & 0.002 & 3.41 & \\
\hline $\mathrm{OH} 47$ & $1990-08-22$ & $11: 07$ & 0.04 & 2059.463 & 15.091 & 0.003 & 3.45 & \\
\hline $\mathrm{OH}_{47}$ & $1990-08-29$ & $11: 47$ & 0.02 & 2066.491 & 7.028 & 0.003 & 3.47 & $\begin{array}{l}\text { Red-brown mud in collection bottle, cleaned } \\
\text { out. }\end{array}$ \\
\hline $\mathrm{OH} 47$ & $1990-09-05$ & $10: 45$ & NA & 2073.448 & & & 3.47 & Trace. \\
\hline $\mathrm{OH} 47$ & $1990-09-13$ & $10: 45$ & 0.15 & 2081.448 & 14.957 & 0.010 & 3.62 & \\
\hline $\mathrm{OH} 47$ & $1990-10-18$ & $09: 54$ & 0.13 & 2116.412 & 34.864 & 0.004 & 3.75 & \\
\hline
\end{tabular}


This page left intentionally blank 
This page left intentionally blank 


\section{APPENDIX B \\ GRAPHS OF BRINE ACCUMULATION DATA}


This page left intentionally blank 


\section{APPENDIX B GRAPHS OF BRINE ACCUMULATION DATA}

This appendix contains graphs of data presented in Appendix A for selected locations. As described in Deal and Case (1987), much of the variability in the quantity of brine collected resulted from limitations of the collection techniques, rather than variations in the actual inflow of brine from bedrock at the collecting locations. As a result, plotting of the inflow data from the data tables (Appendix A) results in an irregular plot that implies variations in inflow which, in fact, do not exist. The graphed data included in this report were processed and plotted by a standard software program (STSC Statgraphics) ${ }^{1}$ on an IBM XT microcomputer, using an 11 -point moving average to smooth the curve, unless othenvise stated. The smoothed data reflect trends in the body of the curve that are representative of the brine seepage rates. while still showing variations that are probably the result of collection techniques.

At the beginning and end of each curve, the smoothing program projects the calculated trend. As a result, initial and ending real values, usually zero, and maximum inflow values within the first few data points, tend to be distorted by the smoothing program. In order to correct the distortion caused by the smoothing program, the smoothed data are replaced by the actual data for the first and last few data points prior to plotting. Additional discussion of the collection and data handling is provided in Deal and Case (1987).

'Statgraphics, 1989. Version 4.0, Statistical Graphics Corporation. Rockville, Matryland. 
This page left intentionally blank 

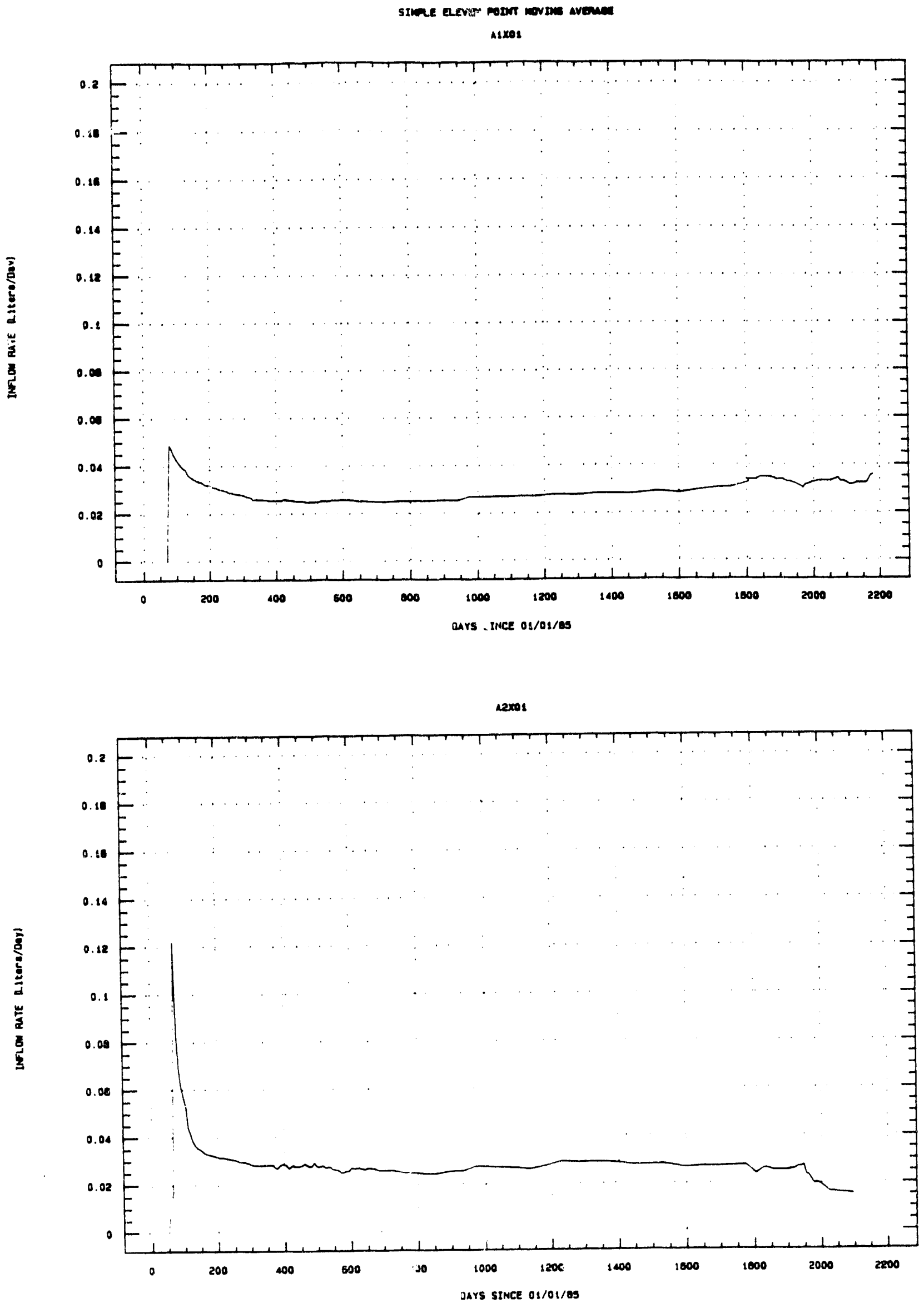

B.3 

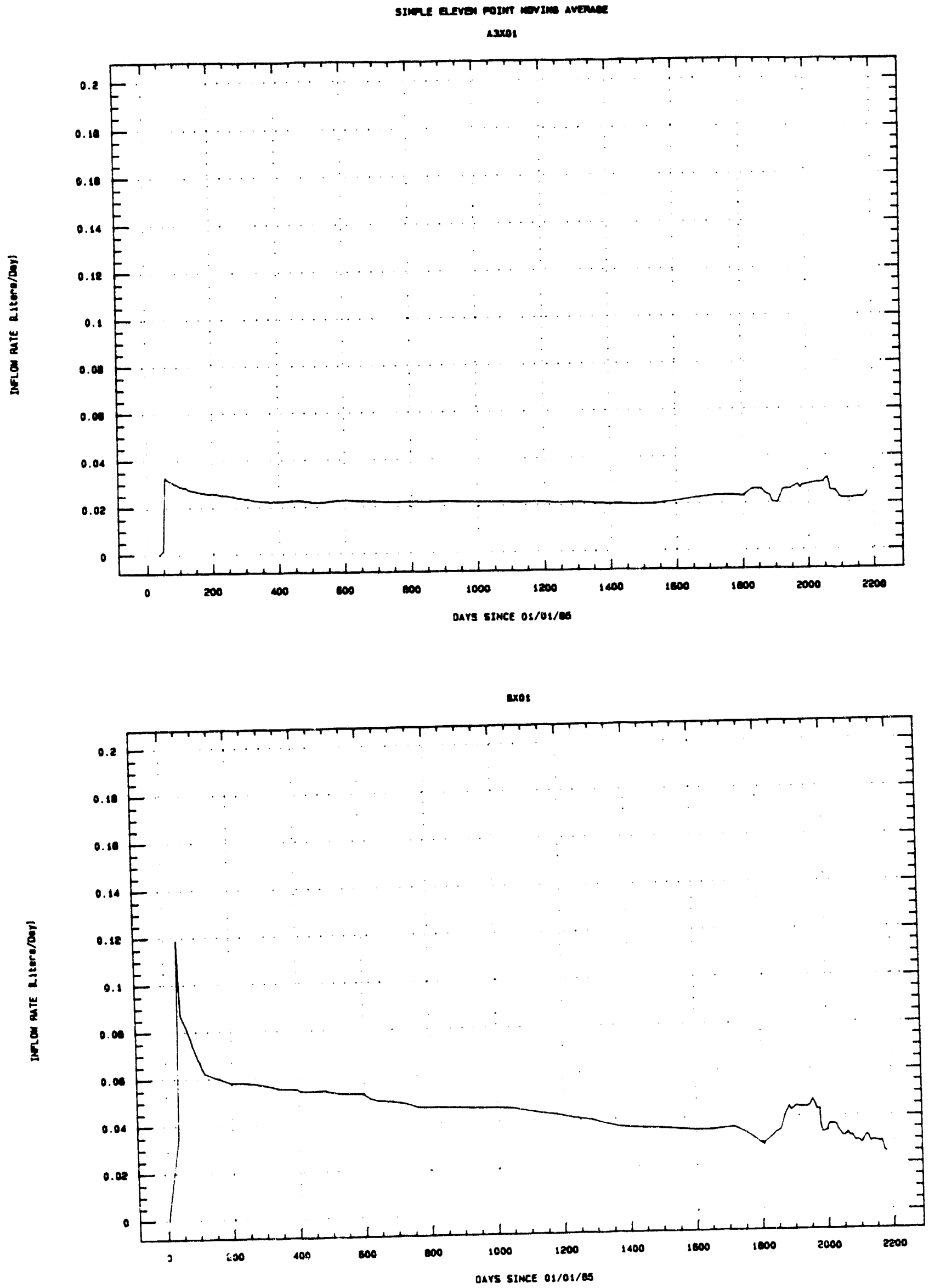

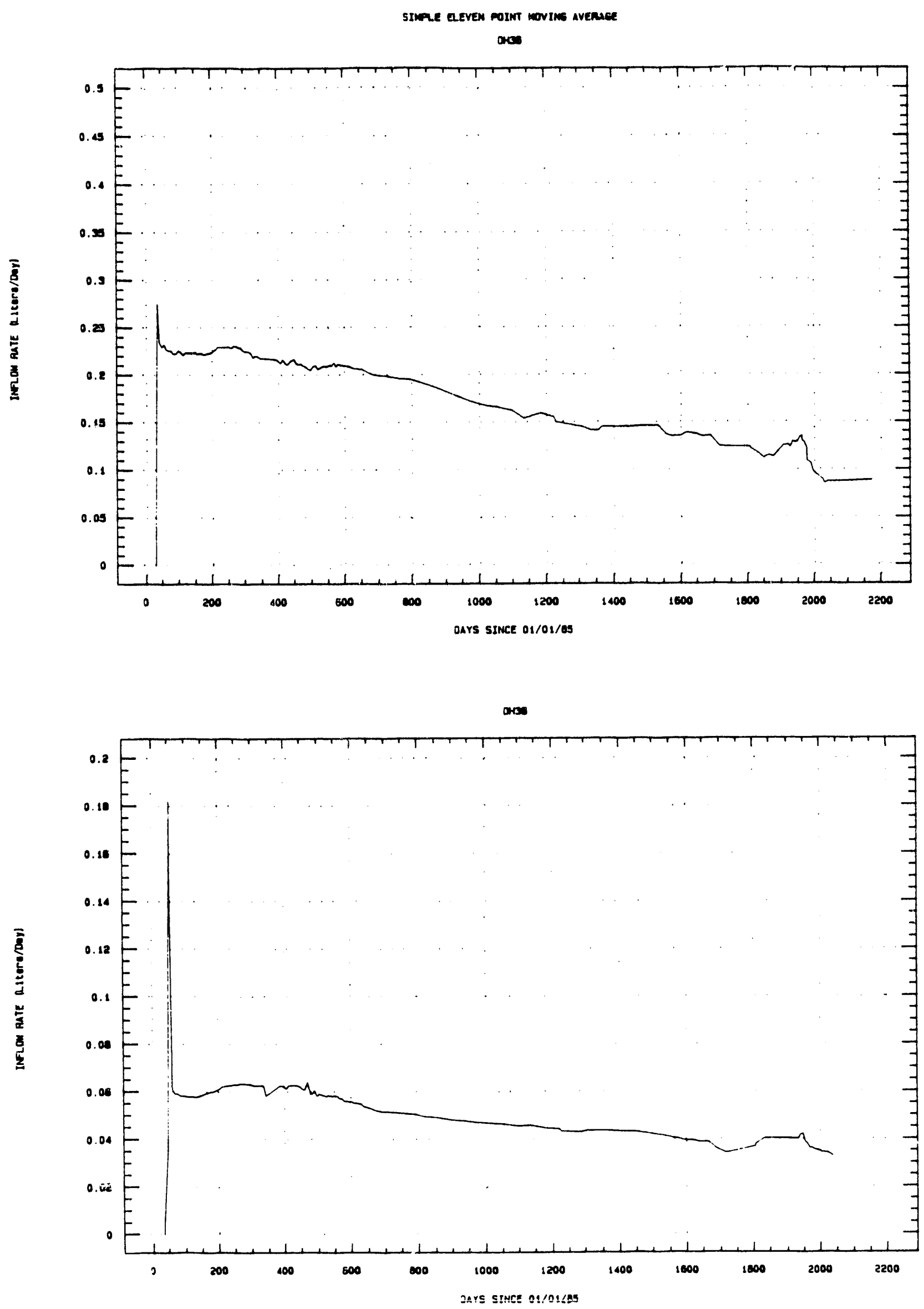

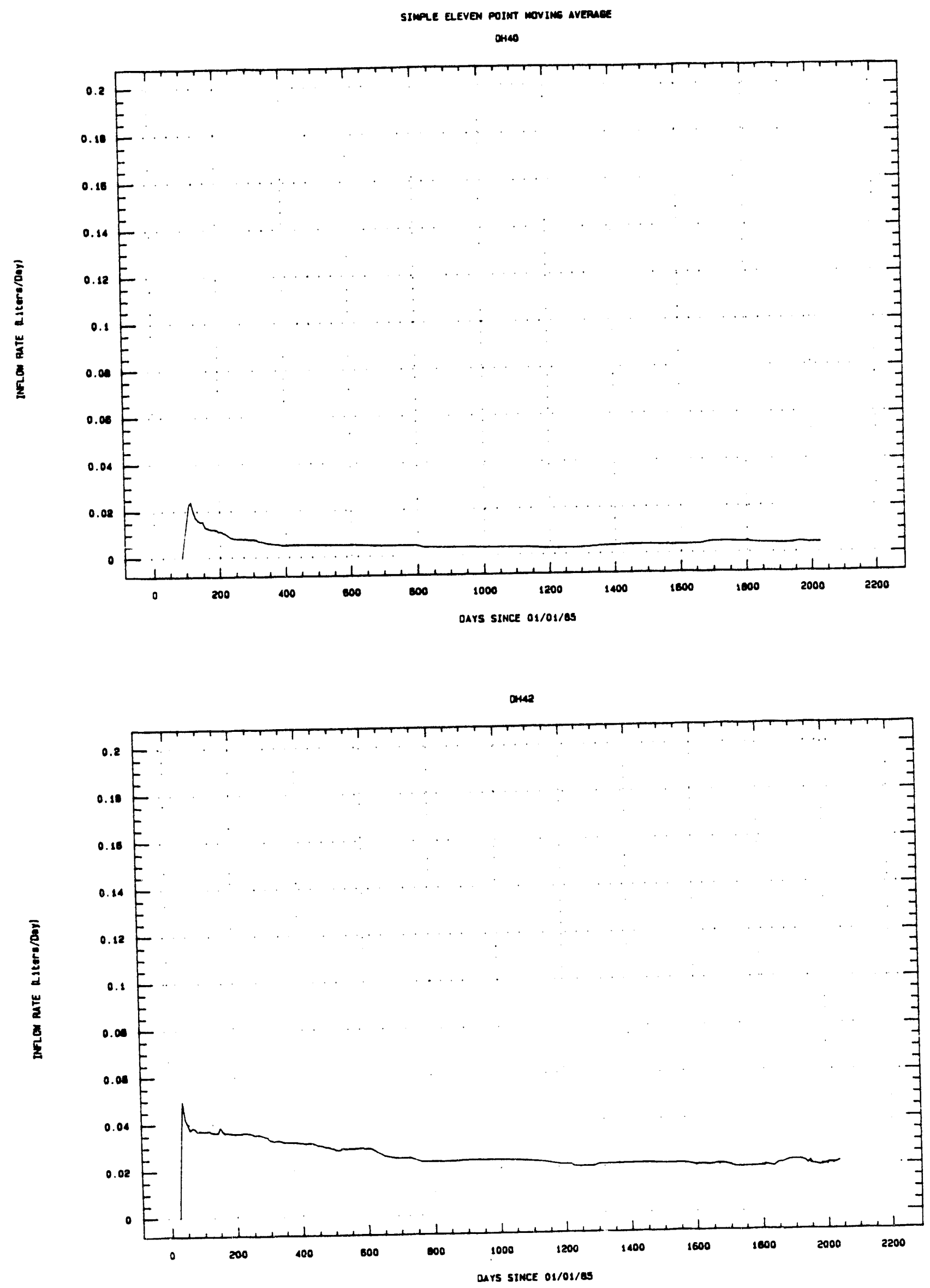

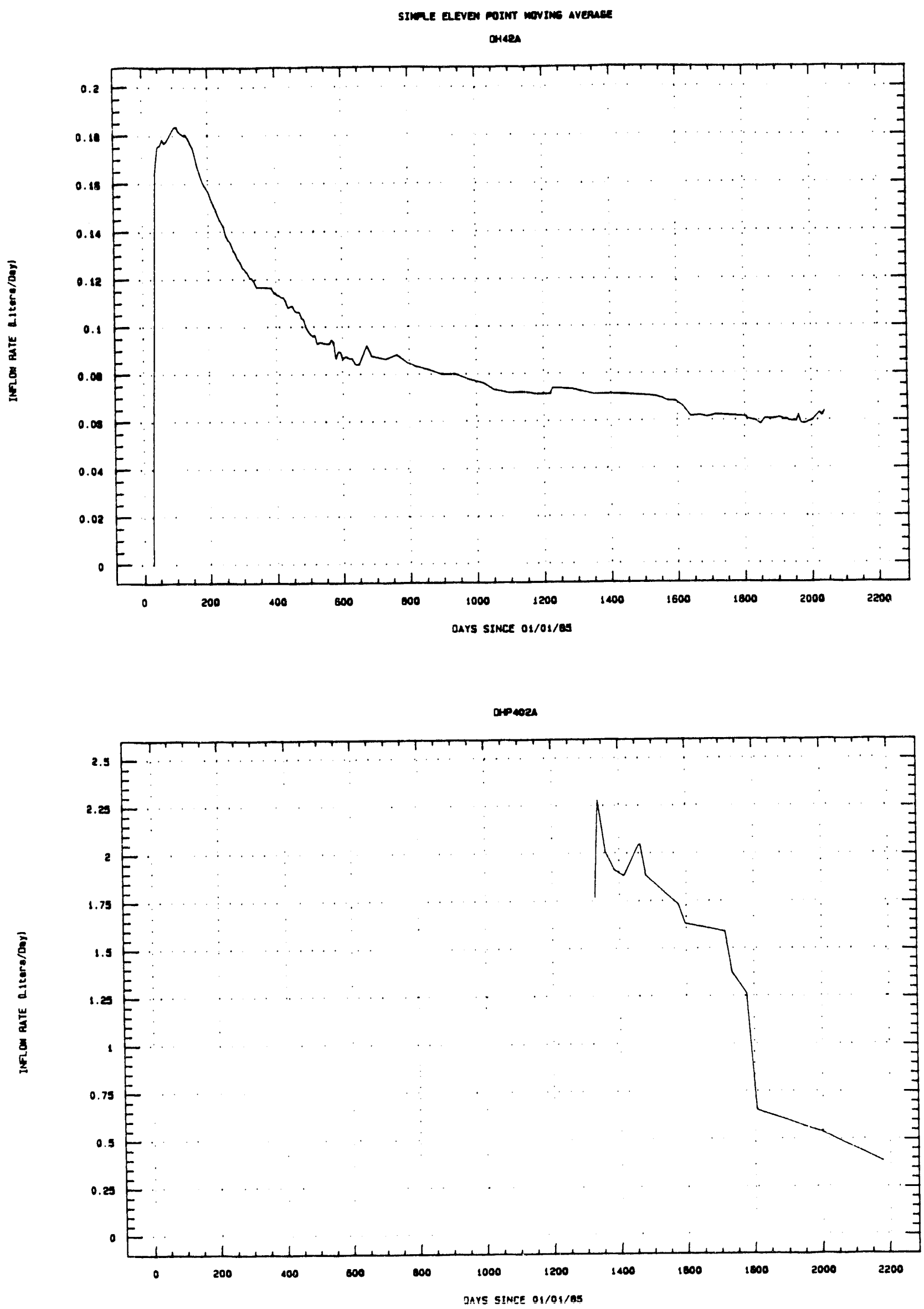

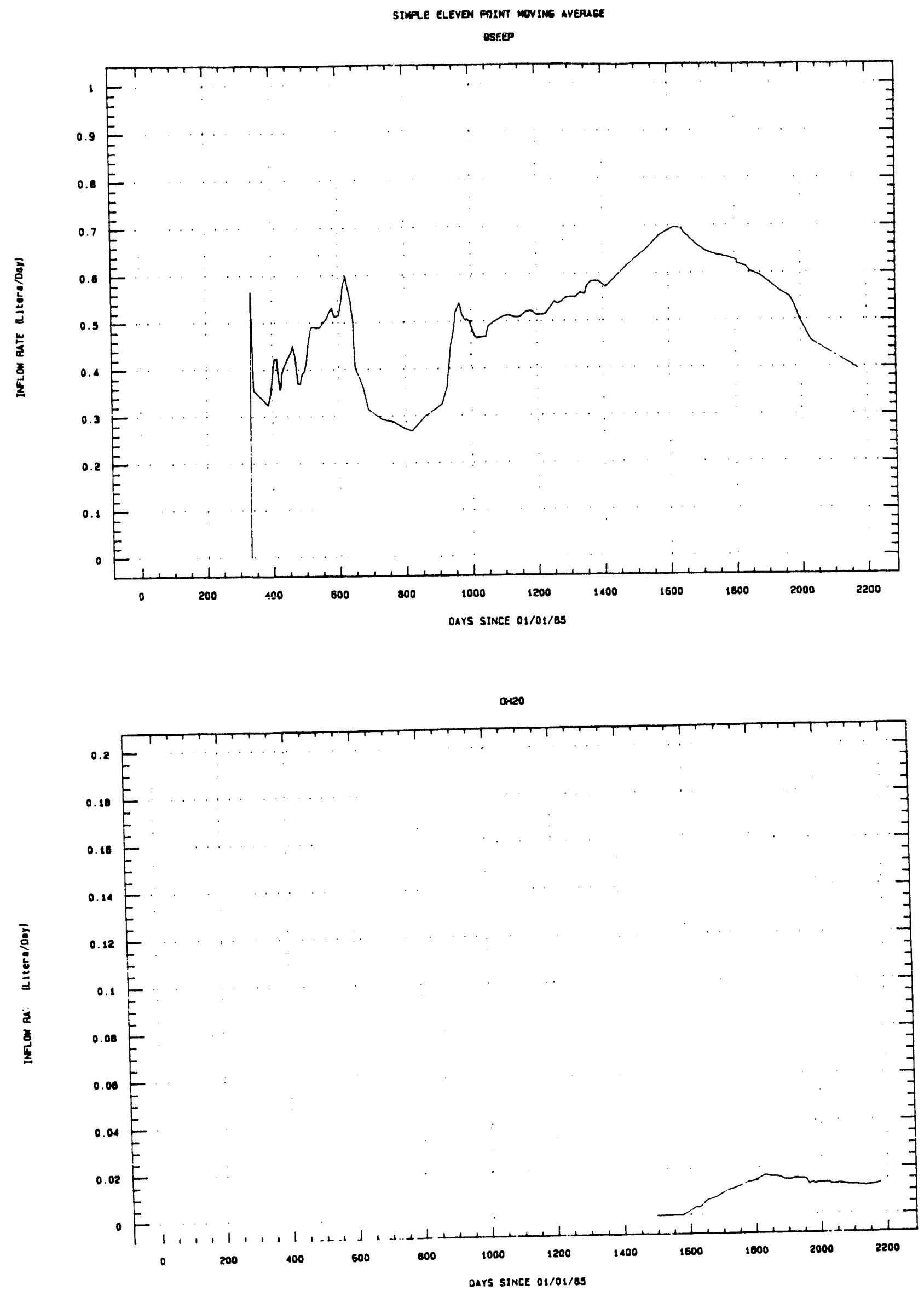

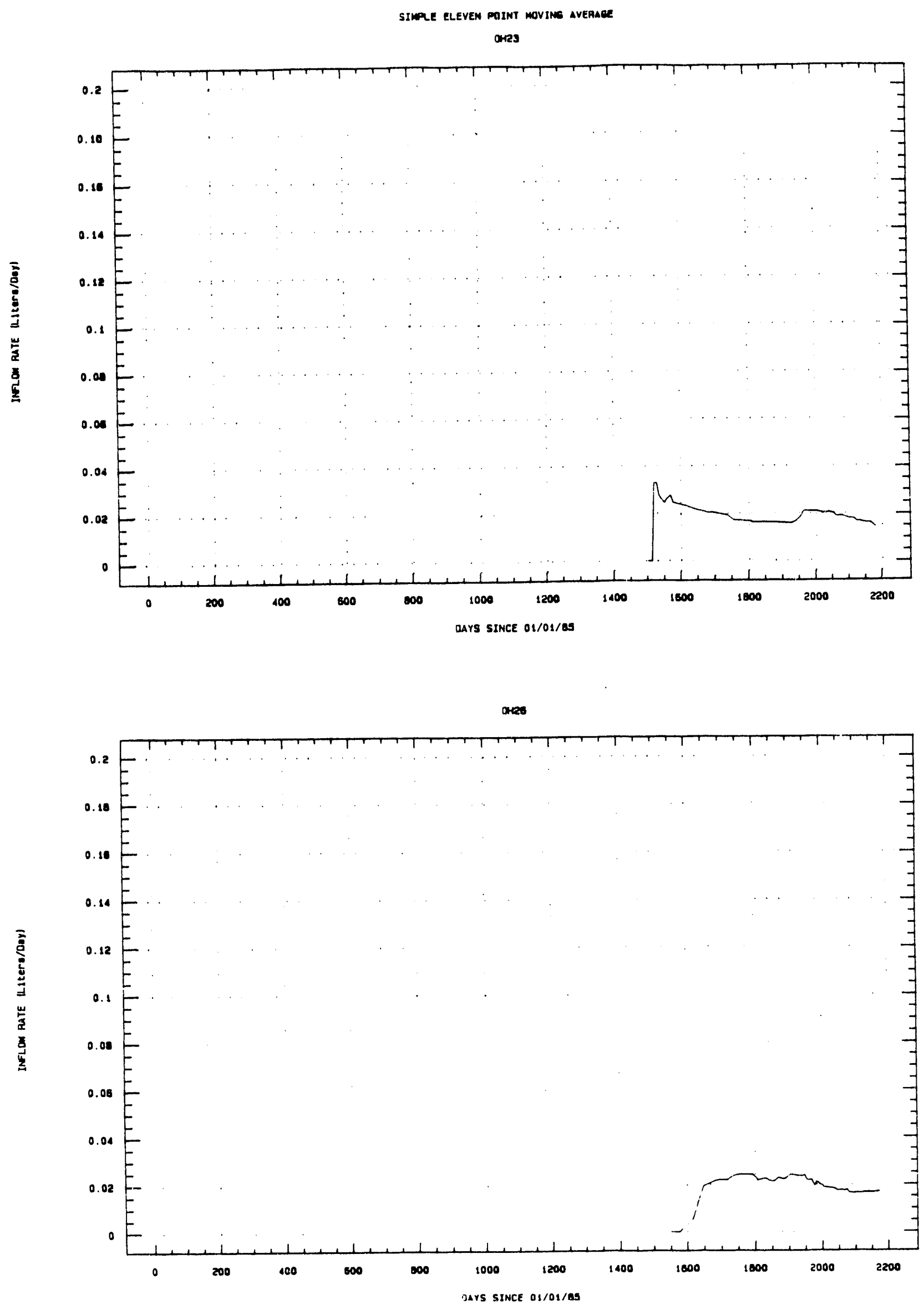

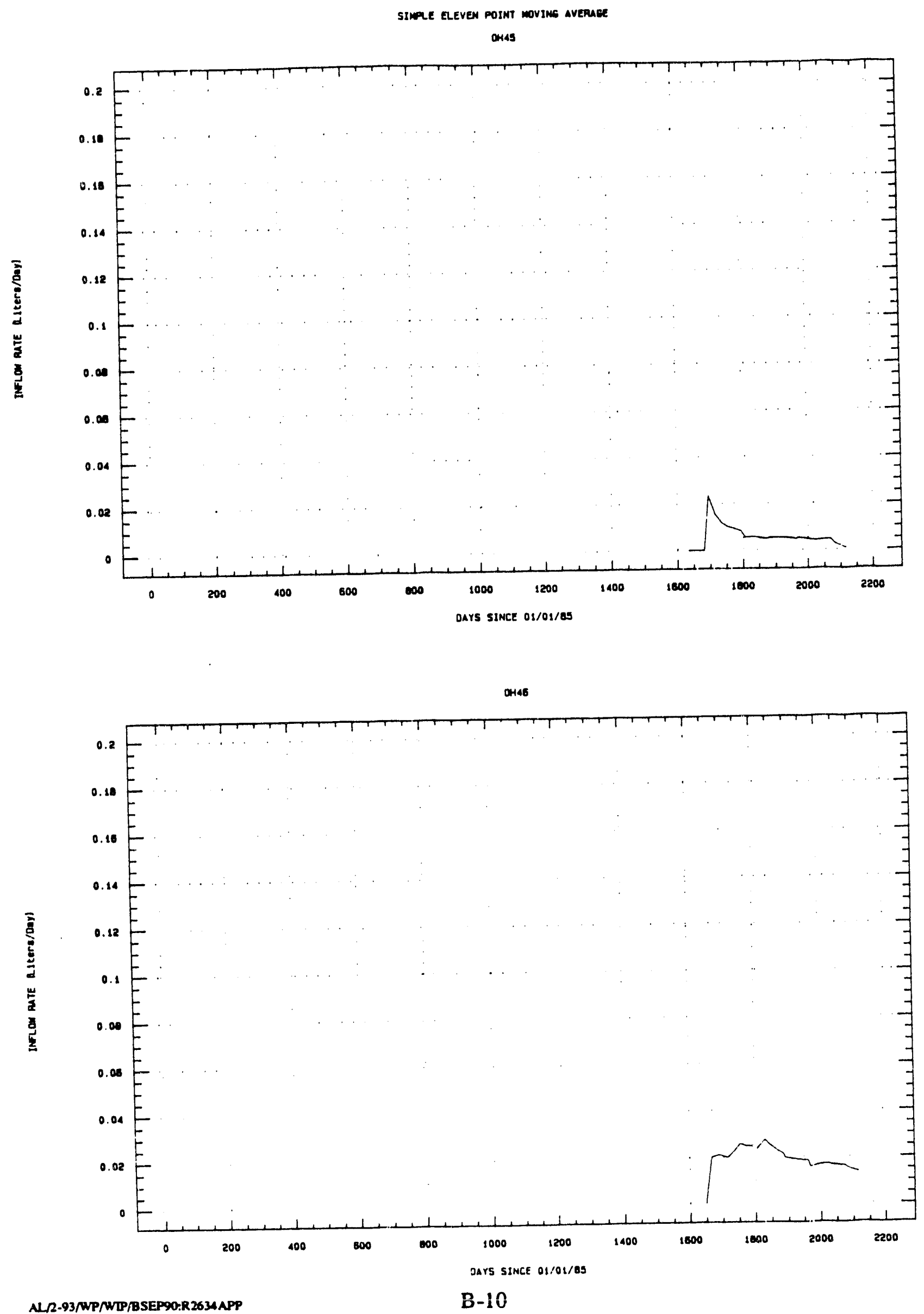


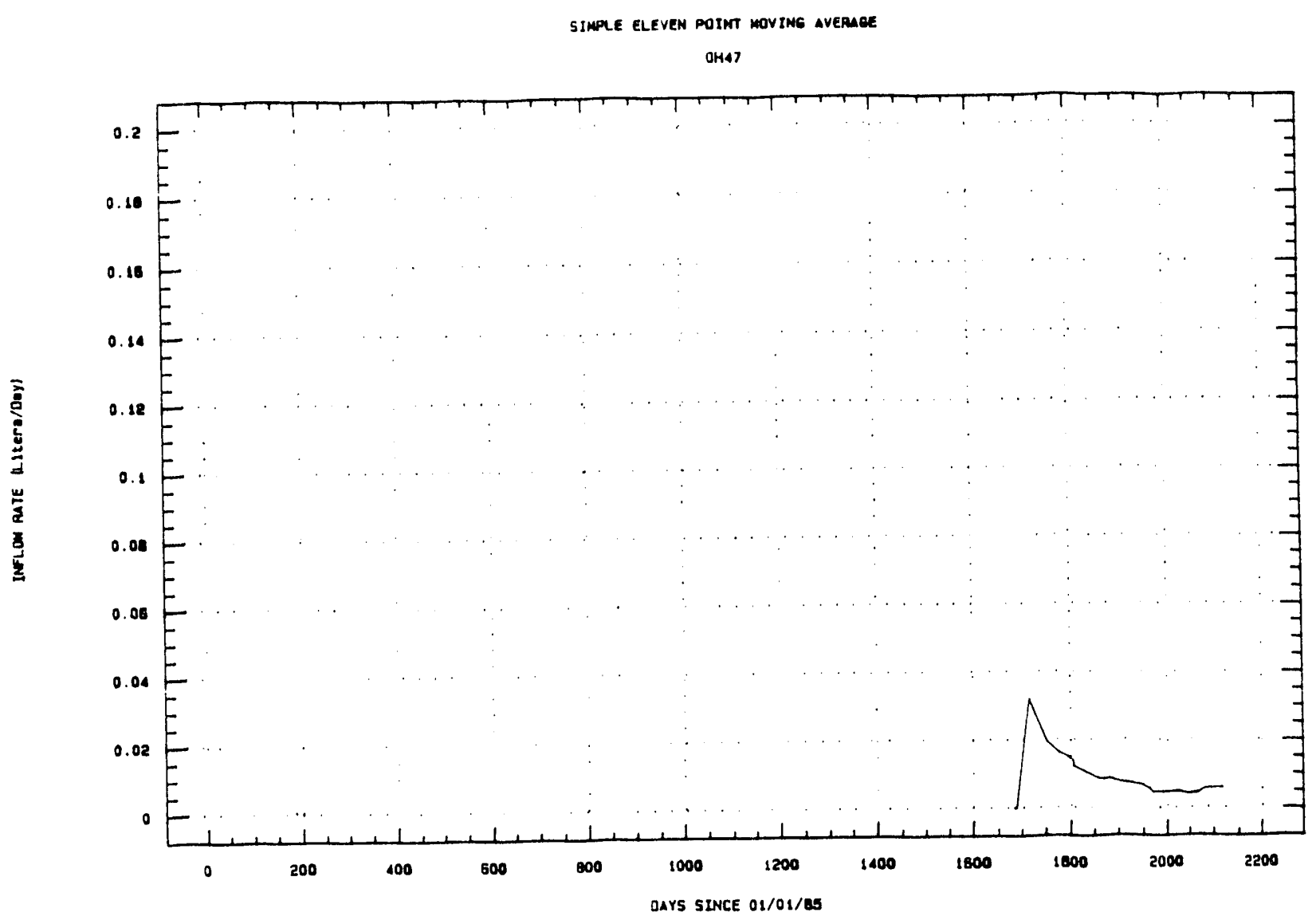


This page left intentionally blank 
APPENDIX C 1990 ANALYTICAL RESULTS 
This page left intentionally blank 
This page left intentionally blank 


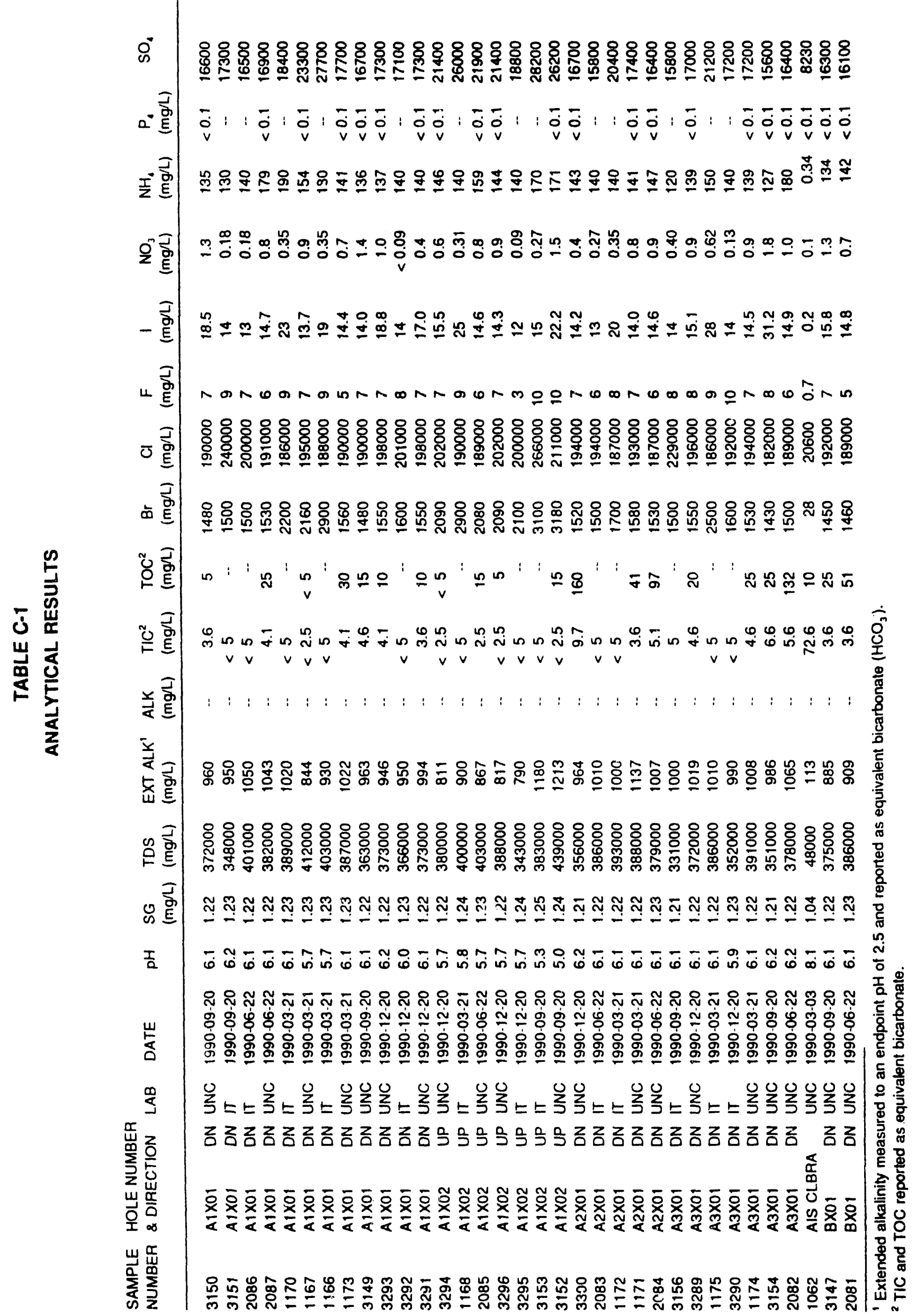




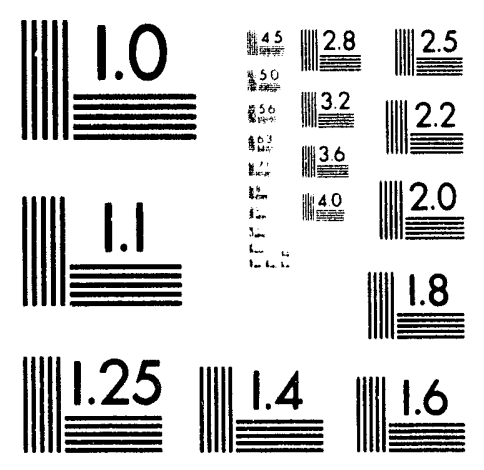



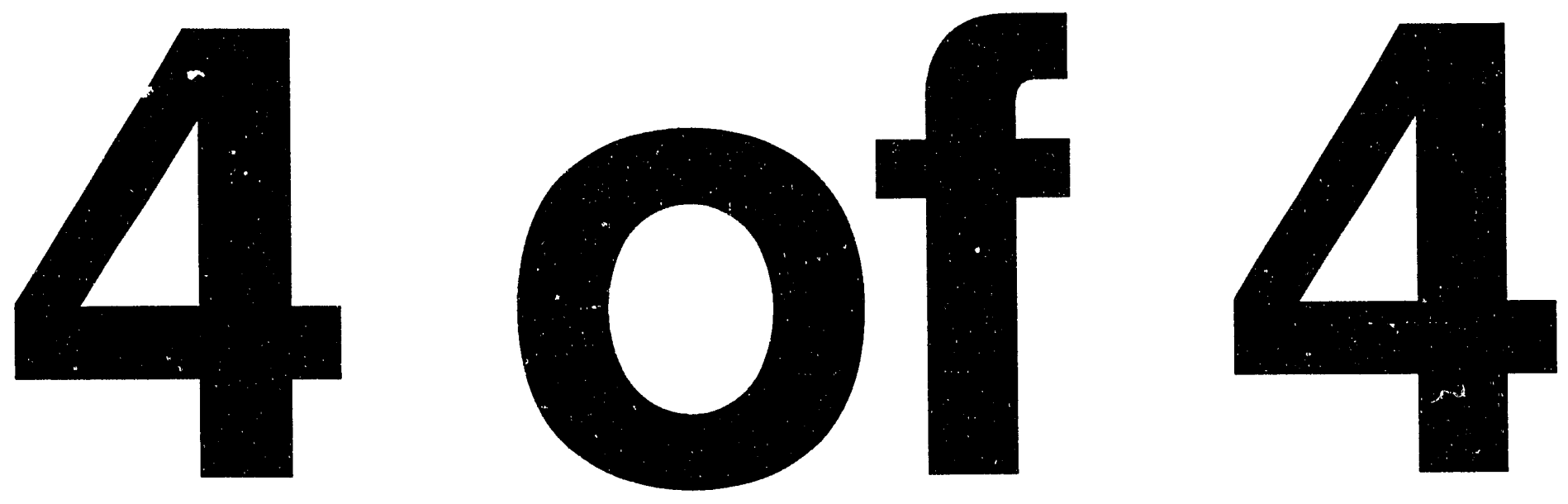


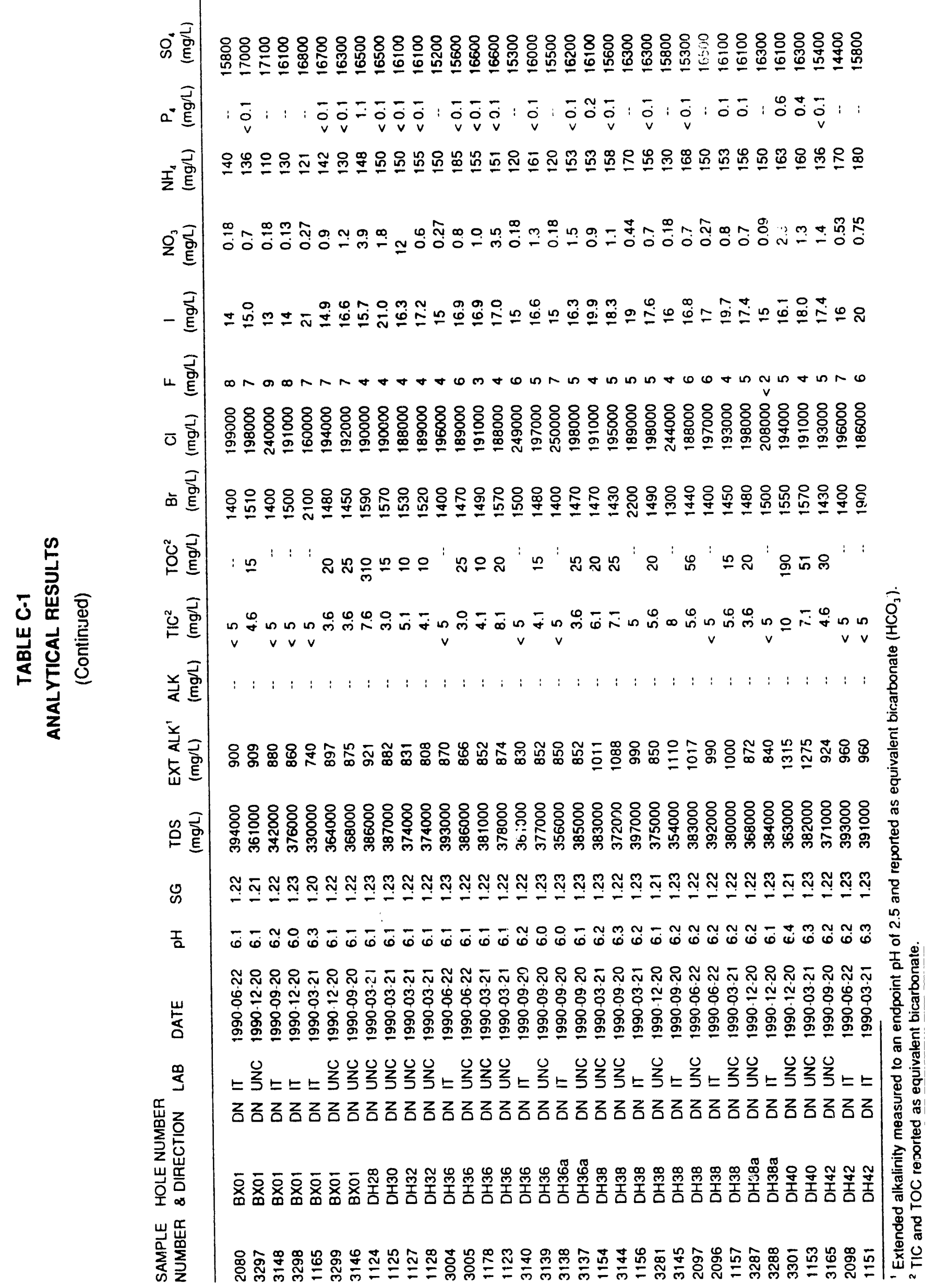




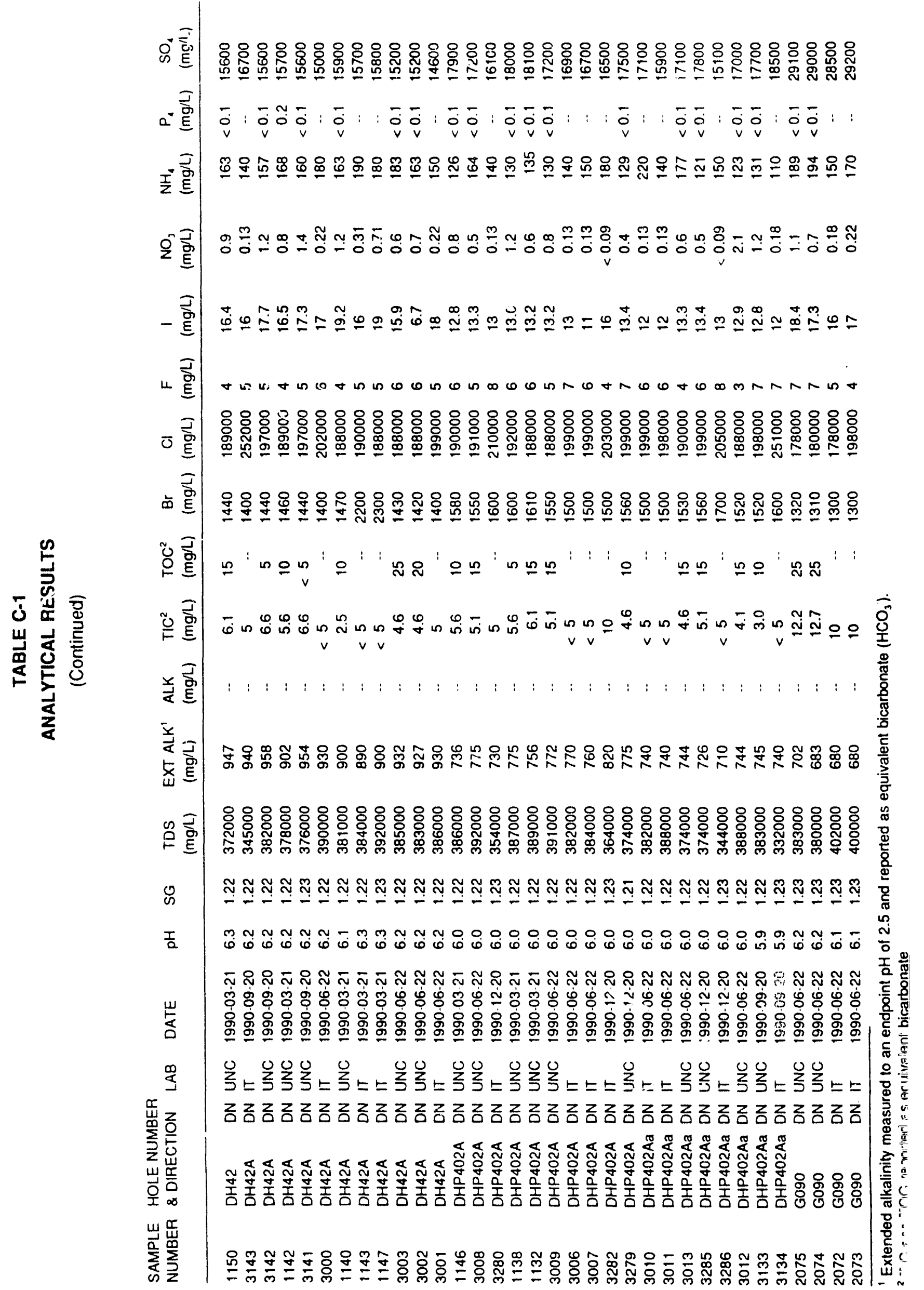




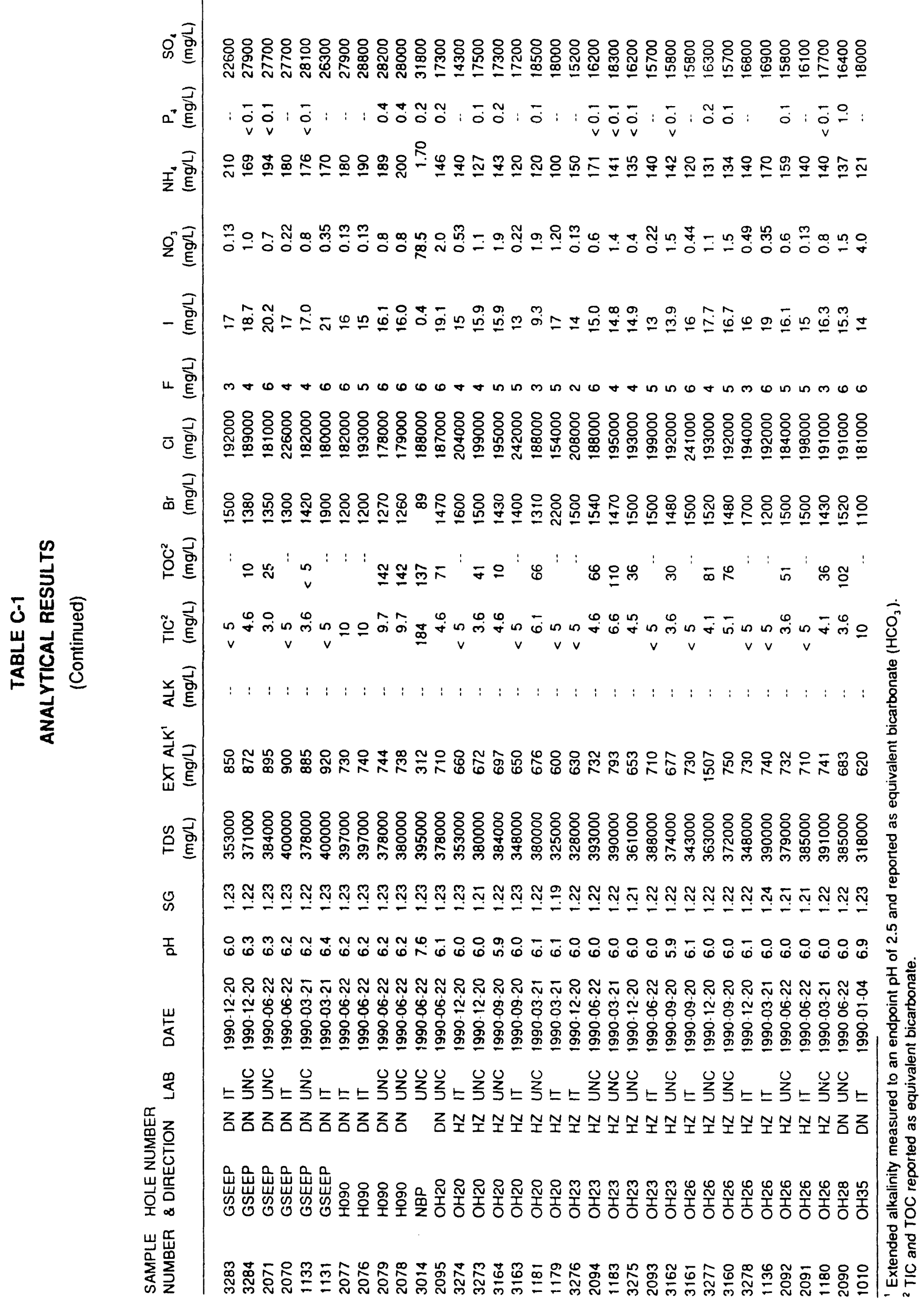




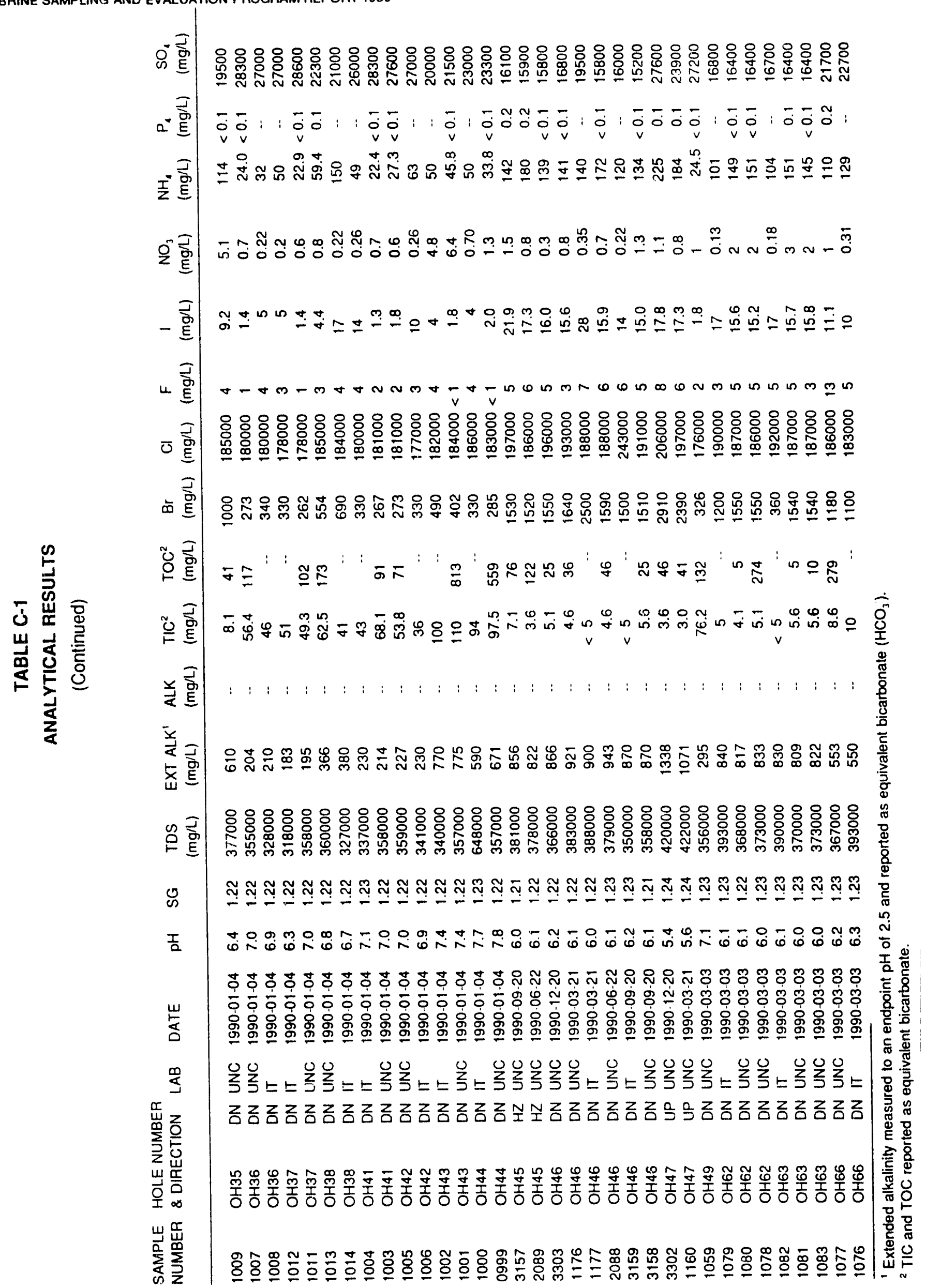




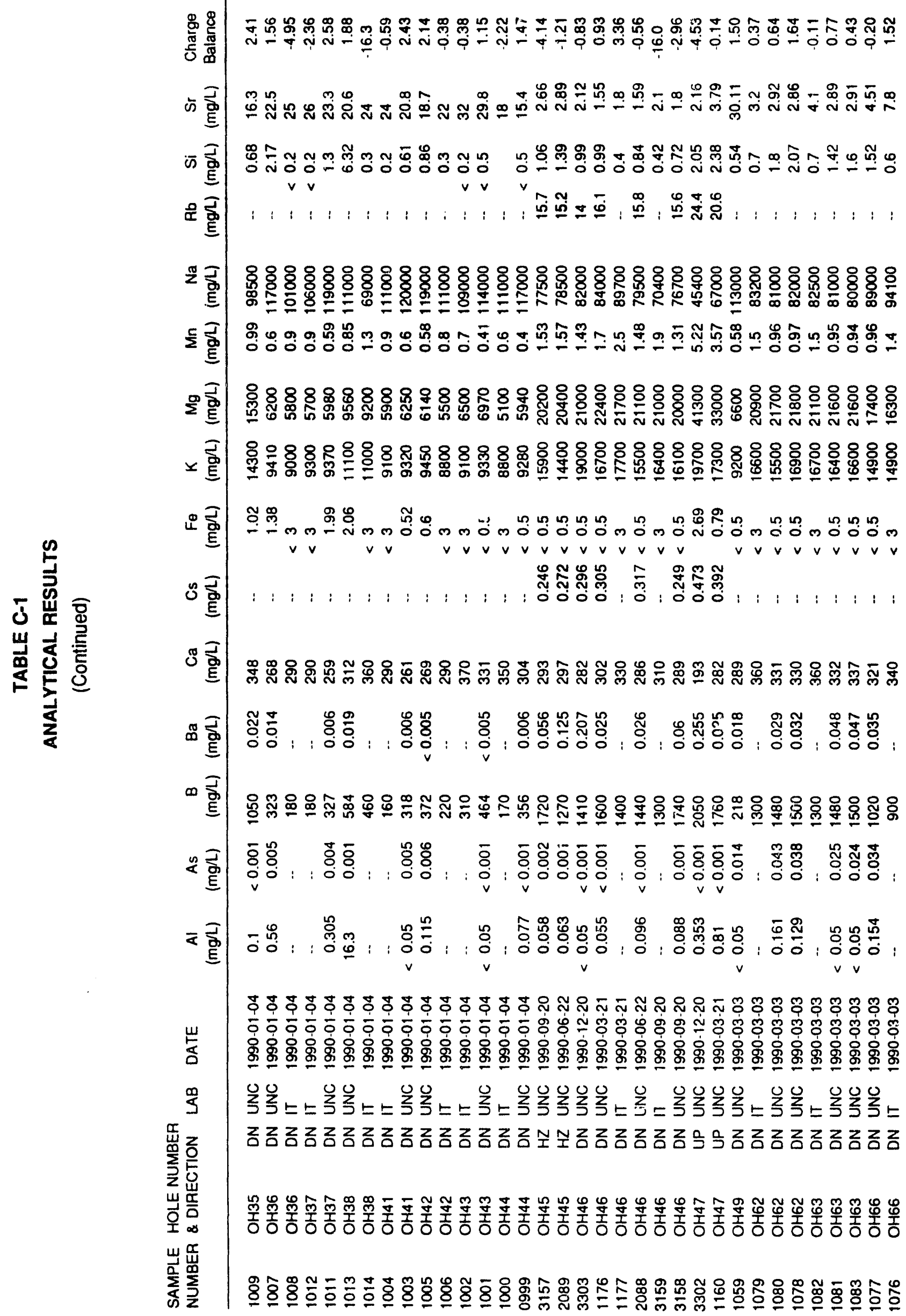




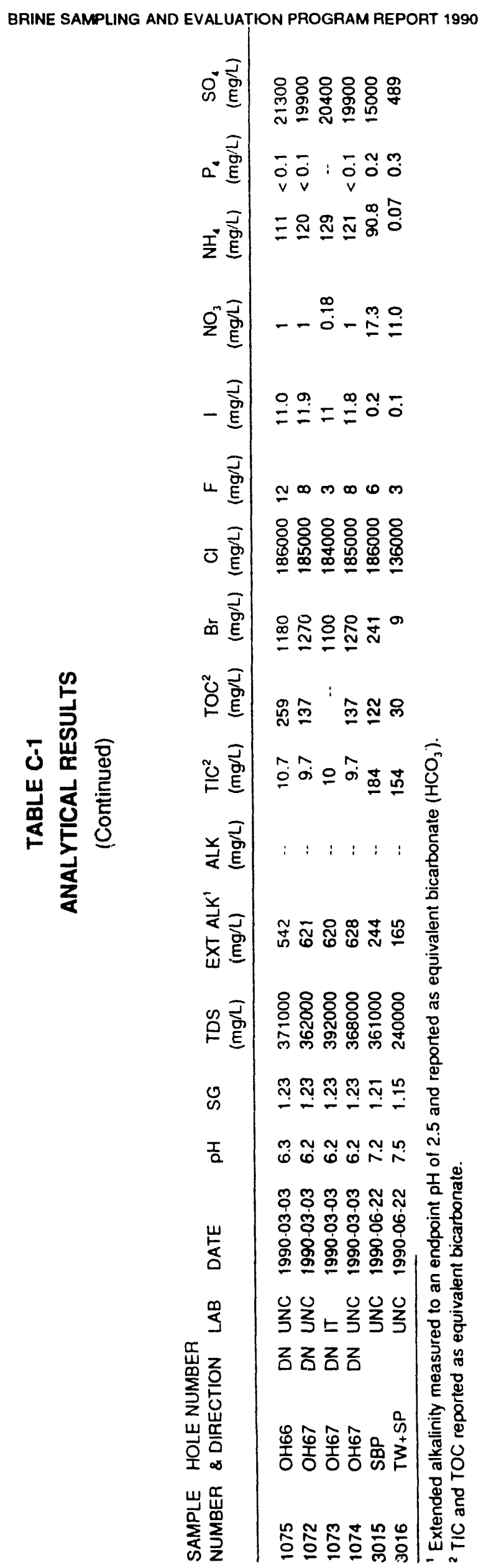



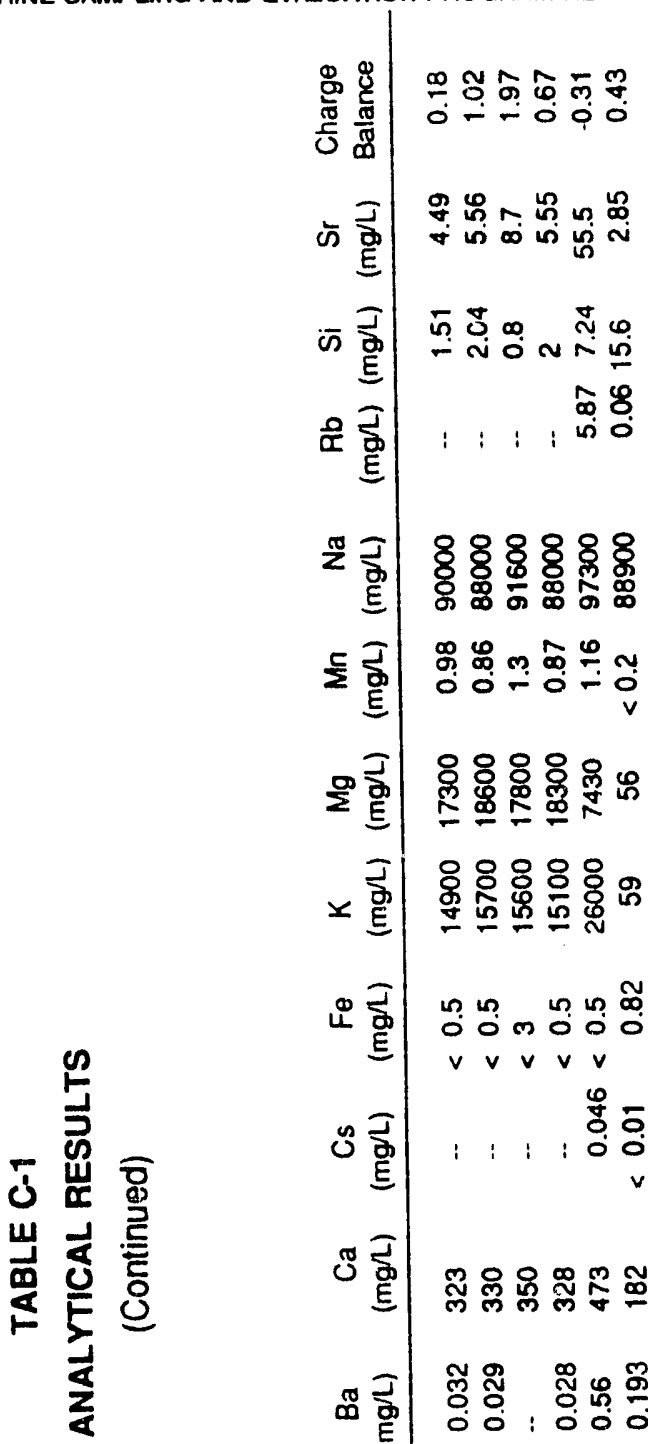

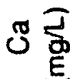

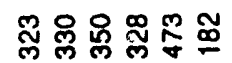

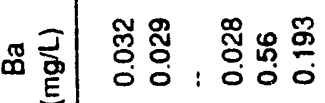

$\infty \stackrel{\text { ఫ }}{\mathrm{g}}$

융 응 8

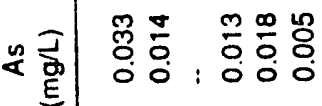

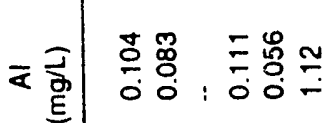

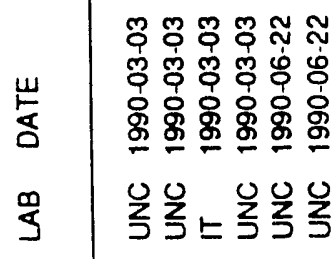

爵る るるるる

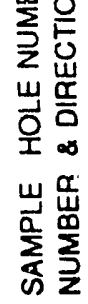

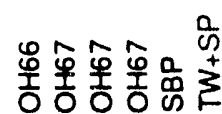

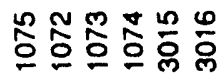


This page left intentionally blank 


\section{APPENDIX D SIMPLE STATISTICS}


This page left intentionally blank 
Table D-1

IT Simple Statistics for 1989 and 1990 Analyses

\begin{tabular}{|c|c|c|c|c|c|c|c|c|c|}
\hline & & A1X01-d & & & $A 1 \times 02-u$ & & & $A 2 \times 01-d$ & \\
\hline & $N$ & $x$ & $\mathbf{S}$ & $N$ & $x$ & $\mathbf{S}$ & $N$ & $x$ & $\mathbf{S}$ \\
\hline SG & 8 & 1.22 & 0.01 & 9 & 1.22 & 0.03 & 5 & 1.22 & 0.02 \\
\hline TDS & 8 & 369000 & 27000 & 9 & 368000 & 25000 & 5 & 360000 & 28000 \\
\hline $\mathrm{pH}$ & 8 & 6.0 & 0.2 & 9 & 5.6 & 0.2 & 5 & 6.1 & 0.0 \\
\hline ALK & 8 & 1009 & 60 & 9 & 843 & 172 & 5 & 1012 & 88 \\
\hline$T_{1}{ }^{a}$ & 8 & 4.4 & 4.4 & 9 & 2.5 & 0.0 & 5 & 3.5 & 1.4 \\
\hline $\mathrm{Br}^{-}$ & 8 & 1780 & 510 & 9 & 2400 & 600 & 5 & 1500 & 200 \\
\hline $\mathrm{Cl}^{-}$ & 8 & 200000 & 18000 & 9 & 203000 & 25000 & 5 & 192000 & 7000 \\
\hline$F^{-}$ & 8 & 8 & 1 & 9 & 7 & 2 & 5 & 7 & 1 \\
\hline$I^{-}$ & $7^{b}$ & 16 & 4 & $8^{b}$ & 19 & 8 & $4^{b}$ & 15 & 4 \\
\hline $\mathrm{NH}_{4}^{+}$ & 8 & 154 & 21 & 9 & 148 & 23 & 5 & 143 & 6 \\
\hline $\mathrm{NO}_{3}^{-}$ & 6 & 0.35 & 0.28 & 8 & 0.15 & 0.11 & 4 & 0.28 & 0.10 \\
\hline $\mathrm{SO}_{4}^{-2}$ & 8 & 18100 & 4100 & 9 & 21200 & 4800 & 5 & 16700 & 2500 \\
\hline B & 8 & 1400 & $<100$ & 9 & 1600 & 400 & 5 & 1400 & 0 \\
\hline $\mathrm{Ca}$ & 8 & 280 & 20 & 9 & 300 & 90 & 5 & 290 & 20 \\
\hline $\mathrm{Fe}$ & 1 & 3 & & 1 & 3 & & 2 & 28 & 18 \\
\hline $\mathrm{K}$ & 8 & 17200 & 900 & 9 & 17200 & 2800 & 5 & 17100 & 900 \\
\hline $\mathrm{Mg}$ & 8 & 23700 & 1000 & 9 & 36300 & 9700 & 5 & 23500 & 500 \\
\hline$M n$ & 8 & 2.4 & 0.2 & 9 & 6.6 & 1.3 & 5 & 2.5 & 0.2 \\
\hline $\mathrm{Na}$ & 8 & 79500 & 4000 & 9 & 61000 & 11200 & 5 & 79400 & 2700 \\
\hline Si & 8 & 0.6 & 0.2 & 9 & 0.5 & 0.1 & 3 & 0.4 & 0.1 \\
\hline $\mathrm{Sr}$ & 8 & 2.2 & 0.8 & 9 & 6.5 & 1.7 & 5 & 1.2 & 0.5 \\
\hline
\end{tabular}

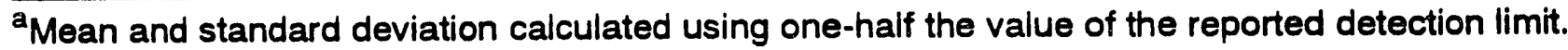

${ }^{b}$ Outlier values omitted in statistical calculations.

$\mathrm{N}=$ number of samples.

$X=$ mean.

$S=$ standard deviation. 
Table D-1 (Continued)

IT Simple Statistics for 1989 and 1990 Analyses

\begin{tabular}{|c|c|c|c|c|c|c|c|c|c|}
\hline & & $A 3 \times 01-d$ & & & BX01-d & & & DH30-d & \\
\hline & $\mathbf{N}$ & $x$ & $\mathbf{S}$ & $\mathbf{N}$ & $x$ & $\mathbf{S}$ & $\mathbf{N}$ & $x$ & $\mathbf{S}$ \\
\hline SG & 6 & 1.22 & 0.01 & 8 & 1.21 & 0.02 & 2 & 1.22 & 0.00 \\
\hline TDS & 6 & 353000 & 23000 & 8 & 359000 & 27000 & 2 & 368000 & 28000 \\
\hline $\mathrm{pH}$ & 6 & 6.1 & 0.1 & 8 & 6.1 & 0.1 & 2 & 6.1 & 0.0 \\
\hline ALK & 6 & 1002 & 58 & 8 & 855 & 69 & 2 & 870 & 0 \\
\hline$T I C^{a}$ & 6 & 3.8 & 1.4 & 8 & 3.4 & 1.3 & 2 & 3.8 & 1.8 \\
\hline $\mathrm{Br}^{-}$ & 6 & 1600 & 500 & 8 & 1500 & 400 & 2 & 1900 & 400 \\
\hline $\mathrm{Cl}^{-}$ & 6 & 198000 & 17000 & 8 & 191000 & 23000 & 2 & 181000 & 1000 \\
\hline $\mathrm{F}^{-}$ & 6 & 8 & 1 & 8 & 7 & 1 & 2 & 3 & 1 \\
\hline$I^{-}$ & $5^{b}$ & 17 & 6 & $7^{b}$ & 16 & 4 & 2 & 15 & 2 \\
\hline $\mathrm{NH}_{4}^{+}$ & 6 & 144 & 17 & 8 & 130 & 13 & 2 & 140 & 0 \\
\hline $\mathrm{NO}_{3}^{-}$ & 5 & 0.35 & 0.22 & 7 & 0.16 & 0.08 & 2 & 0.2 & $<0.1$ \\
\hline $\mathrm{SO}_{4}^{-2}$ & 6 & 16600 & 2600 & 8 & 15800 & 1400 & 2 & 17000 & 1000 \\
\hline B & 6 & 1400 & 100 & 8 & 1500 & 100 & 2 & 1500 & 100 \\
\hline $\mathrm{Ca}$ & 6 & 290 & 30 & 8 & 290 & 30 & 2 & 360 & 10 \\
\hline $\mathrm{Fe}$ & 1 & 3 & & 1 & 4 & & 0 & $<3$ & \\
\hline K & 6 & 16600 & 1500 & 8 & 17300 & 1000 & 2 & 18600 & 100 \\
\hline $\mathbf{M g}$ & 6 & 23400 & 1400 & 8 & 22100 & 2100 & 2 & 20400 & 0 \\
\hline$M n$ & 6 & 2.2 & 0.2 & 8 & 2.1 & 0.2 & 2 & 1.9 & 0.1 \\
\hline $\mathrm{Na}$ & 6 & 76800 & 7800 & 8 & 81000 & 6200 & 2 & 86300 & 3300 \\
\hline $\mathrm{Si}$ & 6 & 0.6 & 0.1 & 8 & 0.5 & 0.1 & 2 & 0.4 & 0.0 \\
\hline $\mathrm{Sr}$ & 6 & 2.4 & 0.6 & 8 & 2.3 & 0.8 & 2 & 3.0 & 0.1 \\
\hline
\end{tabular}

a Mean and standard deviation calculated using one-half the value of the reported detection limit.

boutlier values omitted in statistical calculations.

$\mathrm{N}=$ number of samples.

$X=$ mean.

$S=$ standard deviation. 
Table D-1 (Continued)

IT Simple Statistics for 1989 and 1990 Analyses

\begin{tabular}{|c|c|c|c|c|c|c|c|c|c|}
\hline & & DH32-d & & & DH34-d & & & DH36-d & \\
\hline & $\mathbf{N}$ & $x$ & $S$ & $N$ & $x$ & $\mathbf{S}$ & $\mathbf{N}$ & $x$ & $\mathbf{S}$ \\
\hline SG & 3 & 1.22 & 0.01 & 3 & 1.22 & 0.00 & 8 & 1.22 & 0.01 \\
\hline TDS & 3 & 355000 & 38000 & 3 & 341000 & 11000 & 8 & 347000 & 25000 \\
\hline $\mathrm{pH}$ & 3 & 6.1 & 0.0 & 3 & 6.1 & 0.0 & 8 & 6.1 & 0.0 \\
\hline ALK & 3 & 855 & 52 & 3 & 838 & 45 & 8 & 855 & 42 \\
\hline$T I C^{a}$ & 3 & 3.3 & 1.4 & 3 & 7.5 & 4.3 & 8 & 4.1 & 2.0 \\
\hline $\mathrm{Br}^{-}$ & 3 & 1700 & 600 & $2^{b}$ & 1800 & 300 & 8 & 1500 & 300 \\
\hline $\mathrm{Cl}^{-}$ & 3 & 185000 & 6000 & 3 & 187000 & 5000 & 8 & 198000 & 21000 \\
\hline $\mathrm{F}^{-}$ & 3 & 4 & 1 & 2 & 4 & 1 & 8 & 5 & 1 \\
\hline$I^{-}$ & $2^{b}$ & 15 & 1 & $2^{b}$ & 14 & 0 & $7^{b}$ & 16 & 1 \\
\hline $\mathrm{NH}_{4}^{+}$ & 3 & 143 & 5 & 3 & 147 & 11 & 8 & 154 & 18 \\
\hline $\mathrm{NO}_{3}^{-}$ & 3 & 0.16 & 0.03 & 3 & 0.19 & 0.02 & 5 & 0.18 & 0.06 \\
\hline $\mathrm{SO}_{4}^{-2}$ & 3 & 15600 & 600 & 3 & 16100 & 900 & 8 & 15000 & 2000 \\
\hline B & 3 & 1500 & 100 & 3 & 1500 & 100 & 8 & 1400 & 100 \\
\hline $\mathrm{Ca}$ & 3 & 350 & 10 & 3 & 450 & 10 & 8 & 340 & 20 \\
\hline $\mathrm{Fe}$ & 0 & $<3$ & & 0 & $<3$ & & 1 & 2 & \\
\hline K & 3 & 19300 & 700 & 3 & 18600 & 300 & 8 & 19300 & 1400 \\
\hline Mg & 3 & 20500 & 500 & 3 & 18800 & 400 & 8 & 18600 & 500 \\
\hline Mn & 3 & 1.6 & 0.1 & 3 & 1.6 & 0.1 & 8 & 1.5 & 0.1 \\
\hline $\mathrm{Na}$ & 3 & 88100 & 500 & $2^{b}$ & 86600 & 2300 & 8 & 86400 & 5400 \\
\hline $\mathrm{Si}$ & 3 & 0.9 & 0.1 & 3 & 0.7 & 0.0 & 8 & 0.9 & 0.1 \\
\hline $\mathrm{Sr}$ & 3 & 2.5 & 0.2 & 3 & 3.6 & 1.6 & 8 & 1.7 & 0.1 \\
\hline
\end{tabular}

a Mean and standard deviation calculated using one-half the value of the reported detection limit.

${ }^{b}$ Outlier values omitted in statistical calculations.

$\mathrm{N}=$ number of samples.

$X=$ mean.

$S=$ standard deviation. 
Table D-1 (Continued)

\section{IT Simple Statistics for 1989 and 1990 Analyses}

\begin{tabular}{|c|c|c|c|c|c|c|c|c|c|}
\hline & & DH38-d & & & DH42-d & & & DH42A-d & \\
\hline & $N$ & $x$ & $s$ & $\mathbf{N}$ & $x$ & $s$ & $\mathbf{N}$ & $x$ & $S$ \\
\hline SG & 6 & 1.22 & 0.01 & 3 & 1.23 & 0.01 & 10 & 1.22 & 0.01 \\
\hline TDS & 6 & 366000 & 23000 & 3 & 378000 & 25000 & 10 & 361000 & 27000 \\
\hline pH & 6 & 6.2 & 0.0 & 3 & 6.3 & 0.1 & 10 & 6.2 & 0.1 \\
\hline ALK & 6 & 980 & 76 & 3 & 960 & 10 & 10 & 901 & 38 \\
\hline$T C^{a}$ & 6 & 5.1 & 1.7 & 3 & 3.3 & 1.4 & 10 & 3.3 & 1.2 \\
\hline $\mathrm{Br}^{-}$ & 6 & 1700 & 300 & 3 & 1700 & 300 & $9^{b}$ & 1600 & 400 \\
\hline $\mathrm{Cl}^{-}$ & 6 & 198000 & 24000 & 3 & 187000 & 8000 & 10 & 200000 & 19000 \\
\hline$F^{-}$ & 6 & 6 & 1 & 3 & 7 & 1 & 10 & 5 & 1 \\
\hline $1^{\circ}$ & 6 & 17 & 2 & 3 & 18 & 2 & $9^{b}$ & 17 & 1 \\
\hline $\mathrm{NH}_{4}^{+}$ & 6 & 160 & 20 & 3 & 170 & 10 & 10 & 170 & 17 \\
\hline $\mathrm{NO}_{3}^{4}$ & 5 & 0.27 & 0.10 & 3 & 0.52 & 0.24 & 8 & 0.27 & 0.19 \\
\hline $\mathrm{SO}_{4}^{-2}$ & 6 & 16900 & 1600 & 3 & 15100 & 700 & 10 & 14700 & 1400 \\
\hline$B^{4}$ & 6 & 1400 & $<100$ & 3 & 1400 & 0 & 10 & 1400 & 100 \\
\hline $\mathrm{Ca}$ & 6 & 330 & 20 & 3 & 340 & 10 & 10 & 340 & 20 \\
\hline $\mathrm{Fe}$ & 0 & $<3$ & & 0 & $<3$ & & 0 & $<3$ & \\
\hline K & 6 & 18700 & 1300 & 3 & 18400 & 500 & 10 & 19500 & 1200 \\
\hline Mg & 6 & 18000 & 100 & 3 & 17100 & 200 & 10 & 17600 & 500 \\
\hline Mn & 6 & 1.5 & 0.1 & 3 & 1.6 & 0.1 & 10 & 1.4 & 0.1 \\
\hline $\mathrm{Na}$ & 6 & 86800 & 7900 & 3 & 88700 & 4600 & $9^{b}$ & 86200 & 7400 \\
\hline $\mathrm{Si}$ & 6 & 0.8 & $<0.1$ & 3 & 0.8 & 0.2 & 10 & 0.9 & 0.1 \\
\hline $\mathrm{Sr}$ & 6 & 1.0 & 0.1 & 3 & 1.3 & 0.3 & 10 & 1.1 & 0.3 \\
\hline
\end{tabular}

a Mean and standard deviation calculated using one-half the value of the reported detection limit. boutlier values omitted in statistical caisulations.

$N=$ number of samples.

$X=$ mean.

$\mathrm{S}=$ standard deviation. 
'rable D-1 (Continued)

IT Simple Statistics for 1989 and 1990 Analyses

\begin{tabular}{|c|c|c|c|c|c|c|c|c|c|}
\hline & \multicolumn{3}{|c|}{ DHP402A-d } & \multicolumn{3}{|c|}{ DHP402Aa-d ${ }^{c}$} & \multicolumn{3}{|c|}{ G090-d } \\
\hline & $\mathbf{N}$ & $x$ & $\mathbf{S}$ & $N$ & $x$ & $S$ & $N$ & $x$ & $\mathbf{S}$ \\
\hline SG & 8 & 1.22 & 0.01 & 4 & 1.23 & 0.01 & 2 & 1.23 & 0.00 \\
\hline TDS & 8 & 344000 & 32000 & 4 & 362000 & 28000 & 2 & 401000 & 1000 \\
\hline $\mathrm{pH}$ & 8 & 6.0 & 0.0 & 4 & 6.0 & $<0.1$ & 2 & 6.1 & 0.0 \\
\hline ALK & 8 & 774 & 34 & 4 & 730 & 20 & 2 & 680 & 0 \\
\hline$T_{I C}{ }^{a}$ & 8 & 4.4 & 2.6 & 4 & 2.5 & 0.0 & 2 & 10 & 0 \\
\hline $\mathrm{Br}^{-}$ & 8 & 1700 & 300 & 4 & 1600 & 100 & 2 & 1300 & 0 \\
\hline $\mathrm{Cl}^{-}$ & 8 & 195000 & 11000 & $3^{b}$ & 201000 & 4000 & 2 & 188000 & 14000 \\
\hline$F^{-}$ & 8 & 7 & 1 & 4 & 7 & 1 & 2 & 5 & 1 \\
\hline$r^{-}$ & $7^{b}$ & 17 & 6 & 4 & 12 & 1 & 2 & 17 & 1 \\
\hline $\mathrm{NH}_{4}^{+}$ & 8 & 141 & 21 & 4 & 160 & 50 & 2 & 160 & 10 \\
\hline $\mathrm{NO}_{3}^{-}$ & 5 & 0.13 & 0.00 & 3 & 0.15 & 0.03 & 2 & 0.20 & 0.03 \\
\hline $\mathrm{SO}_{4}^{-2}$ & 8 & 17600 & 1500 & 4 & 16700 & 1500 & 2 & 28900 & 500 \\
\hline B & 8 & 1400 & 200 & 4 & 1200 & 100 & 2 & 1400 & 0 \\
\hline $\mathrm{Ca}$ & 8 & 340 & 20 & 4 & 340 & 10 & 2 & 250 & 0 \\
\hline $\mathrm{Fe}$ & 4 & 53 & 39 & 0 & $<3$ & & 2 & 21 & 4 \\
\hline K & 8 & 15500 & 1600 & 4 & 14900 & 500 & 2 & 13100 & 0 \\
\hline $\mathrm{Mg}$ & 8 & 23600 & 2100 & 4 & 24300 & 600 & 2 & 13300 & 0 \\
\hline Mn & 8 & 2.8 & 0.6 & 4 & 3.5 & 0.1 & 2 & 2.6 & 0.0 \\
\hline $\mathrm{Na}$ & 8 & 80400 & 5000 & 4 & 83000 & 10500 & 2 & 107000 & 0 \\
\hline $\mathrm{Si}$ & 4 & 0.5 & 0.3 & 0 & $<0.2$ & & 0 & $<0.2$ & \\
\hline $\mathrm{Sr}$ & 8 & 4.1 & 1.1 & 4 & 3.8 & 1.0 & 2 & 2.7 & 0.1 \\
\hline
\end{tabular}

a Mean and standard deviation calculated using one-half the value of the reported detection limit.

boutlier values omitted in statistical calculations.

${ }^{c}$ Archived DHP402A brine that was analyzed approximately 6 months after collection.

$\mathrm{N}=$ number of samples.

$X=$ mean.

$S=$ standard deviation. 
Table D-1 (Continued)

IT Simple Statistics for 1989 and 1990 Analyses

\begin{tabular}{|c|c|c|c|c|c|c|c|c|c|}
\hline & & GSEEP- $d$ & & & H090-d & & & OH2O-h & \\
\hline & $\mathbf{N}$ & $x$ & $\mathbf{S}$ & $\mathbf{N}$ & $\mathrm{x}$ & $\mathrm{S}$ & $\mathbf{N}$ & $x$ & $\mathbf{S}$ \\
\hline SG & 11 & 1.23 & 0.01 & 2 & 1.23 & 0.00 & 4 & 1.22 & 0.02 \\
\hline TDS & 11 & 356000 & 28000 & 2 & 397000 & 0 & 4 & 347000 & 16000 \\
\hline $\mathrm{pH}$ & 11 & 6.2 & 0.1 & 2 & 6.2 & 0.0 & 4 & 6.1 & 0.1 \\
\hline ALK & 11 & 914 & 53 & 2 & 740 & 10 & 4 & 640 & 30 \\
\hline$T I C^{a}$ & 11 & 3.2 & 1.8 & 2 & 10 & 0 & 4 & 4.4 & 3.8 \\
\hline $\mathrm{Br}^{-}$ & $9^{b}$ & 1500 & 200 & 2 & 1200 & 0 & $3^{b}$ & 1700 & 400 \\
\hline $\mathrm{Cl}^{-}$ & 11 & 187000 & 14000 & 2 & 188000 & 8000 & 4 & 195000 & 37000 \\
\hline$F$ & 11 & 3 & 1 & 2 & 6 & 1 & 4 & 5 & 1 \\
\hline $1^{\circ}$ & $9^{b}$ & 18 & 2 & 2 & 16 & 1 & 4 & 17 & 5 \\
\hline $\mathrm{NH}_{4}^{+}$ & 11 & 178 & 14 & 2 & 190 & 10 & 4 & 120 & 20 \\
\hline $\mathrm{NO}_{3}^{-}$ & 9 & 0.2 & 0.1 & 2 & 0.13 & 0.00 & 4 & 0.89 & 0.62 \\
\hline $\mathrm{SO}_{4}^{-2}$ & 11 & 26100 & 2100 & 2 & 28400 & 600 & 4 & 17400 & 2400 \\
\hline B & 11 & 1500 & 100 & 2 & 1400 & 0 & 4 & 1200 & 100 \\
\hline $\mathrm{Ca}$ & 11 & 290 & 20 & 2 & 290 & 0 & 4 & 350 & 40 \\
\hline $\mathrm{Fe}$ & 0 & $<3$ & & 0 & $<3$ & & 1 & 20 & \\
\hline $\mathrm{K}$ & 11 & 14500 & 900 & 2 & 13000 & 100 & 4 & 15700 & 700 \\
\hline Mg & 11 & 14500 & 400 & 2 & 13900 & 100 & 4 & 20600 & 1300 \\
\hline Mn & 9 & 1.0 & 0.1 & 2 & 1.2 & 0.1 & 4 & 2.9 & 0.6 \\
\hline $\mathrm{Na}$ & 11 & 99300 & 3700 & 2 & 105000 & 1000 & 4 & 78700 & 7700 \\
\hline $\mathrm{Si}$ & 11 & 0.5 & 0.1 & 2 & 0.5 & 0.0 & 4 & 0.7 & 0.1 \\
\hline $\mathrm{Sr}$ & 11 & 2.5 & 0.8 & 2 & 3.6 & 0.1 & 4 & 3.0 & 1.6 \\
\hline
\end{tabular}

${ }^{a}$ Mean and standard deviation calculated using one-haff the value of the reported detection limit. ${ }^{b}$ Outlier values omitted in statistical calculations.

$\mathrm{N}=$ number of samples.

$X=$ mean.

$\mathrm{S}=$ standard deviation . 
Table D-1 (Continued)

\section{IT Simple Statistics for 1989 and 1990 Analyses}

\begin{tabular}{|c|c|c|c|c|c|c|c|c|c|}
\hline & & OH23-h & & & $\mathrm{OH} 26-\mathrm{h}$ & & & OH46-d & \\
\hline & $\mathbf{N}$ & $x$ & $S$ & $N$ & $x$ & $S$ & $\mathbf{N}$ & $x$ & $\mathbf{S}$ \\
\hline SG & 3 & 1.22 & 0.01 & 6 & 1.22 & 0.01 & 3 & 1.22 & 0.01 \\
\hline TDS & 3 & 357000 & 30000 & 6 & 357000 & 26000 & 3 & 356000 & 30000 \\
\hline $\mathrm{pH}$ & 3 & 6.0 & 0.1 & 6 & 6.0 & 0.1 & 3 & 6.1 & 0.1 \\
\hline ALK & 3 & 695 & 59 & 6 & 730 & 10 & 3 & 880 & 20 \\
\hline$T C^{a}$ & 3 & 2.5 & 0.0 & 6 & 2.9 & 1.0 & 3 & 3.3 & 1.4 \\
\hline $\mathrm{Br}^{-}$ & $2^{b}$ & 1500 & 0 & 6 & 1400 & 200 & 3 & 1900 & 600 \\
\hline $\mathrm{Cl}^{-}$ & 3 & 197000 & 12000 & 6 & 199000 & 21000 & 3 & 202000 & 36000 \\
\hline $\mathrm{F}^{-}$ & 3 & 4 & 2 & 6 & 5 & 1 & 3 & 6 & 2 \\
\hline$\Gamma^{\circ}$ & 3 & 17 & 6 & $5^{b}$ & 17 & 2 & 3 & 21 & 7 \\
\hline $\mathrm{NH}_{4}^{+}$ & 3 & 138 & 13 & 6 & 144 & 17 & 3 & 130 & 10 \\
\hline $\mathrm{NO}_{3}^{-}$ & 3 & 0.32 & 0.26 & 6 & 0.33 & 0.13 & 3 & 0.6 & 0.5 \\
\hline $\mathrm{SO}_{4}^{-2}$ & 3 & 15700 & 600 & 6 & 16400 & 600 & 3 & 17200 & 2000 \\
\hline 8 & 3 & 1700 & 500 & 6 & 1300 & 100 & 3 & 1400 & 100 \\
\hline $\mathrm{Ca}$ & 3 & 300 & 30 & 6 & 320 & 20 & 3 & 340 & 30 \\
\hline $\mathrm{Fe}$ & 0 & $<3$ & & 0 & $<3$ & & 0 & $<3$ & \\
\hline$K$ & 3 & 16400 & 1300 & 6 & 16200 & 800 & 3 & 17600 & 1200 \\
\hline $\mathrm{Mg}$ & 3 & 22000 & 2500 & 6 & 22300 & 800 & 3 & 21800 & 900 \\
\hline$M n$ & 3 & 3.4 & 0.9 & 6 & 2.3 & 0.1 & 3 & 2.6 & 0.7 \\
\hline $\mathrm{Na}$ & 3 & 80100 & 7200 & 6 & 81200 & 11300 & 3 & 81300 & 9900 \\
\hline Si & 3 & 0.8 & 0.1 & 6 & 0.7 & 0.3 & $2^{b}$ & 0.4 & $<0.1$ \\
\hline $\mathrm{Sr}$ & 3 & 1.4 & 0.2 & 6 & 1.4 & 0.2 & 3 & 2.3 & 0.6 \\
\hline
\end{tabular}

\footnotetext{
${ }^{a}$ Mean and standard deviation calculated using one-half the value of the reported detection limit. boutlier values omitted in statistical calculations.

$N=$ number of samples.

$X=$ mean.

$S=$ standard deviation.
} 
Table D-2

UNC Simple Statistics for 1989 and 1990 Analyses

\begin{tabular}{|c|c|c|c|c|c|c|c|c|c|}
\hline & & $A 1 \times 01-d$ & & & A1X02-u & & & $A 2 \times 01-d$ & \\
\hline & $\mathbf{N}$ & $x$ & $S$ & $\mathbf{N}$ & $x$ & $S$ & $N$ & $x$ & $\mathbf{S}$ \\
\hline$S G$ & 13 & 1.22 & 0.01 & 12 & 1.24 & 0.01 & 8 & 1.23 & 0.01 \\
\hline TDS & 13 & 379000 & 13000 & 12 & 397000 & 15000 & 8 & 376000 & 10000 \\
\hline $\mathrm{pH}$ & 13 & 6.1 & 0.1 & 12 & 5.6 & 0.3 & 8 & 6.1 & 0.1 \\
\hline ALK & 13 & 984 & 53 & 12 & 888 & 171 & 8 & 1000 & 68 \\
\hline TIC & 12 & 4.4 & 0.8 & 2 & 2.5 & 0.0 & 8 & 6.1 & 1.9 \\
\hline TOC & 11 & 26 & 20 & 10 & 11 & 5 & 8 & 58 & 52 \\
\hline $\mathrm{Br}^{-}$ & 13 & 1570 & 180 & 12 & 2230 & 410 & 8 & 1540 & 30 \\
\hline $\mathrm{Cl}^{-}$ & 13 & 193000 & 3000 & 12 & 198000 & 7000 & 8 & 192000 & 3000 \\
\hline$F$ & 13 & 6 & 1 & 12 & 7 & 2 & 8 & 6 & 1 \\
\hline 1 & 13 & 16.3 & 2.9 & 12 & 14.1 & 3.2 & 8 & 13.5 & 0.8 \\
\hline $\mathrm{NH}_{4}{ }^{+}$ & 13 & 150 & 15 & 12 & 166 & 21 & 8 & 149 & 10 \\
\hline $\mathrm{NO}_{3}^{-}$ & 9 & 1.1 & 0.4 & 9 & 0.8 & 0.3 & 4 & 0.7 & 0.2 \\
\hline$P$ & 1 & 0.1 & & 3 & 0.3 & 0.2 & 2 & 0.3 & 0.1 \\
\hline $\mathrm{SO}_{4}^{-2}$ & 13 & 17700 & 1700 & 12 & 22700 & 2800 & 8 & 17300 & 800 \\
\hline Al & 11 & 0.20 & 0.21 & 12 & 0.12 & 0.06 & 5 & 0.20 & 0.08 \\
\hline As & 11 & 0.002 & 0.001 & 12 & 0.009 & 0.003 & 3 & 0.001 & 0.00 \\
\hline$B$ & 13 & 1510 & 90 & 12 & 1670 & 350 & 8 & 1450 & 80 \\
\hline $\mathrm{Ba}$ & 13 & 0.04 & 0.02 & 12 & 0.04 & 0.02 & 8 & 0.06 & 0.04 \\
\hline $\mathrm{Ca}$ & 13 & 251 & 21 & 12 & 254 & 30 & 8 & 270 & 34 \\
\hline Cs & 13 & 0.37 & 0.03 & 12 & 0.40 & 0.06 & 8 & 0.37 & 0.04 \\
\hline $\mathrm{Fe}$ & 4 & 1.6 & 1.3 & 0 & $<0.5$ & & 7 & 21.6 & 18.8 \\
\hline K & 13 & 16000 & 700 & 12 & 16000 & 1900 & 8 & 16100 & 600 \\
\hline $\mathbf{M g}$ & 13 & 23700 & 1000 & 12 & 36900 & 6200 & 8 & 23600 & 1300 \\
\hline Mn & 13 & 1.7 & 0.2 & 12 & 4.8 & 0.2 & 8 & 1.9 & 0.2 \\
\hline $\mathrm{Na}$ & 13 & 78800 & 2600 & 12 & 61100 & 8900 & 8 & 78200 & 2700 \\
\hline$R b$ & 7 & 16.1 & 1.0 & 4 & 19.5 & 2.8 & 3 & 16.1 & 1.5 \\
\hline $\mathrm{Si}$ & 13 & 1.4 & 0.4 & 12 & 1.3 & 0.4 & 7 & 1.1 & 0.4 \\
\hline Sr & 13 & 1.7 & 0.1 & 12 & 5.7 & 0.7 & 8 & 0.9 & 0.2 \\
\hline
\end{tabular}

$N=$ number of samples.

$X=$ mean.

$S=$ standard deviation. 
Table D-2 (Continued)

UNC Simple Statistics for 1989 and 1990 Analyses

\begin{tabular}{|c|c|c|c|c|c|c|c|c|c|}
\hline & & $A 3 \times 01-d$ & & & $B \times 01-d$ & & & DH28-d & \\
\hline & $\mathrm{N}$ & $x$ & $S$ & $N$ & $x$ & $S$ & $N$ & $x$ & $S$ \\
\hline SG & 8 & 1.22 & 0.01 & 12 & 1.23 & 0.01 & 5 & 1.23 & 0.01 \\
\hline TDS & 8 & 374000 & 12000 & 12 & 373000 & 8000 & 5 & 375000 & 9000 \\
\hline $\mathrm{pH}$ & 8 & 6.1 & 0.1 & 12 & 6.1 & 0.1 & 5 & 6.1 & 0.1 \\
\hline ALK & 8 & 1004 & 36 & 12 & 874 & 34 & 5 & 861 & 37 \\
\hline TIC & 8 & 5.2 & 0.9 & 12 & 5.8 & 2.2 & 5 & 9.8 & 1.8 \\
\hline TOC & 8 & 40 & 41 & 11 & 38 & 18 & 5 & 120 & 107 \\
\hline$B r^{-}$ & 8 & 1500 & 40 & 12 & 1470 & 20 & 5 & 1470 & 70 \\
\hline $\mathrm{Cl}^{-}$ & 8 & 191000 & 4000 & 12 & 193000 & 2000 & 5 & 191000 & 1000 \\
\hline$F$ & 8 & 7 & 1 & 12 & 7 & 1 & 5 & 3 & 1 \\
\hline$\Gamma$ & 8 & 17.0 & 6.7 & 12 & 14.0 & 1.7 & 5 & 16.6 & 4.0 \\
\hline $\mathrm{NH}_{4}^{+}$ & 8 & 148 & 18 & 12 & 145 & 12 & 5 & 147 & 10 \\
\hline $\mathrm{NO}_{3}^{-}$ & 5 & 1.3 & 0.5 & 7 & 0.9 & 0.3 & 5 & 1.5 & 1.4 \\
\hline$P$ & 1 & 0.1 & & 0 & $<0.1$ & & 2 & 0.7 & 0.6 \\
\hline $\mathrm{SO}_{4}^{-2}$ & 8 & 16800 & 500 & 12 & 16900 & 400 & 5 & 16600 & 200 \\
\hline Al & 5 & 0.22 & 0.14 & 8 & 0.53 & 0.62 & 5 & 1.3 & 0.7 \\
\hline As & 7 & 0.001 & 0.001 & 11 & 0.002 & 0.001 & 5 & 0.004 & 0.001 \\
\hline$B$ & 8 & 1510 & 120 & 12 & 1460 & 80 & 5 & 1460 & 40 \\
\hline $\mathrm{Ba}$ & 8 & 0.04 & 0.02 & 12 & 0.04 & 0.02 & 5 & 0.04 & 0.02 \\
\hline $\mathrm{Ca}$ & 8 & 267 & 29 & 12 & 265 & 22 & 5 & 360 & 22 \\
\hline Cs & 8 & 0.36 & 0.04 & 12 & 0.35 & 0.04 & 5 & 0.27 & 0.03 \\
\hline $\mathrm{Fe}$ & 3 & 1.2 & 0.2 & 7 & 2.1 & 1.4 & 5 & 1.9 & 0.6 \\
\hline $\mathrm{K}$ & 8 & 15700 & 900 & 12 & 16100 & 1000 & 5 & 17000 & 200 \\
\hline $\mathrm{Mg}$ & 8 & 23600 & 1100 & 12 & 22500 & 800 & 5 & 20400 & 300 \\
\hline $\mathrm{Mn}$ & 8 & 1.4 & 0.1 & 12 & 1.4 & 0.2 & 5 & 1.4 & 0.4 \\
\hline $\mathrm{Na}$ & 8 & 77700 & 3800 & 12 & 80000 & 1800 & 5 & 85300 & 1000 \\
\hline $\mathrm{Rb}$ & 4 & 15.9 & 0.8 & 5 & 15.4 & 0.9 & 0 & & \\
\hline Si & 8 & 1.6 & 0.2 & 12 & 1.6 & 0.7 & 5 & 2.7 & 0.6 \\
\hline $\mathrm{Sr}$ & 8 & 1.8 & 0.3 & 12 & 2.0 & 0.1 & 5 & 1.7 & 0.3 \\
\hline
\end{tabular}

$N=$ number of samples.

$X=$ mean.

$S=$ standard deviation. 
Table D-2 (Continued)

UNC Simple Statistics for 1989 ane 1990 Analyses

\begin{tabular}{|c|c|c|c|c|c|c|c|c|c|}
\hline & \multicolumn{3}{|c|}{ DH30-d } & \multicolumn{3}{|c|}{ DH32-d } & \multicolumn{3}{|c|}{ DH-34-d } \\
\hline & $N$ & $x$ & $S$ & $N$ & $x$ & $S$ & $N$ & $x$ & $S$ \\
\hline SG & 7 & 1.22 & 0.01 & 9 & 1.22 & 0.00 & 6 & 1.22 & 0.00 \\
\hline TDS & 7 & 372000 & 12000 & 9 & 366000 & 12000 & 6 & 368000 & 8000 \\
\hline $\mathrm{pH}$ & 7 & 6.1 & 0.0 & 9 & 6.1 & 0.0 & 6 & 6.1 & $<0.1$ \\
\hline ALK & 7 & 819 & 41 & 9 & 820 & 13 & 6 & 771 & 14 \\
\hline TIC & 7 & 6.1 & 1.7 & 9 & 5.9 & 2.1 & 6 & 8.6 & 1.6 \\
\hline TOC & 7 & 22 & 15 & 9 & 11 & 3 & 5 & 18 & 9 \\
\hline $\mathrm{Br}^{-}$ & 7 & 1450 & 60 & 9 & 1430 & 60 & 6 & 1350 & 50 \\
\hline $\mathrm{Cr}^{-}$ & 7 & 190000 & 2000 & 9 & 191000 & 2000 & 6 & 191000 & 3000 \\
\hline$F$ & 7 & 4 & 1 & 9 & 4 & 1 & 6 & 4 & 1 \\
\hline$\Gamma^{-}$ & 7 & 16.3 & 2.2 & 9 & 15.4 & 0.9 & 6 & 15.9 & 1.9 \\
\hline $\mathrm{NH}_{4}^{+}$ & 7 & 151 & 16 & 9 & 153 & 12 & 6 & 152 & 20 \\
\hline $\mathrm{NO}_{3}^{-}$ & 6 & 0.9 & 0.5 & 7 & 2 & 4 & 3 & 0.8 & 0.4 \\
\hline $\mathbf{P}$ & 1 & 0.2 & & 0 & $<0.1$ & & 0 & $<0.1$ & \\
\hline $\mathrm{SO}_{4}^{-2}$ & 7 & 16400 & 200 & 9 & 16100 & 100 & 6 & 16800 & 100 \\
\hline Al & 7 & 0.80 & 0.74 & 8 & 0.30 & 0.21 & 6 & 0.43 & 0.07 \\
\hline As & 7 & 0.005 & 0.002 & 9 & 0.003 & 0.001 & 6 & 0.004 & 0.001 \\
\hline$B$ & 7 & 1510 & 60 & 9 & 1510 & 100 & 6 & 1460 & 90 \\
\hline $\mathrm{Ba}$ & 7 & 0.04 & 0.01 & 9 & 0.03 & 0.01 & 6 & 0.04 & 0.01 \\
\hline $\mathrm{Ca}$ & 7 & 326 & 40 & 9 & 329 & 32 & 6 & 427 & 44 \\
\hline Cs & 7 & 0.28 & 0.03 & 9 & 0.26 & 0.02 & 6 & 0.25 & 0.03 \\
\hline $\mathrm{Fe}$ & 7 & 0.7 & 0.3 & 3 & 2.6 & 0.7 & 3 & 2.8 & 0.4 \\
\hline K & 7 & 17500 & 400 & 9 & 17500 & 500 & 6 & 17400 & 300 \\
\hline $\mathrm{Mg}$ & 7 & 20200 & 300 & 9 & 19900 & 600 & 6 & 18800 & 700 \\
\hline Mn & 7 & 1.2 & $<0.1$ & 9 & 1.0 & 0.1 & 6 & 1.1 & 0.1 \\
\hline $\mathrm{Na}$ & 7 & 85300 & 900 & 9 & 87000 & 2100 & 6 & 87000 & 700 \\
\hline $\mathrm{Rb}$ & 0 & & & 0 & & & 0 & & \\
\hline $\mathrm{Si}$ & 7 & 3.1 & 2.6 & 9 & 2.7 & 1.0 & 6 & 2.7 & 0.4 \\
\hline $\mathrm{Sr}$ & 7 & 2.5 & 0.3 & 9 & 2.4 & 0.1 & 6 & 4.1 & 0.2 \\
\hline
\end{tabular}

$N=$ number of samples.

$\mathrm{X}=$ mean.

$S=$ standard deviation. 
Table D-2 (Continued)

\section{UNC Simple Statistics for 1989 and 1990 Analyses}

\begin{tabular}{|c|c|c|c|c|c|c|c|c|c|}
\hline & & DH36-d & & & DH38-d & & & DH40-d & \\
\hline & $\mathbf{N}$ & $x$ & $S$ & $N$ & $x$ & $S$ & $N$ & $x$ & $S$ \\
\hline SG & 10 & 1.23 & 0.01 & 11 & 1.22 & 0.01 & 2 & 1.22 & 0.01 \\
\hline TDS & 10 & 373000 & 10000 & 11 & 372000 & 10000 & 2 & 373000 & 13000 \\
\hline $\mathrm{pH}$ & 10 & 6.1 & 0.1 & 11 & 6.2 & 0.1 & 2 & 6.4 & 0.1 \\
\hline ALK & 10 & 853 & 15 & 11 & 958 & 68 & 2 & 1295 & 28 \\
\hline TIC & 10 & 5.6 & 2.0 & 11 & 7.7 & 3.1 & 2 & 9 & 2 \\
\hline TOC & 10 & 16 & 7 & 11 & 22 & 12 & 2 & 121 & 98 \\
\hline $\mathrm{Br}$ & 10 & 1460 & 60 & 11 & 1430 & 40 & 2 & 1560 & 10 \\
\hline $\mathrm{Cl}^{-}$ & 10 & 192000 & 3000 & 11 & 192000 & 4000 & 2 & 193000 & 2000 \\
\hline$F$ & 10 & 4 & 1 & 11 & 4 & 1 & 2 & 5 & 1 \\
\hline${ }^{\circ}$ & 10 & 16.0 & 1.0 & 11 & 18.8 & 4.1 & 2 & 17.1 & 1.3 \\
\hline $\mathrm{NH}_{4}{ }^{+}$ & 10 & 162 & 11 & 11 & 159 & 7 & 2 & 162 & 2 \\
\hline $\mathrm{NO}_{3}^{-}$ & 6 & 1.3 & 1.1 & 8 & 0.9 & 0.2 & 2 & 1.8 & 0.7 \\
\hline$P$ & 1 & 0.2 & & 5 & 0.2 & 0.1 & 2 & 0.5 & 0.1 \\
\hline $\mathrm{SO}_{4}^{-2}$ & 10 & 16200 & 300 & 11 & 16000 & 300 & 2 & 16200 & 100 \\
\hline Al & 9 & 0.40 & 0.30 & 9 & 0.33 & 0.19 & 2 & 0.09 & 0.04 \\
\hline As & 10 & 0.011 & 0.005 & 10 & 0.007 & 0.004 & 1 & 0.002 & \\
\hline B & 10 & 1520 & 70 & 11 & 1530 & 50 & 2 & 1580 & 110 \\
\hline $\mathrm{Ba}$ & 10 & 0.03 & 0.02 & 11 & 0.03 & 0.02 & 2 & 0.11 & 0.09 \\
\hline $\mathrm{Ca}$ & 10 & 318 & 20 & 11 & 318 & 25 & 2 & 316 & 35 \\
\hline Cs & 10 & 0.28 & 0.03 & 11 & 0.27 & 0.03 & 2 & 0.26 & 0.00 \\
\hline $\mathrm{Fe}$ & 1 & 0.9 & & 1 & 0.5 & & 0 & $<0.5$ & \\
\hline $\mathrm{K}$ & 10 & 17800 & 800 & 11 & 18000 & 800 & 2 & 17800 & 400 \\
\hline $\mathrm{Mg}$ & 10 & 19100 & 800 & 11 & 18500 & 600 & 2 & 18600 & 800 \\
\hline Mn & 10 & 1.0 & 0.1 & 11 & 1.0 & 0.1 & 2 & 1.2 & $<0.1$ \\
\hline $\mathrm{Na}$ & 10 & 86500 & 1800 & 11 & 86600 & 2200 & 2 & 83400 & 5200 \\
\hline$R b$ & 3 & 15.0 & 0.3 & 5 & 14.2 & 0.8 & 2 & 14.0 & 1.4 \\
\hline Si & 10 & 2.4 & 0.6 & 10 & 2.4 & 0.7 & 2 & 3.3 & 0.2 \\
\hline Sr & 10 & 1.4 & 0.3 & 11 & 0.9 & 0.2 & 2 & 0.6 & 0.1 \\
\hline
\end{tabular}

$\mathrm{N}=$ number of samples.

$X=$ mean.

$S=$ standard deviation. 
Table D-2 (Continued)

UNC Simple Statistics for 1989 and 1990 Analyses

\begin{tabular}{|c|c|c|c|c|c|c|c|c|c|}
\hline & & DH42-d & & & DH42A-d & & & $H P 402 A-C$ & \\
\hline & $N$ & $x$ & $\mathbf{s}$ & $\mathbf{N}$ & $x$ & $S$ & $\mathrm{~N}$ & $x$ & $S$ \\
\hline SG & 5 & 1.22 & 0.01 & 11 & 1.22 & 0.01 & 10 & 1.22 & $<0.01$ \\
\hline TDS & 5 & 369000 & 4000 & 11 & 375000 & 9000 & 10 & 378000 & 17000 \\
\hline pH & 5 & 6.2 & 0.1 & 11 & 6.1 & 0.1 & 10 & 6.0 & $<0.1$ \\
\hline ALK & 5 & 935 & 19 & 11 & 903 & 36 & 10 & 757 & 17 \\
\hline TIC & 5 & 6.5 & 2.7 & 11 & 5.1 & 1.2 & 9 & 5.0 & 1.0 \\
\hline TOC & 5 & 37 & 15 & 8 & 20 & 11 & 9 & 14 & 7 \\
\hline $\mathrm{Br}^{-}$ & 5 & 1420 & 30 & 11 & 1420 & 30 & 10 & 1530 & 60 \\
\hline $\mathrm{Cr}^{-}$ & 5 & 190000 & 3000 & 11 & 192000 & 4000 & 10 & 191000 & 3000 \\
\hline$F$ & 5 & 4 & 1 & 11 & 5 & 1 & 10 & 6 & 1 \\
\hline$\Gamma^{-}$ & 5 & 18.5 & 4.5 & 11 & 16.2 & 4.5 & 10 & 12.4 & 1.0 \\
\hline $\mathrm{NH}_{4}^{+}$ & 5 & 161 & 15 & 11 & 166 & 10 & 10 & 133 & 13 \\
\hline $\mathrm{NO}_{3}^{-}$ & 5 & 3 & 4 & 8 & 1.0 & 0.4 & 10 & 0.7 & 0.2 \\
\hline$P$ & 1 & 0.1 & & 2 & 0.3 & 0.1 & 0 & $<0.1$ & \\
\hline $\mathrm{SO}_{4}^{-2}$ & 5 & 15800 & 700 & 11 & 15700 & 300 & 10 & 17800 & 300 \\
\hline Al & 3 & 0.71 & 0.44 & 7 & 0.25 & 0.18 & 8 & 0.19 & 0.17 \\
\hline As & 4 & $0 . n 05$ & 0.002 & 7 & 0.004 & 0.001 & 2 & 0.007 & 0.001 \\
\hline B & 5 & 1470 & 40 & 11 & 1510 & 50 & 10 & 1300 & 60 \\
\hline $\mathrm{Ba}$ & 5 & 0.04 & 0.02 & 11 & 0.03 & 0.02 & 10 & 0.05 & 0.02 \\
\hline $\mathrm{Ca}$ & 5 & 317 & 25 & 11 & 321 & 27 & 10 & 312 & 22 \\
\hline Cs & 5 & 0.27 & 0.03 & 10 & 0.25 & 0.04 & 10 & 0.37 & 0.04 \\
\hline $\mathrm{Fe}$ & 2 & 0.8 & $<0.1$ & 2 & 2.2 & 0.7 & 10 & 44.5 & 38.3 \\
\hline K & 5 & 17600 & 1300 & 11 & 18000 & 800 & 10 & 14100 & 600 \\
\hline Mg & 5 & 17800 & 200 & 11 & 17900 & 500 & 10 & 24700 & 700 \\
\hline Mn & 5 & 1.0 & 0.1 & 11 & 1.0 & 0.1 & 10 & 2.3 & 0.4 \\
\hline $\mathrm{Na}$ & 5 & 86800 & 1400 & 11 & 87900 & 1900 & 10 & 78500 & 2200 \\
\hline $\mathbf{R b}$ & 3 & 14.3 & 0.6 & 6 & 14.3 & 0.2 & 6 & 15.9 & 0.7 \\
\hline Si & 5 & 2.2 & 0.8 & 11 & 2.3 & 0.6 & 2 & 1.4 & 0.1 \\
\hline $\mathrm{Sr}$ & 5 & 0.9 & 0.1 & 11 & 0.8 & 0.1 & 10 & 4.2 & 0.4 \\
\hline
\end{tabular}

$N=$ number of samples.

$X=$ mean.

$S=$ standard deviation. 
Table D-2 (Continued)

UNC Simple Statistics for 1989 and 1990 Analyses

\begin{tabular}{|c|c|c|c|c|c|c|c|c|c|}
\hline & \multicolumn{3}{|c|}{ DHP402Aa-d ${ }^{a}$} & \multicolumn{3}{|c|}{ G090-d } & \multicolumn{3}{|c|}{ GSEEP- $d$} \\
\hline & $N$ & $\mathrm{x}$ & $S$ & $N$ & $x$ & $\mathrm{~S}$ & $N$ & $x$ & $\mathbf{S}$ \\
\hline$S G$ & 4 & 1.22 & 0.00 & 2 & 1.23 & 0.00 & 11 & 1.23 & 0.01 \\
\hline TDS & 4 & 380000 & 7000 & 2 & 382000 & 2000 & 11 & 373000 & 6000 \\
\hline $\mathrm{pH}$ & 4 & 6.0 & $<0.1$ & 2 & 6.2 & 0.0 & 11 & 6.3 & 0.1 \\
\hline ALK & 4 & 740 & 9 & 2 & 693 & 13 & 11 & 891 & 16 \\
\hline בוּ & 4 & 4.2 & 0.9 & 2 & 12.5 & 0.4 & 9 & 4.0 & 0.8 \\
\hline TOC & 4 & 14 & 3 & 2 & 25 & 0 & 9 & 19 & 7 \\
\hline $\mathrm{Br}$ & 4 & 1530 & 20 & 2 & 1320 & 10 & 11 & 1360 & 30 \\
\hline $\mathrm{Cl}^{-}$ & 4 & 194000 & 6000 & 2 & 179000 & 1000 & 11 & 184000 & 3000 \\
\hline$F$ & 4 & 5 & 2 & 2 & 7 & 0 & 11 & 4 & 1 \\
\hline$r$ & 4 & 13.1 & 0.3 & 2 & 17.9 & 0.8 & 11 & 17.0 & 1.3 \\
\hline $\mathrm{NH}_{4}^{+}$ & 4 & 138 & 26 & 2 & 192 & 4 & 11 & 176 & 11 \\
\hline $\mathrm{NO}_{3}^{-}$ & 4 & 1.1 & 0.7 & 2 & 0.9 & 0.3 & 7 & 0.7 & 0.2 \\
\hline$P$ & 0 & $<0.1$ & & 0 & $<0.1$ & & 3 & 0.2 & 0.1 \\
\hline $\mathrm{SO}_{4}^{-2}$ & 4 & 17400 & 400 & 2 & 29100 & 100 & 11 & 28200 & 300 \\
\hline Al & 2 & 0.08 & 0.02 & 2 & 0.06 & 0.00 & 5 & 0.06 & 0.01 \\
\hline As & 0 & $<.001$ & & 0 & $<0.001$ & & 11 & 0.006 & 0.001 \\
\hline B & 4 & 1250 & 70 & 2 & 1470 & 10 & 11 & 1580 & 60 \\
\hline $\mathrm{Ba}$ & 4 & 0.08 & 0.04 & 2 & 0.03 & 0.01 & 11 & 0.02 & 0.01 \\
\hline $\mathrm{Ca}$ & 4 & 298 & 4 & 2 & 224 & 1 & 11 & 267 & 19 \\
\hline Cs & 4 & 0.36 & 0.02 & 2 & 0.20 & 0.04 & 11 & 0.21 & 0.02 \\
\hline $\mathrm{Fe}$ & 1 & 1.5 & & 2 & 22.3 & 3.6 & 0 & $<0.5$ & \\
\hline$K$ & 4 & 13800 & 900 & 2 & 12200 & 100 & 11 & 13500 & 300 \\
\hline $\mathrm{Mg}$ & 4 & 23900 & 400 & 2 & 13400 & 200 & 11 & 14600 & 400 \\
\hline$M n$ & 4 & 2.6 & 0.1 & 2 & 2.0 & 0.0 & 11 & 0.6 & $<0.1$ \\
\hline $\mathrm{Na}$ & 4 & 75600 & 400 & 2 & 96900 & 100 & 11 & 98000 & 2200 \\
\hline$R b$ & 4 & 15.7 & 0.8 & 2 & 11.7 & 0.0 & 3 & 11.8 & 0.8 \\
\hline $\mathrm{Si}$ & 0 & $<0.5$ & & 0 & $<0.5$ & & 11 & 1.2 & 0.3 \\
\hline $\mathrm{Sr}$ & 4 & 4.0 & 0.1 & 2 & 2.0 & 0.0 & 11 & 2.0 & 0.3 \\
\hline
\end{tabular}

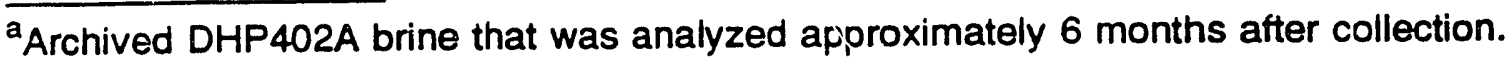

$N=$ number of samples.

$X=$ mean.

$S=$ standard deviation. 
Table D-2 (Continued)

\section{UNC Simple Statistics for 1989 and 1990 Analyses}

\begin{tabular}{|c|c|c|c|c|c|c|c|c|c|}
\hline & & H090-d & & & $\mathrm{OH} 20-\mathrm{h}$ & & & $\mathrm{OH} 23-\mathrm{h}$ & \\
\hline & $N$ & $x$ & $S$ & $N$ & $x$ & $s$ & $N$ & $x$ & $S$ \\
\hline SG & 2 & 1.23 & 0.00 & 6 & 1.22 & 0.01 & 10 & 1.22 & 0.01 \\
\hline TDS & 2 & 379000 & 1000 & 6 & 382000 & 4000 & 10 & 376000 & 12000 \\
\hline $\mathrm{pH}$ & 2 & 6.2 & 0.0 & 6 & 6.1 & 0.1 & 10 & 6.0 & $<0.1$ \\
\hline ALK & 2 & 741 & 4 & 6 & 682 & 24 & 10 & 759 & 73 \\
\hline TIC & 2 & 9.7 & 0.0 & 6 & 5.5 & 1.5 & 10 & 4.5 & 1.1 \\
\hline TOC & 2 & 142 & 0 & 6 & 75 & 51 & 10 & 129 & 79 \\
\hline $\mathrm{Br}^{-}$ & 2 & 1270 & 10 & 6 & 1360 & 120 & 10 & 1530 & 60 \\
\hline $\mathrm{Cl}^{-}$ & 2 & 179000 & 1000 & 6 & 191000 & 5000 & 10 & 193000 & 3000 \\
\hline$F$ & 2 & 6 & 0 & 6 & 4 & 1 & 10 & 4 & 1 \\
\hline$r$ & 2 & 16.1 & 0.1 & 6 & 19.9 & 10.6 & 10 & 20.3 & 8.6 \\
\hline $\mathrm{NH}_{4}{ }^{+}$ & 2 & 195 & 8 & 6 & 130 & 12 & 10 & 150 & 12 \\
\hline $\mathrm{NO}_{3}^{-}$ & 2 & 0.8 & 0.0 & 6 & 1.9 & 0.5 & 8 & 1.2 & 0.4 \\
\hline$P$ & 2 & 0.4 & 0.0 & 6 & 0.2 & 0.2 & 6 & 0.3 & 0.2 \\
\hline $\mathrm{SO}_{4}^{-2}$ & 2 & 28100 & 100 & 6 & 18200 & 1700 & 10 & 17200 & 900 \\
\hline Al & 1 & 0.09 & & 5 & 0.09 & 0.02 & 10 & 0.16 & 0.08 \\
\hline As & 1 & 0.001 & & 6 & 0.003 & 0.001 & 10 & 0.007 & 0.015 \\
\hline B & 2 & 1440 & 40 & 6 & 1250 & 120 & 10 & 1450 & 70 \\
\hline $\mathrm{Ba}$ & 2 & 0.04 & 0.02 & 6 & 0.05 & 0.03 & 10 & 0.07 & 0.02 \\
\hline $\mathrm{Ca}$ & 2 & 262 & 0 & 6 & 334 & 6 & 10 & 316 & 38 \\
\hline Cs & 2 & 0.22 & $<0.01$ & 6 & 0.27 & 0.03 & 10 & 0.31 & 0.04 \\
\hline $\mathrm{Fe}$ & 1 & 1.0 & & 1 & 1.3 & & 10 & $<0.5$ & \\
\hline$K$ & 2 & 11900 & 200 & 6 & 15500 & 300 & 10 & 16300 & 800 \\
\hline $\mathrm{Mg}$ & 2 & 14300 & 600 & 6 & 20400 & 800 & 10 & 23300 & 1500 \\
\hline$M n$ & 2 & 0.7 & 0.0 & 6 & 2.3 & 0.4 & 10 & 2.1 & 0.4 \\
\hline $\mathrm{Na}$ & 2 & 95300 & 600 & 6 & 84100 & 4100 & 10 & 79600 & 2200 \\
\hline$R \mathbf{R}$ & 2 & 11.5 & 0.1 & 4 & 14.6 & 0.9 & 4 & 15.6 & 1.2 \\
\hline $\mathrm{Si}$ & 2 & 1.0 & 0.0 & 6 & 1.7 & 0.7 & 10 & 2.0 & 0.7 \\
\hline $\mathrm{Sr}$ & 2 & 2.8 & 0.0 & 6 & 2.9 & 1.8 & 10 & 1.3 & 0.3 \\
\hline
\end{tabular}


Table D-2 (Continued)

UNC Simple Statistics for 1989 and 1990 Analyses

\begin{tabular}{|c|c|c|c|c|c|c|c|c|c|}
\hline & & OH26-h & & & OH45-h & & & OH46-d & \\
\hline & $N$ & $x$ & $S$ & $N$ & $x$ & $S$ & $N$ & $x$ & $s$ \\
\hline SG & 8 & 1.22 & 0.01 & 3 & 1.22 & 0.01 & 7 & 1.22 & 0.01 \\
\hline TDS & 8 & 377000 & 12000 & 3 & 368000 & 19000 & 7 & 375000 & 10000 \\
\hline $\mathrm{pH}$ & 8 & 6.0 & 0.0 & 3 & 6.1 & 0.1 & 7 & 6.1 & $<0.1$ \\
\hline ALK & 8 & 851 & 266 & 3 & 828 & 26 & 7 & 882 & 35 \\
\hline TIC & 8 & 4.0 & 0.6 & 3 & 5.3 & 1.8 & 7 & 5.4 & 2.0 \\
\hline TOC & 8 & 80 & 28 & 3 & 112 & 32 & 7 & 60 & 37 \\
\hline $\mathrm{Br}^{-}$ & 8 & 1490 & 30 & 3 & 1510 & 20 & 7 & 1570 & 40 \\
\hline $\mathrm{Cl}^{-}$ & 8 & 191000 & 3000 & 3 & 192000 & 6000 & 7 & 192000 & 3000 \\
\hline$F$ & 8 & 4 & 1 & 3 & 5 & 2 & 7 & 5 & 1 \\
\hline$r$ & 8 & 18.7 & 3.7 & 3 & 19.4 & 2.3 & 7 & 18.4 & 4.2 \\
\hline $\mathrm{NH}_{4}^{+}$ & 8 & 146 & 13 & 3 & 154 & 22 & 7 & 154 & 17 \\
\hline $\mathrm{NO}_{3}^{-}$ & 8 & 0.9 & 0.3 & 3 & 1.1 & 0.4 & 7 & 1.1 & 0.7 \\
\hline$P$ & 7 & 0.2 & 0.1 & 3 & 0.3 & 0.2 & 0 & $<0.1$ & \\
\hline $\mathrm{SO}_{4}^{-2}$ & 8 & 16800 & 800 & 3 & 16500 & 900 & 7 & 16300 & 700 \\
\hline Al & 8 & 0.17 & 0.05 & 2 & 0.06 & 0.004 & 4 & 0.45 & 0.75 \\
\hline As & 6 & 0.002 & 0.001 & 3 & 0.002 & 0.002 & 2 & 0.002 & 0.001 \\
\hline B & 8 & 1420 & 100 & 3 & 1480 & 230 & 7 & 1530 & 110 \\
\hline $\mathrm{Ba}$ & 8 & 0.05 & 0.02 & 3 & 0.09 & 0.04 & 7 & 0.07 & 0.06 \\
\hline $\mathrm{Ca}$ & 8 & 308 & 33 & 3 & 326 & 53 & 7 & 300 & 20 \\
\hline Cs & 8 & 0.30 & 0.03 & 3 & 0.26 & 0.02 & 7 & 0.29 & 0.02 \\
\hline $\mathrm{Fe}$ & 0 & $<0.5$ & & 0 & $<0.5$ & & 1 & 10.1 & \\
\hline$K$ & 8 & 15600 & 700 & 3 & 15900 & 1500 & 7 & 17200 & 1300 \\
\hline Mg & 8 & 22700 & 1200 & 3 & 21100 & 1400 & 7 & 22000 & 1300 \\
\hline Mn & 8 & 1.6 & 0.1 & 3 & 1.5 & 0.1 & 7 & 2.6 & 2.3 \\
\hline $\mathrm{Na}$ & 8 & 80600 & 3500 & 3 & 78800 & 1500 & 7 & 80800 & 3000 \\
\hline$R b$ & 4 & 15.5 & 0.9 & 2 & 15.5 & 0.4 & 4 & 15.4 & 0.9 \\
\hline Si & 8 & 1.6 & 1.0 & 3 & 1.8 & 1.0 & 7 & 1.6 & 1.3 \\
\hline Sr & 8 & 1.2 & 0.3 & 3 & 3.0 & 0.4 & 7 & 2.0 & 0.4 \\
\hline
\end{tabular}

$N=$ number of samples.

$X=$ mean.

$S=$ standard deviation. 
Table D.2 (Continued)

UNC Simple Statistics for 1989 and 1990 Analyses

\begin{tabular}{|c|c|c|c|c|c|c|c|c|c|}
\hline & & $\mathrm{OH} 47-\mathrm{u}$ & & & OH62-d & & & OH63-d & \\
\hline & $N$ & $x$ & $S$ & $N$ & $x$ & $s$ & $N$ & $x$ & $S$ \\
\hline SG & 4 & 1.24 & 0.01 & 2 & 1.23 & 0.01 & 2 & 1.23 & 0.00 \\
\hline TDS & 4 & 406000 & 25000 & 2 & 371000 & 4000 & 2 & 372000 & 2000 \\
\hline $\mathrm{pH}$ & 4 & 5.6 & 0.1 & 2 & 6.1 & 0.1 & 2 & 6.0 & 0.0 \\
\hline ALK & 4 & 1170 & 123 & 2 & 825 & 11 & 2 & 816 & 9 \\
\hline TIC & 2 & 3.3 & 0.4 & 2 & 4.6 & 0.7 & 2 & 5.6 & 0.0 \\
\hline TOC & 4 & 44 & 3 & 2 & 140 & 190 & 2 & 8 & 4 \\
\hline $\mathrm{Br}^{-}$ & 4 & 2460 & 310 & 2 & 1550 & 0 & 2 & 1540 & 0 \\
\hline $\mathrm{Cr}^{-}$ & 4 & 197000 & 6000 & 2 & 187000 & 1000 & 2 & 187000 & 0 \\
\hline$F$ & 4 & 6 & 2 & 2 & 5 & 0 & 2 & 4 & 1 \\
\hline$\Gamma$ & 4 & 16.6 & 1.3 & 2 & 15.4 & 0.3 & 2 & 15.8 & 0.1 \\
\hline $\mathrm{NH}_{4}^{+}$ & 4 & 217 & 29 & 2 & 150 & 1 & 2 & 148 & 4 \\
\hline $\mathrm{NO}_{3}^{-}$ & 4 & 1.0 & 0.2 & 2 & 2 & 0 & 2 & 3 & 1 \\
\hline $\mathrm{P}$ & 4 & 0.3 & 0.3 & 0 & $<0.1$ & & 1 & 0.1 & \\
\hline $\mathrm{SO}_{4}^{-2}$ & 4 & 25200 & 1600 & 2 & 16400 & 0 & 2 & 16400 & 0 \\
\hline Al & 4 & 0.33 & 0.34 & 2 & 0.15 & 0.02 & 0 & $<0.05$ & \\
\hline As & 1 & 0.002 & & 2 & 0.040 & 0.004 & 2 & 0.025 & 0.001 \\
\hline B & 4 & 1810 & 160 & 2 & 1490 & 10 & 2 & 1490 & 10 \\
\hline $\mathrm{Ba}$ & 4 & 0.09 & 0.11 & 2 & 0.03 & 0.01 & 2 & 0.05 & 0.00 \\
\hline $\mathrm{Ca}$ & 4 & 270 & 60 & 2 & 331 & 1 & 2 & 335 & 4 \\
\hline Cs & 4 & 0.40 & 0.05 & 0 & & & 0 & & \\
\hline $\mathrm{Fe}$ & 4 & 1.6 & 0.8 & 0 & $<0.5$ & & 0 & $<0.05$ & \\
\hline K & 4 & 18100 & 1200 & 2 & 16200 & 1000 & 2 & 16500 & 100 \\
\hline Mg & 4 & 36100 & 3800 & 2 & 21800 & 100 & 2 & 21600 & 0 \\
\hline$M n$ & 4 & 4.3 & 0.7 & 2 & 1.0 & 0.0 & 2 & 1.0 & $<0.1$ \\
\hline $\mathrm{Na}$ & 4 & 60000 & 9800 & 2 & 82000 & 1000 & 2 & 81000 & 1000 \\
\hline$R b$ & 2 & 22.5 & 2.7 & 0 & & & 0 & & \\
\hline Si & 4 & 2.0 & 0.4 & 2 & 1.9 & 0.2 & 2 & 1.5 & 0.1 \\
\hline $\mathrm{Sr}$ & 4 & 3.9 & 1.3 & 2 & 2.9 & 0.0 & 2 & 2.9 & 0.0 \\
\hline
\end{tabular}

$\mathrm{N}=$ number of samples.

$X=$ mean.

$\mathrm{S}=$ standard deviation. 
Table D-2 (Continued)

UNC Simple Statistics for 1989 and 1990 Analyses

\begin{tabular}{|c|c|c|c|c|c|c|}
\hline & & $\mathrm{OH} 66-\mathrm{d}$ & & & OH67-d & \\
\hline & $\mathrm{N}$ & $x$ & $s$ & $\mathbf{N}$ & $x$ & $S$ \\
\hline SG & 2 & 1.23 & 0.00 & 2 & 1.23 & 0.00 \\
\hline TDS & 2 & 369000 & 3000 & 2 & 365000 & 4000 \\
\hline $\mathrm{pH}$ & 2 & 6.3 & 0.1 & 2 & 6.2 & 0.0 \\
\hline ALK & 2 & 548 & 8 & 2 & 625 & 5 \\
\hline TIC & 2 & 9.6 & 1.5 & 2 & 9.7 & 0.0 \\
\hline TOC & 2 & 269 & 14 & 2 & 137 & 0 \\
\hline $\mathrm{Br}^{-}$ & 2 & 1180 & 0 & 2 & 1270 & 0 \\
\hline $\mathrm{Cr}^{-}$ & 2 & 186000 & 0 & 2 & 185000 & 0 \\
\hline$F$ & 2 & 13 & 1 & 2 & 8 & 0 \\
\hline$r$ & 2 & 11.1 & 0.1 & 2 & 11.9 & 0.1 \\
\hline $\mathrm{NH}_{4}{ }^{+}$ & 2 & 111 & 1 & 2 & 121 & 1 \\
\hline $\mathrm{NO}_{3}^{-}$ & 2 & 1 & 0 & 2 & 1 & 0 \\
\hline$P^{0}$ & 1 & 0.2 & & 0 & $<0.1$ & \\
\hline $\mathrm{SO}_{4}^{-2}$ & 2 & 21500 & 300 & 2 & 19900 & 0 \\
\hline $\mathrm{Al}^{\circ}$ & 2 & 0.13 & 0.04 & 2 & 0.10 & 0.02 \\
\hline As & 2 & 0.034 & 0.001 & 2 & 0.014 & 0.001 \\
\hline B & 2 & 1020 & 0 & 2 & 1160 & 10 \\
\hline $\mathrm{Ba}$ & 2 & 0.03 & $<0.01$ & 2 & 0.03 & 0.00 \\
\hline $\mathrm{Ca}$ & 2 & 322 & 1 & 2 & 329 & 1 \\
\hline Cs & 0 & & & 0 & & \\
\hline $\mathrm{Fe}$ & 0 & $<0.5$ & & 0 & $<0.5$ & \\
\hline$K$ & 2 & 14900 & 0 & 2 & 15400 & 400 \\
\hline $\mathrm{Mg}$ & 2 & 17400 & 100 & 2 & 18500 & 200 \\
\hline $\mathrm{Mn}$ & 2 & 1.0 & 0.0 & 2 & 0.9 & 0.0 \\
\hline $\mathrm{Na}$ & 2 & 90000 & 1000 & 2 & 88000 & 0 \\
\hline $\mathrm{Rb}$ & 0 & & & 0 & & \\
\hline $\mathrm{Si}$ & 2 & 1.5 & 0.0 & 2 & 2.0 & 0.0 \\
\hline $\mathrm{Sr}$ & 2 & 4.5 & 0.0 & 2 & 5.6 & 0.0 \\
\hline
\end{tabular}


This page left intentionally blank 


\section{APPENDIX E ACTIVITY PLAN}

BRINE SAMPLING AND EVALUATION PROGRAM PHASE II, III, AND IV SUBHORIZONTAL OBSERVATION HOLES

Rev. 1

September 1991 
This page left intentionally blank 


\subsection{Introduction}

Since excavations at the Waste Isolation Pilot Plant (WIPP) were initiated in 1982, much has been learned about the nature of brine found in the Salado Formation, in which the WIPP is being constructed. This activity plan details a proposed drilling program designed to provide new brine sampling holes that will yield additional brine inflow data to support modeling for performance assessment.

Possible brine inflow systems have been discussed by Deal and Roggenthen (1991). There are basically two systems: one in which far-field flow occurs through undisturbed rock outside of the zone of rock deformation known as the Disturbed Rock Zone (DRZ) and a local near-field system where brine is redistributed within the DRZ. Additional effects, such as gas exsolution, development of enhanced porosity and permeability within the DRZ, and preferential flow along bedding planes may modify brine inflow, but it is fundamentally important to distinguish between far-field sources and local, relatively limited redistribution of brine in the immediate vicinity of the WIPP excavations.

The relative importance of these two systems needs to be determined to assess long-term facility performance. For example, if there is enough far-field flow into the repository, then sufficient brine may come into the excavations to completely corrode the metal in the waste and the waste drums; therefore, the potential for hydrogen generation due to corrosion will be limited by the total metal inventory. If the brine seepage is purely a local phenomena due to redistribution of brine in the immediate vicinity of the excavations, there may be insufficient brine available to cause much corrosion after closure. In the latter case, hydrogen generation will be limited by the brine available and may not be a potential problem. Even if both of the proposed systems yield similar volumes of brine during the pressurization phase, the predicted consequences of human intrusion events, the fate of waste-generated gases, and the migration of hazardous constituents during undisturbed performance are all sensitive to brine inflow assumptions.

Human Intrusion. If the far-field model is valid, a human-intrusion event (drilling into the sealed repository at a future date) will lower fluid pressure in the rooms, create pressure gradients toward the rooms, and reinstate far-field flow. This will lead to a greater release of radionuclides from the repository as the inflowing brine infiltrates through the waste and flows up the borehole. Alternatively, if the near-field model is valid, the only brine available for transport of radionuclides is the volume of brine that is trapped in the room at the time of sealing. 
Waste-Generated Gases. Predicting the fate of waste-generated gases is also dependent upon the hydrologic system assumed to be operational. If brine can flow through the farfield, excess gas pressure can probably be dissipated through the host rock; but if far-field flow is not a viable mechanism, gas generation from microbial or radiolytic decomposition of organic materials may yield very high local pressures. Analyses by the WIPP Engineered Alternatives Task Force (EATE) have shown that predicted peak pressures are highly dependent upon the assumed mechanisms by which fluids can flow through the undisturbed host rock.

Migration of Hazardous Constituents. Another long-term performance concern is the migration of RCRA-listed hazardous constituents from the repository. If far-field flow is valid, then the generation of excess gas pressure within the repository may force gas (possibly contaminated with VOCs) across the RCRA unit boundary. However, if far-field flow does not occur, there will be less of a potential for VOC migration.

The main objectives of this plan are to evaluate the effects of stratigraphy on brine inflow and to determine which of these two hydrologic systems is dominant. Brine sampling from the new boreholes will become a routine part of the WIPP Brine Sampling and Evaluation Program (BSEP).

\subsection{Objectives}

The proposed drilling program has three specific objectives: to determine whether the brine inflow underground is stratigraphically controlled; if so, to quantify inflow to boreholes from the different stratigraphic units exposed at the repository level; and to determine whether there is a significant far-field component of brine flow in the Salado Formation surrounding the WIPP.

\subsection{Theory}

Recently completed work shows that the moisture content of the rocks exposed in the repository excavations varies directly with clay content (Deal and others, 1989). The lack of weeps on the back of the workings and the permeability testing of Beauheim (Beauheim and Howarth, 1991) support the contention that brine seepage occurs horizontally, preferentially along stratigraphic partings of interbeds, rather than vertically or through clear halite (Deal and Roggenthen, 1991). This leads to the suggestion that most brine seeping out of repository walls may be associated with the clays above and below the orange band, argillaceous halite salt, and clay $F$ near the back (Deal and others, 1991). 


\subsection{Previous Investigations}

During 1989 (Phase I), eleven subhorizontal brine sampling holes were drilled to investigate the variability in seepage rates from different stratigraphic horizons. The holes are oriented slightly downward to accumulate brine at the end of the hole where it can be collected and measured without loss to fractures near the excavations. Ten of the eleven holes were drilled in the future entries to Panels 7 and 8 at S1600, S1950, and S2150 (Figure E-1). Three of the holes (OH20, OH23, and $\mathrm{OH} 26$ ) are 150-foot ( $\mathrm{ft}$ ), 3-inch-diameter boreholes, started in the clayey halite (map unit 4) above the orange band and angled downward so that they end in the clear halite (map unit 0 ) below the orange band (Figure E-2). The 150-ft holes reached the orange band about $50 \mathrm{ft}$ into the holes. Hole OH27A was started at the initial location for $\mathrm{OH} 27$ but was terminated at a depth of $4.1 \mathrm{ft}$ due to drilling problems. The six remaining 50-ft holes were drilled either above or below the orange band about $50 \mathrm{ft}$ into the holes.

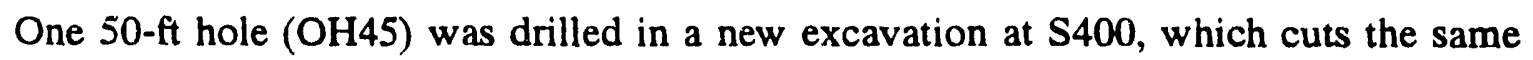
stratigraphic interval as the three $150-\mathrm{ft}$ holes.

The holes are monitored for brine inflow. When tubing was removed from the $150-\mathrm{ft}$ holes for maintenance of the moisture collection devices, dry tubing was observed for about the first $50 \mathrm{ft}$. The device was pulled twice in OH23. Both times, approximately 40 to $50 \mathrm{ft}$ of tubing was dry. It is not known conclusively what rock unit is encountered at that depth in the holes (these holes were not cored) nor whether there is brine inflow from deeper than $50 \mathrm{ft}$.

Several of the holes have produced measurable quantities of brine (Deal and others, 1991). However, the $150-\mathrm{ft}$ holes have all produced orders of magnitude more brine than the 50- $\mathrm{ft}$ holes, and the longer holes are still producing while the shorter holes are dry, with one exception- $\mathrm{OH} 45$, a 50 - $\mathrm{ft}$ hole that cuts the same stratigraphic interval as the 150 - $\mathrm{ft}$-long holes-which was drilled in a more recently mined area. It is noted that OH45 is located over 1,000 $\mathrm{ft}$ north of $\mathrm{OH} 20, \mathrm{OH} 23$, and $\mathrm{OH} 26$. Lateral variation may play a minor role in the difference in brine seepage. This is considered to be unlikely, as Deal and others (1989) found no significant lateral variation in moisture content for any of the stratigraphic units exposed in the excavations.

Two explanations can be offered for the brine inflow results: the longer holes are tapping an area that is not dewatered because they extend past the DRZ developed around the W170 drift. Therefore, they may only tap about $100 \mathrm{ft}$ of undisturbed salt (in this case, the one 50 -ft hole would still produce brine because it was drilled from a young excavation where a 
$\frac{1}{\alpha}$
$\frac{8}{8}$
$\overline{8}$

\section{Legend}

Completed Excavation 12/31/88

Planned Excavation

Drill hole(s) used for brine 0 obsorvation

Represents 2 or more drill $\Longrightarrow$ holes

\section{Note}

1. Mine coordinates in foot from the center of the salt handling shatt

2. Dritt widths not to scale, enlarged $2 \times$ for clarity

${ }_{0}^{0} \quad 400 \quad 800 F T$

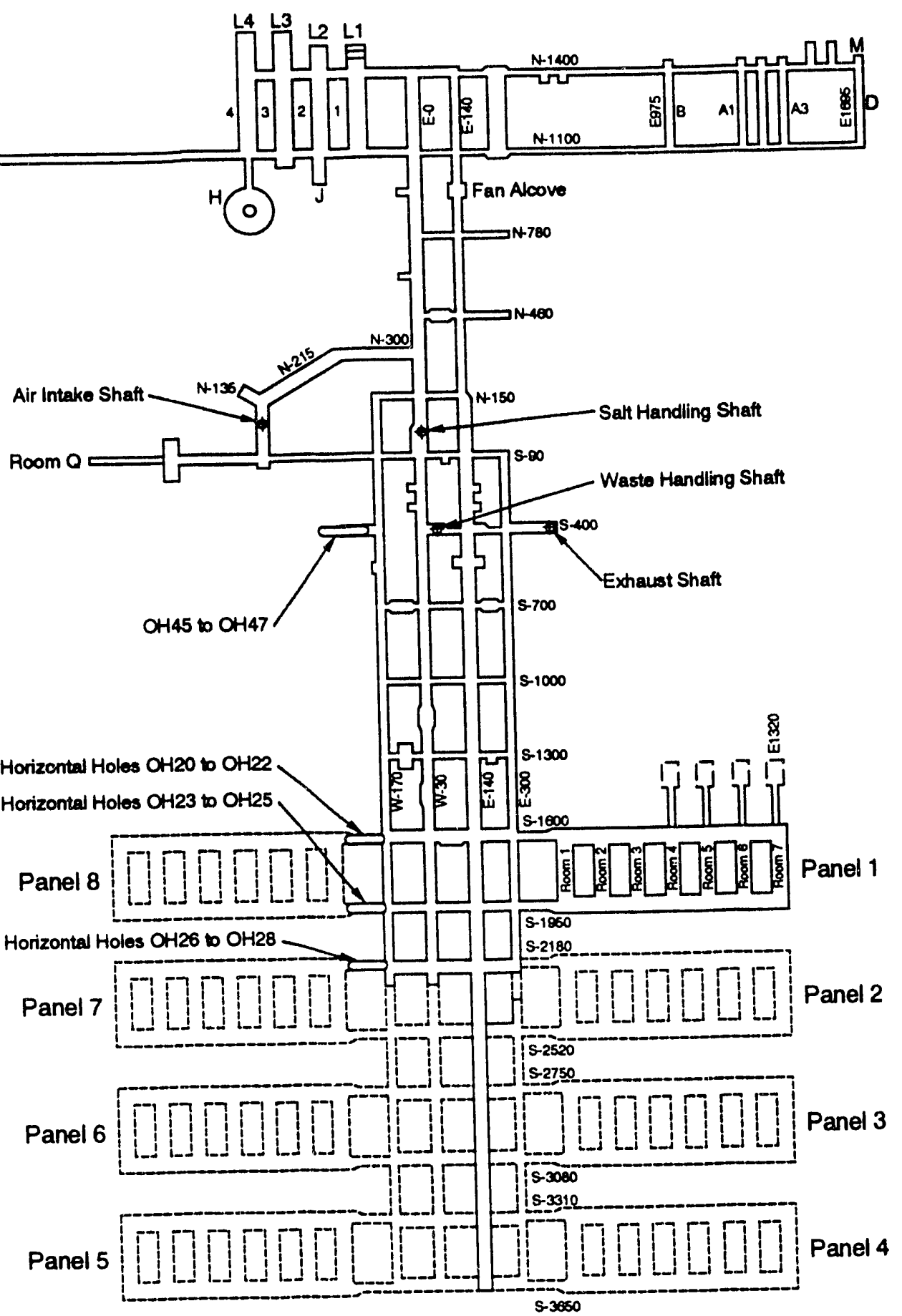

Figure E-1

Locations of the OH Series Subhorizontal Holes 


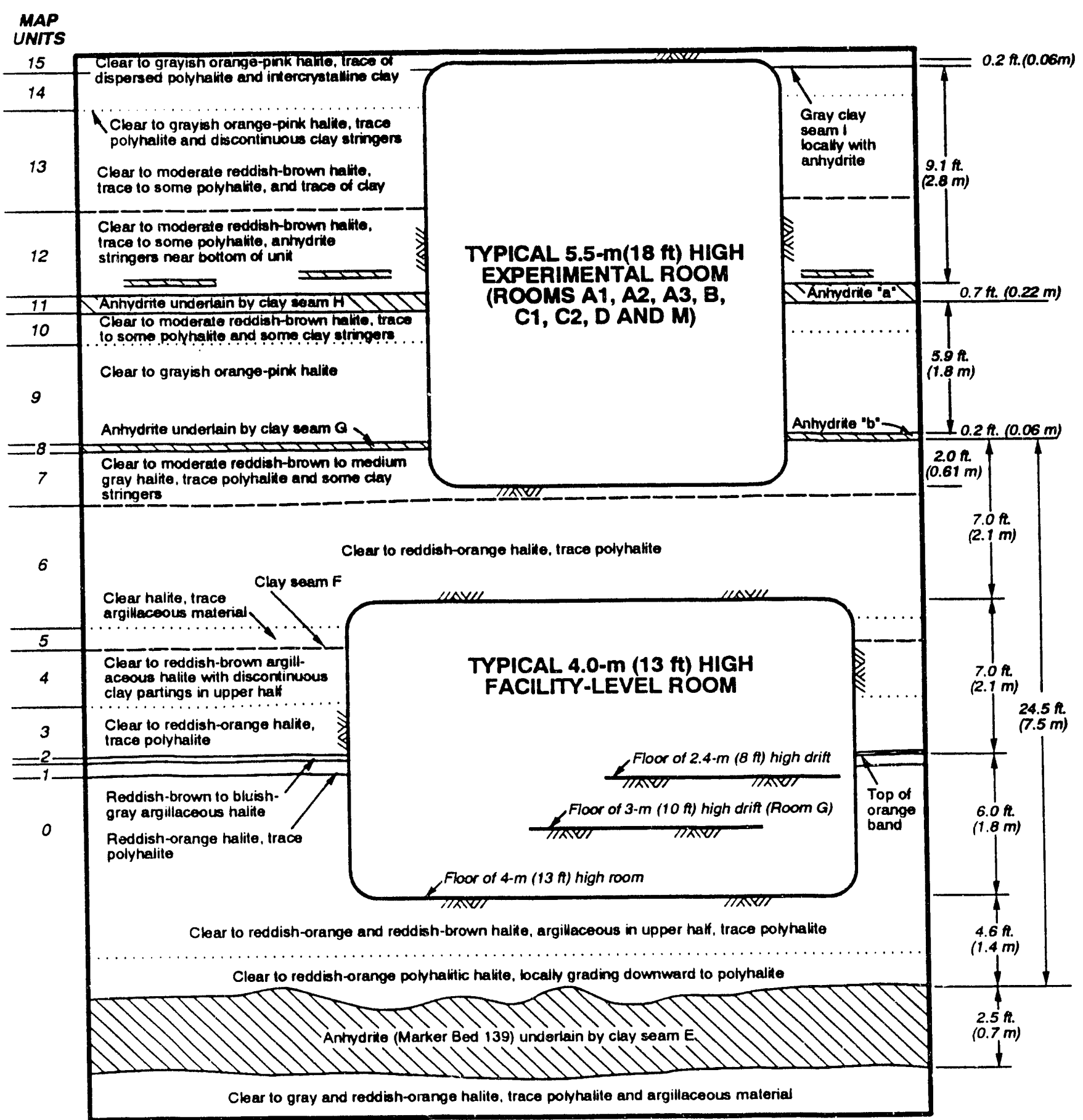

NOTES:

1. Dimensions and lithobogic descriptions are derived primarity from corehole and geologic mapping data from the four test rooms and experimental area.

2. Unit thicknesses are approximale and vary slightly.

3. Room dimensions have changed with time due to salt-creep closure.

(After Deal and Case, 1987)

\section{Figure E-2}


significant DRZ had not yet developed); or brine flows preferentially along stratigraphic boundaries, such as the clay units at the top and bottom of the orange band. Therefore, only the four holes ( $\mathrm{Cr} 20, \mathrm{OH} 23, \mathrm{OH} 26$, and $\mathrm{OH} 45)$ that cut the orange band accumulate brine and only from that part of the drill hole that intersects the clay units.

To improve the understanding of the mechanisms that affect brine seeping from the Salado Formation at the WIPP site, this drilling program is designed to consider various relevant effects separately. Dilling programs that discriminate between three different possible brine seepage mechanisms are outlined in the following sections.

\subsection{Logistics.}

The boreholes will be drilled by WIPP Experimental Operations. Drilling operations will be observed by a geologist fiom Geotechnical Engineering, who will log the cores. W'hen ine holes are completed, pressure-suction moisture collection devices (identical to those presently in use by the BSEP) will be instailed to monitor brine seepage. The boreholes will then become the responsibility of BSEP (Geotechnical Engineering), who will measure brine seepage volumes and obtain the brine chemistry analyses.

\subsection{Phase II Drilling Program}

This plan was initialiy proposed in J:Aly 1991, when the N460 and N780 drifts east of E140 were relatively new drifts. If implementation of this plan is delayed, relocating the drilling of Phase II holes to a recently mined drift is required; however, the theory behind this plan is not affected.

The hypothesis to be tested in Phase II is whether horizontal brine flow around horizontal discontinuities in the Salado Formation is significantly different for various stratigraphic units at the facility level. Drilling is proposed in an area that does not have a well-developed DRZ (i.e., a newly mined drift). New drifts have been excavated along E140 at N460 and N780 (Figure E-3). Drilling should commence in these areas as soon as is practicable. Two arrays of holes will be drilled: one in the south face of N460 east of E140 and ore in the south face of N780 east of E140. According to the structure contour map of the orange band (Figure E-4), the map units in tilat area of the underground are dipping 1 to 2 degrees to the south. Holes will be drilicd paiallel to the dip so that they slope downward away from the collar to effectively collect any brine inriow at their far end and still remain within a single stratiun. 


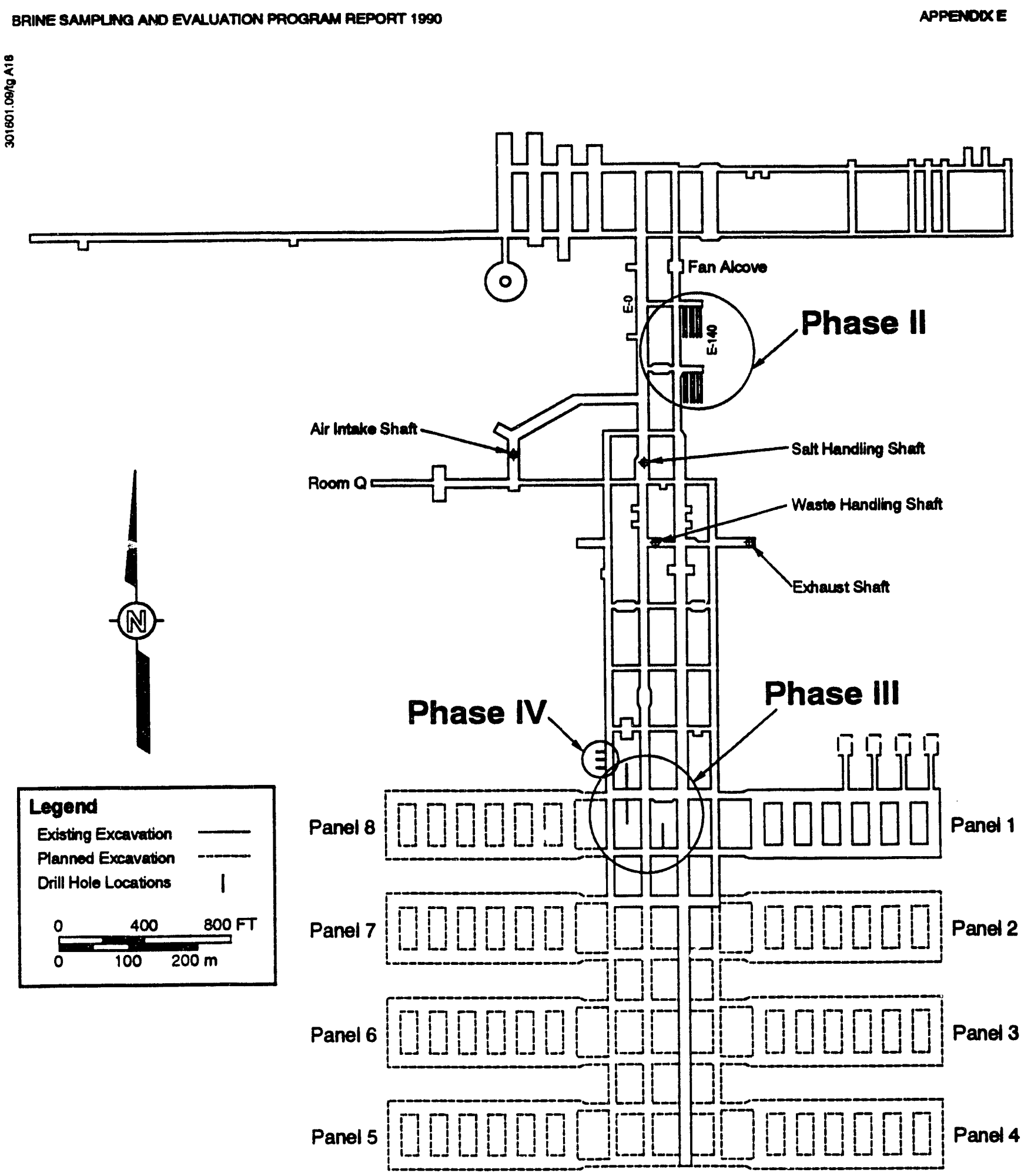

Figure E-3

Proposed Location of Phase II, III, and IV Drill Holes 


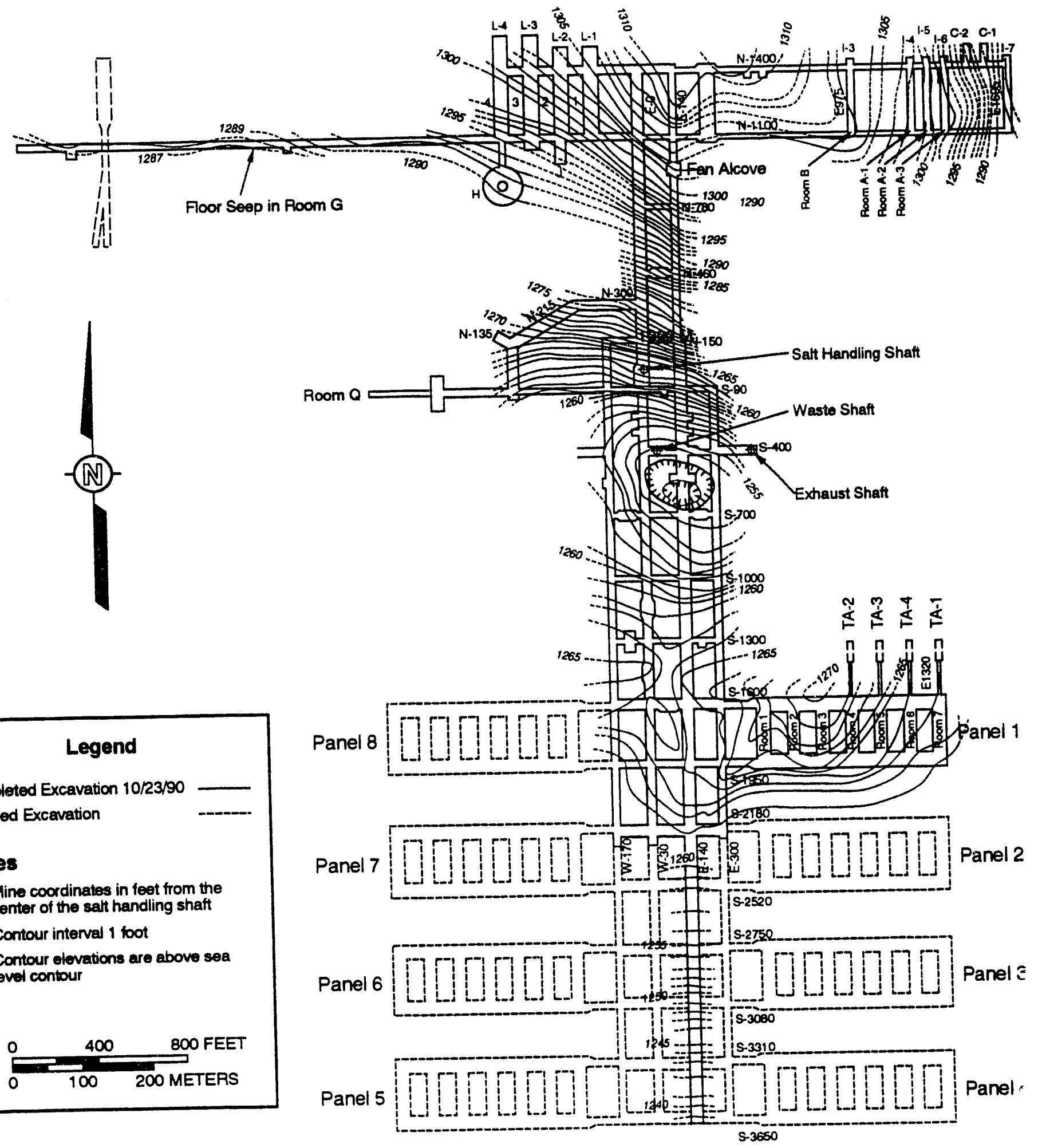

Figure E-4

Structure Contour Map on the Top of the Orange Band. Contour Interval is 1 Foot, and Elevations are in Feet (Francke and Others, 1990). 
Figure E-5 illustrates the arrangement of drill holes for this phase. Each array will consist of three sets of five holes up to 150-ft long, drilled one above the other in each of five stratigraphic units, plus six additional 150 - $\mathrm{ft}$-long drill holes in units 1 and 2 . These units are, from top to bottom: clay $\mathrm{F}$ and the base of map unit 4, argillaceous halite; map unit 3, clear halite; map units 1 and 2, halite and argillaceous halite (map unit 1 is the orange band); map unit 0 , the argillaceous halite interval; and map unit 0 , the clear halite interval. The holes in each array will be drilled with a target depth of $150 \mathrm{ft}$. If coring indicates that the hole has deviated from the desired stratigraphic unit, the drilling will be stopped, leaving the holes shorter than planned but remaining in the intended stratum.

\subsection{Phase III Drilling Program}

A third phase of the drilling program will examine the possibility of far-field brine flow. Assuming brine flow is primarily horizontal and controlled by strata, there would be no means by which brine could replenish dewatered interior pillars.

This phase will consist of three 150- $\mathrm{ft}$ holes cutting the same stratigraphy as $\mathrm{OH} 20, \mathrm{OH} 23$, and $\mathrm{OH} 26$, which are the $150-\mathrm{ft}$ holes that are still producing brine. Like the $150-\mathrm{ft} \mathrm{OH}$ holes, they will begin about $1 \mathrm{ft}$ above the orange band and bottom in map unit 0 below the orange band. Two will be drilled in S1600 between W30 and W170, one to the north and one to the south. A third hole will be drilled north in S1950 between W30 and E140 (Figure E-3). If a significant far-field component of flow is dominant along stratigraphic partings, the new holes should be dry or soon become dry. However, the existing long holes $(\mathrm{OH} 20, \mathrm{OH} 23$, and $\mathrm{OH} 26)$ located outside the pillars should continue to produce brine and approach steady state. If the new holes in the interior pillars have brine inflow patterns similar to the exterior holes and all of the drill holes become dry, that would support the idea that the seepage is from a very local, near-field source. If a far-field flow is without horizontal constraints, brine inflow into all drill holes that extend beyond the DRZ around drifts should become steady state.

The locations for these holes were selected because they are in interior pillars in a part of the working where traffic is relatively light. The area is in close proximity to existing boreholes, and the strata are equivalent, so the results from these holes may reasonably be compared with data from the $\mathrm{OH} 20, \mathrm{OH} 23$, and $\mathrm{OH} 26$. 


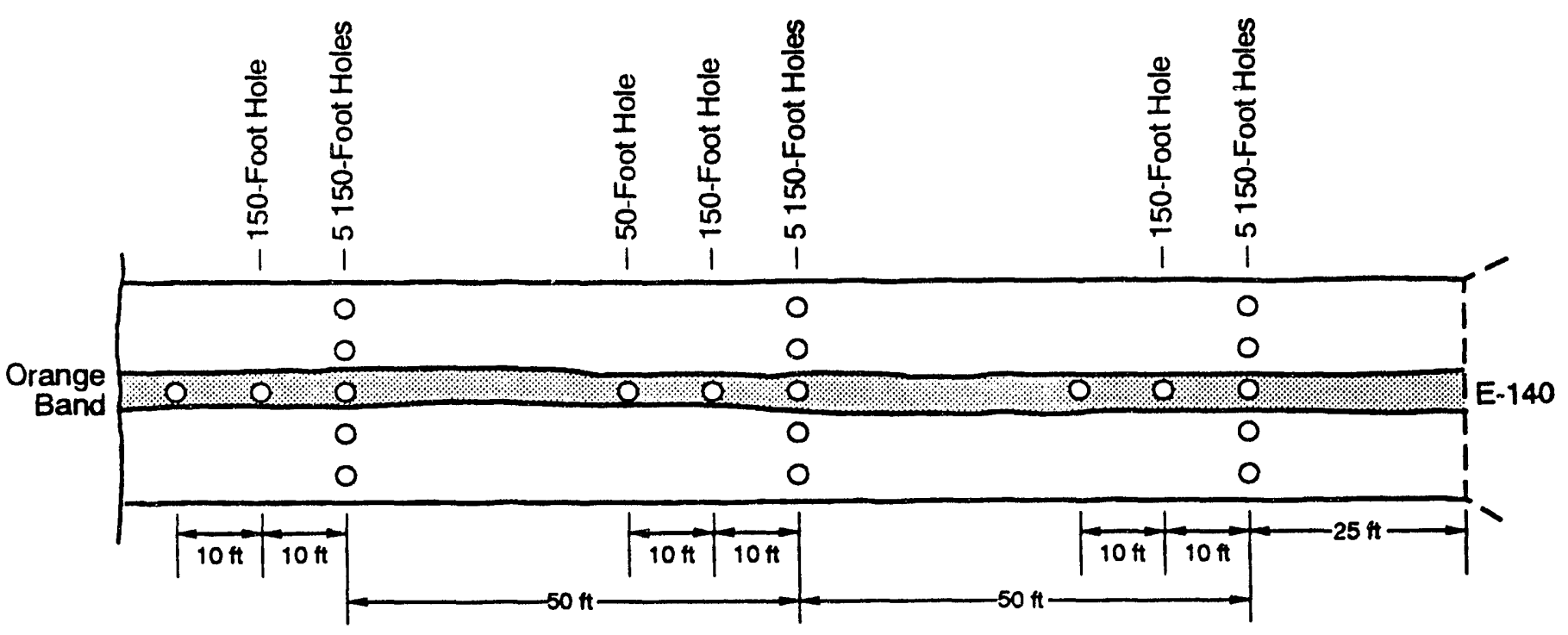

Note: All drill holes slope down away from the collar, parallel to dip, and remain in the same stratum for their entire length.
2 Sets of Holes:

1. N-460, Looking South

2. N-780, Looking South

Figure E-5

Phase II Drill Hole Arrangement

E-10 


\subsection{Phase IV Drilling Program}

This fourth phase of drilling is intended to further define whether the DRZ around the W170 drift has already been dewatered. This phase will determine whether the first $50 \mathrm{ft}$ of holes $\mathrm{OH} 20, \mathrm{OH} 23$, and $\mathrm{OH} 26$ are dry because no brine seeps into the holes from map unit 3 or because the DRZ around W170 at S1600, S1950, and S2150 was dewatered before the holes were drilled. As described in Chapter 4, the 50-ft boreholes in the series are dry, while the 150 - $\mathrm{ft}$ holes produce brine. The 50 - $\mathrm{ft}$ holes in this phase will cross the same stratigraphy as the 150-ft holes drilled during Phase $\mathrm{I}$ in 1989. If brine flows into the 50- $\mathrm{ft}$ holes that cross the orange band, it may be concluded that the brine is related to the orange band or the units flanking it rather than being strictly a function of depth into the ribs and the DRZ around the W170 drift.

The drilling will consist of three subhorizontal 50-ft holes drilled on 50-ft spacings north of S1600 west into W170, starting approximately 50-ft north of OH21 (Figures E-5 and E-6). These holes will be drilled to cross the orange band, just as the 150- $\mathrm{ft} \mathrm{OH} 20, \mathrm{OH} 23$, and $\mathrm{OH} 26$ holes do. This data will supplement existing data for an overall interpretation.

\subsection{References}

Beauheim, R. L., and S. Howarth, 1991, "Status of Room Q Experiments and Salado Permeability Tests," Presentation to the WIPP Review Panel, National Academy of Sciences and Board of Radioactive Waste Management, Albuquerque, New Mexico.

Deal, D. E., and R. M. Roggenthen, 1991, "Evolution of Hydrologic Systems and Brine Geochemistry in a Deforming Salt Medium: Data from WIPP Brine Seeps", Waste Management '91, Waste Processing, Transportation, Storage and Disposal, Technical Programs and Public Education, R. G. Post, ed., Vol. 2, pp. 507-516.

Deal, D. E., R. J. Abitz, D. S. Belski, J. B. Clark, M. E. Crawley, and M. L. Martin, 1991, "Brine Sampling and Evaluation Program, 1989 Report," DOE-WIPP-91-009, prepared for U.S. Department of Energy by IT Corporation and Westinghouse Electric Corporation, Albuquerque, New Mexico.

Deal, D. E., R. J. Abitz, J. B. Case, M. E. Crawley, R. M. Deshler, P. E. Drez, C. A. Givens, R. B. King, B. A. Lauctes, J. Myers, S. Niou, J. M. Pietz, W. M. Roggenthen, J. R. Tyburski, M. G. Wallace, and D. S. Belski, 1989, "Brine Sampling and Evaluation Program, 1988 Report," DOE/WIPP-89-015, prepared for the U.S. Department of Energy by IT Corporation and Westinghouse Electric Corporation, Carlsbad, New Mexico. 


$\frac{100}{O H 21}$

Note: Drill holes are 50 feet long and slope downward away from the collar so that the far end is close to the level of the floor of the W170 drift.

Figure E-6

Phase IV Drill Hole Arrangement 

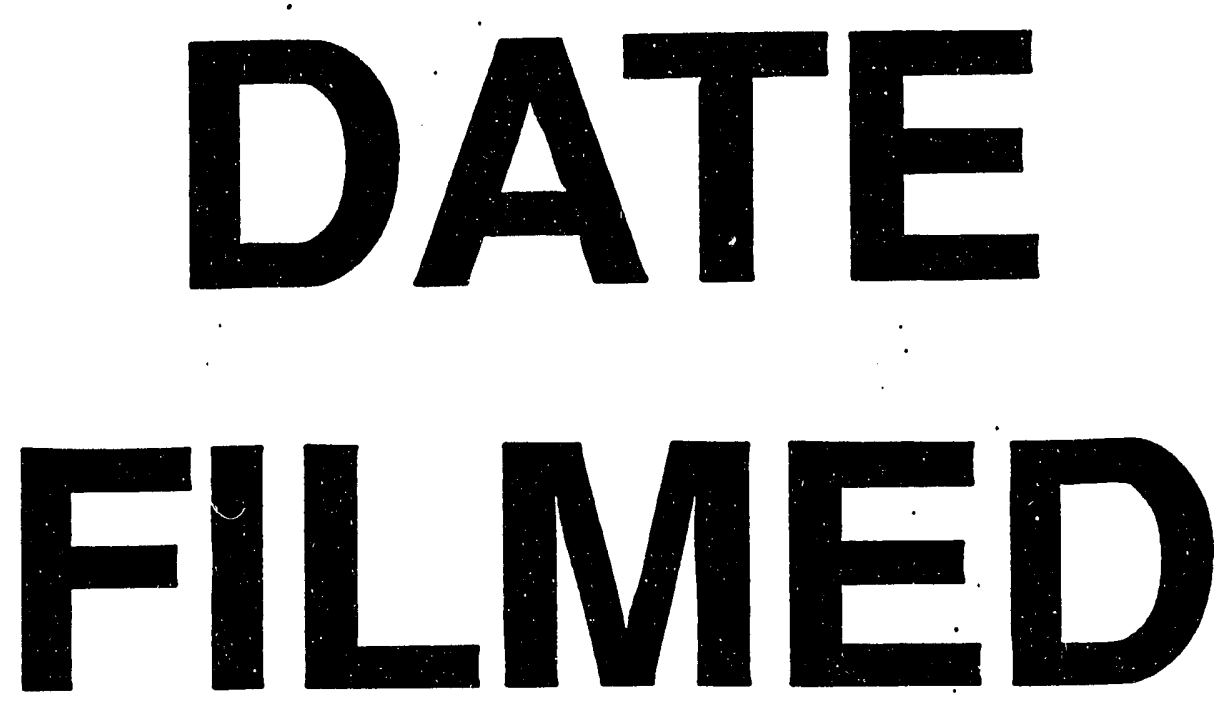

$10 / 15 / 93$
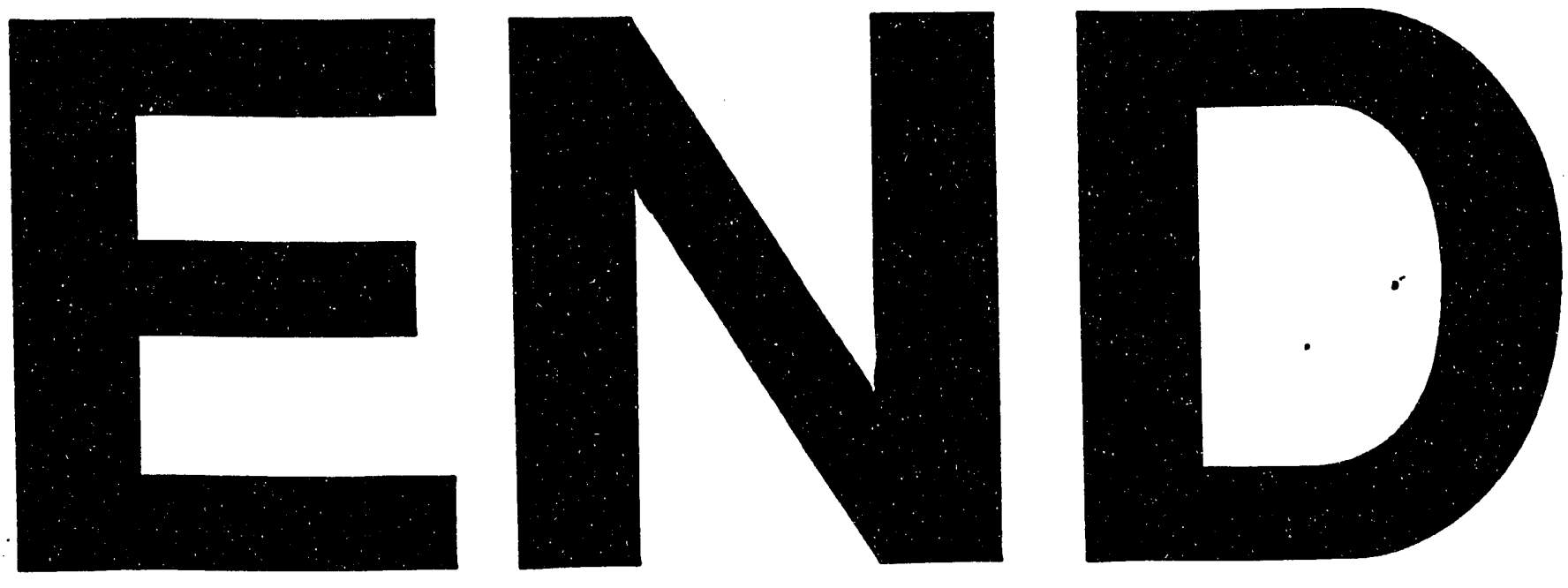
